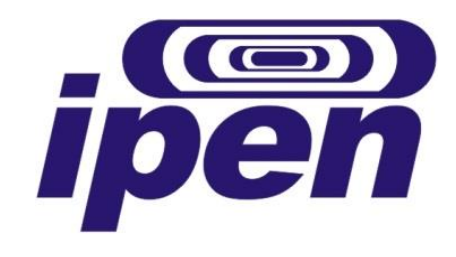

INSTITUTO DE PESQUISAS ENERGÉTICAS E NUCLEARES

Autarquia associada à Universidade de São Paulo

MARCADORES À BASE DE TERRAS RARAS PARA DETECÇÃO DE ESTROGÊNIOS SINALIZADORES EM FLUÍDOS BIOLÓGICOS

DÉBORA CHRISTINA SALUM

SÃO PAULO

2014 


\section{ipen}

INSTITUTO DE PESQUISAS ENERGÉTICAS E NUCLEARES

Autarquia associada à Universidade de São Paulo

MARCADORES À BASE DE TERRAS RARAS PARA DETECÇÃO DE ESTROGÊNIOS SINALIZADORES EM FLUÍDOS BIOLÓGICOS

DÉBORA CHRISTINA SALUM

Tese apresentada como partes dos requisitos para obtenção do Grau de Doutor em Ciências na Área de Tecnologia Nuclear - Materiais.

Orientadora: Dra. Maria Cláudia França da Cunha Felinto

SÃO PAULO 
in memorian

Ao meu sempre presente pai Renato, com amor e orgulho sem igual.

"A saudade é a nossa alma dizendo para onde ela quer voltar."

Rubem Alves 


\section{Dedicatória}

À minha amada mãe Helena, por ter dedicado sua vida por mim, por seu amor incondicional e por ser a mãe e o pai que eu preciso.

Ao José Renato, por ter me dado o privilégio de conhecer e viver o amor mais genuíno que existe, o amor de mãe. 


\section{AGRADECIMENTOS}

A Deus, presença, cuidado e direção constante em minha vida.

À minha orientadora, Dra. Maria Cláudia França da Cunha Felinto, minha efusiva admiração e gratidão pelos ensinamentos profissionais e os ensinamentos de vida.

À minha mãe pelo apoio e amor incondicional, ao meu irmão Renato pelo suporte, à minha cunhada Ana Cristina pela amizade verdadeira, ao meu companheiro Rhayner pelo apoio. Vocês foram essenciais em todos os momentos.

Às minhas amigas Elen, Liana e Clarissa pelo apoio constante, pelas experiências de vida e lealdade sem igual.

Aos meus amigos: Jacinete, Paula, Klauss, Everton, Thelma, Edison Gibelli, Edson Gaiollo, Eduardo Gosik, Heloísa e Pedro pelo apoio e carinho.

Aos amigos do Instituto de Química-USP: Lucas, Cássio, Ivan, Israel, José e Ernesto pela prontidão em ajudar e instruir, e pela amizade.

Ao Prof. Dr. Hermi pela colaboração em análises, cursos, ensinamentos e amizade.

À Dra. Cláudia Akemi pela colaboração, amizade e valiosas discussões.

Ao Dr. Eduardo Sanches pelas discussões e contribuições.

Ao Dr. Oscar Vega pelos ensinamentos, presteza e preciosa amizade.

Aos técnicos Valdelei, João, Pereira e Takeshi pela amizade, presteza e alegria diária.

Ao apoio financeiro cedido pela CAPES e ao Instituto Nacional de Ciência e Tecnologia de Nanotecnologia para Marcadores Integrados inctINAMI. 
Quanto mais me aprofundo na ciência, mais me aproximo de Deus. 


\title{
MARCADORES À BASE DE TERRAS RARAS PARA DETECÇÃO DE ESTROGÊNIOS SINALIZADORES EM FLUÍDOS BIOLÓGICOS
}

\author{
DÉBORA CHRISTINA SALUM
}

\begin{abstract}
RESUMO
O desenvolvimento de nanosensores luminescentes, não tóxicos e biocompatíveis estão sendo utilizados para marcação e visualização de células em biologia celular e imunoensaios ultrassensíveis. Neste trabalho, marcadores biológicos à base de terras raras para a detecção do 17- $\beta$-estradiol (E2), em fluido biológico (plasma) foram estudados. Os complexos precursores à base de terras raras $\left(\mathrm{Eu}^{3+} \mathrm{e}\right.$ $\mathrm{Tb}^{3+}$ ) foram sintetizados e caracterizados. O complexo contendo tta- de $\mathrm{Eu}^{3+}$ e ligante auxiliar TOPO $\left[\mathrm{Eu}(\mathrm{tta})_{3}(\mathrm{TOPO})_{2}\right]$ registrou a maior eficiência de luminescência dentre todos os demais compostos estudados e foi escolhido como sonda luminescente para desenvolvimento das etapas seguintes deste trabalho. Este complexo foi incorporado às matrizes poliméricas, PMMA e PHB, em diferentes concentrações de dopagens por dois métodos distintos: nanoprecipitação crioscópica e pela técnica de emulsãodifusão. As nanopartículas poliméricas de PMMA demonstraram maior eficiência luminescente quando dopadas com concentração de $5 \%$ do complexo precursor $\left[\mathrm{Eu}(\mathrm{tta})_{3}(\mathrm{TOPO})_{2}\right]$. Estas nanopartículas foram funcionalizadas com 1,6 hexodiamino e posteriormente foram ligadas a um dialdeído que servirá como ponte na reação com as entidades biológicas. No entanto, devido à transferência de energia do sistema orgânico Ac-Ac/nanossensor, as nanopartículas poliméricas luminescentes de PHB demonstraram maior intensidade de sinal para a detecção do 17- $\beta$-estradiol por espectrofluorimetria. Pode-se concluir que as nanopartículas produzidas e testadas neste trabalho são fortes candidatas para a detecção do 17- $\beta$-estradiol em plasma sanguíneo ou outras entidades biológicas, apresentando opções diagnósticas, conduta extremamente importante para direcionamento terapêutico.
\end{abstract}




\title{
MARKERS BASED ON RARE EARTHS FOR DETECTION OF ESTROGEN INDICATORS IN BIOLOGICAL FLUIDS
}

\author{
DÉBORA CHRISTINA SALUM
}

\begin{abstract}
The development of luminescent, non-toxic and biocompatible nanosensors are being used for marker and imaging of cells in cellular biology and ultrasensitive immunoassays. In this work, biological markers based on rare earths for detection of 17 $\beta$-estradiol (E2), in biological fluids (Plasmon), were studied. The precursor complexes based on rare earths $\left(\mathrm{Eu}^{3+}\right.$ and $\mathrm{Tb}^{3+}$ ) were synthesized and characterized. The complex containing tta $\mathrm{Eu}^{3+}$ and secondary ligand - TOPO- [Eu(tta $)_{3}(\mathrm{TOPO})_{2}$ ] registered the highest luminescence efficiency among all other compounds studied and was chosen as luminescent probe for the following development stages of this work. This complex was doped into polymer matrices, PMMA and PHB, at different concentrations of doping by two different methods: cryoscopic nanoprecipitation and emulsion-diffusion technique. The PMMA polymer nanoparticles demonstrated higher luminescence efficiency when doped with $5 \%$ concentration of the precursor complex [Eu(tta)3(TOPO)2]. These nanoparticles were functionalized with 1,6 diaminohexane and later they were linked to a dialdehyde that will serve as a bridge in the reaction with the biological entities. These nanoparticles were functionalized with 1,6 diaminohexane and later they were linked to a dialdehyde that can serve as a bridge in the reaction with the biological entities. Due to the energy transfer Ac- Ac/nanosensor, the PHB polymeric nanoparticles showed higher luminescence intensity signal for the detection of 17- $\beta$ estradiol by spectrofluorimetry. It can be concluded that the nanoparticles produced and tested in this work are strong candidates for the detection of $17 \beta$ - estradiol in the blood plasma or others biological entities, presenting diagnostic options, an extremely important conduct for therapeutic direction.
\end{abstract}




\section{LISTA DE FIGURAS}

FIGURA 1.1 - A escala métrica de elementos naturais e dos produzidos pelo homem

FIGURA 3.1 - Tabela periódica dos elementos 8

FIGURA 3.2 - Representação esquemática (qualitativa) do mecanismo de transferência de energia entre um ligante orgânico e o íon $\mathrm{Eu}^{3+}(\mathrm{Cl}=$ Conversão Interna/ CIS= Cruzamento Intersistema/ TE= Transferência de Energia) 19

FIGURA 3.3 - Diagrama de Energia dos íons $\mathrm{TR}^{3+}$ obtidos a partir de cristais de $\mathrm{LaF}_{3}$ 21

FIGURA 3.4 - Fórmulas estruturais dos ânions $\beta$-dicetonatos ACAC, TTA e DBM 25

FIGURA 3.5 - Estrutura molecular dos ligantes fosfinóxidos: Trifenilfosfinóxido (TPPO) e Tri-n-octilfosfinóxido(TOPO) 27

FIGURA 3.6 - Estrutura molecular do precursor 2-(o-hidroxifenóxi)etil éter e do dibenzo-[18]-coroa-6 27 
FIGURA 3.7 - Estruturas de Éteres Coroa comuns (em destaque: DB18C6 e 18C6) 29

FIGURA 3.8 - Produção mundial de terras raras dos principais países produtores 33

FIGURA 3.9 - Histórico dos preços de óxidos de terras raras 34

FIGURA 3.10 - Aplicações mundiais das terras raras conforme relatado pelo United States Geological Survey Mineral Commodity Summary em 2012 38

FIGURA 3.11 - Representação gráfica do número de citações sobre NPPs durante o período de $1991-2014$ 42

FIGURA 3.12 - Representação gráfica do número de publicações citadas in Scopus sobre NPPs durante o período de 1991 - 2014 43

FIGURA 3.13 - Representação das estruturas químicas de um monômero, mero e polímero 44

FIGURA 3.14 - Estrutura química do PHB e do seu copolímero PHB-HV, respectivamente 49 
FIGURA 3.15 - Estruturas químicas do metacrilato de metila e do polimetilmetacrilato 50

FIGURA 3.16 - Representação das glândulas endócrinas 54

FIGURA 3.17 - Representação da localização do hipotálamo e da hipófise 54

FIGURA 3.18 - Diferenciação sexual de um núcleo hipotalâmico reprodutivamente relevante 55

FIGURA 3.19 - Esquema representativo da regulação hormonal no homem 58

FIGURA 3.20 - Concentração de gonadotrofinas e hormônios ovarianos no plasma durante o ciclo sexual feminino normal 58

FIGURA 3.21 - Produção dos estrogênios a partir da conversão periférica da testosterona 60

FIGURA 3.22 - Fórmulas químicas dos estrogênios 60

FIGURA 4.1 - Fluxograma de uma rota geral de síntese adotada para obtenção das nanopartículas poliméricas de PHB e PMMA dopadas com complexos de terras raras 
FIGURA 4.2 - Fotografias da cominuição mecânica a 77K dos aglomerados de nanopartículas PMMA:[TR(ß-dicetonato $\left.)_{3}(\mathrm{TOPO})_{2}\right]$ obtidos 96

FIGURA 4.3 - Feixe de luz laser proveniente de um apontador laser 101

FIGURA 4.4 - Amostras dos filmes PMMA:5\%[Eu(tta $\left.)_{3}(\mathrm{TOPO})_{2}\right]$ e PHB:3\%[Eu(tta) $\left.)_{3}(\mathrm{TOPO})_{2}\right]$, respectivamente, sob radiação ultravioleta (420-380 $\mathrm{nm})$ 102

FIGURA 4.5 - Sistema de preparação dos filmes submetidos à análise de hemocompatibilidade 103

FIGURA 4.6 - Ilustração da reação que ocorre entre as nanopartículas poliméricas e 1,6- hexametileno diamino 104

FIGURA 4.7 - Esquema representativo do protocolo desenvolvido para a detecção e quantificação do 17ß-estradiol 109

FIGURA 4.8 - Esquema representativo da reação do nanomarcador luminescente com o glutaraldeído 110

FIGURA 4.9 - Esquema representativo da conjugação do nanomarcador com o hormônio $17 \beta$-estradiol $(\mathrm{Ag})$ 111 
FIGURA 4.10 - Esquema ilustrativo da preparação dos poços da placa utilizada para o imunoensaio de indentificação e quantificação do hormônio em diferentes concentrações das soluções de anti-17ß-estradiol/lgG. do nanomarcador 113

FIGURA 5.1 - Fotografias do complexo $\left[\mathrm{Tb}(\mathrm{acac})_{3}(\mathrm{TOPO})_{2}\right]$,a) sob luz ambiente; b) sob irradiação ultravioleta 119

FIGURA 5.2 - Fotografias do complexo [Eu(tta $)_{3}(\mathrm{TOPO})_{2}$ ], a) sob luz ambiente; b) sob irradiação ultravioleta 120

FIGURA 5.3 - Efeito mesoiônico do grupo fenila nos complexos com $\beta$ dicetonatos 125

FIGURA 5.4 - Espectros de infravermelho dos complexos [ $\left.\mathrm{Tb}(\mathrm{acac})_{3}(\mathrm{~L})_{2}\right]$ (onde $\mathrm{L}=18 \mathrm{C} 6$, DB18C6, TPPO e TOPO) na região de 400 a $4000 \mathrm{~cm}^{-1}$ estudados neste trabalho 126

FIGURA 5.5 - Espectros de infravermelho dos complexos de [Gd(acac $\left.)_{3}(\mathrm{~L})_{2}\right]$ (onde $\mathrm{L}=18 \mathrm{C6}$, DB18C6, TPPO e TOPO) na região de 400 a $4000 \mathrm{~cm}^{-1}$ estudados nesse trabalho 127

FIGURA 5.6 - Espectros de infravermelho dos complexos de $\left[\mathrm{Eu}(\mathrm{tta})_{3}(\mathrm{~L})_{2}\right]$ (onde $\mathrm{L}=18 \mathrm{C} 6$, DB18C6, TPPO e TOPO) na região de 400 a $4000 \mathrm{~cm}^{-1}$ estudados nesse trabalho 129 
FIGURA 5.7 - Espectros de infravermelho dos complexos de $\left[\mathrm{Gd}(\mathrm{tta})_{3}(\mathrm{~L})_{2}\right]$ (onde $L=18 C 6$, DB18C6, TPPO e TOPO) na região de 400 a $4000 \mathrm{~cm}^{-1}$ estudados nesse trabalho 129

FIGURA 5.8 - Curvas TGA/DTGA registradas no intervalo de 0 a $1000 \stackrel{\circ}{ } \mathrm{C}$, sob atmosfera dinâmica de $\mathrm{N}_{2}$, do complexo $\left[\mathrm{Tb}(\mathrm{acac})_{3}(\mathrm{TPPO})_{2}\right]$ 133

FIGURA 5.9 - Curvas TGA/DTG registradas no intervalo de 0 a $1000 \stackrel{\circ}{ } \mathrm{C}$, sob atmosfera dinâmica de $\mathrm{N}_{2}$, do complexo $\left[\mathrm{Tb}(\mathrm{acac})_{3}(\mathrm{TOPO})_{2}\right]_{3}$ 133

FIGURA 5.10 - Curvas TGA/DTG registradas no intervalo de 0 a $1000 \stackrel{\circ}{\circ}$, sob atmosfera dinâmica de $\mathrm{N}_{2}$, do complexo $\left[\mathrm{Tb}(\mathrm{acac})_{3}(\mathrm{DB} 18 \mathrm{C} 6)_{2}\right]$ 134

FIGURA 5.11 - Curvas TGA/DTG registradas no intervalo de 0 a $1000 \stackrel{\circ}{ } \mathrm{C}$, sob atmosfera dinâmica de $\mathrm{N}_{2}$, do complexo $\left[\mathrm{Tb}(\mathrm{acac})_{3}(18 \mathrm{C} 6)_{2}\right]$ 134

FIGURA 5.12 - Curvas TGA/DTG registradas no intervalo de 0 a $1000{ }^{\circ} \mathrm{C}$, sob atmosfera dinâmica de $\mathrm{N}_{2}$, do complexo $\left[\mathrm{Eu}(\mathrm{tta})_{3}(\mathrm{TPPO})_{2}\right]$ 136

FIGURA 5.13 - Curvas TGA/DTG registradas no intervalo de 0 a $1000{ }^{\circ} \mathrm{C}$, sob atmosfera dinâmica de $\mathrm{N}_{2}$, do complexo $\left[\mathrm{Eu}(\mathrm{tta})_{3}(\mathrm{TOPO})_{2}\right]$ 137

FIGURA 5.14 - Curvas TGA/DTG registradas no intervalo de 0 a $1000 \stackrel{\circ}{\circ}$, sob atmosfera dinâmica de $\mathrm{N}_{2}$, do complexo $\left[\mathrm{Eu}(\mathrm{tta})_{3}(\mathrm{DB} 18 \mathrm{C} 6)_{2}\right]$ 137 
FIGURA 5.15 - Curvas TGA/DTG registradas no intervalo de 0 a $1000{ }^{\circ} \mathrm{C}$, sob atmosfera dinâmica de $\quad \mathrm{N}_{2}$, do complexo $\left[\mathrm{Eu}(\mathrm{tta})_{3}(18 \mathrm{C} 6)_{2}\right]_{1} \quad 137$

FIGURA 5.14 - Curvas TGA/DTG registradas no intervalo de 0 a $1000 \stackrel{\circ}{\circ}$, sob atmosfera dinâmica de $\mathrm{N}_{2}$, do complexo $\left[\mathrm{Eu}(\mathrm{tta})_{3}(\mathrm{DB} 18 \mathrm{C} 6)_{2}\right]_{3}$ 137

FIGURA 5.15 - Curvas TGA/DTG registradas no intervalo de 0 a $1000{ }^{\circ} \mathrm{C}$, sob atmosfera dinâmica de $\mathrm{N}_{2}$, do complexo $\left[\mathrm{Eu}(\mathrm{tta})_{3}(18 \mathrm{C} 6)_{2}\right]$ 138

FIGURA 5.16 - Espalhamento de raios-X em uma dada família de Planos 139

FIGURA 5.17 - Difratogramas de raios $X$ dos complexos $\left[\operatorname{Tb}(\operatorname{acac})_{3}(L)_{2}\right]$ (onde $\mathrm{L}=18 \mathrm{C} 6$, DB18C6, TOPO e TPPO) no intervalo de 5 a $40{ }^{\circ} \mathrm{C}$ 142

FIGURA 5.18 - Difratogramas de raios $X$ dos complexos $\left[\mathrm{Eu}(\mathrm{tta})_{3}(\mathrm{~L})_{2}\right]$ (onde $\mathrm{L}=$ 18C6, DB18C6, TOPO e TPPO) no intervalo de 5 a $40^{\circ} \mathrm{C}$ 143

FIGURA 5.19 - Difratogramas de raios $X$ dos complexos $\left[\mathrm{Gd}(\mathrm{acac})_{3}(\mathrm{~L})_{2}\right]$ (onde $\mathrm{L}=18 \mathrm{C} 6$, DB18C6, TOPO e TPPO) no intervalo de 5 a $40^{\circ} \mathrm{C}$ 145

FIGURA 5.20 - Difratogramas de Raios X dos complexos $\left[\mathrm{Gd}(\mathrm{tta})_{3}(\mathrm{~L})_{2}\right]$ (onde $\mathrm{L}=18 \mathrm{C} 6$, DB18C6, TOPO e TPPO) no intervalo de 5 a $40{ }^{\circ} \mathrm{C}$ 146 
FIGURA 5.21 - Micrografia do complexo [Tb(acac) $\left.)_{3}(\mathrm{TPPO})_{2}\right]$ com magnificação de $(7000 x)$ 148

FIGURA 5.22 - Micrografia do complexo [Tb(acac) $\left.)_{3}(\mathrm{TOPO})_{2}\right]$ com magnificação de $(10000 x)$ 149

FIGURA 5.23 - Micrografia do complexo $\left[\mathrm{Tb}(\mathrm{acac})_{3}(\mathrm{DB} 18 \mathrm{C} 6)_{2}\right]$ com magnificação de (10000x) 149

FIGURA 5.24 - Micrografia do complexo $\left[\mathrm{Tb}(\mathrm{acac})_{3}(18 \mathrm{C} 6)_{2}\right]$ com magnificação de $(7000 x)$ 150

FIGURA 5.25 - Micrografia do complexo $\left[\mathrm{Eu}(\mathrm{tta})_{3}(\mathrm{TPPO})_{2}\right.$ ] com magnificação de $(7000 x)$ 151

FIGURA 5.26 - Micrografia do complexo [Eu(tta $)_{3}(\mathrm{DB} 18 \mathrm{C} 6)_{2}$ ] com magnificação de $(5000 x)$ 151

FIGURA 5.28 - Micrografia do complexo $\left[\mathrm{Gd}(\mathrm{acac})_{3}(\mathrm{TPPO})_{2}\right]$ com magnificação de (7000x) 153 
FIGURA 5.29 - Micrografia do complexo $\left[\mathrm{Gd}(\mathrm{acac})_{3}(\mathrm{TOPO})_{2}\right]$ com magnificação de $(7000 x)$ 153

FIGURA 5.30 - Micrografia do complexo $\left[\mathrm{Gd}(\mathrm{acac})_{3}(\mathrm{DB} 18 \mathrm{C} 6)_{2}\right]$ com magnificação de (10000x) 154

FIGURA 5.31 - Micrografia do complexo $\left[\mathrm{Gd}(\operatorname{acac})_{3}(18 \mathrm{C} 6)_{2}\right]$ com magnificação de $(2000 x)$ 154

FIGURA 5.32 - Micrografia do complexo $\left[\mathrm{Gd}(\mathrm{tta})_{3}(\mathrm{TPPO})_{2}\right]$ com magnificação de $(7000 x)$ 156

FIGURA 5.33 - Micrografia do complexo $\left[\mathrm{Gd}(\mathrm{tta})_{3}(\mathrm{DB} 18 \mathrm{C} 6)_{2}\right]$ com magnificação de $(7000 x)$ 156

FIGURA 5.34 - Micrografia do complexo $\left[\mathrm{Gd}(\mathrm{tta})_{3}(18 \mathrm{C} 6)_{2}\right]$ com magnificação de $(10000 x)$ 157

FIGURA 5.35 - Espectros de emissão dos complexos de acac de $\mathrm{Gd}^{3+}$ com diferentes ligantes orgânicos auxiliares no intervalo de 400-900 nm, registrados à baixa temperatura, e sob excitação em $366 \mathrm{~nm}$ 159

FIGURA 5.36 - Espectros de emissão dos complexos de tta de $\mathrm{Gd}^{3+}$ com diferentes ligantes orgânicos auxiliares no intervalo de 400-900 nm, registrados a baixa temperatura, e sob excitação em $366 \mathrm{~nm}$ 159 
FIGURA 5.37 - Supressão dos níveis emissores ${ }^{5} \mathrm{D}_{0}$ e ${ }^{5} \mathrm{D}_{4}$ dos íons $\mathrm{Eu}^{3+}$ e $\mathrm{Tb}^{3+}$, respectivamente, pela presença de osciladores $\mathrm{O}-\mathrm{H}$ 162

FIGURA 5.38 - Espectro de excitação do complexo [Tb(acac $\left.)_{3}\left(\mathrm{H}_{2} \mathrm{O}\right)_{3}\right]$, registrado a temperatura ambiente, no intervalo de $245-525 \mathrm{~nm}$, com emissão monitorada em $545 \mathrm{~nm}$ 165

FIGURA 5.39 - Espectros de excitação dos complexos [Tb(acac $\left.)_{3}(\mathrm{TPPO})_{2}\right]$, $\left[\mathrm{Tb}(\mathrm{acac})_{3}(\mathrm{TOPO})_{2}\right],\left[\mathrm{Tb}(\mathrm{acac})_{3}(\mathrm{DB} 18 \mathrm{C} 6)_{2}\right]$ e $\left[\mathrm{Tb}(\mathrm{acac})_{3}(18 \mathrm{C} 6)_{2}\right]$ registrado a temperatura ambiente, no intervalo de 250 a 500 nm, com emissão monitorada em $549 \mathrm{~nm}$ 166

FIGURA 5.40 - Espectros de emissão do complexo $\left[\mathrm{Tb}(\mathrm{acac})_{3}\left(\mathrm{H}_{2} \mathrm{O}\right)_{3}\right]$ e dos complexos $\left[\mathrm{Tb}(\mathrm{acac})_{3}(\mathrm{~L})_{2}\right]$ registrado à temperatura ambiente, no intervalo de 450 a 750 nm, com excitação monitorada em 320 nm 167

FIGURA 5.41 - Curvas de decaimento da luminescência do estado emissor dos complexos ${ }^{5} \mathrm{D}_{4}$ do íon $\mathrm{Tb}^{3+}$ 172

FIGURA 5.42 - Espectros de excitação dos complexos de tta de $\mathrm{Eu}^{3+}$ com ligantes orgânicos auxiliares TPPO, TOPO, DB18C6 e 18C6 no intervalo de 250-600 nm, registrados à temperatura ambiente, e sob emissão em 615 $\mathrm{nm}$ 178 
FIGURA 5.43 - Espectros de emissão dos complexos de tta de $\mathrm{Eu}^{3+}$ com diferentes ligantes orgânicos auxiliares no intervalo de 400-800 nm, registrados à temperatura ambiente, e sob excitação em 380 nm 180

FIGURA 5.44 - Curvas de decaimento da luminescência do estado emissor dos complexos ${ }^{5} \mathrm{D}_{0}$ do íon $\mathrm{Eu}^{3+}$ 182

FIGURA 5.45 - Curvas das cores padrões CIE para $x(\lambda), y(\lambda)$ e $z(\lambda)$ 187

FIGURA 5.46 - Diagrama de cromaticidade CIE ilustrando as coordenadas de cores da região espectral visível 188

FIGURA 5.47 - Diagrama de cromaticidade CIE ilustrando as coordenadas das cores emitidas pelos complexos $\operatorname{TR}(\beta \text {-dicetonatos) })_{3}$ L2 a)TR=Gd e $\beta$ dicetonatos =acac; b) TR=Tb e $\beta$-dicetonatos =acac e c) TR=Eu e $\beta$ dicetonatos =tta; representados por círculo. 1)H2O; 2) TOPO; 3)TPPO; 4) 18C6 e 5)DB18C6 189

FIGURA 5.48 - Fotografias das nanopartículas poliméricas de PMMA e PHB dopadas com o complexo $\left[\mathrm{Eu}(\mathrm{tta})_{3}(\mathrm{TOPO})_{2}\right] ;$ a) sob luz ambiente; b) sob irradiação ultravioleta $(366 \mathrm{~nm})$; c) PMMA:5\%[Eu(tta $\left.)_{3}(\mathrm{TOPO})_{2}\right]$ sob irradiação ultravioleta $(366 \mathrm{~nm})$ 193 
FIGURA 5.49 - Fotografias das nanopartículas poliméricas de PMMA e PHB dopadas com o complexo $\left[\mathrm{Gd}(\mathrm{tta})_{3}(\mathrm{TOPO})_{2}\right]$ a) sob luz ambiente; b) sob irradiação ultravioleta $(250 \mathrm{~nm})$ 194

FIGURA 5.50 - Espectros de absorção no infravermelho registrado à temperatura ambiente no intervalo de 400 a $4000 \mathrm{~cm}^{-1}$, das nanopartículas $\mathrm{PHB}: \mathrm{X} \%\left[\mathrm{Eu}(\mathrm{tta})_{3}(\mathrm{TOPO})_{2}\right]$ e do complexo $\left[\mathrm{Eu}(\mathrm{tta})_{3}(\mathrm{TOPO})_{2}\right]$ 196

FIGURA 5.51 - Espectros de absorção na região do infravermelho registrado à temperatura ambiente no intervalo de 400 a $4000 \mathrm{~cm}^{-1}$, das nanopartículas PMMA:X\% [Eu(tta $\left.)_{3}(\mathrm{TOPO})_{2}\right]$ e do complexo [Eu(tta) $\left.)_{3}(\mathrm{TOPO})_{2}\right]$ 196

FIGURA 5.52 - Curvas TGA/DTG registradas no intervalo de 0 a $540{ }^{\circ} \mathrm{C}$, sob atmosfera dinâmica de $\mathrm{N}_{2}$, A) do polímero PMMA e B) do sistema polimérico PMMA:0,5\%[Eu(tta) $\left.)_{3}(\mathrm{TOPO})_{2}\right]$ 199

FIGURA 5.53 - Curvas TGA/DTG registradas no intervalo de 0 a $540{ }^{\circ} \mathrm{C}$, sob atmosfera dinâmica de $\mathrm{N}_{2}$, do sistema polimérico PMMA:1\%[Eu(tta) $\left.)_{3}(\mathrm{TOPO})_{2}\right]$ 200

FIGURA 5.54 - Curvas TGA/DTG registradas no intervalo de 0 a $540{ }^{\circ} \mathrm{C}$, sob atmosfera dinâmica de $\mathrm{N}_{2}$, do sistema polimérico PMMA:3\%[Eu(tta $\left.)_{3}(\mathrm{TOPO})_{2}\right]$ 200 
FIGURA 5.55 - Curvas TGA/DTG registradas no intervalo de 0 a $540{ }^{\circ} \mathrm{C}$, sob atmosfera dinâmica de $\mathrm{N}_{2}$, do sistema polimérico PMMA:5\%[Eu(tta) $\left.)_{3}(\mathrm{TOPO})_{2}\right]$ 201

FIGURA 5.56 - Curvas TGA/DTG registradas no intervalo de 0 a $540{ }^{\circ} \mathrm{C}$, sob atmosfera dinâmica de $\mathrm{N}_{2}$, do sistema polimérico PMMA:7\%[Eu(tta $\left.)_{3}(\text { TOPO })_{2}\right]$

FIGURA 5.57 - Curvas TGA/DTG registradas no intervalo de 0 a $540{ }^{\circ} \mathrm{C}$, sob atmosfera dinâmica de $\mathrm{N}_{2}, \quad$ A) do PHB e B) do sistema polimérico PHB:0,5\%[Eu(tta) $\left.)_{3}(\mathrm{TOPO})_{2}\right]$

FIGURA 5.58 - Curvas TGA/DTG registradas no intervalo de 0 a $540{ }^{\circ} \mathrm{C}$, sob atmosfera dinâmica de $\mathrm{N}_{2}$, do sistema polimérico PHB: $1 \%\left[\mathrm{Eu}(\mathrm{tta})_{3}(\mathrm{TOPO})_{2}\right]$

FIGURA 5.59 - Curvas TGA/DTG registradas no intervalo de 0 a $540{ }^{\circ} \mathrm{C}$, sob atmosfera dinâmica de $\mathrm{N}_{2}$, do sistema polimérico $\mathrm{PHB}: 3 \%\left[\mathrm{Eu}(\mathrm{tta})_{3}(\mathrm{TOPO})_{2}\right]$

FIGURA 5.60 - Curvas TGA/DTG registradas no intervalo de 0 a $540{ }^{\circ} \mathrm{C}$, sob atmosfera dinâmica de $\mathrm{N}_{2}$, do sistema polimérico $\mathrm{PHB}: 5 \%\left[\mathrm{Eu}(\mathrm{tta})_{3}(\mathrm{TOPO})_{2}\right]$ 206 
FIGURA 5.61 - Curvas TGA/DTG registradas no intervalo de 0 a $540{ }^{\circ} \mathrm{C}$, sob atmosfera dinâmica de $\mathrm{N}_{2}$, do sistema polimérico $\mathrm{PHB}: 7 \%\left[\mathrm{Eu}(\mathrm{tta})_{3}(\mathrm{TOPO})_{2}\right]$ 206

FIGURA 5.62 - Curvas TGA/DTG registradas no intervalo de 0 a $540{ }^{\circ} \mathrm{C}$, sob atmosfera dinâmica de $\mathrm{N}_{2}$, do sistema polimérico PHB:7\%[Eu(tta) $\left.)_{3}(\mathrm{TOPO})_{2}\right]$ 208

FIGURA 5.63 - Curvas TGA/DTG registradas no intervalo de 0 a $540{ }^{\circ} \mathrm{C}$, sob atmosfera dinâmica de $\mathrm{N}_{2}$, do sistema polimérico PMMA:3\%[Gd(tta $\left.)_{3}(\mathrm{TOPO})_{2}\right]$

FIGURA 5.64 - Difratogramas de raios X (método de pó) das NPs poliméricas PHB em diferentes concentrações de dopagem do complexo [Eu(tta $\left.)_{3}(\mathrm{TOPO})_{2}\right]$ : PHB, PHB:X\%[Eu(tta) $\left.)_{3}(\mathrm{TOPO})_{2}\right](\mathrm{X}=0,5 ; 1 ; 3 ; 5$ e $7 \%)$ 210

FIGURA 5.65 - Difratogramas de raios X (método de pó) das NPs poliméricas PMMA em diferentes concentrações de dopagem do complexo $\left[\mathrm{Eu}(\mathrm{tta})_{3}(\mathrm{TOPO})_{2}\right]: \quad \mathrm{PMMA}, \quad \mathrm{PMMA}: \mathrm{X} \% \mathrm{Eu}(\mathrm{tta})_{3}(\mathrm{TOPO})_{2} \quad(\mathrm{X}=0,5 ; 1 ; 3 ; 5$ e 7\%) 211

FIGURA 5.66 - Difratogramas de raios X (método de pó) das NPs poliméricas PHB em diferentes concentrações de dopagem do complexo [Gd(tta $\left.)_{3}(\mathrm{TOPO})_{2}\right]$ : PHB, PHB:X\%Gd(tta) $)_{3}(\mathrm{TOPO})_{2}(\mathrm{X}=0,5 ; 1 ; 3 ; 5$ e $7 \%)$ 212 
FIGURA 5.67 - Difratogramas de raios X (método de pó) das NPs poliméricas PMMA em diferentes concentrações de dopagem do complexo $\left[\mathrm{Gd}(\mathrm{tta})_{3}(\mathrm{TOPO})_{2}\right]:$ PMMA, PMMA:X\%[Gd(tta $\left.)_{3}(\mathrm{TOPO})_{2}\right] \quad(\mathrm{X}=0,5 ; 1 ; 3 ; 5$ e $7 \%)$ 213

FIGURA 5.68 - Micrografia das NPs PHB dopadas com complexo $\left[\mathrm{Eu}(\mathrm{tta})_{3}(\mathrm{TOPO})_{2}\right]$ em concentração mássica de $0,5 \%$ com magnificação de $(10000 x)$ 214

FIGURA 5.69 - Micrografia das NPS PHB dopadas com complexo $\left[\mathrm{Eu}(\mathrm{tta})_{3}(\mathrm{TOPO})_{2}\right]$ em concentração mássica de $1 \%$ com magnificação de $(5000 x)$ 215

FIGURA 5.70 - Micrografia das NPS PMMA dopadas com complexo $\left[\mathrm{Eu}(\mathrm{tta})_{3}(\mathrm{TOPO})_{2}\right]$ em concentração mássica de 3\% com magnificação de $(5000 X)$ 215

FIGURA 5.71 - Micrografia das NPs PMMA dopadas com complexo $\left[\mathrm{Eu}(\mathrm{tta})_{3}(\mathrm{TOPO})_{2}\right]$ em concentração mássica de $5 \%$ com magnificação de $(10000 X)$ 216

FIGURA 5.72 - Micrografia das NPs PMMA dopadas com complexo $\left[\mathrm{Eu}(\mathrm{tta})_{3}(\mathrm{TOPO})_{2}\right]$ em concentração mássica de $7 \%$ com magnificação de $(5000 X)$ 216 
FIGURA 5.73 - Micrografia das NPs PMMA dopadas com complexo $\left[\mathrm{Gd}(\mathrm{tta})_{3}(\mathrm{TOPO})_{2}\right]$ em concentração mássica de $0,5 \%$ com magnificação de $(7000 X)$ 217

FIGURA 5.74 - Espectros de fosforescência das nanopartículas de PHB e PMMA, dopado com o complexo $\left[\mathrm{Gd}(\mathrm{tta})_{3}(\mathrm{TOPO})_{2}\right.$ ] e registrado no intervalo de 425 a 750 nm, sob excitação em 380 nm, em diversas concentrações de dopagens $(0,5 ; 1 ; 3 ; 5$ e $7 \%)$ 220

FIGURA 5.75 - Espectros de excitação do complexo [Eu(tta) $\left.)_{3}(\mathrm{TOPO})_{2}\right]$ dopado em concentrações de 0,$5 ; 1 ; 3 ; 5$ e 7 em PHB e PMMA a temperatura ambiente e emissão monitorada em $614 \mathrm{~nm}$ 222

FIGURA 5.76 - Espectros de emissão do complexo [Eu(tta $\left.)_{3}(\mathrm{TOPO})_{2}\right]$ dopado em concentrações de 0,$5 ; 1 ; 3 ; 5$ e 7 em A) PHB e B) PMMA a temperatura ambiente e sob excitação em $380 \mathrm{~nm}$ 224

FIGURA 5.77 - Diagramas de cromaticidade CIE ilustrando as coordenadas das $\begin{array}{llll}\text { cores emitidas pelo sistema polimérico } & \text { PHB:x\% }\end{array}$ $\left[\mathrm{Eu}(\mathrm{tta})_{3}(\mathrm{TOPO})_{2}\right]$ 226

FIGURA 5.78 - Diagramas de cromaticidade CIE ilustrando as coordenadas das

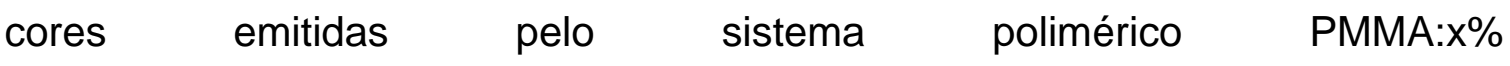
$\left[\mathrm{Eu}(\mathrm{tta})_{3}(\mathrm{TOPO})_{2}\right]$ 227 
FIGURA 5.79 - Espalhamento de luz pelas partículas dispersas em um sistema coloidal (Efeito Tyndall) 229

FIGURA 5.80 - Teste do Efeito Tyndal das amostras a) $\mathrm{H}_{2} \mathrm{O}$; b) $\mathrm{PHB}: 3 \%\left[\mathrm{Eu}(\mathrm{tta})_{3}(\mathrm{TOPO})_{2}\right]$ 230

FIGURA 5.81 - Teste do Efeito Tyndal das amostras a) $\mathrm{H}_{2} \mathrm{O}$; b) $\mathrm{PMMA}: 5 \%\left[\mathrm{Eu}(\mathrm{tta})_{3}(\mathrm{TOPO})_{2}\right]$ 230

FIGURA 5.82 - MEV do filme de PHB:3\%[Eu(tta) $\left.)_{3}(\mathrm{TOPO})_{2}\right]$ exposto ao sangue humano 230

FIGURA 5.83 - Imagem de MEV do filme de PMMA:5\%[Eu(tta $\left.)_{3}(\mathrm{TOPO})_{2}\right]$ exposto ao sangue humano 231

FIGURA 5.84 - Fotografias das NPs de PHB produzidas pela técnica de emulsão-difusão sob irradiação ultravioleta (366 nm), a) NPs + Tween 20 e b) NPs + PVA + sacarose 233

FIGURA 5.85 - Micrografia das NPs PHB dopadas com complexo $\left[\mathrm{Eu}(\mathrm{tta})_{3}(\mathrm{TOPO})_{2}\right]$ contendo PVA+sacarose com magnificação de $(7000 X)$ 234 
FIGURA 5.86 - Imagens de TEM das amostras contendo nanopartículas poliméricas a) e b): $\quad$ PHB:[Eu(tta $\left.)_{3}(\mathrm{TOPO})_{2}\right]+$ Tween20; c) PHB:[Eu(tta $\left.)_{3}(\mathrm{TOPO})_{2}\right]+\mathrm{PVA}+$ sacarose 236

FIGURA 5.87 - Espectro de excitação das NPs PHB:[Eu(tta $\left.)_{3}(\mathrm{TOPO})_{2}\right]+$ Tween 20 e PHB:[Eu(tta $\left.)_{3}(\mathrm{TOPO})_{2}\right]$ à temperatura ambiente, no intervalo de 250 a 590 $\mathrm{nm}$, e sob emissão em $\sim 613 \mathrm{~nm}$. 237

FIGURA 5.88 - Espectro de emissão das NPs PHB:[Eu(tta $\left.)_{3}(\mathrm{TOPO})_{2}\right]+$ Tween 20 à temperatura ambiente, no intervalo de 400 a 800 nm, e sob excitação em $352 \mathrm{~nm}$ 239

FIGURA $\quad 5.89 \quad$ - $\quad$ Espectro de excitação das NPs PHB:[Eu(tta) $\left.)_{3}(\mathrm{TOPO})_{2}\right]+\mathrm{PVA}+$ sacarose à temperatura ambiente e sob emissão em 613 nm 240

FIGURA 5.90 - Espectro de emissão das nanopartículas PHB: $\left[\mathrm{Eu}(\mathrm{tta})_{3}(\mathrm{TOPO})_{2}\right] \mathrm{PVA}+$ sacarose à temperatura ambiente e sob excitação em $358 \mathrm{~nm}$ 241

FIGURA 5.91 - Teste do Efeito Tyndal das amostras a) $\mathrm{H}_{2} \mathrm{O}$; b) PHB:[Eu(tta) $\left.)_{3}(\mathrm{TOPO})_{2}\right]+$ Tween 20 242 
FIGURA 5.92 - Teste do Efeito Tyndal das amostras a) $\mathrm{H}_{2} \mathrm{O}$; b) $\mathrm{PHB}:\left[\mathrm{Eu}(\mathrm{tta})_{3}(\mathrm{TOPO})_{2}\right]+\mathrm{PVA}+$ sacarose 242

FIGURA 5.93 - Fotografias das NPs PMMA e PHB amino-funcionalizadas sob irradiação ultravioleta, a) $\quad$ PMMA:0,5\%[Eu(tta $\left.)_{3}(\mathrm{TOPO})_{2}\right]$, b) PMMA:5\%[Eu(tta) $\left.)_{3}(\mathrm{TOPO})_{2}\right]$, c) PMMA:7\%[Eu(tta $\left.)_{3}(\mathrm{TOPO})_{2}\right] \quad$ e d) $\mathrm{PHB}: 3 \%\left[\mathrm{Eu}(\mathrm{tta})_{3}(\mathrm{TOPO})_{2}\right]$ 244

FIGURA 5.94 - Nanopartículas poliméricas de PHB amino-funcionalizadas $\left(\mathrm{PHB}:\left[\mathrm{Eu}(\mathrm{tta})_{3}(\mathrm{TOPO})_{2}\right]+\mathrm{PVA}+\right.$ sacarose)-amina quando submetidas a radiação UV 245

FIGURA 5.95 - Espectros de absorção no infravermelho registrado à temperatura ambiente no intervalo de 4000 a $400 \mathrm{~cm}^{-1}$, do sistema PMMA:0,5\%[Eu(tta) $\left.)_{3}(\mathrm{TOPO})_{2}\right] \quad$ aminofuncionalizado e não aminofuncionalizado 246

FIGURA 5.96 - Espectros de absorção no infravermelho registrado à temperatura ambiente no intervalo de 400 a $4000 \mathrm{~cm}^{-1}$, dos sistema PMMA:0,5\%[Gd(tta) $\left.)_{3}(\mathrm{TOPO})_{2}\right]$; PMMA:5\%[Eu(tta) $\left.)_{3}(\mathrm{TOPO})_{2}\right]$

PHB:3\%[Gd(tta) $\left.)_{3}(\mathrm{TOPO})_{2}\right]$

e PHB:3\%[Eu(tta) $\left.)_{3}(\mathrm{TOPO})_{2}\right]$ 
FIGURA 5.97 - Difratogramas de raios X (método de pó) das nanopartículas poliméricas PMMA: $5 \%\left[\mathrm{Eu}(\mathrm{tta})_{3}(\mathrm{TOPO})_{2}\right]$ funcionalizadas e não funcionalizadas 248

FIGURA 5.98 - Espectro de excitação e emissão das NPs aminofuncionalizadas $\quad$ PMMA:5\%[Eu(tta $\left.)_{3}(\mathrm{TOPO})_{2}\right], \quad$ à $\quad$ temperatura ambiente 250

FIGURA 5.99 - Espectro de excitação e emissão das NPs aminofuncionalizadas $\quad$ PMMA:7\%[Eu(tta $\left.)_{3}(\mathrm{TOPO})_{2}\right], \quad$ à $\quad$ temperatura ambiente 251

FIGURA 5.100 - Espectro de excitação e emissâo das NPs amino-funcionalizadas $\mathrm{PHB}: 3 \%\left[\mathrm{Eu}(\mathrm{tta})_{3}(\mathrm{TOPO})_{2}\right]$, temperatura ambiente 252

FIGURA 5.101 - Espectro de emissão das NPs amino-funcionalizadas PHB:3\%[Eu(tta) $\left.)_{3}(\mathrm{TOPO})_{2}\right]$ e $\mathrm{PHB}: 3 \%\left[\mathrm{Gd}(\mathrm{tta})_{3}(\mathrm{TOPO})_{2}\right], \quad$ à temperatura ambiente, no intervalo de 400 a 800 nm, e com excitação em 380 e 360 nm respectivamente 253

FIGURA 5.102 - Curva padrão construída a partir da concentração de glicina com absorbância medida em 570 nm 254 
FIGURA 6.1 - Ilustração da interação Ac-Ac-Agmarcado ocorrida no imunoensaio por ELISA de captura. 268

FIGURA 6.2 - Fotografia do fluorímetro Victor2D da Perkin Elmer 270

FIGURA 6.3 - Influência da concentração de IgG (1:1, 1:10, 1:100 e 1:100 (lgG/ TBS)na resposta de detecção de conjugação do nanomarcador 1 na concentração de $0,5 \mu \mathrm{g} / \mathrm{mL}$ de anticorpo específico 272

FIGURA 6.4 - Influência da concentração de lgG (1:1, 1:10, 1:100 e 1:100 (lgG/ TBS)na resposta de detecção de conjugação do nanomarcador 1 na concentração de $1 \mu \mathrm{g} / \mathrm{mL}$ de anticorpo específico 272

FIGURA 6.5 - llustração dos poços da placa de poliestireno contendo as informações colorimétricas do sinal emitido pelo sistema de conjugação biológica contendo o nanomarcador1nas diferentes concentrações de anticorpo específico anti-17ß-estradiol 273

FIGURA 6.6 - Influência da concentração de $\lg$ (1:1, 1:10, 1:100 e 1:100 (lgG/ TBS) na resposta de detecção de conjugação do nanomarcador 2 na concentração de $0,1 \mu \mathrm{g} / \mathrm{mL}$ de anticorpo específico 274

FIGURA 6.7 - Influência da concentração de $\lg G(1: 1,1: 10,1: 100$ e 1:100 (lgG/ TBS)na resposta de detecção de conjugação do nanomarcador 2 na concentração de $0,5 \mu \mathrm{g} / \mathrm{mL}$ de anticorpo específico 274 
FIGURA 6.8 - Influência da concentração de IgG (1:1, 1:10, 1:100 e 1:100 (IgG/ TBS) na resposta de deteç̧ão de conjugação do nanomarcador 2 na concentração de $1 \mu \mathrm{g} / \mathrm{mL}$ de anticorpo específico); amostras branco (Ac Ac-Ag) e amostras padrão (nanomarcador - Ag) 275

FIGURA 6.9 - llustração dos poços da placa de poliestireno contendo as informações colorimétricas do sinal emitido pelo sistema de conjugação biológica contendo os nanomarcadores 1 e 2 , respectivamente 275

FIGURA 6.10 - Influência da concentração de IgG (1:1, 1:10, 1:100 e 1:100 (lgG/TBS) na resposta de detecção de conjugação do nanomarcador 3 na concentração de $0,1 \mu \mathrm{g} / \mathrm{mL}$ de anticorpo específico

FIGURA 6.11 - Influência da concentração de IgG (1:1, 1:10, 1:100 e 1:100 (lgG/TBS) na resposta de detecção de conjugação do nanomarcador 3 na concentração de $0,5 \mu \mathrm{g} / \mathrm{mL}$ de anticorpo específico

FIGURA 6.12 - Influência da concentração de $\lg G(1: 1,1: 10,1: 100$ e 1:100 (IgG/TBS) na resposta de detecção de conjugação do nanomarcador 3 na $\begin{array}{llllll}\text { concentração de } & 1 & \mu g / m L & \text { de } & \text { anticorpo }\end{array}$ específico. 278

FIGURA 6.13 - llustração dos poços da placa de poliestireno contendo as informações colorimétricas do sinal emitido pelo sistema de conjugação biológica contendo o nanomarcador 3 nas diferentes concentrações de anticorpo específico anti-17 $\beta$-estradiol 278 
FIGURA 6.14 - Influência da concentração de IgG (1:1, 1:10, 1:100 e 1:100 (IgG/TBS) na resposta de detecção de conjugação do nanomarcador 4 na concentração de $0,1 \mu \mathrm{g} / \mathrm{mL}$ de anticorpo específico 280

FIGURA 6.15 - Influência da concentração de IgG (1:1, 1:10, 1:100 e 1:100 (IgG/ TBS) na resposta de detecção de conjugação do nanomarcador 4 na concentração de $0,5 \mu \mathrm{g} / \mathrm{mL}$ de anticorpo específico 280

FIGURA 6.16 - Influência da concentração de $\lg G(1: 1,1: 10,1: 100$ e 1:100)(lgG/ TBS)na resposta de detecção de conjugação do nanomarcador 4 na concentração de $1 \mu \mathrm{g} / \mathrm{mL}$ de anticorpo específico 281

FIGURA 6.17 - llustração dos poços da placa de poliestireno contendo as informações colorimétricas do sinal emitido pelo sistema de conjugação biológica contendo o nanomarcador 4 nas diferentes concentrações de anticorpo específico anti-17ß-estradiol 


\section{LISTA DE TABELAS}

TABELA 3.1 - Cores dos íons TR $^{3+}$ 10

TABELA 3.2 - Observação visual das cores das TR 11

TABELA 3.3 - Produção anual de óxidos de TR no mundo e nos principais países produtores 33

TABELA 3.4 - Estimativa da excreção diária de estrogênios por homens e mulheres em diversas condições 67

TABELA 3.5 - Métodos de detecção de quantificação de hormônios e seus respectivos marcadores 71

TABELA 4.1 - Solventes e reagentes usados na síntese dos complexos de terras raras, nanopartículas poliméricas e imunoensaios 90 
TABELA 5.1 - Análise elementar de C, H, S e titulação complexométrica de $\mathrm{TR}^{3+}$ 122

TABELA 5.2 - Atribuição das frequências $\left(\mathrm{cm}^{-1}\right)$ dos principais modos vibracionais dos complexos de acac de térbio e gadolínio estudados 127

TABELA 5.3 - Atribuição das frequências $\left(\mathrm{cm}^{-1}\right)$ dos principais modos vibracionais dos complexos contendo tta de európio e gadolínio Estudados 130

TABELA 5.4 - Dados de perda de massa dos complexos [ $\mathrm{Tb}(\mathrm{acac})_{3}(\mathrm{TPPO})_{2}$ ], $\left[\mathrm{Tb}(\mathrm{acac})_{3}(\mathrm{TOPO})_{2}\right],\left[\mathrm{Tb}(\mathrm{acac})_{3}(\mathrm{DB} 18 \mathrm{C} 6)_{2}\right]$ e $\left[\mathrm{Tb}(\mathrm{acac})_{3}(18 \mathrm{C} 6)_{2}\right]$ no intervalo de temperatura 0 a $1000^{\circ} \mathrm{C}$ 135

TABELA 5.5 - Dados de perda de massa dos complexos [Eu(tta $)_{3}(\mathrm{TPPO})_{2}$ ], $\left[\mathrm{Eu}(\mathrm{tta})_{3}(\mathrm{TOPO})_{2}\right], \quad\left[\mathrm{Eu}(\mathrm{tta})_{3}(\mathrm{DB} 18 \mathrm{C} 6)_{2}\right]$ e $\left[\mathrm{Eu}(\mathrm{tta})_{3}(18 \mathrm{C} 6)_{2}\right]$ no intervalo de temperatura 0 a $1000 \stackrel{\circ}{C}$ 138

TABELA 5.6 - Atribuição do estado $T_{1}$ emissor dos ligantes $\beta$-dicetonatos e ligantes auxiliares a partir dos dados espectrais dos complexos de $\mathrm{Gd}^{3+}$ no estado estacionário 160

TABELA 5.7 - Transições oriundas do estado emissor ${ }^{5} \mathrm{D}_{4}$ para os níveis ${ }^{7} \mathrm{~F}_{\mathrm{J}}$ 163 
TABELA 5.8 - Faixas espectrais, intensidades relativas e baricentros usualmente observados para as transições ${ }^{5} \mathrm{D}_{4} \rightarrow{ }^{7} \mathrm{~F}_{\jmath}$ do íon $\mathrm{Tb}^{3+}$ 164

TABELA 5.9 - Energias das transições ${ }^{5} \mathrm{D}_{4} \rightarrow{ }^{7} \mathrm{~F}_{\mathrm{J}}$ referentes aos espectros de emissão dos complexos $\left[\mathrm{Tb}(\mathrm{acac})_{3}(\mathrm{~L})_{2}\right]$; valores $\mathrm{em} \mathrm{cm}^{-1} ; 298 \mathrm{~K}$ 168

TABELA 5.10 -Tempos de vida do nível emissor do $\mathrm{Tb}^{3+}$ 173

TABELA 5.11 - Faixas espectrais, intensidades relativas e baricentros freqüentemente observados para as transições ${ }^{5} \mathrm{D}_{0} \rightarrow{ }^{7} \mathrm{~F}_{\mathrm{J}}$ do íon $\mathrm{Eu}^{3+}$ 176

TABELA 5.12 - Atribuição das energias das transições ${ }^{5} \mathrm{D}_{0} \rightarrow{ }^{7} \mathrm{~F}_{0-4}\left(\mathrm{~cm}^{-1}\right)$ observados nos espectros de emissão dos complexos $\left[\mathrm{Eu}(\mathrm{TTA})_{3} \cdot(\mathrm{L})_{2}\right]$ onde $L=$ $\mathrm{H}_{2} \mathrm{O}$ TPPO, TOPO, DB18C6 e 18C6, a $300 \mathrm{~K}$ 181

TABELA 5.13 - Tempos de vida do nível emissor do $\mathrm{Eu}^{3+}$ 183

TABELA 5.14 - Parâmetros de intensidade experimental $\left(\Omega_{\lambda}\right)$, eficiência

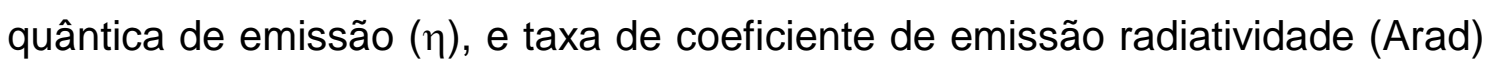
e não radiatividade (Anrad) para os complexos $\left[\mathrm{Eu}(\mathrm{tta})_{3}(\mathrm{~L})_{2}\right]$ 186

TABELA 5.15 - Valores aproximados das coordenadas de cores dos materiais funcionalizados 190 
TABELA 5.16 - Atribuição das frequências $\left(\mathrm{cm}^{-1}\right)$ dos principais modos vibracionais das nanopartículas poliméricas $\mathrm{PHB}$ 197

TABELA 5.17 - Atribuição das frequências $\left(\mathrm{cm}^{-1}\right)$ dos principais modos vibracionais das nanopartículas poliméricas PMMA 197

TABELA 5.18 - Dados de perda de massa dos sistemas poliméricos PMMA:X\%[Eu(tta) $)_{3}(\mathrm{TOPO})_{2}(\mathrm{X}=0,5 ; 1 ; 3 ; 5 ; 7 ;)$ no intervalo de temperatura 0 a $540 \stackrel{\circ}{\mathrm{C}}$ 202

TABELA 5.19 - Dados de perda de massa dos sistemas poliméricos $\mathrm{PHB}: \mathrm{X} \% \mathrm{Eu}(\mathrm{tta})_{3}(\mathrm{TOPO})_{2}(\mathrm{X}=0,5 ; 1 ; 3 ; 5 ; 7)$ no intervalo de temperatura 0 a $540 \stackrel{\circ}{\mathrm{C}}$ 219

TABELA 5.20 - Energias do estado $T_{1}$ das NPs poliméricas dopadas com complexo de gadolínio em diferentes concentrações $\mathrm{X} \%\left[\mathrm{Gd}(\mathrm{tta})(\mathrm{TOPO})_{2}\right](\mathrm{X}=$ $0,5 ; 1 ; 3 ; 5$ e 7$)$ 225

TABELA 5.21 - Parâmetros de intensidade experimental $\left(\Omega_{\lambda}\right)$, eficiência quântica de emissão $(\eta)$, tempos de vida $(\tau)$, e taxa de coeficiente de emissão radiatividade (Arad) e não radiatividade (Anrad) para amostras dos sistemas PMMA e PHB, e para os complexos $\left[\mathrm{Eu}(\mathrm{tta})_{3}(\mathrm{~L})_{2}\right]$ 228

TABELA 5.22 - Concentração de aminas primárias das nanopartículas aminofuncionalizadas antes da reação com o glutaraldeído, em mmol mg-1, determinadas pelo método da ninidrina 256 
TABELA 5.23 - Concentração de aminas primárias das nanopartículas aminofuncionalizadas após a reação com o glutaraldeído, em $\mathrm{mmol}^{\mathrm{mg}^{-1}}$, determinadas pelo método da ninidrina 256

TABELA 6.1 - Valores das emissões de sinal luminescente nas diferentes concentrações de cada espécie biológica utilizada nos imunoensaios de conjugação:IgG, amostras padrão (17ß-estradiol-nanomarcador), anti-17ßestradiol e amostras branco (IgG-anti-17ß-estradiol-17ß-estradiol) 282 
1

INTRODUÇÃO 


\section{INTRODUÇÂO}

Nanociência é o estudo das propriedades das estruturas em dimensão mais reduzida, da ordem de várias centenas de nanômetros $(\mathrm{nm})$. A nanotecnologia consiste em técnicas para a concepção e fabricação destas estruturas, bem como aplicações decorrentes destas.

O desenvolvimento da nanociência e da nanotecnologia está alinhado com a tendência de miniaturização (FIG. 1.1). As barreiras entre as tradicionais disciplinas científicas e tecnológicas tornaram-se mais permeáveis. Hoje, há uma forte interação entre a eletrônica, química, física, biologia, ciências médicas, ciências da informação e comunicação. Isto é descrito como um processo de "convergência" de áreas do conhecimento [1]. Dentro deste contexto, uma das maiores expectativas para a sua aplicação reside na biotecnologia e na área de saúde, nomeadamente nas implicações que podem ter na qualidade da saúde para as sociedades futuras ${ }^{[2]}$.

O desenvolvimento de nanomateriais luminescentes, não tóxicos e biocompatíveis que estão sendo buscados para utilização de marcação biológica, visualização de células em biologia celular e imunoensaios ultrassensíveis tem sido um desafio ${ }^{[3,4]}$. Neste caso, tentou-se contribuir na área de marcação biológica, através da obtenção de marcadores biológicos à base de terras raras para a detecção do 17ß-estradiol (E2), pertencente à classe hormonal dos estrogênios, sendo o esteróide ovariano circulante predominante ${ }^{[5]}$, em fluido biológico, no caso, o plasma sanguíneo. Tem-se como interesse principal a identificação e quantificação deste hormônio para viabilizar a detecção de doenças responsivas ao nível sérico deste, responsável por diversas condições clínicas, tendo como objetivo opções diagnósticas, conduta extremamente importante para direcionamento terapêutico.

As aplicações dos fósforos de terras raras são inúmeras e têm alcançado uma posição importante na sociedade moderna. Na biologia e na medicina, os elementos terras raras têm sido extensivamente estudados, 
devido às suas propriedades excepcionais, principalmente as espectroscópicas e magnéticas que tem características ímpares ${ }^{[4]}$. Os íons lantanídeos, todavia, interagem com materiais biológicos através de ligações específicas onde entidades, aqui designadas como espaçadores, são responsáveis por estes tipos de interação. Esse método baseado no uso de marcadores luminescentes conjugados às espécies biológicas de reconhecimento é chamado de fluoroimunoensaio e é utilizado na detecção e quantificação de: enzimas, anticorpos, células, hormônios, entre outros, além de atuarem na clivagem de DNA ${ }^{[5-8]}$.

As vantagens em utilizar os íons lantanídeos como marcadores luminescentes para detecção de espécies biológicas são várias, podendo-se listar: é um método seguro, de baixo custo e apresenta maior especificidade ${ }^{[9]}$. Os ensaios são mais sensíveis que radioimunoensaios, e a luminescência pode ser medida rapidamente, com alto grau de sensibilidade e exatidão ${ }^{[10-17]}$.

Desenvolver um material luminescente que identifique o $17 \beta$-estradiol no plasma sanguíneo nos leva, respectivamente, à sinalização de anormalidades pelo desencadeamento de oscilações em nível sérico deste hormônio, oscilações estas específicas ao subtipo estrogênico alvo deste trabalho, o $17 \beta$ estradiol. 


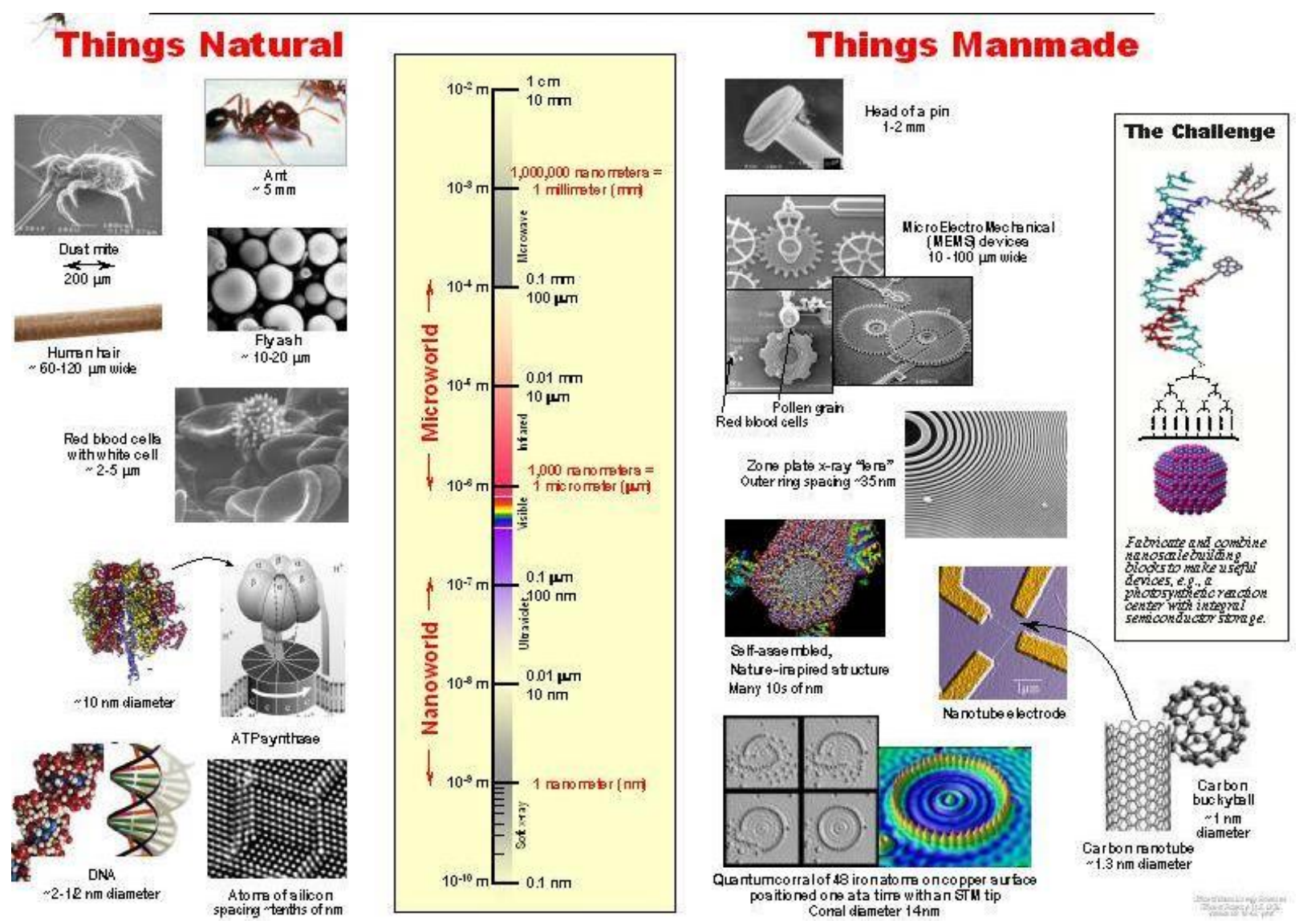

FIGURA 1.1 - A escala métrica de elementos naturais e dos produzidos pelo homem. ${ }^{[18]}$. 


\section{REFERÊNCIAS BIBLIOGRÁFICAS}

[1] EUGÉNIO, J.; FATAL, V. Evolução da Nanotecnologia - Abordagem Nacional e Internacional. INPI, Julho 2010, [URL: http://www.marcasepatentes.pt/files/collections/pt_PT/1/300/303/Evolu\%C3\%A 7\%C3\%A30\%20da\%20Nanotecnologia\%20\%20Abordagem\%20Nacional\%20e \%20Internacional.pdf], acedido em 21-03-2013.

[2] PARREIRA, D.B.; EUGÉNIO, J. Nanopartículas para aplicação oncológica. INPI, Outubro $2011 . \quad$ [URL: http://www.marcasepatentes.pt/files/collections/pt_PT/1/300/303/Nanopart\%C3 \%ADculas\%20para\%20aplica\%C3\%A7\%C3\%A30\%20oncol\%C3\%B3gica.pdf], acedido em 21-03-2013.

[3] WHITE, G. F.; LITVINENKO, K. L.; MEECH, S. R.; ANDREWS, D.L.; THOMSON, A.J. Multiphoton-excited luminescence of a lanthanide ion in a protein complex: $\mathrm{Tb}(3+)$ bound to transferrin. Photochem. Photobiol . Sci., 3, $47-55,2004$.

[4] MARTINS, T.S.; ISOLANI, P.C. Rare Earths: industrial and biological applications. Química Nova, vol. 28, p. 11-117, 2005.

[5] FRUZZETTI, F.; BITZER, J. Review of clinical experience with estradiol in combined oral contraceptives. Contraception, v.81, Issue 1, Italy, 2010.

[6] WILMOTT, N.S.; MILLER, J.N.; TYSON, J.F. Analyst March, 109, 343, 1984.

[7] HEMMILA, I.; Fluoroimmunoassays and immunofluorometric assays. Clinical Chemistry, v. 31, p.359-70, 1985. 
[8] HEMMILA, I. J. Luminescent Lanthanide Chelates - A way to more sensitive diagnostic methods. Journal of Alloys Compounds. 225 (1-2), p. 480-485, 1995.

[9] PEURALAHTI, J.; PUUKKA K.; HAKALA H.; MUKKALA, V.M.; MULARI O.; HURSKAINEN P., HOVINEN J. Bioconjugate Chem. 13:876, 2002.

[10] VILA NOVA, S.P. Novos macrociclos de lantanídeos: marcadores fotônicos projetados para aplicações biotecnológicas. (Tese doutorado) Departamento de Química Fundamental, Universidade Federal de Pernambuco, 2003.

[11] FENG, S.; WANG, J.; CHEN, X., FAN, J. Spectrochim. Acta. Part A 61, $841,2005$.

[12] PALEOLOGOS, E. K.; STALIKAS, C. D.; TZOUWARA-KARAYANNI, S. M.; KARAYANNIS, M. I. Anal. Chim. Acta 436(1), 49, 2001.

[13] SONG, Z. H.; ZHANG, N. Talanta 60, 161, 2003.

[14] TANG, Z.; GRAEFE, K.; MARCH, C.; KARNES, H. T. Microchim. Acta. 144, 1, 2004.

[15] CHEN, G.; SCHNEIDER, M. J.; DARWISH, A. M.; LEHOTAY, S. J.; FREEMAN, D. W. Europium-sensitized luminescence determination of oxytetracycline in catfish muscle. Talanta. 64(1):252-7, 2004

[16] SCHNEIDER, M. J.; J. Agric. Food Chem. 54, 7809, 2004.

[17] CHEN, X.; LIU, Y.;TU, D. Lanthanide-Doped Luminescent Nanomaterials From Fundamentals to Bioapplications, Springer-Verlag Berlin Heidelberg, 208p., 2014. 
[18] National Nanotechnology Initiative. Nano.gov http://www.nano.gov/html/facts/The_scale_of_things.html , acedido em $15 / 04 / 2014$. 


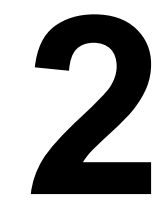

OBJETIVOS 


\section{OBJETIVOS}

Este trabalho tem como principal objetivo preparar e caracterizar nanopartículas poliméricas de poli-(3-hidroxibutirato) (PHB) e poli(metilmetacrilato de metila) (PMMA) dopadas com complexos de terras raras, visando à obtenção de marcadores luminescentes de tempo de vida longo para utilização em ensaios biológicos, mais especificamente na atuação em diagnóstico para dosagem do estrogênio $17 \beta$ - estradiol.

Como objetivos específicos pode-se citar:

- Preparar complexos de terras raras trivalentes $\left(\mathrm{TR}^{3+}\right)$ hidratados, em que $\mathrm{TR}^{3+}=\mathrm{Eu}^{3+}, \mathrm{Gd}^{3+}$ e $\mathrm{Tb}^{3+}$, contendo ânions acetilacetonato (acac') e 2tenoiltrifluoroacetonato (tta'), e ligantes orgânicos auxiliares: fosfinóxidos, como o trifenilfosfinóxido (TPPO), e o óxido de trioctilfosfina (TOPO), e ligantes macrocíclicos como os éteres coroa: Dibenzo-18-Coroa-6 (DB18C6) e o 18-Coroa-6 (18C6)

- Caracterizar estes complexos e estudar suas propriedades espectroscópicas.

- Após caracterização e estudo das propriedades espectroscópicas destes complexos, utilizar o(s) de melhor eficiência luminescente para a obtenção de nanopartículas poliméricas dopadas com este (s) luminóforo (s).

- Caracterizar e estudar as propriedades luminescentes destas nanopartículas poliméricas.

- Funcionalizar estas nanopartículas com entidades químicas, daqui por diante designados espaçadores, para atuarem como pontes de ligação na bioconjugação dando origem aos marcadores biológicos.

- De posse destas nanopartículas, desenvolver um método para utilizar estes materiais em reações de conjugação com a parte biológica de interesse. 


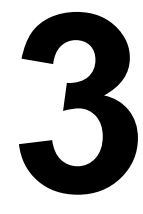

REVISÃO

\section{BIBLIOGRÁFICA}




\section{REVISÃO BIBLIOGRÁFICA}

\subsection{A Química das Terras Raras}

A FIGURA 3.1 apresenta a tabela periódica onde se podem observar os elementos terras raras (TR), que segundo a classificação da IUPAC (International Union of Pure and Applied Chemistry) compreendem 17 elementos a partir do lântanio (La) até o lutécio (Lu), incluindo o escândio (Sc) e o ítrio (Y). Os elementos da série do lantânio restringem o número de elementos e compreendem os elementos a partir do La até o Lu. Os lantanídeos restringem ainda mais o número de elementos e compreendem os elementos a partir do Cério (Ce) ao Lutécio (Lu) ${ }^{[1-3]}$.

\begin{tabular}{|c|c|c|c|c|c|c|c|c|c|c|c|c|c|c|c|c|c|}
\hline $\mathrm{Li}$ & $\mathrm{Be}$ & & & & & & & & & & & B & C & $\mathrm{N}$ & $\mathrm{O}$ & $\mathrm{F}$ & $\mathrm{Ne}$ \\
\hline $\mathrm{Na}$ & $\mathrm{Mg}$ & & & & & & & & & & & Al & $\mathrm{Si}$ & $P$ & S & $\mathrm{Cl}$ & $\mathrm{Ar}$ \\
\hline $\mathrm{K}$ & $\mathrm{Ca}$ & $\mathrm{Sc}$ & $\mathrm{T}_{\mathrm{i}}$ & $\mathrm{V}$ & $\mathrm{Cr}_{\mathrm{r}}$ & $\mathrm{Mn}$ & $\mathrm{Fe}$ & $\mathrm{Co}$ & $\mathrm{Ni}$ & $\mathrm{Cu}$ & $\mathrm{Zn}_{\mathrm{n}}$ & $\mathrm{Ga}$ & $\mathrm{Ge}$ & As & $\mathrm{Se}$ & $\mathrm{Br}$ & $\mathrm{Kr}$ \\
\hline $\mathrm{Rb}$ & $\mathrm{Sr}$ & $\mathrm{Y}$ & $\mathrm{Zr}$ & $\mathrm{Nb}$ & Mo & $\mathrm{Tc}_{\mathrm{c}}$ & $\mathrm{Ru}$ & $\mathrm{Rh}$ & $\mathrm{Pd}$ & $\mathrm{Ag}$ & $\mathrm{Cd}$ & In & $\mathrm{Sn}_{\mathrm{n}}$ & $\mathrm{Sb}$ & $\mathrm{Te}$ & I & $\mathrm{Xe}$ \\
\hline$C_{s}$ & $\mathrm{Ba}$ & $\mathrm{La}$ & $\mathrm{Hf}$ & $\mathrm{Ta}$ & W & $\operatorname{Re}$ & Os & Ir & $\mathrm{Pt}$ & $\mathrm{Au}$ & $\mathrm{Hg}$ & $\mathrm{T} 1$ & $\mathrm{~Pb}$ & $\mathrm{Bi}$ & Po & At & $\mathrm{Rn}_{n}$ \\
\hline$F_{r}$ & $\mathrm{Ra}$ & $A c$ & $\mathrm{Rf}$ & $\mathrm{Db}$ & $\mathrm{Sg}$ & $\mathrm{Bh}$ & $\mathrm{Hs}$ & $\mathrm{M}$ & 110 & 111 & 112 & & & & & & \\
\hline
\end{tabular}

\begin{tabular}{|l|l|l|l|l|l|l|l|l|l|l|l|l|l|}
\hline $\mathrm{Ce}$ & $\mathrm{Pr}$ & $\mathrm{Nd}$ & $\mathrm{Pm}$ & $\mathrm{Sm}$ & $\mathrm{Eu}$ & $\mathrm{Gd}$ & $\mathrm{Tb}$ & $\mathrm{Dy}$ & $\mathrm{Ho}$ & $\mathrm{Er}$ & $\mathrm{Tm}$ & $\mathrm{Yb}$ & $\mathrm{Lu}$ \\
\hline $\mathrm{Th}$ & $\mathrm{Pa}$ & $\mathrm{U}$ & $\mathrm{Np}$ & $\mathrm{Pu}$ & $\mathrm{Am}$ & $\mathrm{Cm}$ & $\mathrm{Bk}$ & $\mathrm{Cf}$ & $\mathrm{Es}$ & $\mathrm{Fm}$ & $\mathrm{Md}$ & $\mathrm{No}$ & $\mathrm{Lw}$ \\
\hline
\end{tabular}

FIGURA 3.1 - Tabela periódica dos elementos.

Os elementos lantanídeos apresentam grande similaridade entre si no que se refere às propriedades químicas e físicas. As mudanças de suas 
propriedades são muito pequenas com o aumento do número atômico. Tanto que os elementos La e Lu apresentam comportamento químico muito mais similar do que elementos alcalinos adjacentes como sódio e potássio ${ }^{[1,2]}$.

A química das TR é predominantemente iônica e determinada principalmente pelo tamanho de seus cátions trivalentes. Deve-se mencionar ainda que o ítrio apresenta-se também como cátion tripositivo semelhante, com o núcleo de gás nobre, e tem raios atômico e iônico próximos aos valores dos elementos térbio ( $\mathrm{Tb}$ ) e disprósio (Dy). Ele se encontra na natureza acompanhando os lantanídeos e se assemelha aos cátions $\mathrm{Tb}^{3+}$ e $\mathrm{Dy}^{3+}$ em seus compostos. Já o escândio, situado no mesmo Grupo III juntamente com Y e La, tem raio iônico menor, de modo que seu comportamento químico permite situá-lo entre o alumínio (Al) e os lantanídeos.

Os potenciais de ionização são relativamente baixos, de modo que as TR são altamente eletropositivas e seus compostos são essencialmente iônicos. Todos os lantanídeos, $\mathrm{Y}$ e Sc, formam cátions trivalentes $\left(\mathrm{R}^{3+}\right)$. Alguns lantanídeos podem apresentar os estados $+\mathrm{Il}$, e $+\mathrm{IV}$, i.e., $\mathrm{R}^{\mathrm{Z+}}$ e $\mathrm{R}^{4+}$, mas estes íns são sempre menos estáveis que os cátions trivalentes. Sc, $Y$ e La formam somente íons $R^{3+}$, pois a retirada de três elétrons conduz à configuração de gás nobre. Semelhantemente gadolínio (Gd) e Lu formam apenas cátions $R^{3+}$, pois eles têm os estados estáveis $4 f^{7}$ e $4 f^{14}$. Nesses cinco elementos nunca é possível remover menos de três elétrons quimicamente, porque os cátions $R^{2+}$ e $\mathrm{R}^{+}$teriam tamanhos muito maiores que os correspondentes cátions $\mathrm{R}^{3+[3]}$.

Os íons $\mathrm{R}^{2+}$ e $\mathrm{R}^{4+}$ mais estáveis são formados pelos elementos que podem apresentar as configurações $f^{0}$ e $f^{7}$ ou $f^{14}$, como é o caso do $C e^{+}$ (configuração fi) e $\mathrm{Tb}^{4+}$ (configuração $f^{T}$ ), enquanto os divalentes $\mathrm{Eu}^{2+}$ e $\mathrm{Yb}^{2+}$ são estabilizados pelas configurações $f^{T}$ e $f^{14}$, respectivamente ${ }^{[2]}$.

Vários dos lantanídeos se apresentam como íons coloridos, e o aparecimento da cor é devido às transições f-f. Interessante é observar que a sequência das cores se repete em duas séries, La a Gd, e Lu a Gd, e, como consequência das transições $f-f$, virtualmente as cores são independentes do ambiente dos íons (TAB. 3.1).

Importante destaque no comportamento espectroscópico das TR é a existência dos fenômenos de luminescência ou fluorescência de certos íons, 
especialmente Eu e Tb, quando usados como ativadores em óxidos, silicatos e outros "fósforos". Alguns ânions de complexos orgânicos das $\mathrm{TR}^{3+}$ apresentam

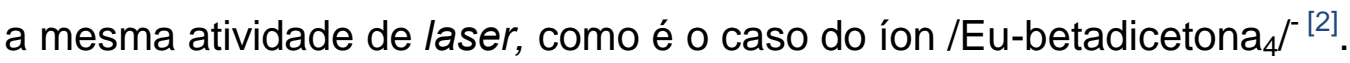

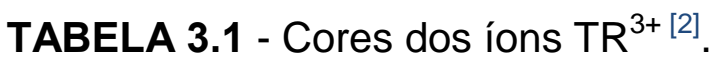

\begin{tabular}{llll}
\hline Íon & Cor & Íon & Cor \\
\hline La & Incolor & Lu & Incolor \\
Ce & Incolor & Yb & Incolor \\
Pr & Verde & Tm & Verde \\
Nd & Lilás & Er & Lilás \\
Pm & Róseo, amarelo & Ho & Róseo, amarelo \\
Sm & Amarelo & Dy & Amarelo \\
Eu & Róseo claro & Tb & Verde \\
Gd & Incolor & Gd & Incolor \\
\hline
\end{tabular}

As cores das $\mathrm{TR}^{3+}$, apresentadas como observação por visão direta, sempre apresentam algumas diferenças, variando de autor para autor. $\mathrm{Na}$ TABELA 3.2 estão indicadas as cores em função dos estados de valência, em solução. 
TABELA 3.2 - Observação visual das cores das TR ${ }^{[2]}$.

\begin{tabular}{|cccc|}
\hline Íons & Cor & Íons & Cor \\
\hline La-III & Incolor & Gd-III & Incolor \\
\hline Ce-III & Incolor & Tb-III & levemente róseo \\
\hline Ce-IV & vermelho, laranja & Ho-III & Amarelo \\
\hline Pr-III & Verde & Er-III & Avermelhado \\
\hline Nd-III & Avermelhado & Tm-III & Verde \\
\hline Sm-III & Avermelhado & Yb-III & Incolor \\
\hline Sm-II & Avermelhado & Lu-Lii & Incolor \\
\hline Eu-II & amarelo pálido & Y-III & Incolor \\
\hline Eu-III & levemente róseo & & \\
\hline
\end{tabular}

\subsubsection{Estado Trivalente das Terras Raras}

O estado trivalente é característico para todas as TR. Elas formam óxidos do tipo $\mathrm{R}_{2} \mathrm{O}_{3}$, parecidos com os óxidos dos elementos alcalino-terrosos, como $\mathrm{CaO}$ e $\mathrm{BaO}$, absorvem dióxido de carbono e água do ar para formar os correspondentes carbonatos e hidróxidos, respectivamente. Os hidróxidos, $\mathrm{R}(\mathrm{OH})$ s, são compostos definidos, com estrutura hexagonal, e não apenas óxidos hidratados. A basicidade dos hidróxidos decresce com o aumento do número atômico, o que é esperado pela diminuição do raio iônico. Eles são precipitados de soluções aquosas por $\mathrm{NH}_{3}, \mathrm{NH}_{4} \mathrm{OH}$ ou hidróxidos alcalinos diluídos; os precipitados são gelatinosos, mas não são anfóteros. Dos haletos, os fluoretos são de particular importância por causa de sua insolubilidade, a adição de ácido fluorídrico ou de íons fluoreto às soluções contendo os cátions $\mathrm{R}^{3+}$ precipitam os fluoretos, mesmo em $\mathrm{HNO}_{3} 3 \mathrm{M}$, o que constitui um dos testes característicos das $\mathrm{TR}^{3+}$. Os fluoretos, especialmente dos lantanídeos pesados, são levemente solúveis em excesso de ácido fluorídrico devido à formação de complexos ${ }^{[2]}$. Os fluoretos das TR podem ser redissolvidos em $\mathrm{HNO}_{3} 3 \mathrm{M}$ saturado com ácido bórico, removendo o fluoreto como $\mathrm{BF}_{4}$. 
Os cloretos de $\mathrm{TR}^{3+}$ são solúveis em água, de onde podem ser recristalizados como hidratos. Os do grupo La-Nd geralmente cristalizam com $7 \mathrm{H}_{2} \mathrm{O}$ e os do grupo $\mathrm{Nd}-\mathrm{Lu}$, incluíndo o $\mathrm{Y}$, com $6 \mathrm{H}_{2} \mathrm{O}$; outros hidratos podem também ser obtidos.

Os cloretos anidros não podem ser obtidos facilmente a partir dos hidratos correspondentes, por aquecimento, pois perdem $\mathrm{HCl}$ para formarem os oxicloretos $(\mathrm{MOCl})$ mais facilmente do que perdem água. Porém, Sc e Ce formam os óxidos $\mathrm{SC}_{2} \mathrm{O}_{3}$ e $\mathrm{CeO}_{2}$ quando desidratatos em atmosfera de ar. Uma via usada para a obtenção dos cloretos anidros é o aquecimento da mistura com cloreto de amônio ${ }^{[2]}$ a $300{ }^{\circ} \mathrm{C}: \mathrm{R}_{2} \mathrm{O}_{3}+6 \mathrm{NH}_{4} \mathrm{Cl} \rightarrow 2 \mathrm{RCl}_{3}+3 \mathrm{H}_{2} \mathrm{O}+$ $6 \mathrm{NH}_{3}$. Uma segunda via, mais dispendiosa, é o tratamento dos metanolatos $\mathrm{RCL}_{3} .4 \mathrm{H}_{3} \mathrm{COH}$ com 2,2,-dimetoxipropano) ${ }^{[2,4]}$.

Os brometos e iodetos são semelhantes aos cloretos. Os sulfetos, que apresentam propriedades semicondutoras, podem ser obtidos pela reação dos

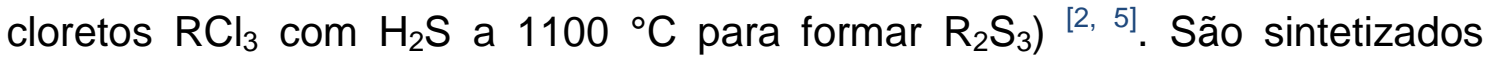
também os compostos das $\mathrm{TR}^{3+}$ com os elementos da família V: RN, RP,RAs, RBi e são conhecidos também os boretos do tipo $R_{4}$ e $R B_{6}$ e os carbetos $M C_{2}$ e $\mathrm{M}_{2} \mathrm{C}_{3}$, de interesse em cerâmicas especiais.

Os sais hidratados contendo os cátions $/ R\left(\mathrm{H}_{2} \mathrm{O}\right)_{n} /^{3+}$ são facilmente preparados pela dissolução dos óxidos com os ácidos comuns e depois cristalizados. Uma das propriedades das $\mathrm{TR}^{3+}$ é a formação de sais duplos. Os nitratos duplos do tipo $2 \mathrm{R}\left(\mathrm{NO}_{3}\right)_{3} \cdot 3 \mathrm{Mg}\left(\mathrm{NO}_{3}\right)_{2} .24 \mathrm{H}_{2} \mathrm{O}$ e R(NO$\left.)_{3}\right)_{3} \cdot 2 \mathrm{NH}_{4} \mathrm{NO}_{3} \cdot 4 \mathrm{H}_{2} \mathrm{O}$ e os sulfatos duplos $\mathrm{R}_{2}\left(\mathrm{SO}_{4}\right)_{3} .2 \mathrm{Na}_{2} \mathrm{SO}_{4} .12 \mathrm{H}_{2} \mathrm{O}$ têm importância no fracionamento das $\mathrm{TR}^{3+}$. Os sulfatos duplos são classificados em dois grupos, de acordo com sua solubilidade: Grupo do Cério: La-Eu e Grupo do Ítrio: Gd-Lu e Y.

Os oxalatos são sais pouco solúveis de muita importância na tecnologia das $\mathrm{TR}^{3+}$. São precipitados quantitativamente de soluções ácidas diluídas e permitem uma separação específica e seletiva das $\mathrm{TR}^{3+}$ como um grupo, permitindo ainda a determinação como óxidos após a calcinação.

Os fosfatos são sais pouco solúveis em ácidos diluídos. Os carbonatos das $\mathrm{TR}^{3+}$ são sais pouco solúveis em água e têm papel importante na tecnologia das $\mathrm{TR}^{3+}$. Dos carbonatos, um grande número é de carbonatos 
básicos. Os carbonatos normais são melhores obtidos pela hidrólise dos cloracetatos $^{[2,3]}$.

\subsection{2 Óxidos de Terras Raras}

Os óxidos das TR são obtidos por calcinação dos oxalatos: nitratos, hidróxidos e sulfatos acima de $800^{\circ} \mathrm{C}$. O praseodímio e o térbio dão óxidos de composição compreendida entre dióxido e sesquióxido e, quando reduzidos com hidrogênio acima de $800^{\circ} \mathrm{C}(\mathrm{Pr})$ e $500^{\circ} \mathrm{C}(\mathrm{Tb})$, produzem os sesquióxidos $\mathrm{Pr}_{2} \mathrm{O}_{3}$ e $\mathrm{Tb}_{2} \mathrm{O}_{3}$.

No caso do Cério, o óxido obtido é $\mathrm{CeO}_{2}$, de cor amarelo pálido. Quando obtido pela calcinação do sulfato básico ao ar, acima de $1000{ }^{\circ} \mathrm{C}$, apresenta-se esbranquiçado. $\mathrm{O}$ óxido de Lantânio, $\mathrm{La}_{2} \mathrm{O}_{3}$, branco, absorve com facilidade $\mathrm{CO}_{2}$. O sesquióxido de Praseodímio, $\mathrm{Pr}_{2} \mathrm{O}_{3}$, amarelo-esverdeado, passa a óxidos intermediários entre $\mathrm{Pr}_{2} \mathrm{O}_{3}$ e $\mathrm{PrO}_{2}$, quando aquecido ao ar. Pela calcinação do oxalato ao ar forma-se $\mathrm{Pr}_{6} \mathrm{O}$ marrom escuro. $\mathrm{O}$ dióxido $\mathrm{PrO}_{2}$ puro é preto, mas obtido por oxidação anódica de $\mathrm{Pr}_{2} \mathrm{O}_{3}$ fundido em $\mathrm{KOH} \cdot \mathrm{H}_{2} \mathrm{O}$, ou então por decomposição térmica do nitrato a $4000{ }^{\circ} \mathrm{C}{ }^{[2]}$.

$\mathrm{O}$ óxido $\mathrm{Nd}_{z} \mathrm{O}_{3}$ é pálido lilás, com nuance azul quando puro, mas traços de $\mathrm{PrZO}_{3} \mathrm{O}$ torna castanho. Absorve $\mathrm{CO}_{2}$ do ar e se transforma em carbonato róseo pálido.

$\mathrm{O}$ óxido $\mathrm{Eu}_{\mathrm{z}} \mathrm{O}_{3}$ é róseo pálido. $\mathrm{O}$ óxido $\mathrm{Tb}_{\mathrm{z}} \mathrm{O}_{3}$ é branco quando obtido por calcinação do oxalato e tratado com $\mathrm{H}_{2}$ quente. Aquecido ao ar se transforma em $\mathrm{Tb}_{4} \mathrm{O}_{7}$, castanho escuro.

Os óxidos básicos mais fortes deslocam $\mathrm{NH}_{3}$ dos sais de amônio e absorvem $\mathrm{CO}_{2}$ do ar ${ }^{[2]}$.

Os óxidos de terras raras utilizados neste trabalho foram: $\mathrm{Tb}_{4} \mathrm{O}_{7}, \mathrm{Eu}_{2} \mathrm{O}_{3}$ e $\mathrm{Gd}_{2} \mathrm{O}_{3}$. 


\subsubsection{Cloretos de Terras Raras}

Os cloretos são muito solúveis e cristalizam-se com seis ou, às vezes, sete moléculas de água: $\mathrm{RCb} .6 \mathrm{H}_{2} \mathrm{O}$ ou $\mathrm{RCb} .7 \mathrm{H}_{2} \mathrm{O}$. Os cloretos anidros são obtidos por desidratação a quente com corrente de $\mathrm{HCl}$ anidro ou podem ser obtidos por reação dos $\mathrm{R}_{2} \mathrm{O}_{3}$ com mistura $\mathrm{SCl}_{2}+\mathrm{C}_{12}$ ou vapor de $\mathrm{CCl}_{4}$. Os brometos anidros podem ser obtidos de modo igual. Os iodetos anidros são facilmente obtidos por reação dos $\mathrm{R}_{3} \mathrm{O}_{3} \operatorname{com~} \mathrm{NH}_{41}$ a $400{ }^{\circ} \mathrm{C}$. Os fluoretos anidros podem ser obtidos pela precipitação a partir das soluções de cloretos com HF concentrado, lavando-se os precipitados com etanol absoluto várias vezes. Os haletos são higroscópicos. Os iodetos são amarelados ou verdes escuros, muito solúveis em etanol e piridina, e ao ar se transformam nos iodetos básicos. Os haletos de TR se distribuem entre fase orgânica constituída por álcoois, cetonas e éteres, propriedade essa usada para separar algumas das TR em procedimentos analíticos ${ }^{[2,6]}$.

Os cloretos anidros podem absorver $\mathrm{NH}_{3}$, formando amoniatos com 2,4, 8, 12 e até 20 moléculas de $\mathrm{NH}_{3}$ por RCh. Os cloretos hidratados formam, por secagem ao ar, os correspondentes oxicloretos, que são insolúveis em água.

Os cloretos das terras raras trivalentes $\left(T R^{3+}\right)$ são muito solúveis em água (ca.500g óxido/litro). As soluções são apenas levemente ácidas. Os cloretos cristalizados fundem-se parcialmente e inicia-se a desidratação abaixo de $100{ }^{\circ} \mathrm{C}$. Os cloretos das $\mathrm{TR}^{3+}$ mais leves, mais básicas, se desidratam com apenas leve hidrólise, mas os das TR pesadas são hidrolisados intensamente [2, 7-9].

Os cloretos anidros são obtidos por aquecimento dos cloretos hidratados com cloreto de amônio ou pela reação dos óxidos com carvão e cloro, ou, ainda, com o tratamento com vapor $\mathrm{CCl}_{4}$ em temperaturas elevadas. Os pontos de fusão (PF) dos cloretos anidros variam de 580 a $900{ }^{\circ} \mathrm{C}$ e os pontos de ebulição (PE) de 1400 a $1800{ }^{\circ} \mathrm{C}$; a vaporização já é apreciável a $730-950{ }^{\circ} \mathrm{C}$ [8]. Em altas temperaturas, os cloretos de Sm-III, Eu-III e Yb-III se dissociam para produzir os dicloretos. Os PF aproximados são: $\mathrm{SmClz}-740{ }^{\circ} \mathrm{C}, \mathrm{EuCl}_{z}-$ $727^{\circ} \mathrm{C}$ e $\mathrm{YbCh}-727^{\circ} \mathrm{C}$. Os dicloretos também são obtidos por redução, em solução aquosa, com Zn ou outro metal ativo, com adição de $\mathrm{HCl}$ concentrado 
ou $\mathrm{HCl}$ gasoso. Este procedimento é eficiente para a purificação de európio. Como o íon $\mathrm{Cé}^{+}$oxida o íon cloreto, não se pode obter o cloreto cérico. Os cloretos anidros das $\mathrm{TR}^{3+}$ leves são livremente solúveis (mais de $200 \mathrm{~g} / \mathrm{L}$ ) em metanol, etanol e vários outros mono e poliálcoois ${ }^{[2,9]}$.

\subsection{Luminescência de ĺons Terras Raras}

A história da espectroscopia óptica dos lantanídeos teve seu início no final do século XIX. Entretanto, somente a partir de 1929, com o trabalho de $\mathrm{H}$. A. Bethe ${ }^{[10]}$, o interesse nos lantanídeos cresceu de forma significativa. Bethe estimou a ordem de grandeza da magnitude do campo elétrico cristalino sobre os níveis de energia dos orbitais $4 \mathrm{~d}$ e $4 \mathrm{f}$ a partir de um modelo bastante simples, conhecido como o modelo das cargas pontuais. Oito anos depois, J. H. Van Vleck ${ }^{[11]}$ discutiu o problema das intensidades espectrais dos lantanídeos na presença de um campo cristalino, atribuindo ao espectro de absorção óptico, observado nos experimentos, às transições entre os níveis eletrônicos da configuração $4 \mathrm{f}^{\mathrm{n}}{ }^{[12]}$.

Sabe-se que os elétrons da camada $4 f$ dos íons $\mathrm{TR}^{3+}$ sofrem uma forte blindagem pelos elétrons das camadas externas $5 \mathrm{~s}$ e $5 \mathrm{p}$. Esta blindagem faz com que TR não sintam significativamente a influência do campo cristalino presente no interior das matrizes ou ligantes nos quais estão atrelados, assim estes estados de energia apresentam caráter atômico em diferentes ambientes químicos. Além disso, os íons TR possuem um grande número de níveis que podem proporcionar emissões desde o infravermelho até o ultravioleta, sendo que muitas destas emissões ocorrem na região do visível.

\subsubsection{Intensidades das Transições $4 f \rightarrow 4 f$}

Como dito anteriormente, as propriedades espectroscópicas dos íons $\mathrm{TR}^{3+}$ vêm despertando grande interesse, a partir do trabalho publicado por Van Vleck em $1937^{[13]}$. Segundo Van Vleck as bandas finas presentes nos 
espectros eletrônicos dos compostos $\mathrm{TR}^{3+}$ oriundas de transições intraconfiguracionais $4 \mathrm{f}-4 \mathrm{f}$ deveriam ocorrer principalmente pelo mecanismo de dipolo magnético (DM). No entanto, Broer e colaboradores ${ }^{[14]}$ mostraram semiquantitativamente que as intensidades exibidas pelos íons $\mathrm{TR}^{3+}$ são devidas, principalmente, ao mecanismo de dipolo-elétrico forçado (DEF).

\subsubsection{Teoria Judd-Ofelt}

Uma análise mais detalhada das intensidades das transições intraconfiguracionais $4 f-4 f$ foi feita por Judd ${ }^{[15]}$ e Ofelt ${ }^{[16]}$ em 1962, em publicações independentes.

Posteriormente, esse estudo ficou conhecido como Teoria de Judd-Ofelt, que se baseia na mistura dos termos de uma configuração $4 \mathrm{fN}$ com aqueles de paridades opostas, considerando que as transições intraconfiguracionais são estritamente proibidas por paridade. Uma diferença encontrada nestes dois trabalhos é que no artigo de Judd além de levar em conta o modelo estático, onde são consideradas somente transições puramente eletrônicas, foram incluídas também as contribuições vibrônicas no estudo das transições de DE. A teoria Judd-Ofelt considera que a mistura de estados de configurações opostas é induzida pelas componentes ímpares no Hamiltoniano do campo ligante, $\mathrm{HCL}$ (ímpar).

Pode-se entender das propriedades espectroscópicas observando os mecanismos da absorção e emissão ópticas desses íons:

Absorção: Os íons lantanídeos absorvem radiação em bandas definidas e muito estreitas (transições f-f). De acordo com as regras de seleção para 0 espectro atômico ${ }^{[17]}$, as transições f-f dos íons lantanídeos isolados são proibidas. Esta regra diz que em uma molécula centrossimétrica ou íon, as únicas transições permitidas são aquelas acompanhadas da troca de paridade [18], como por exemplo, a transição f-d. Lembrando que os números quânticos secundários $p$ e $f$ são ímpares e $s$ e $d$ são pares. Assim, por exemplo, quando a simetria do íon é removida com um campo externo anti-simétrico e/ou com a 
mistura de algum estado de paridade oposta, as transições passam a ser permitidas, como as $f-f$, por exemplo. A blindagem dos elétrons do orbital $4 f$ também mostra que o espectro de absorção dos íons lantanídeos é fracamente perturbado depois da complexação desses íons com ligantes orgânicos.

Luminescência: as emissões dos íons TR surgem de transições radiativas entre os níveis de configurações eletrônicas $4 \mathrm{f}^{\mathrm{N}}$. $\mathrm{Na}$ ausência de qualquer interação entre os elétrons, os níveis estariam degenerados. Mas, devido às interações Colombianas, a degenerescência é removida e os níveis separamse, podendo atingir valores próximos de $20.000 \mathrm{~cm}^{-1}$. Existe ainda algumas outras interações que é possível considerar, como é o caso das interações spin-órbita que podem levar a separações da ordem de $1000 \mathrm{~cm}^{-1}$. Os valores relativamente grandes das constantes de acoplamento spin-órbita fazem com que os níveis individuais $\mathrm{J}$ estejam bem separados. Assim, aproximadamente, cada íon lantanídeo trivalente é caracterizado por um estado fundamental, com um valor único do momento orbital angular $\mathrm{J}$ e por um primeiro estado excitado numa energia $\mathrm{kT}$, muitas vezes acima do estado fundamental.

\subsubsection{Efeito Antena}

Em 1942, observou-se que o íon $\mathrm{Eu}^{3+}$ quando ligado a compostos orgânicos apresenta uma intensidade de emissão maior quando o sistema é excitado na transição do ligante ${ }^{[19,20]}$, criando um caminho alternativo, que é chamado de sensibilização de luminescência ou efeito antena ${ }^{[20]}$. A parte orgânica do complexo absorve a radiação ultravioleta que é transferida para o íon $\mathrm{TR}^{3+}$, o qual, por sua vez, emite luz com comprimento de onda característico do íon $\mathrm{TR}^{3+}$. Considera-se que ocorre uma transferência de energia intramolecular do ligante para o íon metálico central, observa-se ainda que a eficiência desta transferência de energia depende da estrutura eletrônica do ligante coordenado ao íon terra rara trivalente ${ }^{[12,19]}$.

A FIGURA 3.2 apresenta o mecanismo de luminescência ${ }^{[21]}$, o qual envolve a absorção de energia pela parte orgânica do complexo. Esta, por sua vez, 
excita os elétrons do estado singleto fundamental $\left(\mathrm{S}_{0}\right)$ ao estado singleto excitado $\left(\mathrm{S}_{1}\right.$, por exemplo). Nesta etapa existem três alternativas:

i) Fluorescência do ligante: ocorre a depopulação do estado singleto excitado com decaimento radiativo de $S_{1}$ para $S_{0}$, a qual resulta em fluorescência de tempo de vida curto. Outra ocorrência seria 0 decaimento não radiativo de $\mathrm{S}_{1}$ pelo processo de conversão interna $(\mathrm{Cl})$.

ii) Fosforescência do ligante: ocorre o processo de cruzamento intersistema (CIS) de $S_{1}$ para o estado tripleto $\left(T_{1}\right)$, a partir do qual a excitação pode decair radiativamente para o estado fundamental por meio de uma transição proibida $\left(T_{1}-S_{0}\right)$, a qual resulta na fosforescência com tempo de vida longo.

iii) Emissão do íon $\mathrm{TR}^{3+}$ : ocorre a transferência de energia (TE) intramolecular do ligante ao estado excitado do íon $\mathrm{TR}^{3+}$, e os estados excitados do íon são depopulados radiativamente para o estado

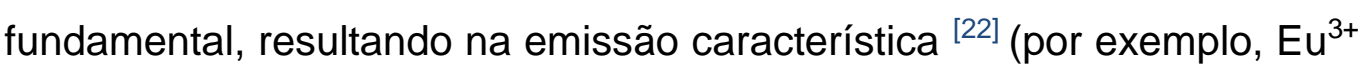
emite a cor vermelha em $\sim 615 \mathrm{~nm}$, a qual origina-se da transição $\left.{ }^{5} \mathrm{D}_{0} \rightarrow{ }^{7} \mathrm{~F}_{2}\right)$. 


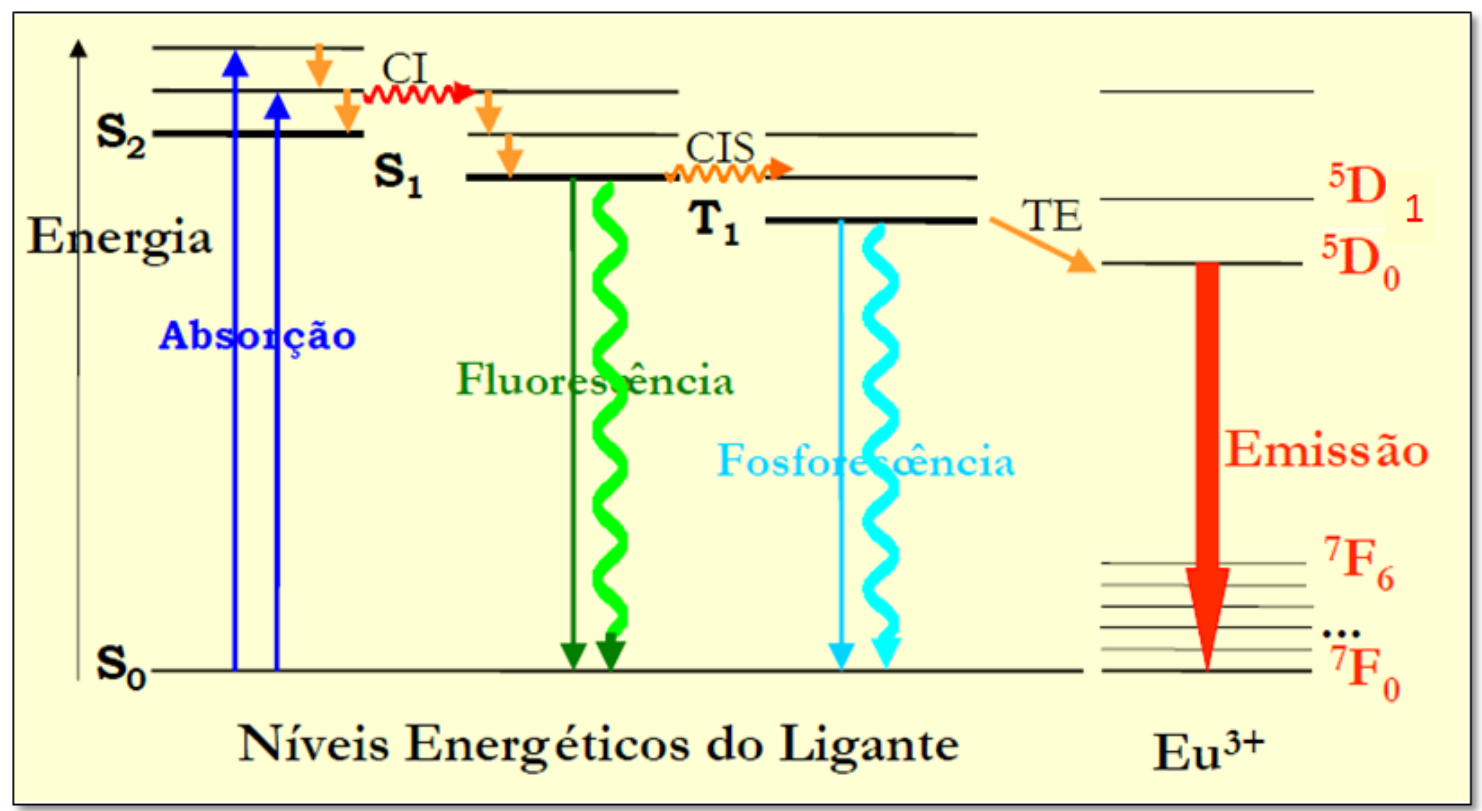

FIGURA 3.2 - Representação esquemática (qualitativa) do mecanismo de transferência de energia entre um ligante orgânico e o íon $\mathrm{Eu}^{3+}(\mathrm{Cl}=$ Conversão Interna/ $\mathrm{CIS}=$ Cruzamento Intersistema/ TE $=$ Transferência de Energia) ${ }^{[12]}$.

As transições características dos íons $\mathrm{TR}^{3+}$ são permitidas por mecanismos de dipolo elétrico forçado (DEF) entre os níveis multipletos ${ }^{[12,20]}$, os quais são resultantes das transições intraconfiguracionais $4 \mathrm{f}^{\mathrm{N}}$. Tais transições podem ser observadas nas linhas de emissão e absorção destes íons. Complexos contendo íons terras raras trivalentes (em particular, $\mathrm{Sm}^{3+}$, $\mathrm{Eu}^{3+}, \mathrm{Tb}^{3+}$ e $\mathrm{Tm}^{3+}$ ) apresentam emissão como resultado da transferência de energia intramolecular dos estados eletrônicos do ligante aos níveis de energia dos íons $\mathrm{TR}^{3+}$. No entanto, para que haja transferência eficiente de energia dos ligantes orgânicos para o íon terra rara central, os níveis de energia do estado tripleto do ligante ou algum de seus níveis populacionais populados devem estar ressoantes com o nível emissor da $\mathrm{TR}^{3+}$ ou localizado logo acima do nível emissor deste ${ }^{[20,23]}$. Desta forma, com os dados espectrais dos compostos dos íons $\mathrm{TR}^{3+}$ é possível quantificar as energias dos níveis fundamentais e excitados destes íons, conforme FIGURA 3.3.

Em princípio, os íons $\mathrm{TR}^{3+}$ podem ser classificados em três grupos ${ }^{[23]}$, em virtude de suas faixas de emissão. São eles: 
1) $\mathrm{Sm}^{3+}, \mathrm{Eu}^{3+}, \mathrm{Tb}^{3+}$ e $\mathrm{Dy}^{3+}$ : são emissores fortes. Todos esses íons têm fluorescências na região visível $\left(\mathrm{Tb}^{3+}: 545 \mathrm{~nm},{ }^{5} \mathrm{D}_{4} \rightarrow{ }^{7} \mathrm{~F}_{4} ; \mathrm{Dy}^{3+}: 573 \mathrm{~nm}\right.$, $\left.{ }^{4} \mathrm{~F}_{9 / 2} \rightarrow{ }^{6} \mathrm{H}_{13 / 2} ; \mathrm{Eu}^{3+}: 614 \mathrm{~nm},{ }^{5} \mathrm{D}_{0} \rightarrow{ }^{7} \mathrm{~F}_{2} ; \mathrm{Sm}^{3+}: 643 \mathrm{~nm},{ }^{4} \mathrm{G}_{5 / 2} \rightarrow{ }^{6} \mathrm{H}_{11 / 2}\right)$.

2) $\mathrm{Er}^{3+}, \mathrm{Pr}^{3+}, \mathrm{Nd}^{3+}, \mathrm{Ho}^{3+}, \mathrm{Tm}^{3+}$ e $\mathrm{Yb}^{3+}$ : são emissores fracos na região do infravermelho próximo. A fraca luminescência desses íons é atribuída ao fato de que eles têm níveis eletrônicos muito próximos uns dos outros, fazendo com que as transições não radiativas sejam favorecidas. Para o íon erbio, ainda existem duas transições características: uma na região do visível, em torno de $550 \mathrm{~nm}\left({ }^{4} S_{3 / 2} \rightarrow{ }^{4} I_{15 / 2}\right)$ e outra em $1,55 \mu \mathrm{m}\left({ }^{4} I_{13 / 2} \rightarrow{ }^{4} I_{15 / 2}\right)$, a mais importante delas, devido às suas aplicações comerciais, como por exemplo, o uso de fibras ópticas dopadas com Érbio em amplificadores de luz.

3) $\mathrm{La}^{3+}, \mathrm{Gd}^{3+}$ e $\mathrm{Lu}^{3+}$ : não exibem fluorescência porque seu primeiro nível excitado está muito acima dos níveis de tripleto de qualquer matriz ou ligante usado comumentemente. 


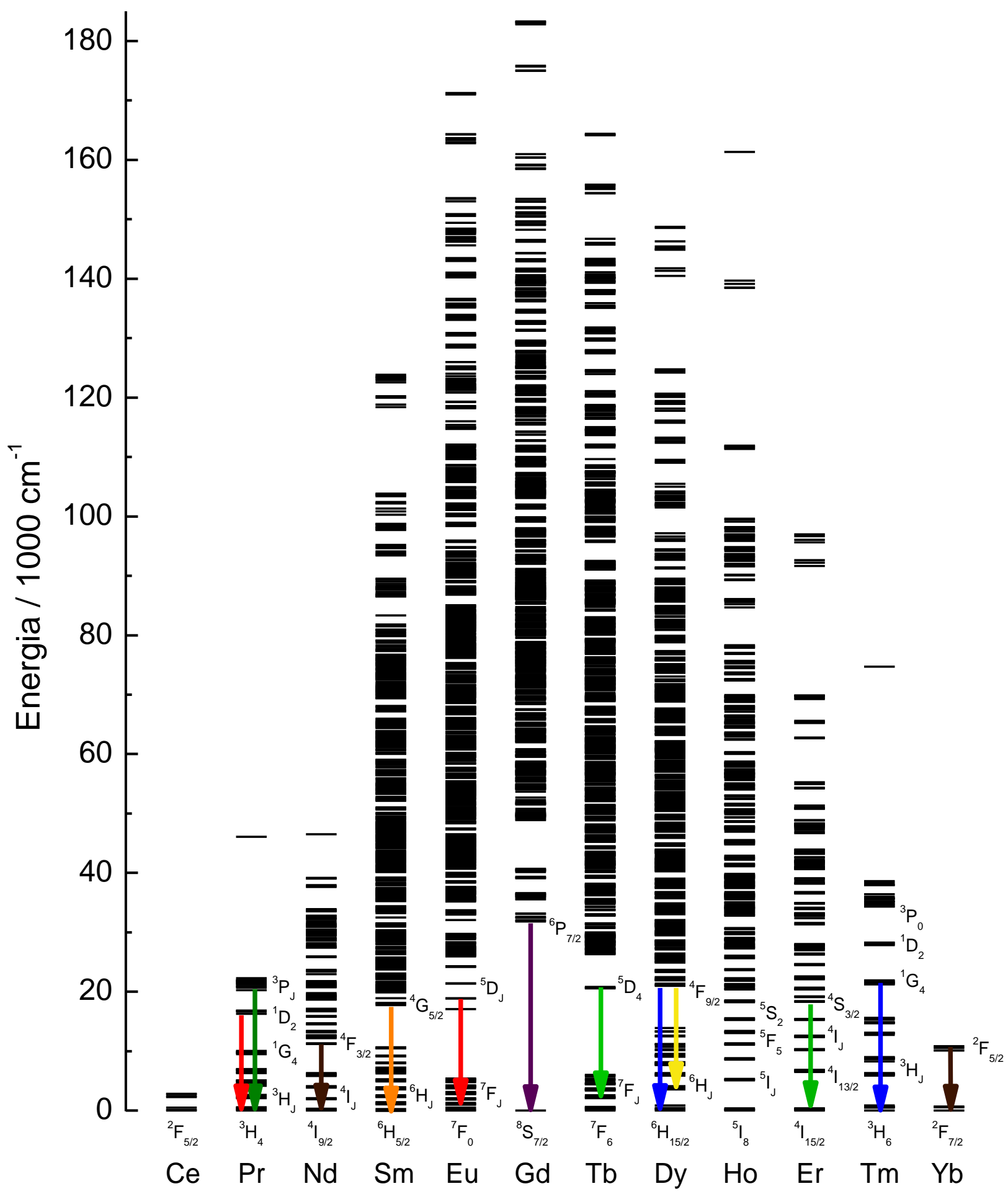

FIGURA 3.3 - Diagrama de Energia dos íons $\mathrm{TR}^{3+}$ obtidos a partir de cristais de $\mathrm{LaF}_{3}{ }^{[24]}$. 
Nos processos de transferência de energia intramolecular, para que 0 ligante seja considerado uma "antena eficiente" (bom sensibilizador luminescente), é necessário que ele contenha um grupo que contribua para sua alta absortividade (grupo cromóforo) e apresente condição de ressonância entre seus estados e os níveis emissores do íon TR. Adicionalmente, o ligante não pode apresentar canais de supressão de luminescência, tais como, modos vibracionais de alta freqüência e estados eletrônicos com energia abaixo do nível emissor do íon $\mathrm{TR}^{3+}$. Neste contexto, várias classes de ligantes têm sido testadas como "antenas", sendo os ânions $\beta$-dicetonatos os que apresentam maior interesse ${ }^{[20]}$.

\subsection{Química de Coordenação dos ĺons $\mathrm{TR}^{3+}$}

Os íons $\mathrm{TR}^{3+}$ são caracterizados por apresentarem propriedades químicas muito semelhantes, ao contrário do que é observado na química de coordenação dos íons metálicos de transição $d$ que apresentam uma grande variação nas propriedades químicas ao longo da série. Nos íons $\mathrm{TR}^{3+}$ tais variações são menos pronunciadas e são, principalmente, uma conseqüência da "contração lantanídica" que contribui para a diminuição do raio. Estes íons são essencialmente esféricos e apresentam interações com os ligantes similarmente àquelas apresentadas pelos íons alcalinos terrosos.

Deve-se considerar que a sobreposição dos orbitais $4 f$ dos íons $T^{3+}$ com os orbitais dos ligantes é pequena, devido à proteção da interação do campo ligante pelas subcamadas $5 \mathrm{~s} 5 \mathrm{p}$ preenchidas. Além disso, os íons $\mathrm{TR}^{3+}$ apresentam valores de raios iônicos grandes, que estão entre os maiores valores para íons trivalentes, resultando em uma razão carga/raio relativamente baixa o que conduz a uma fraca habilidade polarizante. Esse comportamento é refletido no caráter predominantemente iônico da ligação $\operatorname{TR}^{3+}$-ligante ${ }^{[23,24]}$. Portanto, a interação Metal - Ligante apresenta caráter não direcional sendo descrita preferencialmente em termos iônicos. Neste caso, o número de coordenação e a geometria dos complexos são determinados quase que exclusivamente pelas características dos ligantes (propriedades 
conformacionais, tamanho e natureza do grupo coordenante). Portanto, a natureza e tipo de compostos formados por íons terras raras trivalentesTR ${ }^{3+}$ diferem significantemente daqueles formados pelos íons de transição $d$.

Os íons $\mathrm{TR}^{3+}$ são considerados como ácidos "duros", de acordo com a definição de Pearson ${ }^{[28]}$ e pertencentes à classe a na denominação de Ahrland, Chatt e Davies ${ }^{[26]}$. De acordo com estas definições, estes íons têm preferência para se ligarem a sítios "duros" em uma molécula orgânica ou em sistema inorgânico. As interações das moléculas orgânicas com íons terras raras trivalentes são preferencialmente feitas através de átomos de oxigênio negativamente carregados (dicetonatos) e de coordenantes neutros (sulfóxidos, água etc.) que possuam grande momento dipolar (bases "duras"). É importante relatar que nos compostos de $\mathrm{TR}^{3+}$ os átomos coordenantes apresentam a seguinte ordem de preferência de ligação: $\mathrm{O}>\mathrm{N}>\mathrm{S}$.

Como uma conseqüência da dureza dos íons $\mathrm{TR}^{3+}$, existe uma forte competição entre os ligantes orgânicos com os íons hidróxidos e as moléculas de água, de tal modo que em solução aquosa as principais moléculas coordenadas aos íons $\mathrm{TR}^{3+}$ são geralmente ligantes tais como: carboxilatos, sulfonatos, fosfatos, fosfinatos, etc. Geralmente, em meio aquoso os grupos contendo átomos de oxigênio neutros ligam-se aos íons $\mathrm{TR}^{3+}$ somente quando estes estão presentes em ligantes multidentados, preferencialmente se um de seus grupos coordenantes apresentam átomos de oxigênio carregados negativamente. No caso de complexos formados a partir de ligantes monodentados contendo oxigênio neutro, tais como álcoois, ésteres e cetonas, é observada uma baixa estabilidade quando comparados com aqueles formados com oxigênio carregados negativamente. Além disso, esses compostos devem ser preparados em um solvente com fraca habilidade coordenante.

A química de coordenação dos íons $\mathrm{TR}^{3+}$ tem sido agrupada de acordo com o tipo de átomo coordenante nos ligantes orgânicos. Os três principais grupos nos quais estes compostos são classificados relacionam àqueles contendo nitrogênio, oxigênio e ambos como átomos ligantes ${ }^{[26]}$. 


\subsubsection{Ligantes $\beta$-dicetonatos}

1,3-Dicetonas, também frequentemente conhecidas como $\beta$-dicetonas, são uma família dos ligantes mais amplamente investigados nos complexos de lantanídeos ${ }^{[29]}$.

Os ligantes $\beta$-dicetonas são excelentes quelatos para íons de transição d e $\mathrm{TR}^{3+}$, onde o grupo 1,3-dicarbonila apresenta um sítio de coordenação eficiente. Os primeiros complexos de terras raras com $\beta$-dicetonas foram os acetilacetonatos, reportados por Urbain no final do século XIX ${ }^{[30]}$. Na década de 60 , vários estudos foram realizados sobre os $\beta$-dicetonatos de terras raras relatando os efeitos dos grupos substituintes e do tamanho do raio do íon metálico sobre as estabilidades desses complexos em solução. Esses estudos foram voltados para o desenvolvimento de técnicas de extração dos íons TR. De acordo com os valores de log $k$ para os derivados da acetilacetona, observou-se que esses valores aumentam com o tamanho do grupo alquila na presença de substituintes aromáticos.

A maioria dos complexos $\beta$-dicetonatos de TR são obtidos na forma de triscomplexos hidratados. No entanto, complexos anidros com fórmula $\mathrm{Sc}(\beta$ dicetonatos) $)_{3}$ são geralmente sintetizados quando os grupos substituintes nos $\beta$-dicetonatos são relativamente grandes, como por exemplo o grupo t-butila. Os complexos tris(acetilacetonatos) podem também ser obtidos sob condições controladas, usando solventes anidros e ânion com baixa habilidade coordenante. A adição de um quarto ligante $\beta$-dicetonato na primeira esfera de coordenação formam os tetrakis-derivados ${ }^{[30]}$ e, geralmente, envolvem ligantes com substituintes pequenos o suficiente para minimizar interações estéricas. Nestes casos, os complexos obtidos apresentam fórmulas $M[T R(\beta-$ dicetonatos)4], onde $\mathrm{M}$ é geralmente um cátion $\mathrm{Li}^{+}, \mathrm{Na}^{+}, \mathrm{K}^{+}$ou um cátion orgânico. A FIGURA 3.4 ilustra alguns $\beta$-dicetonatos: acetilacetonato (ACAC), tenoiltrifluoroacetonato (TTA) e dibenzoilmetanato (DBM).

Todos os complexos estudados neste trabalho são octacoordenados, ou seja, o íon terra rara está ligado a oito átomos de oxigênio e/ou nitrogênio provenientes dos ligantes, sendo que eles seguem a seguinte regra: o íon trivalente central está ligado por um ligante $\beta$-dicetona e outro ligante auxiliar 
orgânico (por exemplo, um heteroaromático como óxidos fosfinatos (TPPO, TOPO) ou éteres coroa (DB18C6 e 18C6)) ${ }^{[31,32]}$. O ligante $\beta$-dicetona é o principal responsável por absorver a energia de excitação e transferí-la para o íon central. $O$ outro ligante (auxiliar) contribui para a absorção de energia de excitação, porém, o principal papel desse ligante é completar as oito coordenações para impedir a coordenação de água com o íon lantanídeo. Isto é extremamente importante, porque os modos de vibração da água são uma grande fonte de perda de energia (relaxações não radiativas) ${ }^{[31,33]}$.

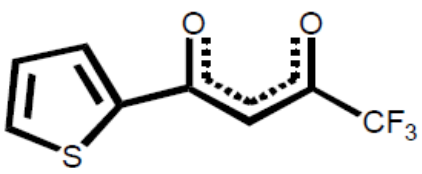

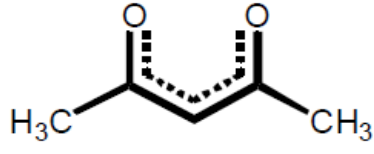

ACAC

TTA

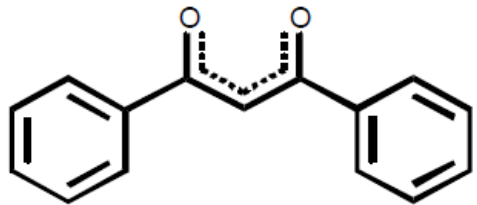

DBM

FIGURA 3.4 - Fórmulas estruturais dos ânions $\beta$-dicetonatos ACAC, TTA e DBM ${ }^{[25]}$.

\subsubsection{Ligantes $Q_{n} X \rightarrow 0$}

A classe de complexos contendo ligante $\mathbf{Q}_{\mathbf{n}} \mathbf{X} \rightarrow \mathbf{O}$ (onde $Q$ é um grupo orgânico e $X=N$, $S$ ou $P$ ) é uma das mais extensas da química de coordenação de íons $\mathrm{TR}^{3+}$. Além de se coordenarem ao íon $\mathrm{TR}^{3+}$ como único coordenante, estes ligantes, assim como os $\mathrm{N}$-coordenantes, são geralmente empregados como uma segunda classe de ligantes formando adutos com dicetonatos. Os ligantes mais utilizados desta série são aqueles onde o $\mathrm{X}$ é igual a N-heterocíclico, $\mathrm{S}$ e $\mathrm{P}$. No que se refere à habilidade coordenante, os compostos de TR com esses ligantes assemelham-se àqueles formados por 
ligantes carbonílicos e o número de coordenação é largamente dependente do ânion ${ }^{[25]}$.

\subsubsection{Ligantes $R_{3} P=0$}

Os fosfinóxidos formam uma série de ligantes de grande relevância na química de coordenação dos elementos do bloco $f$ (terras raras e actinídeos), devido sua facilidade de se coordenar aos íons TR e actinídeos (Ac) ${ }^{[34]}$. Esses ligantes são capazes de formar compostos inorgânicos e organometálicos estáveis ${ }^{[12,13,34,35]}$ com íons metálicos de diferentes estados de oxidação. A maioria dos complexos de TR com ligantes de estrutura $R_{3} P=O$ contendo oxigênio como átomo coordenante são aqueles que envolvem os ligantes hexametilfosforamida (HMPA) e o trifenilfosfinóxido (TPPO) ${ }^{[36-39]}$.

Recentemente, Berthet e colaboradores [40] fizeram um estudo comparativo entre as interações dos íons do bloco-f $\left(\mathrm{TR}^{3+}\right.$ e $\left.\mathrm{Ac}^{3+}\right)$ com o ligante TPPO onde foi evidenciado que a diferença na interação metal- ligante é uma conseqüência do tamanho dos íons. As estruturas dos complexos de terras raras TR com ligantes trimetil e difenilmetilfosfinóxidos também têm sido obtidas e seus estudos fotoluminescentes foram reportados ${ }^{[41,42]}$. Ligantes fosfinóxidos, em particular TPPO e trioctilfosfinóxido (TOPO) (FIG. 3.5), vêm sendo largamente usados na síntese de complexos mistos com dicetonatos de TR. Deste modo, a primeira esfera de coordenação do íon metálico é saturada, protegendo-o das moléculas do solvente, com objetivo de diminuir a supressão de luminescência tanto em solução quanto no estado sólido. Por exemplo, a substituição das moléculas dos solventes pelos ligantes TPPO e TOPO nos complexos de európio intensifica a luminescência tornando-os eficientes conversores de luz exibindo grande potencialidade na aplicação como marcadores em exames imunológicos e como camadas emissoras em dispositivos eletroluminescentes ${ }^{[26,43-48]}$. 


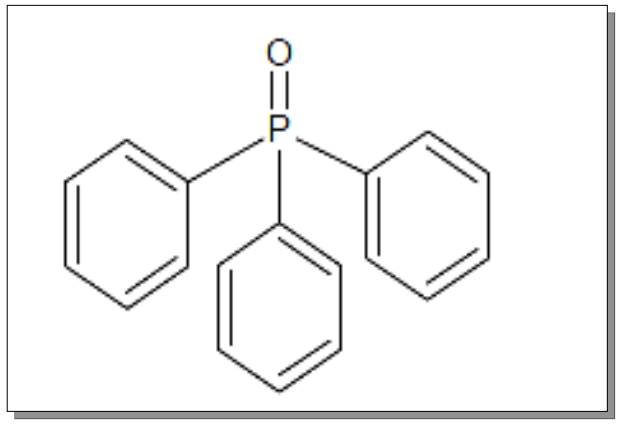

Trifenilfosfinóxido (TPPO)

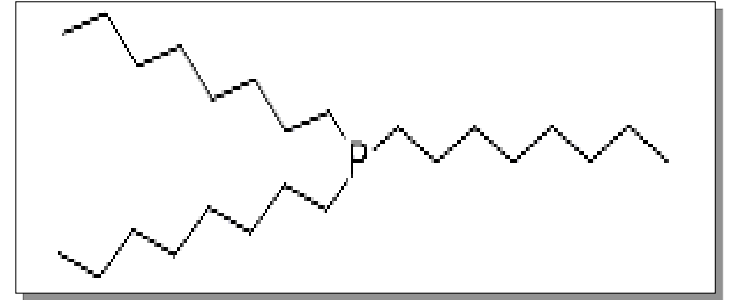

Tri-n-octilfosfinóxido

FIGURA 3.5 - Estrutura molecular dos ligantes fosfinóxidos: Trifenilfosfinóxido (TPPO) e Tri-n-octilfosfinóxido (TOPO).

\subsubsection{Ligantes Éteres Coroa}

Em 1967, quando o químico norte-americano C. J. Pedersen (ganhador de Prêmio Nobel de 1987) tentava sintetizar o 2-(o-hidroxifenóxi) etil éter (FIG. 3.6) a partir da reação do 1,5-dicloro-3-oxapentano com sal de sódio de catecol, obteve, como subproduto, uma pequena quantidade de cristais brancos fibrosos. Tais cristais foram identificados como sendo o 2,3,11,12dibenzo-1,4,7,10,13,16-hexaoxacicloctadodeca-2,11-dieno, atualmente conhecido como dibenzo-[18]-coroa-6 (DB18C6) (FIG. 3.6) ${ }^{[49-51]}$.

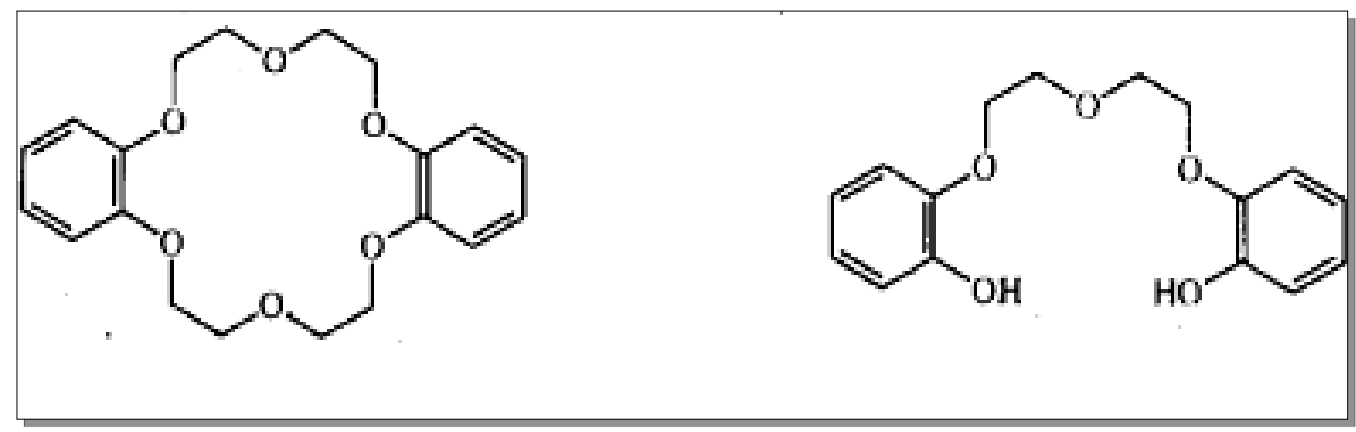

2-(o-hidroxifenóxi) etil éter

dibenzo-[18]-coroa-6

FIGURA 3.6 - Estrutura molecular do precursor 2-(o-hidroxifenóxi)etil éter e do dibenzo-[18]-coroa-6 ${ }^{[31]}$. 
Compostos como estes são chamados "éteres de coroa", pois formam uma espécie de coroa quando complexam com um íon metálico (exemplo $\left.\mathrm{Eu}^{3+}\right)$.

"Dibenzo" significa que existem dois benzenos ligados ao anel, enquanto que 18 entre colchetes simboliza o número de átomos no anel e 6 o número de átomos doadores ${ }^{[50,51]}$. Esta notação é normalmente utilizada para descrever poliéteres cíclicos cujos átomos de oxigênio estão separados por grupo etileno e possuem benzeno ou ciclo-hexano ligado ao anel ${ }^{[51]}$.

A utilização dos éteres coroa leva à capacidade de formação de complexos estáveis com muitos sais de metais alcalinos, alcalinos terrosos e alguns metais de transição. Esta particular propriedade levou Pedersen a estudar a utilização desse composto como uma espécie de catalisador de transferência de fase que promovesse a solubilização de sais inorgânicos, como, por exemplo, $\mathrm{KCl}, \mathrm{KF}, \mathrm{KMnO}_{4}$, em solventes orgânicos apolares, tornando possível uma série de reações desses sais, que de maneira usual não ocorreriam ${ }^{[52,53]}$. Esses poliéteres complexantes foram denominados ionóforos por apresentarem capacidade de transferir íons de um meio aquoso para uma fase hidrofóbica, que pode ser um solvente apolar em contato com um solvente polar (clorofórmio e água). A partir dos resultados apresentados por Pedersen, abriu-se uma nova perspectiva na química dos agentes complexantes ${ }^{[31]}$.

As propriedades do dibenzeno-[18]-coroa-6 levaram vários pesquisadores a sintetizar uma série de compostos relacionados (FIG. 3.7), primeiramente variando o tamanho do anel e o tipo dos heteroátomos doadores de elétrons e, depois, preparando compostos bicíclicos e oligocíclicos.

A denticidade do poliéter influência na afinidade do éter coroa para com os cátions. Por exemplo, 18-coroa- 6 tem alta afinidade para cátions $\mathrm{K}^{+}$; 15 coroa- 5 tem afinidade com cátions $\mathrm{Na}^{+}$; 12 -coroa-4 tem afinidade para cátions $\mathrm{Li}^{+}$. A alta afinidade por $\mathrm{K}^{+}$do $18-$ coroa- 6 contribui para sua toxicidade ${ }^{[54]}$.

$\mathrm{O}$ que se refere à aplicação destas estruturas na luminescência dos complexos de $\mathrm{TR}^{3+}$, Weissman ${ }^{[19]}$ ao demonstrar o processo de sensibilização da luminescência dos complexos de íons lantanídeos, notou que um ligante orgânico apresentando alto coeficiente de absortividade molar, e quando coordenado ao íon metálico, é capaz de transferir energia eficientemente para 
o íon lantanídeo, intensificando assim sua luminescência ${ }^{[54]}$. Portanto, alguns ligantes auxiliares foram escolhidos para estudo neste trabalho, os fosfinóxidos, já descritos anteriormente (item 3.3.2.1), e os éteres coroas Dibenzo[18]Coroa-6 (DB18C6) e o [18]-Coroa-6 (18C6) (FIG. 3.7).
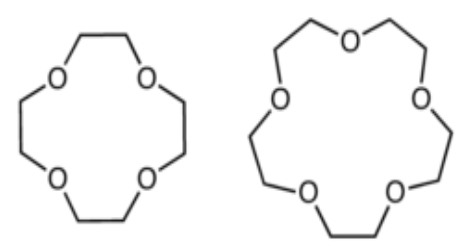

12-Coroa-4 15-Coroa-5

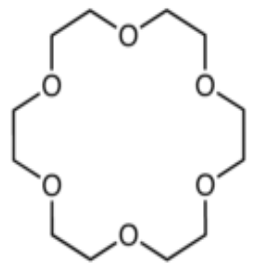

18-Coroa-6

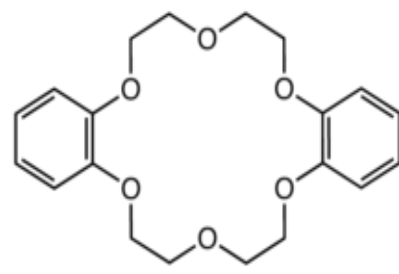

Dibenzo-18-Coroa-6

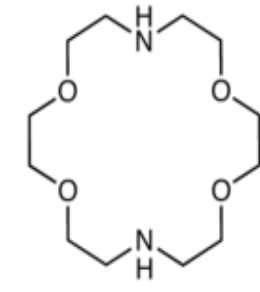

Diaza-18-Coroa-6

FIGURA 3.7 - Estruturas de Éteres Coroa comuns (em destaque: DB18C6 e 18C6) ${ }^{[55] .}$

\subsection{Ocorrência/ Abundância das Terras Raras}

Como mencionado anteriormente, os elementos lantanídeos originariamente são conhecidos como terras raras, dada a sua ocorrência em óxidos ou "terras" na nomenclatura arcaica, mas na verdade trata-se de uma mistura de óxidos. No entanto, sabe-se que estes elementos não são raros, e a abundância na litosfera é relativamente alta. $O$ elemento Túlio, o menos abundante, é tão comum como o Bismuto (ca. $2 \times 10^{-5} \%$ ) e mais comum que As, $\mathrm{Cd}, \mathrm{Hg}$ e Se, elementos estes que não são considerados raros ${ }^{[56]}$.

As maiores reservas encontram-se na China, na Comunidade dos Estados Independentes (CEI), nos Estados Unidos da América (EUA), na Índia e na Austrália ${ }^{[57]}$.

Além de proprietária de grandes reservas minerais, a China é o principal produtor dos elementos de TR, e controla cerca de $95 \%$ da oferta mundial. Entre os maiores consumidores dos compostos e metais estão a própria China, o Japão, os EUA, a Alemanha, a França e a Áustria. Em 2010, o consumo chinês foi de setenta mil toneladas ${ }^{[57]}$. 
De 1886 a meados da segunda década do século XX, o Brasil foi o maior exportador de monazita, um mineral portador de TR. As reservas de monazita litorâneas foram exploradas até meados dos anos 1990. Por conter elementos radioativos, o aproveitamento da monazita para a obtenção de TR foi descartado. As reservas atuais localizam-se nos estados de Minas Gerais e do Rio de Janeiro, e totalizam cerca de 31 mil toneladas de metais contidos. Sabe-se, também, que o país dispõe de reservas minerais significativas, ainda não exploradas, localizadas nos municípios de Presidente Figueiredo (AM) e de Catalão (GO) ${ }^{[56,58,59]}$.

A produção atual de óxidos de TR no Brasil é de cerca de 550 toneladas, das quais a maior parte é de lantânio. As principais indústrias nacionais consumidoras diretas de produtos de TR são as fabricantes de catalisadores, vidros e cerâmicas; e consumidoras indiretas, as fabricantes de motores e turbinas eólicas. A demanda brasileira de TR é incipiente, correspondendo a cerca de $1 \%$ da demanda mundial. O consumo de produtos de TR na forma de compostos químicos e manufaturados foi de 1.315 toneladas, em $2010^{\text {[56, 59] }}$.

As importações brasileiras de TR, em 2010, somaram US $\$ 14.371$ milhões, e as exportações US $\$ 1,4$ milhão. Hoje existem diversos projetos de exploração em desenvolvimento, a maioria deles concentrada na China, EUA, CEI e Canadá. O aporte desses novos projetos deverá gerar uma sobreoferta já a partir de 2015, o que pode aumentar ainda mais a volatilidade dos preços desses elementos, que já é muito alta ${ }^{[56]}$.

\subsubsection{Oferta Mundial de Terras Raras}

Desde a descoberta, em 1886, das areias monazíticas em Cumuruxatiba, na Bahia, até 1915, o Brasil foi o maior produtor isolado de minério de $\operatorname{TR}^{[56]}$.

Entre 1915 e 1960, o país dividiu essa liderança com a Índia. Durante os anos 1950, a África do Sul atingiu a posição de produtor mundial depois da descoberta de veios pegmatíticos ricos em monazita. Dos anos 1960 aos anos 
1980, a mina de Mountain Pass, na Califórnia, tornou-se a maior produtora de minérios de $\operatorname{TR}^{[56,60]}$.

Atualmente, a produção mundial de óxidos de TR, de cerca de 134 mil toneladas, é composta por $97 \%$ de participação chinesa. Além disso, praticamente toda a oferta de TR pesadas é suprida pela China, com cerca de $97 \%$ em 2010. As preocupações com o suprimento intensificaram-se em virtude dos recentes movimentos do principal produtor de TR. Nos últimos dois anos, a China vem anunciando algumas restrições ao comércio de TR, que incluem tributos mais altos sobre os minérios, restrições rigorosas às exportações e pressões para o processamento do minério no próprio país. Estas medidas foram complementadas pela repressão ao contrabando de substâncias minerais ${ }^{[60,61]}$.

Em setembro de 2009, a China anunciou planos de redução da quota de exportação em 35 mil toneladas entre 2010 e 2015, sob a alegação de conservar suas reservas e proteger o meio ambiente. Em outubro de 2010, o jornal China Daily publicou que o país reduziria as quotas de exportação de TR em cerca de 30\% para proteger suas reservas da sobre-exploração. Já no fim de 2010, foi anunciado que a primeira rodada de quotas de exportação de 2011 seria de aproximadamente 14,5 mil toneladas, o que representava uma queda de $35 \%$ da primeira quota de 2010 . Além das medidas restritivas internas, a China realizou aquisições de mineradoras e de áreas em países africanos com o propósito de garantir o suprimento de minerais de TR. Em consequência do aumento da demanda e das restrições da oferta exportada iniciadas pela China, novas pesquisas de fontes de TR estão em curso na África do Sul, na Austrália, no Brasil, no Canadá, na Groenlândia e nos EUA. As minas nesses países foram fechadas quando houve a acelerada queda de preços, nos anos 1990, provocada pela abundante oferta chinesa ${ }^{[56,57,59,61]}$.

Conforme já comentado, está em processo de reabertura a mina de Mountain Pass, na Califórnia. Outros depósitos importantes em desenvolvimento incluem os projetos Nolans e Mount Weld, na Austrália, e o projeto HoidasLake, no Canadá. Este último projeto tem potencial para suprir cerca de $10 \%$ do consumo anual de TR nos EUA ${ }^{[56,62]}$. 
Cogita-se ainda, como mencionado anteriormente, a reativação das minas no complexo intrusivo alcalino de Thor Lake, no Canadá, outras no Vietnã, nos EUA (Nebrasca) e em Kvanefjeld, Groenlândia. Além disso, a mineradora australiana Lynas está concluindo uma refinaria de processamento de TR no porto de Kuantan, na Malásia, onde será processado o minério de baixa radioatividade da mina de Mount Weld. A empresa espera suprir cerca de um terço da demanda mundial de TR, ex-China ${ }^{[56,58]}$.

Uma fonte significativa de óxidos de TR encontra-se no lixo eletrônico e de outros equipamentos que contêm componentes produzidos com TR. Os recentes avanços na tecnologia de reciclagem estão viabilizando a extração dessas substâncias. No Japão, estima-se que existam trezentas mil toneladas de TR armazenadas em produtos eletrônicos fora de uso. Há também quantidades significativas de óxidos de TR em rejeitos acumulados em cinquenta anos de extração de minérios de urânio e de loparita de $\operatorname{TR}^{[56,61,62]}$. A TABELA 3.3 expõe a produção anual de óxido de TR no mundo e nos principais países produtores.

Apesar de disporem de reservas expressivas, tanto os EUA quanto a Austrália interromperam a produção nos anos relacionados na TABELA $3.3 \mathrm{em}$ razão dos baixos preços.

Conforme explicitado, embora a China domine a oferta mundial de TR (FIG. 3.8), diversos projetos se encontram em desenvolvimento em outros países. O período de maturação de um projeto novo, até o início da produção, é de seis a dez anos ${ }^{[56,62]}$.

Correlacionando a produção ao preço das terras raras, a FIGURA 3.9 mostra o histórico dos preços comerciais das terras raras de 2009 a 04/2013. Nota-se o aumento dos custos a partir de 2010, apresentando pico no ano de 2011 e decréscimo do custo em 2013. 
TABELA 3.3 - Produção anual de óxidos de TR no mundo e nos principais países produtores ${ }^{[62]}$.

\begin{tabular}{lllllllll} 
& \multicolumn{8}{c}{ Em toneladas de óxidos de TR contidos } \\
País & $\mathbf{2 0 0 3}$ & $\mathbf{2 0 0 4}$ & $\mathbf{2 0 0 5}$ & $\mathbf{2 0 0 6}$ & $\mathbf{2 0 0 7}$ & $\mathbf{2 0 0 8}$ & $\mathbf{2 0 0 9}$ & $\mathbf{2 0 1 0}$ \\
Brasil & ND & ND & ND & 730 & 650 & 650 & 550 & 550 \\
CEI & 2.000 & 2.000 & ND & ND & ND & ND & ND & ND \\
China & 92.000 & 95.000 & 119.000 & 119.000 & 120.000 & 120.000 & 129.000 & 130.000 \\
Índia & 2.700 & 2.700 & 2.700 & 2.700 & 2.700 & 2.700 & 2.700 & 2.700 \\
Malásia & 250 & 250 & 750 & 200 & 380 & 380 & 350 & 350 \\
Tailândia & 2.200 & 2.200 & --- & --- & ND & ND & ND & ND \\
Outros & --- & --- & 400 & ND & ND & ND & ND & ND \\
Mundo & $\mathbf{9 9 . 1 0 0}$ & $\mathbf{1 0 2 . 0 0 0}$ & $\mathbf{1 2 3 . 0 0 0}$ & $\mathbf{1 2 3 . 0 0 0}$ & $\mathbf{1 2 4 . 0 0 0}$ & $\mathbf{1 2 4 . 0 0 0}$ & $\mathbf{1 3 3 . 0 0 0}$ & $\mathbf{1 3 4 . 0 0 0}$
\end{tabular}

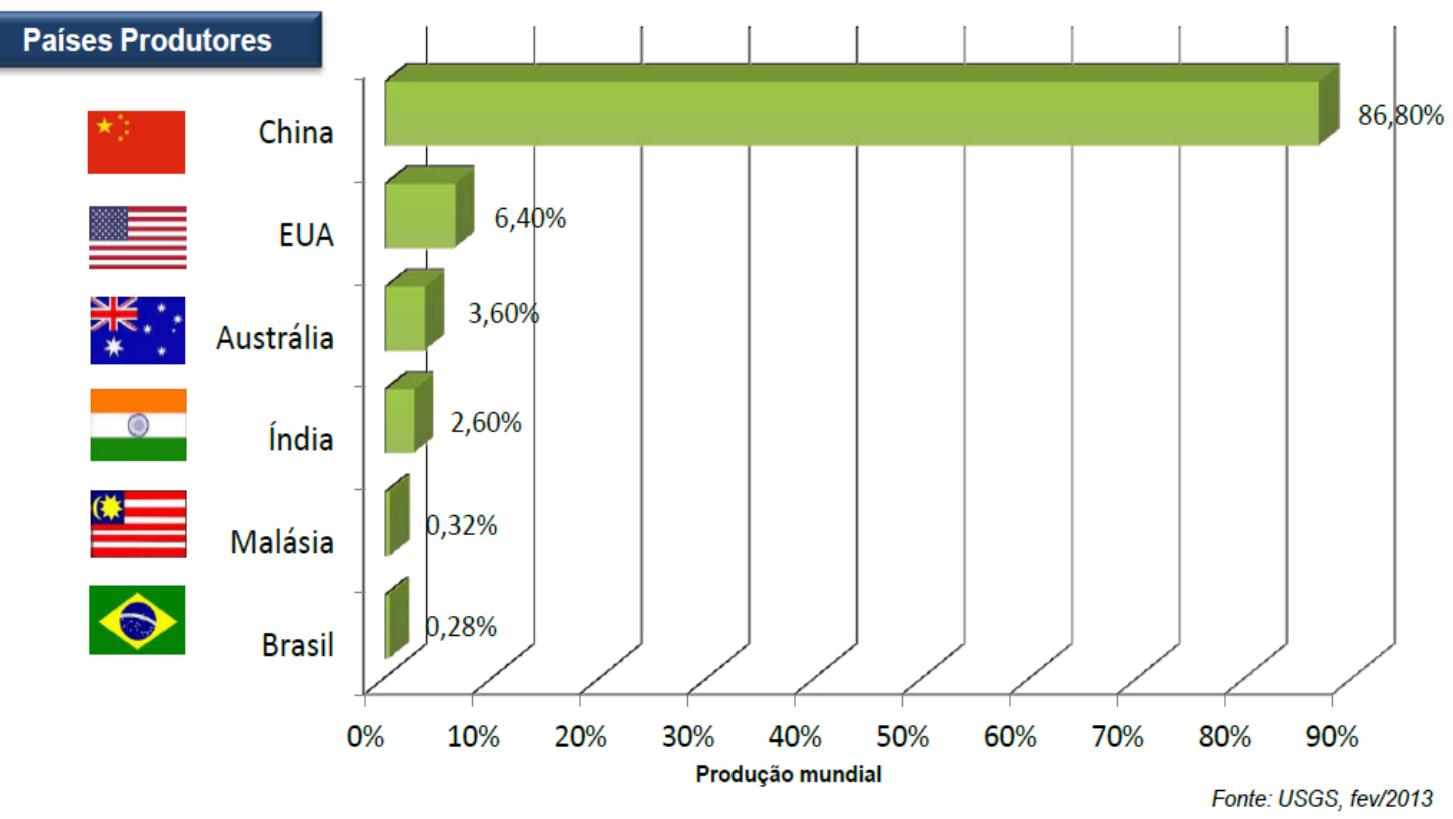

FIGURA 3.8 - Produção mundial de terras raras dos principais países produtores ${ }^{[62]}$. 


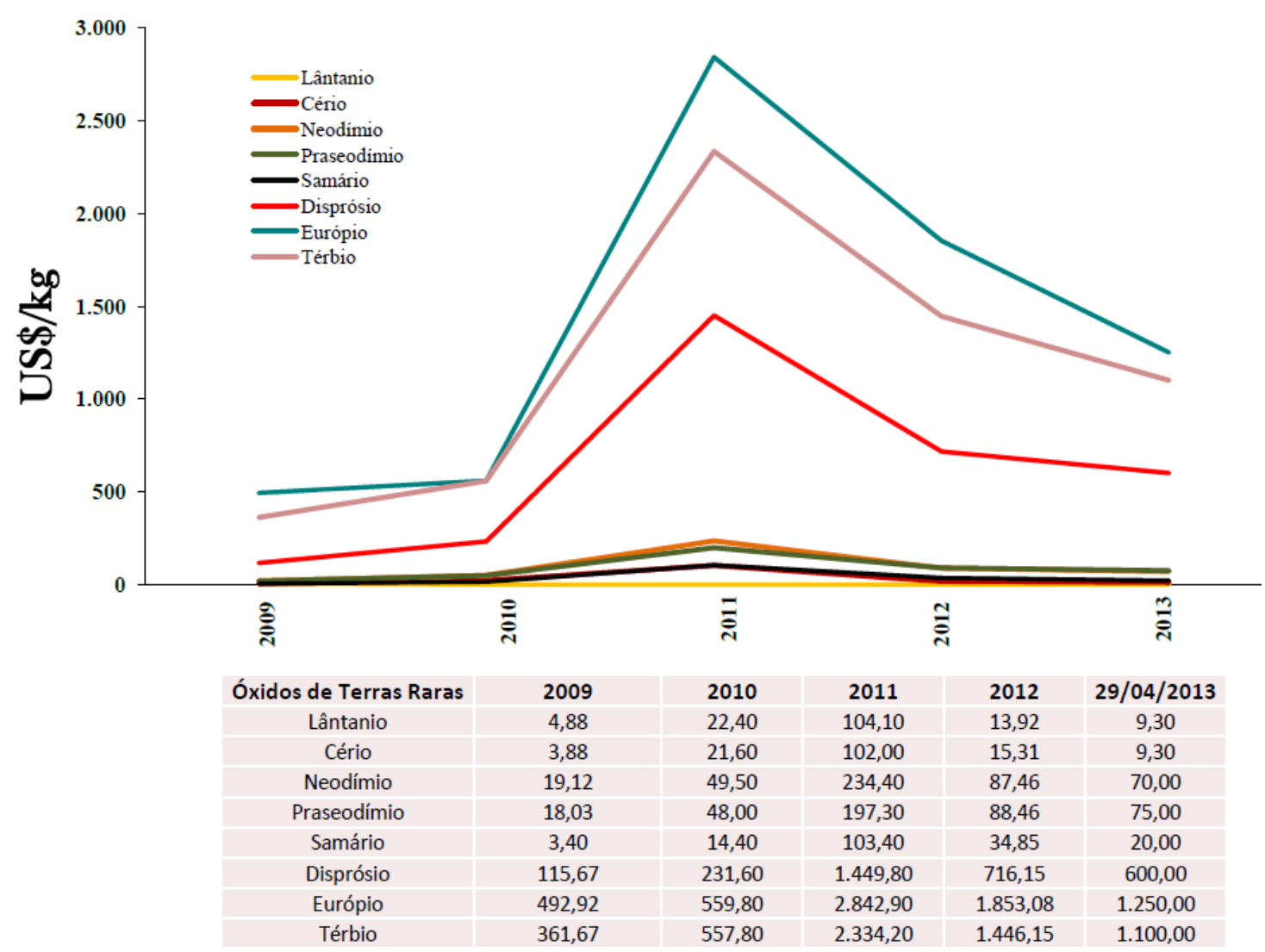

FIGURA 3.9 - Histórico dos preços de óxidos de terras raras ${ }^{[63]}$.

\subsection{Desenvolvimento Recente em Aplicações das Terras Raras}

As TR são hoje consideradas essenciais em inúmeras aplicações, como catalisadores automotivos e de petróleo, super-ímãs usados em motores e geradores elétricos de grande eficiência, ligas metálicas de alto desempenho, LEDs, aplicações militares sofisticadas e outras. Essas aplicações são altamente específicas e seus substitutos conhecidos têm desempenho inferior [64].

De acordo com Fernando Rizzo, diretor do Centro de Gestão e Estudos Estratégicos (CGEE), a China começou a investir nesses elementos há 30 anos e o valor de mercado era tão baixo que os demais países não valorizaram a sua necessidade. Quando houve aumento do preço, os Estados Unidos e outros países instalaram empresas na China para evitar uma crise no abastecimento. "O Brasil despertou para a importância desses elementos em 2011. Neste ano (2013), o CGEE, iniciou o trabalho", acrescenta Rizzo. No entanto, segundo aponta o estudo, o Brasil acompanha a 
tendência de outros países e não é considerado nem avançado nem atrasado no assunto ${ }^{[64]}$.

As principais aplicações dos elementos terras raras estão classificadas de acordo com o elemento:

- $\quad$ Escândio (Sc): em ligas de alumínio para componentes aeroespaciais; também é adicionado ao mercúrio em lâmpadas a vapor.

- $\quad$ Ítrio $(\mathrm{Y})$ : Em laser de ítrio-alumínio; supercondutores de alta temperatura; em vanadato de Ítrio como receptor do európio (pigmento vermelho em tubos de raios catódicos); filtro de micro-ondas de ítrio-ferro.

- Lantânio (La): Vidros de alto índice de refração; armazenamento de hidrogênio; eletrodos de bateria; lentes de câmeras; catalisadores de fluidos em refinarias de petróleo.

- $\quad$ Cério (Ce): Agente oxidante; pó para polimento; colorante amarelo em vidros e cerâmicas; catalisadores em fornos autolimpantes; catalisadores de fluídos em refinarias de petróleo.

- Praseodímio (Pr): Ímãs; lasers; iluminação de arco de carbono; colorantes em vidros e esmaltes; aditivo em lentes de óculos de soldagem.

- $\quad$ Neodímio (Nd): Ímãs; lasers; colorante violeta em vidros e cerâmicas; capacitores de cerâmica.

- $\quad$ Promécio $(\mathrm{Pm})$ : baterias nucleares.

- Samário (Sm): Ímãs; lasers; captura de nêutrons.

- Európio (Eu): Pigmento em tubos de raios catódicos; lasers; adicionado ao mercúrio em lâmpadas a vapor; agente de relaxação em ressonância magnética nuclear. 
- Gadolínio (Gd): Ímãs; vidros de alto índice de refração; lasers; tubos de raios X; chips de memória; captura de nêutrons; agente de contraste em imagens de ressonância magnética; agente de relaxação em ressonância magnética nuclear.

- Térbio (Tb): Ímãs permanentes; pigmento verde em tubos de raios catódicos; lasers; lâmpadas fluorescentes.

- $\quad$ Disprósio (Dy): Ímãs permanentes; lasers.

- Hólmio (Ho): Lasers.

- Érbio (Er): Lasers; liga de aço-vanádio.

- Túlio (Tm): Máquinas portáteis de raios $\mathrm{X}$.

- Itérbio (Yb): Lasers de infravermelho; agente químico redutor.

- Lutécio (Lu): Detectores para tomografia por emissão de pósitrons; vidros de alto índice de refração ${ }^{[56,65]}$.

Diversos estudos são feitos por pesquisadores todos os anos com o intuito de otimizar as aplicações já conhecidas. No entanto, há um grande avanço científico envolvendo novas aplicações das terras raras, com descobertas de novas utilidades do uso delas.

O aquecimento global é uma preocupação mundial e um grande foco da política atual para os governos e agências nacionais e internacionais. $O$ elementos de TR estão desempenhando um papel vital em limitar as emissões de gases, por intermédio de seu aplicativo exclusivo em tecnologias de energia "verde", incluindo veículos híbridos e elétricos, e geradores de energia eólica, reduzindo o consumo de hidrocarbonetos ${ }^{[66,67]}$.

Os governos estão legislando para normas de emissões mais baixas em ambos os ambientes domésticos e industriais, por meio de comércio de 
carbono e outras políticas, impulsionando uma mudança a essas tecnologias de energia "verde", panorama que necessita das possibilidades que os elementos TR podem trazer.

Aplicações de alta tecnologia caracterizam a era moderna, com produtos digitais contribuindo para cada parte da vida moderna. Os elementos de TR participam desta tecnologia, com novos materiais e novas aplicações que permitem melhor eficiência, materiais de maior desempenho que satisfazem a demanda por produtos mais rápidos, menores e mais leves, com maior duração da bateria ${ }^{[67]}$.

O uso prudente de reservas de combustível fóssil é vital no mundo do "carbono moderno". O crescimento da população e a elevação dos padrões de vida têm como consequência maiores exigências sobre os recursos energéticos do mundo. Elementos TR desempenham um papel vital na conservação dessas reservas, melhorando a eficiência e confiabilidade dos hidrocarbonetos que impulsionam máquinas. Baterias de $\mathrm{Ni}$ são uma fonte rentável e eficiente de energia transportável.

A saúde e a tecnologia médica estão se desenvolvendo em um ritmo acelerado. A comunidade científica está fazendo grandes avanços: identificação de novas aplicações de compostos orgânicos e inorgânicos, e desenvolvimento de novas técnicas e máquinas para detectar e tratar doenças e monitorar a saúde humana. Elementos de TR desempenham um papel vital em tais novas tecnologias, sendo essencial em aparelhos de ressonância magnética usados para imaginologia médica e diagnóstico clínico, nanotecnologia em fósforos de alta intensidade utilizados na criação de bioimagens (upconvesion) ${ }^{[68]}$, e como traçadores ${ }^{[68,69]}$.

A FIGURA 3.10 mostra o uso de elementos de terras raras no mundo durante 2012. Estes usos estão relacionados ao fato de que muitos veículos usam catalisadores de TR em seus sistemas de exaustão para controle de poluição do ar. Um grande número de ligas são feitas mais duráveis por meio da adição de metais de TR. Vidro, granito, mármore e pedras preciosas são frequentemente polidos com pó de óxido de Cério. Muitos motores e geradores contêm ímãs feitos com elementos de TR. Os fósforos usados em monitores digitais, monitores e televisores são criados com óxidos de TR, além das 
crescentes aplicações na área de medicina diagnóstica como biossensores e marcadores biológicos. A maioria das baterias de computador, telefone celular e veículos elétricos são feitas com metais de terras raras ${ }^{[70]}$.

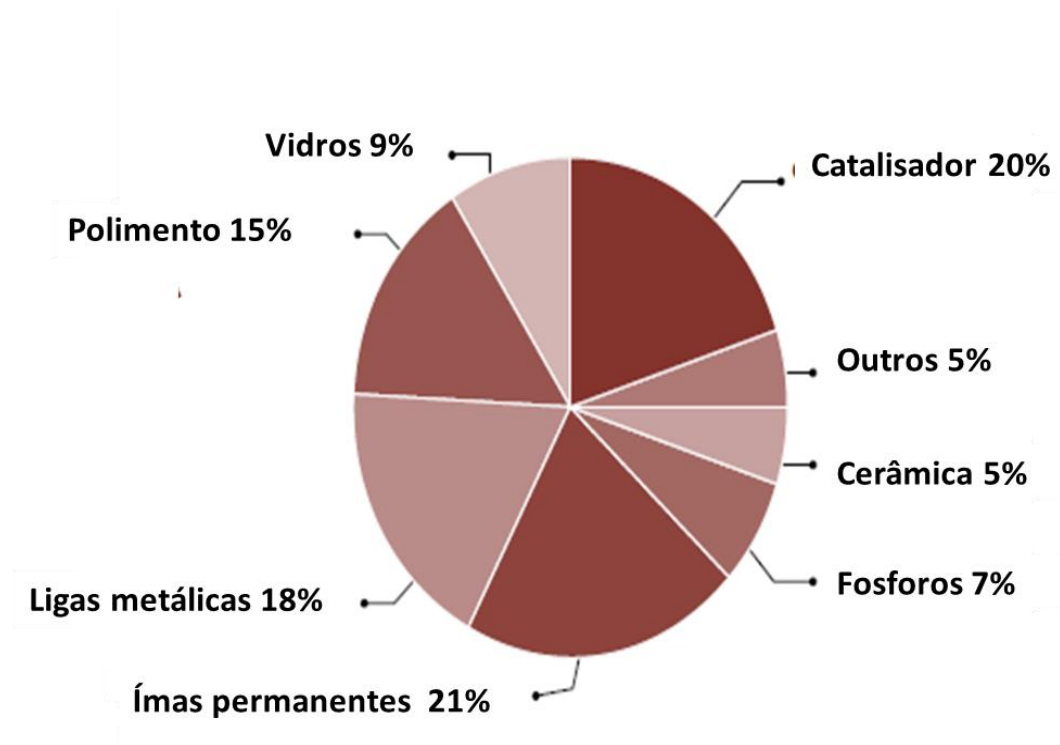

FIGURA 3.10 - Aplicações mundiais das terras raras conforme relatado pelo United States Geological Survey Mineral Commodity Summary em $2012{ }^{[70]}$.

\subsection{Aplicações das Terras Raras como Marcadores Biológicos e Suas Vantagens}

Os íons TR, devido às suas propriedades luminescentes, têm vasta aplicação em dispositivos visuais e conversores de radiação, e atuam também como sondas espectroscópicas ou sensores (químicos ou biológicos). $\mathrm{Na}$ composição de nanomateriais ampliam sua aplicabilidade devido às inúmeras vantagens de estarem em dimensão nanométrica. Em biologia e medicina vem crescendo exponencialmente a utilização de tais nanomateriais como marcadores luminescentes em imunoensaios para detecção de diferentes espécies. A busca por novos marcadores e sistemas de detecção com alta sensibilidade óptica e seletividade, sem autofluorescência, compatibilidade com células vivas e estabilidade em ambientes aquosos aerados tem aumentado 0 interesse na utilização de luminóforos de TR para estes fins. Luminóforos de TR com conversão ascendente (upconversion) também têm demonstrado 
inúmeras vantagens como marcadores no estudo de sistemas biológicos ${ }^{[68]}$. A morfologia é definida de acordo com o tipo de monitoramento devendo manter eficiência quântica o suficiente para produção de sinal detectável.

Historicamente, a primeira aplicação de íons terras raras para análise de sistemas biológicos envolveu a investigação de sítios de íons metálicos em

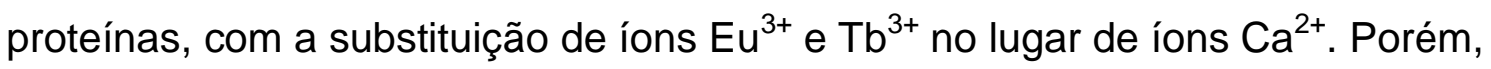
um grande avanço do fluoroimunoensaios surgiu nos anos $80 \mathrm{em}$ uma pequena companhia em Turku, Finlândia, chamada Wallac Oy, que utilizou a luminescência do íon $\mathrm{Eu}^{3+}$ em bioensaio resolvido no tempo ${ }^{[71,72]}$.

A utilização de imunoensaios luminescentes tem evoluído cada vez mais na busca por sistemas com maior sensibilidade, estabilidade e alta especificidade na detecção de macromoléculas específicas ${ }^{[73-75]}$, além do desenvolvimento de moléculas orgânicas capazes de encapsular os íons $\operatorname{TR}^{3+}$ e melhorar suas propriedades luminescentes. Esse interesse crescente em construir dispositivos de moléculas orgânicas também é motivado pelo desenvolvimento de novas aplicações nas ciências biológicas, devido ao seu potencial em diagnósticos médicos não invasivos ${ }^{[76]}$, tais como marcação de DNA ${ }^{[77]}$, ensaios para determinação de proteínas ${ }^{[78]}$ e hormônios ${ }^{[79]}$.

Em resumo, o marcador luminescente é acoplado quimicamente a um anticorpo, o qual se liga de uma forma específica a uma dada biomolécula ou organismo. Desta forma, a presença de luminescência pode ser relacionada à presença de certas moléculas ou organismos, possibilitando sua detecção ${ }^{[73,}$ $75,80]$.

Geralmente, as amostras a serem analisadas têm sua própria luminescência. Quando marcadores de TR são utilizados, como a luminescência relativa aos materiais biológicos usualmente apresenta curta duração, e íons como $\mathrm{Eu}^{3+}$ e $\mathrm{Tb}^{3+}$ têm estados emissores com tempos de vida longos, podem-se facilmente separar estes dois tipos de emissão. Desde que toda a determinação é feita em meio aquoso, o íon TR tem que estar protegido do ambiente em que se encontra, caso contrário sua luminescência é fortemente suprimida pelas moléculas de água. Desta forma, é necessária a inserção do íon em molécula(s) que o isolem do meio, daí o freqüente uso de quelatos neste tipo de aplicação ${ }^{\text {[71-74, 80-83]. }}$. 
Outra vantagem é que esses materiais luminescentes atuam como marcadores não radioativos em ensaios biológicos, apresentando um diferencial relacionado à segurança ${ }^{[84,85]}$.

\subsection{Nanotecnologia Aplicada}

\subsubsection{Panorama do Setor}

De uma forma simples, pode-se definir nanotecnologia como sendo o termo utilizado para descrever a criação, manipulação e exploração de materiais com escala nanométrica. Cabendo outra definição, um nanômetro $(\mathrm{nm})$ é um metro dividido por um bilhão, ou seja, $1 \mathrm{~nm}$ é igual a $10^{-9} \mathrm{~m}^{[85]}$.

"O desenvolvimento da nanotecnologia está acontecendo perto de nós, a cada momento surgem produtos em todos os setores da economia. Não se trata de uma onda, trata-se de sobrevivência coletiva." (Dr. Fernando Galembeck, professor titular do Instituto de Química da Unicamp e membro da Academia Brasileira de Ciências).

O Brasil ocupa a 19a posição em produção de nanotecnologia, uma produção que aparece no mapa mundial da área, porém ainda modesta. A nanotecnologia agrega valor aos produtos, sendo um desafio 0 desenvolvimento nacional de matérias-primas para a produção de insumos e produtos de base ${ }^{[86,87]}$.

Segundo o instituto de pesquisas internacional Lux Research, a nanotecnologia movimentará US\$3,1 trilhões em 2015, $15 \%$ do mercado global.

A produção e distribuição de produtos nanotecnológicos estão cada vez mais globalizadas, aportando atualmente mais de 500 empresas em mais de 20 países comercializando nanoprodutos que se encontram disponíveis em shopping centers ou pela internet. Existe um número crescente de produtos originários de nanotecnologia na costa do Pacífico, especialmente de países como China e Coreia do Sul e as nanopartículas mais freqüentemente encontradas em produtos comercialmente disponíveis são: prata, carbono, titânio, silício, zinco e ouro ${ }^{[86-88]}$. 
A nanotecnologia aplicada para o desenvolvimento de novos materiais para diagnósticos clínicos tem crescido muito nos últimos anos. O Brasil está tratando a nanotecnologia como área estratégica para o desenvolvimento industrial. O Governo anunciou a criação do Sistema Nacional de Laboratórios em Nanotecnologias (SisNano), por meio de uma portaria do Ministério da Ciência, Tecnologia e Inovação, publicada em 2012 no Diário Oficial. Essa tecnologia fornece soluções que vão desde a produção de medicamentos e traçadores biológicos até vestuários, usando componentes em escalas muito pequenas (algumas até microscópicas) ${ }^{[63-67,89]}$.

Fãs de ficção-científica e quadrinhos já escutam sobre a nanotecnologia há tempos, mas a tecnologia faz parte do cotidiano atual em diversas áreas. $O$ mercado internacional de nanotecnologia atingiu cerca de US\$ 693 bilhões até o final de 2012 e alavancará cerca de US\$2,95 trilhões em 2015, segundo dados da Agência Brasileira de Desenvolvimento Industrial [64].

O desenvolvimento da nanotecnologia está ligado ao Plano Brasil Maior, criado pelo governo federal para aumentar o peso da atividade industrial no Produto Interno Bruto. De acordo com o documento, o SisNano deve "estruturar a governabilidade" para as nanotecnologias; desenvolver um programa de mobilização de empresas instaladas no Brasil e de apoio às suas atividades; e otimizar a infraestrutura de pesquisa de 16 institutos nacionais de ciência e tecnologia (INCTs) dedicados a estudos na área.

A maior parte dos estudos está concentrada em São Paulo, especialmente na Universidade de São Paulo (USP) ${ }^{[89]}$.

As nanopartículas têm emergido como uma ferramenta promissora tanto para estudos de mecanismos básicos de células e animais, quanto para liberação controlada de drogas ou outras substâncias in vitro e in vivo ${ }^{[90]}$.

Dentre uma larga produção de materiais nanométricos, as nanopartículas de TR com propriedades luminescentes tem atraído um grande interesse científico por possuírem um amplo potencial de aplicações tecnológicas ${ }^{[97]}$. Em vários trabalhos descritos na literatura, verifica-se uma relação da luminescência destas nanopartículas com o tamanho ${ }^{[98]}$, devido à elevada razão área/volume, tornando os efeitos de superfície de grande influência na redução da intensidade de emissão ${ }^{[99]}$. O uso de agentes 
passivadores tem minimizado estes efeitos, além de facilitar a dispersão de nanopartículas em solventes orgânicos e em matrizes poliméricas ${ }^{[100]}$.

\subsubsection{Nanopartículas Poliméricas}

O campo das nanopartículas poliméricas (NPPs) está expandindo rapidamente e desempenhando um papel crucial em um amplo espectro de áreas que vai desde a eletrônica e fotônica, como a produção materiais condutores para sensores, até medicina para biotecnologia, controle de poluição para a tecnologia ambiental, e assim por diante ${ }^{[71-101]}$.

Este fato pode ser comprovado pelo constante aumento do número de citações (FIG. 3.11) na área no período de 1991 a 2014.

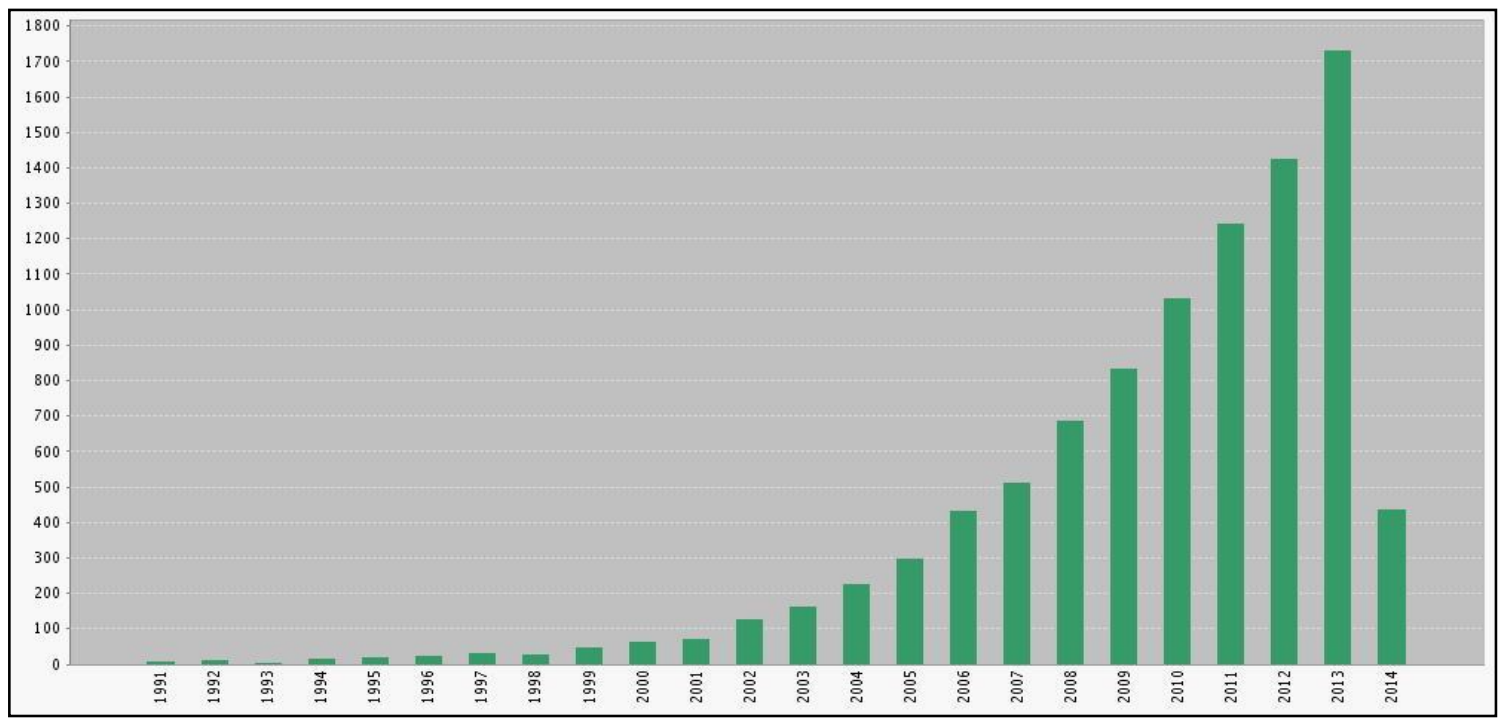

FIGURA 3.11 - Representação gráfica do número de citações sobre NPPs durante o período de 1991 - 2014. 
Essa tendência é devido às propriedades novas e pouco comuns, que satisfazem uma vasta gama de aplicações e necessidades do mercado. As propriedades das NPPs devem ser otimizadas em função das aplicações particulares. E, a fim de alcançar as propriedades de interesse, o modo de preparo tem um papel vital. Assim, é altamente vantajoso desenvolver técnicas de preparação para obtenção de NPPs com as propriedades desejadas para determinada aplicação, uma destas aplicações é extensivamente investigada, a aplicação como marcadores biológicos e de drogas ${ }^{[101,102]}$.

As NPPs podem apresentar-se na forma de nanocápsulas ou nanoesferas. As nanocápsulas e as nanoesferas são suspensões aquosas, que apresentam partículas de diâmetro submicrométrico, diferenciando-se unicamente pela presença de óleo na formulação das primeiras.

Diferentes métodos são encontrados para o preparo de nanopartículas poliméricas, embora algumas das informações sobre estas metodologias de preparação estejam dispersas na literatura e sejam restritas a poucas áreas ${ }^{[102,}$ ${ }^{103]}$. Estes métodos permitem a modulação de sua estrutura, da sua composição e das suas propriedades fisiológicas, como: evaporação do solvente, saltingout, nanoprecipitação, diálise, tecnologia de fluído supercrítico, entre outras. 
O conceito de materiais híbridos surgiu nas últimas três décadas [104, 105], interesse em abordar as propriedades fotoluminescentes de íons TR em materiais híbridos tem crescido consideravelmente na última década. Com o desenvolvimento de materiais com propriedades controláveis, ficou demonstrada uma oportunidade à ciência de materiais e tecnologias relacionadas, como implicações significativas na área de nanotecnologia de

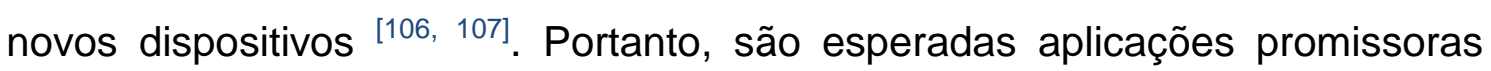
com íons TR para sensores biomédicos ${ }^{[108-111]}$.

Neste trabalho foram produzidas NPPs de PHB e PMMA dopadas com complexo de $\mathrm{Eu}^{3+}$ para servir de sonda em sistema biológico de detecção do hormônio 17- $\beta$-estradiol, beneficiando-se, portanto, do conceito de materiais híbridos com propriedades fotoluminescentes.

\subsubsection{Compostos Poliméricos como Biomateriais}

A palavra polímero origina-se do grego "poli" (muitos) e "mero" (unidade de repetição). Portanto, o polímero é uma macromolécula formada por dezenas de milhares de "meros" unidos por meio de ligação covalente ${ }^{[112]}$, como mostra a FIGURA 3.12. Os polímeros são formados por moléculas grandes constituídas da união química de muitas moléculas pequenas chamadas monômeros ${ }^{[113]}$.

$$
\begin{array}{ll}
\mathrm{H} & \mathrm{H} \\
\mathrm{C}= & \mathrm{C} \\
\mathrm{H} & \mathrm{H}
\end{array}
$$

Monômero

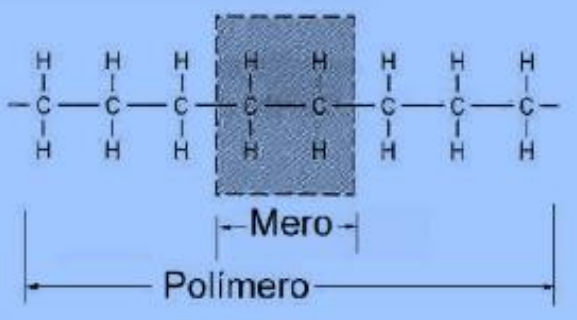

Polimero

FIGURA 3.12 - Representação das estruturas químicas de um monômero, mero e polímero. 
No entanto, é importante ressaltar que esta definição nem sempre foi bem aceita ${ }^{[14-116]}$. Muita da resistência inicial partia dos químicos sintéticos que, estavam interessados na síntese e caracterização de compostos "puros" (aqueles que possuiam uma estequiometria bem definida) e que rejeitavam os produtos secundários da reação, produtos negros ou oleosos, e que justificavam como sendo devidos a um "estado coloidal" e não aos compostos de elevado peso molecular ${ }^{[115]}$. Existiam, no entanto, exceções a este tipo de interpretação. Uma delas foi do quimico português Lourenço que foi a primeira pessoa a sintetizar, e a reconhecer, o arranjo estrutural do poli (óxido de etileno) e dos poliésteres ${ }^{[116]}$. O químico francês Berthelot estudou os compostos vinílicos tendo observado que podiam ser convertidos em compostos de cadeia mais longa ${ }^{[110]}$. Em um nível mais técnico, o nitrato de celulose já era conhecido no início do século XIX ${ }^{[118]}$ estando, no final deste século, a ser processado sob a forma de filmes para utilização no, então emergente, mundo do cinema. Pelo ano de 1862, o isopreno foi reconhecido como estrutura da borracha natural ${ }^{[118]}$, apesar da forma como estas unidades eram ligadas, umas as outras, não ser ainda bastante clara.

No início do século XX, Baekland preparou a primeira resina sintética, fenolformadeido ${ }^{[119]}$, a qual designou como Baquelite, tendo sido largamente utilizada em produtos tão variados e distintos como botões e rádios. No entanto, só nos anos 20, com o trabalho de Staudinger em polímeros sintéticos [120] e de Svedberg, que utilizou a ultracentrifugação, para caracterizar a hemoglobina e outras proteínas [121], o conceito de polímeros, ou macromoléculas, tal como o utilizamos nos nossos dias, começou a ser aceito.

Apenas a partir do século XIX, com a possibilidade de observação ao microscópio, foi também possível um maior domínio dos materiais e dos seus processos de fabricação e transformação. E nesse domínio dos materiais em que é permitido atualmente ao homem oferecer resposta às exigências das tecnologias modernas. Para tal, é necessario combinar propriedades que parecem incompatíveis, tendo como principal objetivo a obtenção de um material final com propriedades superiores à dos seus componentes, para determinadas aplicações ${ }^{[114]}$. 
Neste sentido, surgiram os materiais compósitos: materiais que, combinando as características dos seus componentes de forma adequada, apresentam um desempenho estrutural melhor do que estes, sob condições específicas de utilização ${ }^{[114,122]}$.

Atualmente é comum combinar materiais com uma segunda matéria orgânica ou inorgânica, para produzir um material composto. Uma alternativa é a produção de nanocompósitos produzidos a partir da dispersão de nanopartículas no seio de uma matriz ${ }^{[122]}$. Entre os materiais compósitos existentes, tem-se verificado um aumento da importância dos que apresentam uma matriz polimérica.

Algumas décadas atrás, os materiais poliméricos eram apenas caracterizados por uma boa capacidade de isolamento elétrico e por propriedades mecânicas versáteis. No entanto, este estatuto foi alterado quando no início dos anos 80 foram encontradas nestes materiais algumas propriedades com elevado interesse para aplicação na indústria e tecnologia $[114,122]$.

Quando comparados com materiais inorgânicos, os compostos poliméricos apresentam algumas vantagens: são leves, flexiveis e robustos; são obtidos na forma de filmes finos ou ultra finos, fibras ou mesmo como cristais líquidos; são facilmente transformados na configuração desejada; as suas propriedades físicas podem ser controladas num amplo intervalo, por meio de apropriadas modificações químicas e alguns deles são biocompatíveis [122].

Materiais poliméricos multifuncionais com características diversas têm sido preparados e caracterizados com consequente desenvolvimento. Materiais híbridos orgânicos e inorgânicos contendo polímeros têm despertado recentemente grandes interesses combinando as vantagens dos componentes orgânicos e inorgânicos, permitindo a obtenção de dispositivos com aplicações abrangentes e inovadoras, nomeadamente aplicações biomédicas ${ }^{[123]}$, então caracterizado como um biomaterial.

Um biomaterial é definido como qualquer substância natural ou sintética produzida para interagir com sistemas biológicos ${ }^{[124,125]}$. Biomateriais devem 
ser biocompatíveis, o que significa que devem desempenhar sua função com uma resposta apropriada ${ }^{[126]}$, característica esta inerente a alguns polímeros.

Para atender às necessidades da comunidade biomédica, materiais compostos de todos os metais e cerâmicas para óculos e polímeros têm sido pesquisados. Os polímeros possuem um potencial significativo porque a flexibilidade na química dá origem a materiais com uma grande diversidade de propriedades físicas e mecânicas. Polímeros degradáveis são de maior interesse, porque esses biomateriais são capazes de quebrar e serem excretados ou reabsorvidos sem remoção cirúrgica ${ }^{[125,126]}$.

\subsection{Poli(3-hidroxibutirato)}

O poli(3-hidroxibutirato)s (PHB) é um composto de uma classe dos polímeros termoplástico chamados poli(3-hidroxialcanoato)s que servem a muitas bactérias como uma maneira de armazenar dentro da célula, materiais que podem servir de reserva para obtenção de carbono e como fonte de energia para o caso de ausência de um dos dois ${ }^{[127]}$. O PHB e seu copolímero poli(hidroxibutirato-hidroxivalerato) (PHB-HV) (FIG. 3.13) têm despertado interesse comercial, devido à possibilidade de produção por rotas biotecnológicas a partir de substrato renovável e por apresentar-se como uma alternativa à substituição de alguns plásticos convencionais derivados do petróleo, os quais possuem lenta degradação, provocando acúmulo de resíduos sólidos contaminando o ambiente ${ }^{[128]}$. As plantas modificadas geneticamente para produção de PHB como a batata (Solanum tuberosum) e tabaco (Nicotiana tabacum), podem fornecer outros meios de produzir este polímero.

O PHB pode ser usado na fabricação de embalagens para produtos de limpeza, higiene, cosméticos e produtos farmacêuticos. Também é utilizado para produzir sacos e vasilhames para fertilizantes e defensivos agrícolas, vasos para mudas e produtos injetáveis. Além disso, por ser biocompatível e facilmente absorvido pelo organismo humano, pode ser empregado na área médico-farmacêutica, prestando-se à fabricação de fios de sutura, próteses 
ósseas e cápsulas que liberam gradualmente medicamentos na corrente sanguínea ${ }^{[127,129]}$.

O PHB é conhecido pela sua biocompatibilidade. $O$ termo biocompatibilidade refere-se à aceitabilidade mútua do polímero e do meio fisiológico que o cerca. A biocompatibilidade pode ser descrita como dois fenômenos complementares: os efeitos do meio fisiológico no polímero e os efeitos do polímero neste meio. O primeiro influenciará a degradação do polímero e o segundo a resposta do tecido ao implante polimérico ${ }^{[130,131]}$.

Kennedy et al. ${ }^{[132]}$ realizaram um estudo da biocompatibilidade in vivo e in vitro do PHB e copolímeros de $\mathrm{P}(\mathrm{HB}-\mathrm{HV})$. A biocompatibilidade in vivo foi estudada através do monitoramento de inflamações em ratos Wistar machos. Os autores administraram injeções intramusculares do polímero $(20-40 \mu \mathrm{m})$ nos músculos da coxa dos ratos, uma análise enzimática utilizando fosfatase alcalina e ácida foi empregada para monitorar inflamações agudas e crônicas, respectivamente. Embora tenha ocorrido como resposta uma inflamação aguda, ela foi atribuída a um trauma mecânico inicial da injeção. Nenhuma inflamação crônica foi detectada pela análise enzimática.

A biocompatibilidade destes polímeros ainda foi estudada pela técnica de cultura de células. Os efeitos dos copolímeros no crescimento de CHO-K1 (ovários de ratos chineses) em culturas de células foram monitorados durante um período de $60 \mathrm{~h}$. Os polímeros, usados na forma de filmes, não inibiram o crescimento destas células durante este período, sugerindo uma boa biocompatibilidade ${ }^{[133]}$.

Um estudo da biocompatibilidade in vivo do PHB através da injeção de microesferas $(100 \mu \mathrm{m})$ no músculo de ratos também foi efetuado por Juni e Nakano ${ }^{[134]}$, onde eles obtiveram resultados similares aos encontrados por Kennedy et al. ${ }^{[132]}$ na inflamação aguda transiente, a qual terminava após 7 dias após injeção.

Doyle e Bonfield ${ }^{[135]}$ investigaram a utilização de PHB como implantes ósseos na coxa, eles realizaram estudos preliminares em coelhos obtendo uma boa integração entre o PHB e o osso sem nenhuma evidência de inflamação crônica em resposta ao procedimento. Eles reportaram posteriormente que estudos in vitro com PHB e compósitos de PHB-Hidroxiapatita sugeriram que 
este polímero não é citotóxico. Apesar da inflamação aguda inicial observada em vários estudos in vivo para os copolímeros e para o homopolímero, as quais ocorreram provavelmente em resposta a um trauma na implantação ou injeção, eles apresentaram boa biocompatibilidade tanto nos testes in vitro como in vivo. Espera-se que os produtos solúveis de degradação, geralmente os próprios monômeros, também sejam biocompatíveis, pelos resultados dos experimentos realizados ${ }^{[133]}$.

A escolha do PHB para servir de matriz para o complexo luminescente à base de terras raras foi exatamente pela evidência de uma boa biocompatibilidade.

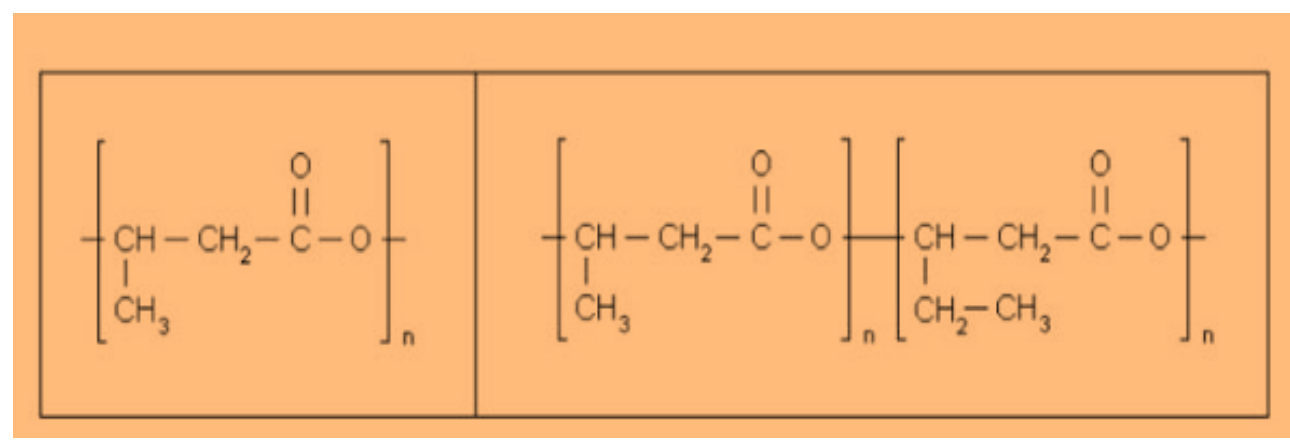

FIGURA 3.13 - Estrutura química do PHB e do seu copolímero PHB-HV, respectivamente ${ }^{[128]}$.

\subsection{Poli(metacrilato de metila)}

O poli(metacrilato de metila) (PMMA) é um polímero de adição formado pela união sucessiva de muitas unidades de moléculas de metacrilato de metila ${ }^{[136]}$, conforme mostra a FIGURA 3.14. 


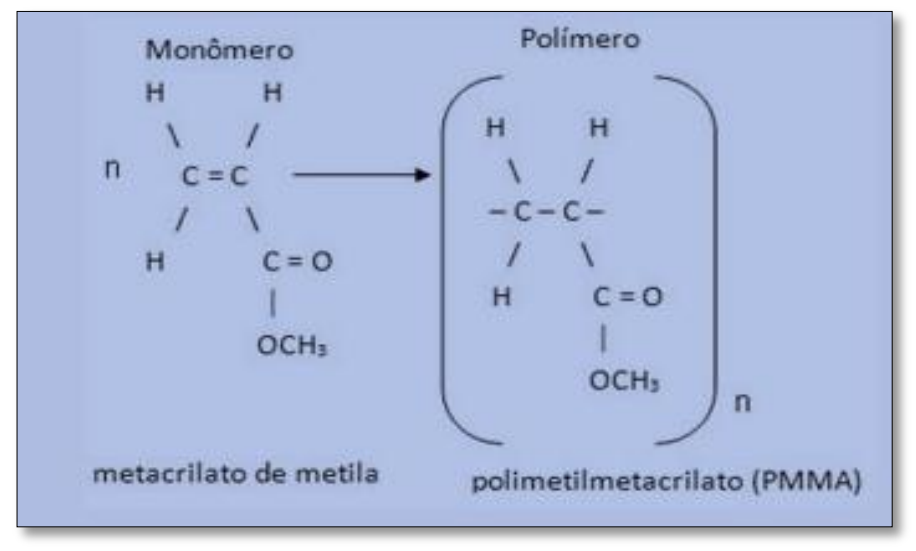

FIGURA 3.14 - Estruturas químicas do metacrilato de metila e do poli(metacrilato de metila).

Nessa reação obtém-se uma massa pastosa que é então derramada sobre um molde onde a polimerização irá terminar. O resultado é um plástico transparente e cristalino, semelhante ao aspecto do vidro, porém com algumas vantagens sobre ele, tais como: maior leveza (densidade aproximada de 1,18 $\mathrm{g} / \mathrm{cm}^{3}$ ), maior resistência ao impacto, além de os acrílicos também poderem ser cerrados ${ }^{[57,113]}$.

O PMMA apresenta excelente transparência com transmissão de luz visível de $92 \%$. Os valores de opacidade (medida por luz transmitida ao passar por corpo de prova a 2,5ำ em relação à média do feixe) variam de 1 a $3 \%$. 0 índice de refração tem valor de 1,49. Uma limitação da utilização do PMMA em aplicações ópticas é quanto à resistência à abrasão quando comparado ao vidro, mas em relação aos outros termoplásticos transparentes é o que tem maior resistência ${ }^{[57,136]}$.

O PMMA tem uma faixa de temperatura de distorção térmica entre 74 e $106^{\circ} \mathrm{C}$, com temperatura típica de trabalho contínuo próxima de $85 \stackrel{\circ}{ } \mathrm{C}$. $\mathrm{O}$ PMMA apresenta o coeficiente de expansão térmica em torno de $65.10^{-6}$ $\mathrm{m} / \mathrm{m}^{\circ} \mathrm{C}$ que é muito maior que os metais ${ }^{[136]}$.

Por apresentar propriedades adequadas na utilização em dispositivos ópticos, este polímero assim como o PHB foram utilizados neste trabalho como matriz na preparação das nanopartículas poliméricas com o intuito de produzir nanomarcadores luminescentes aplicáveis à detecção e quantificação do hormônio 17- $\beta$-estradiol. 


\subsection{O Sistema Endócrino}

O sistema endócrino é formado pelo conjunto de glândulas endócrinas, as quais são responsáveis pela secreção de substância denominadas hormônios. As glândulas endócrinas (do grego endos, dentro, e krynos, secreção), representadas na FIGURA 3.15, são assim chamadas porque lançam sua secreção (hormônios) diretamente no sangue, por onde eles atingem todas as células do corpo. Cada hormônio atua apenas sobre alguns tipos de células, denominadas células alvo.

As células alvo de determinado hormônio possuem, na membrana ou no citoplasma, proteínas denominadas receptores hormonais, capazes de se combinar especificamente às moléculas do hormônio. É apenas quando a combinação correta ocorre que as células alvo exibem as respostas características da ação hormonal ${ }^{[137-139]}$.

A espécie humana possui diversas glândulas endócrinas, algumas delas responsáveis pela produção de mais de um tipo de hormônio:

\section{O O Hipotálamo}

Localiza-se na base do encéfalo, sob uma região encefálica denominada tálamo. A função endócrina do hipotálamo está a cargo das células neurosecretoras, que são neurônios especializados na produção e na liberação de hormônios. A FIGURA 3.16 mostra o hipotálamo (acima) e a hipófise (abaixo).

\section{○ $\quad$ A Hipófise (Glândula Pituitária)}

A hipófise é dividida em três partes, denominadas lobos anterior, posterior e intermédio, esse último é pouco desenvolvido no homem. O lobo anterior (maior) é designado adeno-hipófise e o lobo posterior, neuro-hipófise.

Alguns hormônios são produzidos no lobo anterior da hipófise, como por exemplo, Somatotrofina (GH), caracterizado como o hormônio do crescimento; o hormônio tireotrófico (TSH) que estimula a glândula tireóide, o hormônio adrenocorticotrófico $(\mathrm{ACTH})$ que age sobre o córtex das glândulas supra- 
renais; o hormônio folículo-estimulante (FSH) que age sobre a maturação dos folículos ovarianos e dos espermatozoides, o hormônio luteinizante (LH) que estimula as células intersticiais do ovário e do testículo; provocando a ovulação e formação do corpo amarelo; o hormônio lactogênico (LTH) ou prolactina que interfere no desenvolvimento das mamas, na mulher e na produção de leite [139].

Os hormônios designados pelas siglas FSH e LH podem ser reunidos sob a designação geral de gonadotrofinas ${ }^{[137]}$.

Outros hormônios são produzidos pelo lobo posterior da hipófise, como por exemplo, a oxitocina que age particularmente na musculatura lisa da parede do útero, facilitando, assim, a expulsão do feto e da placenta; o hormônio antidiurético (ADH) ou vasopressina que se constitui em um mecanismo importante para a regulação do equilíbrio hídrico do organismo $[137,139]$.

\section{- A Tireoide}

Situada na porção anterior do pescoço, a tireóide consta dos lobos direito, esquerdo e piramidal. Os lobos direito e esquerdo são unidos na linha mediana por uma porção estreitada, chamada istmo. A tireóide é regulada pelo hormônio tireotrófico (TSH) da adeno-hipófise. Seus hormônios, tiroxina e triiodotironina, requerem iodo para sua elaboração ${ }^{[138]}$.

\section{As Paratireoides}

Constituídas geralmente por quatro massas celulares, as paratireóides medem, em média, cerca de $6 \mathrm{~mm}$ de altura por 3 a $4 \mathrm{~mm}$ de largura e apresentam 0 aspecto de discos ovais achatados. Localizam-se junto à tireóide. Seu hormônio - o paratormônio - é necessário para o metabolismo do cálcio. 


\section{As Supra-Renais ou Adrenais}

Em cada glândula supra-renal há duas partes distintas; o córtex e a medula. Cada parte tem função diferente. Os vários hormônios produzidos pelo córtex - as corticosteronas - controlam o metabolismo do sódio e do potássio e o aproveitamento dos açúcares, lipídios, sais e águas, entre outras funções.

A medula produz adrenalina (epinefrina) e noradrenalina (norepinefrina). Esses hormônios são importantes na ativação dos mecanismos de defesa do organismo diante de condições de emergência, tais como: emoções fortes, "stress", choque, entre outros; ou seja, preparam o organismo para a fuga ou luta.

\section{Hormônios produzidos pelas llhotas de Langerhans (no Pâncreas)}

\section{- Insulina}

Facilita a penetração da glicose, presente no sangue circulante, nas células, em particular nas do fígado, onde é convertida em glicogênio (reserva de glicose).

\section{- Glucagon (glucagônio)}

Responsável pelo desdobramento do glicogênio em glicose e pela elevação de taxa desse açúcar no sangue circulante.

\section{- Ovários}

$\mathrm{Na}$ puberdade, a adeno-hipófise passa a produzir quantidades crescentes do hormônio folículo-estimulante (FSH). Sob a ação do FSH, os folículos imaturos do ovário continuam seu desenvolvimento, o mesmo acontecendo com os óvulos neles contidos. O folículo em desenvolvimento secreta hormônios denominados estrógenos ou estrogênios, responsáveis pelo aparecimento das características sexuais secundárias femininas. 
Outro hormônio produzido pela adeno-hipófise - hormônio luteinizante (LH) - atua sobre o ovário, determinando o rompimento do folículo maduro, com a expulsão do óvulo (ovulação).

O corpo amarelo (corpo lúteo) continua a produzir estrogênios e inicia a produção de outro hormônio - a progesterona - que atuará sobre o útero, preparando-o para receber o embrião caso tenha ocorrido a fecundação ${ }^{[139]}$.

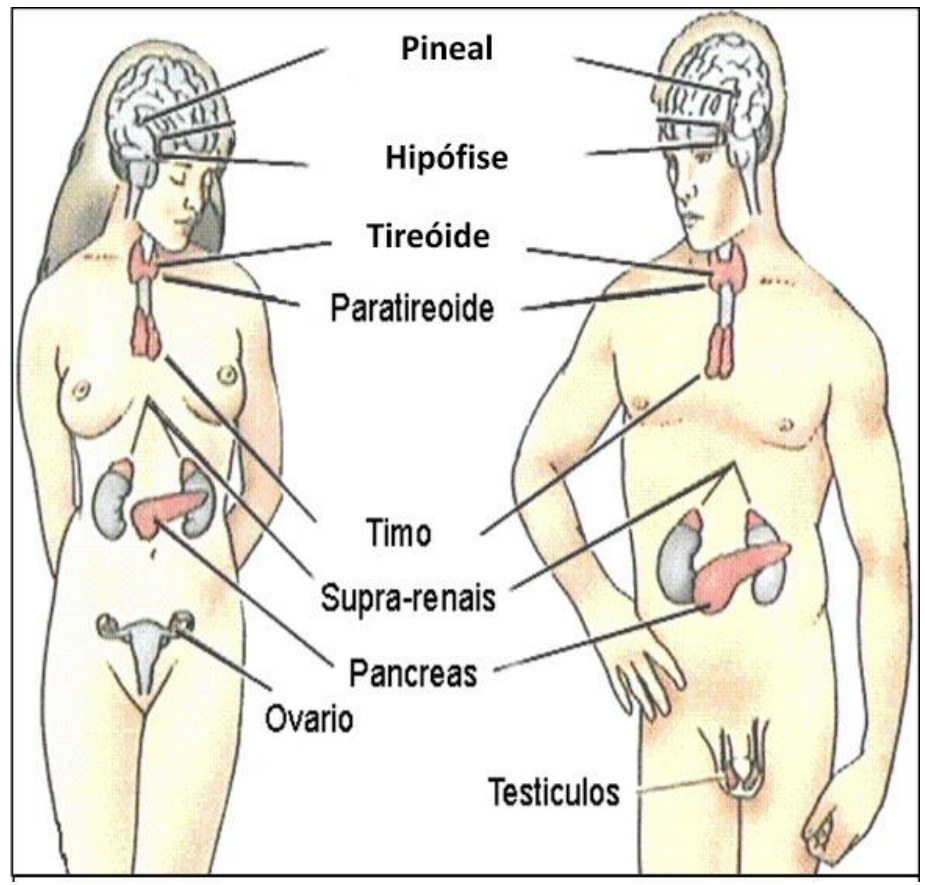

FIGURA 3.15 - Representação das glândulas endócrinas ${ }^{[137]}$.

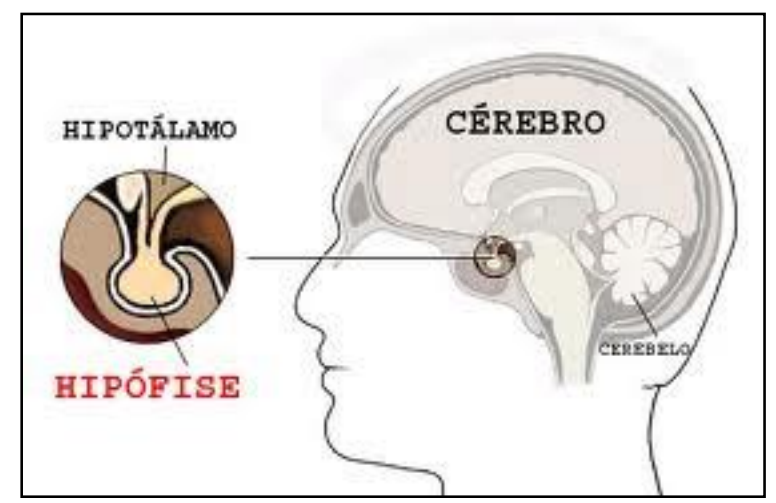

FIGURA 3.16 - Representação da localização do hipotálamo e da hipófise ${ }^{[140]}$. 


\subsubsection{Desenvolvimento e Hormônios Gonadais}

O encéfalo começa a vida como um elemento genérico, sem definição de macho ou fêmea, aguardando para ser impactado pelo perfil hormonal circulante, que será determinado pelas gônadas. A melhor exemplificação disto é o rato de laboratório, a partir do qual sabemos que em um pré-determinado ponto do tempo durante o desenvolvimento, no final da gestação, o testículo fetal libera grandes quantidades de testosterona para a circulação. Por intermédio do sangue, a testosterona ganha acesso ao cérebro, onde é localmente aromatizada para estradiol, um estrogênio, hormônio responsável pela diferenciação do substrato neural para um fenótipo masculino (FIG. 3.17). O encéfalo embrionário do rato é bipotente. $O$ fenótipo do encéfalo de um macho adulto resulta da exposição ao estradiol no período final da gestação/ neonatal, que é aromatizada a partir da testosterona. A administração exógena da testosterona ou estradiol em um animal fêmea geneticamente resulta em um fenótipo masculino completo para as respostas reprodutivas do hipotálamo. Já a ausência de hormônios gonadais em ratos recém-nascidos irá constituir um encéfalo feminilizado e que representará os reflexos das ações hormonais do adulto sobre seu comportamento.

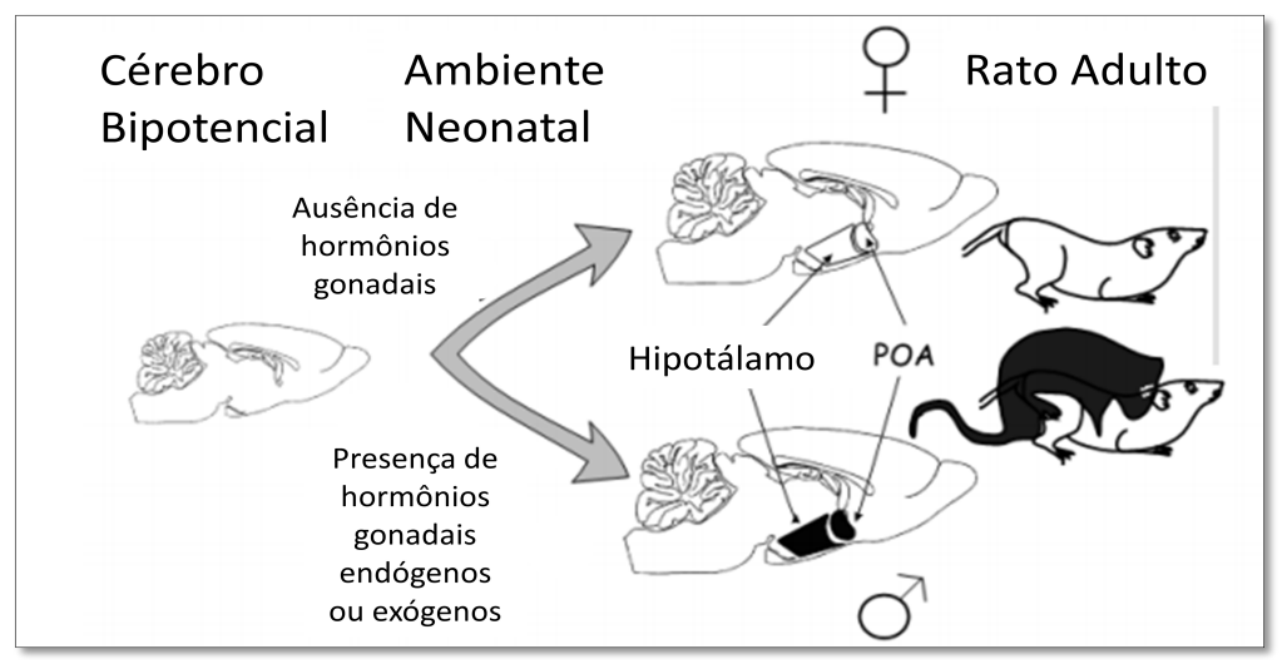

FIGURA 3.17 - Diferenciação sexual de um núcleo hipotalâmico reprodutivamente relevante ${ }^{[142]}$. 
A testosterona e seu produto reduzido, a diidrotestosterona, também exercem efeitos diferenciando o sistema nervoso; sendo um bom exemplo o núcleo espinhal bulbocavernoso. Em outras espécies, especialmente em primatas, a maioria da diferenciação, considerada masculinização, é medida por andrógenos em exposição aos estrogênios ${ }^{[142]}$.

O conceito de diferenciação sexual do encéfalo foi dado em um artigo de Phoenix ${ }^{[143]}$, que postulou a hipótese organizacional/ativacional da ação de hormônios esteróides sobre o encéfalo. Este quadro conceitual fora construído com base em evidências de uma extensa variedade de espécies, mas foi empiricamente estabelecido pelo tratamento hormonal em porquinhas-da-índia gestantes, e da observação do comportamento da prole adulta. Colocando de forma simples, os fetos que foram expostos a andrógenos iriam se comportar como machos quando adultos se novamente expostos aos andrógenos, mas se eles não tinham a exposição ao andrógeno durante o desenvolvimento, eles não assumiam tal comportamento. Outros estudos realizados na mesma época, em ratos, observaram que os filhotes recém-nascidos do sexo feminino expostos aos andrógenos resultavam em adultos inférteis devido a efeitos na ovulação. Parecia bastante evidente, em retrospecto, que deveria ter havido uma mudança permanente na arquitetura neural que regula o controle da secreção de gonadotrofinas e o comportamento sexual, e que logo deveria haver diferenças sexuais que ocorreria naturalmente no encéfalo, mas naquele momento não era claro que as mudanças simplesmente não se limitavam ao ovário ou a hipófise.

O sistema hormonal feminino é classificado da seguinte forma:

1. Os fatores liberadores hipotalâmicos - o fator liberador do hormônio folículo estimulante (FRF) e o fator liberador do hormônio luteinizante (LRF) (que podem ser de fato, um mesmo fator).

2. Os hormônios da adeno-hipófise - o hormônio folículo-estimulante (FSH) e o hormônio luteinizante (LH) - secretados em resposta aos fatores liberadores ou fatores do hipotálamo. 
3. Os hormônios ovarianos - o estrogênio e a progesterona - que são secretados pelos ovários em resposta aos dois hormônios da glândulahipófise ${ }^{[137]}$.

Os hormônios gonadais masculinos são produzidos nos testículos. São os hormônios que determinam as características sexuais secundárias, induzem a formação dos gametas masculinos e promovem o impulso sexual, além de diversas atuações orgânicas.

Entre os 11 e 14 anos de vida, dois hormônios produzidos pela adenohipófise agem sobre os testículos, estimulando a produção de testosterona, o principal hormônio masculino. Esses hormônios são o hormônio folículoestimulante (FSH) e $\circ$ hormônio luteinizante ( $(\mathrm{LH})$, também chamados de gonadotrofinas por atuarem sobre as gônadas (FIG. 3.18).

No homem, o hormônio luteinizante também pode ser chamado de hormônio estimulador das células intersticiais (ICSH), porque age estimulando as células intersticiais, ou de Leydig, a produzirem testosterona. A testosterona e os hormônios gonadotróficos FSH e $\mathrm{LH}$ atuam juntos na ativação da espermatogênese (produção de espermatozoides) ${ }^{[137,138]}$.

Como já mencionado, os estrogênios $17-\beta$-estradiol e a estrona são também produzidos no homem, normalmente derivados da testosterona e androstenediona.

Os vários hormônios não são secretados em quantidades constantes, fixas, mas em proporções que diferem em níveis drásticos, tanto em homens quanto nas mulheres e as diferentes fases do ciclo feminino.

A FIGURA 3.19 indica as alterações nas concentrações dos hormônios da adeno-hipófise, FSH e LH, e os hormônios ovarianos, estradiol (estrogênio) e progesterona. Apesar de ainda não se terem efetuado medidas detalhadas, é razoável crer que os fatores liberadores hipotalâmicos também sofram variações cíclicas. 


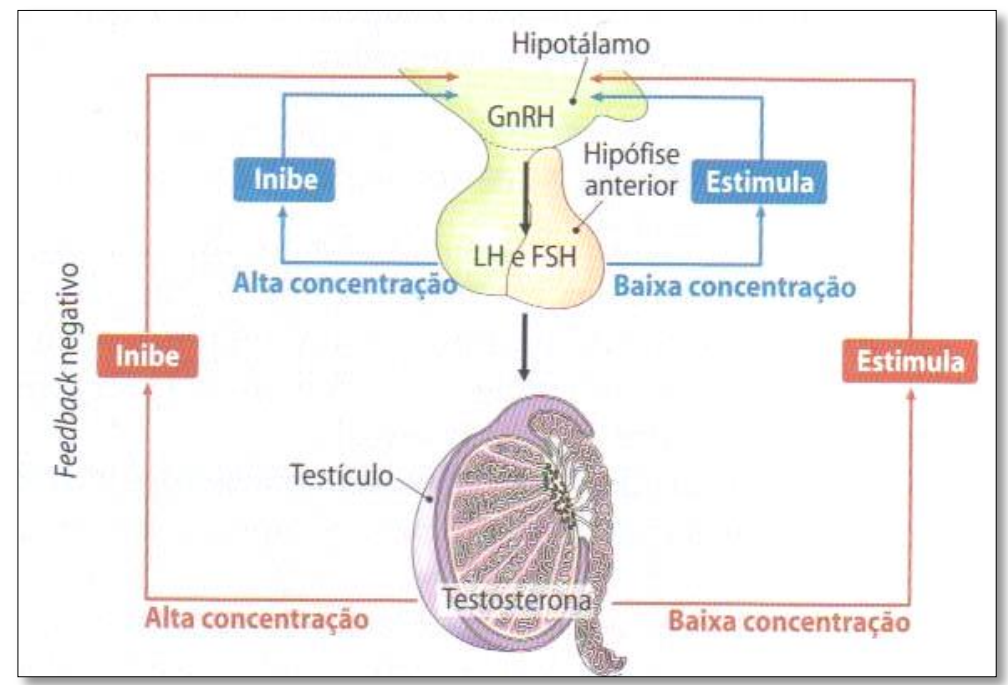

FIGURA 3.18 - Esquema representativo da regulação hormonal no homem.

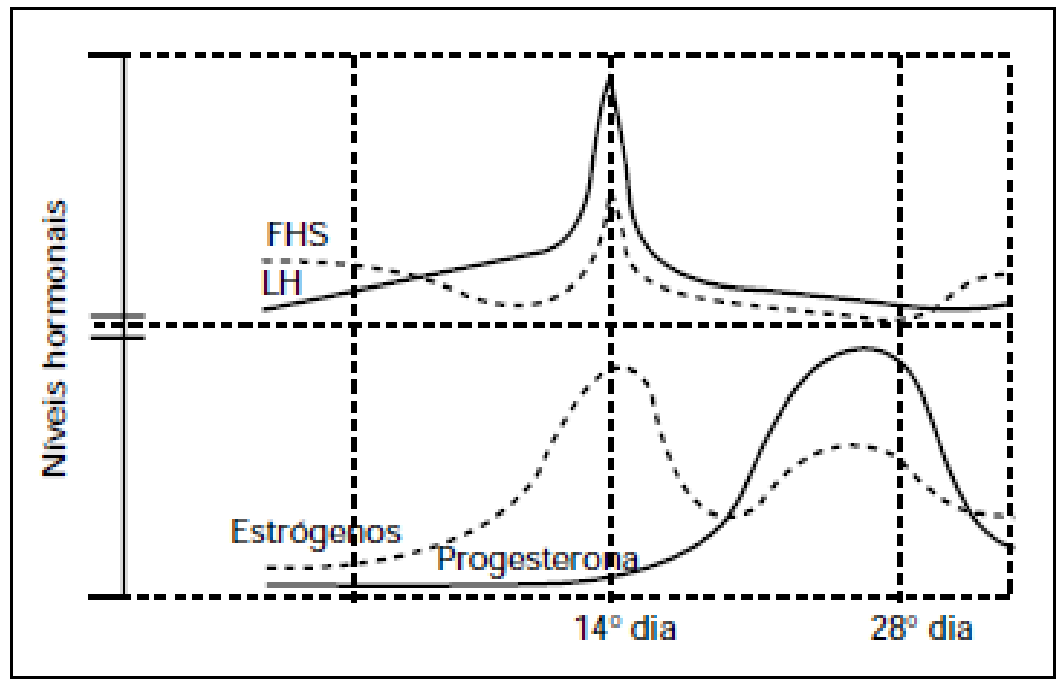

FIGURA 3.19 - Concentração de gonadotrofinas e hormônios ovarianos no plasma durante o ciclo sexual feminino normal.

\subsubsection{Os Estrogênios}

$\mathrm{Na}$ fêmea normal, não grávida, os estrogênios são secretados em maiores quantidades apenas pelos ovários, embora quantidades mínimas 
também sejam produzidas pelo córtex adrenal. Nos homens, é produzido nos testículos e a partir da conversão periférica da testosterona, sendo que mais de $80 \%$ do estradiol circulante em homens é derivado da aromatização da testosterona, como mostra FIGURA 3.20.

$\mathrm{Na}$ gravidez, a placenta também secreta enormes quantidades, acima de 50 vezes a quantidade secretada pelos ovários durante o ciclo mensal normal.

Pelo menos seis estrogênios naturais diferentes foram isolados do plasma de mulheres, mas somente três estão presentes em quantidades significativas, o 17- $\beta$-estradiol (ou estradiol), a estrona e o estriol, cujas fórmulas estão ilustradas na FIGURA 3.21. Tanto o $17-\beta$-estradiol como a estrona estão presentes em grandes quantidades no sangue venoso dos ovários, enquanto 0 estriol é um produto oxidativo derivado destes dois, ocorrendo a conversão principalmente no fígado, e em outros locais do organismo, em menor proporção.

A potência estrogênica do $17-\beta$-estradiol é 12 vezes maior que a da estrona e 80 vezes a do estriol. Considerando estas potências relativas, 0 efeito estrogênico total do 17- $\beta$-estradiol, usualmente, é muitas vezes maior que os outros dois juntos. Por este motivo, 17- $\beta$-estradiol é considerado 0 principal estrogênio, embora os efeitos estrogênicos da estrona não possam ser negligenciados ${ }^{[137]}$. 


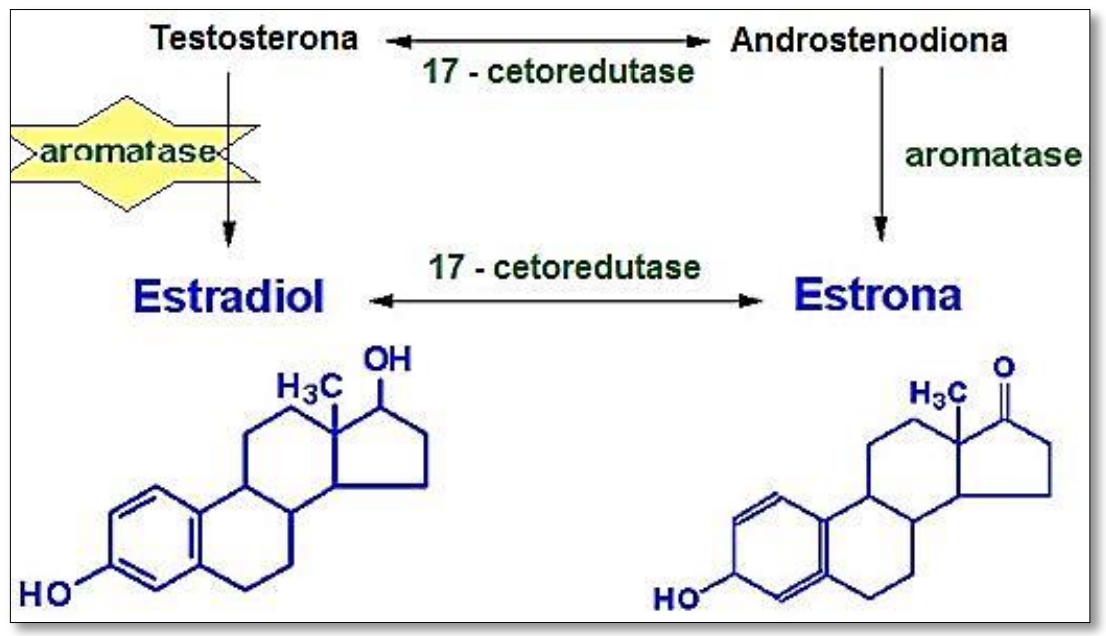

FIGURA 3.20 - Produção dos estrogênios a partir da conversão periférica da testosterona.

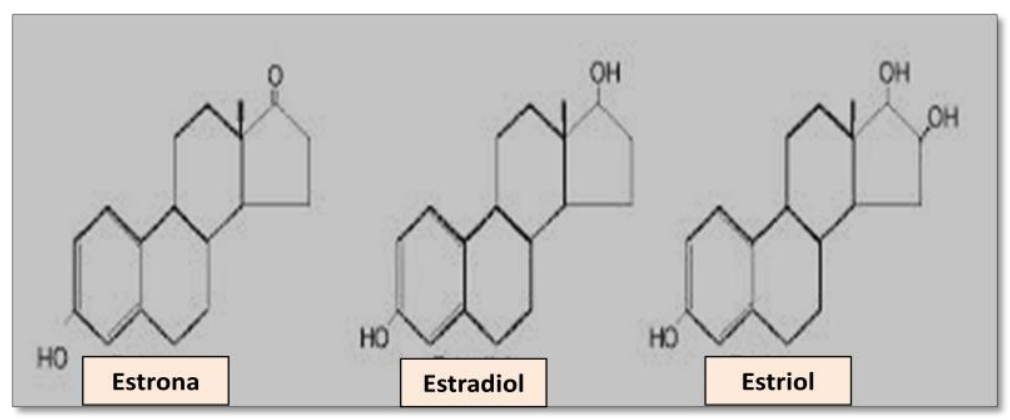

FIGURA 3.21 - Fórmulas químicas dos estrogênios.

\subsection{Química dos Estrogênios}

Os estrogênios são esteroides possuindo 18 ou 19 átomos de carbono. Eles são caracterizados quimicamente por um anel aromático $A$ e um grupo hidroxila no átomo de Carbono 3 , no qual é fenólico. Não existe um grupo metil angular entre os anéis $\mathrm{A}$ e $\mathrm{B}$, o que vai de contraste com outros hormônios esteroides e os esteróis. 
Os estrogênios foram os primeiros hormônios esteroides a serem isolados em forma cristalina pura. Este fato foi registrado em 1929 por dois laboratórios independentes: Doisy, Veler and Thayer, 1929; Butenandt, 1929. Pouco tempo depois Marrian (1930) anunciou o isolamento do estriol, e dez anos depois o 17- $\beta$-estradiol foi isolado da urina humana de grávida [139]. Nenhum outro estrogênio foi isolado durante os quinze anos seguintes, mas nos anos 1955-1960 nove outros foram isolados da urina humana de grávidas.

\subsection{Síntese dos Estrogênios}

Observando pelas fórmulas dos estrogênios na FIGURA 3.21, podemos concluir que todos são esteróides. Eles são sintetizados nos ovários a partir do colesterol, ou da acetilcoenzima $A$, e as unidades acetato podem se conjugar para formar o núcleo esteróide apropriado. É particularmente interessante que a progesterona, bem como a testosterona, o hormônio sexual masculino, são sintetizados primeiro, e então convertidos a estrogênios. Na verdade, mesmo normalmente, quantidades mínimas de testosterona são secretadas pelos ovários ${ }^{[137]}$.

\subsection{Funções dos Estrogênios - Efeitos sobre as características sexuais primárias e secundárias}

A principal função dos estrogênios é provocar a proliferação celular e o crescimento dos tecidos dos órgãos sexuais e outros tecidos relacionados à reprodução.

Efeitos sobre os órgãos sexuais - durante a infância são secretados estrogênios apenas em pequenas quantidades, mas, após a puberdade, sob a influência dos hormônios gonadotróficos hipofisários, esta quantidade aumenta até 20 vezes ou mais. Nesta ocasião, os órgãos sexuais femininos mudam suas características infantis para as de adulto. Há um aumento de tamanho das 
Trompas de Falópio, do útero e da vagina, bem como da genitália externa, com deposição de gordura no monte pubiano e grandes lábios, e aumento dos pequenos lábios.

Além do aumento do tamanho da vagina, os estrogênios alteram o epitélio vaginal do tipo cúbico para o tipo estratificado, que é consideravelmente mais resistente aos traumas e infecções que o epitélio prépúbere. As infecções nas crianças, tal como uma vaginite gonorreica, podem realmente ser curadas pela administração de estrogênios, simplesmente devido ao aumento resultante na resistência do epitélio vaginal à infecção.

Poucos anos após a puberdade, o tamanho do útero duplica ou triplica. Mais importante, entretanto, que o aumento em tamanho, são as alterações ocorridas no endométrio sob a ação dos estrogênios, pois estes possuem acentuada proliferação do mesmo, e o desenvolvimento de glândulas que, mais tarde, serão usadas no auxílio da nutrição do óvulo implantado.

Efeitos sobre as Trompas de Falópio - Os estrogênios exercem, sobre a mucosa que recobre as trompas de Falópio, um efeito semelhante ao exercido sobre o endométrio uterino: levam a uma proliferação dos tecidos glandulares e - especialmente importante - produzem um aumento do número de células ciliadas que recobrem as trompas. Além disso, a atividade dos cílios é consideravelmente aumentada, e estes sempre apresentam um movimento no sentido do útero. Isto, indubitavelmente, ajuda a propulsão do óvulo fertilizado em direção ao útero.

Efeito sobre as Mamas - As mamas primitivas de machos e fêmeas são exatamente iguais, e, sob a influência dos hormônios adequados, as masculinas, pelo menos durante as primeiras duas décadas de vida, podem desenvolver-se o suficiente para produzir leite, da mesma maneira que as mamas femininas.

Os estrogênios levam à deposição de gordura nas mamas, ao desenvolvimento de um extenso sistema de ductos. Os lóbulos e os alvéolos das mamas desenvolvem-se um pouco, mas são a progesterona e a prolactina que levam a um crescimento determinante e ao funcionamento destas estruturas. Em resumo, os estrogênios iniciam o crescimento das mamas, e do aparelho produtor de leite, e também são responsáveis pela aparência externa 
característica da mama feminina madura, mas não completam o trabalho de conversão das mamas em órgãos produtores de leite.

Efeitos sobre o Esqueleto - Os estrogênios provocam aumento da atividade osteoblástica e, portanto, na puberdade, quando a mulher entra em seu período reprodutivo, sua taxa de crescimento torna-se rápida durante vários anos. Entretanto, os estrogênios têm outro efeito sobre o crescimento do esqueleto, isto é, causam a união das epífises com o eixo dos ossos longos. Este efeito é muito mais forte na mulher que o efeito semelhante da testosterona no homem e, em consequência, geralmente o crescimento da mulher cessa muitos anos antes que o do homem. A fêmea-eunuco, que é completamente desprovida de produção de estrogênio, quase sempre tem mais altura do que as normais, devido às suas epífises não se unirem precocemente.

Efeito sobre a Pélvis - Os estrogênios exercem um efeito especial no alargamento da pélvis, mudando seu contorno estreito, como um contorno de funil no homem, em um contorno largo e ovóide. A importância funcional desta mudança para o nascimento de um bebê é óbvia.

Efeito sobre a Retenção de Cálcio e Fosfato - A testosterona produz uma retenção de cálcio e fosfato bem acima do normal, efeito também verificado para os estrogênios, mas em menor grau, devido aos estrogênios, como a testosterona, promoverem o crescimento dos ossos, ocasionando uma deposição de quantidades crescentes de matriz óssea, com subsequente retenção de ambos, cálcio e fosfato.

Efeito sobre a Deposição de Proteínas - Os estrogênios ocasionam um leve aumento na proteína total do corpo, o que é evidenciado por um pequeno balanceamento de nitrogênio positivo, quando estas substâncias são administradas. Isto provavelmente resulta do efeito de promoção do crescimento dos órgãos sexuais induzidos pelos estrogênios, e sobre alguns outros tecidos do organismo. O aumento da deposição de proteína produzida pela testosterona é muito mais geral, e muitas vezes mais poderoso do que 0 induzido pelos estrogênios.

Efeito sobre o Metabolismo e Deposição de Gordura - Os estrogênios aumentam levemente a taxa metabólica, mas não tanto quanto o hormônio 
sexual masculino, a testosterona. Entretanto, produzem a deposição de quantidades crescentes de gordura nos tecidos subcutâneos: como resultado, a gravidade específica total do corpo feminino, quando tomada pela flutuação na água, é consideravelmente menor que a do corpo masculino, que contém mais proteína e menos gordura. Além da deposição de gordura nas mamas e nos tecidos subcutâneos, os estrogênios causam uma deposição de gordura especialmente marcante nas nádegas e coxas, levando a um alargamento dos quadris, que é característico da figura feminina.

Efeito sobre a Pele - Os estrogênios levam ao desenvolvimento de uma textura de pele macia e normalmente lisa, contudo mais espessa que a pele de crianças e de mulheres castradas. Os estrogênios também tornam a pele mais vascularizada, este feito frequentemente está associado a um aumento do calor da pele, com frequência resulta em maior sangramento dos cortes superficiais que o observado nos homens.

Efeito sobre o Equilíbrio Eletrolítico - Foi estabelecida a similaridade entre os hormônios estrogênicos e os hormônios adrenocorticais; e os estrogênios, como os hormônios adrenocorticais, levam a uma retenção de Sódio e água pelos túbulos renais. No entanto, este efeito dos estrogênios é leve, e raramente de importância significativa, exceto durante a gravidez.

Funções Intracelulares dos Estrogênios - Os estrogênios circulam no sangue apenas por poucos minutos antes de alcançarem as células alvo, onde se combinam, dentro de 10 a 15 segundos, com um receptor proteico no citoplasma e, então, em combinação com esta proteína, migram para o núcleo, que imediatamente inicia o processo de transcrição e em poucos minutos começa a ser produzido o ácido ribonucleico (ARN ou, em inglês, RNA). Além disso, durante muitas horas também é produzido o ácido desoxirribonucleico (ADN ou, em inglês, DNA), resultando eventualmente em divisão da célula. $O$ ARN se difunde para o citoplasma, onde origina um grande aumento da formação de proteína e subsequentemente da função celular ${ }^{[137]}$.

Melvin et al., em $1999{ }^{[144]}$, estudaram as mutações dos genes CYP19 que codifica a aromatase (que converte a testosterona em estrogênios) em seis mulheres e dois homens, e um receptor estrogênico mutante em um homem, para definir o papel dos estrogênios no homem. Foi estudado o papel do 
estrogênio no estirão pubertário, na maturação do esqueleto, e seu papel na manutenção da massa óssea, e finalmente na fusão epifisária em ambos os sexos.

A síntese do estrogênio é limitada antes da puberdade e a sua deficiência não parece afetar a idade puberal. No homem, a deficiência de estrogênio leva a um hipogonadotropismo, macoorquidismo e aumento do nível de testosterona. A falta de estrogênio tem um efeito significativo sobre o metabolismo dos hidratos de carbono e lípides, e a resistência estrogênica foi associada à arterioesclerose coronariana prematura no homem. Estas observações têm elucidado a síntese dos estrogênios extraglandulares e ações intrácrina e parácrina. No homem, a deficiência e a resistência estrogênica não parecem afetar a identidade e nem o desenvolvimento psicossexual. As repercurssões clínicas da mutação do CYP19 sobre a unidade fetoplacentária têm elucidado o maior papel da aromatase placentária na proteção do feto feminino do excesso de andrógenos, portanto, previnindo o pseudohermafroditismo induzido por andrógenos e a virilização materna.

Os autores relatam casos de três homens adultos com estatura elevada, epífises ainda abertas, osteopenia, proporções esqueléticas eunucoides, genu valgo progressivo devido à mutação hereditária genética autossômica recessiva no gene que codifica a aromatase.Todos os três tiveram um início normal de puberdade com concentrações normais ou elevadas de testosterona. Os dois homens com deficiência de aromatase foram tratados com estrogênio levando a uma normalização do quadro. O mesmo não ocorreu com o portador de resistência ao estrogênio. De acordo com Dr. Nuvarti Setian, "o papel da atuação do estrogênio no homem ainda se restringe aos dados clínicos de adultos (como os citados acima) que não conseguem realizar a fusão epifisária na ausência do estrogênio. Não se sabe, porém, exatamente, quais os outros papéis deste hormônio no comportamento e no metabolismo do homem".

Logo após ser secretado pelo ovário, o estradiol e a estrona que não podem entrar nas células para executar suas funções fisiológicas são oxidados a estriol, esta oxidação ocorre principalmente no fígado, mas também em pequena proporção em outras partes do organismo. O fígado também efetua a 
conjugação dos estrogênios para formar glicuronideos e sulfatos, e cerca de um quinto destes produtos conjugados é excretado na bile, enquanto quase todo o restante é excretado na urina. O fígado efetua ainda uma ligação fraca dos estrogênios com uma proteína para formar a chamada estroproteína, e é principalmente nesta forma que os estrogênios circulam nos líquidos extracelulares ${ }^{[137]}$.

Assim, o fígado exerce um papel-chave no metabolismo do estrogênio, porque converte os estrogênios potentes - estradiol e estrona - em um estrogênio quase totalmente impotente - o estriol, e porque secreta quantidades moderadas no intestino, diminuindo a função do fígado realmente aumenta a atividade dos estrogênios no organismo, às vezes causando hiperestinismo.

\subsection{Quantidade Excretada de Estrogênios por Homens e Mulheres}

A produção de estrogênios por homens e mulheres varia em função de fatores como gênero, idade e ciclo reprodutivo. Mulheres produzem e excretam mais estrogênios do que os homens e a produção é mais abundante durante a fase fértil do que no período pós-menopausa. A maioria dos estrogênios naturais tem vida curta e não acumulam nos tecidos. Por outro lado, estrogênios sintéticos como 17a-etinilestradiol e dietilstilbestrol (DES) são mais estáveis e permanecem no corpo mais tempo do que os estrogênios naturais [145].

Baseados em pesquisas e medições prévias da excreção de estrogênios por humanos, Johnson et al. (2000) ${ }^{[146]}$ estimaram a excreção diária de estrogênios por homens e mulheres, cujos valores são mostrados na TABELA 3.4 . 
TABELA 3.4 - Estimativa da excreção diária de estrogênios por homens e mulheres em diversas condições.

17- $\beta$ -

Sexo e Condições fisiológicas

estradiol Estrona Estriol

\begin{tabular}{c|c|c|c}
\hline Homens & 1,6 & 3,9 & 1,5 \\
\hline Mulheres na Fase Fértil (15 a 59 anos) & 3,5 & 8 & 4,8 \\
\hline Mulheres na menopausa (acima de 59 anos) & 2,3 & 4 & 1 \\
\hline Gestantes & 259 & 600 & 6000 \\
\hline Mulheres que tomam contraceptivo & - & - & - \\
\hline
\end{tabular}

\subsection{O Mais Abundante e Importante Estrogênio: 17ß-estradiol}

O 17ß-estradiol é o estrogênio mais bioativo e importante na mulher em idade reprodutiva e, exatamente por este motivo, foi escolhido como o estrogênio a ser utilizado como alvo do estudo de marcação luminescente para detecção e quantificação deste. Ele também está presente nos homens, em um nível superior comparado às mulheres menopausadas ${ }^{[137]}$.

Os níveis séricos normais de estradiol para mulheres na fase prémenopausa variam amplamente durante o ciclo mentrual:

- Fase folicular: 1,0 a $30,0 \mathrm{ng} / \mathrm{dl}$ (37 a $1100 \mathrm{pmol} / \mathrm{l})$.

- Pico ovulatório: 15,0 a 60,0 ng/dl (550 a 2200 pmol/l).

- Fase lútea: 5,0 a 30,0 ng/dl (183 a 1100 pmol/l).

- Menopausa: inferior a 3,0 ng/dl (inferior a $110 \mathrm{pmol} / \mathrm{l}$ ).

Os níveis séricos normais para homens adultos são de 1,0 a 6,0 ng/dl (37 a $220 \mathrm{pmol} / \mathrm{l}$ ). Em crianças, níveis séricos normais são inferiores a 0,48 $\mathrm{ng} / \mathrm{dL}(18,0 \mathrm{pg} / \mathrm{mL})^{[147]}$. 


\subsection{Importância da Monitoração dos Níveis Séricos Normais do 17 - $\beta$-estradiol}

Muito se sabe sobre as consequências das disfunções ocasionadas por níveis séricos diminuídos ou aumentados do 17- $\beta$-estradiol. A oscilação anormal dos níveis séricos deste hormônio pode estar relacionado a:

- Tumores secretores de estrogênios: tumores ovarianos e tumores feminilizantes adrenais.

- Puberdade precoce ou tardia: níveis aumentados ou diminuídos do hormônio.

- Distúrbios menstruais: diferenças de produção dos estrogênios.

- Infertilidade: Por ter efeito direto sobre as trompas de falópio, a deficiência do 17- $\beta$-estradiol pode afetar a fertilidade.

- Doença hepática: A hipofunção do fígado está diretamente relacionada ao aumento dos efeitos estrogênicos, e a dosagem sérica em níveis altos deste hormônio pode estar relacionada à disfunção hepática.

- Avaliação de anormalidade de crescimento ósseo feminino: quase sempre em estatura muito acima da média feminina, mais característica às fêmeas-eunuco.

- Insuficiência ovariana: Valores diminuídos podem estar relacionados à insuficiência ovariana (inicialmente seus níveis urinários e séricos diminuídos são acompanhados por altos níveis séricos de LH e FSH, em contraste com a situação encontrada em doença hipotalâmica ou pituitária) [137].

- Hipogonadismo masculino: Quando os níveis de testosterona no soro declinam, existe uma diminuição concomitante dos níveis séricos de estradiol, no entanto, as consequências do hipogonadismo masculino são rotineiramente atribuídas unicamente à deficiência androgênica, sendo o papel potencial do declínio concomitante em estrogênios geralmente ignorado. Tornou-se claro, no entanto, que a deficiência de estrogênio pode ser importante na patogênese de algumas consequências do hipogonadismo masculino, como a perda de massa óssea. O papel potencial da deficiência de estrogênio na patogênese de outras consequências do hipogonadismo, tais 
como alterações na composição corporal ou função sexual, é em grande parte desconhecido.

- Menopausa: níveis séricos diminuídos do hormônio.

- $\quad$ Síndrome de Turner: devido à deficiência de estrogênios, as portadoras não desenvolvem as características sexuais secundárias ao atingir a puberdade, sendo, portanto, identificadas facilmente pela falta desses caracteres; assim, por exemplo, elas não menstruam (isto é, tem amenorréia primária); grandes lábios despigmentados; pêlos pubianos reduzidos ou ausentes; desenvolvimento pequeno e amplamente espaçados das mamas ou mamas ausentes; pelve andróide, isto é, masculinizada; pele frouxa devido à escassez de tecidos subcutâneos, o que the dá aparência senil; unhas estreitas; tórax largo em forma de barril; anomalias renais, cardiovasculares e ósseas ${ }^{[148]}$.

- Determinar uso de contraceptivos orais.

- Determinar gravidez ectópica: associada ao aumento dos níveis séricos de estrogênios, juntamente com o aumento da prolactina, progesterona, cortisol e somatomamotrofina coriônica.

- Avaliação de atraso no desenvolvimento sexual feminino: devido à deficiência de estrogênios, o desenvolvimento sexual é afetado ${ }^{[137]}$.

- Composição corporal, força e função sexual em homens: Em estudo realizado pelo Dr. Finkelstein e colaboradores do Hospital Geral de Massachusetts, publicado no New England Journal of Medicine em 2013, os pesquisadores procuraram determinar o grau relativo de deficiência da testosterona, estradiol ou ambos, em que alterações indesejáveis na composição corporal, força e função sexual começam a ocorrer e se essas alterações são devidas à deficiência androgênica, estrogênica ou ambas. Para isto, realizaram a determinação das doses de testosterona relativas e os níveis séricos associados em que a composição corporal, força e função sexual começam a declinar. Ao examinar essas relações com e sem supressão da síntese de estrogênio, os pesquisadores descobriram que a massa magra, massa muscular e força são reguladas por androgênios, o acúmulo de gordura é principalmente uma consequência da deficiência do estrogênio, e a função sexual é regulada por ambos, androgênios e estrogênios ${ }^{[149]}$. 


\subsection{Métodos Existentes de Detecção de Hormônios}

Os métodos existentes para detecção de hormônios em geral baseiamse em imunoensaios: competitivos e não competitivos

1. Competitivos: Há competição entre o hormônio presente na amostra (ou o padrão) e outro marcado com alguma substância geradora de sinal, por uma quantidade limitada de anticorpos específicos.

2. Não Competitivos: São utilizados dois anticorpos, um ligado à fase sólida e outro marcado com alguma substância geradora de sinal, que se ligam ao hormônio em estudo - mais preciso, reprodutível, e possui níveis de sensibilidade analítica superiores. Desvantagem: precisam ter dois epítodos [150].

Os métodos existentes são:

- Radioimunoensaio (RIE): apresenta alta especificidade e sensibilidade, baixo custo, requer pouca amostra, rápido. Desvantagens: instabilidade dos radioisótopos, risco operacional, necessidade de medidas especiais, elevado custo de biossegurança e problemas com o descarte do material.

- Imunorradiométrico (IRMA): Tipo de radioimunoensaio no qual o excesso do anticorpo específico ligado é adicionado diretamente para o teste do antígeno a ser medido. Desvantagens: grande quantidade de material biológico (anticorpos) de detecção, uso de radioisótopos, risco operacional, necessidade de medidas especiais, elevado custo de biossegurança e problemas com o descarte do material.

- Enzimaimunoensaio (EIA): a técnica de enzimaimunoensaio (ex: ELISA)

é um método quantitativo em que a reação de antígeno-anticorpo é monitorizada por medida da atividade enzimática. O ensaio é detectado por leitura visual ou fotométrica, apresentando como vantagens, baixo custo, rapidez, automação, especificidade e elevada sensibilidade.

- Imunofluorimétrico (IFMA): técnica basicamente automatizada que utiliza, em geral, anticorpo marcado com fluorocromo (rodamina, fluoresceína e európio são os mais utilizados). Caso a reação seja positiva ocorre a associação do fluorocromo (após lavagens sucessivas) com uma solução 
amplificadora de fluorescência e conseqüente emissão de luz fluorescente, que é intensa porém pouco duradoura, daí a necessidade de automação.

- Quimioluminescencia (ICMA): tipo de reação química, que ao se processar gera energia luminosa durante uma reação química, os reagentes se transformam em estados intermediários eletronicamente excitados, e ao passarem para um estado menos excitado, liberam a energia absorvida na forma de luz. O composto químico Luminol é um dos representantes mais conhecidos da quimioluminescência. Quando em contato com o sangue, por exemplo, utiliza o ferro da hemoglobina como catalisador para a reação de liberação de luz. Esse composto é muito usado em perícia criminal. Laboratorialmente, hormônios, drogas e microorganismos podem ser identificados por testes colorimétricos. Tais métodos utilizam-se de anticorpos ligados a um marcador luminescente (cromógeno) que pode ser o próprio luminol ou mais modernamente derivados de acridina, sistema avidina-biotina, entre outros ${ }^{[150]}$. A TABELA $\mathbf{3 . 5}$ apresenta os métodos utilizados para detecção e quantificação de hormônios e seus respectivos marcadores.

TABELA 3.5 - Métodos de detecção de quantificação de hormônios e seus respectivos marcadores.

\begin{tabular}{|l|c|}
\multicolumn{1}{c|}{ Marcador } & Método \\
\hline Isótopo radioativo & Radioimunoensaio (RIE) \\
Imunorradiométrico (IRMA)
\end{tabular}




\section{REFERÊNCIAS BIBLIOGRÁFICAS}

[1] NYIAMA, E. Complexos de Terras Raras Trivalentes (Eu, Tb, Tm e Nd) com ligantes orgânicos utilizados como emissores em OLED. Tese de doutorado. Universidade Federal do Rio Grande do Sul, Porto Alegre, 2008.

[2] ABRÃO, A. Química e Tecnologia das Terras Raras: uma revisão. Série Tecnologia Mineral no 73 CETEM/CNPq: Rio de Janeiro, 1997.

[3] VIEIRA, E.V.; LINS, F.F. Concentração de minérios de terras raras: uma revisão. Série: Tecnologia Mineral oㅡ 73 CETEM, Rio de Janeiro, 1997.

[4] QUIL, L. L.; CLINK, L. G. Preparation of lanthanide chloride methanolates using 2,2-dimethoxypropane. Inorg. Chem., p 1433-1435, 1967.

[5] WENDLANDT, W. W. The thermal decomposition of the heavier rare earth metal chloride hydrates. J. Inorg. \& Nucl. Chem., p 136-139, 1959.

[6] HOPKINS, B. S.; QUILL, L. L. Use of non-aqueous solvents in the study of earth group. Proc. Natl. Acad. Sci. US, 19:64-68, 1933.

[7] WENDLANDT, W. W.; BEAR, J. L. The characterization and identification of the rare-earth chloride hydrates by differential thermal analysis. Anal. Chim.Acta, v.21, p. 439-442, 1959.

[8] ZIMMERMAN, J. B. and INGLES, J. c., Isolation of Rare Earth Elements. Chlorination-Volatilization Procedure. Anal. Chem., 32(2), p. 241-246, 1960.

[9] SPEDDING, F.H.; PIKAL, M.J.; AYERS, B.O. Apparent Molal Volumes of Some Aqueous Rare Earth Chloride and Nitrate Solutions at $25^{\circ 1}$. J. Phys. Chem. 70 (8), pp 2440-2449, 1966. 
[10] BETHE, H. A. Splitting of Terms in Crystals. Ann. Physik. 3, 133-206, 1929.

[11] VAN VLECK, J. H., J. Chem. Physics 3, 807, 1937.

[12] LIMA. P.P.; MALTA, O.L.; ALVES JÚNIOR, S. Estudo espectroscópico de complexos de $\mathrm{Eu}^{3+}, \mathrm{Tb}^{3+} \mathrm{E} \mathrm{Gd}{ }^{3+}$ com ligantes derivados de ácidos dicarboxílicos. Quím. Nova, vol.28 n.5, São Paulo, 2005.

[13] VAN VLECK, J.H. J. The Puzzle of Rare-earth Spectra in Solids. Chem. Phys., 41, 67, 1937.

[14] BROER, L.J.F.; GORTER, C. J.; HOOGSCHAGEN, J. Physica, 11, 231, 1945.

[15] JUDD, B.R. Optical absorption intensities in rare-earth ions. Phys. Rev., 127, 750, 1962.

[16] OFELT, G.S. Intensities of crystal spectra of rare-earth ions. J. Chem. Phys., 37, 511, 1962.

[17] QUIRINO, W.G. Espectroscopia Óptica de Vidros Tetrafosfatos Dopados com $\mathbf{Y b}^{3+}$. Dissertação (Mestrado), Departamento de Física, Universidade Federal de Juiz de Fora, 2003.

[18] ATKINS, P. W.; PHYSIKALISCHE CHEMIE. VCH Verlagsgesellschaft mbH, Wein- heim, 2. Aufl.,1990.

[19] WEISSMAN, S.I. Intramolecular Energy Transfer. The Fluorescence of Complexes of Europium. J. Chem. Phys., v.10, p.214-217, 1942. 
[20] HANNINEN, P.; HARMA, H. Lanthanide Luminescence: Photophysical, Analytical and Biological Aspects. Springer Series on Fluorescence 7, Finland, 2011.

[21] SABBATINI, S.; GUARDIGLI, M. Coord. Chem. Rev., 123, 201, 1993.

[22] BLASSE, G.; GRABMAIER, B.C. Luminescent Materials. Springer-Verlag: Berlim, 1994.

[23] WHAN, R. E.; CROSBY, G. A. Journal of Molecular Spectroscopy, vol. 8 issue 1-6, p. 315-327, 1962.

[24] RODRIGUES, L.C.V. Preparação e desenvolvimento do mecanismo da luminescência persistente de materiais dopados com íons terras raras (Tese de Doutorado). Instituto de Química, Universidade de São Paulo, 2012.

[25] TEOTONIO, E. E. S. Síntese e investigação das propriedades fotoluminescentes de dispositivos moleculares conversores de luz (DMCL) de complexos dicetonatos de terras raras com ligantes amidas. (Tese de Doutorado) Instituto de Química, Universidade de São Paulo, 2004.

[26] THOMPSON, L.C.; Handbook of the Physics and Chemistry of Rare Earths, Gscheidner, K. A.; Eyring, L.; Eds., North-Holland Physics Publishing, Amsterdam, cap. 25, 1978.

[27] PEARSON, R.G. Hard and soft acids and bases. Amer. Chem. Soc., 85:3533-9, 1963.

[28] AHRLAND, S.; CHATT, J.; DAVIES, R.R. The relative affinities of ligand atoms for acceptor molecules and ions. Quart. Rev. Chem. Soc. 12:265-276, 1958. 
[29] HUANG, C. Rare Earth Coordination Chemistry - Fundamentals and Applications. Peking University, China, 2010.

[30] URBAIN, G. Bull. Soc. Chim., 15, 347, 1896.

[31] QUIRINO, W.G. Produção e Caracterização de Dispositivos Orgânicos Eletroluminescentes (OLEDS) baseados em Complexos (Beta)Dicetonatos de Terras Raras. Tese (doutorado). PUC-RIO, Rio de Janeiro, 2007.

[32] BAUER, H.; BLANC, J.; ROSS, D.L. Octacoordinate Chelates of Lanthanides. 2 Series of Compounds. J. Am. Chem. Soc., 86, 5125-5131, 1964.

[33] HART, F.A.; in WILKINSON, G.; GUILLARD, R.D.; MCCLEVERTY, J.A.; Eds, Comprehensive Coordination Chemistry, vol. 3, Pergamon, Oxford, 1987.

[34] SILVA JR, F.A. Síntese e Propriedades Fotoluminescentes de complexos bis-dicetonatos de íons lantanídeos trivalentes com ligantes fosfinóxidos. Dissertação de mestrado. Universidade Federal da Paraíba, João Pessoa, 2011.

[35] LeVAnson, W.; NeWMAN, E.H.; Webster, M.; Polyhedron, 19, 2697, 2000.

[36] FAWCETT, J.; PLATT, A.W.G., RUSSELL, D.R. Synthesis, structure and properties of lanthanide dithionates and their triphenylphosphine oxide complexes. Inorg. Chim. Acta, v 274, n 2, pp. 177-183(7),1998. 
[37] TSURUTA, H.; YAMAGUCHI, K.; IMAMOTO, T. Tandem mass spectrometric analysis of rare earth(III) complexes: evaluation of the relative strength of their Lewis acidity. Tetrahedron, v. 59, n. 52, pp. 10419-10438(20), 2003.

[38] COSGRIFF, J.E.; DEACON, G.B.; DELBRIDGE, E.E., JONES, C.; SKELTON, B.W.; WHITE, A.H. Heterocyclic Complexes. Mater. Sci. Forum, 315-317, 136. 81, 1999.

[39] BERTHET, J.C.; NIERLICH, M.; EPHRIT IKHINE, M. A comparison of analogous 4f- and 5f-element compounds: syntheses and crystal structures of triphenylphosphine oxide complexes of lanthanide(III) and uranium(III) triflates and iodides [MX2(OPPh3)4][X] (X=OTf and $\mathrm{M}=\mathrm{Ce}$ or $\mathrm{U} ; \mathrm{X}=\mathrm{I}$ and $\mathrm{M}=\mathrm{Nd}, \mathrm{Ce}, \mathrm{La}$, U), Polyhedron, 22, 3475, 2003.

[40] NICHOLAS, J.H.; LAI, S.L.; WILLIAM, L.; MICHAEL, W.; Inorg. Chim. Acta, 343, 169, 2003.

[41] BOSSON, M.; LEVASON, W.; PATEL, T.; POPHAM, M.C.; WEBSTER, M. Lanthanide nitrate complexes of diphenylmethylphosphine oxide: synthesis and spectroscopic studies. Crystal structures of $\left[\mathrm{La}\left(\mathrm{Ph}_{2} \mathrm{MePO}\right)_{3}\left(\mathrm{NO}_{3}\right)_{3}\right]$, $\left[\mathrm{La}\left(\mathrm{Ph}_{2} \mathrm{MePO}\right)_{4}\left(\mathrm{NO}_{3}\right)_{3}\right] \cdot \mathrm{XMe}_{2} \mathrm{CO}$ and $\left[\mathrm{Yb}\left(\mathrm{Ph}_{2} \mathrm{MePO}\right)_{4}\left(\mathrm{NO}_{3}\right)_{2}\right] \mathrm{PF}_{6}$. Polyhedron, v. 20 , n. 15, pp. 2055-2062(8), 2001.

[42] PANIGRAHI, B.S.; GAJENDRAN, N.; SURYAMURTHY, N. Fluorimetric estimation of DNA content using sensitized lanthanide fluorescence. Spectrochim Acta A Mol Biomol Spectrosc. 59(8):1905-10, 2003.

[43] MATSUMOTO, K.; TSUKAHARA, Y.; UEMURA, T.; TSUNODA, K.; KUME, H.; KAWASAKI, S.; TADANO, J.; MATSUYA, T.J. Highly sensitive time-resolved fluorometric determination of estrogens by high-performance liquid chromatography using a $\beta$-diketonate europium chelate. Chomatogr. 773, 135, 2002. 
[44] TU, S.I.; GOLDEN, M.; ANDREOTTI, P.; IRWIN, P.; J. Rapid Meth. Aut. Mic. 10, 37, 2002.

[45] FU, Y.J.; WONG, T.K.S.; YAN, Y.K.; WANG, G.M.; HU, X. Synthesis, characterisation and luminescent properties of europium (III) chelate complexes. Thin Solid Films, 417, pp.78-84, 2002.

[46] REYES, R.; HERING, E.N.; CREMONA, M.; DA SILVA, C.F.B.; BRITO, H.F.; ACHETE, C.A. Growth and characterization of OLEDs with europium complex as emission layer. Thin Solid Films, 420, 23, 2002.

[47] QIAN, G.D.; YANG, Z.; WANG, M.Q.; J. Lumin., 96, 211, 2002.

[48] GOKEL, G. W.; DURST, H. D. Principles and Synthetic Applications in Crown. Ether Chemistry. Synthesis, 168, 1976.

[49] PEDERSEN, C. J. Cyclic polyethers and their complexes with metal salts $\mathbf{J}$. Amer. Chem. Soc., 89, 2495, 7017,1967.

[50] LIN, W.O.; BRITO NETO, J.T.X. Agentes complexantes: podante, coroante e criptante classificação e nomenclatura. Quim. Nova, vol. 21, n5, ISSN01004042, São Paulo, 1998.

[51] VOTGLE, F.; WEBER, E. Kontakte (Merk), 1, 11, 1977.

[52] PEDERSEN, C. J.; FRENSDORFF, H. K. Makrocyclische Polyather und ihre Kom- plexe. Angew. Chem.,84, 16, 1972.

[53] NABESHIMA, T.; TSUKADA, N.; NISHIJIMA, K.; OHSHIRO, H.; YANO, Y.; "Remarkably Selective Ag. +. Extraction and Transport by Thiolariat Ethers. J. Org. Chem. 61, 4342,1966. 
[54] LEOTERIO, D.M.S.; ALVES JR., S.; SILVA, W.E., BELIAN, M.F. Síntese, Caracterização e Estudo Espectroscópico de Complexos de Európio com 18-coroa-6. Departamento de Química Fundamental, Universidade Federal de Pernambuco, 50670-901. Recife, 1998.

[55] SUZUKI, K.; WATANABE, K.; MATSUMOTO, Y.; KOBAYASSHI, M.; SATO, S.; SISWANTA, D.; HISAMOTO, H. Design and Synthesis of Calcium and Magnesium Ionophores Based on Double-Armed Diazacrown Ether Compounds and Their Application to an Ion Sensing Component for an IonSelective Electrode. Anal. Chem. 67 (2): 324-334, 1995.

[56] VIEIRA, E. V.; LINS, F.F. Concentração de Minérios de Terras Raras: uma revisão. Série Tecnologia Mineral ํ73 CETEM/CNPq: Rio de Janeiro, 1997.

[57] ROCIO, M. A. R.; SILVA, M.M.; CARVALHO, P.S.L., CARDOSO, J.G.R. Terras-raras: situação atual e perspectivas. BNDES Setorial 35, p. $369-420$, 2010.

[58] ERNST \& YOUNG. Technology minerals - The rare earths race is on! Reino Unido: Apr., 2011.

[59] GWMG - Great Western Minerals Group presentation. Rare earthmagnets and their raw materials supply. In: 5th International Rare Earths Conference. Hong Kong: nov. 2009.

[60] OAKDENE HOLLINS RESEARCH \& CONSULTING LTD. Lanthanide resources and alternatives. Aylesbury, May 2010.

[61] ROSENTAL, S. Terras-raras. Rio de Janeiro: CETEM, dez. 2008.(Comunicação Técnica: CT2008-188-00). 
[62] USGS - United States Geological Survey. Mineral Commodity Summaries: rare earths, 2011.

[63] TOPF, A. Rare Earths Outlook: Prices to rise, Western producers cutting into Chinese Monopoly. http://rareearthinvestingnews.com/19313-rare-earthsoutlook-prices-to-rise-western-producers-cutting-into-chinese-monopoly.html acesso em 10/01/2014. CGCEE. Notícias. Terras Raras.

http://www.cgee.org.br/noticias/viewBoletim.php?in news=829\&boletim $=38$ acesso em 10/01/2014.

[65] BBC News World - What are 'rare earths' used for? - 13 de março de 2012. http://www.bbc.co.uk/news/world-17357863 acesso em 12/01/2014.

[66] MARTINS, T.S.; ISOLANI, P.C. Terras Raras: Aplicações Industriais e Biológicas. Química Nova. vol.28, ㄲo1. ISSN 0100-4042. Rio de Janeiro, 2005.

[67] ENGBIOTEC. Catalisadores a base de terras raras. http://engbiotec.wordpress.com/tag/hidrocarbonetos/ acesso em 12/01/2014.

[68] WANG, S.; FENG, J.; SONG, S.; ZHANG, H. Rare earth fluorides upconversion nanophosphors: from synthesis to applications in bioimaging. Cryst Eng Comm. Issue 36, 2013.

[69] LOURENÇO, A.V.S.; KODAIRA, C.A.; RAMOS-SANCHEZ, E.M.; FELINTO, M.C.F.C.; GOTO, H.; GIDLUND, M.; MALTA, O.L.; BRITO, H.F. Luminescent material based on the $\left[\mathrm{Eu}(\mathrm{TTA})_{3}\left(\mathrm{H}_{2} \mathrm{O}\right)_{2}\right]$ complex incorporated into modified silica particles for biological applications. Journal of Inorg.Chem. vol.123, p11-17, 2013.

[70] Geoscience News and Information. Rare Earth Elements, 2013. http://geology.com/articles/rare-earth-elements/ acesso em 12/01/2014. 
[71] KAI, J. Desenvolvimento de Sistemas Luminescentes à base dos polímeros PHB e PMMA dopados com complexos de terras raras. Tese (Doutorado). Universidade de São Paulo - Instituto de Química, 2009.

[72] BUNZLI, J-C.G. Metal íons in Biological Systems, New York: Marcel Dekker Inc., v.42, cap. 2, pag.39-75, 2004.

[73] RIBEIRO, R.E.; PIRES, A.M.; GELAMOS, J.P.; CAMACHO, S.A.; LARANJA, M.L. Aminofuncionalized nanophosphor conjugated with sulfoSMPD crosslinker for biological application. UNESP, 2010.

[74] GELAMOS, J. P.; ALVINO, K. C. L.; CAMACHO, S. A.; LARANJA, M. L.; PIRES, A. M. Conjugação de Albumina e Nanopartículas Luminescentes Funcionalizadas para Aplicação Biológica. In: XIX CIC - Congresso de Iniciação Científica - Área de Exatas, 2007, Presidente Prudente - SP. ANAIS. São Paulo: CGB/PROPe UNESP, 2007.

[75] HUN, X.; ZHANG, Z. A novel sensitive staphylococcal enterotoxin C1 fluoroimmunoassay based on functionalized fluorescent core-shell nanoparticle labels. Food Chemistry, v. 105, p. 1623-1629. 2007.

[76] KOKKO, L.; LOVGREN, T.; SOUKKA, T. Europium(III)-chelates embedded in nanoparticles are protected from interfering compounds present in assay media. Anal.Chim.Acta, v.585, p 17-23, 2007.

[77] OLLIKKA, P.; YLIKOSKI, A.; KAATRASALO, A.; HARVALA, H.; HAKALA, H.; HOVINEN, J. Minisequencing with acyclonucleoside triphosphates tethered to lanthanide (III) chelates. Bioconjugate Chem., v.19, p.1269-1273, 2008.

[78] GAO, F.; LUO, F.; TANG, L.; DAÍ, L.; WANG, L. Preparation of a novel fluorescence probe of terbium-europium co-luminescence composite nanoparticles and its application in the determination of proteins. J. Lumin., v.128, p.462-468, 2008. 
[79] PELKKIKANGAS, A.M.; JAAKOHUHTA, S.; LOVGREN, T.; HARMA, H. Simple, rapid, and sensitive thyroid-stimulating hormone immunoassay using europium (III) nanoparticle label. Anal. Chim. Acta, v.517, p.169-176, 2004.

[80] CHEllampillai, B. \& PAWAR, A. P. - Eur. J. Drug Metab. Pharmacokinet.,35, p.123 http://dx.doi.org/10.1007/s13318- 010-0016-7, 2011.

[81] ZHANG, W.; GAO, J.; ZHU, Q.; ZHANG, M.; DING, X.; WANG, X.; HOU, X.; FAN, W.; DING, B.; WU, X. \& GAO, S. - Int. J. Pharm., 402, p.205 http://dx.doi.org/10.1016/j.ijpharm.2010.09.037, 2010.

[82] RUDENKO, N. V.; SINEGINA, L. L.; ARZHANOV, M. A.; KSENZENKO, V. N.; IVASHINA, T. V.;MORENKOV, O. S.; SHALOIKO, L. A.; VINOKUROV, L. M.; Barnase-barstar high affinity interaction phenomenon as the base for the heterogenous bioluminescence pseudorabies virus' immunoassay. J. Biochem. Biophys.Methods, v. 70, p. 605-611, 2007.

[83] NARA, S.; TRIPATHI, V.; CHAUBE, S. K.; RANGARI, K.; SINGH, H.; KARIYA, K. P.; SHRIVASTAV, T. G. Use of biotin-streptavidin system for developing a viable, sensitive and specific antigen heterologous assay for hapten. Talanta, v. 77, p. 210-216. 2008.

[84] GECKELER, K.E.; ROSENBERG, E. (Eds.) Functional nanomaterials, American Scientific Publishers, Valencia, USA, 2006.

[85] HOSOKAWA, K.; NOGI, M.; NAITO, T.; YOKOYAMA. Nanoparticle technology handbook. Elsevier, Amsterdam, Netherlands, 2007.

[86] GECKELER, K.E.; NISHIDE, H. (Eds.), Advanced nanomaterials, WileyVCH Publishers, Weinheim, Germany, 2010.

[87] LIU, D.; WANG, L.; LIU, Z.; ZHANG, C. \& ZHANG, N. - J. Biomed. Nanotechnol.,6, p.675. http://dx.doi.org/10.1166/jbn.2010.1160, 2010. 
[88] ANANCHARUNGSUK, W.; POLPANICH, D.; JANGPATARAPONGSA, K.; TANGBORIBOONRAT, P. Colloids Surf. B Biointerfaces, 78, p.328 PMid:20392612. http://dx.doi.org/10.1016/j.colsurfb.2010.03.025, 2010.

[89] Notícias UOL. Brasil cria sistema integrado para desenvolver $\begin{array}{llll}\text { nanotecnologia no } & \text { Brasil. }\end{array}$ http://blogs.ne10.uol.com.br/mundobit/2012/04/09/brasil-cria-sistema-integradopara-desenvolver-nanotecnologia-no-brasil/) acesso em 13/10/2013.

[90] IVERSEN, T-G.; SKOTLAND, T.; SANDVIG, K. Endocytosis and intracellular transport of nanoparticles: Presente knowledge and need for future studies. Review. Nano Today. 6, 176-185, 2011.

[91] JAMIESON, T.; BAKSHI, R,; PETROVA, D.; POCOCK, R.; IMANI, M.; SEIFALIAN, A.M. Biomaterials, 28, 4717-4732, 2007.

[92] MICHALET, X.; PINAUD, F.F.; BENTOLILA, L.A.; TSAY, J.M.; DOOSE, S.; LI, J.J.; SUNDARESAN, G.; WU, A.M.; GAMBHIR, S.S.; WEISS, S. Science 307, 538-544, 2005.

[93] VASIR, J.K.; LABHASETWAR, V. Adv. Drug Deliv. Rev.59, 718-728, 2007.

[94] AGASTI, S.S.; RANA, S.; PARK, M.H.; KIM, C.K.; YOU, C.C.; ROTELLO, V.M. Adv. Drug Deliv. 62, 316-328, 2010.

[95] SKOTLAND, T.; IVERSEN, T.G.; SANDVIG, K. Nanomedicine 6, 730-737, 2010.

[96] CHIELLINI, E.E.; SOLARO, R. Bioerodible polymeric nanoparticles for targeted delivery of proteic drugs, J. Nanosci. Nanotechnol. 6, 3040-3047, 2006. 
[97] TROJAN-PIEGZA, J.; ZYCH, E.; HRENIAK, D.; STREK, W.; KEPINSKI, L. J. Phys.: Condens. Matter. 6983, 2004.

[98] KONRAD, A.; HERR, U.; TIDECKS, R.; KUMMER, F.; SAMWER, K.; J. Appl. Phys. 90, 3516,2001.

[99] SUDARSAN, V.; VAN VEGGEL, F. C. J. M.; HERING, R. A.; RAUDSEPP, M. J. Mater. Chem.,15, 1332,2005.

[100] GASPAR, R.D.L.; RODRIGUEZ, E. M.; BELINI, T.C.; SIGOLI, F.A. Nanopartículas de óxido de gadolínio, de lantânio e de ítrio dopadas com európio (III) passivadas por trioctilfosfinóxido.32ํㅡㄹ Reunião Anual da Sociedade Brasileira de Química (SBQ), Ceará, 2009.

[101] KREUTER, J. Nanoparticles, J. Kreuter (Ed.), Colloidal drug delivery systems, vol. 66Marcel Dekker, New York, pp. 219-342, 1994.

[102] REDDY, S.T.; REHOR, A.; SCHMOEKEL, H.G.; HUBBELL, J.A.; SWARTZ, M.A. In vivo targeting of dendritic cells in lymph nodes with poly(propylene sulfide) nanoparticles, J. Control. Release 112,26-34, 2006.

[103] ARAÚJO, J.; VEJA, V.; LOPES, C. M.; EGEA, M. A.; GARCÍA, M. L. \& SOUTO, E. B. - Colloid Surf. B Biointerfaces, 72, p.48, 2009.

[104] GUTERRES, S. S.; MULLER, C. R.; BASSANI, V. L; POHLMANN, A. R., DALLA COSTA, T. C. T. Processo de secagem de suspensões coloidais de nanocápsulas e nanoesferas poliméricas por aspersão. Universidade Federal do Rio Grande do Sul (pedido patente), 1999.

[105] BRINKER, C.J.; SCHERER, G.W. Sol-Gel Science. The Physics and Chemistry of Sol-Gel Processing. U.S.A.: Academic Press San Diego , 1990. 
[106] SCHMIDT, H. Considerations about the sol-gel process: From the classical sol-gel route to advanced chemical nanotechnologies. J Sol-Gel Sci. Technol., v.40, p. 115-130, 2006.

[107] BUNZLI, J-C, G.; COMBY, S.; CHAUVIN, A.-S.; VANDEVYVER, C.D.B. New opportunities for lanthanide luminescence.J. Rare Earths, v.25, p.257274, 2007.

[108] CARLOS, L.D.; FERREIRA, R.A.S.; BERMUDEZ, V.Z.; RIBEIRO, S.J.L.; Lanthanide-containing Light-Emitting Organic-Inorganic Hybrids: A Bet on the Future, Adv. Mater., v.2, p.509-534, 2009.

[109] BEECROFT, L.L.; OBER, C.K. Nanocomposite materials for optical applications ,Chem. Mater., v.9, p.1302-1317, 1997.

[109] LEBEAU, B.; SANCHEZ, C. Sol-gel derived hybrid inorganic-organic nanocomposites for optics.Curr. Opin. Solid State Mater. Sci., v.4, p.11-23, 1999.

[110] SANCHEZ, C.; LEBEAU, B. Design and properties of hybrid organicinorganic nanocomposites for photonics. Mater. Res. Bull., v.26, p.377-387, 2001.

[111] ESCRIBANO, P.; JULIAN-LOPEZ, B.; PLANELLES-ARAGO, J.; CORDONCILLO, E.; VIANA, B.; SANCHEZ, C. Photonic and nanobiophotonic properties of luminescent Ihantanide-doped hybrid organic-inorganic materials. J. Mater. Chem., v.18, p.23-40, 2008.

[112] CANeVAROLO JR, S.V. Ciência dos Polímeros. São Paulo: Artiliber, 183p., 2002.

[113] CHANG, R. Química Geral. McGraw-Hill, 4 ed., cap.22, p.716-734, São Paulo, 2006. 
[114] CONDE, L.M.S. Polímeros naturais para aplicações biomédicas. Dissertação De Mestrado. Universidade do Minho - Escola de Ciências, 2011.

[115] FLORY, P.J. Principles of Polymer Chemistry, Comell University Press, Ithaca, 1953.

[116] LOURENCO, A.Y. Ann. Chim. Phys. 67, 257,1863.

[117] BERTHELOT, M. Ann. chim. phys., vol. 5, p. 289. 762, 1875.

[118] STEVENS, M.P. Polymer Chemistry, 20d edn., Oxford University Press, Oxford, 1990.

[119] BAEKLAND, L.H. Ind. Eng. Chem.5,506,1913.

[120] STAUDINGER, H. Ber. Dcseh. Chem. Ces.53, 1073,1920.

[121] SVEDBERG. T. Kolloid-Z. 51, 10,1930.

[122] LOPES, A. C. T. Desenvolvimento de Compósitos Poliméricos baseados em Zeólitos. Dissertação de Mestrado em Fisica, Universidade do Minho, 2009.

[123] Citação Fapesp http://www.bv.fapesp.br/pt/bolsas/43958/estudopreparacao-matrizeshibridasvia/. Acedido em 14/01/2014.

[124] WILLIAMS, D. F. Biomaterials 30, 5897-5909, 2009.

[125] ULERY, B.D.; NAIR, L.S.; LAURENCIN, C.T. Biomedical Applications of Biodegradable Polymers, Pol. Phis., Connecticut, 2011.

[126] WILLIAMS, D. F., Ed.;The Williams Dictionary of Biomaterials. Liverpool University Press: Liverpool, 1999. 
[127] BOHMERT, K.; BALBO, I.; STEINBÜCHEL, A.; TISCHENDORF, G.; WILLMITZER, L. 2002. Constitutive Expression of the _-Ketothiolase Gene in Transgenic Plants. A Major Obstacle for Obtaining PolyhydroxybutyrateProducing Plants. Plant Physiol. 128:1282-1290.

[128] MACHADO, A.R.T.; MARTINS, P.F.Q.; FONSECA, E.M.B.; REIS, K.C. Compósitos biodegradáveis a base de polihidroxibutirato-hidroxivalerato (PHB-HV) reforçados com resíduos do beneficiamento do café. Matéria (R.J.), vol.15, no 3, 2010.

[129] COUTINHO, B.C.; MIRANDA, G.B.; SAMPAIO, G.R.; DE SOUZA, L.B.S.; SANTANA, W.J.; COUTINHO, H.D.M. A importância e as vantagens do polihidroxibutirato. Holos, ano 20, 2004.

[130] LEITE, H.M.E. Formulação e Caracterização de Matrizes de Polihidroxibutirato para Liberação Controlada de Fármacos. Centro de Ciências e Tecnologia da Universidade Estadual do Norte Fluminense, 2004.

[131] WILLIAMS, D.F. Techniques of Biocompatibility Testing. CRC Press, Boca Raton, FI, Vol.2, 1986.

[132] KENNEDY, J.E.; NOTARIANNI L.J.; POUTON, C.W. Biocompatibility of a Biodegradable Polyester in Rats. Journal of Pharmaceutics and Pharmacology 39, 58, 1987.

[133] POUTON, C.W.; KENNEDY, J.E.; NOTARIANNI, L.J.; GOULD, P.L. Biocompatibility of Polyhydroxybutirate and Related Copolymers. Proc. International Symposium Controlled Release Bioactivies Materials 15, 179-180, 1988.

[134] JUNI, K.; NAKANO, M. Poly(hydroxy Acids) in Drug Delivery. CRC Criticals Reviews Therapy Drug Carrier Systems 3, 209-232, 1987. 
[135] DOYLE, C.; BONFIELD, W. Biodegradable Composites. In: S.A. Paipets and G.C. Papanicolaou (Eds), Engineering Applications of New Composites, Omega Scientific, Wallingford, 114-118, 1988.

[136] MARK, J.E. (Ed.) Polymer Data Book. 1 ed. New York: Oxford University Press Inc., p.1040, 1999.

[137] GUYTON, A. C.; HALL, J.E. Tratado de Fisiologia Médica. 12ํㅡ. Ed. Editora Elsevier, 2011.

[138] SOLOMONS, G.; FRYHLE, C. Química Orgânica, 7aㅡ ed., LCT: Rio de Janeiro, 2000.

[139] SAAD, M.J.A.; MACIEL, R.M.B.; MENDONÇA, B.B. Endocrinologia. Ed. Atheneu. Pag. 456 a 986, 2007.

[140] Ações dos hormônios hipotalâmicos, adenohipofisários, e glandulares. $\quad$ http://www.colorado.edu/intphys/Class/IPHY3430200/022endocrine1.htm acesso em 21/01/2014.

[141] GEHLEN, G. Efeito dos hormônios gonadais sobre os filamentos intermediários de astrócitos hipocampais, durante o desenvolvimento e 0 ciclo estral: uma abordagem imunoistoquímica. Tese (Doutorado). Universidade do Rio Grande do Sul, Porto Alegre, 2009.

[142] MCCARTHY, M.M.; KONKLE, A.T.M. When is a sex difference not a sex difference? Front. Neuroendocrinal. 26, 85-102, 2005.

[143] PHOENIX, C.H.; GOY, R.W.; GERALL, A.A.; YOUNG, W.C. Organizing action of prenatally administered testosterone propionate on the tissues mediating mating behavior in the female guinea pig. Endocrinology 65:369382, 1959. 
[144] MELVIN, M.; GRUMBACH; AUCHUS, R.J. J. Clin. Endocrinol. Metab., 84:4677-94, 1999.

[145] TAPIERO, H., NGUYEN BA, G., TEW, K. D. Estrogens and Environmental Estrogens. Biomed Pharmacother, v. 56, pp. 36-44, 2002.

[146] JOHNSON, A. C., BELFROID, A., DI CORCIA, A. Estimating Steroid Oestrogen Inputs into Activated Sludge Treatment Works and Observations on their Removal from the Effluent. The Science of the Total Environment, v. 256, pp. 163-173, 2000.

[147] GUTHRIE, J.R.; DENNERSTEIN, L.; HOPPER, J.L.; BURGER, H.G.; Hot flushes, menstrual status, and hormone levels in a population-based sample of midlife women. Obstet. Gynecol. 75, 26S-30S, 1996.

[148] Síndrome de Turner relacionado aos níveis séricos de estradiol. genoma.ib.usp.br, acesso em 19/01/2014.

[149] NETO, R.F.A. O papel dos hormônios esteroides gonadais na força e função sexual dos homens. Jan, 2014. http://www.robertofrancodoamaral.com.br/blog/hormonios/o-papel-dos hormonios-esteroides-gonadais-na-forca-e-funçâo-sexual-dos-homens/ acesso em 21/01/2014.

[150] NAOUM, P.F. Métodos de Avaliação Laboratorial. Academia de Ciência e Tecnologia. http://www.ciencianews.com.br/aulavirt/metodos.pdf acesso em 20/01/2014. 


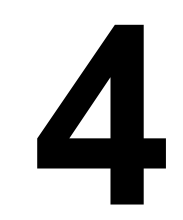

\section{PARTE}

\section{EXPERIMENTAL}




\section{PARTE EXPERIMENTAL}

Neste trabalho foram sintetizados compostos luminescentes a partir de $\beta$-dicetonatos ( $\beta$-dicetonatos $=$ acac $^{-}$e tta $)$de terras raras $\left(\mathrm{TR}^{3+}=\mathrm{Tb}^{3+}, \mathrm{Eu}^{3+} \mathrm{e}\right.$ $\mathrm{Gd}^{3+}$ ) seguido da complexação a ligantes orgânicos auxiliares fosfinóxidos (TPPO, TOPO) e macrocíclicos (DB18C6 e 18C6), por diferentes rotas de síntese. A partir dos resultados de eficiência de luminescência observou-se que o complexo contendo $\mathrm{Eu}^{3+}$ e ligantes tta ${ }^{-}$e TOPO ([Eu(tta) $\left.\left.)_{3}(\mathrm{TOPO})_{2}\right]\right)$ teve maior intensidade de luminescência quando comparado aos demais complexos estudados. Com isso, foram realizadas as dopagens deste complexo em diferentes concentrações, nos polímeros PHB e PMMA, produzindo nanopartículas poliméricas luminescentes. Para determinar o estado tripleto do ligante, o complexo contendo $\mathrm{Gd}^{3+}\left(\left[\mathrm{Gd}(\mathrm{tta})_{3}(\mathrm{TOPO})_{2}\right]\right)$ para mimetizar o ligante, foi dopado nos polímeros em concentrações equivalentes. Caracterizações, funcionalização e teste de hemocompatibilidade foram realizados e serão descritos no texto a seguir. A partir destes resultados, as nanopartículas poliméricas que apresentaram melhor eficiência luminescente e efetiva funcionalização foram conjugadas aos materiais biológicos de interesse deste trabalho (o 17- $\beta$-estradiol).

\subsection{Materiais}

As substâncias empregadas neste estudo foram utilizadas sem tratamento prévio. Na TABELA 4.1 encontra-se a relação destas substâncias, suas fórmulas gerais e suas respectivas procedências. 
TABELA 4.1 - Solventes e reagentes usados na síntese dos complexos de terras raras, nanopartículas poliméricas e imunoensaios.

\begin{tabular}{|c|c|c|}
\hline Substâncias & Fórmula Geral & Procedência \\
\hline Albumina de Soro Bovino (BSA) & & Abcam \\
\hline Acetilacetona (Hacac) & $\mathrm{C}_{5} \mathrm{H}_{8} \mathrm{O}_{2}$ & Merck \\
\hline Acetona P.A. & $\mathrm{C}_{3} \mathrm{H}_{6} \mathrm{O}$ & Vetec \\
\hline $\begin{array}{l}\text { Ácido Clorídrico concentrado } \\
37 \%\end{array}$ & $\mathrm{HCl}$ & Synth \\
\hline Ácido Nítrico & $\mathrm{HNO}_{3}$ & Synth \\
\hline Alaranjado de Xilenol & $\mathrm{C}_{31} \mathrm{H}_{28} \mathrm{~N}_{2} \mathrm{Na}_{4} \mathrm{O}_{13} \mathrm{~S}$ & \\
\hline Álcool Etílico P.A. & $\mathrm{C}_{2} \mathrm{H}_{6} \mathrm{O}$ & Synth \\
\hline Álcool Metílico P.A. & $\mathrm{CH}_{3} \mathrm{OH}$ & Synth \\
\hline Álcool Isopropílico P.A. & $\mathrm{C}_{3} \mathrm{H}_{7} \mathrm{OH}$ & Synth \\
\hline $\begin{array}{l}\text { Anticorpo IgG ovelha (produzido } \\
\text { em coelho) }\end{array}$ & & $\mathrm{KPL}$ \\
\hline $\begin{array}{l}\text { Anticorpo Policlonal Estradiol } \\
\text { (ovelha) }\end{array}$ & & Thermo Scientific \\
\hline Cloreto de Sódio & $\mathrm{NaCl}$ & Synth \\
\hline Clorofórmio P.A. & $\mathrm{CHCl}_{3}$ & Vetec \\
\hline Dibenzo-18-coroa-6 (DB18C6) & $\mathrm{C}_{20} \mathrm{H}_{24} \mathrm{O}_{6}$ & Sigma \\
\hline Fosfato de sódio & $\mathrm{Na}_{3} \mathrm{PO}_{4}$ & Synth \\
\hline Glicina & $\mathrm{C}_{2} \mathrm{H}_{5} \mathrm{NO}_{2}$ & \\
\hline Glutaraldeído & $\mathrm{C}_{5} \mathrm{H}_{8} \mathrm{O}_{2}$ & Vetec \\
\hline Ninidrina & $\mathrm{C}_{9} \mathrm{H}_{6} \mathrm{O}_{4}$ & Sigma \\
\hline Óxidos de terras raras $99,99 \%$ & $\mathrm{TR}_{2} \mathrm{O}_{3} ; \mathrm{Tb}_{4} \mathrm{O}_{7}$ & Sigma \\
\hline $\begin{array}{c}\text { Óxido de tri-n- } \\
\text { octilfosfina (TOPO) }\end{array}$ & $\left(\mathrm{C}_{8} \mathrm{H}_{17}\right)_{3} \mathrm{P}=\mathrm{O}$ & Sigma \\
\hline $\begin{array}{c}\text { Piridina } \\
\end{array}$ & $\mathrm{C}_{5} \mathrm{H}_{5} \mathrm{~N}$ & Baker \\
\hline Poli(metacrilato de metila) (PMMA) & $\left(\mathrm{C}_{5} \mathrm{O}_{2} \mathrm{H}_{8}\right)_{n}$ & Sigma \\
\hline Poli-3-hidroxibutirato (PHB) & $\left(\mathrm{C}_{4} \mathrm{O}_{2} \mathrm{H}_{6}\right)_{n}$ & $\begin{array}{l}\text { Usina da Pedra } \\
\text { (Serrana-SP) }\end{array}$ \\
\hline Sacarose & $\mathrm{C}_{12} \mathrm{H}_{22} \mathrm{O}_{11}$ & Vetec \\
\hline \multirow{2}{*}{$\begin{array}{l}\text { Solução de glutaraldeído } \mathbf{5 0 \%} \\
\text { Trifenilfosfinóxido (TPPO) }\end{array}$} & $\mathrm{C}_{5} \mathrm{H}_{8} \mathrm{O}_{2}$ & Sigma \\
\hline & $\left(\mathrm{C}_{6} \mathrm{H}_{5}\right)_{3} \mathrm{P}=\mathrm{O}$ & Sigma \\
\hline Tenoilfluoroacetona (Htta) & $\mathrm{C}_{8} \mathrm{H}_{5} \mathrm{~F}_{3} \mathrm{O}_{2} \mathrm{~S}$ & Sigma \\
\hline 18-crown-6 (18C6) & {$\left[\mathrm{C}_{2} \mathrm{H}_{4} \mathrm{O}\right]_{6}$} & Sigma \\
\hline 17ß- Estradiol 99\% & $\mathrm{C}_{18} \mathrm{H}_{24} \mathrm{O}_{2}$ & Abcam \\
\hline 1,6 Diamino-hexano 99\% & $\mathrm{C}_{6} \mathrm{H}_{16} \mathrm{~N}_{2}$ & Fluka \\
\hline
\end{tabular}




\subsection{Métodos}

\subsubsection{Síntese dos Precursores Luminescentes e das Nanopartículas Poliméricas}

Uma rota geral da síntese adotada para o objetivo proposto neste trabalho está ilustrada na FIGURA 4.1, onde, a partir dos óxidos de terras raras foram sintetizados os cloretos como precursores; a partir dos cloretos, os $\beta$ dicetonatos de terras raras, seguido da complexação aos ligantes orgânicos secundários. E, então, o complexo de alta eficiência luminescente $\left[\mathrm{Eu}(\mathrm{tta})_{3}(\mathrm{TOPO})_{2}\right]$ e o complexo similar contendo o íon $\mathrm{Gd}^{3+}\left[\mathrm{Gd}(\mathrm{tta})_{3}(\mathrm{TOPO})_{2}\right]$ foram dopados em diferentes concentrações mássicas nos polímeros PHB e PMMA.

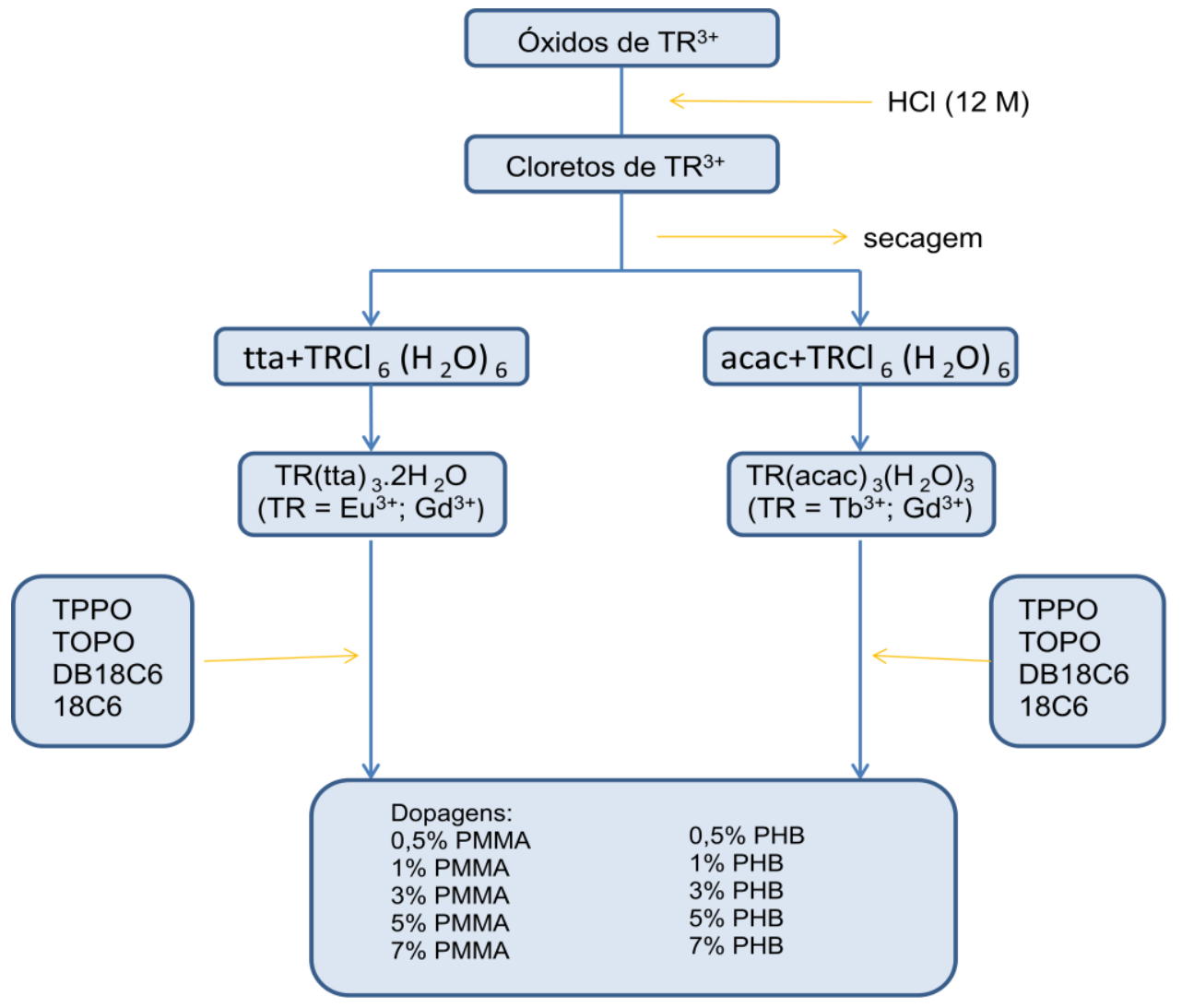

FIGURA 4.1 - Fluxograma de uma rota geral de síntese adotada para obtenção das nanopartículas poliméricas de PHB e PMMA dopadas com complexos de terras raras. 


\subsubsection{Síntese dos Cloretos de Terras Raras}

Os respectivos compostos $\left[\mathrm{TRCl}_{3}\right]\left(\mathrm{TR}=\mathrm{Tb}^{3+} ; \mathrm{Eu}^{3+}\right.$ e $\left.\mathrm{Gd}^{3+}\right)$ foram obtidos a partir da reação dos óxidos de terras rara em suspensão aquosa com ácido clorídrico (12 M). Vale lembrar que o sistema foi mantido sob aquecimento (aproximadamente $60 \stackrel{\circ}{\circ}$ ) e agitação constantes até que, na dispersão, restasse apenas uma pequena quantidade do óxido de terra rara em suspensão, resultando em solução de aspecto translúcido. As amostras foram filtradas e secas em banho maria a $100^{\circ} \mathrm{C}$ e, posteriormente, colocadas no dessecador para armazenagem do cloreto de terras raras.

\subsubsection{Síntese dos Complexos $\beta$-dicetonatos de Terras Raras Hidratados}

Neste trabalho duas espécies de $\beta$-dicetonas foram sintetizadas, acac ${ }^{-} \mathrm{e}$ tta'. Este fato justifica-se pela busca de marcadores com emissão na região do vermelho ( $610 \mathrm{~nm}$ ) e do verde ( $540 \mathrm{~nm}$ ). Os complexos de tta de térbio apresentam o estado tripleto do tta abaixo do primeiro nível excitado do íon térbio, portanto não apresentam luminescência, sendo necessário utilizar-se uma $\beta$-dicetona que apresentasse o nível do estado tripleto acima do ${ }^{5} D_{4,3}$ do íon térbio, que é o caso do acac ${ }^{[1]}$. Neste trabalho sintetizaram-se complexos de $\beta$-dicetonas tta- e acac ${ }^{-}$como descritos a seguir.

\subsubsection{Síntese do tta־ de Terras Raras Hidratado}

O complexo $\left[\mathrm{TR}(\mathrm{tta})_{3}\left(\mathrm{H}_{2} \mathrm{O}\right)_{2}\right]\left(\mathrm{TR}=\mathrm{Eu}^{3+} ; \mathrm{Gd}^{3+}\right)$ foi obtido a partir da dissolução de $6 \mathrm{mmol}$ do 3-tenoiltrifluoroacetona (Htta) em $30 \mathrm{~mL}$ de etanol moderadamente aquecido. $\mathrm{O} \mathrm{pH}$ da solução foi ajustado com aproximadamente $6 \mathrm{mmol}$ de hidróxido de sódio $(\mathrm{NaOH})(6 \mathrm{M})$ até atingir pH 7 . Então, adicionou-se lentamente a quantidade de $2 \mathrm{mmol}$ de uma solução aquosa do cloreto de $\mathrm{TR}^{3+}$. Novamente $\mathrm{opH}$ da solução foi ajustado para $\mathrm{pH} 7$ com $\mathrm{NaOH}(6 \mathrm{M})$. A 
solução resultante foi agitada durante 2 horas, com temperatura constante em $\sim 60 \stackrel{\circ}{\circ}$, formando um óleo, seguido da precipitação do complexo. $\mathrm{O}$ precipitado foi filtrado e lavado com água e etanol.

\subsubsection{Síntese do acac ${ }^{-}$de Terras Raras Hidratado}

O complexo $\left[\mathrm{TR}(\mathrm{acac})_{3}\left(\mathrm{H}_{2} \mathrm{O}\right)_{3}\right]\left(\mathrm{TR}=\mathrm{Tb}^{3+} ; \mathrm{Gd}^{3+}\right)$ foi obtido a partir da reação entre o cloreto de $\operatorname{TR}^{3+}(2 \mathrm{mmol})$ e a acetilacetona(Hacac) $(6 \mathrm{mmol})$ em $30 \mathrm{~mL}$ de etanol. $\mathrm{O}$ pH da solução foi ajustado com uma solução aquosa de hidróxido de sódio $6 \mathrm{M}(\mathrm{NaOH})$ até atingir o $\mathrm{pH} 7$ para desprotonar a $\beta$ dicetona. Então, foi adicionado lentamente à solução aquosa de cloreto de $\mathrm{TR}^{3+}$ sob agitação. Novamente $\mathrm{opH}$ da solução foi ajustado para $\mathrm{pH} 7 \mathrm{com}$ $\mathrm{NaOH}(6 \mathrm{M})$. Houve a precipitação imediata, a emulsão foi agitada por duas horas e posteriormente filtrada.

\subsubsection{Obtenção dos complexos $\beta$-dicetonatos de terras raras com ligantes orgânicos secundários.}

\subsubsection{Síntese dos $\left[T R(t \operatorname{ta})_{3}(L)_{2}\right]$}

Os complexos $\left[\mathrm{TR}(\mathrm{tta})_{3}(\mathrm{~L})_{2}\right]$, onde $\mathrm{TR}=\mathrm{Eu}^{3+}, \mathrm{Gd}^{3+}$ e $\mathrm{L}=\mathrm{TPPO}$, TOPO, DB18C6 e 18C6, foram obtidos a partir da dissolução do complexo [TR(tta $)_{3}$. $\left.2 \mathrm{H}_{2} \mathrm{O}\right]\left(\mathrm{TR}=\mathrm{Eu}^{3+} ; \mathrm{Gd}^{3}\right)$ em acetona, seguido da adição do ligante secundário já dissolvido em acetona em razão estequiométrica complexo:ligante secundário1:2. As soluções finais foram agitadas por 2 horas e, com evaporação do solvente, houve a formação dos complexos na forma de pó cristalino e estes foram mantidos no dessecador.

\subsubsection{Síntese dos $\left[\mathrm{TR}(\mathrm{acac})_{3}(\mathrm{~L})_{2}\right]$}

Os complexos $\left[\mathrm{TR}(\mathrm{acac})_{3}(\mathrm{~L})_{2}\right]$, onde $\mathrm{TR}=\mathrm{Tb}^{3+}$ e $\mathrm{Gd}^{3+}$, e $\mathrm{L}=\mathrm{TPPO}$, TOPO, DB18C6 e 18C6, foram obtidos a partir da dissolução do complexo 
[TR $\left.(\mathrm{acac})_{3} .3 \mathrm{H}_{2} \mathrm{O}\right]\left(\mathrm{TR}^{3+}=\mathrm{Tb}^{3+} ; \mathrm{Gd}^{3}\right)$ em acetona, seguido da adição do ligante secundário já dissolvido em acetona em razão estequiométrica complexo:ligante secundário1:3. As soluções finais foram agitadas por 2 horas e, após evaporação do solvente, houve a formação dos complexos na forma de pó cristalino e estes foram mantidos no dessecador.

\subsubsection{Preparação das Nanopartículas Poliméricas}

Muitos métodos são frequentemente avaliados para a preparação de nanopartículas poliméricas utilizando polímeros pré-formados por: nanoprecipitação e deposição interfacial ${ }^{[1]}$, salting-out ${ }^{[2]}$, emulsificação por evaporação ${ }^{[3,4]}$ e emulsificação por difusão ${ }^{[5]}$. Neste trabalho foram utilizadas as técnicas de nanoprecipitação com evaporação do solvente e emulsificação por difusão.

\subsubsection{Nanopartículas Poliméricas PMMA e PHB Luminescentes pela Técnica de Nanoprecipitação por Crioscopia}

Neste trabalho foram utilizadas as matrizes poliméricas PHB e PMMA para obtenção das nanopartículas luminescentes pelo método de nanoprecipitação. As matrizes poliméricas foram dopadas com os complexos de $\mathrm{TR}^{3+}:\left[\mathrm{TR}^{3+}(\mathrm{tta})_{3}(\mathrm{TOPO})_{2}\right]\left(\mathrm{TR}^{3+}=\mathrm{Eu}^{3+}, \mathrm{Gd}^{3+}\right)$ usando concentrações de: $0,5 \% ; 1 \% ; 3 \% ; 5 \%$ e $7 \%$ em peso do complexo em relação a massa do polímero a partir da dissolução deste complexo em acetona, e da dissolução dos polímeros separadamente em clorofórmio, seguido da junção destas duas soluções sob agitação constante por 1 hora. As amostras foram secas por evaporação do solvente, onde as que contêm PHB precipitaram e as contendo PMMA formaram um filme. Todas as amostras sofreram cominuição à baixa temperatura $(77 \mathrm{~K})$ como mostra a FIGURA 4.2, obtendo-se as nanopartículas. 


\subsubsection{Preparação das Nanopartículas Poliméricas PHB pela Técnica de Emulsificação-Difusão}

\subsection{Dispersante Tween 20}

Para a obtenção das nanopartículas foram preparadas duas soluções: uma orgânica e uma aquosa. A solução orgânica foi preparada pela dissolução de aproximadamente $10 \mathrm{mg}$ do polímero PHB e a mesma massa do complexo de terra rara em $6 \mathrm{~mL}$ de clorofórmio, com aquecimento de até $60 \stackrel{\circ}{\circ} \mathrm{em}$ um sistema com refluxo. Essa solução foi misturada com aproximadamente $74 \mathrm{~mL}$ de solução aquosa com $2 \mathrm{~mL}$ do dispersante Tween 20. A mistura foi agitada por 5 minutos com o auxílio de um dispersor extrator marca Quimis, obtendo-se uma pré-emulsão, a qual foi vertida em $150 \mathrm{~mL}$ de solução aquosa com $2 \mathrm{~mL}$ do dispersante Tween 20.

O sistema foi mantido sob agitação moderada a aproximadamente $40 \stackrel{\circ}{C}$ e pressão reduzida. Após 2 horas o sistema foi mantido apenas com agitação magnética baixa por 24 horas. Este método foi elaborado com base em trabalhos reportados na literatura ${ }^{[6-10]}$, com algumas modificações.

\subsection{Estabilizante de PVA e Crioprotetor Sacarose}

Quitanar-Guerreiro e colaboradores ${ }^{[5]}$ consideraram eficiente a formação de nanopartículas utilizando a técnica de emulsificação-difusão por meio de interações das cadeias do agente estabilizante ((poli (álcool vinílico) - PVA) na gota de interface (ex.: redução da tensão interfacial, estabilização mecânica e estabilização estérica) e na solução bulk (estabilização hidrodinâmica).Neste trabalho, além do uso do estabilizante PVA, foi adicionado ao sistema um crioprotetor (a sacarose) para proteção de danos de congelamento em caso de armazenamento ou liofilização ${ }^{[11]}$.

Para a obtenção das nanopartículas utilizando PVA e sacarose foram preparadas duas soluções, uma em solvente orgânico e uma aquosa. A solução em solvente orgânico foi preparada pela dissolução de aproximadamente $10 \mathrm{mg}$ do composto polimérico PHB, e a mesma massa do 
complexo de terra rara em $6 \mathrm{~mL}$ de clorofórmio, com aquecimento de até $60 \stackrel{\circ}{\mathrm{C}}$ em um sistema de refluxo. Essa solução foi misturada com aproximadamente $74 \mathrm{~mL}$ de solução aquosa contendo $4 \%$ do dispersante PVA e $10 \%$ de sacarose. As duas soluções foram juntadas e, então, a solução final foi agitada por 2 horas. Houve a precipitação do material por evaporação do solvente e mantido no dessecador até secagem completa do material.

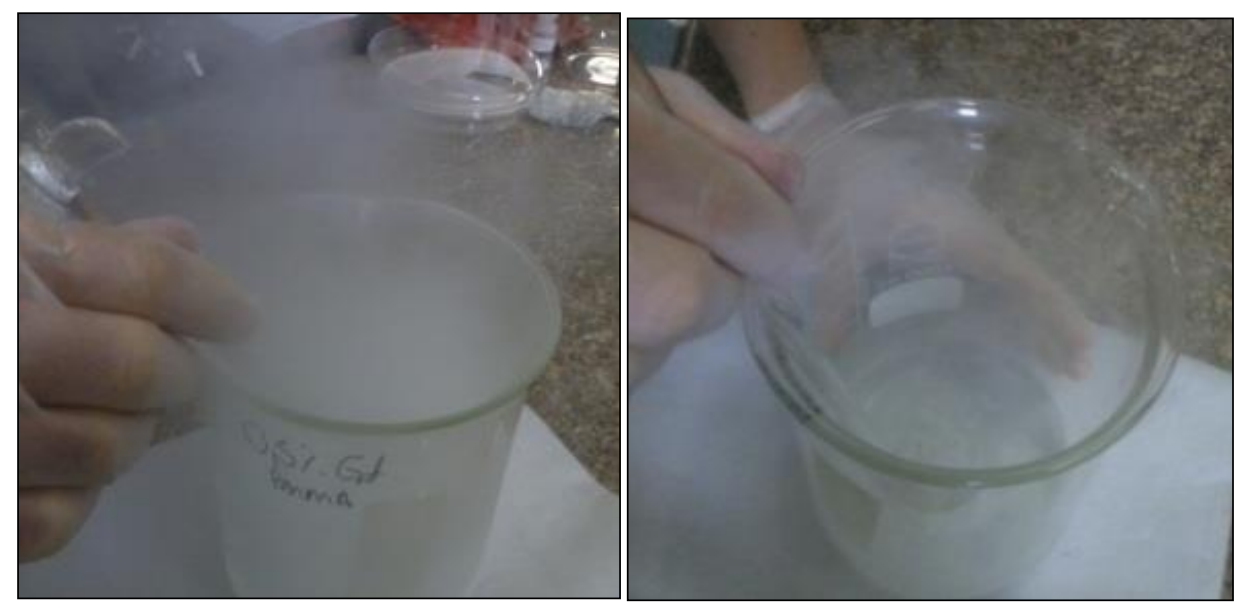

FIGURA 4.2 - Fotografias da cominuição mecânica a $77 \mathrm{~K}$ dos aglomerados de nanopartículas PMMATR( $\beta$-dicetonato $)_{3}(\mathrm{TOPO})_{2}$ ] obtidos.

\subsubsection{Caracterizações dos complexos e nanopartículas sintetizadas}

Para a caracterização dos complexos e nanopartículas poliméricas obtidas neste trabalho foram usadas as técnicas de complexometria para determinação dos metais; análise elementar de C, H, S; Espectroscopia de Absorção no Infravermelho por Transformada de Fourrier (FTIR); Análise Termogravimétrica (TGA/DTG); Difração de Raio - X (DRX), Microscopia Eletrônica de Varredura (MEV) e Microscopia Eletrônica de Transmissão (MET)As propriedades espectroscópicas foram determinadas a partir dos espectros de excitação e emissão, e pelo registro das curvas de decaimento experimental do ${ }^{5} D_{0}$. 


\subsubsection{Titulação Complexométrica usando Ácido Etilenodiaminotetracético (EDTA)}

As porcentagens em massa dos íons $\operatorname{TR}\left(\mathrm{TR}=\mathrm{Eu}^{3+}, \mathrm{Tb}^{3+}\right.$ e $\left.\mathrm{Gd}^{3+}\right)$ nas amostras contendo complexos $\beta$-dicetonatos e ligantes orgânicos secundários foram obtidas por titulação complexométrica utilizando solução de EDTA 10 $\mathrm{mmol} / \mathrm{L}$ como complexante e alaranjado de xilenol como indicador. Uma massa de aproximadamente $10 \mathrm{mg}$ do complexo foi pesada e dissolvida em ácido nítrico $\left(\mathrm{HNO}_{3}\right)$, então a solução foi aquecida com intuito de eliminar o excesso de ácido. Posteriormente, foram acrescentados $5 \mathrm{~mL}$ de uma solução tampão ácido acético/acetato $(\mathrm{pH}=4,5)$, uma gota de piridina e, aproximadamente, 10 gotas de uma solução alcoólica do indicador (alaranjado de xilenol) a $0,1 \%$ à solução resultante, conforme descrito na literatura ${ }^{[12-14]}$. A análise foi feita em duplicata de cada complexo seguindo o mesmo procedimento.

Para as amostras contendo as nanopartículas poliméricas (PMMA e PHB) foi realizada previamente a queima de aproximadamente $10 \mathrm{mg} \mathrm{em}$ massa de cada amostra a $500^{\circ} \mathrm{C}$ em uma mufla EDG 10P-S para eliminar os compostos orgânicos, restando assim os óxidos das terras raras para titulação. Os óxidos foram abertos com ácido clorídrico seguindo-se desta etapa de titulação padrão utilizado para determinação estequiométrica dos complexos.

As análises de titulação complexométrica por EDTA foram realizadas no Laboratório de Química Supramolecular e Nanotecnologia do Centro de Química e Meio Ambiente (CQMA) no Instituto de Pesquisas Energéticas e Nucleares (IPEN).

\subsubsection{Análise Elementar de Carbono, Hidrogênio e Enxofre (C, H, S)}

Os percentuais de carbono e enxofre foram obtidos no aparelho Carbon Sulfur Determinator Analyzer CS-400A da Leco Corporation, pertencente ao laboratório de Análises Química e Ambiental (LAQA) do Centro de Química e Meio Ambiente no IPEN e na Central Analítica do Instituto de Química da USP 
(IQ-USP). Os percentuais de hidrogênio e carbono foram obtidos na Central Analítica do Instituto de Química da USP.

\subsubsection{Espectroscopia de Absorção no Infravermelho por Transformada de Fourier (FTIR)}

Os espectros de absorção na região do infravermelho (de 4000 a 400 $\mathrm{cm}^{-1}$ ) dos complexos de terras raras e das nanopartículas poliméricas foram obtidos em um espectrômetro Thermo Scientific Nicolet 6700 FT-IR, Smart Orbit, Diamond $30000-400 \mathrm{~cm}^{-1}$; Class 1 laser product por Refletância Total Atenuada (ATR). As análises foram obtidas à temperatura ambiente ( $298 \mathrm{~K})$. O equipamento utilizado pertence ao Laboratório de Polímeros do Centro de Química e Meio Ambiente no IPEN.

\subsubsection{Termogavimetria (TG/DTG)}

As curvas de decomposição termogavimétricas (TGA) e de termogavimetria diferencial (DTGA) foram obtidas em uma termo balança SDTA-822 (Mettler Toledo) usando amostras de aproximadamente $10 \mathrm{mg} \mathrm{em}$ cadinho de alumina, sob atmosfera dinâmica de nitrogênio, com vazão de 50 $\mathrm{mL} \min ^{-1}$ e razão de aquecimento de $10 \stackrel{\circ}{\circ} \mathrm{min}^{-1}$. As curvas DTGA foram obtidas a partir da diferenciação eletrônica do sinal TG. $O$ equipamento utilizado pertence ao Laboratório de Polímeros do Centro de Química e Meio Ambiente no IPEN.

\subsubsection{Difração de Raios X (DRX)}

Os dados de difração de Raios $X$ pelo método do pó foram obtidos em um Difratômetro de Raios X Rigaku, modelo MiniFlex II. Foi utilizado com fonte de radiação $\operatorname{CuK}_{\alpha}(\lambda=1,54$ Ăe filtro de $\mathrm{Ni}$. As amostras foram dispersas em 
lâminas de quartzo. O equipamento utilizado pertence ao Laboratório de Química Supramolecular e Nanotecnologia do Centro de Química e Meio Ambiente no IPEN.

\subsubsection{Microscopia Eletrônica de Varredura (MEV)}

Para obtenção das micrografias foi utilizado um microscópio eletrônico de varredura marca Philips modelo XR-30. As amostras foram pulverizadas sobre um suporte metálico adequado e recobertas com ouro pela técnica de sputtering. O microscópio utilizado pertence ao Laboratório de MEV do Centro de Ciência e Tecnologia dos Materiais no IPEN. As imagens foram obtidas fazendo fotografias com aumento de 1000 a 10000 vezes.

\subsubsection{Microscopia Eletrônica de Transmissão (TEM)}

As micrografias das nanopartículas foram obtidas no Laboratório de Microscopia Eletrônica de Transmissão, do Centro de Ciência e Tecnologia dos Materiais, no IPEN, em um TEM modelo JEM2100, marca Jeol, operando a 200 $\mathrm{keV}$.

\subsubsection{Estudos de Fotoluminescência}

Os espectros de luminescência correspondentes à excitação e emissão foram obtidos à temperatura ambiente em um espectrofluorímetro SPEXFLUOROLOG 2, programa computacional DM3000F, com monocromadores duplos SPEX 1680 utilizando lâmpada de xenônio de $450 \mathrm{~W}$ como fonte de excitação. Os dados espectrais foram coletados em um ângulo de $22,5^{\circ}$ (face frontal). As fendas de excitação foram utilizadas com aberturas entre 0,1 e 2,0 $\mathrm{mm}$. 
As curvas de decaimento de luminescência e os espectros de emissão resolvidos no tempo foram registrados a temperatura ambiente. Utilizou-se um fosforímetro SPEX 1934D acoplado ao espectrofluorímetro, sendo todos estes controlados pelo DM3000F. Todas as medidas foram feitas utilizando as fendas entre 0,5 e 2,0 mm nos monocromadores de excitação e emissão, respectivamente. A fonte utilizada foi uma lâmpada pulsada de xenônio de 150 W.

Todas as medidas de espectrofotometria foram obtidas nos equipamentos pertencentes ao Laboratório dos Elementos do Bloco f (LEBf), no Instituto de Química da USP.

\subsection{Medidas de Tempo de Vida}

Para a obtenção das curvas de decaimento das emissões foi utilizada uma lâmpada pulsada de xenônio de $150 \mathrm{~W}$ até $11 \mathrm{~ms}$. Todos os dados

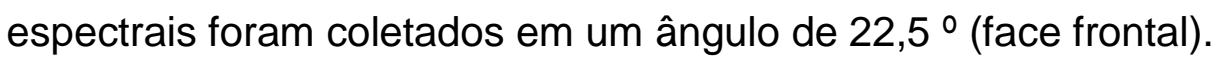

\subsection{Parâmetros de Intensidades Experimetais}

O estudo tanto teórico quanto experimental dos parâmetros de intensidade de Judd-Ofelt $\left(\Omega_{\lambda}\right)$ é um fator importante na caracterização e design de compostos que tenham potenciais aplicações em sistemas luminescentes. Neste sentido, foram estudados e calculados os parâmetros de intensidades experimentais dos complexos e partículas luminescentes sintetizados neste trabalho.

\subsubsection{Diagramação de Cromaticidade}

As cores do espectro visível das amostras estudadas foram expressas com uma projeção bidimensional num plano $x y$, tal plano definido como 
diagrama de cromaticidade. Foram calculadas as coordenadas $x y$ a partir dos espectros de emissão obtidos das amostras.

\subsubsection{Classificação de Dispersão Coloidal pelo Efeito Tyndall}

A observação da existência do efeito Tyndall nas soluções contendo amostras de NPs foi realizada incidindo um feixe de laser nas amostras em solução aquosa. O sobrenadante resultante da centrifugação $(3000 \mathrm{rpm} / 10$ minutos) foi exposto ao feixe de laser (FIG. 4.3). Frente à possibilidade de se observar o feixe no interior do sistema caracterizou-se um colóide; quando da impossibilidade, caracterizou-se sistema homogêneo ${ }^{[15]}$.

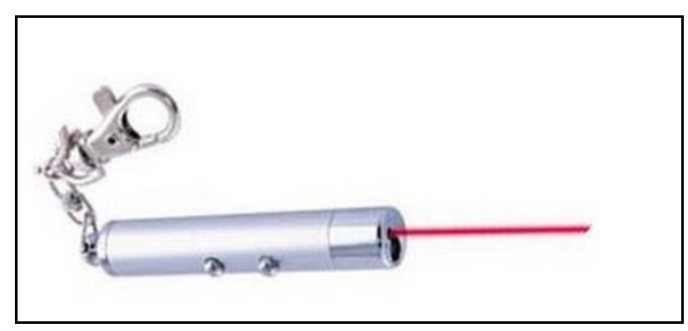

FIGURA 4.3 - Feixe de luz laser proveniente de um apontador laser.

\subsubsection{Teste de Hemocompatibilidade por Adesão de Plaquetas}

As amostras dos filmes feitos a partir do complexo [Eu(tta $)_{3}(\mathrm{TOPO})_{2}$ ] dopado em concentrações que apresentaram melhor eficiência luminescente (5\%no PMMA e $3 \%$ no PHB) (FIG. 4.4) foram usados para desenvolver os testes de hemocompatibilidade, os quais seguiram as normas internacionais (ISSO 10993-4, 1992) ${ }^{[16]}$.Para testar a adesão plaquetária na superfície das amostras, foram coletados $8 \mathrm{~mL}$ de sangue humano em meio anticoagulante (ACD) na proporção de $1 \mathrm{~mL}$ de sangue : 0,25 $\mathrm{mL}$ de ACD. Após centrifugação (1000 rpm por $15 \mathrm{~min}$ ), células vermelhas foram separadas e um plasma rico em plaquetas foi obtido. 
Os filmes luminescentes foram cortados $\left(25 \mathrm{~mm}^{2}\right)$ e aderidos em lamínulas de vidro com fita adesiva dupla face. As lamínulas contendo os filmes foram colocadas em uma placa de Petri e esta foi colocada dentro de outra placa de Petri maior contendo água. $\mathrm{O}$ conjunto de placas foi mantido a $37^{\circ} \mathrm{C}$ por 15 minutos a fim de umidificar o meio. Em seguida, a superfície dos filmes foi totalmente recoberta com uma quantidade de aproximadamente $4 \mathrm{~mL}$ de plasma, sendo novamente acondicionados no conjunto de placas de Petri e levados à estufa a $37^{\circ} \mathrm{C}$ (por 1 minuto) (FIG. 4.5). As amostras foram então lavadas com solução salina $(0,2 \mathrm{M})$ e imersas em glutaraldeído $(2,5 \%)$ por 10 minutos à temperatura ambiente, e desidratadas com etanol nas concentrações de $50 \%$ (5 minutos), $75 \%$ (10 minutos) e $95 \%$ (15 minutos).

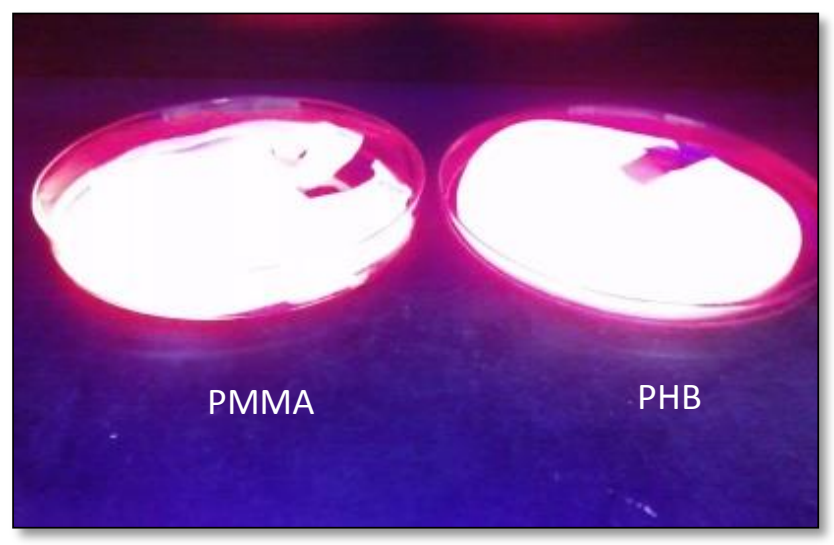

FIGURA 4.4 - Amostras dos filmes PMMA:5\%[Eu(tta) $\left.)_{3}(\mathrm{TOPO})_{2}\right]$ e $\mathrm{PHB}: 3 \%\left[\mathrm{Eu}(\mathrm{tta})_{3}(\mathrm{TOPO})_{2}\right]$, respectivamente, sob radiação ultravioleta $(420-380$ $\mathrm{nm})$. 


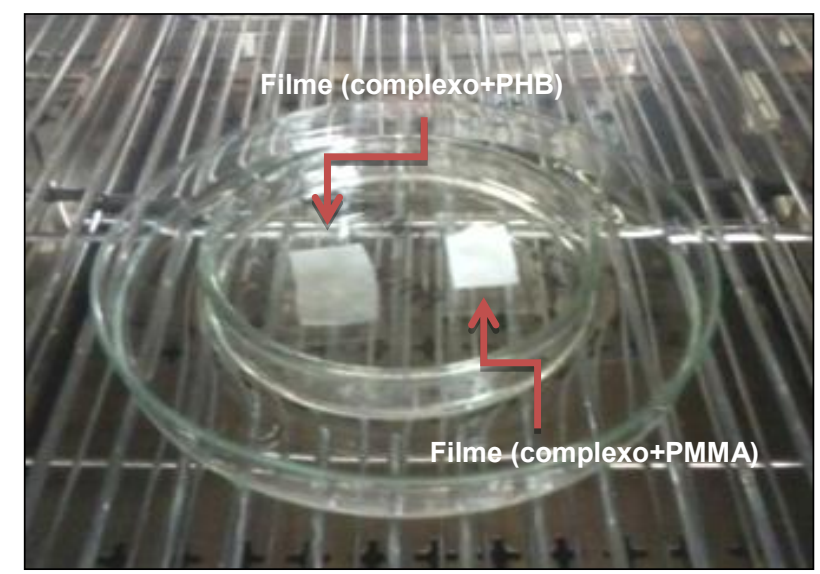

FIGURA 4.5 - Sistema de preparação dos filmes submetidos à análise de hemocompatibilidade.

\subsubsection{Funcionalização das Nanopartículas Poliméricas PHB e PMMA}

Para a funcionalização das nanopartículas poliméricas PHB e PMMA foram utilizadas nove amostras de diferentes marcadores, e o critério de seleção foi a intensidade de luminescência destes. As amostras que foram utilizadas estão listadas a seguir:

$\checkmark$ PMMA:0,5\%[Eu(tta) $\left.)_{3}(\text { TOPO })_{2}\right]$;

$\checkmark$ PMMA:5\%[Eu(tta) $\left.)_{3}(\mathrm{TOPO})_{2}\right]$;

$\checkmark$ PMMA:7\%[Eu(tta) $\left.)_{3}(\mathrm{TOPO})_{2}\right]$

$\checkmark$ PHB:3\%[Eu(tta) $\left.)_{3}(\mathrm{TOPO})_{2}\right]$,

$\checkmark$ PHB: 3\%[Gd(tta $\left.)_{3}(\mathrm{TOPO})_{2}\right]$;

$\checkmark$ PMMA:5\%[Eu(tta) $\left.)_{3}(\text { TOPO })_{2}\right]+$ dispersante Tween 20;

$\checkmark$ PHB:3\%[Eu(tta) $\left.)_{3}(\mathrm{TOPO})_{2}\right]+$ dispersante Tween 20;

$\checkmark$ PMMA:5\%[Eu(tta) $\left.)_{3}(\text { TOPO })_{2}\right]+P V A+$ sacarose;

$\checkmark$ PHB:3\%[Eu(tta) $\left.)_{3}(\mathrm{TOPO})_{2}\right]+\mathrm{PVA}+$ sacarose;

Estas amostras foram funcionalizadas pelo método descrito por Fixe et al. ${ }^{[11]}$ e descrito a seguir (FIG. 4.6). As amostras foram lavadas com isopropanol (99\%), 
mantidas em temperatura ambiente até decantação e, então, lavadas com água Milli-Q. Subsequentemente, as amostras foram incubadas com 10\% (m/v) de uma solução de 1,6 hexametileno-diamino em 100 mM de tampão borato $\mathrm{pH}$ 11,5 overnight. Então, as amostras foram lavadas duas vezes com água MILLIQ por 10 minutos cada e, finalmente, mantidas à temperatura ambiente dentro do dessecador para secagem.

Para quantificação dos grupamentos $\mathrm{NH}_{2}$ na superfície das nanopartículas poliméricas, utilizou-se o método da Ninidrina (FIG. 4.6), descrito no item abaixo.

$\mathrm{O}$

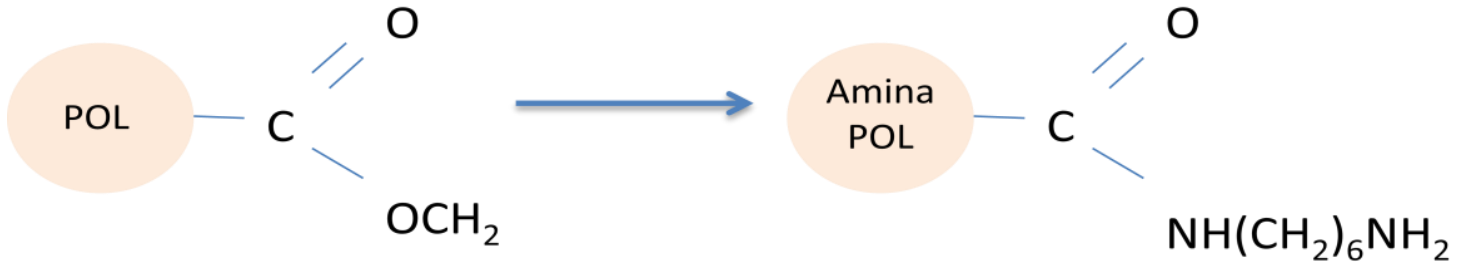

FIGURA 4.6 - llustração da reação que ocorre entre as nanopartículas poliméricas e 1,6- hexametilenodiamina.

\subsubsection{Determinação de Aminas Primárias - Método da Ninidrina}

A fim de comprovar quantitativamente a eficácia da funcionalização, ou seja, a determinação dos grupamentos de aminas primárias livres, realizou-se um estudo espectroscópico de determinação destas aminas primárias, o método da ninidrina (2,2, -dihidroxi-1,3-indanodiona) consiste na reação colorimétrica entre aminas primárias e ninidrina com a formação de complexo colorido (roxo) em pH5,5 - 6,4 ${ }^{[17-19]}$.

O método da ninidrina, apesar de requerer uma série de cuidados, é eficiente para estimativa e comprovação da presença de grupos $\mathrm{NH}_{2}$ em nanopartículas funcionalizadas ${ }^{[20]}$. 
As leituras foram obtidas em um espectrofotômetro SHIMADZU, modelo Multispec 1501 e utilizando-se cubetas de quartzo com $1 \mathrm{~cm}$ de caminho óptico.

A curva de calibração foi construída utilizando-se glicina como material padrão, que forma um complexo de cor roxa com um máximo de absorção em $570 \mathrm{~nm}$.

\subsubsection{Ensaios Imunológicos}

\subsubsection{Desenvolvimento do Imunoensaio para Determinar o 17- $\beta$ Estradiol}

Neste trabalho foi desenvolvido um protocolo para o ensaio biológico (imunoensaio) utilizando um marcador luminescente à base de terras raras que também foi desenvolvido neste trabalho. $O$ objetivo do fluoroimunoensaio foi detectar e quantificar a reação Ag-Ac (antígeno-anticorpo), empregando o anticorpo policlonal anti-17ß-estradiol (anticorpo específico ao hormônio estrogênico 17ß-estradiol) e o antígeno chamado neste trabalho de $17 \beta$ estradiol, o hormônio alvo. Os ensaios se basearam na sensibilização de uma microplaca de poliestireno (suporte sólido) com a imunoglobulina $G(\lg G)$. A microplaca é lavada para retirar o excesso de anticorpo e então se adiciona um agente de bloqueio. Em seguida, o anti-17ß-estradiol é adicionado, a nanopartícula funcionalizada contendo o espaçador glutaraldeído conjugada com o antígeno (hormônio) é adicionada na placa. Então após a reação $\mathrm{Ag}-\mathrm{Ac}$, a placa é lavada. Os dados de intensidades luminescentes da placa foram obtidos no fluorímetro da Perkin Elmer, Victor ${ }^{2} D$. É um método baseado na afinidade molecular do hormônio 17ß-estradiol (chamado antígeno) ao anticorpo policlonal específico ao lgG sensibilizado na placa, em uma interação antígeno-anti-anticorpo. 


\subsection{Ensaio Imunoabsorvente ligado à Enzima (ELISA)}

Os métodos imunológicos desenvolvidos para quantificar a concentração de antígenos e anticorpos, por apresentarem grande sensibilidade e especificidade, tornaram-se técnicas padronizadas para pesquisa e aplicações clínicas. Entre esses métodos, um dos mais usados é o ELISA (Enzyme-linked immuno sorbent assay) ${ }^{[21-23]}$.

Foi inicialmente desenvolvido por Engvall \& Perlman e por van Weeman \& Schuurse, posteriormente, muito utilizado como teste diagnóstico. Trata-se de um método eficiente, pois permite detectar quantidades de antígenos da ordem de nanogramas $\left(10^{-9} \mathrm{~g}\right)^{[22]}$.

No ELISA deve-se selecionar um par de anticorpos, que podem ser monoclonais ou policlonais. O uso de anticorpos monoclonais resulta em maior especificidade. No entanto, neste trabalho, foi utilizado um anticorpo policlonal.

O teste baseia-se em uma interação inata do organismo, a interação antígeno-anticorpo. Quando o sistema imunológico do corpo encontra um antígeno específico (por exemplo, uma proteína característica na superfície de um vírus ou bactéria), os anticorpos que são específicos para o antígeno interceptam-no com uma ligação física a ele em uma reação do tipo "chave e fechadura", neutralizando assim o antígeno. O ELISA é uma técnica fundamental para avaliações imunológicas e bioquímicas, utilizada para detectar o antígeno ou anticorpo em uma amostra, com base em interações antígeno-anticorpo. Se um antígeno (ou da mesma forma, um anticorpo) é detectado, um sinal é produzido na forma de uma mudança mensurável ${ }^{\text {[22, 23] }}$.

Para avaliar a presença de um antígeno específico em uma amostra, um "teste de ELISA" pode ser realizado da seguinte maneira: Uma solução de anticorpo, que é específico (isto é, tem reconhecimento exclusivo) ao antígeno putativo, é imobilizada em uma superfície sólida em um poço de uma placa de microtitulação. É aplicado, em seguida, à amostra a ser analisada, condições que permitam o antígeno ligar-se aos anticorpos imobilizados específicos. 0 material não ligado é lavado, e o antígeno ligado é reconhecido mais uma vez em condições de ligação com a adição de uma solução de um segundo anticorpo específico para o mesmo antígeno, que desta vez é acoplado ou 
ligado a uma enzima que catalisa a conversão de seu substrato a uma forma detectável e possivelmente quantificável ${ }^{[21]}$.

Esses anticorpos ligados a uma enzima que estão vinculados ao complexo antígeno-anticorpo imobilizado são resistentes a ciclos de lavagem e, finalmente, o substrato é adicionado e incubado de modo que a enzima possa catalisar a conversão do substrato para o sinal de detecção do antígeno específico. Ensaios por ELISA costumam empregar qualquer substrato cromogênico ou um fluorogênico, que produz uma cor ou fluorescência, respectivamente, após a conversão pela enzima ligada ao segundo anticorpo.

A conversão do substrato é convenientemente observada ou quantificada em um leitor de placas, por medidas de densidade óptica ou intensidade de fluorescência.

Em resumo, mudar a cor ou a fluorescência sinaliza a atividade da enzima, que sinaliza a presença do segundo anticorpo, que sinaliza a presença do antígeno procurado ${ }^{[21-24]}$.

Existem vários modelos de testes de ELISA. Serão apresentados resumidamente cada um desses tipos:

- $\quad$ ELISA indireto: o método indireto é utilizado para detecção de anticorpos. Neste caso o antígeno fica aderido aos poços da microplaca. Em seguida coloca-se o soro problema e em seguida um anticorpo marcado com uma enzima que reage com o substrato fazendo com que o cromógeno mude de cor. A presença de cor nos poços indica a presença do anticorpo, e os poços que não mudarem de cor indica a ausência do anticorpo em questão.

- ELISA direto ou sanduíche: o método de sanduíche, ou captura, é indicado para identificação de antígenos, e este antígeno fica entre dois anticorpos. Assim, um anticorpo primário específico ao antígeno é adsorvido no poço da microplaca. Em seguida o antígeno na solução problema é adicionado. Depois o segundo anticorpo específico ao antígeno é marcado com uma enzima é adicionado. Esta enzima que reage com o substrato fazendo com que o cromógeno mude de cor. A presença de cor nos poços indica a presença do 
antígeno, e os poços que não mudarem de cor indica a ausência do antígeno em questão.

- ELISA Competitivo: o método competitivo é mais usado para identificação de antígenos, mas pode também ser empregado para a detecção de anticorpos. Neste método primeiro se adsorve o anticorpo no poço da microplaca. Após a adsorção do anticorpo, uma solução que possivelmente contém o antígeno é adicionada sobre os anticorpos adsorvidos. O próximo passo é adicionar o antígeno marcado com uma enzima ou um marcador luminescente. Os poços que não possuem o antígeno primário (da solução problema) aderido ao anticorpo ficam coloridos, enquanto que os poços que possuem antígenos aderidos aos anticorpos não mudam de cor, o inverso ocorre para o nanomarcador.

O teste ELISA também pode ser utilizado de diversas outras formas. Utilizando-se de um método semelhante ao método de imunoradioensaio, pode-se transformar muitas outras substâncias em antígeno e obter um anticorpo do mesmo. Assim, é possível utilizar o teste para se detectar outras substâncias de interesse como, por exemplo, hormônios. Pelo fato do radioimunoensaio ser muito caro, o teste ELISA pode ser uma alternativa muito mais simples e barata ${ }^{[25]}$.

Como mencionado anteriormente, o protocolo desenvolvido neste trabalho tem como princípio o ELISA direto, com a adição de um nanomarcador luminescente para atuar como sonda fluorescente no ensaio de captura ao $17 \beta$-estradiol.

A FIGURA 4.27 ilustra o mecanismo molecular do protocolo desenvolvido. Imunoglobulinas $\mathrm{G}$ (anticorpos lgGs) de ovelha (produzidos em coelho) sensibilizam a microplaca, em seguida é adicionado o policlonal anti$17 \beta$-estradiol que se liga ao primeiro anticorpo ( $\lg G)$, a solução contendo o hormônio $17 \beta$-estradiol já conjugado à nanopartícula luminescente se liga especificamente ao anti-17ß-estradiol, formando uma cascata de sinalização molecular, onde é emitido o sinal luminescente, determinado espectroscopicamente, proporcional à quantidade do hormônio no poço da placa. 


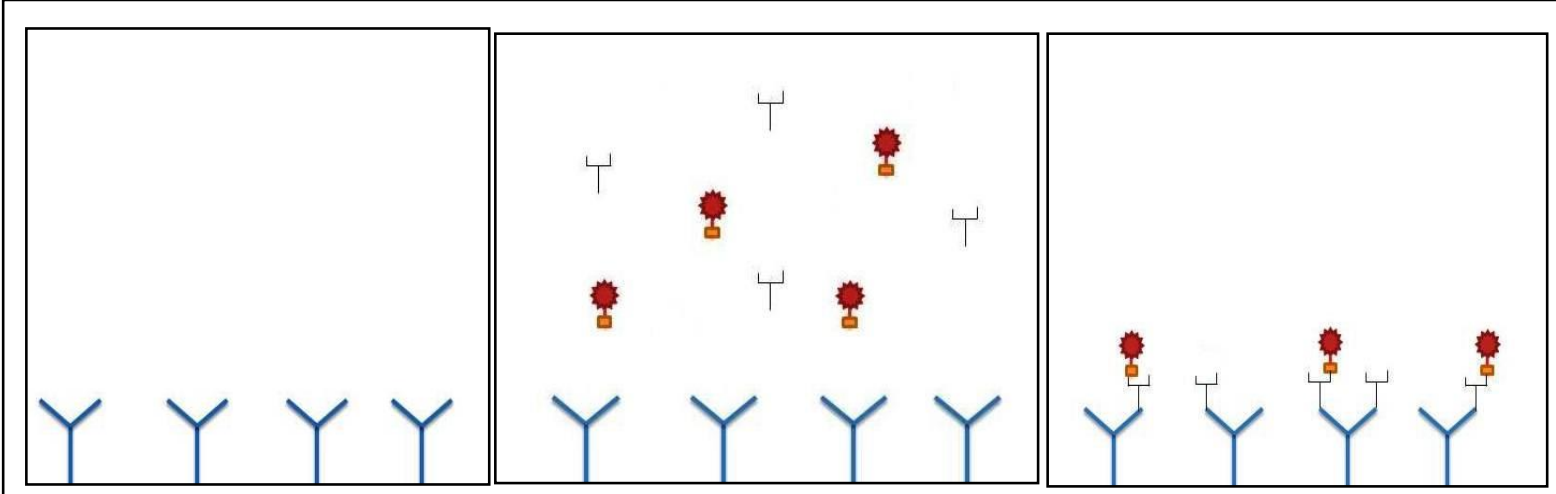

Legenda:

Y $\lg G$

Nanopartícula luminescente ligada ao 17 $\beta$-estradiol (marcador)

$\uparrow$ Policlonal anti-17ß-estradiol

FIGURA 4.27 - Esquema representativo do protocolo desenvolvido para a detecção e quantificação do $17 \beta$-estradiol.

\subsection{Protocolo do Teste de Detecção e Quantificação do 17 $\beta$-Estradiol}

1) Reação das Nanopartículas Luminescentes Funcionalizadas (POL.X\%[Eu(tta) $\left.)_{3}(\mathrm{TOPO})_{2}\right]$-Amina) com o Espaçador Glutaraldeído

A nanopartícula com 0 espaçador glutaraldeído (POL.X\%[Eu(tta) $\left.)_{3}(\mathrm{TOPO})_{2}\right]$-Amina-Glu), onde POL. = PMMA e PHB, e X= 5 e $3 \%$, respectivamente, foi preparada a partir de $1 \mathrm{mg}$ da partícula ((POL.X\%[Eu(tta) $\left.)_{3}(\mathrm{TOPO})_{2}\right]$-Amina) com $200 \mu \mathrm{L}$ de solução PBS (concentração $0,05 \mathrm{~mol} \mathrm{~L}^{-1}$ ) contendo $5 \%$ de glutaraldeído (FIG. 4.28), mantida à temperatura de $4 \stackrel{\circ}{ } \mathrm{C}$ por $12 \mathrm{~h}$. Em seguida, o sistema contendo as nanopartículas foram lavadas quatro vezes com PBS ${ }^{[17]}$. 


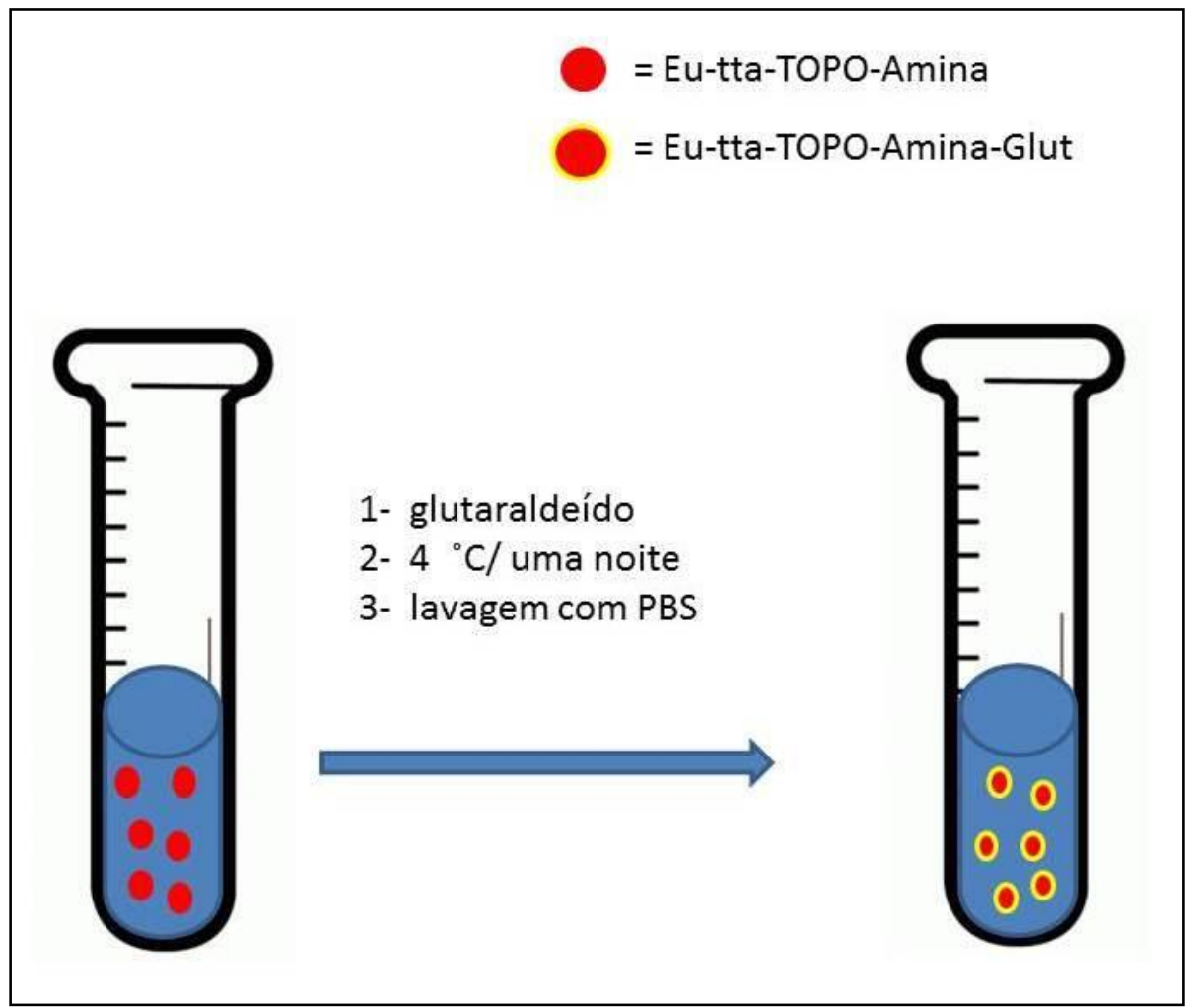

FIGURA 4.28 - Esquema representativo da reação do nanomarcador luminescente com o glutaraldeído.

\section{2) Reação do Nanomarcador Luminescente (POL.X\%[Eu(tta) $\left.)_{3}(\mathrm{TOPO})_{2}\right]$ - Amina-Glu) com o 17 $\beta$-Estradiol (Ag)}

Primeiro, o hormônio 17ß-estradiol (chamado antígeno) foi diluído em diferentes concentrações em solução de PBS $\left(25.10^{-3}, 25.10^{-4}, 25.10^{-5}\right.$ e $25.10^{-}$ ${ }^{6} \mathrm{mg} \mathrm{mL}^{-1}$ ). Em seguida, adicionou-se $200 \mu \mathrm{L}$ de solução do hormônio em cada microtubo contendo 1,0 mg de nanopartícula com o espaçador glutaraldeído (4 marcadores diferentes) e mantido a $4{ }^{\circ} \mathrm{C}$ overnight. Foi acrescido ao meio reacional $\mathrm{NaBH}_{4}$ e $20 \mu \mathrm{L}$ de solução de glicina $\left(0,5 \mathrm{~mol} \mathrm{~L}{ }^{-1}\right)$ mantido em repouso a $4{ }^{\circ} \mathrm{C}$ por $30 \mathrm{~min}{ }^{[26]}$. Finalmente, o sistema Eu(tta)(TOPO)-aminaGlut-Ag (partículas com o espaçador após a reação com o Ag) foi lavado quatro vezes com PBS [17, 27]. O esquema representativo desta reação é apresentado na FIGURA 4.29. 


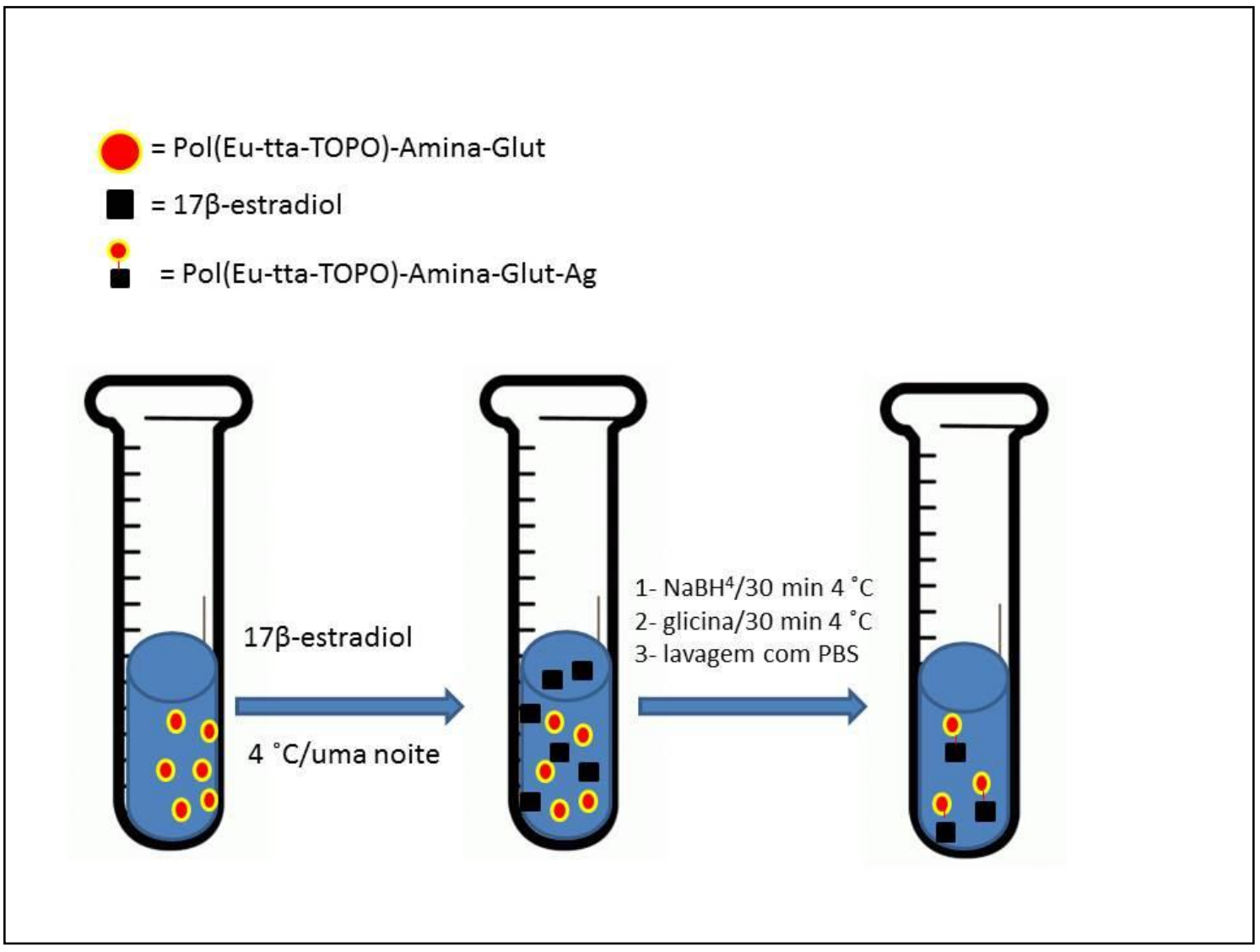

FIGURA 4.29 - Esquema representativo da conjugação do nanomarcador com o hormônio $17 \beta$-estradiol $(\mathrm{Ag})$.

\section{3) Sensibilização das Placas com o lgG}

O IgG utilizado neste protocolo serve como anticorpo de captura ou primeiro anticorpo, é um anticorpo purificado por afinidade isolado a partir de um "pool" de soro de coelhos imunizados com lgG de ovelha purificado.

Cada um dos 96 poços da placa de poliestireno foram sensibilizados com a adição de $100 \mu \mathrm{L}$ de uma solução contendo lgG e TBS (trishidroximetilaminometano), em concentração de $1 \mu \mathrm{g} / \mathrm{mL}$. A placa contendo a solução nos poços foi incubada a $4{ }^{\circ}$ Cpor uma noite. Lavou-se a placa quatro vezes com PBS $\left(0,05 \mathrm{~mol} \mathrm{~L}^{-1}, \mathrm{pH} 7,4\right)$. Foi então adicionado $100 \mu \mathrm{L}$ da solução de bloqueio (proteína do leite 
$5 \% \mathrm{~m} / \mathrm{v}$ em PBS), em cada poço, à temperatura ambiente por 1:30 hora. Finalmente, a placa foi lavada quatro vezes com PBS.

\section{4) Reação do Anti-17ß-Estradiol com o IgG}

Foi utilizado o anticorpo policlonal específico ao 17ß-estradiol (anti-17 $\beta$ estradiol) com isotipo de ovelha para se ligar ao anticorpo de captura (IgG de ovelha). Uma solução contendo o anti-17ß-estradiol e PBS $\left(0,05 \mathrm{~mol} \mathrm{~L}^{-1}, \mathrm{pH}\right.$ $7,4)$ foi preparada em concentrações de $0,1 \mu \mathrm{g} / \mathrm{mL} ; 0,5 \mu \mathrm{g} / \mathrm{mL}$ e $1 \mu \mathrm{g} / \mathrm{mL}$. Foi adicionado aos poços sensibilizados com IgG $100 \mu \mathrm{L}$ desta solução. A placa foi acondicionada a $4^{\circ} \mathrm{C}$ overnight. Lavou-se a placa quatro vezes com PBS $(0,05$ mol L-1, $\mathrm{pH} 7,4)$.

\section{5) Determinação da Concentração de Antígeno no Sistema $\mathrm{Eu}(\mathrm{tta})_{3}(\mathrm{TOPO})_{2}$-Amina-Glut-Ag}

O sistema nanopartícula-amina-Glut-Ag foi disperso em PBS (0,05 mol $\left.\mathrm{L}^{-1}, \mathrm{pH} 7,4\right)$ em concentrações de $2 \mathrm{mg} / 12 \mathrm{~mL}$ (sistema/PBS). Adicionou-se 150 $\mu \mathrm{L}$ da dispersão para cada poço da placa de imunoensaio sensibilizada com IgG e contendo o anti-17ß-estradiol. A placa foi lavada quatro vezes com PBS $\left(0,05 \mathrm{~mol} \mathrm{~L}^{-1}, \mathrm{pH} \mathrm{7,4)}\right.$ contendo Tween 20. A leitura de fluorescência da placa de 96 poços foi realizada em um fluorímetro Victor ${ }^{2}$ D modelo Wallac 1420D (Perkin Elmer) usando lâmpada de tungstênio-halogênio contínua (150 W). Filtros utilizados: 340 nm (excitação) e 615 nm (emissão). O fluorímetro pertence ao Centro de Química e Meio Ambiente do Instituto de Pesquisas Energéticas e Nucleares (CQMA-IPEN).

O esquema deste imunoensaio pode ser observado na FIGURA 4.30. Foi realizado um cálculo da média obtida das dosagens realizadas em triplicatas. 


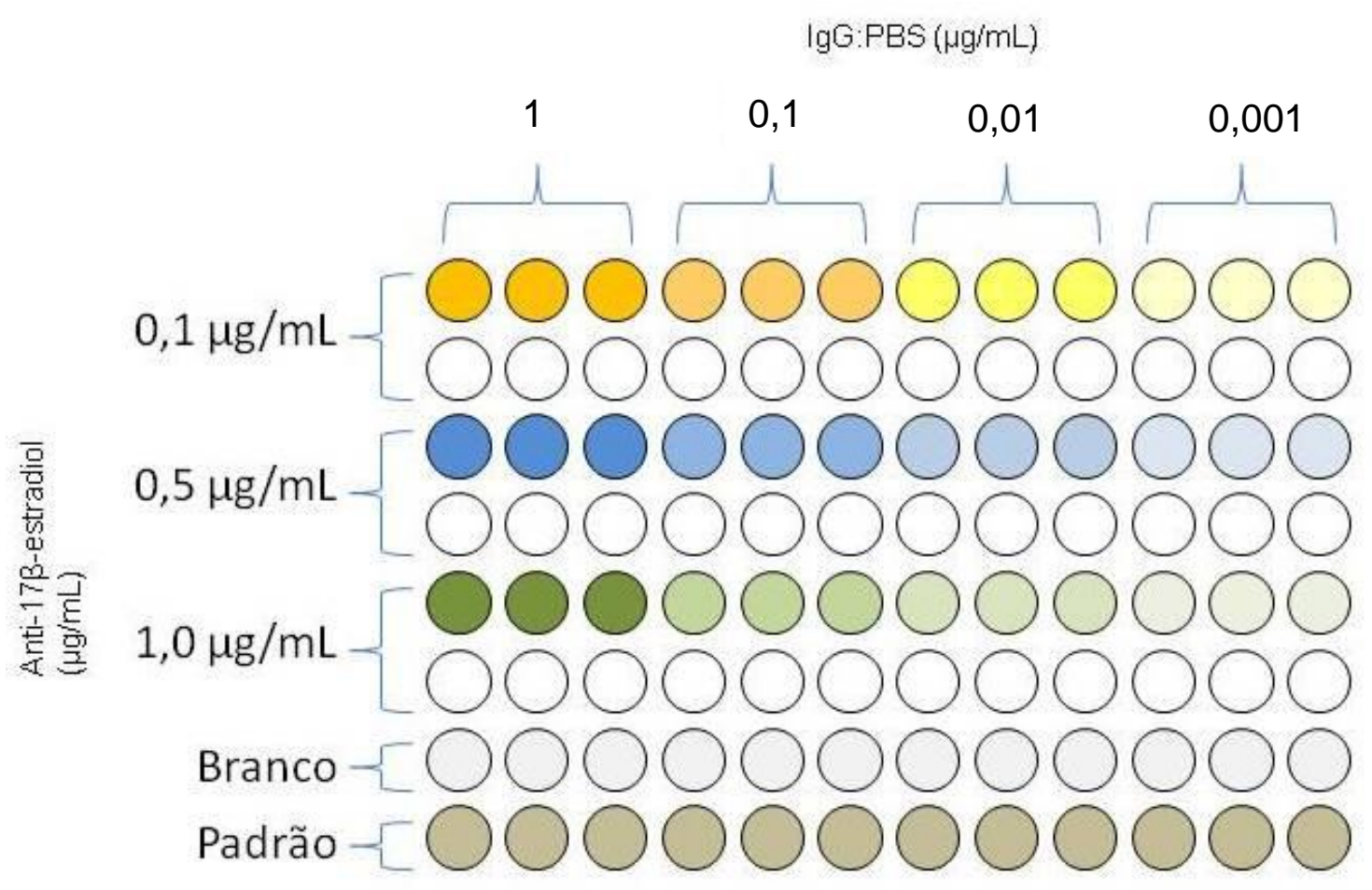

FIGURA 4.30 - Esquema ilustrativo da preparação dos poços da placa utilizada para o imunoensaio de indentificação e quantificação do hormônio em diferentes concentrações das soluções de anti-17ß-estradiol/lgG. do nanomarcador. 


\section{REFERÊNCIAS BIBLIOGRÁFICAS}

[1] FESSI, H.; PUISIEUX, F.; DEVISSAGUET, J. P.; Ammoury, N.; BENITA, S. Nanocapsule formationby interfacial polymer deposition following solvent displacement. Int. J. Pharm. 55, R1-R4, 1989.

[2] GALINDO-RODRIGUEZ, S.; ALLEMANN, E.; FESSI, H.;DOELKER, E.Physicochemical parameters associated with nanoparticle formation in the salting-out, emulsification-diffusion, and nanoprecipitation methods. Pharm. Res. 21, 1428-1439, 2004.

[3] BUDHIAN, A.; SIEGEL, S.J.; WINEY, K.I.Haloperidol-loaded PLGA nanoparticles: systematic study of particle size and drug content. Int. J. Pharm. 336, 367-375, 2007.

[4] BABAK, V.G.; BAROS, F.; BOULANOUAR, O.; BOURY, F.; FROMM, M.;KILDEEVA, N.R.; UBRICH, N.; MAINCENT, P. Impact of bulk and surface properties of some biocompatible hydrophobic polymers on the stability of methylene chloride-in-water mini-emulsions used to prepare nanoparticles by emulsification-solvent evaporation. Colloids Surf. B 59, 194-207, 2007.

[5] QUINTANAR-GUERRERO, D.; ALLEMANN, E.; DOELKER, E.; FESSI, H. Preparation and characterization of nanocapsules from preformed polymers by a new process based on emulsification-diffusion technique. Pharm. Res. 15, 1056- 1062, 1998.

[6] POHLManN, A.R.; POLETTO, F.S; FIEL, L.A.; DONIDA, B.; RÉ, M.I.; GUTERRES, S.S. Controlling the size of poly (hidroxybutyrate-co-hidroxy valerate) nanoparticles prepared by emulsification-diffusion technique using ethanol as surface agent. Colloids and Surfaces A: Physicochemical and Engeneering Aspects. v.324, p.105-112, 2008. 
[7] NEUFELD, R.J.; REIS, C.P.; RIBEIRO, A.J.; VEIGA, F. Nanoencapsulation I. Methods for preparation of drug-loaded polymeric nanoparticles. Nanomedicine: Nanotechnology, Biology and Medicine. v.2, p.8-21, 2005.

[8] RAO, J.P; GECKELER, K.E. Polymer nanoparticles preparation techniques and size-control parameters. Elsevier, 887-913, 2011.

[9] SCHAFFAZICK, S.R.; GUTERRES, J.J.; FREITAS, L.L.; POHLMANN, A.R. Caracterização e estabilidade físico-química de sistemas poliméricos nanoparticulados para administração de fármacos. Química Nova, v.26, n.5, p.726-737, 2003.

[10] ENGELMANN, K. Síntese de nanomarcadores luminescentes contendo íons terras raras para aplicação em testes de diagnóstico para doença de Chagas. (Dissertação Mestrado). Instituto de Pesquisas Enérgéticas e Nucleares, Universidade de São Paulo, 2012.

[11] ARAÚJO, R. S. Desenvolvimento, caracterização e liofilização de nanopartículas e encapsulamento de antibiótico de uso veterinário. (Dissertação de mestrado) UFOP/Ciências Farmacêuticas, 2009.

[11] FIXE, F.; DUFVA, M.; TElleman, P.; CHRISTENSEN, C.B.V. Funcionalization of poly(methyl methacrylate) (PMMA) as a substrate for DNA microarrays. Nucl. Ac. Research, vol. 32, n.1, 2004.

[12] SCHIMID G. Nanoparticles: from theory to applications. Weinheim, Germany: Wiley-VCH Publishers; 2004.

[13] GECKELER K.E., ROSENBERG E., editors. Functional nanomaterials. Valencia, USA: American Scientific Publishers; 2006.

[14] HOSOKAWA, M.; NOGI, K.; NAITO, M.; YOKOYAMA, T. Nanoparticle technologyhandbook. Amsterdam, Netherlands: Elsevier; 2007. 
[15] USBERCO, J.; SALVADOR, Química. volume 2: físico-química, - 12 ed. reform. Saraiva, São Paulo, 2009.

[16] LOURENÇO, A.V.S.; KODAIRA, C.A.; SOUZA, E.R.; FELINTO, M.C.F.C.; MALTA, O.L.; BRITO, H.F. Preparation and photoluminescence properties of funcionalized silica materials incorporating europium complexes. Opt. Materials., v. 33, p. 1548-1552, 2011.

[17] LOURENÇO, A.V.S. Partículas de sílica funcionalizadas contendo complexos de $T R^{3+}$ para aplicação como marcadores em ensaios biológicos. Tese (doutorado). Universidade de São Paulo, São Paulo, 2010.

[18] THANH, N.T.K.; GREEN, L.A.W. Functionalisation of nanoparticles for biomedical application. Nano Today, v.5, p.213-230, 2010.

[19] TAYLOR, I.; HOWARD, A.G. Measurement of primary amine groups on surface-modified and their role in metal binding. Anal. Chim. Acta.v.271, p.7784, 1993.

[20] PIRES, A.M; SERRA, O.A.; DAVOLOS, M.R.J. Alloys Compd., 374, 182, 2004.

[21] ALVINO, K.C.L.; GElAMOS, J.P.; SERRA, O.A.; PIRES, A.M. Determinação de grupos $\mathrm{NH} 2$ em nanopartícula com conversão ascendente aminofuncionalizada. 30ํำ Reunião SBQ, São Paulo, 2007.

[22] ABBAS, K. A.; LICHTMAN, A.H. Imunologia Celular e Molecular. Quinta Edição, Elsevier Editora, 2005.

[23] EDWARS, R. Immunodiagnostics: A Pratical Approach. Oxford University Press, 256pp. Reino Unido, 1999. 
[24] YANG, W.; ZHANG, C.G.; QU, H.Y.; YANG, H.H.; XU, J.G. Novel fluoroscent sílica nanoparticles probe for ultrasensitive immunoassays.Anal.Chim.Acta, v.503, p.163-169, 2004.

[25] LOURENÇO, A.V.S.; KODAIRA, C.A.; SOUZA, E.R.; FELINTO, M.C.F.C.; MALTA, O.L.; BRITO, H.F. Preparation and photoluminescence properties of funcionalized silica materials incorporating europium complexes. Opt. Materials., v. 33, p. 1548-1552, 2011.

[26] LYLE, S.J.; WITTS, A.D. A critical examination of some methods for the preparation of tris and tetrakis diketonates of europium (III). Inorg. Chim. Acta, v.5, p.481-484, 1971.

[27] VAZ, A.J.; TAKEI, K.; BUENO, E.C. Imunoensaios: Fundamentos e Aplicações. Ed. 1ํ Guanabara, 258-326, 2007. 


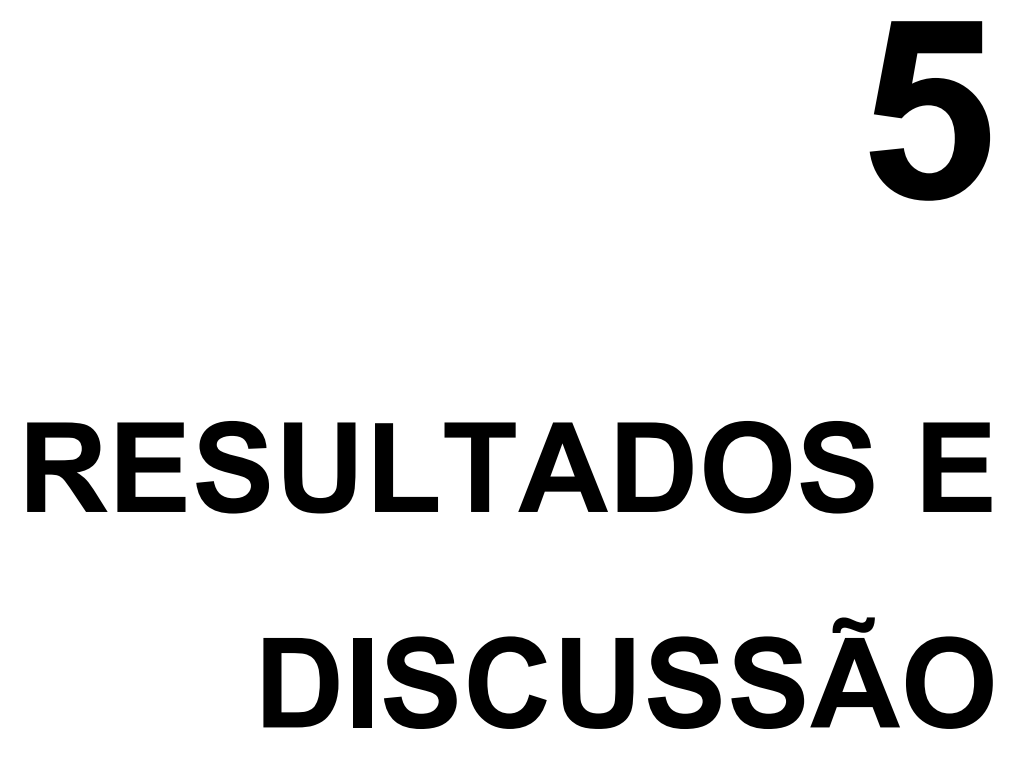




\section{RESULTADOS E DISCUSSÃO}

Neste capítulo serão apresentados e discutidos os resultados obtidos no desenvolvimento deste trabalho. Eles estão divididos em quatro partes que são: i) síntese e caracterização dos complexos de terras raras com alta eficiência de luminescência para dopagem nas matrizes poliméricas poli (metacrilato de metila) (PMMA) e poli(3-hidroxibutirato) (PHB); ii) obtenção das nanopartículas poliméricas e luminescentes e caracterizações destas; iii) funcionalização das nanopartículas poliméricas luminescentes com o espaçador 1,6 hexanodiamina para possibilitar a conjugação destas com a parte biológica (anticorpo, antígeno, DNA, entre outros) e, finalizando, iv) conjugação destas partículas com a parte biológica e desenvolvimento de um protocolo para o reconhecimento de estrogênios, neste caso o 17- $\beta$-estradiol pela técnica TR-FIA (Time Resolved Fluoroimunoassay).

\subsection{Síntese e caracterização dos complexos precursores, [TR( $\beta$ - dicetonatos) ${ }_{3}\left(\mathrm{H}_{2} \mathrm{O}\right)_{n}$ ] (onde $\beta$-dicetonatos = acac e tta; $\mathrm{TR}=\mathrm{Eu}^{3+}, \mathrm{Gd}^{3+}$ e $\mathrm{Tb}^{3+} ; \mathrm{n}=2,3$ )}

Neste trabalho foram sintetizados e caracterizados quatro complexos que serviram como precurssores dos complexos com ligantes auxiliares: $\operatorname{TR}(\beta-$ dicetonatos) ${ }_{3}\left(\mathrm{H}_{2} \mathrm{O}\right)_{n}$ ] (onde $\beta$-dicetonatos = acac e tta; $\mathrm{TR}=\mathrm{Eu}^{3+} \mathrm{Gd}^{3+} \mathrm{e} \mathrm{Tb}^{3+} ; \mathrm{n}=$ 2 e 3). Estes complexos foram sintetizados de acordo com método de síntese descrito na literatura: item 4.2.3 \{4.2.3.1, 4.2.3.2\} deste trabalho. Para os complexos com ligantes auxiliares: $\left[\operatorname{TR}\left(\beta\right.\right.$-dicetonatos) $\left.{ }_{3}(L)_{2}\right]$ (onde $\beta$-dicetonatos = acac e tta; $\mathrm{TR}=\mathrm{Eu}^{3+} \mathrm{Gd}^{3+}$ e $\mathrm{Tb}^{3+}$ ) foram utilizados dois ligantes fosfinóxidos e dois ligantes éteres coroas. A seguir descrever-se-ão as características qualitativas dos precussores e dos complexos de $\beta$-dicetonatos de terras raras. 
5.1.1 Características qualitativas do acetilacetonato de térbio e dos complexos de acetilacetonato de térbio com ligantes auxiliares

O acetilacetonato de térbio tri-hidratado $\left[\mathrm{TR}(\mathrm{acac})_{3}\left(\mathrm{H}_{2} \mathrm{O}\right)_{3}\right]$ (onde $\mathrm{TR}=\mathrm{Tb}^{3}$ ${ }^{+}$) foi obtido como um sólido cristalino branco. Este complexo apresentou solubilidade em solventes orgânicos comuns como acetona, álcool, metanol, clorofórmio etc., o que facilitou a reação de substituição das moléculas de $\mathrm{H}_{2} \mathrm{O}$ pelos ligantes orgânicos na síntese dos complexos hidrofóbicos. Os complexos contendo ligantes auxiliares orgânicos $\left[\mathrm{Tb}(\mathrm{acac})_{3}(\mathrm{~L})_{2}\right]$, onde $\mathrm{L}=\mathrm{TPPO}$, TOPO, DB18C6 e 18C6 foram sintetizados segundo item 4.2.4 (4.2.4.2) deste trabalho onde os complexos obtidos a partir da reação do aquocomplexo de Tb com os ligantes supracitados também apresentaram-se como sólidos cristalinos brancos.

A FIGURA 5.1 apresenta fotografias obtidas com um câmera digital registradas do complexo $\left[\mathrm{Tb}(\mathrm{acac})_{3}(\mathrm{TOPO})_{2}\right]$ sob luz ambiente e sob irradiação ultravioleta (366 nm), respectivamente, exibindo emissão de cor verde.
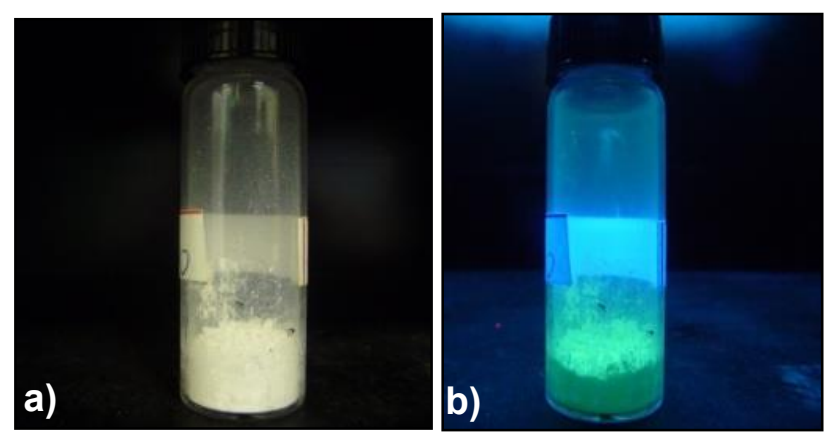

FIGURA 5.1 - Fotografias do complexo [Tb(acac $\left.)_{3}(\mathrm{TOPO})_{2}\right]$, a) sob luz ambiente; b) sob irradiação ultravioleta.

\subsubsection{Características qualitativas do tenoiltrifluoracetonato de európio e dos complexos de tenoiltrifluoracetonato de európio com ligantes auxiliares}


O complexo precursor $\left[\mathrm{TR}(\mathrm{tta})_{3}\left(\mathrm{H}_{2} \mathrm{O}\right)_{2}\right]\left(\right.$ onde $\left.\mathrm{TR}=\mathrm{Eu}^{3+}\right)$ foi obtido como sólido cristalino amarelo-alaranjado. A solubilidade deste complexo também se dá em solventes comuns como acetona, álcool, metanol, clorofórmio etc, facilitando a reação de substituição das $\mathrm{H}_{2} \mathrm{O}$ pelos ligantes orgânicos auxiliares. Todos os complexos contendo os ligantes auxiliares foram obtidos como sólidos cristalinos amarelados, exceto o complexo contendo o ligante auxiliar TOPO: $\left[\mathrm{Eu}(\mathrm{tta})_{3}(\mathrm{TOPO})_{2}\right]$, que foi obtido como substância líquida pastosa de cor amarelo-alaranjado, com elevada intensidade luminescente quando submetido à irradiação ultravioleta (366 nm), como mostram as fotografias obtidas com uma câmera digital (FIG. 5.2).
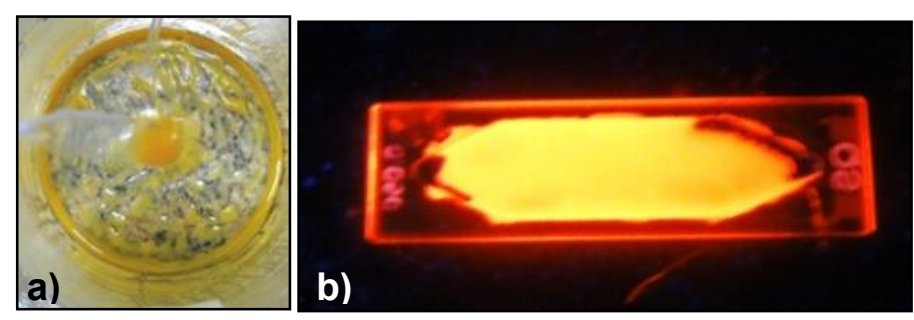

FIGURA 5.2 - Fotografias do complexo $\left[\mathrm{Eu}(\mathrm{tta})_{3}(\mathrm{TOPO})_{2}\right]$, a) sob luz ambiente; b) sob irradiação ultravioleta.

\subsubsection{Características qualitativas do tenoiltrifluoracetonato e acetilacetonato de gadolínio e dos complexos de tenoiltrifluoracetonato e acetilacetonato de gadolínio com ligantes auxiliares}

Os complexos [TR $\left.(\mathrm{acac})_{3}\left(\mathrm{H}_{2} \mathrm{O}\right)_{3}\right]$ e $\left[\mathrm{TR}(\mathrm{tta})_{3}\left(\mathrm{H}_{2} \mathrm{O}\right)_{2}\right.$ ] (onde $\mathrm{TR}=\mathrm{Gd}^{3+}$ ) foram obtidos como sólidos cristalinos brancos. A solubilização destes complexos, como nos demais lantanídeos estudados, dá-se em solventes comuns como acetona, álcool, metanol, clorofórmio etc. Os complexos resultantes são obtidos como sólidos cristalinos brancos.

O complexo contendo o ligante auxiliar TOPO foi obtido em estado líquido pastoso, de cor amarelo-alaranjado, muito semelhante à característica do mesmo complexo contendo o íon $\mathrm{Eu}^{3+}$ (item a da FIG. 5.2). 


\subsubsection{Caracterização estequiométrica}

\subsubsection{Complexos $\beta$-dicetonatos de terras raras hidratados $\left(\operatorname{TR}^{3+}(\beta\right.$ - dicetonatos $)_{3}\left(\mathrm{H}_{2} \mathrm{O}\right)_{x}$ e $\beta$-dicetonatos de terras raras com ligantes auxiliares $\left[\mathrm{TR}^{3+}(\beta \text {-dicetonatos })_{3}(\mathrm{~L})_{\mathrm{x}}\right]$}

Os dados de análise elementar de carbono, hidrogênio e enxofre $(C, H$, S) e da titulação complexométrica (TAB. 5.1) para os íons terras raras mostram que os complexos sintetizados e utilizados neste trabalho como dopantes possuem estequiometria $\left[\mathrm{TR}^{3+}(\beta \text {-dicetonatos })_{3}\left(\mathrm{H}_{2} \mathrm{O}\right)_{x}\right]$, em que $\mathrm{TR}^{3+}=\mathrm{Tb}^{3+}, \mathrm{Eu}^{3+}$ e $\mathrm{Gd}^{3+} ; \beta$-dicetonatos $=$ acac $^{-}$, tta', e $\mathrm{x}=3$ e 2, para 0 acac e tta', respectivamente.

O número variável da molécula água de coordenação nos complexos com os ligantes é uma consequência das estruturas de complexos de $\beta$ dicetonatos acac e tta'. O ligante acac é o que apresenta os grupos orgânicos substituintes menores, levando a um menor impedimento estérico em torno do íon terra rara, permitindo assim a acomodação de maior número de moléculas de água ${ }^{[1]}$.

Devido à insolubilidade em água dos complexos contendo terras raras, a alternativa encontrada para utilizar a titulação com EDTA foi solubilizar os complexos de terras raras em $\mathrm{HNO}_{3}$ (ácido nítrico) para protonação dos grupos bidentados dos ligantes $\beta$-dicetonatos ( $\mathrm{acac}^{-}$e tta) por meio do abaixamento do $\mathrm{pH}$ a aproximadamente 1, provocando a lise (quebra) do complexo. Desta forma, foi possível determinar quantitativamente a percentagem de íons $\mathrm{TR}^{3+}$ existentes em cada complexo. 
TABELA 5.1 - Análise elementar de $\mathrm{C}, \mathrm{H}, \mathrm{S}$ e titulação complexométrica de $\mathrm{TR}^{3+}$.

\begin{tabular}{|c|c|c|c|c|c|c|c|c|}
\hline \multirow{2}{*}{ Complexo } & \multicolumn{2}{|c|}{$\mathrm{C}(\%)$} & \multicolumn{2}{|c|}{$H(\%)$} & \multicolumn{2}{|c|}{$S(\%)$} & \multicolumn{2}{|c|}{$\operatorname{TR}(\%)$} \\
\hline & Cal. & Exp. & Cal. & Exp. & Cal. & Exp. & Cal. & Exp. \\
\hline PHB & 55,96 & 45,97 & 6,32 & 6,64 & & & - & - \\
\hline PMMA & 59,21 & 64,59 & 8,05 & 7,78 & & & - & - \\
\hline $\mathrm{Eu}(\mathrm{tta})_{3}\left(\mathrm{H}_{2} \mathrm{O}\right)_{2}$ & 33,85 & 33,50 & 1,89 & 1,90 & - & - & 17,85 & 17,78 \\
\hline $\mathrm{Eu}(\mathrm{tta})_{3}(\mathrm{TPPO})_{2}$ & 54,32 & 54,46 & 3,94 & 3,07 & 6,59 & 6,52 & 10,41 & 10,22 \\
\hline $\mathrm{Eu}(\mathrm{tta})_{3}(\mathrm{TOPO})_{2}$ & 55,90 & 55,64 & 7,76 & 7,24 & 5,74 & 5,71 & 9,07 & 9,05 \\
\hline $\mathrm{Eu}(\mathrm{tta})_{3}(\mathrm{DB} 18 \mathrm{C} 6)_{2}\left(\mathrm{H}_{2} \mathrm{O}\right)_{2}$ & 50,66 & 51,52 & 4,80 & 4,79 & 5,80 & 5,82 & 9,16 & 9,53 \\
\hline $\mathrm{Eu}(\mathrm{tta})_{3}(18 \mathrm{C} 6)_{2}$ & 45,31 & 44,63 & 5,28 & 5,23 & 6,72 & 6,70 & 10,62 & 10,68 \\
\hline $\mathrm{Gd}(\mathrm{tta})_{3}\left(\mathrm{H}_{2} \mathrm{O}\right)_{2}$ & 33,64 & 33,79 & 1,88 & 1,92 & & & 18,35 & 18,20 \\
\hline $\mathrm{Gd}(\mathrm{tta})_{3}(\mathrm{TPPO})_{2}$ & 54,13 & 53,23 & 3,92 & 3,96 & 6,57 & 6,15 & 10,74 & 11,02 \\
\hline $\mathrm{Gd}(\mathrm{tta})_{3}(\mathrm{TOPO})_{2}$ & 55,72 & 54,92 & 7,73 & 7,57 & 5,72 & 5,93 & 9,35 & 9,15 \\
\hline $\mathrm{Gd}(\mathrm{tta})_{3}(\mathrm{DB} 18 \mathrm{C} 6)_{2}$ & 51,62 & 50,32 & 4,64 & 4,32 & 5,91 & 6,18 & 9,65 & 9,83 \\
\hline $\mathrm{Gd}(\mathrm{tta})_{3}(18 \mathrm{C} 6)_{2}$ & 45,15 & 46,11 & 5,26 & 5,54 & 6,70 & 7,21 & 10,95 & 11,20 \\
\hline $\mathrm{Gd}(\mathrm{acac})_{3}\left(\mathrm{H}_{2} \mathrm{O}\right)_{3}$ & 35,42 & 35,79 & 5,35 & 5,75 & - & - & 30,92 & 30,79 \\
\hline Gd(acac) $)_{3}(\text { TPPO })_{2}$ & 60,40 & 60,10 & 5,37 & 5,82 & - & - & 15,51 & 15,23 \\
\hline $\mathrm{Gd}(\mathrm{acac})_{3}(\mathrm{TOPO})_{2}$ & 60,91 & 61,13 & $\begin{array}{c}10,2 \\
2\end{array}$ & $\begin{array}{c}10,8 \\
5\end{array}$ & - & - & 13,07 & 12,94 \\
\hline $\mathrm{Gd}(\mathrm{acac})_{3}(\mathrm{DB} 18 \mathrm{C} 6)_{2}$ & 56,06 & 55,02 & 6,16 & 6,36 & - & - & 13,34 & 13,61 \\
\hline $\mathrm{Gd}(\mathrm{acac})_{3}(18 \mathrm{C} 6)_{2}$ & 47,50 & 47,00 & 7,36 & 7,16 & - & - & 15,94 & 16,24 \\
\hline $\mathrm{Tb}(\mathrm{acac})_{3}\left(\mathrm{H}_{2} \mathrm{O}\right)_{3}$ & 35,31 & 34,98 & 5,33 & 5,23 & - & - & 31,14 & 31,45 \\
\hline $\mathrm{Tb}(\mathrm{acac})_{3}(\mathrm{TPPO})_{2}\left(\mathrm{H}_{2} \mathrm{O}\right)$ & 59,25 & 58,72 & 5,46 & 5,49 & - & - & 15,37 & 14,96 \\
\hline $\mathrm{Tb}(\mathrm{acac})_{3}(\mathrm{TOPO})_{2}$ & 63,83 & 63,72 & $\begin{array}{c}10,5 \\
7\end{array}$ & $\begin{array}{c}11,1 \\
9\end{array}$ & - & - & 13,19 & 13,26 \\
\hline $\mathrm{Tb}(\mathrm{acac})_{3}(\mathrm{DB} 18 \mathrm{C} 6)_{2}\left(\mathrm{H}_{2} \mathrm{O}\right)_{2}$ & 54,32 & 55,38 & 6,30 & 6,35 & - & - & 13,07 & 13,18 \\
\hline
\end{tabular}




\subsubsection{Espectroscopia de infravermelho com transformada de Fourrier (FTIR) dos complexos de terras raras estudados}

A espectroscopia de absorção na região do infravermelho (espectroscopia IV) é uma ferramenta útil para a compreensão do comportamento vibracional molecular. Tal técnica vem sendo amplamente utilizada qualitativamente na determinação estrutural de substâncias e na quantificação de um ou vários constituintes em misturas complexas. A espectroscopia IV relaciona-se aos movimentos de torção, rotação e vibração dos átomos de uma molécula ${ }^{[2,3]}$. Na interação da radiação infravermelha com a molécula, parte desta radiação é absorvida e movimentos característicos de grupos funcionais são detectados para determinados comprimentos de onda, que envolvem a modificação no momento de dipolo ${ }^{[2,3]}$.

Para a caracterização de compostos de coordenação, este estudo se fundamenta nas alterações das freqüências de absorção tais como: deslocamento, alargamento, desdobramento e número de bandas ${ }^{[4]}$. Geralmente a interpretação dos dados espectrais fornece informação a respeito da coordenação do ligante ao centro metálico e quais átomos participam da ligação. Na coordenação das espécies, às vezes, pode-se determinar como estes átomos estão coordenados, se é mono, bi, tridentado ou formando ponte entre centros metálicos. Ademais, é possível verificar a presença de água ou de outro solvente na estrutura dos compostos através das bandas características destas espécies ${ }^{[5]}$.

Espectros de infravermelho dos complexos de terras raras estudados neste trabalho foram registrados na região de 4000 a $400 \mathrm{~cm}^{-1}$ e à temperatura ambiente ( 298 K). Os símbolos que aparecem neste estudo são identificados como: $v$ (estiramento), $\delta$ (deformação angular), $s$ (simétrico) e as (assimétrico).

Os espectros vibracionais na região do infravermelho fornecem valiosas informações a respeito da natureza dos grupos carbonílicos dos $\beta$-dicetonatos e macrocíclicos e/ou fosfinóxidos ligados aos íons metálicos nos compostos de coordenação ${ }^{[6,7]}$. As principais bandas envolvidas nos estudos da interação $\beta$ dicetonatos - íon metálico são aquelas associadas às frequências de estiramento $v_{\mathrm{s}}(\mathrm{C}=\mathrm{O})\left(\sim 1600 \mathrm{~cm}^{-1}\right), v_{\mathrm{ass}}(\mathrm{C}=\mathrm{O})\left(\sim 1400 \mathrm{~cm}^{-1}\right), v_{\mathrm{s}}(\mathrm{C}=\mathrm{C})(1531$ 
$\left.\mathrm{cm}^{-1}\right)$ e $v(\mathrm{O}-\mathrm{Mn}+)\left(\sim 450 \mathrm{~cm}^{-1}\right){ }^{[8]}$. O comportamento dos modos vibracionais $v(\mathrm{C}=\mathrm{O})$ e $v(\mathrm{C}=\mathrm{C})$ nos $\beta$-dicetonatos foram intensivamente estudados por Holtzclaw e Collman ${ }^{[9]}$, que sugeriram que o caráter de ligação dupla $C=C$ no anel quelante dos $\beta$-dicetonatos é relativamente fraca e que a freqüência de absorção do grupo carbonila está relacionada com:

i) A densidade eletrônica relativa das ligações $s$, que são geralmente controladas pelos grupos substituintes ligados aos carbonos carbonílicos;

ii) A massa dos grupos substituintes ligados aos grupos carbonílicos;

iii) A interação dos grupos carbonílicos com os orbitais do íon metálico.

Nakamoto e colaboradores ${ }^{[10]}$ fizeram um estudo comparativo entre os espectros dos complexos acetilacetonato e seus derivados contendo os grupos substituintes alquil, aril e fluorometil. Nesse estudo, foi observado que as substituições do grupo metil no acetilacetonato por grupos trifluorometil, resultando o trifluoro e hexafluoroacetilacetonatos, causam deslocamentos das freqüências de estiramento $C=O$ e $C=C$ para regiões de freqüências maiores e M-O no sentido contrário. Esse comportamento tem sido explicado com base no efeito indutor negativo (receptor de elétrons) do grupo $\mathrm{CF}_{3}$ que faz com que haja uma diminuição na densidade eletrônica na ligação $\mathrm{M}-\mathrm{O}$ e um aumento na densidade envolvendo o grupo quelante do dicetonato. Quando os grupos $\mathrm{CH}_{3}$ foram substituídos por grupos fenilas houve um aumento nos estiramentos $M$ $O$, no entanto, foi observada uma irregularidade nas freqüências de estiramento $\mathrm{C}=\mathrm{O}$ e $\mathrm{C}=\mathrm{C}$. Isto se deve às interações mesoméricas do grupo fenila com o anel quelante quase-aromático, que conduz a um deslocamento nos elétrons $p$ do anel quelante de acordo com as estruturas mostradas na FIGURA 5.3. As estruturas II e III, que apresentam uma carga negativa sobre $o$ átomo de oxigênio, são mais significativas nos complexos de íons metálicos que pode formar ligações $p$ com o $\beta$-dicetonato, conduzindo a um aumento na freqüência de estiramento da ligação $\mathrm{MO}$ e um efeito contrário para a ligação $\mathrm{C}=\mathrm{O}$. Por outro lado, a estrutura I tem maior contribuição nos complexos com íons de metais alcalinos terrosos, uma vez que estes íons não formam ligações 
p e, neste caso, são esperados deslocamentos das freqüências das ligações $\mathrm{M}-\mathrm{O}$ e $\mathrm{C}=\mathrm{O}$ para energias maiores.

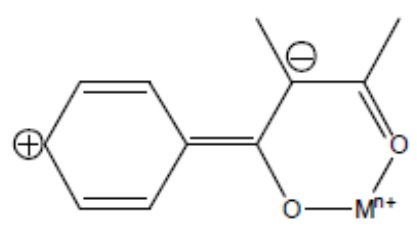

I

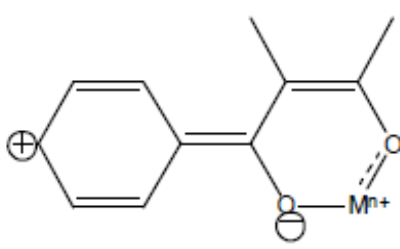

II

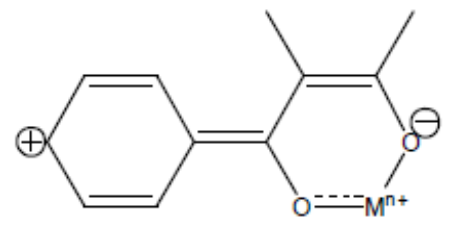

III

FIGURA 5.3 - Efeito mesoiônico do grupo fenila nos complexos com $\beta$ dicetonatos ${ }^{[10]}$

Os espectros de infravermelho dos ligantes macrocíclicos apresentam modos de vibração do grupamento $v(\mathrm{C}-\mathrm{O})$ em $1105 \mathrm{~cm}^{-1} v(\mathrm{C}-\mathrm{O}-\mathrm{C})$ em $1635 \mathrm{~cm}^{-}$ 1. O modo de vibração do éter etileno é deslocado para freqüências mais baixas de 1635 para $1615 \mathrm{~cm}^{-1}$ em complexos contendo os éteres coroas.

Oxidos de fosfinas terciárias coordenam-se a metais por meio de seus átomos de oxigênio. $\mathrm{O}$ estiramento $v(\mathrm{P}=\mathrm{O})$ do óxido de trifenilfosfina em 1193 $\mathrm{cm}^{-1}$ é deslocado aproximadamente $35 \mathrm{~cm}^{-1}$ para baixa frequência quando coordenado por exemplo ao $\mathrm{Zn}^{2+}$.

5.1.5.1 Espectros de infravermelho dos complexos $\beta$-dicetonato de térbio e gadolínio com ligantes auxiliares $\left[\operatorname{TR}^{3+}(\beta \text {-dicetonato })_{3}(L)_{x}\right]$ (onde $\beta$ dicetonato= acac e $L=18 C 6$, DB18C6, TOPO e TPPO).

A ligação dos íons $\mathrm{Tb}^{3+}$ e $\mathrm{Gd}^{3+}$ com o ligante acac para formação do complexo [TR(acac $\left.)_{3}\left(\mathrm{H}_{2} \mathrm{O}_{2}\right)\right]$ pode ser confirmada pelas bandas presentes em $\sim 1520 \mathrm{~cm}^{-1}, \sim 1590 \mathrm{~cm}^{-1} \mathrm{e} \sim 1515 \mathrm{~cm}^{-1}$, bandas atribuídas ao estiramento $v_{a s}$ $\left(\mathrm{COO}^{-}\right), \mathrm{v}_{\operatorname{sim}}\left(\mathrm{COO}^{-}\right)$e vs $(\mathrm{C}=\mathrm{C})$. Nos complexos com ligantes auxiliares estas bandas estão localizadas em 1510, 1595 e $1520 \mathrm{~cm}^{-1}$.

A banda principal observada nos espectros de infravermelho dos complexos de Térbio com éter coroa (DB18C6 e 18C6) é a deformação angular 
SC-O-C (FIG. 5.4) que, para o ligante livre, aparece em $1100 \mathrm{~cm}^{-1} \mathrm{e}$, neste trabalho, é deslocada para $\sim 1124 \mathrm{~cm}^{-1}$, indicando a interação do éter coroa com o íon metálico. Já para os compostos de gadolínio ela se desloca para $\sim 1130 \mathrm{~cm}^{-1}$ (FIG. 5.5).

Para os complexos de térbio contendo fosfinóxidos (TPPO e TOPO), duas bandas de estiramento $\mathrm{v}(\mathrm{P}=\mathrm{O})$ foram observadas na região de 1201-1190 $\mathrm{cm}^{-1}$ para TOPO e 1190-1167 $\mathrm{cm}^{-1}$ para TPPO (FIG. 5.4). Esse comportamento sugere a coordenação dos ligantes fofinóxidos aos íons lantanídeos através do átomo de oxigênio do grupo $P=O$. A TABELA 5.2 apresenta a atribuição das frequências $\left(\mathrm{cm}^{-1}\right)$ dos principais modos vibracionais dos complexos estudados.

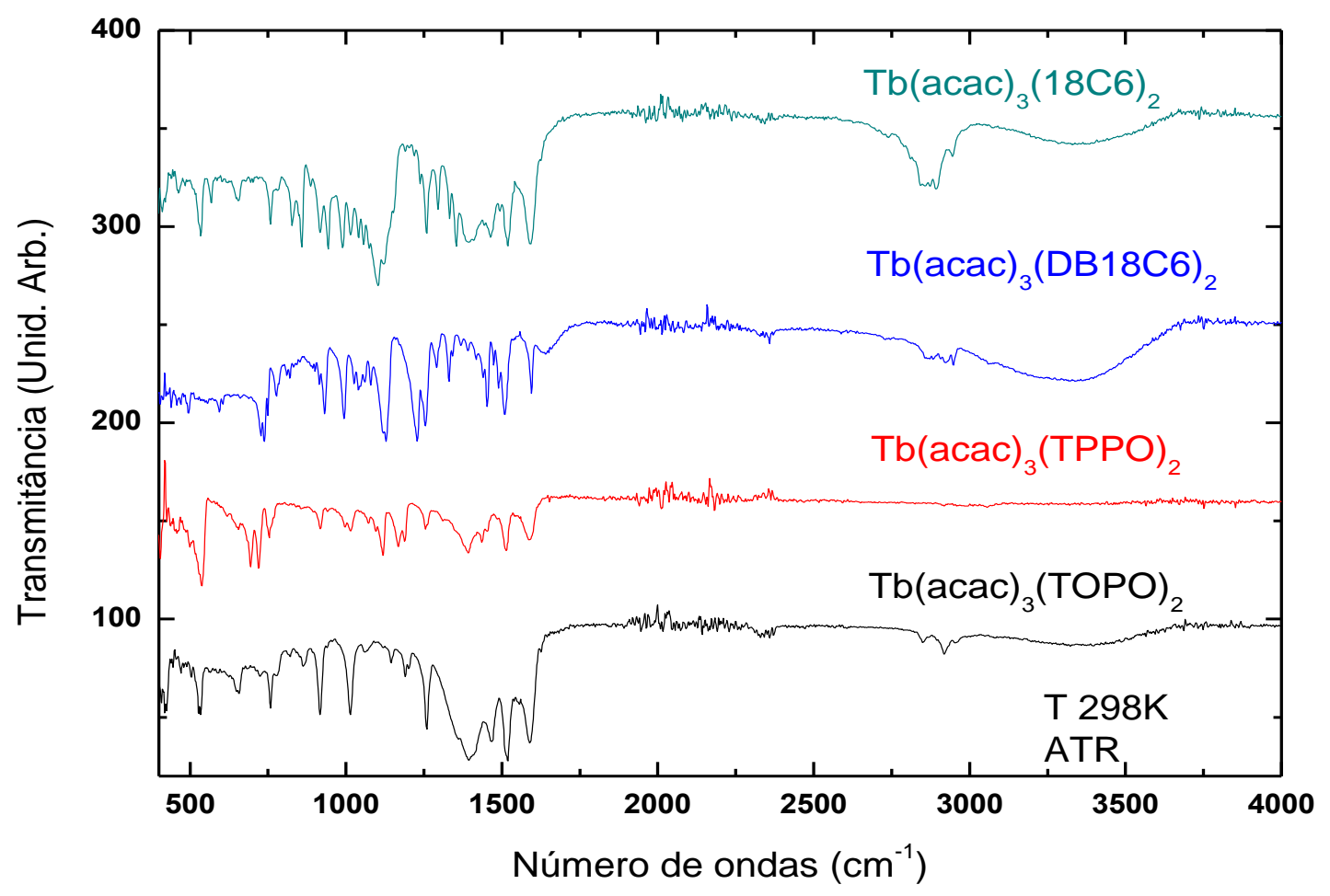

FIGURA 5.4 - Espectros de infravermelho dos complexos $\left[\mathrm{Tb}(\mathrm{acac})_{3}(\mathrm{~L})_{2}\right]$ (onde $\mathrm{L}=18 \mathrm{C} 6$, DB18C6, TPPO e TOPO) na região de 400 a $4000 \mathrm{~cm}^{-1}$ estudados neste trabalho. 


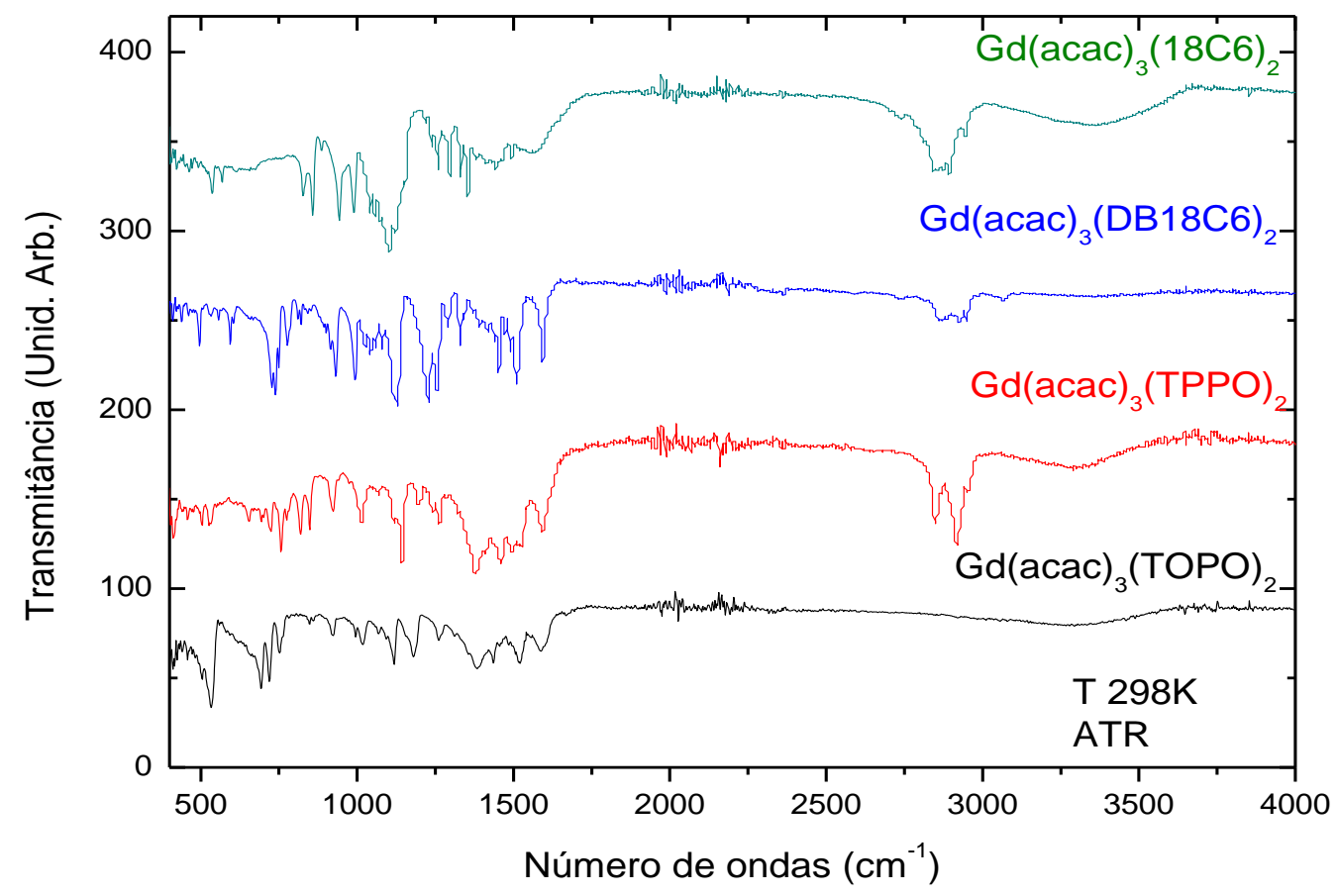

FIGURA 5.5 - Espectros de infravermelho dos complexos de $\left[\mathrm{Gd}(\mathrm{acac})_{3}(\mathrm{~L})_{2}\right]$ (onde $\mathrm{L}=18 \mathrm{C} 6$, DB18C6, TPPO e TOPO) na região de 400 a $4000 \mathrm{~cm}^{-1}$ estudados nesse trabalho.

TABELA 5.2 - Atribuição das frequências $\left(\mathrm{cm}^{-1}\right)$ dos principais modos vibracionais dos complexos de acac de térbio e gadolínio estudados.

\begin{tabular}{|c|c|c|c|c|}
\hline Complexo & $\mathrm{v}_{a s}\left(\mathrm{COO}^{-}\right)$ & $\mathrm{v}_{s}\left(\mathrm{COO}^{-}\right)$ & $\delta C-O-C$ & $v(P=0)$ \\
\hline $\mathrm{Tb}(\mathrm{acac})_{3}(\mathrm{TPPO})_{2}$ & 1595 & 1517 & - & $1190-1167$ \\
\hline $\mathrm{Tb}(\mathrm{acac})_{3}(\mathrm{TOPO})_{2}$ & 1590 & 1511 & - & $1200-1190$ \\
\hline $\mathrm{Tb}(\mathrm{acac})_{3}(\mathrm{DB} 18 \mathrm{C} 6)_{2}$ & 1596 & 1513 & 1124 & - \\
\hline $\mathrm{Tb}(\mathrm{acac})_{3}(18 \mathrm{C} 6)_{2}$ & 1592 & 1517 & 1124 & - \\
\hline $\mathrm{Gd}(\mathrm{acac})_{3}(\mathrm{TPPO})_{2}$ & 1590 & 1519 & - & 1178 \\
\hline $\mathrm{Gd}(\mathrm{acac})_{3}(\mathrm{TOPO})_{2}$ & 1591 & 1520 & - & 1190 \\
\hline $\mathrm{Gd}(\mathrm{acac})_{3}(\mathrm{DB} 18 \mathrm{C} 6)_{2}$ & 1590 & 1510 & 1130 & - \\
\hline $\mathrm{Gd}(\mathrm{acac})_{3}(18 \mathrm{C} 6)_{2}$ & 1570 & 1490 & 1130 & - \\
\hline
\end{tabular}


5.1.5.2 Espectros de infravermelho dos complexos $\beta$-dicetonato de európio e gadolínio com ligantes auxiliares $\left[\mathrm{TR}^{3+}(\beta \text {-dicetonato })_{3}(\mathrm{~L})_{\mathrm{x}}\right]$ (onde $\beta$-dicetonato= tta e $L=18 C 6$, DB18C6, TOPO e TPPO).

Nas FIGURAS 5.6 e 5.7 apresentam-se os espectros de infravermelho dos complexos de $\left[\mathrm{TR}^{3+}(\mathrm{tta})_{3}(\mathrm{~L})_{2}\right]$, onde $\mathrm{TR}^{3+}=\mathrm{Eu}^{3+}$ e $\mathrm{Gd}^{3+}$. Observam-se bandas atribuídas ao estiramento $\mathrm{vC}=\mathrm{O}$ do $\mathrm{tta}^{-}$em $\sim 1617 \mathrm{~cm}^{-1}$ que são desdobradas e deslocadas para região de menor energia indicando a formação do anel quelato. Estes espectros não apresentam a banda do estiramento simétrico $\left(v_{s} \mathrm{C}=\mathrm{O}\right)$ do grupo carbonil da dicetona. As bandas atribuídas ao estiramento $\mathrm{P}=\mathrm{O}$ para os complexos com ligantes auxiliares TOPO e TPPO aparecem deslocadas para $\sim 1133 \mathrm{~cm}^{-1}$ (TOPO) e para $\sim 1180 \mathrm{~cm}^{-1}$ (TPPO). Para os compostos com ligantes macrocíclicos, as bandas atribuídas à deformação angular $\delta$ C-O-C são observadas na região de 1130 e 1120 para os compostos de DB18C6 de Eu e Gd, respectivamente. A TABELA $\mathbf{5 . 3}$ apresenta a atribuição das frequências $\left(\mathrm{cm}^{-1}\right)$ dos principais modos vibracionais dos complexos estudados.

Os dados espectrais dos sistemas estudados corroboram com os dados obtidos na literatura gerados pelo nosso grupo de pesquisa e que se encontram publicados nas referências ${ }^{[11-19]}$. 


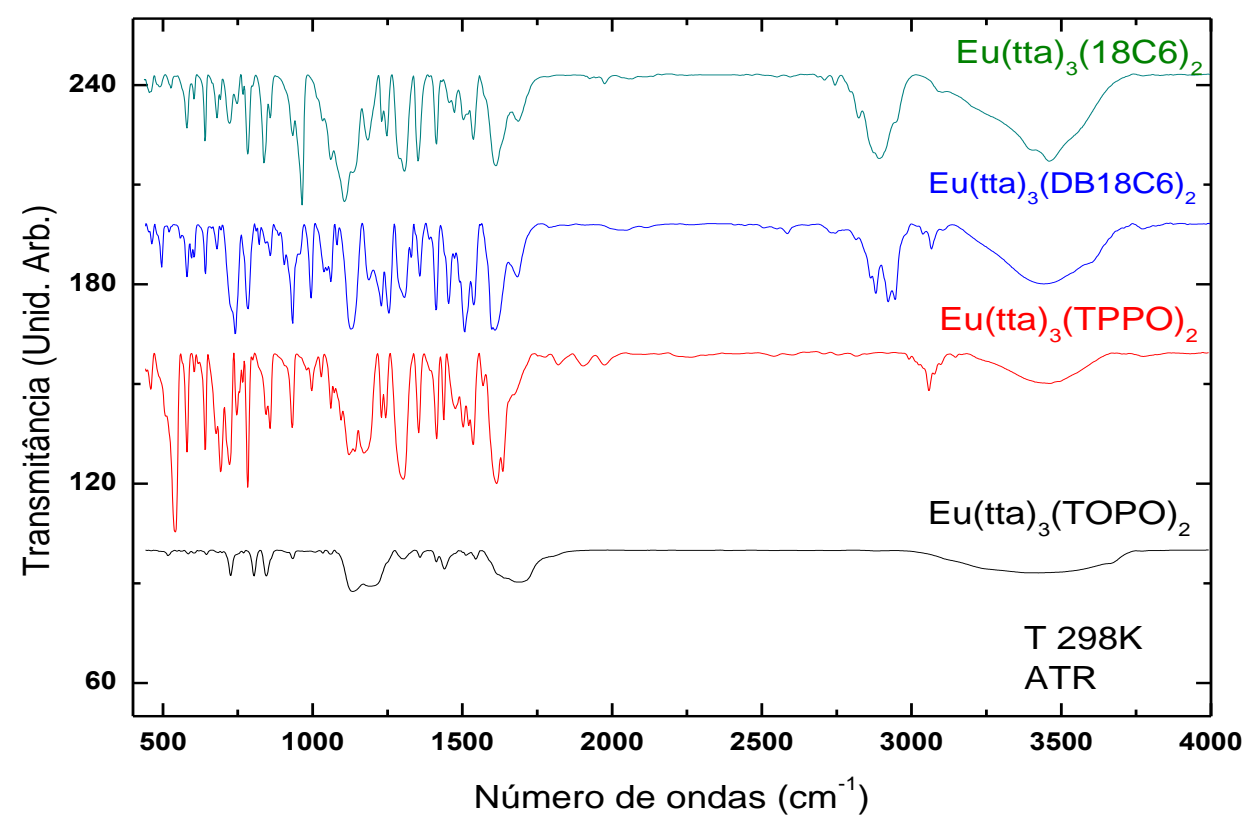

FIGURA 5.6 - Espectros de infravermelho dos complexos de $\left[\mathrm{Eu}(\mathrm{tta})_{3}(\mathrm{~L})_{2}\right]$ (onde $L=18 C 6$, DB18C6, TPPO e TOPO) na região de 400 a $4000 \mathrm{~cm}^{-1}$ estudados nesse trabalho.

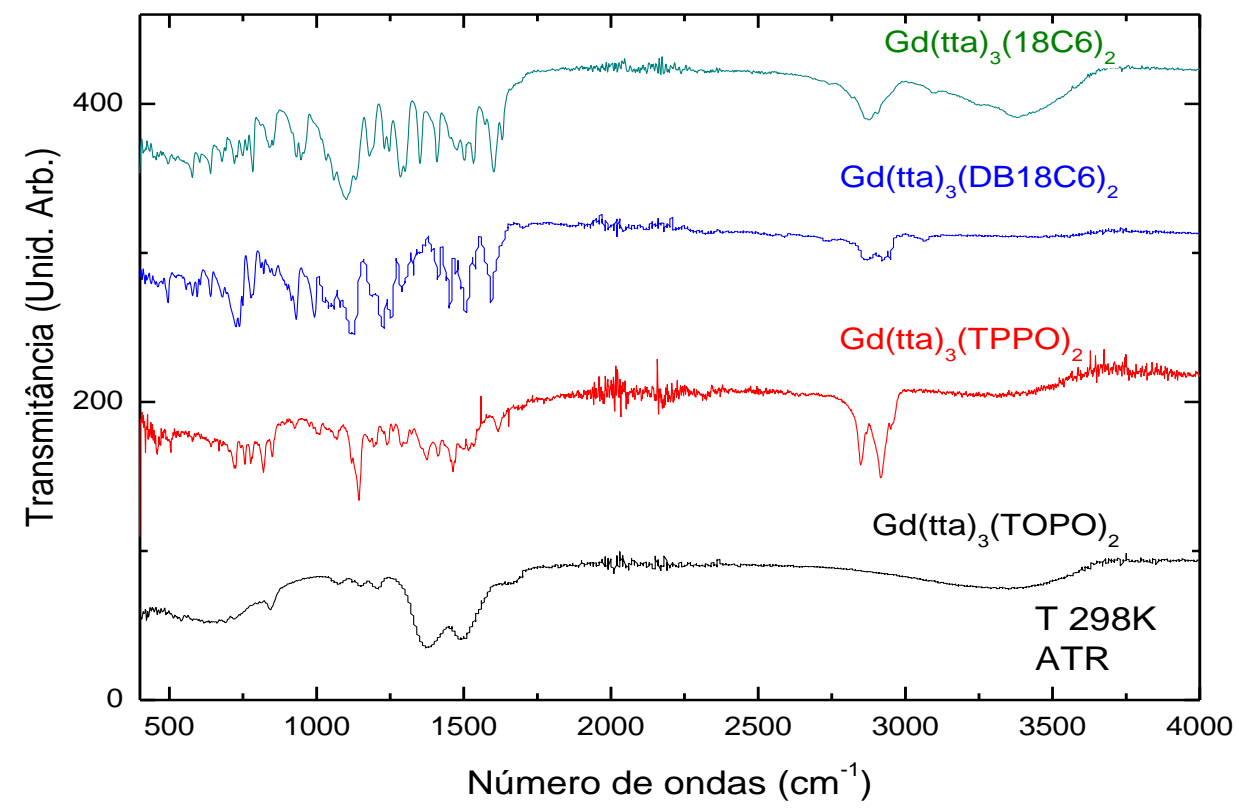

FIGURA 5.7 - Espectros de infravermelho dos complexos de $\left[\mathrm{Gd}(\mathrm{tta})_{3}(\mathrm{~L})_{2}\right]$ (onde $L=18 \mathrm{C} 6$, DB18C6, TPPO e TOPO) na região de 400 a $4000 \mathrm{~cm}^{-1}$ estudados nesse trabalho. 
TABELA 5.3 - Atribuição das frequências $\left(\mathrm{cm}^{-1}\right)$ dos principais modos vibracionais dos complexos contendo tta de európio e gadolínio estudados.

\begin{tabular}{|c|c|c|c|c|}
\hline Complexo & $\mathrm{v}_{a s}\left(\mathrm{COO}^{-}\right)$ & $\mathrm{v}_{s}\left(\mathrm{COO}^{-}\right)$ & $\delta \mathrm{C}-\mathrm{O}-\mathrm{C}$ & $v(P=0)$ \\
\hline $\mathrm{Eu}(\mathrm{tta})_{3}(\mathrm{TPPO})_{2}$ & 1612 & - & - & 1120 \\
\hline $\mathrm{Eu}(\mathrm{tta})_{3}(\mathrm{TOPO})_{2}$ & - & - & - & 1133 \\
\hline $\mathrm{Eu}(\mathrm{tta})_{3}(\mathrm{DB} 18 \mathrm{C} 6)_{2}$ & 1610 & - & 1130 & - \\
\hline $\mathrm{Eu}(\mathrm{tta})_{3}(18 \mathrm{C} 6)_{2}$ & 1612 & - & $\begin{array}{c}1055-1107- \\
1138\end{array}$ & - \\
\hline $\mathbf{G d}(\mathrm{tta})_{3}(\mathrm{TPPO})_{2}$ & - & - & 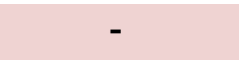 & 1370 \\
\hline $\mathrm{Gd}(\mathrm{tta})_{3}(\mathrm{TOPO})_{2}$ & 1617 & - & - & 1190 \\
\hline $\mathrm{Gd}(\mathrm{tta})_{3}(\mathrm{DB} 18 \mathrm{C} 6)_{2}$ & 1590 & - & 1120 & - \\
\hline $\mathrm{Gd}(\mathrm{tta})_{3}(18 \mathrm{C} 6)_{2}$ & 1600 & - & $\begin{array}{c}1130- \\
1100-1060\end{array}$ & - \\
\hline
\end{tabular}

\subsubsection{Análise Termogravimétrica (TG/DTG)}

A análise térmica compreende uma série de técnicas usadas na determinação de algumas propriedades de um material, quando este é submetido a um regime de temperatura controlada. Dentre as técnicas, existem algumas que merecem destaques quanto aos seus usos para estudos de compostos de coordenação: Termogravimetria (TG), Análise Térmica Diferencial (DTA) e Calorimetria Exploratória Diferencial (DSC). Neste trabalho, foi utilizada somente a primeira técnica e, portanto, será dada uma breve introdução sobre seus principais aspectos. Descrições mais detalhadas sobre as técnicas de análises térmicas podem ser encontradas nas referências ${ }^{[20-23]}$.

A termogravimetria (TG) é uma técnica utilizada para determinar a perda ou ganho de massa de uma amostra como função da temperatura e/ou do tempo.

As curvas obtidas em uma análise termogravimétrica pelo método dinâmico podem ser utilizadas na obtenção de dados para fins quantitativos, como por exemplo, em complexos, pode-se estimar a quantidade de ligante 
que é liberado em uma determinada etapa e, também, o resíduo procedente dessa etapa. Esses dados podem ser determinados com o auxílio da primeira derivada da curva TG, a DTG. A curva DTG fornece a perda de massa sofrida pelas amostras proporcional à área dos picos. Além disso, pela curva DTG, pode-se visualizar melhor o início e término de um processo de termodecomposição.

\subsubsection{Complexos $\left[\mathrm{TR}^{3+}(\beta \text {-dicetonato })_{3}(\mathrm{~L})_{2}\right]\left(\mathrm{TR}=\mathrm{Tb}^{3+} ; \beta\right.$-dicetonato $=$ acac; $L=T P P O$, TOPO, DB18C6 e 18C6)}

Nas FIGURAS $\quad \mathbf{5 . 8}$ a $\quad \mathbf{5 . 9}$ estão apresentadas as curvas termogravimétricas e termogravimétricas diferenciais, TG/DTG, das amostras dos complexos de acac de térbio com ligantes auxiliares TPPO, TOPO, DB18C6 e 18C6 respectivamente, obtidas em atmosfera inerte de nitrogênio $\left(\mathrm{N}_{2}\right)$. As curvas TGs dos complexos apresentam diferentes perfis de decomposição. O complexo $\left[\mathrm{Tb}(\mathrm{acac})_{3}(\mathrm{TPPO})_{2}\right]$ apresenta temperatura de decomposição inicial $\left(T_{\text {onset }}=T_{1}\right)$ de $183^{\circ} \mathrm{C}$ (FIG. 5.8). Os resultados apresentam perda de massa na região de $35 \stackrel{\circ}{\circ}$, intervalo que compreende a faixa determinada como um evento de desidratação do complexo, onde água de higroscopicidade são eliminadas. Outro evento também foi observado começando em $230^{\circ} \mathrm{C}$ referente à perda dos ligantes tta e TPPO. O complexo mantém-se instável com perdas de massa conforme o aumento da temperatura até a temperatura máxima da análise que é de $1000^{\circ} \mathrm{C}$.

Na FIGURA 5.9 são apresentadas as curvas TG/DTG da amostra do complexo de acac de térbio com o ligante auxiliar TOPO, apresentando $T_{1}$ de $144 \stackrel{\circ}{\circ}$. Os resultados também apresentaram pequena perda de massa na região de $38{ }^{\circ} \mathrm{C}$, reconhecido como evento de desidratação do complexo. A partir de $200 \stackrel{\circ}{\circ}$ há perda de massa que compreende a perda dos ligantes acac e TOPO, o complexo mantém-se instável com perdas de massa conforme o aumento da temperatura até a temperatura máxima da análise que é de 1000 $\stackrel{\circ}{ } \mathrm{C}$.

Na FIGURA 5.10 são apresentadas as curvas TG/DTG da amostra do complexo de acac de térbio com o ligante auxiliar DB18C6, apresentando $T_{1}$ de 


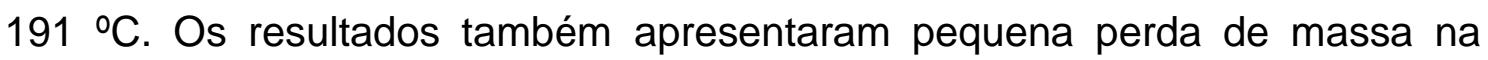
região de $35 \stackrel{\circ}{\circ}$, reconhecido como evento de desidratação do complexo. A partir de $200{ }^{\circ} \mathrm{C}$ há perda de massa que compreende a perda dos ligantes acac e DB18C6, o complexo mantém-se instável conforme o aumento da temperatura até a temperatura de $752^{\circ} \mathrm{C}$, apresentando outra perda de massa referente ao éter coroa após esta temperatura até a temperatura máxima (1000 $\left.{ }^{\circ} \mathrm{C}\right)$ da análise.

As curvas TG/DTG do complexo de acac de térbio com o ligante auxiliar 18C6 estão apresentadas na FIGURA 5.11. As curvas apresentam $T_{1}=$ $108 \stackrel{\circ}{ } \mathrm{C}$. Os resultados também apresentaram pequena perda de massa na região de $40{ }^{\circ} \mathrm{C}$, reconhecido como evento de desidratação do complexo. A partir de $200{ }^{\circ} \mathrm{C}$ há perda de massa que compreende a perda dos ligantes acac. As curvas apresentaram outra perda em $270^{\circ} \mathrm{C}$ atribuída ao éter coroa e o complexo mantêm-se estável conforme o aumento da temperatura até a temperatura máxima $\left(100{ }^{\circ} \mathrm{C}\right)$ da análise.

A TABELA 5.4 resume os dados de comportamento de decomposição térmica dos complexos de térbio estudados. O complexo que apresentou menor perda de massa foi o $\left[\mathrm{Tb}(\mathrm{acac})_{3}(\mathrm{TPPO})_{2}\right]$ restando $57,25 \%$ de resíduo. 


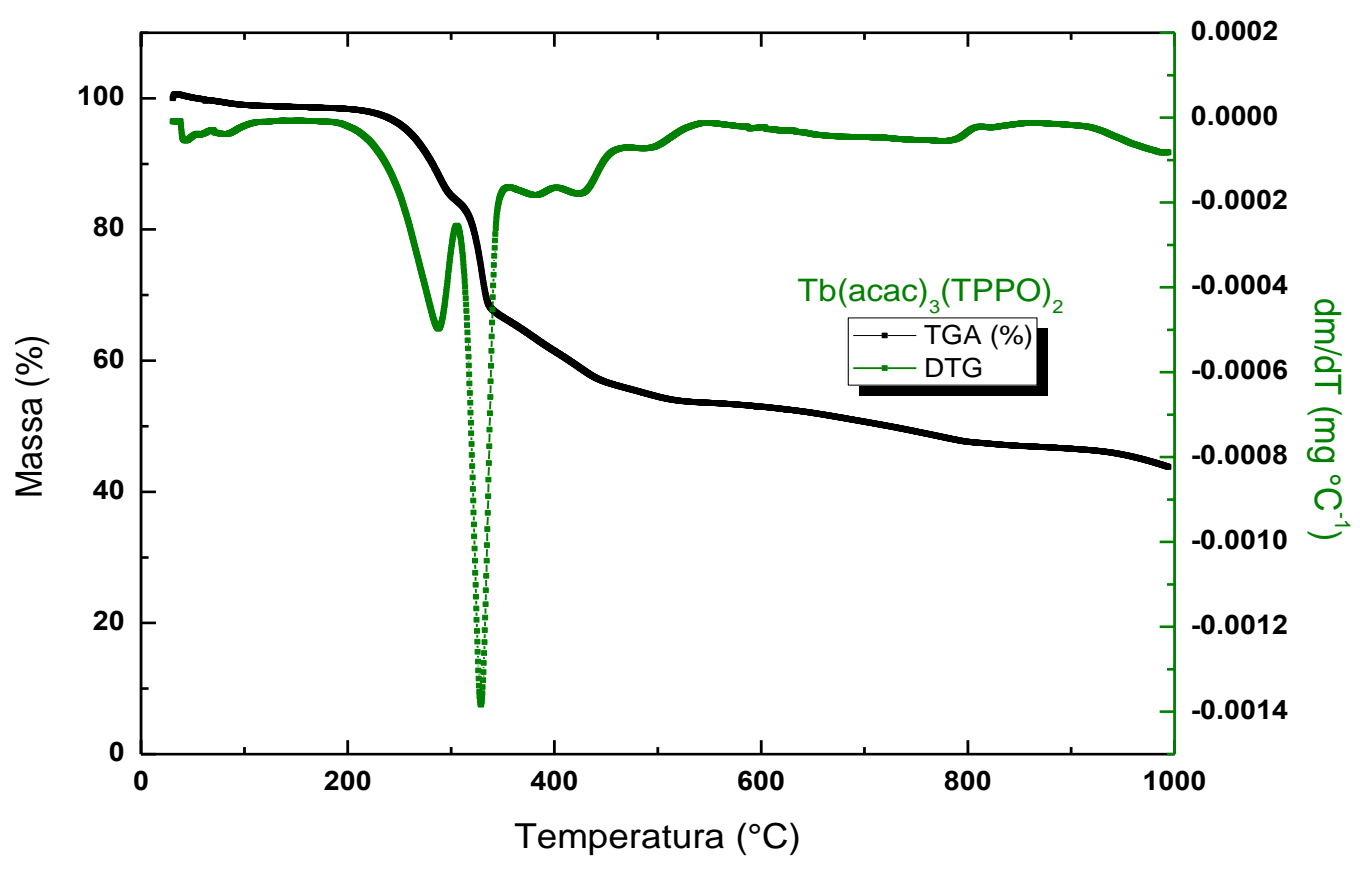

FIGURA 5.8 - Curvas TGA/DTGA registradas no intervalo de 0 a $1000 \stackrel{\circ}{\circ}$, sob atmosfera dinâmica de $\mathrm{N}_{2}$, do complexo $\left[\mathrm{Tb}(\mathrm{acac})_{3}(\mathrm{TPPO})_{2}\right]$.

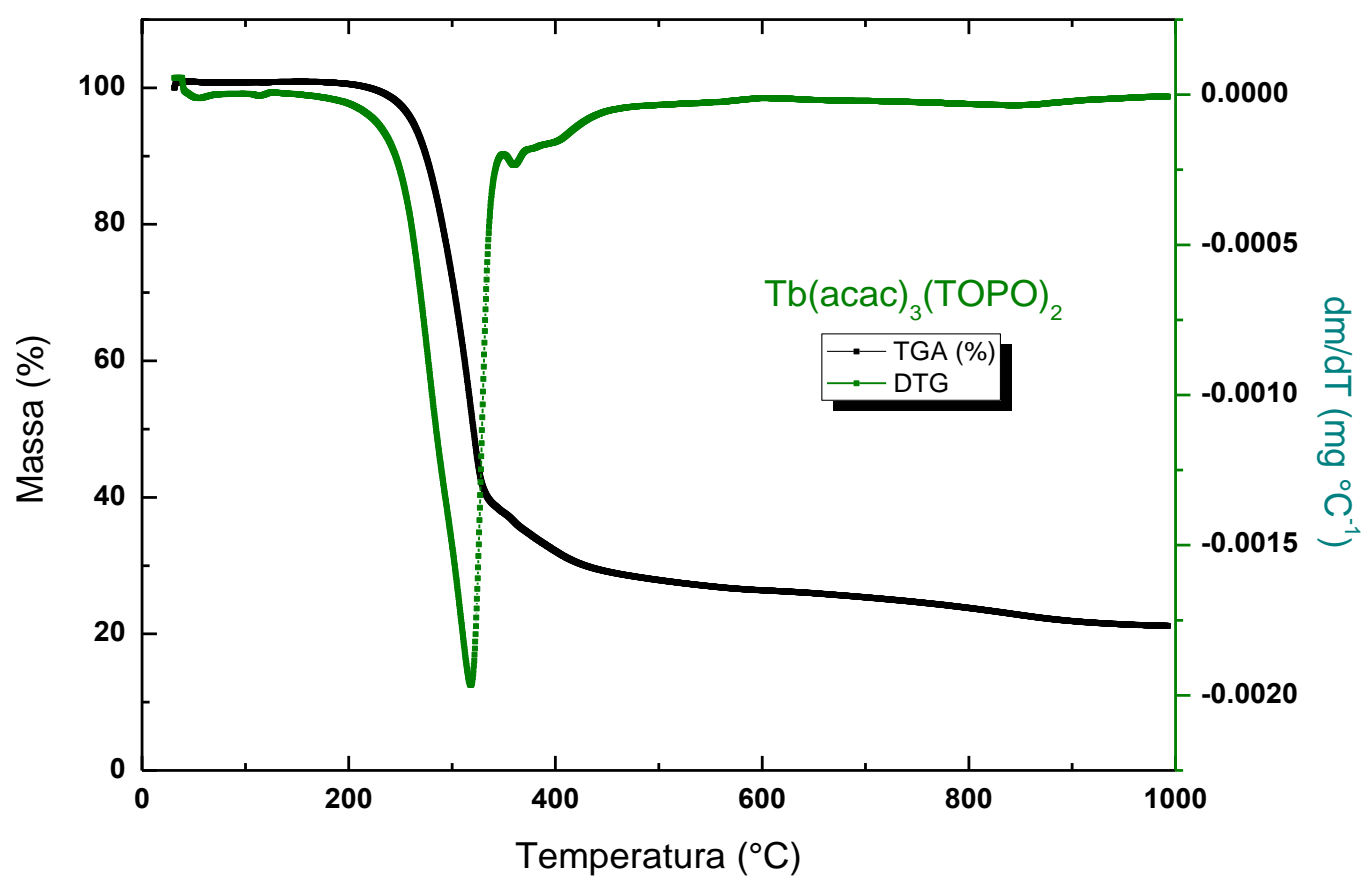

FIGURA 5.9 - Curvas TGA/DTG registradas no intervalo de 0 a $1000{ }^{\circ} \mathrm{C}$, sob atmosfera dinâmica de $\mathrm{N}_{2}$, do complexo [ $\mathrm{Tb}(\mathrm{acac})_{3}(\mathrm{TOPO})_{2}$ ]. 


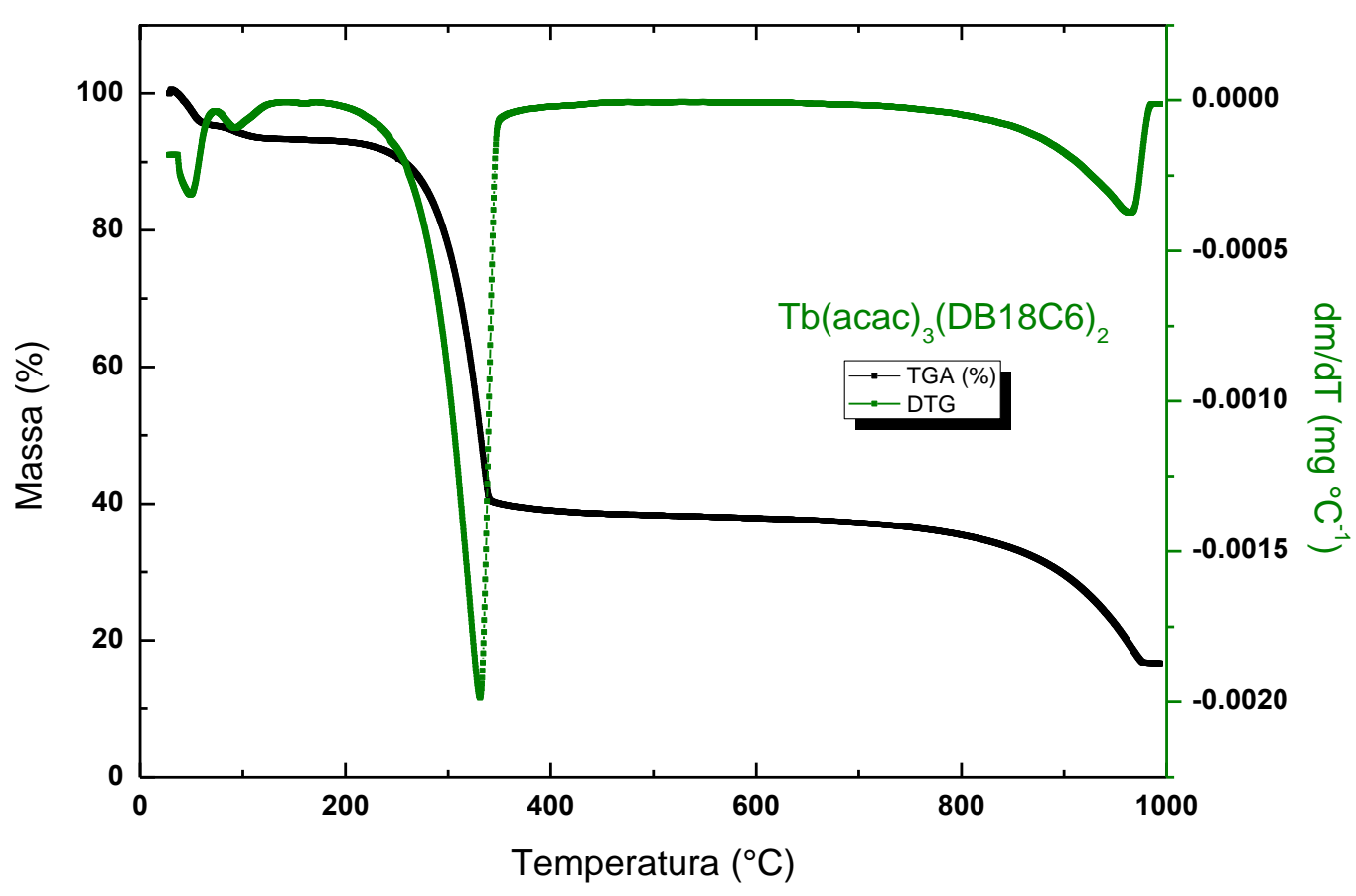

FIGURA 5.10 - Curvas TGA/DTG registradas no intervalo de 0 a $1000 \stackrel{\circ}{\circ}$, sob atmosfera dinâmica de $\mathrm{N}_{2}$, do complexo $\left[\mathrm{Tb}(\mathrm{acac})_{3}(\mathrm{DB} 18 \mathrm{C} 6)_{2}\right]$.

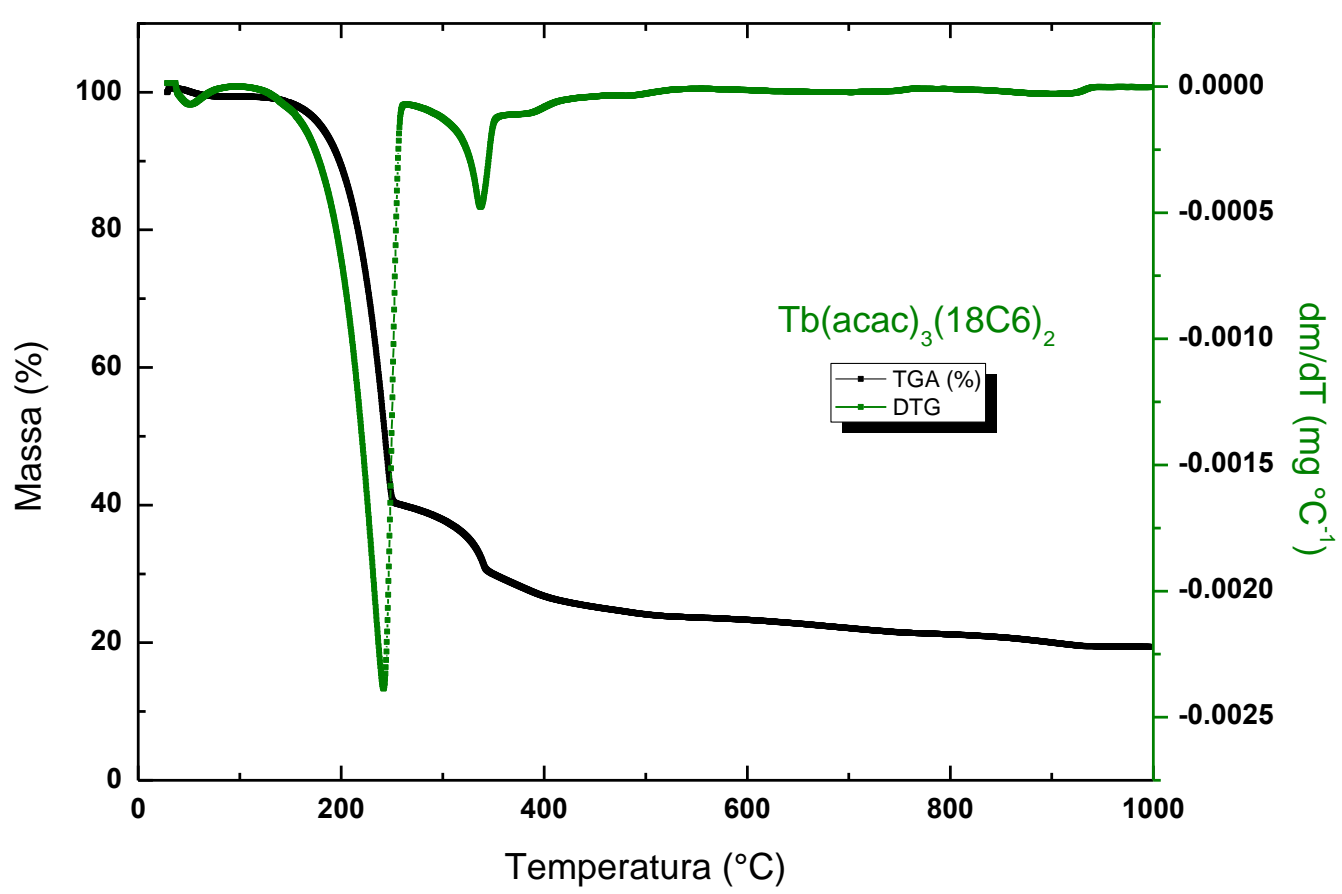

FIGURA 5.11 - Curvas TGA/DTG registradas no intervalo de 0 a $1000{ }^{\circ} \mathrm{C}$, sob atmosfera dinâmica de $\mathrm{N}_{2}$, do complexo $\left[\mathrm{Tb}(\mathrm{acac})_{3}(18 \mathrm{C} 6)_{2}\right]$. 
TABELA 5.4 - Dados de perda de massa dos complexos [ $\operatorname{Tb}(\operatorname{acac})_{3}(\operatorname{TPPO})_{2}$ ], $\left[\mathrm{Tb}(\mathrm{acac})_{3}(\mathrm{TOPO})_{2}\right],\left[\mathrm{Tb}(\mathrm{acac})_{3}(\mathrm{DB} 18 \mathrm{C} 6)_{2}\right]$ e $\left[\mathrm{Tb}(\mathrm{acac})_{3}(18 \mathrm{C} 6)_{2}\right]$ no intervalo de temperatura 0 a $1000 \stackrel{\circ}{\circ}$.

\begin{tabular}{|c|c|c|c|c|}
\hline Amostra & $\mathrm{T}_{\text {onset }}\left({ }^{\circ} \mathrm{C}\right)$ & $\mathrm{T}_{\text {final }}\left({ }^{\circ} \mathrm{C}\right)$ & $\Delta \mathrm{m}(\%)$ & Resíduo (\%) \\
\hline $\mathrm{Tb}(\mathrm{acac})_{3}(\mathrm{TPPO})_{2}$ & 183 & 343 & 42,74 & 57,25 \\
\hline $\mathrm{Tb}(\mathrm{acac})_{3}(\mathrm{TOPO})_{2}$ & 144 & 338 & 78,82 & 21,18 \\
\hline $\mathrm{Tb}(\mathrm{acac})_{3}(\mathrm{DB} 18 \mathrm{C} 6)_{2}$ & 191 & 346 & 83,37 & 16,63 \\
\hline $\mathrm{Tb}(\mathrm{acac})_{3}(18 \mathrm{C} 6)_{2}$ & 108 & 260 & 80,61 & 19,39 \\
\hline
\end{tabular}

\subsubsection{Complexos $\left[\mathrm{TR}^{3+}(\beta \text {-dicetonato })_{3}(\mathrm{~L})_{2}\right]\left(\mathrm{TR}=\mathrm{Eu}^{3+} ; \beta\right.$-dicetonato $=$ tta; L=TPPO, TOPO, DB18C6 e 18C6)}

Nas FIGURAS 5.12 a $\mathbf{5 . 1 5}$ estão apresentadas as curvas TG/DTG (termogavimetria/ termogavimetria diferencial) das amostras dos complexos de tta de európio com ligantes auxiliares TPPO, DB18C6 e 18C6 respectivamente, obtidas em atmosfera inerte de nitrogênio $\left(\mathrm{N}_{2}\right)$. As curvas TGs dos complexos apresentam diferentes perfis de decomposição. O complexo [Eu(tta $)_{3}(\mathrm{TPPO})_{2}$ ] apresenta temperatura de decomposição inicial $\left(\mathrm{T}_{\text {onset }}=\mathrm{T}_{1}\right)$ de $204 \stackrel{\circ}{\circ} \mathrm{C}$ (FIG. 5.12). Os resultados apresentam perda de massa na região de $30-150{ }^{\circ} \mathrm{C}$, intervalo que compreende a faixa determinada como um evento de perda de água de higroscopicidade do complexo e outro evento começando em $196{ }^{\circ} \mathrm{C}$ referente à perda dos ligantes tta e TPPO. O complexo mantém-se instável com perdas de massa conforme o aumento da temperatura até a temperatura máxima da análise que é de $1000 \stackrel{\circ}{\circ}$.

A análise do complexo $\left[\mathrm{Eu}(\mathrm{tta})_{3}(\mathrm{TOPO})_{2}\right]$ (FIG. 5.13) identificou a temperatura $T_{\text {onset }}$ de $221^{\circ} \mathrm{C}$. Os resultados apresentam perda de massa na região que compreende a faixa determinada como dois eventos de desidratação do complexo. Após temperatura de decomposição final do segundo e terceiro eventos $\left(T_{\text {offset }}=T_{2}\right)$ de $358^{\circ} \mathrm{C}$, o complexo continua a sua decomposição com perdas de massa conforme aumento da temperatura. 
O complexo $\left[\mathrm{Eu}(\mathrm{tta})_{3}(\mathrm{DB} 18 \mathrm{C} 6)_{2}\right]$ apresenta temperatura de decomposição inicial $\left(T_{\text {onset }}=T_{1}\right)$ de $183^{\circ} \mathrm{C}$. Os resultados também apresentam perda de massa na região que compreende a faixa determinada como dois eventos de desidratação do complexo. Após temperatura de decomposição final do segundo e terceiro eventos $\left(T_{\text {offset }}=T_{2}\right.$ ) de $379{ }^{\circ} \mathrm{C}$, o complexo continua a sua decomposição com perdas de massa conforme aumento da temperatura até a temperatura máxima da análise (FIG. 5.14).

O complexo $\left[\mathrm{Eu}(\mathrm{tta})_{3}(18 \mathrm{C} 6)_{2}\right]$ apresenta temperatura de decomposição inicial $\left(T_{\text {onset }}=T_{1}\right)$ de $109{ }^{\circ} \mathrm{C}$. Os resultados apresentam perda de massa na região $35^{\circ} \mathrm{C}$ atribuída à água adsorvida. Entre 200 e $330{ }^{\circ} \mathrm{C}$ observam-se dois eventos distintos referentes à perda dos ligantes. Após temperatura de decomposição final $\left(T_{\text {offset }}=T_{2}\right)$ de $330 \stackrel{\circ}{\circ}$, o complexo mantém-se instável com perdas de massa conforme aumento da temperatura (FIG. 5.15).

A TABELA 5.5 resume os dados de comportamento de decomposição térmica dos complexos de európio estudados.

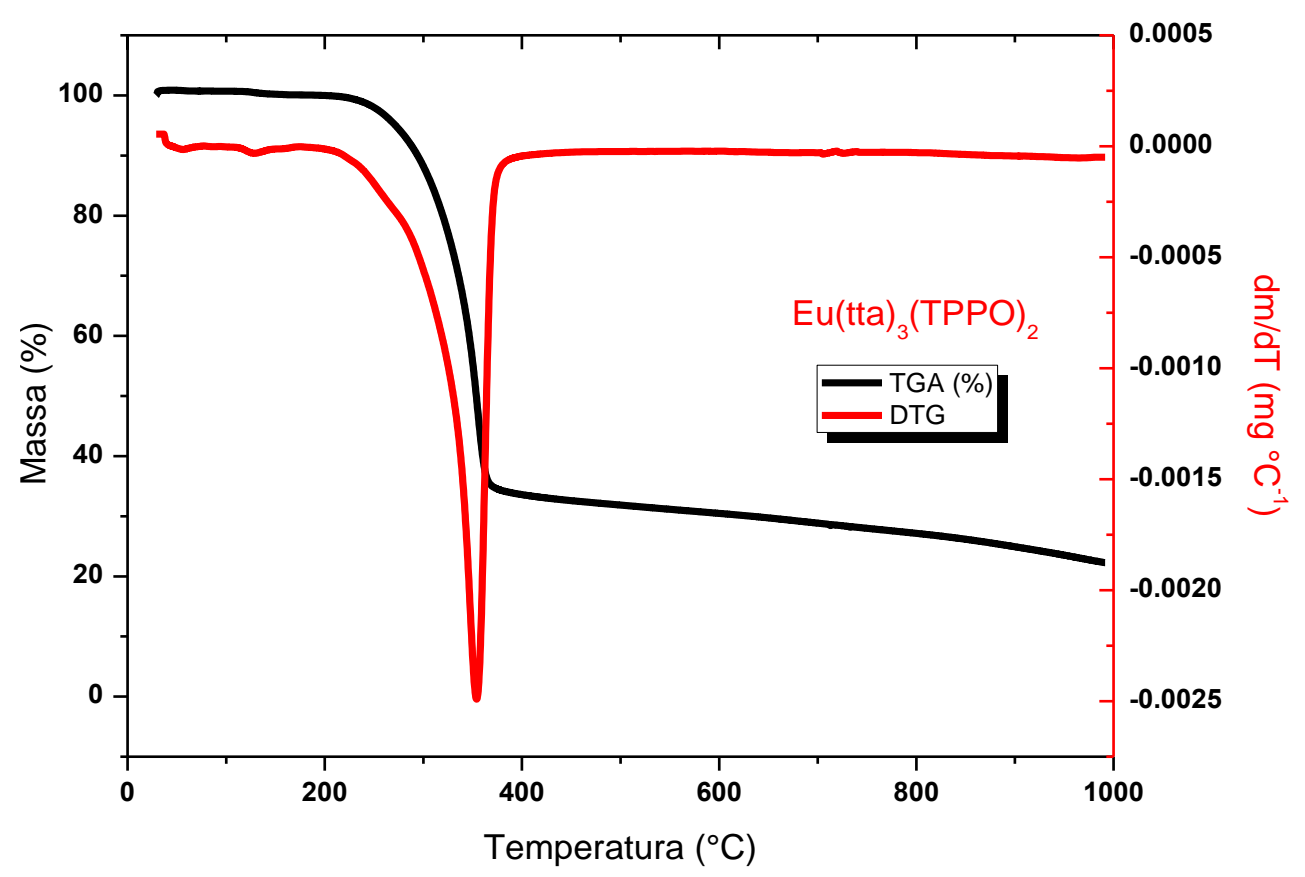

FIGURA 5.12 - Curvas TGA/DTG registradas no intervalo de 0 a $1000{ }^{\circ} \mathrm{C}$, sob atmosfera dinâmica de $\mathrm{N}_{2}$, do complexo $\left[\mathrm{Eu}(\mathrm{tta})_{3}(\mathrm{TPPO})_{2}\right]$. 


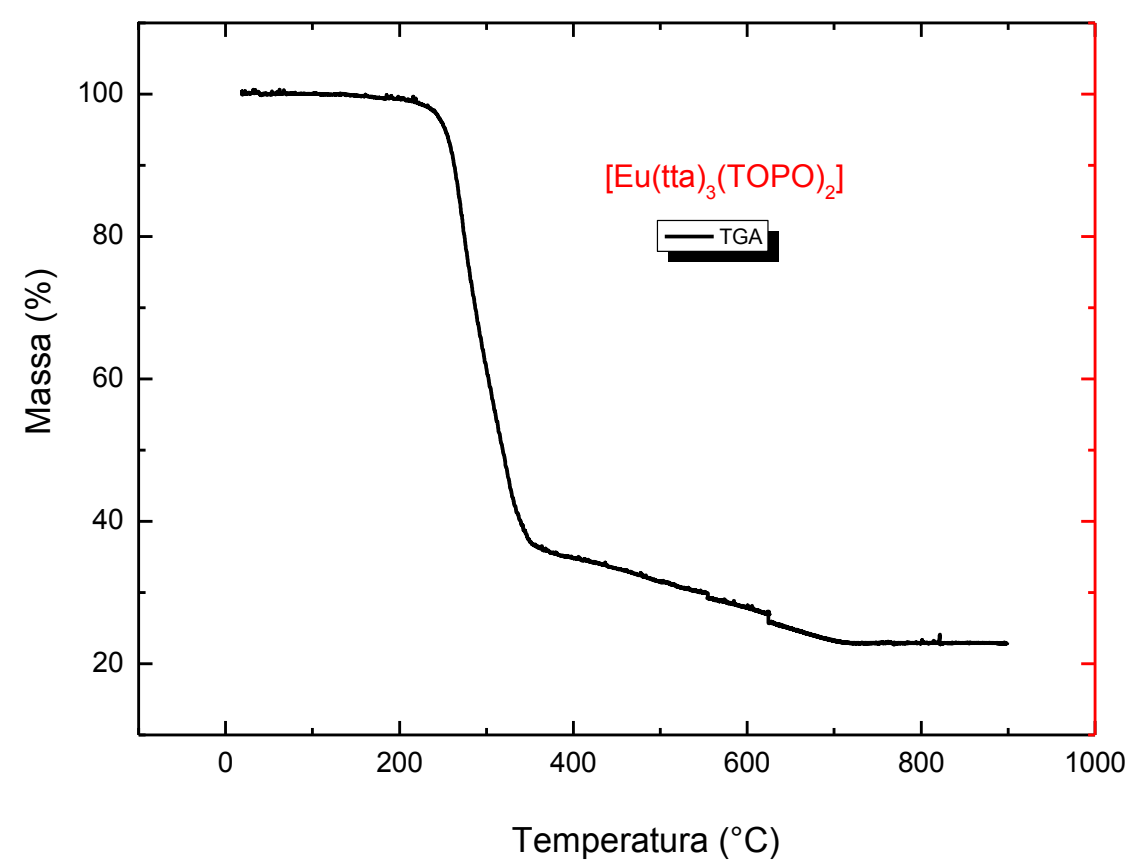

FIGURA 5.13 - Curva TGA registrada no intervalo de 0 a $1000{ }^{\circ} \mathrm{C}$, sob atmosfera dinâmica de $\mathrm{N}_{2}$, do complexo [Eu(tta) $\left.)_{3}(\mathrm{TOPO})_{2}\right]$.

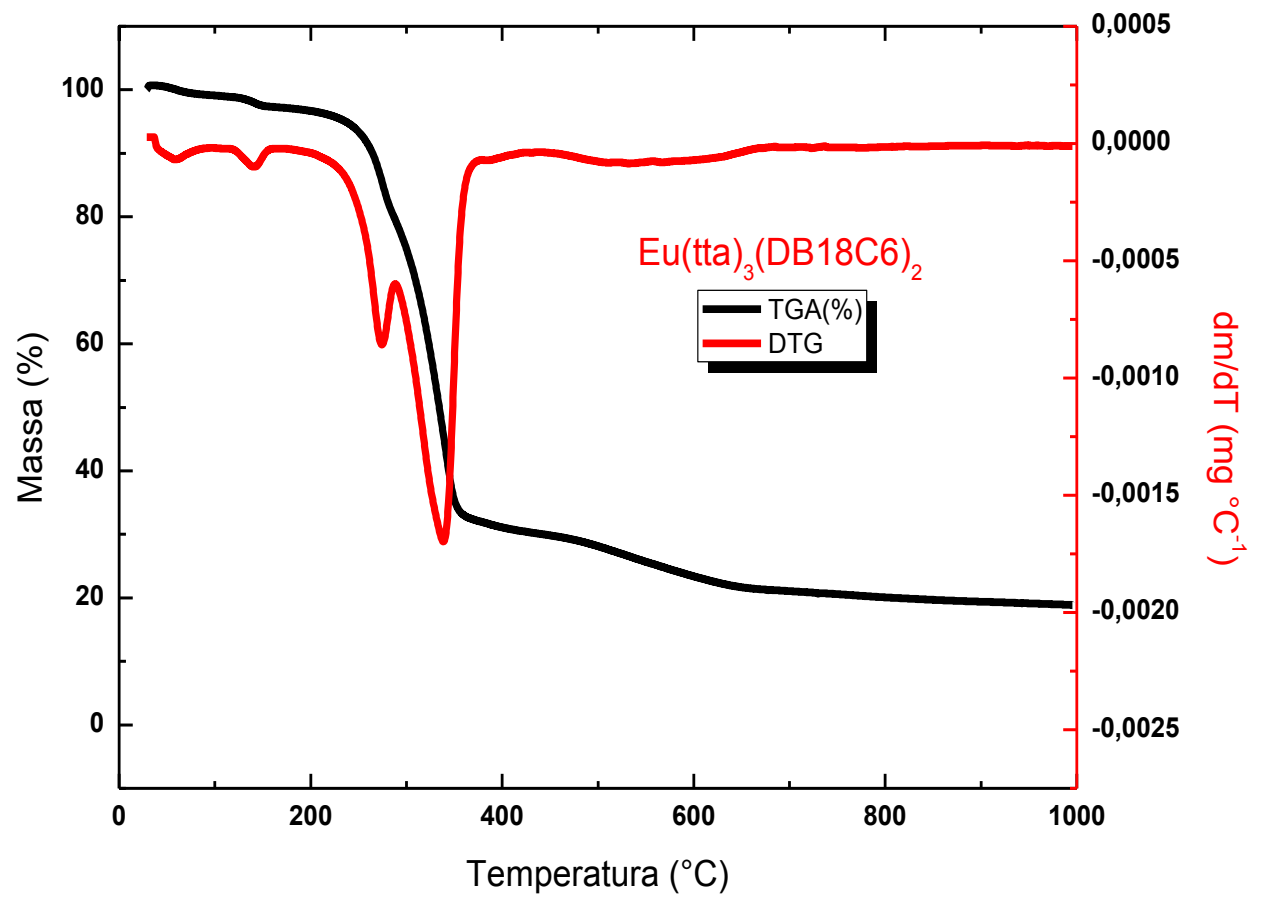

FIGURA 5.14 - Curvas TGA/DTG registradas no intervalo de 0 a $1000 \stackrel{\circ}{\circ}$, sob atmosfera dinâmica de $\mathrm{N}_{2}$, do complexo $\left[\mathrm{Eu}(\mathrm{tta})_{3}(\mathrm{DB} 18 \mathrm{C} 6)_{2}\right]$. 


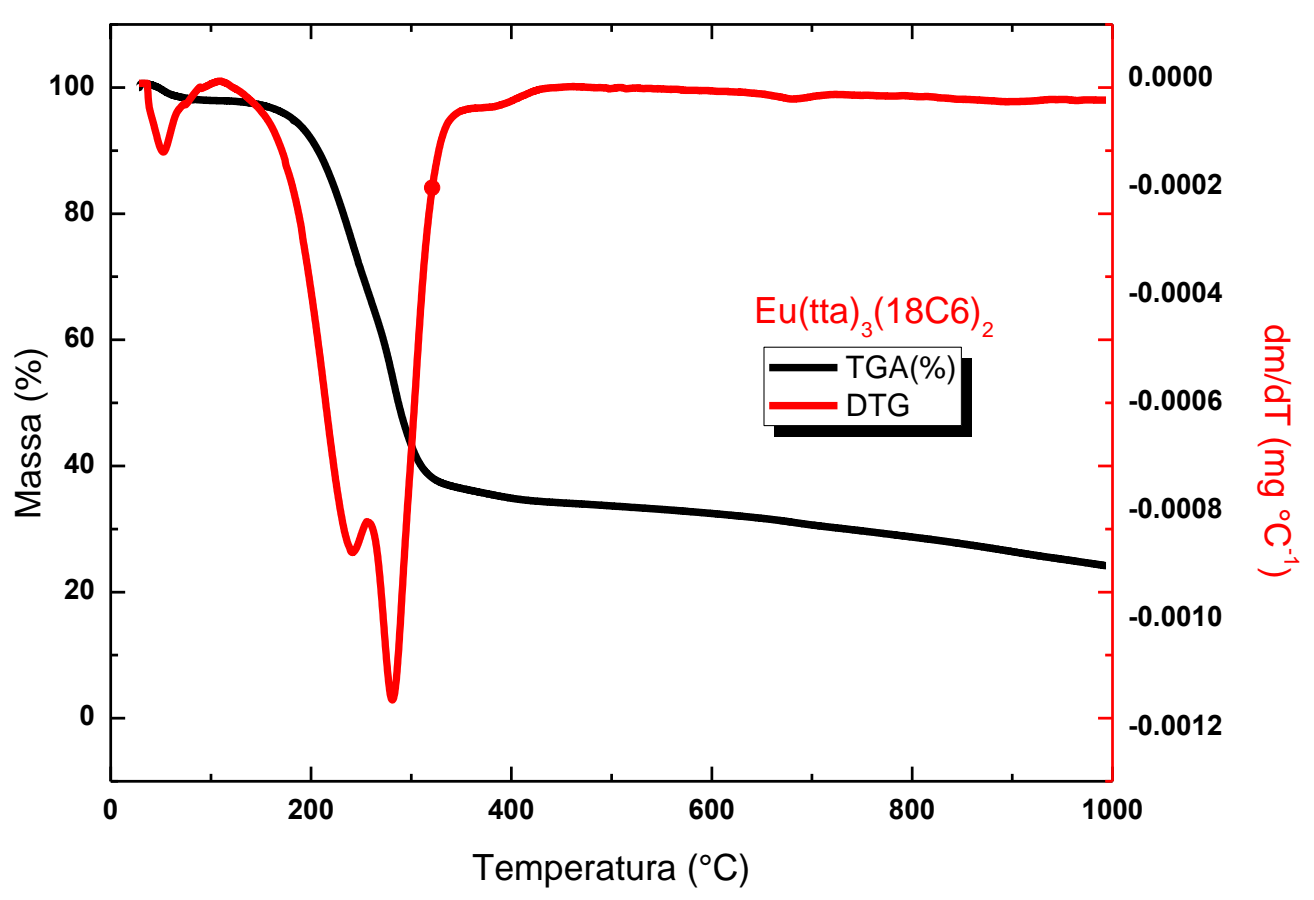

FIGURA 5.15 - Curvas TGA/DTG registradas no intervalo de 0 a $1000{ }^{\circ} \mathrm{C}$, sob atmosfera dinâmica de $\mathrm{N}_{2}$, do complexo $\left[\mathrm{Eu}(\mathrm{tta})_{3}(18 \mathrm{C} 6)_{2}\right]$.

TABELA 5.5 - Dados de perda de massa dos complexos [Eu(tta $)_{3}(\mathrm{TPPO})_{2}$ ], $\left[\mathrm{Eu}(\mathrm{tta})_{3}(\mathrm{TOPO})_{2}\right], \quad\left[\mathrm{Eu}(\mathrm{tta})_{3}(\mathrm{DB} 18 \mathrm{C} 6)_{2}\right]$ e $\left[\mathrm{Eu}(\mathrm{tta})_{3}(18 \mathrm{C} 6)_{2}\right]$ no intervalo de temperatura 0 a $1000{ }^{\circ} \mathrm{C}$.

\begin{tabular}{lcccc}
\hline Amostra & $\mathrm{T}_{\text {onset }}\left({ }^{\circ} \mathrm{C}\right)$ & $\mathrm{T}_{\text {final }}\left({ }^{\circ} \mathrm{C}\right)$ & $\Delta \mathrm{m}(\%)$ & Resíduo (\%) \\
\hline $\mathrm{Eu}(\mathrm{tta})_{3}(\mathrm{TPPO})_{2}$ & 204 & 374 & 77,66 & 22,34 \\
$\mathrm{Eu}(\mathrm{tta})_{3}(\mathrm{TOPO})_{2}$ & 232 & 355 & 71,94 & 28,06 \\
$\mathrm{Eu}(\mathrm{tta})_{3}(\mathrm{DB} 18 \mathrm{C} 6)_{2}$ & 183 & 361 & 81,03 & 18,97 \\
$\mathrm{Eu}(\mathrm{tta})_{3}(\mathbf{1 8 C 6})_{2}$ & 109 & 287 & 75,72 & 24,28 \\
\hline
\end{tabular}




\subsubsection{Difratometria de Raios X (DRX)}

Os raios-X são radiações eletromagnéticas com comprimento de onda entre 0,02 e $100 \AA$. Uma vez que os comprimentos de onda dessas radiações são similares aos tamanhos dos átomos, os raios $X$ são extensivamente empregados para obter informações sobre os arranjos dos átomos em um determinado sistema cristalino. Tais informações são obtidas com base nas intensidades das ondas difratadas por diferentes planos de átomos no cristal (FIG. 5.16). As ondas fora de fase por múltiplos diferentes de $n \lambda$, onde $\lambda$ é 0 comprimento de onda dos raios-X usados e $n=1,2,3 \ldots$, se interferem destrutivamente conduzindo a uma diminuição da amplitude da onda, alcançando um cancelamento quando as ondas estão fora de fase por múltiplos de $1 / 2 \lambda(n / 2 \lambda)$. Enquanto que as ondas que estão fora de fase por múltiplos de $\lambda(\mathrm{n} \lambda)$ interferem-se construtivamente, adicionando-se umas às outras resultando em uma onda com maior amplitude ${ }^{[24,25]}$.

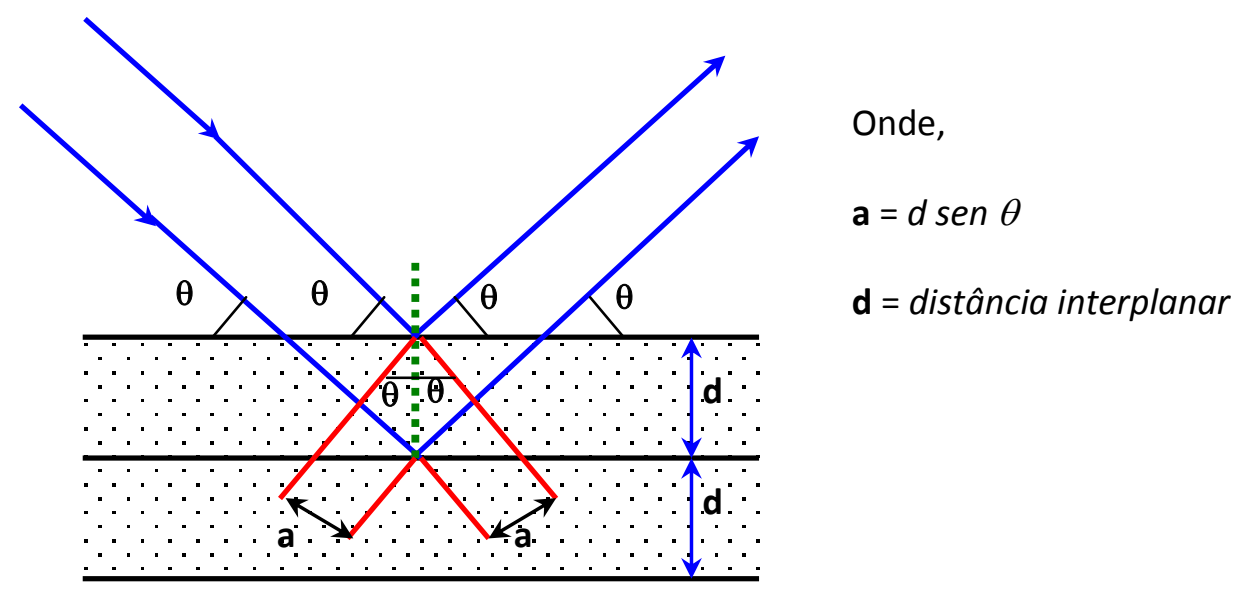

FIGURA 5.16 - Espalhamento de raios X em uma dada família de planos.

Como ilustrado na FIGURA 5.16, o ângulo $\theta$ de reflexão dos raios 1 e 2 são iguais aos ângulos de incidência e para que a interferência seja construtivas é necessário que a diferença do caminho (2a) percorrido pelo raio 1 que interage com o plano superior e o raio 2 interagindo com o plano 2, seja igual a um número inteiro de números de onda $n \lambda$. Se por outro lado, essa 
distância difere de um número inteiro de ondas, interferências destrutivas ocorrerão e a amplitude da onda não será tão alta quanto aquela dos raios incidentes. Essa diferença de caminho é expressa em termos de distâncias interplanares, $d$, na seguinte forma ${ }^{[26]}$,

$$
\mathrm{n} \lambda=2 \mathrm{~d} \operatorname{sen} \theta
$$

essa expressão é conhecida como a Lei de Bragg para a difração de raios X. De acordo com a Lei de Bragg, uma vez que o valor de $\lambda$ é conhecido e os valores de $\theta$ sejam medidos experimentalmente, os valores das distâncias interplanares, $d$, podem ser determinadas.

Os métodos mais utilizados para medidas estruturais são os mtodos de monocristal (single crystal) e o método do pó. No primeiro método um cristal da amostra é reorientado expondo outros planos ao feixe de raios $X$ sendo possível medir todas as distâncias interplanares no cristal e o tamanho da cela unitária. Através de métodos de ajustes de mínimos quadrados as intensidades dos raios-X difratados pelos diferentes átomos na amostra são comparados com um valor esperado tornando possível à determinação da estrutura cristalina. Este método é de grande importância para a determinação das estruturas de biomoléculas, moléculas orgânicas e inorgânicas, considerando que o conhecimento estrutura do sistema é um ponto crucial para o entendimento das propriedades químicas e físicas. Uma das desvantagens do método de monocristais é tempo de coleta dos dados experimentais e a dificuldade na obtenção de um monocristal ${ }^{[27]}$.

No método do pó as medidas são feitas em um tempo consideravelmente curto. Considerando que em uma amostra na forma de pó existem milhares de grãos com orientações aleatórias, deve-se esperar que a maioria dos diferentes planos atômicos seja paralelo. Desta forma, varrendo-se o feixe de raios $X$ no intervalo de 0 a $90^{\circ}$ é possível encontrar todos os ângulos que satisfazem as condições de difração, assim como as distâncias interplanares. Os difratogramas são geralmente um gráfico de intensidades de 
raios $\mathrm{X}$ versus $2 \theta$. Os valores de $2 \theta$ podem ser convertidos em distâncias interplanares, $d$, através da equação de Bragg (Eq. 5.1) ${ }^{[28]}$. Através de uma análise das distâncias e as intensidades relativas das linhas de difração é possível verificar o isomorfismo nos compostos.

Os difratogramas de raios $\mathrm{X}$ dos complexos sintetizados mostraram a cristalinidade destes materiais. No entanto, para os complexos de európio e gadolínio contendo tta e ligante auxiliar TOPO não foi possível realizar a análise, pois se tratam de materiais líquidos com aspecto pastoso.

É importante ressaltar que o principal interesse no uso da técnica de raios $X$ neste trabalho é a avaliação qualitativa, com 0 intuito de obter informações sobre a morfologia dos complexos e das nanopartículas poliméricas preparadas, bem como avaliar diferenças morfológicas entre uma partícula polimérica associada com o complexo marcador, verificando possíveis variações em função da mistura. Portanto, não será aprofundado o estudo e realização de cálculos dos fatores de forma e estrutura.

\subsubsection{Complexos $\left[\mathrm{TR}^{3+}(\beta \text {-dicetonato })_{3}(\mathrm{~L})_{2}\right]\left(\mathrm{TR}=\mathrm{Tb}^{3+} ; \beta\right.$-dicetonato $=$ acac; L=TPPO, TOPO, DB18C6 e 18C6)}

Os difratogramas de raios $\mathrm{X}$ dos complexos de térbio estudados (FIG. 5.17), no intervalo de 5 a $40{ }^{\circ} \mathrm{C}$ apresentam vários picos finos de difração, indicando alta cristalinidade dos compostos de coordenação. O complexo contendo acac de térbio com o ligante auxiliar DB18C6 é o que apresenta maior intensidade dos picos de difração, proporcional à alta cristalinidade do composto. 


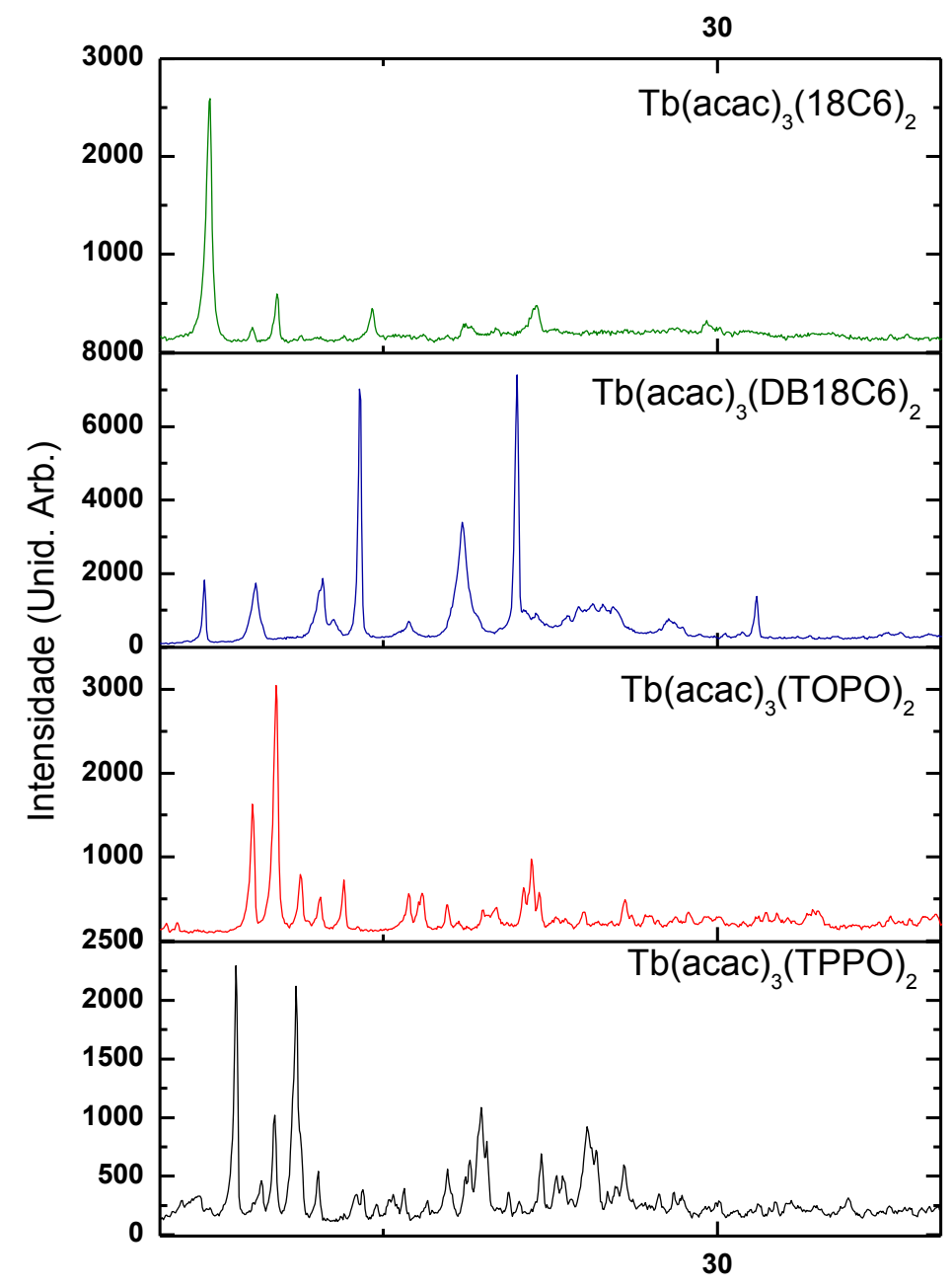

$2 \theta\left(^{\circ}\right)$

FIGURA 5.17 - Difratogramas de raios $X$ dos complexos [Tb(acac) $\left.)_{3}(\mathrm{~L})_{2}\right]$ (onde $\mathrm{L}=18 \mathrm{C} 6$, DB18C6, TOPO e TPPO) no intervalo de 5 a $40^{\circ}$.

\subsubsection{Complexos $\left[\mathrm{TR}^{3+}(\beta \text {-dicetonato })_{3}(\mathrm{~L})_{2}\right]\left(\mathrm{TR}=\mathrm{Eu}^{3+} ; \beta\right.$-dicetonato $=\mathrm{tta}$; L=TPPO, TOPO, DB18C6 e 18C6)}

Os difratogramas de raios $X$ dos complexos de európio, no intervalo de 5 a $40^{\circ}$ estão apresentados na FIGURA 5.18. Os complexos de tta de európio com os ligantes auxiliares TPPO e DB18C6 apresentam vários picos de difração, indicando alta cristalinidade dos compostos de coordenação.

O difratograma do complexo de tta de európio contendo o ligante auxiliar 18C6 apresentou menores quantidades de bandas e bandas mais alargadas e 
menos intensas, caracterizando um perfil semicristalino, assim como o difratograma do complexo de tta de európio.

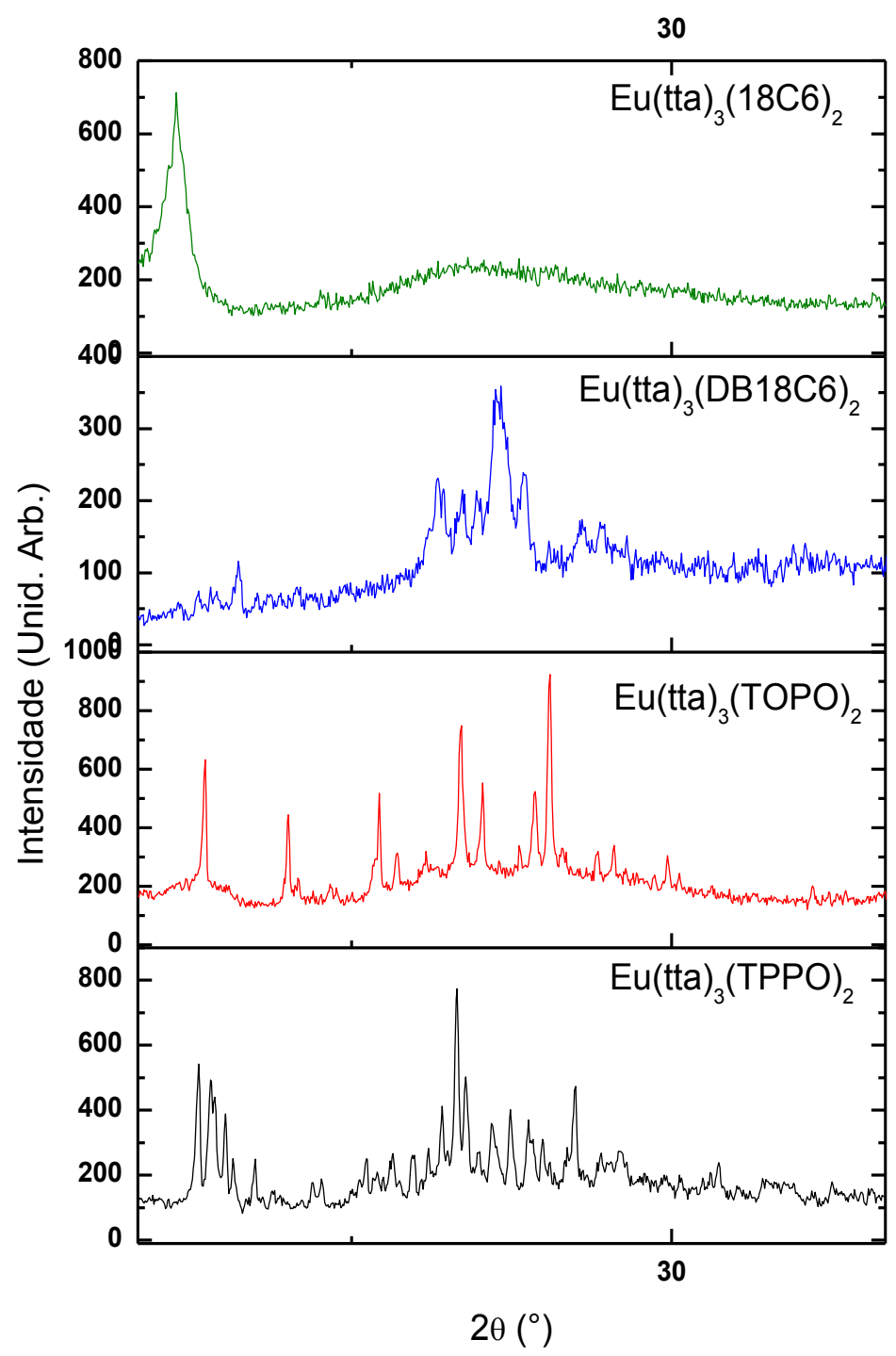

FIGURA 5.18 - Difratogramas de raios $\mathrm{X}$ dos complexos $\left[\mathrm{Eu}(\mathrm{tta})_{3}(\mathrm{~L})_{2}\right]$ (onde $\mathrm{L}=$ 18C6, DB18C6, TOPO e TPPO) no intervalo de 5 a $40^{\circ}$.

\subsubsection{Complexos $\left[\mathrm{TR}^{3+}(\beta \text {-dicetonato })_{3}(\mathrm{~L})_{2}\right]\left(\mathrm{TR}=\mathrm{Gd}^{3+} ; \beta\right.$-dicetonato $=$ acac e tta; L=TPPO, TOPO, DB18C6 e 18C6)}

Os difratogramas de raios $\mathrm{X}$ dos complexos de gadolínio, no intervalo de 5 a $40^{\circ}$, estão apresentados nas FIGURAS 5.19 e 5.20. Na FIGURA 
estão apresentados os difratogramas dos complexos de acac de gadolínio. Observa-se que os complexos contendo os ligantes auxiliares TPPO e DB18C6 apresentam vários picos de difração, picos finos que caracterizam alta cristalinidade dos materiais, comportamento semelhante ao apresentado para os complexos contendo os mesmos ligantes auxiliares, porém com íons terras raras diferentes (FIG. 5.17 e 5.18).

Na FIGURA 5.20 estão apresentados os difratogramas dos complexos de tta de gadolínio, no intervalo de 5 a 40 . Os difratogramas apresentam bandas largas centradas em $2 \theta=14$ e $29^{\circ}$ para complexo contendo $18 \mathrm{C} 6 \mathrm{e} 2 \theta=29^{\circ}$ para complexo contendo TPPO, indicando condição amorfa. São apresentados vários picos de difração para o complexo contendo DB18C6, sugerindo alta cristalinidade deste material. 


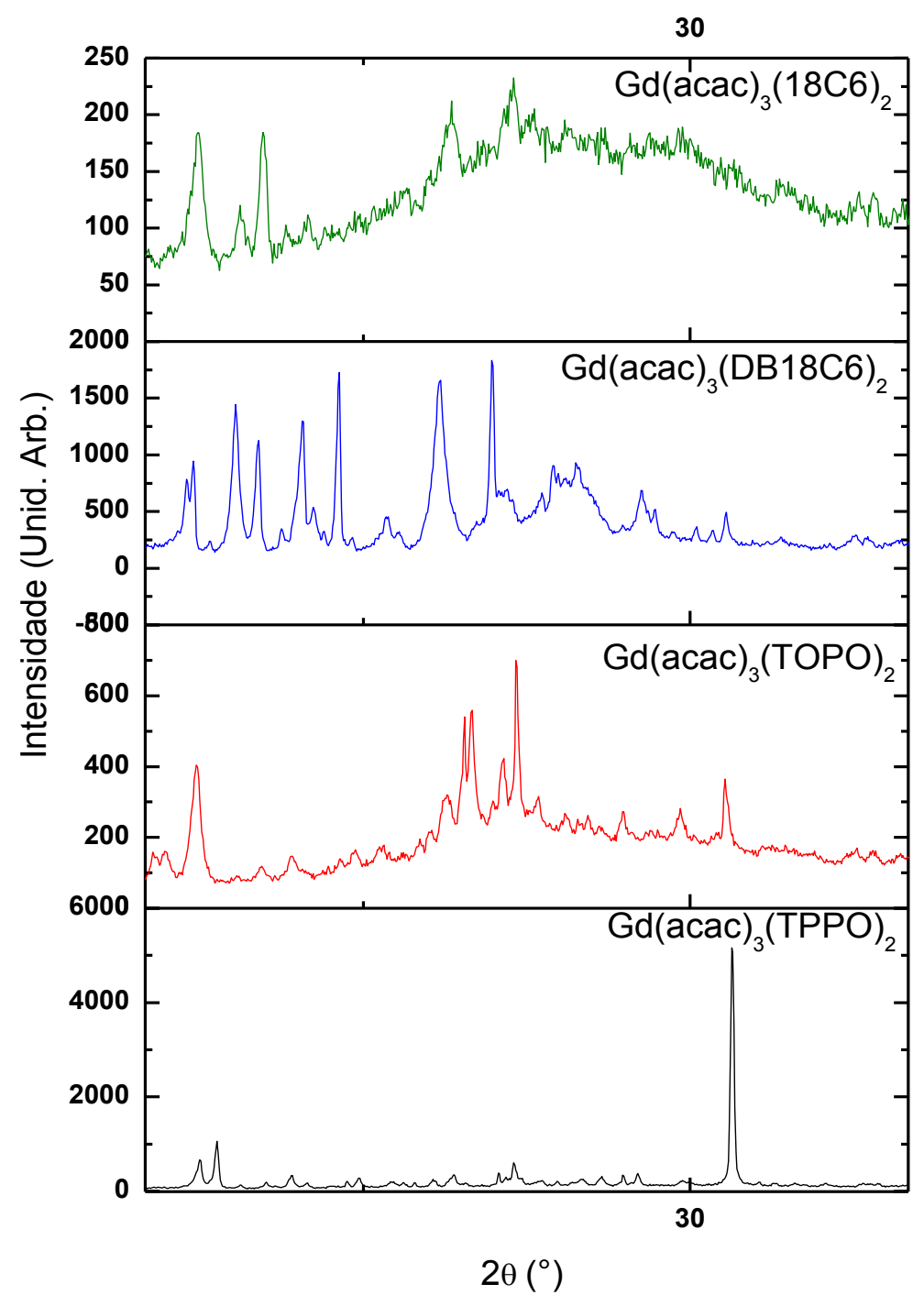

FIGURA 5.19 - Difratogramas de raios $X$ dos complexos $\left[\mathrm{Gd}(\mathrm{acac})_{3}(\mathrm{~L})_{2}\right]$ (onde $\mathrm{L}=18 \mathrm{C} 6$, DB18C6, TOPO e TPPO) no intervalo de 5 a $40^{\circ}$. 


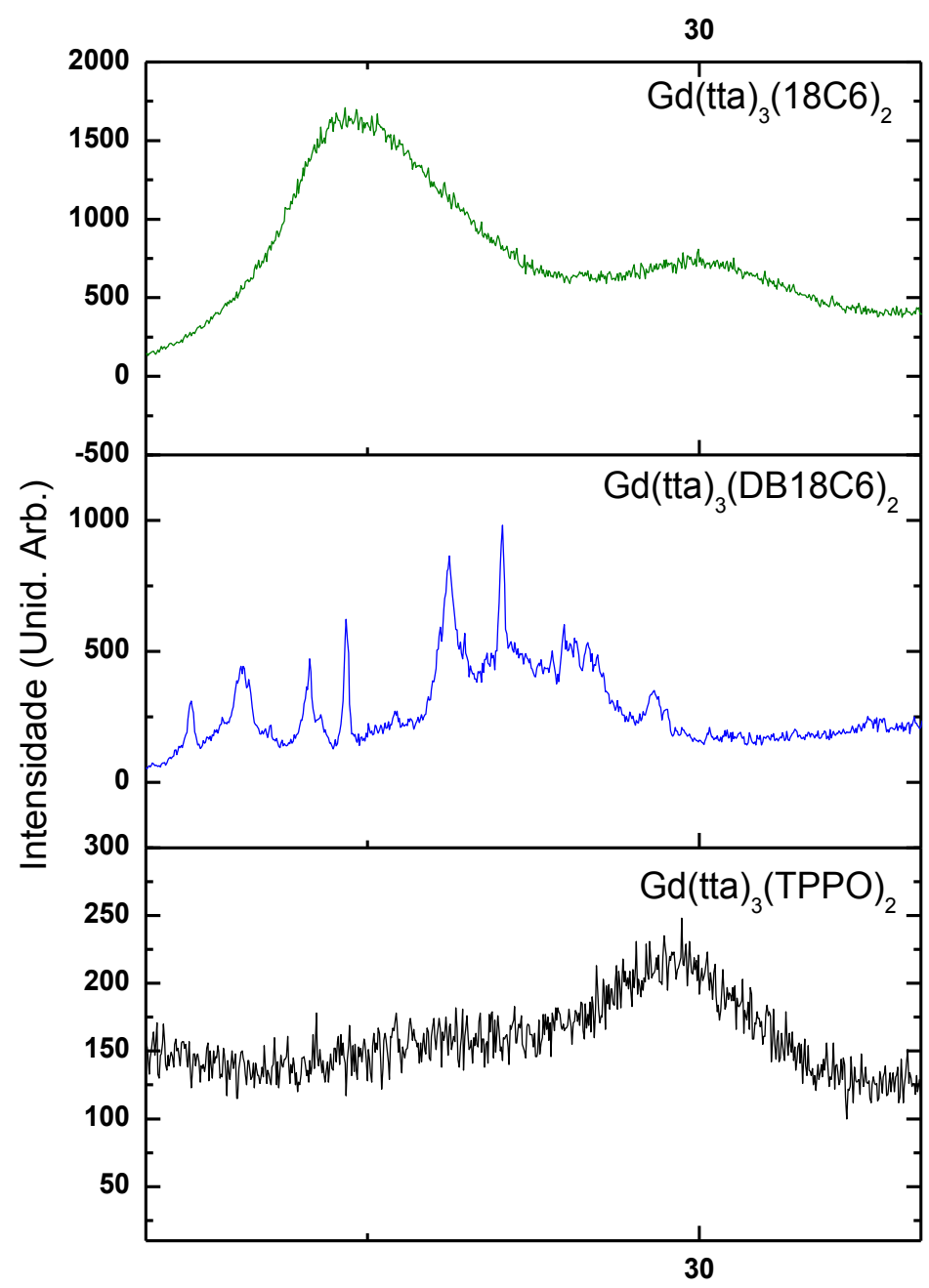

$2 \theta\left(^{\circ}\right)$

FIGURA 5.20 - Difratogramas de raios $X$ dos complexos $\left[\mathrm{Gd}(\mathrm{tta})_{3}(\mathrm{~L})_{2}\right]$ (onde $\mathrm{L}=18 \mathrm{C6}$, DB18C6, TOPO e TPPO) no intervalo de 5 a $40^{\circ}$.

\subsubsection{Microscopia Eletrônica de Varredura (MEV)}

O microscópio eletrônico de varredura (MEV) é um equipamento capaz de produzir imagens de alta ampliação (até 300.000 x) e resolução. As imagens fornecidas pelo MEV possuem um caráter visual, pois o que é observado no monitor do aparelho é a transcodificação da energia emitida pelos elétrons, ao contrário da radiação de luz, a qual se está habitualmente acostumado a obter ${ }^{[29]}$. 
O MEV é uma ferramenta padrão para inspeção e análise utilizada em diversas áreas de pesquisa desde a área de materiais até a área biológica. Particularmente na indústria de semicondutores, em medidas de caracterização para a microeletrônica, existe um conjunto de métodos que oferecem alta resolução e alta precisão. Estes métodos são baseados fundamentalmente na interação da matéria com os elétrons incidentes e a emissão de ondas ou partículas (fótons, elétrons, íons, átomos, nêutrons). Podemos efetuar as seguintes análises utilizando o MEV:

- Obter uma imagem de alguma posição da amostra com resolução alta, desde dimensões entre $500 \mathrm{~nm}$ até dimensões menores de nm;

- Realizar uma análise elementar da amostra;

- Identificar a natureza dos enlaces dos elementos presentes em uma amostra dada;

- Obter informações da composição do material como uma função da profundidade imediatamente abaixo da superfície, geralmente alguns micrometros;

- Determinar localizações precisas sobre a amostra com o objetivo de correlacionar medidas analíticas para especificar características do dispositivo.

O princípio de funcionamento do MEV consiste na emissão de feixes de elétrons por um filamento capilar de tungstênio (eletrodo negativo), mediante a aplicação de uma diferença de potencial que pode variar de 0,5 a 30 KV. Essa variação de voltagem permite a variação da aceleração dos elétrons, e também provoca o aquecimento do filamento. A parte positiva em relação ao filamento do microscópio (eletrodo positivo) atrai fortemente os elétrons gerados, resultando numa aceleração em direção ao eletrodo positivo. A correção do percurso dos feixes é realizada pelas lentes condensadoras que alinham os feixes em direção à abertura da objetiva. A objetiva ajusta o foco dos feixes de elétrons antes dos elétrons atingirem a amostra analisada ${ }^{[29]}$. 


\subsubsection{Microscopia Eletrônica de Varredura (MEV) dos Complexos $\left[\mathrm{TR}^{3+}(\beta \text {-dicetonato })_{3}(\mathrm{~L})_{2}\right]\left(\mathrm{TR}=\mathrm{Tb}^{3+} ; \beta\right.$-dicetonato= acac; $\mathrm{L}=\mathrm{TPPO}, \mathrm{TOPO}$, DB18C6 e 18C6).}

As micrografias dos complexos contendo os ligantes auxiliares TPPO, TOPO e 18C6 apresentam-se em forma de nanocristais aglomerados com homogeneidade de composição. Eles apresentam tamanhos e formas heterogêneas. Os compostos com o ligante TOPO apresenta forma de pequenos bastões. É evidente nas imagens que se tratam de materiais com uma certa higroscopicidade. A micrografia do complexo [Tb(acac) $)_{3}(\mathrm{DB} 18 \mathrm{C6})_{2}$ ] mostra aglomerados de fios com comprimentos micrométricos e diâmetros de aproximadamente $0.8 \mu \mathrm{m}$ com morfologia de espécie fibrosa alongada (FIG. 5.22). Nas FIGURAS 5.21 a $\mathbf{5 . 2 4}$ têm-se exemplos das micrografias destes complexos.

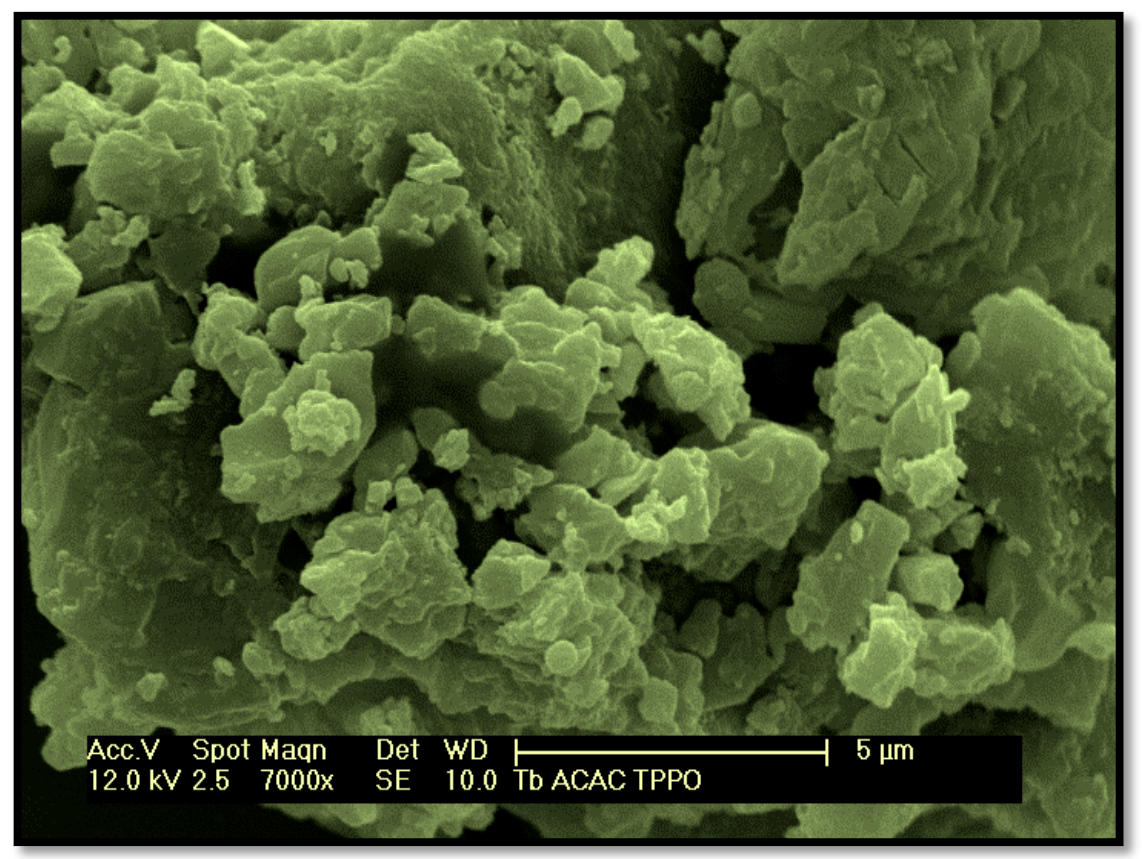

FIGURA 5.21 - Micrografia do complexo $\left[\mathrm{Tb}(\mathrm{acac})_{3}(\mathrm{TPPO})_{2}\right]$ com magnificação de (7000x). 


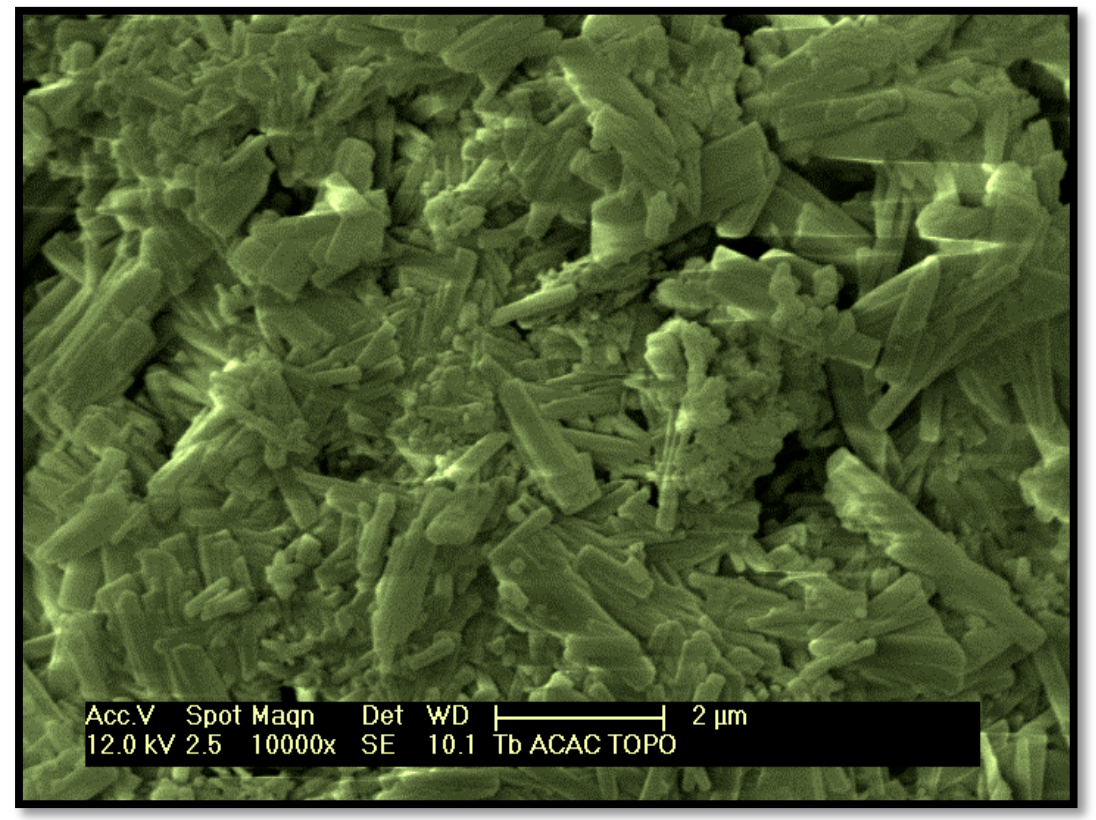

FIGURA 5.22 - Micrografia do complexo $\left[\mathrm{Tb}(\mathrm{acac})_{3}(\mathrm{TOPO})_{2}\right]$ com magnificação de $(10000 x)$.

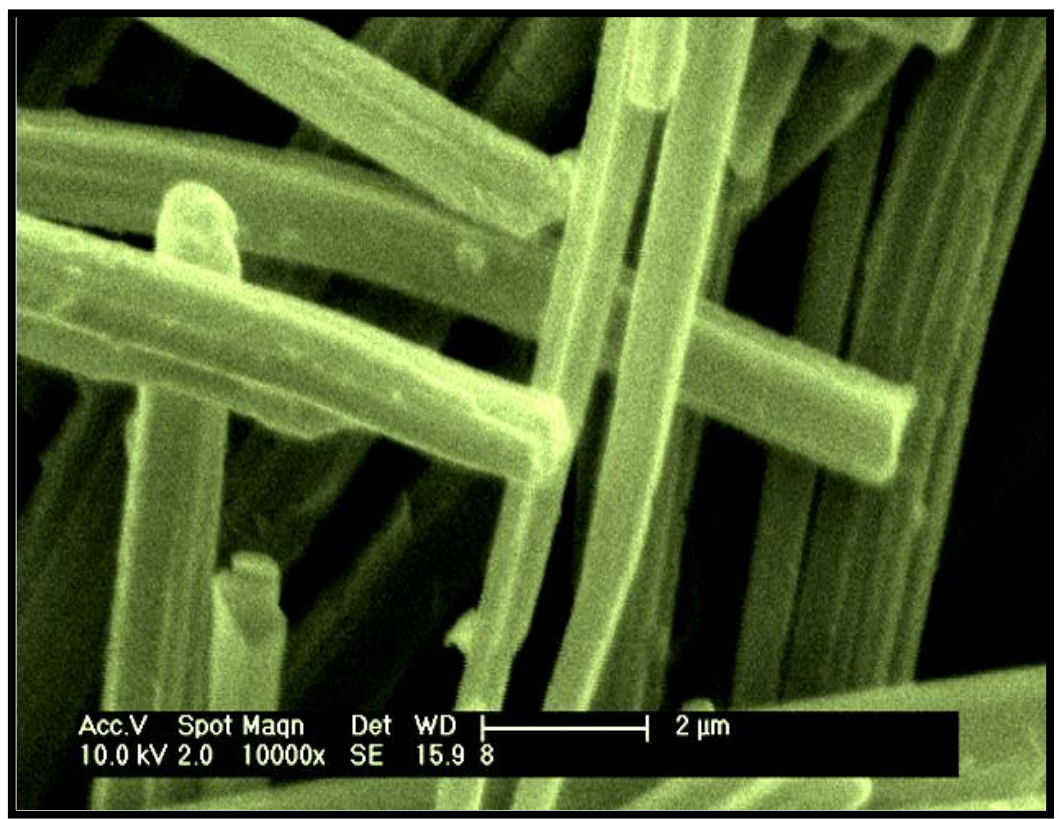

FIGURA 5.23 - Micrografia do complexo [Tb(acac) $\left.)_{3}(\mathrm{DB} 18 \mathrm{C} 6)_{2}\right]$ com magnificação de (10000x). 


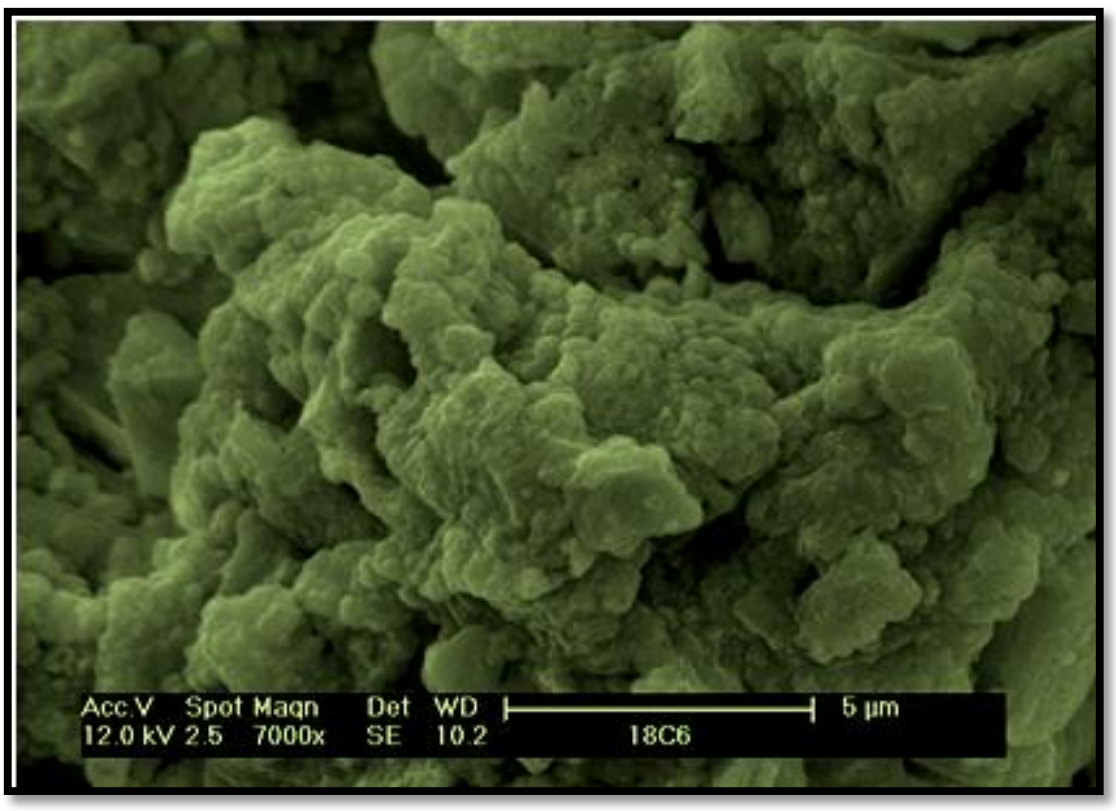

FIGURA 5.24 - Micrografia do complexo $\left[\mathrm{Tb}(\mathrm{acac})_{3}(18 \mathrm{C} 6)_{2}\right]$ com magnificação de $(7000 x)$.

5.1.8.2 Microscopia Eletrônica de Varredura (MEV) dos complexos $\left[\operatorname{TR}^{3+}(\beta-\right.$ dicetonato $\left.)_{3}(\mathrm{~L})_{2}\right]\left(\mathrm{TR}=\mathrm{Eu}^{3+} ; \beta\right.$-dicetonato= tta; L=TPPO, TOPO, DB18C6 e 18C6).

As micrografias dos complexos de $\beta$-dicetonatos de Eu contendo os ligantes auxiliares TPPO, DB18C6 e 18C6 mostram aglomerados de cristais com uma forte higroscopicidade. Eles são homogêneos e tem tamanho de aglomerados variados. A forma física obtida para o complexo contendo o ligante auxiliar TOPO, liquido viscoso, não possibilitou análise por MEV. Nas FIGURAS 5.25 a 5.26 estão ilustradas as micrografias dos complexos contendo TTPPO e DB18C6. 


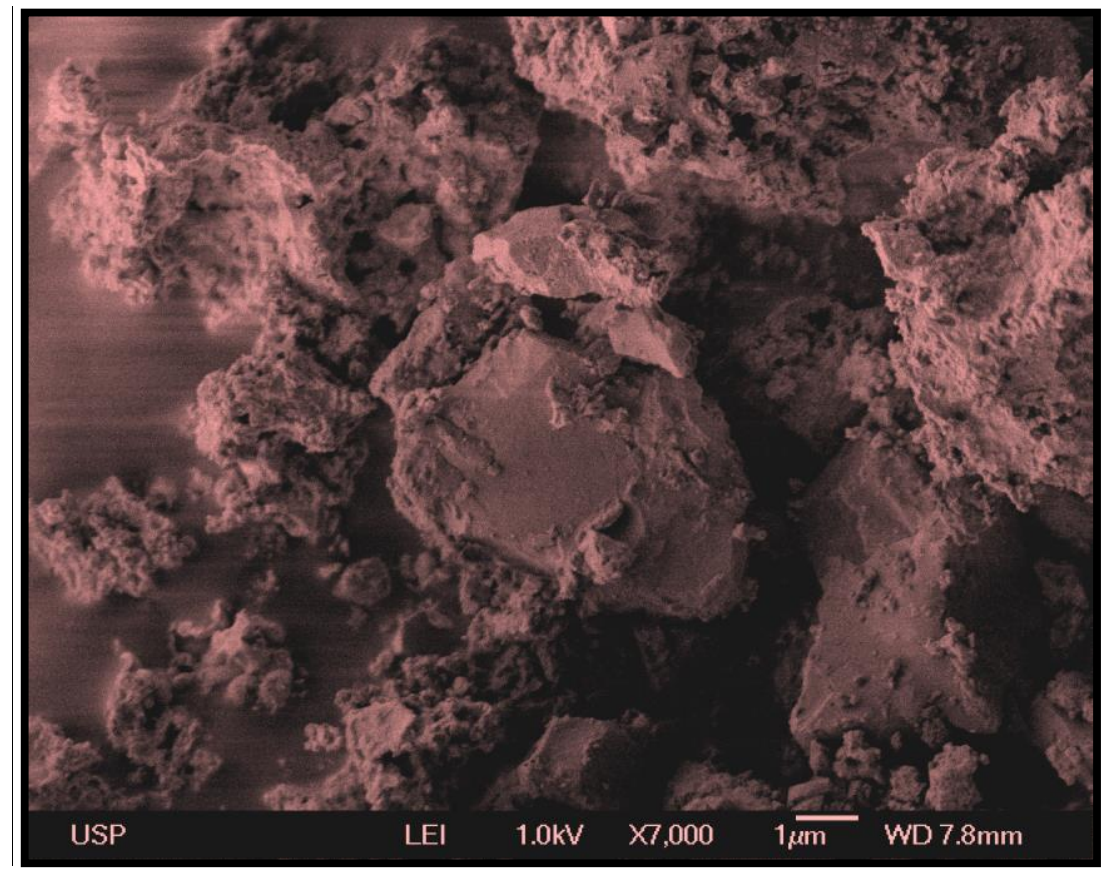

FIGURA 5.25 - Micrografia do complexo $\left[\mathrm{Eu}(\mathrm{tta})_{3}(\mathrm{TPPO})_{2}\right]$ com magnificação de (7000x).

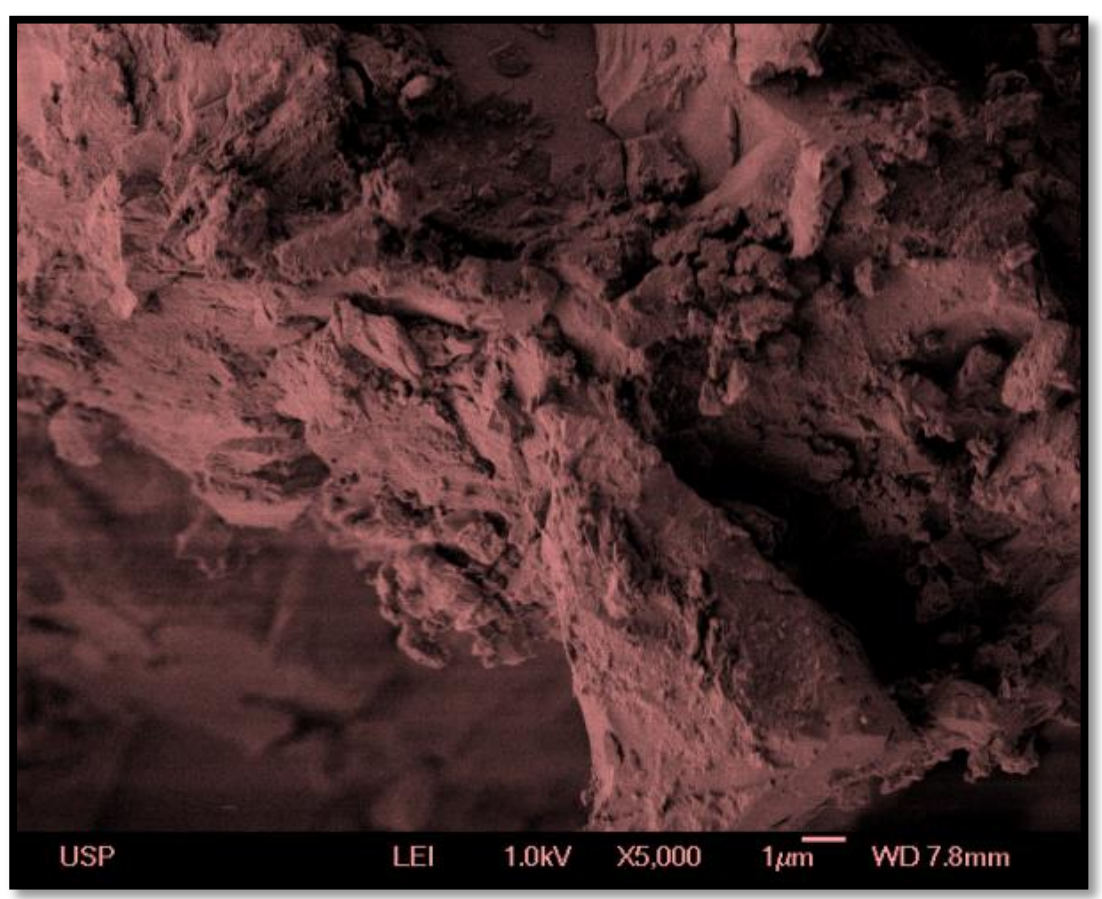

FIGURA 5.26 - Micrografia do complexo [Eu(tta) $\left.)_{3}(\mathrm{DB} 18 \mathrm{C} 6)_{2}\right]$ com magnificação de $(5000 x)$. 


\subsubsection{Complexos $\left[\mathrm{TR}^{3+}(\beta \text {-dicetonato })_{3}(\mathrm{~L})_{2}\right]\left(\mathrm{TR}=\mathrm{Gd}^{3+} ; \beta\right.$-dicetonato $=$ acac e tta; L=TPPO, TOPO, DB18C6 e 18C6)}

As micrografias dos complexos de gadolínio contendo acac e os ligantes auxiliares TPPO, TOPO, DB18C6 e 18C6 mostram cristais aglomerados. Estes cristais têm formas heterogêneas e tamanhos de aglomerados variados. As FIGURAS 5.28 a $\mathbf{5 . 3 1}$ apresentam as micrografias destes complexos. Para o complexo de $\left[\mathrm{Gd}(\mathrm{acac})_{3}(\mathrm{TPPO})_{2}\right]$, Figura 5.28, observa-se a cristalinidade do material e as várias formas de aglomeração dos cristais. Destaca-se do lado direito da micrografia um aglomerado de varias folhas do complexo em forma de flor. O complexo de $\left[\mathrm{Gd}(\mathrm{acac})_{3}(\mathrm{TOPO})_{2}\right.$ ] apresenta também formas diversas de cristalização, destacando-se os bastonetes que são a maioria no campo investigado, Figura 5.29. Já os compostos com ligantes macrocíclicos observase uma tendência a formação de pequenos bastões para o complexo $\left[\mathrm{Gd}(\mathrm{acac})_{3}(18 \mathrm{C} 6)_{2}\right]$ e fios micrométricos para o composto de gadolínio $\left[\mathrm{Gd}(\mathrm{acac})_{3}(\mathrm{DB} 18 \mathrm{C} 6)_{2}\right]$ apresentados nas Figuras $\mathbf{5 . 3 0}$ e $\mathbf{5 . 3 1}$. 


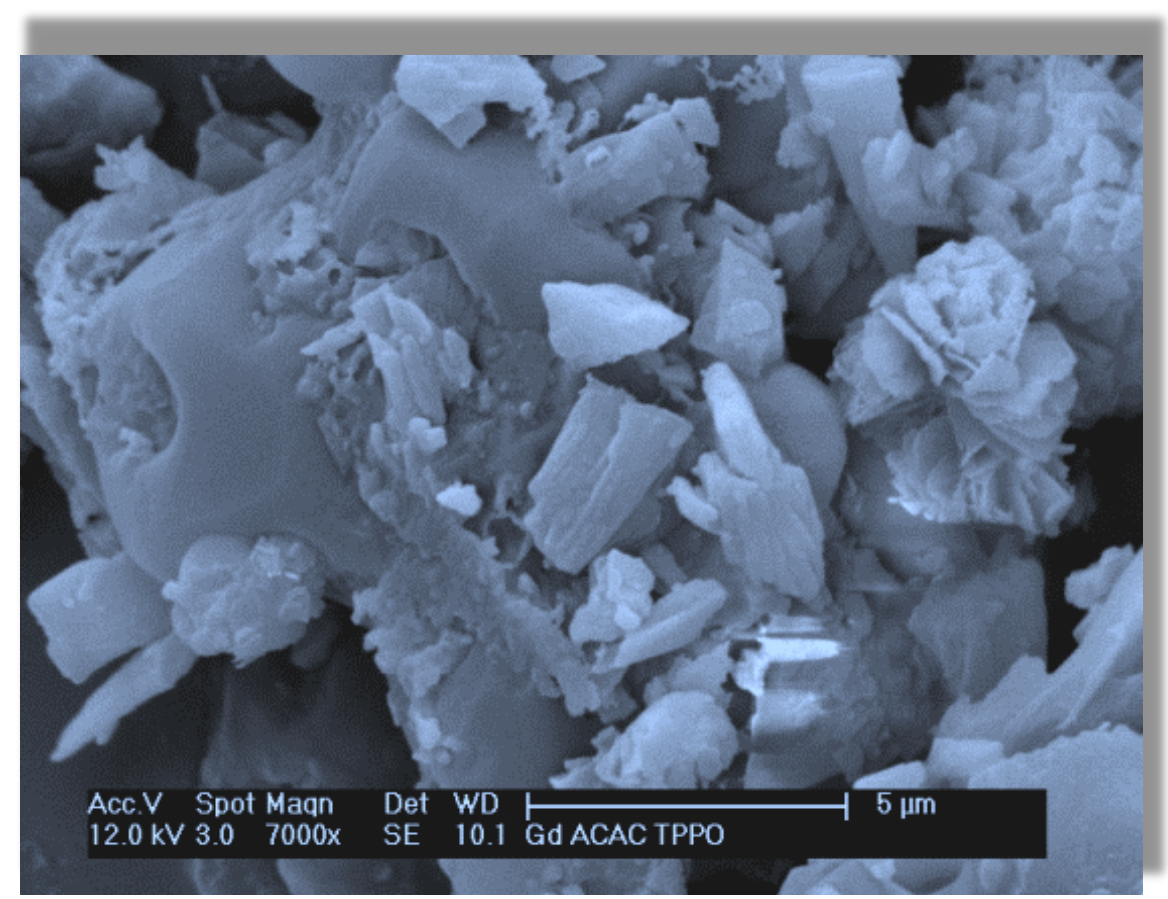

FIGURA 5.28 - Micrografia do complexo $\left[\mathrm{Gd}(\operatorname{acac})_{3}(\mathrm{TPPO})_{2}\right]$ com magnificação de $(7000 x)$.

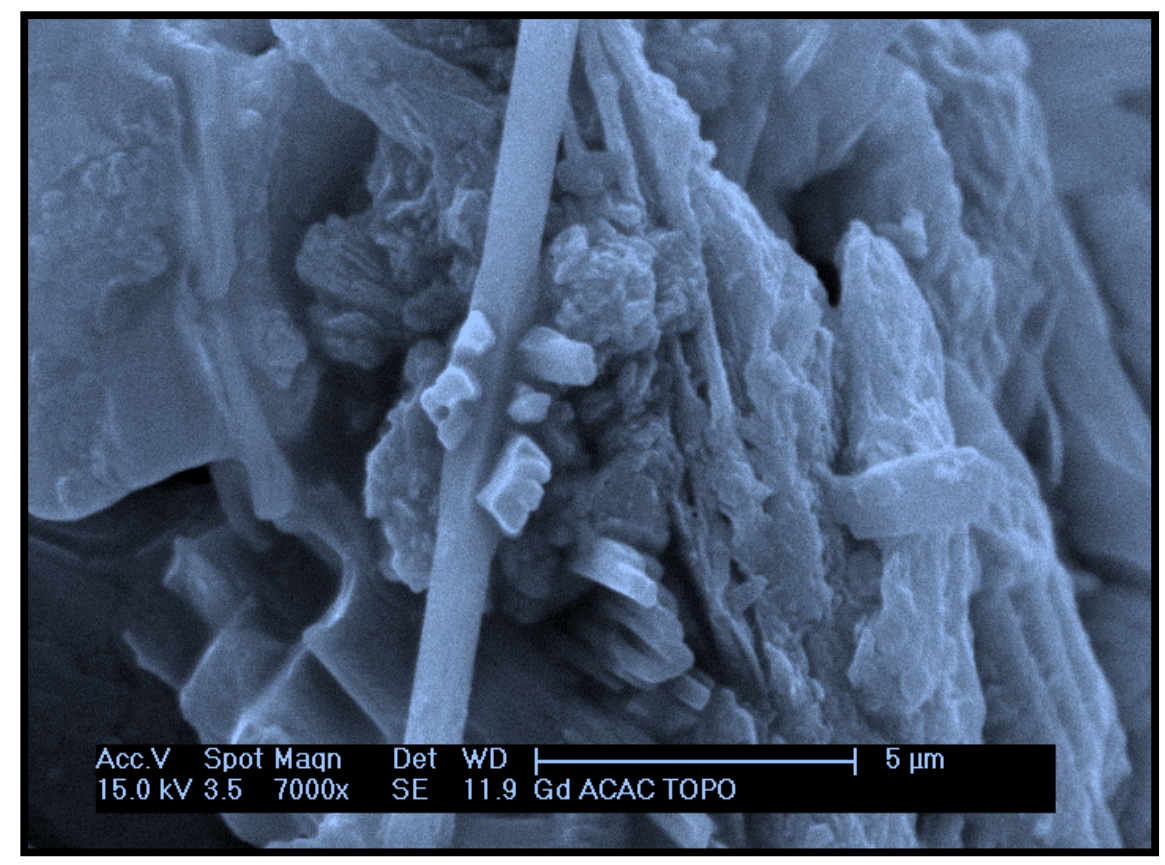

FIGURA 5.29 - Micrografia do complexo $\left[\mathrm{Gd}(\mathrm{acac})_{3}(\mathrm{TOPO})_{2}\right]$ com magnificação de (7000x). 


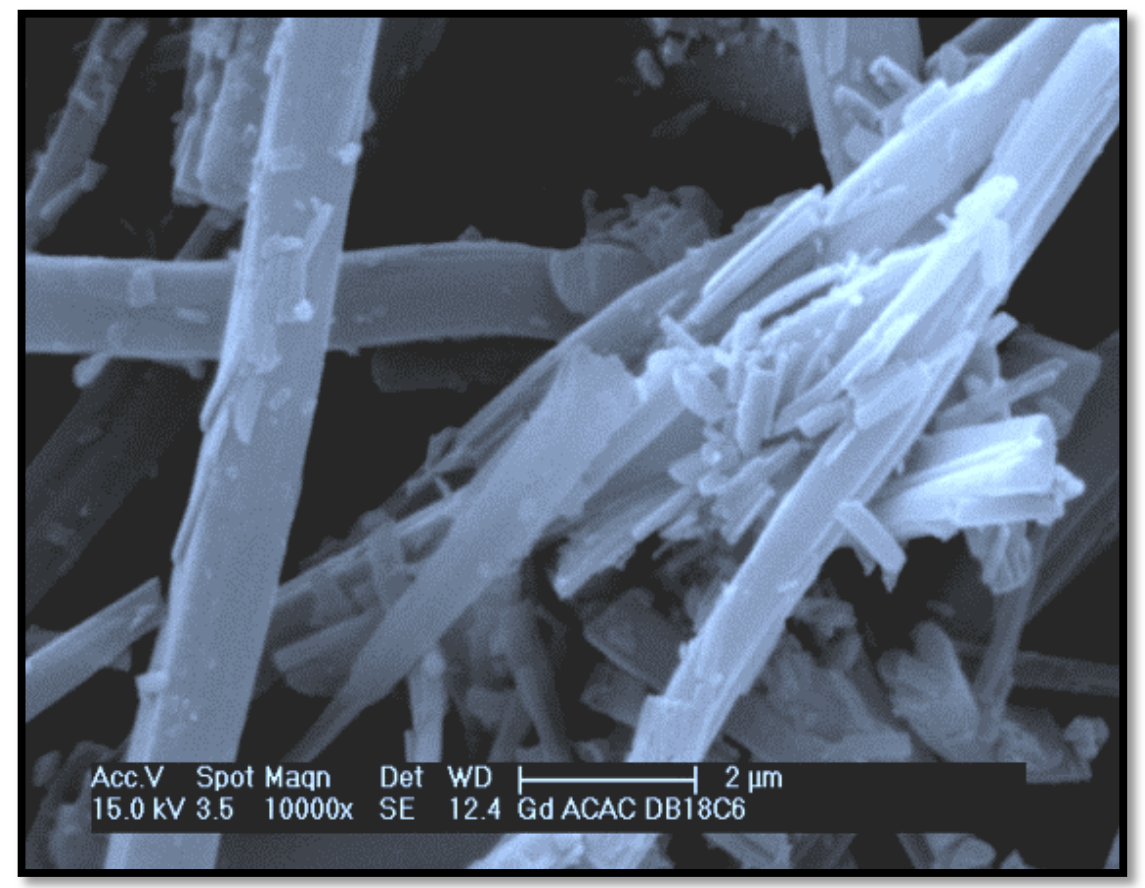

FIGURA 5.30 - Micrografia do complexo $\left[\mathrm{Gd}(\mathrm{acac})_{3}(\mathrm{DB} 18 \mathrm{C} 6)_{2}\right]$ com magnificação de (10000x).

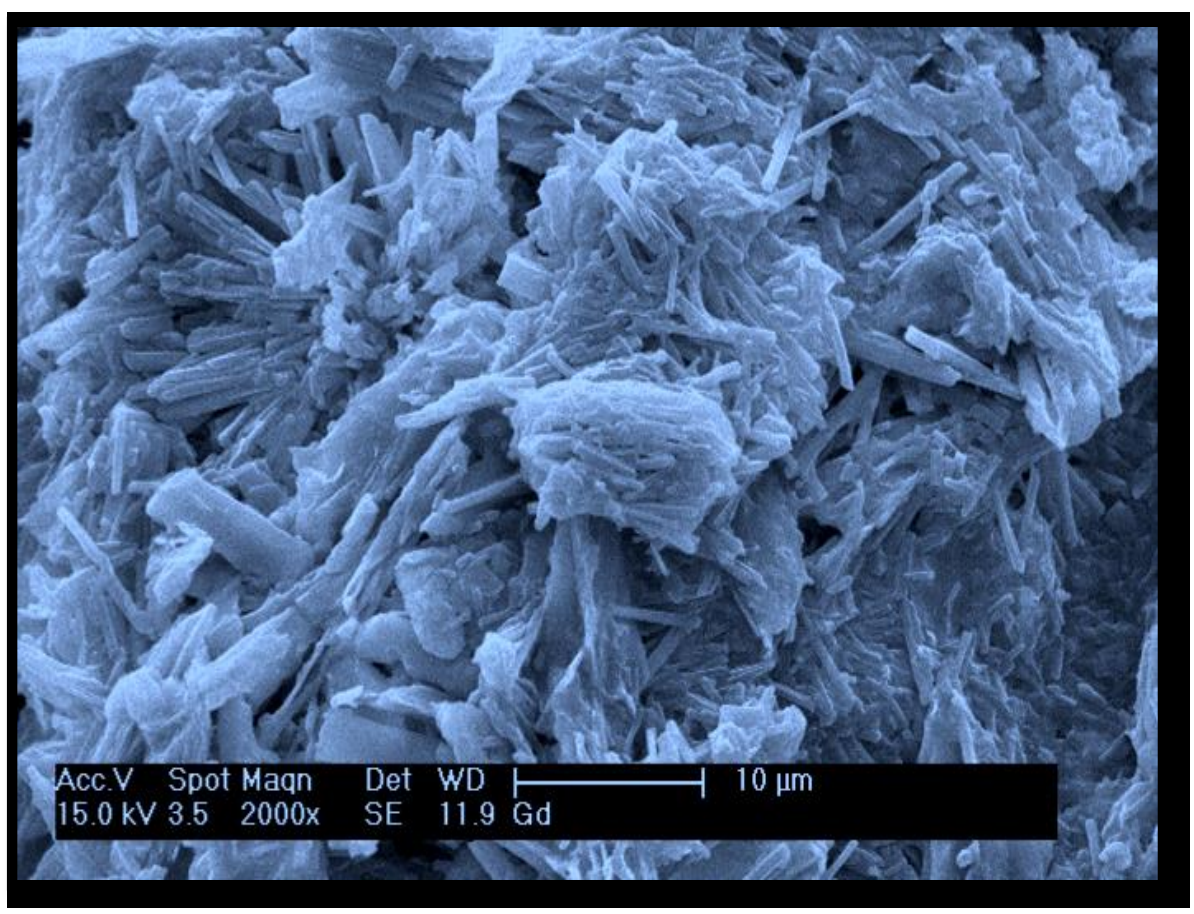

FIGURA 5.31 - Micrografia do complexo $\left[\mathrm{Gd}(\mathrm{acac})_{3}(18 \mathrm{C} 6)_{2}\right]$ com magnificação de (2000x). 
As micrografias dos complexos de tta de gadolínio contendo os ligantes auxiliares TPPO, DB18C6 e 18C6 apresentam-se na forma de cristais aglomerados. Eles são heterogêneos e apresentam tamanho de aglomerados variados. As FIGURAS $\mathbf{5 . 3 2}$ a $\mathbf{5 . 3 4}$ mostram as imagens das micrografias destes complexos. O complexo de $\left[\mathrm{Gd}(\mathrm{tta})_{3}(\mathrm{TPPO})_{2}\right]$ apresenta-se na forma de aglomerados muito pequenos, menores do que $5 \mu \mathrm{m}$ e formados por nanopartículas esféricas como mostrado na FIGURA 5.32. O complexo de $\left[\mathrm{Gd}(\mathrm{tta})_{3}(\mathrm{DB} 18 \mathrm{C} 6)_{2}\right]$, FIGURA 5.33, apresenta uma morfologia heterogênea onde fios bastonetes e napartículas segregadas na superfície compõem a imagem. Já o complexo de $\left[\mathrm{Gd}(\mathrm{tta})_{3}(18 \mathrm{C} 6)_{2}\right]$ mostra moforlogia heterogênea compostas na sua maioria por bastonetes e nanopartículas.

O complexo de $\left[\mathrm{Gd}(\mathrm{tta})_{3}(\mathrm{TOPO})_{2}\right]$ foi obtido no estado liquido, com viscosidade acentuada não sendo possível a obtenção das micrografias. 


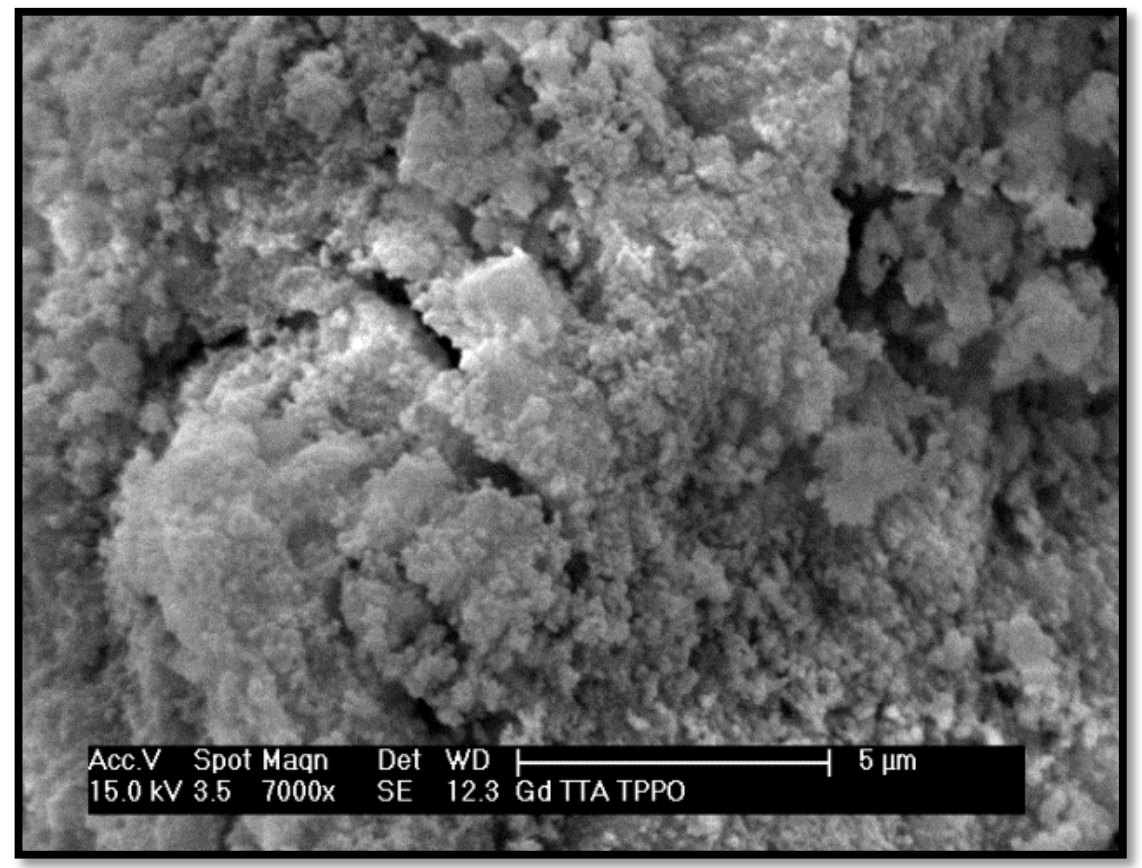

FIGURA 5.32 - Micrografia do complexo $\left[\mathrm{Gd}(\mathrm{tta})_{3}(\mathrm{TPPO})_{2}\right]$ com magnificação de (7000x).

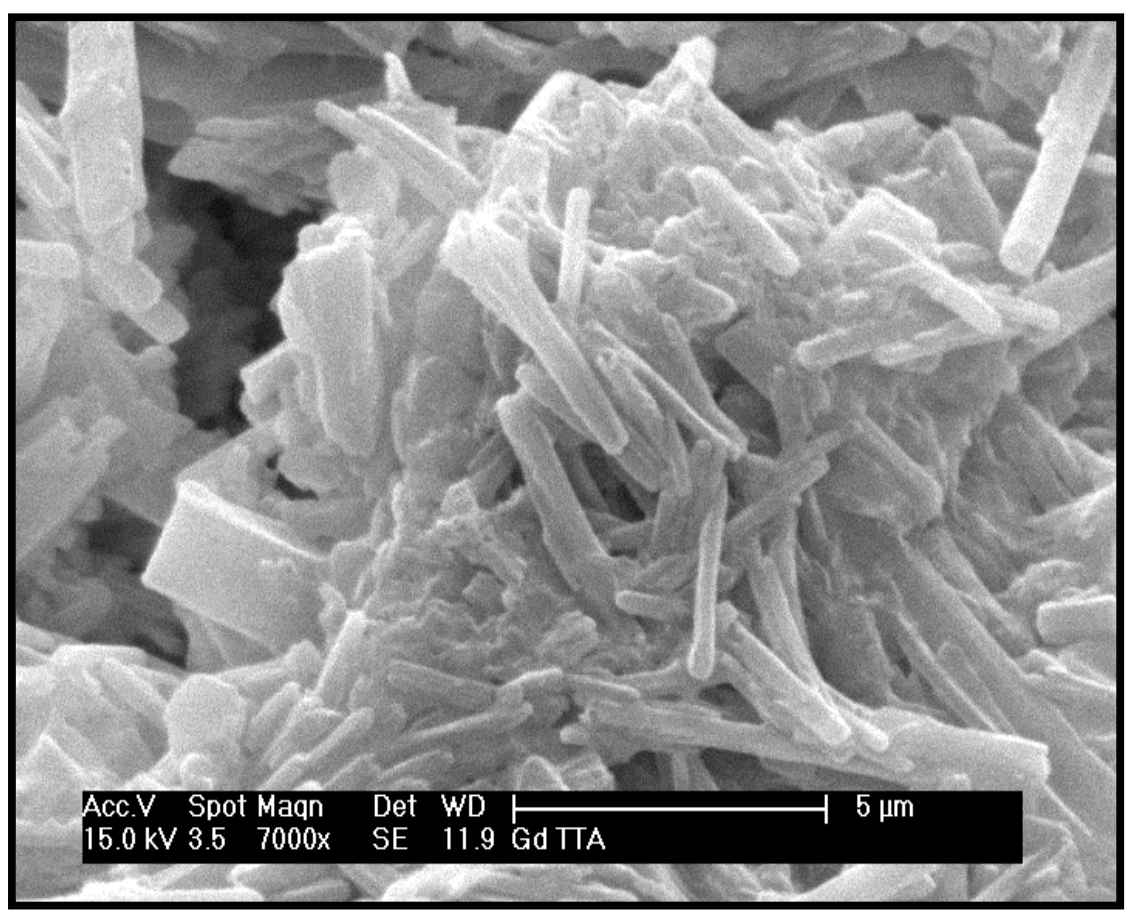

FIGURA 5.33 - Micrografia do complexo $\left[\mathrm{Gd}(\mathrm{tta})_{3}(\mathrm{DB} 18 \mathrm{C} 6)_{2}\right]$ com magnificação de $(7000 x)$. 


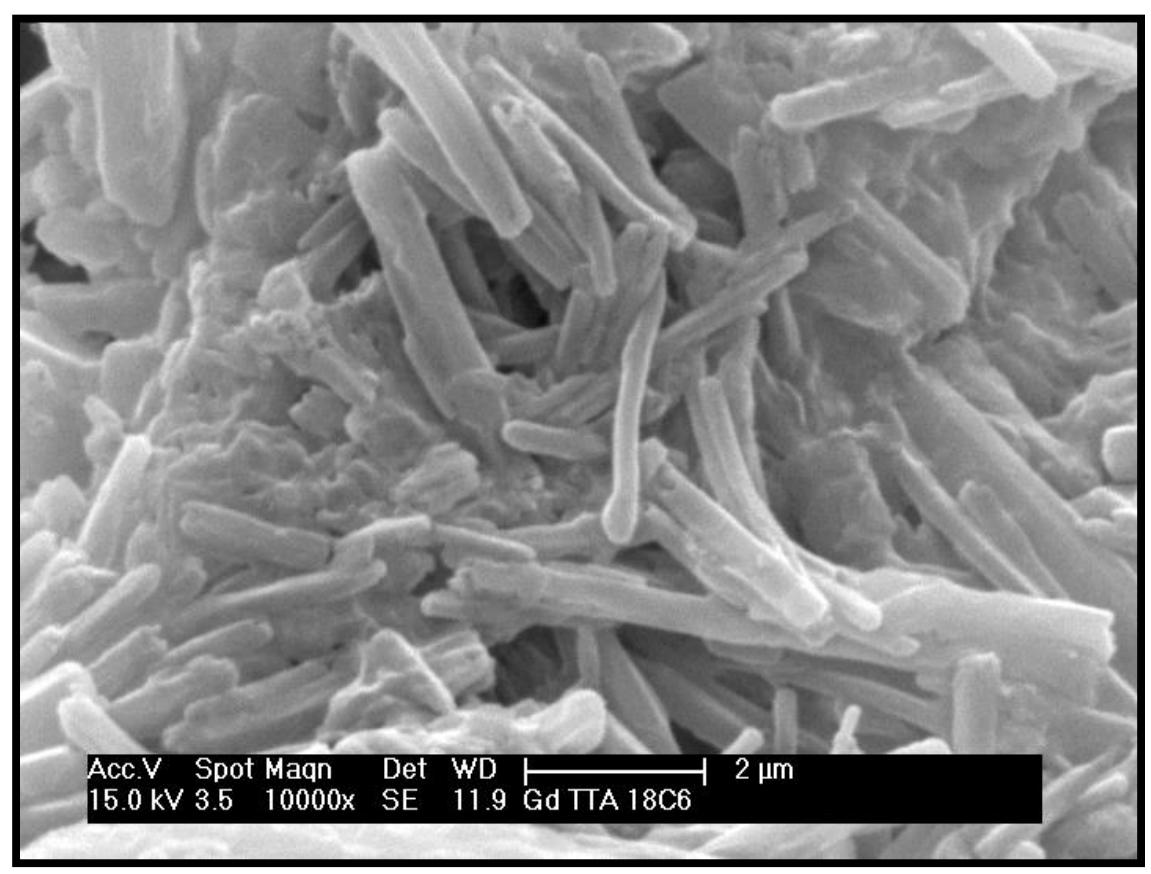

FIGURA 5.34 - Micrografia do complexo $\left[\mathrm{Gd}(\mathrm{tta})_{3}(18 \mathrm{C} 6)_{2}\right]$ com magnificação de (10000x).

5.2 Estudo de luminescência dos complexos $\left[\mathrm{TR}^{3+}(\beta \text {-dicetonato })_{3}(\mathrm{~L})_{2}\right]$ $\left(\mathrm{TR}=\mathrm{Tb}^{3+}, \mathrm{Eu}^{3+}\right.$ e $\mathrm{Gd}^{3+} ; \beta$-dicetonato= acac e tta; L=TPPO, TOPO, DB18C6 e 18C6)

\subsubsection{Estudo de fosforescência dos complexos de $\mathbf{G d}^{3+}$}

O íon gadolínio trivalente $\left(\mathrm{Gd}^{3+}\right)$ configuração $4 \mathrm{f}^{7}$ não apresenta luminescência visível sob excitação na região do ultravioleta como os demais íons terras raras estudados neste trabalho. Porém o íon $\mathrm{Gd}^{3+}$ é utilizado devido ao fato de ser paramagnético e possuir um momento magnético muito alto. Isso é um fator muito importante no efeito de relaxação, pois os íons com maior momento magnético são os mais eficientes nos seus efeitos de relaxação protônica ${ }^{[30,31]}$. Considerando que a fosforescência do ligante é completamente suprimida em temperatura ambiente, é necessário registrar os espectros dos compostos em baixa temperatura, evitando assim, que os estados $\mathbf{T}$ sejam desativados por processos não radiativos. Portanto, para determinar os estados excitados $\mathbf{S}_{1} \mathrm{e}$ $\mathbf{T}_{1}$ dos ligantes $\beta$-dicetonatos (acac e tta), registraram-se os espectros de 
excitação dos respectivos complexos de $\mathrm{Gd}^{3+}$, a $77 \mathrm{~K}$, monitorando-se no comprimento de onda de emissão do estado excitado $\mathbf{T}_{1}$ proveniente da parte orgânica.No entanto, em sistemas contendo íons $\mathrm{TR}^{3+}$, frequentemente se utilizam os espectros de emissão dos complexos de gadolínio, normalmente a baixa temperatura (minimizando efeitos vibracionais), para a determinação dos estados singlete $S_{1}$ e triplete $T_{1}$ do ligantes ${ }^{[32]}$. O nível excitado de mais baixa energia do $\mathrm{Gd}^{3+}\left({ }^{6} \mathrm{P}_{7 / 2}, \sim 32000 \mathrm{~cm}^{-1}\right)$ apresenta energia mais elevada do que $\mathrm{o}$ estado $T_{1}$ de grande maioria dos ligantes. Por apresentar elevado paramagnetismo $(S=7 / 2)$ e efeito de átomo pesado, $\circ \mathrm{Gd}^{3+}$ pode induzir um forte cruzamento intersistema singleto/tripleto em seus ligantes e, consequentemente, uma maior taxa de população do estado tripleto. Pelo acoplamento spin-órbita, o estado tripleto adquire um caráter singleto parcial e as regras de seleção não são obedecidas completamente, resultando em uma intensificação da fosforescência ${ }^{[32,33]}$. O estudo de fosforescência dos estados tripletos das matrizes é de grande importância na interpretação do processo de transferência de energia intramolecular do ligante ao íon $\mathrm{TR}^{3+}$, em particular os

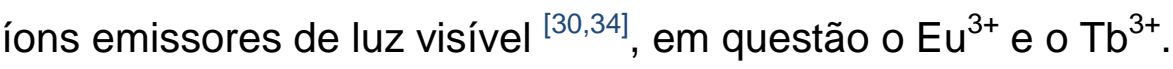

$\mathrm{Na}$ FIGURA 5.35 e 5.36 são apresentados os espectros de emissão dos complexos $\left[\mathrm{Gd}(\beta \text {-dicetonatos })_{3}(\mathrm{~L})_{2}\right](\mathrm{L}=\mathrm{TPPO}, \mathrm{TOPO}, \mathrm{DB} 18 \mathrm{C} 6$ e 18C6). Os espectros mostram bandas alargadas no intervalo de 400 a $750 \mathrm{~nm}$ atribuídas às transições características dos ligantes $\beta$-dicetonatos. Estas bandas largas de fosforescência exibidas nas FIGURAS 5.35 e $\mathbf{5 . 3 6}$ foram atribuídas às transições eletrônicas do ligante, tripleto-singleto $\left(\mathbf{T}_{1} \rightarrow \mathbf{S}_{0}\right)$. A energia máxima de emissão a partir do estado $\mathbf{T}_{1}$ dos complexos com o íon $\mathrm{Gd}^{3}$ + (TAB. 5.6) possibilita prever, para cada ligante $\beta$-dicetonato utilizado, qual íon $\mathrm{TR}^{3+}$ possui o nível aceptor mais adequado para o processo de transferênciade energia ligante $\rightarrow$ íon metálico.Em particular, concordando com os dados da literatura ${ }^{[35]}$, observa-se que o ligante acac é mais adequado para transferir energia ao nível aceptor ${ }^{5} \mathrm{D}_{4}$ do íon $\mathrm{Tb}^{3+}\left(20.400 \mathrm{~cm}^{-1}\right)$ e o ligante tta é mais apropriados para $\mathrm{O}$ íon $\mathrm{Eu}^{3+}$ devido à energia do nível ${ }^{5} \mathrm{D}_{0}$ localizar-se em $\sim 17.000 \mathrm{~cm}^{-1}$, pelo menos para os complexos contendo as moléculas de água.

No caso dos complexos de tta com TOPO ou com TPPO, o estado estacionário é da ordem de $24.575 \mathrm{~cm}^{-1}$, sendo possível também ser utilizado para obter complexos altamente luminescentes com íon $\mathrm{Tb}^{3+}$. 


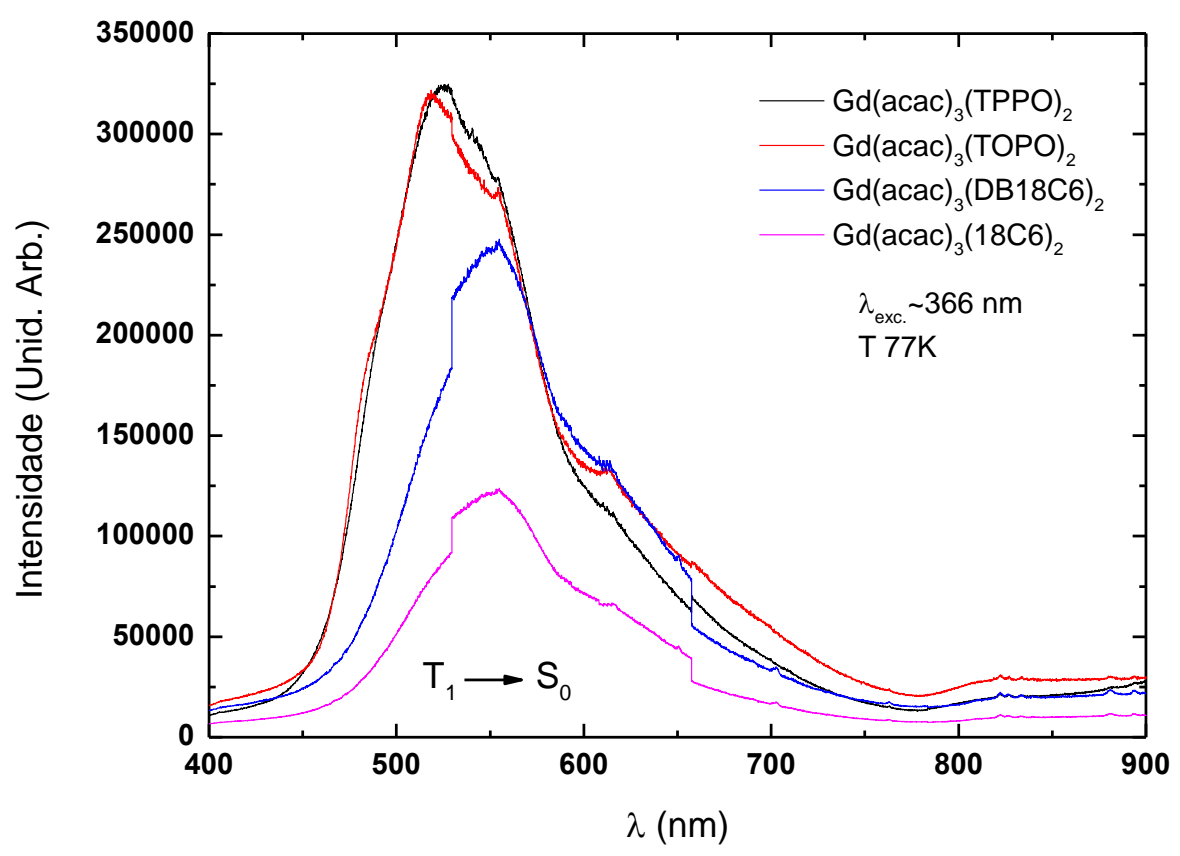

FIGURA 5.35 - Espectros de emissão dos complexos de acac de $\mathrm{Gd}^{3+}$ com diferentes ligantes orgânicos auxiliares no intervalo de 400-900 nm, registrados à baixa temperatura, e sob excitação em $366 \mathrm{~nm}$.

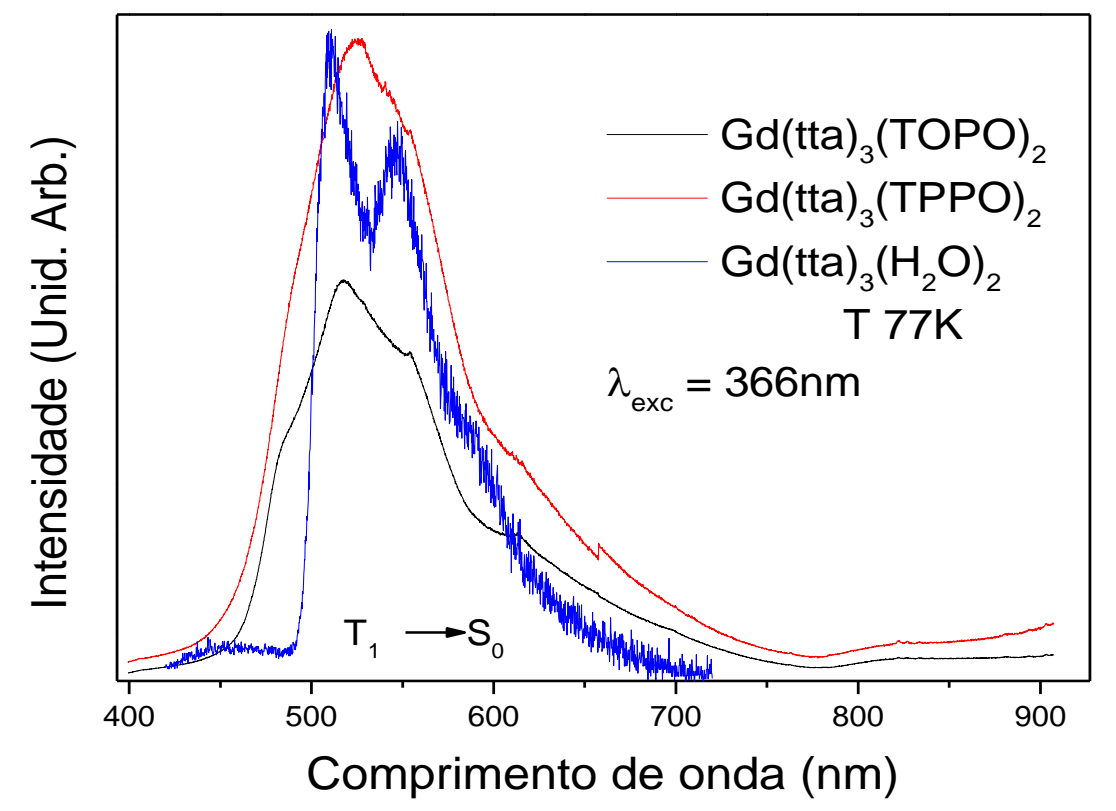

FIGURA 5.36 - Espectros de emissão dos complexos de tta de $\mathrm{Gd}^{3+}$ com diferentes ligantes orgânicos auxiliares no intervalo de 400-900 nm, registrados a baixa temperatura, e sob excitação em $366 \mathrm{~nm}$. 
TABELA 5.6 - Atribuição do estado $\mathrm{T}_{1}$ emissor dos ligantes $\beta$-dicetonatos e ligantes auxiliares a partir dos dados espectrais dos complexos de $\mathrm{Gd}^{3+}$ no estado estacionário.

\begin{tabular}{lcc}
\hline Amostras & $\begin{array}{c}\text { Estado } \\
\text { estacionário } \\
T_{1}\left(\mathrm{~cm}^{-1}\right)\end{array}$ & $\begin{array}{c}\text { Pelo baricentro da banda } \\
\mathrm{T} 1\left(\mathrm{~cm}^{-1}\right)\end{array}$ \\
\hline$\left[\mathrm{Gd}(\mathrm{acac})_{3}\left(\mathrm{H}_{2} \mathrm{O}\right)_{3}\right]$ & 26600 & \\
{$\left[\mathrm{Gd}(\mathrm{acac})_{3}(\mathrm{TOPO})_{2}\right]$} & 24318 & 19286 \\
{$\left[\mathrm{Gd}(\mathrm{acac})_{3}(\mathrm{TPPO})_{2}\right]$} & 24188 & 18951 \\
{$\left[\mathrm{Gd}(\mathrm{acac})_{3}(\mathrm{DB} 18 \mathrm{C} 6)_{2}\right]$} & 24150 & 18018 \\
{$\left[\mathrm{Gd}(\mathrm{acac})_{3}(\mathbf{1 8 C 6})_{2}\right]$} & 24150 & 18018 \\
{$\left[\mathrm{Gd}(\mathrm{tta})_{3}\left(\mathrm{H}_{2} \mathrm{O}\right)_{2}\right]$} & 20492 & 20325 \\
{$\left[\mathrm{Gd}(\mathrm{tta})_{3}(\mathrm{TOPO})_{2}\right]$} & 24575 & 19313 \\
{$\left[\mathrm{Gd}(\mathrm{tta})_{3}(\mathrm{TPPO})_{2}\right]$} & 24575 & 18951 \\
\hline
\end{tabular}

5.2.2 Luminescência dos Complexos $\left[\mathrm{TR}^{3+}(\beta \text {-dicetonato })_{3}(\mathrm{~L})_{2}\right]\left(\mathrm{TR}=\mathrm{Tb}^{3+} ; \beta\right.$ dicetonato= acac; L=TPPO, TOPO, DB18C6 e 18C6)

\subsubsection{Fotoluminescência em complexos de $\mathrm{Tb}^{3+}$}

O íon térbio trivalente $\left(\mathrm{Tb}^{3+}\right)$ tem a configuração eletrônica $4 f^{8}$ e contém os níveis Stark do íon $\mathrm{Eu}^{3+}$, porém invertidos.

Os espectros luminescentes de compostos de $\mathrm{Tb}^{3+}$ (configuração eletrônica $\left.4 f^{8}\right)$ geralmente exibem bandas originadas das transições ${ }^{5} \mathrm{D}_{4} \rightarrow{ }^{7} \mathrm{FJ}_{\mathrm{J}}(\mathrm{J}$ $=6,5,4,3,2,1,0)$ (FIG. 37), com a transição hipersensível ${ }^{5} D_{4} \rightarrow{ }^{7} F_{5}$ em torno de $540 \mathrm{~nm}$ proeminente, e conseqüentemente, estes exibem cores de emissão verde na presença de radiação UV. Seu estado fundamental é representado pelo nível ${ }^{7} F_{6}$, pois possui configuração eletrônica $[X e] 4 f^{8}\left(f^{n} \operatorname{com} n>7 ; J=L\right.$ $+S$ ). 
O íon térbio trivalente $\left(\mathrm{Tb}^{3+}\right)$ tem a configuração eletrônica $4 f^{8}$ e contém os mesmos níveis Stark do íon $\mathrm{Eu}^{3+}$, porém invertidos. Devido à alta degenerescência desses níveis, ambas as atribuições das transições ${ }^{7} F_{6} \rightarrow{ }^{5} D_{5}$ e ${ }^{5} D_{4} \rightarrow^{7} F_{J}$, a partir dos espectros de excitação e emissão, tendem a ser mais complicadas quando comparadas àquela do íon $\mathrm{Eu}^{3+}{ }^{[2]}$ visto que o nível emissor ${ }^{5} D_{4}$ é nona-degenerado. Portanto, o estudo espectroscópico dos compostos derivados do íon $\mathrm{Tb}^{3+}$ tem atraído atenção modesta quando comparado ao íon $\mathrm{Eu}^{3+}{ }^{[1]}$. A diferença de energia entre o estado emissor ${ }^{5} \mathrm{D}_{4} \mathrm{e}$ o estado ${ }^{7} F_{0}$, é de aproximadamente de $15.000 \mathrm{~cm}^{-1}$.

Deve-se salientar que os ligantes $\beta$-dicetonatos bons sensibilizadores de emissão para o íon $\mathrm{Eu}^{3+}$, e que apresentam estados $\mathbf{T}_{1}$ energeticamente abaixo do nível ressonante ${ }^{5} \mathrm{D}_{4}$, transferem pouca ou nenhuma energia para este nível do íon $\mathrm{Tb}^{3+}$. Em função do baixo custo, o ligante acetilacetonato $\left(\mathbf{T}_{1} \cong 26.000\right.$ $\mathrm{cm}^{-1}$ ) é o mais utilizado como antena para o íon $\mathrm{Tb}^{3+}$ dentre as $\beta$-dicetonas. No caso de complexo $\left[\mathrm{Tb}(\mathrm{acac})_{3}\left(\mathrm{H}_{2} \mathrm{O}\right)_{3}\right]$, os ligantes acac não exibem bandas de emissão largas do estado $\mathbf{T}_{1}$ na faixa espectral de 370 a $550 \mathrm{~nm}$, evidenciando uma eficiente transferência de energia do ligante ao nível emissor ${ }^{5} \mathrm{D}_{4}$ do íon $\mathrm{Tb}^{3+}$. Geralmente, a sensibilização luminescente em complexos de $\mathrm{Tb}^{3+}$ é similar àqueles complexos de $\mathrm{Eu}^{3+}$. Por outro lado, o estado $\mathbf{T}_{1}$ dos ligantes beta-dicetonatos tem que estar acima ou em ressonância com o nível emissor ${ }^{4} \mathrm{D}_{4}$ do íon $\mathrm{Tb}^{3+}\left(\cong 20.400 \mathrm{~cm}^{-1}\right)$. 


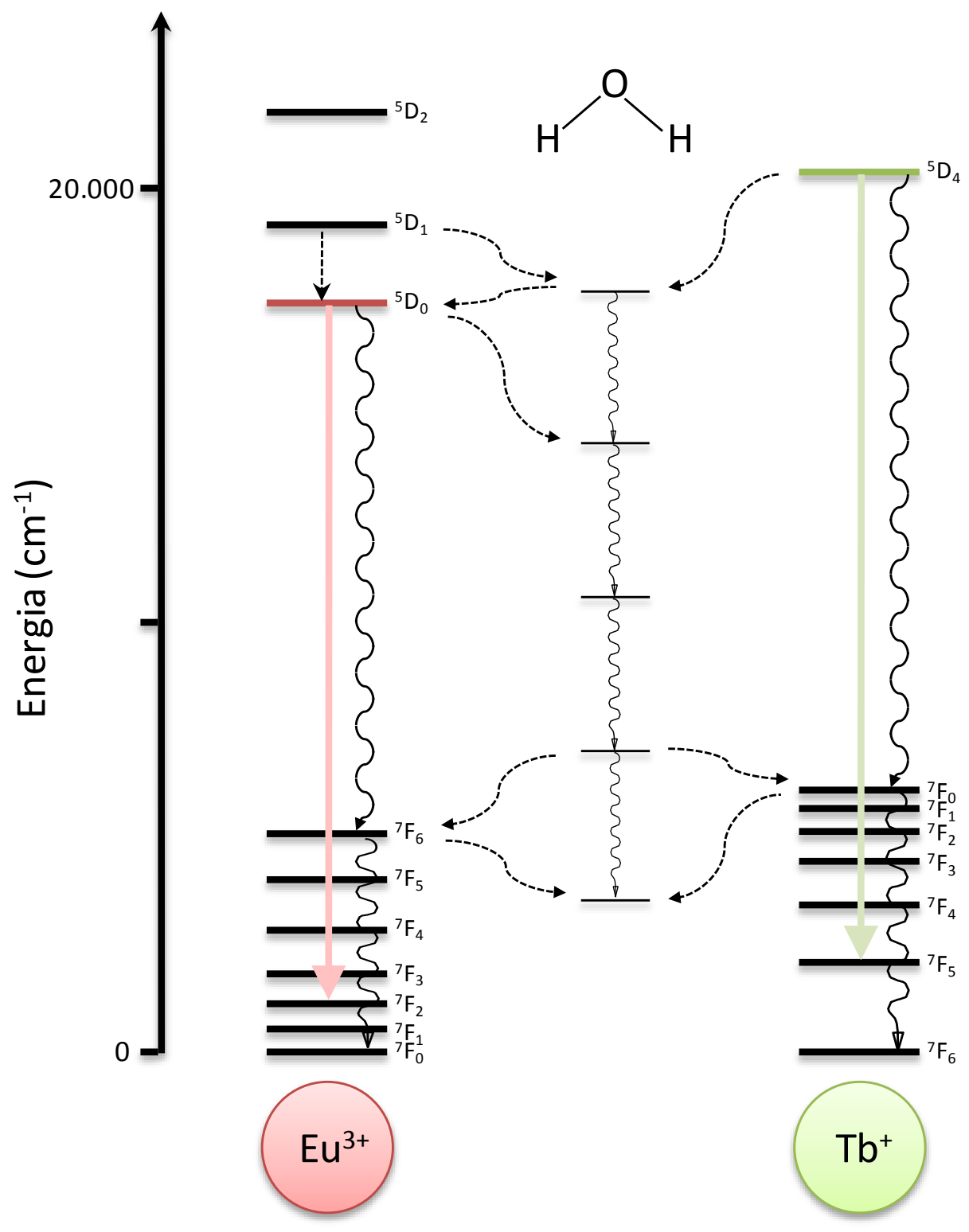

FIGURA 5.37 - Supressão dos níveis emissores ${ }^{5} D_{0}$ e ${ }^{5} D_{4}$ dos íons $E u^{3+}$ e Tb ${ }^{3+}$, respectivamente, pela presença de osciladores $\mathrm{O}-\mathrm{H}^{[36]}$.

Ademais, como o íon $\mathrm{Tb}^{3+}$ não apresenta uma transição de referência semelhante à do $\mathrm{Eu}^{3+}$, assim, as investigações fotoluminescentes dos complexos de $\mathrm{Tb}^{3+}$, no estado sólido, são mais restritas. A respeito das transições oriundas do estado emissor ${ }^{5} \mathrm{D}_{4}$ para os níveis ${ }^{7} \mathrm{~F}_{\mathrm{J}}$, pode-se notar Q(IR). (TAB. 
TABELA 5.7 - Transições oriundas do estado emissor ${ }^{5} D_{4}$ para os níveis ${ }^{7} F_{J}$.

- ${ }^{5} \mathrm{D}_{4} \rightarrow{ }^{7} \mathrm{~F}_{6}$ : sensível ao ambiente químico;

- ${ }^{5} D_{4} \rightarrow{ }^{7} F_{5}$ : hipersensível, forte atividade óptica, mais utilizada como sonda;

- ${ }^{5} \mathrm{D}_{4} \rightarrow{ }^{7} \mathrm{~F}_{4}$ : sensível ao ambiente do íon $\mathrm{Tb}^{3+}$, atividade óptica moderada;

$-{ }^{5} \mathrm{D}_{4} \rightarrow{ }^{7} \mathrm{~F}_{3}:$ forte atividade óptica;

$-{ }^{5} \mathrm{D}_{4} \rightarrow{ }^{7} \mathrm{~F}_{2}$ : sensível ao ambiente químico;

$-{ }^{5} D_{4} \rightarrow{ }^{7} F_{1}$ : baixa intensidade

$-{ }^{5} D_{4} \rightarrow{ }^{7} F_{0}:$ baixa intensidade.

Tem-se observado que os complexos hidratados contendo o íon $\mathrm{Tb}^{3+}$ apresentam uma menor supressão de luminescência do que os respectivos complexos de $\mathrm{Eu}^{3+}$, devido à maior diferença de energia entre os estados ${ }^{5} \mathrm{D}_{4} \mathrm{e}$ $\mathrm{o}^{7} \mathrm{~F}_{0}$ do íon $\mathrm{Tb}^{3+}$ que acoplam com um maior número de osciladores -OH (FIG. 5.37). Desta forma, embora o complexo $\left[\mathrm{Tb}(\mathrm{acac})_{3}\left(\mathrm{H}_{2} \mathrm{O}\right)_{3}\right]$ demonstre forte emissão, prevê-se uma intensificação com a substituição das moléculas de água por outros ligantes que sensibilizem as emissões do íon $\mathrm{Tb}^{3+}$. Neste contexto, este trabalho apresenta a síntese de quatro novos complexos de $(\beta$ dicetonatos) de $\mathrm{Tb}^{3+}$, $\left[\mathrm{Tb}(\mathrm{acac})_{3} \mathrm{~L}_{2}\right]$, onde $\mathrm{L}=\mathrm{DB} 18 \mathrm{C} 6,18 \mathrm{C} 6$, TOPO e TPPO. 
TABELA 5.8 - Faixas espectrais, intensidades relativas e baricentros usualmente observados para as transições ${ }^{5} \mathrm{D}_{4} \rightarrow{ }^{7} \mathrm{~F}_{\mathrm{J}}$ do íon $\mathrm{Tb}^{3+[36-38]}$.

\begin{tabular}{|c|c|c|c|}
\hline Transição & Faixa (nm) & I & Baricentro (nm) \\
\hline${ }^{5} D_{4} \rightarrow^{7} F_{6}$ & 480 a 505 & $\mathrm{~m} \leftrightarrow \mathrm{i}$ & 489 \\
\hline${ }^{5} D_{4} \rightarrow^{7} F_{5}$ & 535 a 555 & $\mathrm{i} \leftrightarrow \mathrm{mi}$ & 544 \\
\hline${ }^{5} D_{4} \rightarrow^{7} F_{4}$ & 580 a 600 & $\mathrm{~m} \leftrightarrow \mathrm{i}$ & 586 \\
\hline${ }^{5} D_{4} \rightarrow^{7} F_{3}$ & 615 a 625 & $\mathrm{~m}$ & 620 \\
\hline${ }^{5} D_{4} \rightarrow^{7} F_{2}$ & 640 a 655 & $\mathrm{~m}$ & 648 \\
\hline${ }^{5} D_{4} \rightarrow{ }^{7} F_{1}$ & 660 a 670 & pi & 667 \\
\hline${ }^{5} \mathrm{D}_{4} \rightarrow{ }^{7} \mathrm{~F}_{0}$ & 675 a 680 & pi & 678 \\
\hline
\end{tabular}

${ }^{\text {(a) }}$ Caráter dipolar predominante: $\mathrm{DE}=$ dipolo elétrico; $\mathrm{DM}=$ dipolo magnético.

(b) Intensidade relativa: $\mathrm{pi}=$ pouco intensa, $\mathrm{m}=$ média, $\mathrm{i}=$ intensa $\mathrm{e} \mathrm{mi}=$ muito intensa.

${ }^{(c)}$ Baricentro aproximado.

\subsection{Investigação a partir dos espectros de excitação}

O espectro de excitação do complexo $\left[\mathrm{Tb}(\mathrm{acac})_{3}\left(\mathrm{H}_{2} \mathrm{O}\right)_{3}\right]$ (FIG. 5.38), exibe desdobramentos característicos para o íon $\mathrm{Tb}^{3^{+}}$apresentando emissões de cor verde ( 546 nm). Observa-se a presença de bandas características das transições do íon $\mathrm{Tb}^{3+}$, atribuídas às transições ${ }^{7} \mathrm{~F}_{6} \rightarrow{ }^{5} \mathrm{G}_{6},{ }^{7} \mathrm{~F}_{6} \rightarrow{ }^{5} \mathrm{D}_{4}$. A FIGURA 5.39 apresenta os espectros de excitação dos complexos de térbio com os ligantes auxiliares apresentando também transições características do íon $\mathrm{Tb}^{3+}$.

A FIGURA 5.39 apresenta os espectros de excitação dos complexos de $\mathrm{Tb}^{3+}$ contendo os ligantes acac e os ligantes auxiliares com emissão monitorada em 549 nm, à $298 \mathrm{~K}$, no intervalo entre 250 a 480 nm. 
Verificou-se uma banda larga na região de 250 a 400 nm com máximo em 302 $\mathrm{nm}$ para o $\mathrm{Tb}(\mathrm{acac})_{3}(\mathrm{DB} 18 \mathrm{C} 6)_{2}$, e em $~ 330 \mathrm{~nm}$ para os espectros dos demais ligantes auxiliares, atribuídas à transição $\mathbf{S}_{0} \rightarrow \mathbf{S}_{1}$ do ligante $\beta$-dicetonato. As bandas finas convoluidas com a banda larga atribuída a transição $\mathbf{S}_{0} \rightarrow \mathbf{S}_{1}$ do ligante $\beta$-dicetonato 302,$8 ; 318,0 ; 340,6 ; 351,0 ; 357,8 ; 369,0 ; 376,8 ; 420,4$; 475,$0 ; 450,2 ; 462,6 ; 467,8$ e 473,4 nm para $\circ \mathrm{Tb}(\mathrm{acac})_{3}(\mathrm{DB} 18 \mathrm{C} 6)_{2}$, e 330,0 ; 358,$4 ; 370,4 ; 377,8 \mathrm{~nm}$, aproximadamente, para os demais complexos correspondem às transições ${ }^{7} \mathrm{~F}_{6} \rightarrow{ }^{5} \mathrm{G} J_{\jmath},{ }^{5} \mathrm{~L}_{\jmath} \mathrm{e}^{5} \mathrm{D}_{\jmath}$ do íon $\mathrm{Tb}^{3+}$.

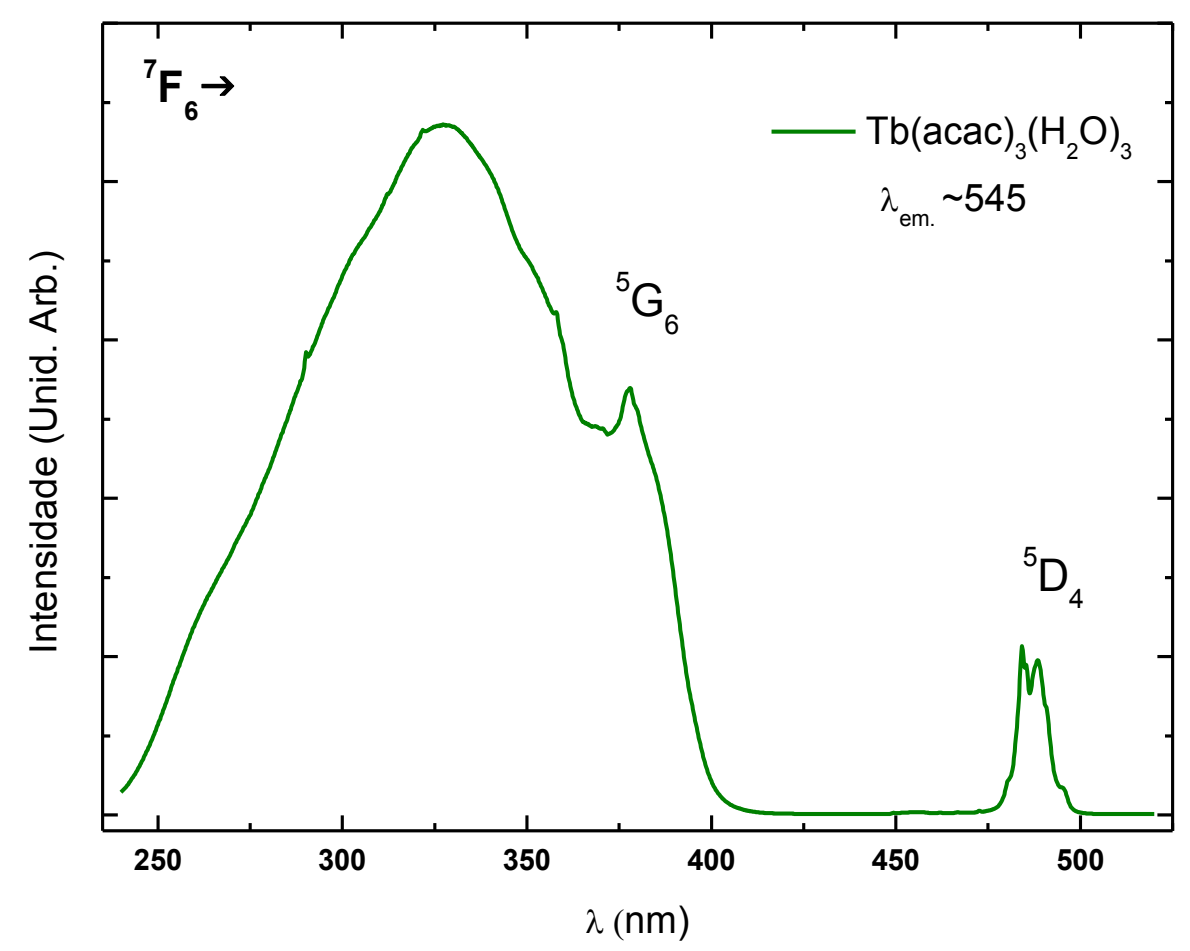

FIGURA 5.38 - Espectro de excitação do complexo $\left[\mathrm{Tb}(\mathrm{acac})_{3}\left(\mathrm{H}_{2} \mathrm{O}\right)_{3}\right]$, registrado à temperatura ambiente, no intervalo de 245-525 nm, com emissão monitorada em $545 \mathrm{~nm}$. 


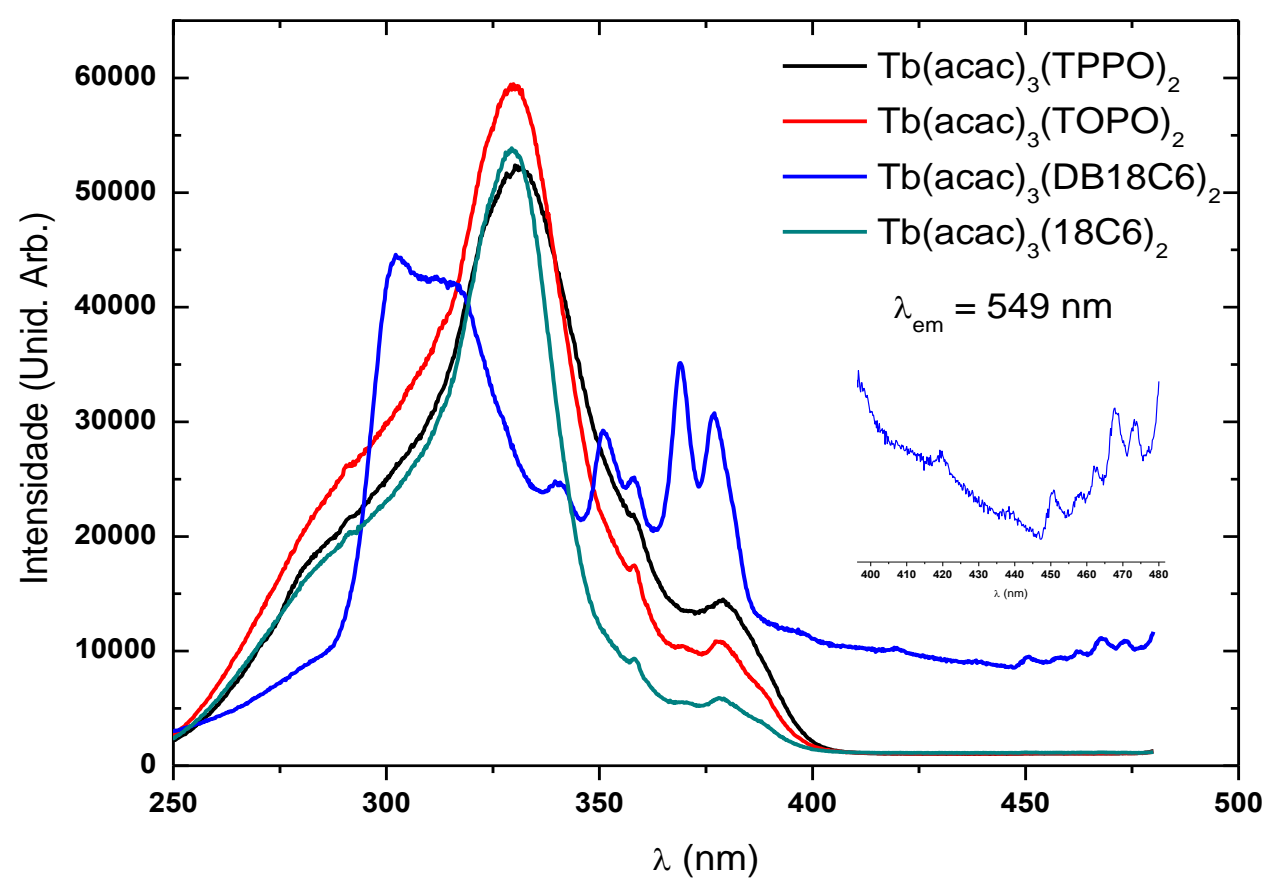

FIGURA 5.39 - Espectros de excitação dos complexos [Tb(acac $\left.)_{3}(\mathrm{TPPO})_{2}\right]$, $\left[\mathrm{Tb}(\mathrm{acac})_{3}(\mathrm{TOPO})_{2}\right],\left[\mathrm{Tb}(\mathrm{acac})_{3}(\mathrm{DB} 18 \mathrm{C} 6)_{2}\right]$ e $\left[\mathrm{Tb}(\mathrm{acac})_{3}(18 \mathrm{C} 6)_{2}\right]$ registrado à temperatura ambiente, no intervalo de 250 a 500 nm, com emissão monitorada em $549 \mathrm{~nm}$.

\subsection{Investigação a partir dos espectros de emissão}

Na FIGURA 5.40 apresentam-se os espectros de emissão dos complexos de $\mathrm{Tb}^{3+}$. São espectros típicos da configuração $4 f^{8}$ do íon térbio, com bandas finas relacionadas às transições ${ }^{5} D_{4} \rightarrow{ }^{7} F_{J^{\prime}}\left(J^{\prime}=0-6\right)$, sendo a ${ }^{5} \mathrm{D}_{4} \rightarrow{ }^{7} \mathrm{~F}_{6}$ em $\sim 491 \mathrm{~nm},{ }^{5} \mathrm{D}_{4} \rightarrow{ }^{7} \mathrm{~F}_{5}$ em $\sim 548 \mathrm{~nm},{ }^{5} \mathrm{D}_{4} \rightarrow{ }^{7} \mathrm{~F}_{4} \mathrm{em} \sim 588 \mathrm{~nm},{ }^{5} \mathrm{D}_{4} \rightarrow{ }^{7} \mathrm{~F}_{3}$ em $\sim 617 \mathrm{~nm},{ }^{5} \mathrm{D}_{4} \rightarrow{ }^{7} \mathrm{~F}_{2}$ em $\sim 650 \mathrm{~nm},{ }^{5} \mathrm{D}_{4} \rightarrow{ }^{7} \mathrm{~F}_{1}$ em $\sim 670 \mathrm{~nm} \mathrm{e}{ }^{5} \mathrm{D}_{4} \rightarrow{ }^{7} \mathrm{~F}_{0}$ em 700 $\mathrm{nm}$ (Tab 5.8). A transição ${ }^{5} \mathrm{D}_{4} \rightarrow{ }^{7} \mathrm{~F}_{5}$ apresenta-se como a de maior intensidade.

Dentre estes complexos, aqueles contendo os ligantes TPPO e TOPO mostram bandas de intensidade maiores (FIG.5.40), caracterizando maior eficiência luminescente.

De acordo com Latva et al. ${ }^{[3]}$, a transferência intramolecular de energia de um ligante para o íon $\mathrm{Tb}^{3+}$ é mais favorecida quando a diferença de energia 
entre o estado $\mathbf{T}$ do ligante e o primeiro nível emissor ${ }^{5} \mathrm{D}_{4}$ do $\mathrm{Tb}^{3+}$ for maior que $2000 \mathrm{~cm}^{-1}$. Em caso contrário pode existir o fenômeno de retrotransferência de energia do íon $\mathrm{Tb}^{3+}$ para o estado tripleto do ligante, ${ }^{5} \mathrm{D}_{4} \rightarrow \mathbf{T}$, que atua como um processo não radiativo e, consequentemente, diminui a eficiência de luminescência ${ }^{[4]}$.

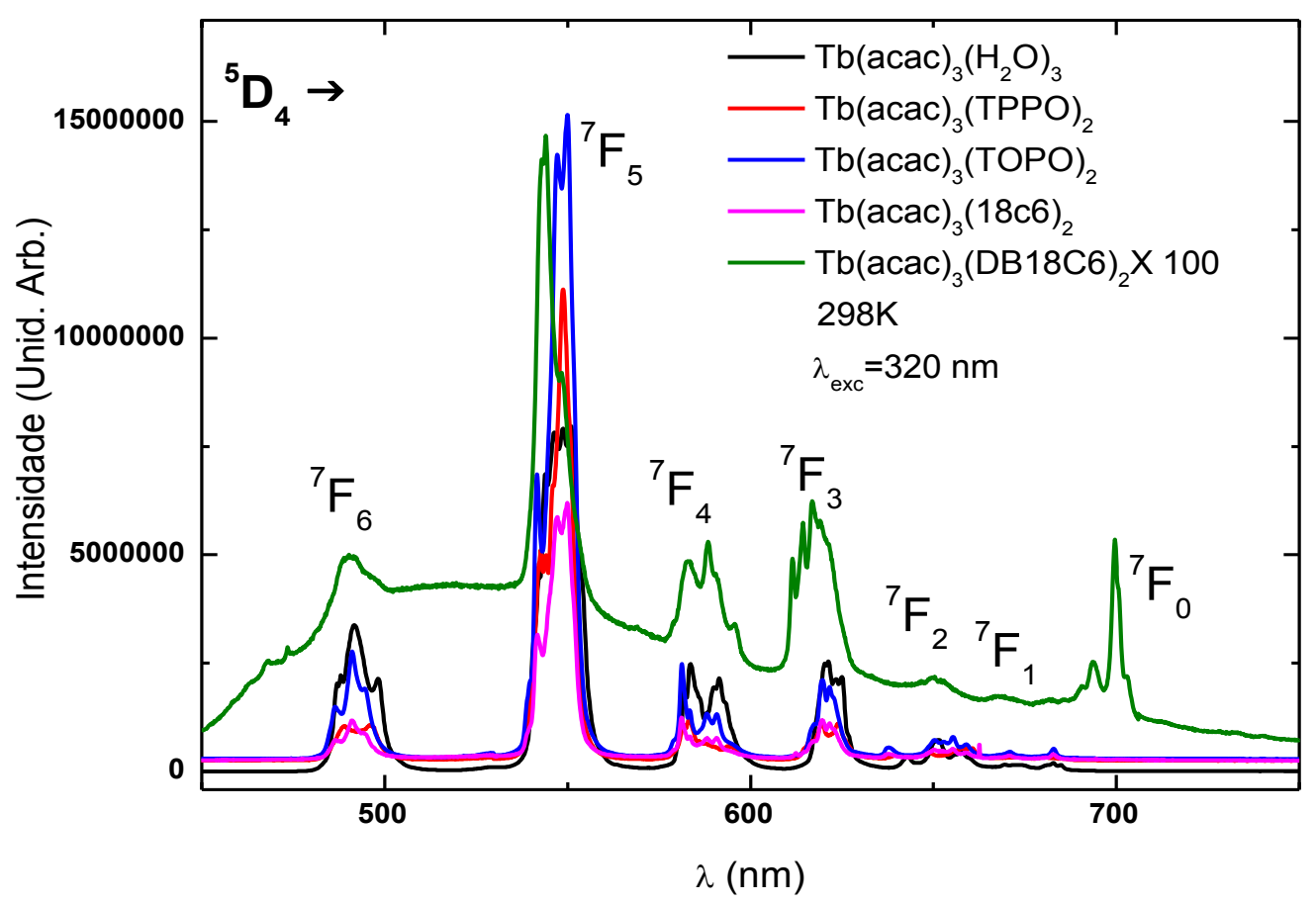

FIGURA 5.40 - Espectros de emissão do complexo $\left[\mathrm{Tb}(\mathrm{acac})_{3}\left(\mathrm{H}_{2} \mathrm{O}\right)_{3}\right]$ e dos complexos $\left[\mathrm{Tb}(\mathrm{acac})_{3}(\mathrm{~L})_{2}\right]$ registrado à temperatura ambiente, no intervalo de 450 a 750 nm, com excitação monitorada em 320 nm. 
TABELA 5.9 - Energias das transições ${ }^{5} D_{4} \rightarrow{ }^{7} F_{J}$ referentes aos espectros de emissão dos complexos $\left[\mathrm{Tb}(\mathrm{acac})_{3}(\mathrm{~L})_{2}\right]$; valores $\mathrm{em} \mathrm{cm}^{-1} ; 298 \mathrm{~K}$.

\begin{tabular}{|c|c|c|c|c|}
\hline Transição & TOPO & TPPO & DB18C6 & $18 C 6$ \\
\hline \multirow[t]{3}{*}{${ }^{5} D_{4} \rightarrow^{7} F_{6}$} & 20555 & 20451 & 20553 & 20394 \\
\hline & 20367 & 20148 & 20367 & 20069 \\
\hline & 20205 & & 20210 & \\
\hline \multirow[t]{6}{*}{${ }^{5} D_{4} \rightarrow^{7} F_{5}$} & 18542 & 18427 & 18414 & 18550 \\
\hline & 18462 & 18383 & 18380 & 18462 \\
\hline & 18357 & 18318 & 18236 & 18349 \\
\hline & 18276 & 18220 & & 18276 \\
\hline & 18186 & 18152 & & 18186 \\
\hline & 18106 & & & 18123 \\
\hline \multirow[t]{6}{*}{${ }^{5} D_{4} \rightarrow{ }^{7} F_{4}$} & 17280 & 17189 & 17279 & 17283 \\
\hline & 17204 & 17144 & 17153 & 17208 \\
\hline & 17141 & 17033 & 16993 & 17141 \\
\hline & 17004 & 16841 & 16934 & 17004 \\
\hline & 16927 & 16706 & 16789 & 16927 \\
\hline & 16798 & & & \\
\hline \multirow[t]{6}{*}{${ }^{5} D_{4} \rightarrow^{7} F_{3}$} & 16203 & 16232 & 16352 & 16332 \\
\hline & 16137 & 16141 & 16278 & 16269 \\
\hline & 16085 & 16024 & 16211 & 16209 \\
\hline & 15677 & & 16154 & 16141 \\
\hline & & & 16092 & 16085 \\
\hline & & & & 16053 \\
\hline
\end{tabular}




\begin{tabular}{l|l|l|l|l}
\hline${ }^{\mathbf{5}} \mathbf{D}_{\mathbf{4}} \rightarrow{ }^{\mathbf{7}} \mathbf{F}_{\mathbf{2}}$ & 15379 & 15617 & 15384 & 15677 \\
\hline & 15324 & 15414 & & 15382 \\
\hline & 15257 & 15257 & & 15335 \\
\hline & 15177 & 15209 & & 15260 \\
\hline${ }^{\mathbf{5}} \mathbf{D}_{\mathbf{4}} \rightarrow{ }^{\mathbf{7}} \mathbf{F}_{\mathbf{1}}$ & 14904 & 14144 & & 14907 \\
\hline & & 14862 & 14971 & 14647 \\
\hline${ }^{\mathbf{5}} \mathbf{D}_{\mathbf{4} \rightarrow}{ }^{\mathbf{7}} \mathbf{F}_{\mathbf{0}}$ & 14645 & 14694 & 14483 & \\
\hline & & 14586 & 14416 & \\
\hline & & & 14294 & \\
\hline & & & 14269 & \\
\hline
\end{tabular}

\subsection{Tempo de Vida do Nível Excitado}

O tempo de vida de luminescência pode ser definido como o tempo médio no qual um sistema emissor (átomo, molécula, íon) permanece no estado excitado. A determinação do tempo de vida é de extrema importância, pois esse dado pode ser correlacionado, por exemplo, com a taxa de transferência de energia. Além disso, o decaimento da luminescência pode revelar detalhes sobre interações entre a espécie luminescente e o ambiente químico ${ }^{[39]}$. Considerando que os processos radiativos e não radiativos atuem no processo de despovoamento do estado excitado, o tempo de vida do estado emissor é dado pela equação 5.2 .

$$
\frac{d N(t)}{d t}=A_{\text {total }} N(t)
$$

Onde $\mathrm{N}(\mathrm{t})$ é o número de espécies no estado excitado em um tempo $\mathrm{t}$ após a excitação e $A_{\text {total }}$ é a taxa total de emissão. Integrando-se a equação 
5.2, obtém-se uma expressão que evidencia um decaimento exponencial da população do estado excitado (eq. 5.3):

$$
(t)=0 \exp (-[\text { Atotal } / t]
$$

Através das curvas de decaimento de luminescência, mede-se diretamente a intensidade de luminescência. No entanto, como a intensidade é proporcional à $\mathrm{N}(\mathrm{t})$, pode-se substituir $\mathrm{N}(\mathrm{t})$ e $\mathrm{N}_{0}$ pelos respectivos valores de intensidade $\mathrm{I}(\mathrm{t})$ e $\mathrm{I}_{0}$, obtendo-se a equação 5.4:

$$
I(t)=I_{0} \exp (-t / \tau)
$$

No entanto, a interação de complexos em superfícies sólidas, pode gerar um ambiente altamente heterogêneo. Assim, várias espécies emissoras podem estar presentes nesses sistemas, havendo a necessidade de curvas de decaimento multiexponencial ${ }^{[40-43]}$. Portanto, a intensidade de luminescência é dada como um somatório das contribuições de cada espécie (eq. 5.5):

$$
I(t)=\sum_{I=1}^{n} \quad l_{i} \exp (-t / \tau i)
$$

Em que $n$ representa o número total de espécies emissoras no material. Quando o decaimento de luminescência de um sistema é multi-exponencial, a maneira natural de definir um tempo de decaimento médio é dado pela equação $5^{[40,44]}$ :

$$
<\tau>=\frac{\Sigma l i \tau i 2}{\Sigma l i \tau i}
$$

Onde li's são os fatores pré-exponenciais ou amplitude e $\tau i$ representa o valor do tempo de vida para cada componente.

Para determinar os valores de tempo de vida para os compostos de $\mathrm{Tb}^{3+}$ estudados foram registradas as curvas de decaimento do nível emissor ${ }^{5} \mathrm{D}_{4}$ à temperatura de $300 \mathrm{~K}$ com emissão monitorada em $544 \mathrm{~nm}$ do íon $\mathrm{Tb}^{3+} \mathrm{e}$ 
excitação em $310 \mathrm{~nm}$. As curvas de decaimento do estado emissor ${ }^{5} \mathrm{D}_{4}$ dos complexos de $\mathrm{Tb}^{3+}$ (FIG. 5.41) mostram um comportamento semelhante entre si para os compostos contendo os ligantes auxiliares TPPO, TOPO e 18C6. Os resultados dos cálculos do tempo de vida sugerem que os complexos de ligantes fosfinóxidos, contendo TOPO e TPPO, apresentam o tempo de vida maior que os demais com ligantes macrocíclicos. A curva de decaimento do estado emissor ${ }^{5} \mathrm{D}_{4}$ do complexo contendo o ligante auxiliar DB18C6 originou baixo tempo de decaimento em comparação aos demais complexos sendo 0 tempo de vida quase nulo $(0,16 \mathrm{~ms})$. Os valores de decaimento dos complexos estão apresentados na TABELA 5.10. Analizando-se as curvas de decaimento do estado emissor ${ }^{5} \mathrm{D}_{4}$ do íon $\mathrm{Tb}^{3+}$ pode-se também observar para alguns dos complexos o tempo de subida, embora não tenha sido calculado para esse trabalho. 


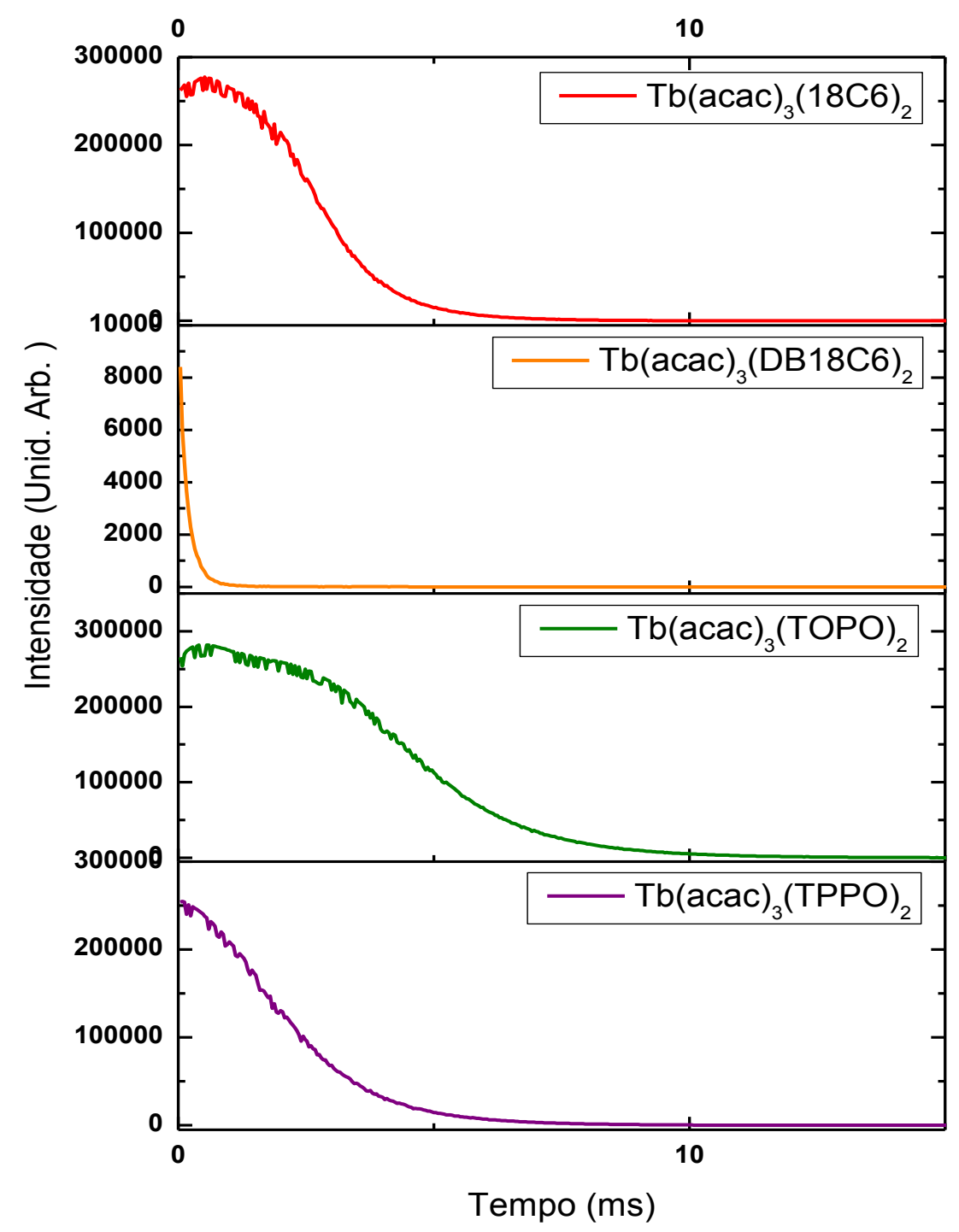

FIGURA 5.41 - Curvas de decaimento da luminescência do estado emissor dos complexos ${ }^{5} \mathrm{D}_{4}$ do íon $\mathrm{Tb}^{3+}$. 
TABELA 5.10 -Tempos de vida do nível emissor do $\mathrm{Tb}^{3+}$.

\begin{tabular}{|c|c|}
\hline Composto & $\begin{array}{l}\text { Tempo de vida } \tau \\
\text { (ms) }\end{array}$ \\
\hline$\left[\mathrm{Tb}(\mathrm{acac})_{3}(\mathrm{TPPO})_{2}\right]\left({ }^{5} \mathrm{D}_{4}\right)$ & 2,13 \\
\hline$\left[\mathrm{Tb}(\mathrm{acac})_{3}(\mathrm{TOPO})_{2}\right]\left({ }^{5} \mathrm{D}_{4}\right)$ & 2,14 \\
\hline$\left[\mathrm{Tb}(\mathrm{acac})_{3}(\mathrm{DB} 18 \mathrm{C} 6)_{2}\right]\left({ }^{5} \mathrm{D}_{4}\right)$ & 0,16 \\
\hline$\left[\mathrm{Tb}(\mathrm{acac})_{3}(18 \mathrm{C} 6)_{2}\right] \quad\left({ }^{5} \mathrm{D}_{4}\right)$ & 1,31 \\
\hline
\end{tabular}

\subsubsection{Complexos $\left[\mathrm{TR}^{3+}(\beta \text {-dicetonato })_{3}(\mathrm{~L})_{2}\right] \quad\left(\mathrm{TR}=\mathrm{Eu}^{3+} ; \beta\right.$-dicetonato= tta; $L=T P P O$, TOPO, DB18C6 e 18C6)}

\subsubsection{Luminescência dos Compostos com ĺon $\mathrm{Eu}^{3+}$}

Os compostos contendo o íon $\mathrm{Eu}^{3+}$ (configuração $[\mathrm{Xe}] \mathrm{ff}^{6}$ ) têm sido extensivamente estudados por apresentarem alta luminescência monocromática de cor vermelha. Além disso, a partir de seus espectros de emissão pode-se obter informações sobre o desdobramento do campo ligante, processos de transferência de energia e eficiência quântica do estado emissor. Os espectros exibidos pelos complexos de $\mathrm{Eu}^{3+}$ apresentam, principalmente, bandas oriundas das transições intraconfiguracionais ${ }^{5} \mathrm{D}_{0} \rightarrow{ }^{7} \mathrm{~F}_{\mathrm{J}}$ (onde $\mathrm{J}=0,1,2$, $3,4,5$ e 6), sendo que as transições ${ }^{5} D_{0} \rightarrow{ }^{7} F_{5}$ e ${ }^{5} D_{0} \rightarrow{ }^{7} F_{6}$ apresentam intensidade muito baixa e dificilmente são observadas nos espectros dos compostos de coordenação Fig 5.37. Como pode ser observado, o principal nível emissor ${ }^{5} \mathrm{D}_{0}$ é não degenerado e não se desdobra em qualquer simetria em torno do íon metálico ${ }^{[45]}$, ao contrário do estado emissor do $\mathrm{Tb}^{3+}\left({ }^{5} \mathrm{D}_{4}\right)$ que tem uma degenerescência igual a nove como visto acima. $O$ número máximo de bandas resultantes de uma transição ${ }^{5} \mathrm{D}_{0} \rightarrow{ }^{7} \mathrm{~F}_{\mathrm{J}}$ é dado pela regra de $(2 \mathrm{~J}+1)$ componentes e o número de bandas associado a cada transição depende da 
simetria pontual ao redor do íon $\mathrm{TR}^{3+}$ e pode ser facilmente determinada usando a teoria de grupos ${ }^{[46]}$.

Quando um espectro apresenta número de picos maior do que da regra $(2 \mathrm{~J}+1)$-componentes isto evidência ou a presença de mais de um sítio de simetria para o íon metálico ou que o composto está impuro, por exemplo em sistemas dinucleares sem centro de inversão, ou mistura de isômeros, ou ainda o aparecimento de transições vibrônicas devido à interação dos níveis eletrônicos e estados de densidade fônons. Este último fenômeno resulta na presença de "bandas satélites" e é observado principalmente nas transições ${ }^{5} \mathrm{D}_{0} \rightarrow{ }^{7} \mathrm{~F}_{2}$, considerando que o nível ${ }^{7} \mathrm{~F}_{2}$ encontra-se na região espectral correspondente as freqüências de estiramentos $v(C=O), v(C=C)$ e $v(N=O)$ presentes nos ligantes orgânicos.

As transições ${ }^{5} D_{0} \rightarrow{ }^{7} F_{0,3,5}$ são proibidas pelas regras de seleção de dipolo-elétrico forçado e dipolo-magnético. No entanto, a primeira regra pode ser relaxada pelo campo ligante conduzindo aos efeitos de misturas dos J's e, consequentemente, apesar de pequeno, existe um momento de transição diferente de zero. A intensidade da transição ${ }^{5} \mathrm{D}_{0} \rightarrow{ }^{7} \mathrm{~F}_{0}$ tem sido caracterizada como sendo, principalmente, devido à mistura do estado ${ }^{7} \mathrm{~F}_{2}$ dentro do estado ${ }^{7} F_{0}$, e essa mistura é expressa em termos do parâmetro $R_{02}$, definido como a razão entre as intensidades das bandas oriundas das transições ${ }^{5} \mathrm{D}_{0} \rightarrow{ }^{7} \mathrm{~F}_{0} \mathrm{e}$ ${ }^{5} \mathrm{D}_{0} \rightarrow{ }^{7} \mathrm{~F}_{2}$. Já a transição ${ }^{5} \mathrm{D}_{0} \rightarrow{ }^{7} \mathrm{~F}_{1}$ é permitida somente por dipolo-magnético e sua intensidade é praticamente insensível ao ambiente químico nas vizinhanças do íon $\mathrm{Eu}^{3+}$, e consequentemente, essa transição tem sido tomada como uma referência interna ${ }^{[47]}$.

As transições ${ }^{5} \mathrm{D}_{0} \rightarrow{ }^{7} \mathrm{~F}_{2,4}$ são permitidas por dipolo-elétrico forçado, sendo que a transição ${ }^{5} \mathrm{D}_{0} \rightarrow{ }^{7} \mathrm{~F}_{2}(\sim 612 \mathrm{~nm})$, hipersensível ao ambiente químico do íon central, é dominante em compostos não-centrossimétricos. Estas transições fornecem informações se grupo o pontual em torno do íon $\mathrm{Eu}^{3+}$ apresenta centro de inversão, considerando que em compostos centrossimétricos as transições ${ }^{5} D_{0} \rightarrow{ }^{7} F_{2,4}$ são estritamente proibidas por mecanismo de dipolo elétrico.

Uma vez que as bandas de emissão do íon $\mathrm{Eu}^{3+}$ na região do visível são de fácil interpretação, devido à estrutura dos seus níveis de energia, este íon 
tem sido utilizado como sonda espectroscópica na obtenção de valiosas informações em sistemas bioinorgânicos, tais como: i) a determinação do número de ambientes químicos ao redor do íon $\mathrm{Eu}^{3+}$ através do número de bandas relativo à transição ${ }^{5} \mathrm{D}_{0} \rightarrow{ }^{7} \mathrm{~F}_{0}$; ii) Constante de ligação dos íons biomolécula-Eu ${ }^{3+}$, determinada por curvas de titulação e iii) distância doadorreceptor $(R)$, normalmente assumindo o mecanismo de acoplamento dipolodipolo fraco ${ }^{[48]}$. Abaixo se apresenta um resumo das transições do íon $\mathrm{Eu}^{3+}$ quanto a sua simetria e regra de seleção:

${ }^{5} D_{0} \rightarrow{ }^{7} F_{0}$ : é não degenerado e ganha intensidade através da mistura de J's em complexos de simetria $\mathrm{C}_{\mathrm{S}}, \mathrm{C}_{\mathrm{n}}$ e $\mathrm{C}_{\mathrm{nv}}$;

${ }^{5} D_{0} \rightarrow{ }^{7} F_{1}$ : permitida por DM; insensível ao ambiente; forte atividade óptica;

${ }^{5} \mathbf{D}_{0} \rightarrow{ }^{7} \mathbf{F}_{2}$ : transição hipersensível $(\Delta J=2)$; ausente se em compostos com centro de inversão;

${ }^{5} \mathbf{D}_{0} \rightarrow{ }^{7} \mathbf{F}_{3}$ : transição proibida, sempre pouco intensa; caráter permitido por mistura de J's;

${ }^{5} D_{0} \rightarrow{ }^{7} F_{4}$ : sensível ao ambiente $(\Delta \mathrm{J}=4)$;

${ }^{5} \mathbf{D}_{0} \rightarrow{ }^{7} \mathbf{F}_{5}$ : transição proibida, raramente observada e

${ }^{5} \mathbf{D}_{0} \rightarrow{ }^{7} \mathbf{F}_{6}$ : raramente observada.

As características das transições ${ }^{5} \mathrm{D}_{0} \rightarrow{ }^{7} \mathrm{~F}_{\mathrm{J}}$ citadas acima devem ser correlacionadas com a TABELA 5.11. Por exemplo, a transição ${ }^{5} \mathrm{D}_{0} \rightarrow{ }^{7} \mathrm{~F}_{2}$, denominada hipersensível, é a de maior intensidade em sistemas nãocentrossimétricos e, portanto, é responsável pela emissão de cor vermelha em todos os compostos contendo como centro emissor o íon $\mathrm{Eu}^{3+}{ }^{349]}$. 
TABELA 5.11 - Faixas espectrais, intensidades relativas e baricentros

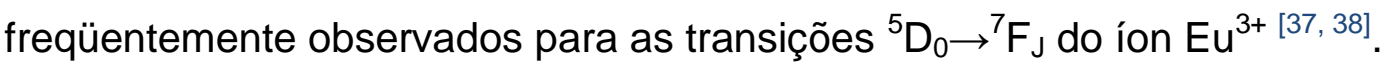

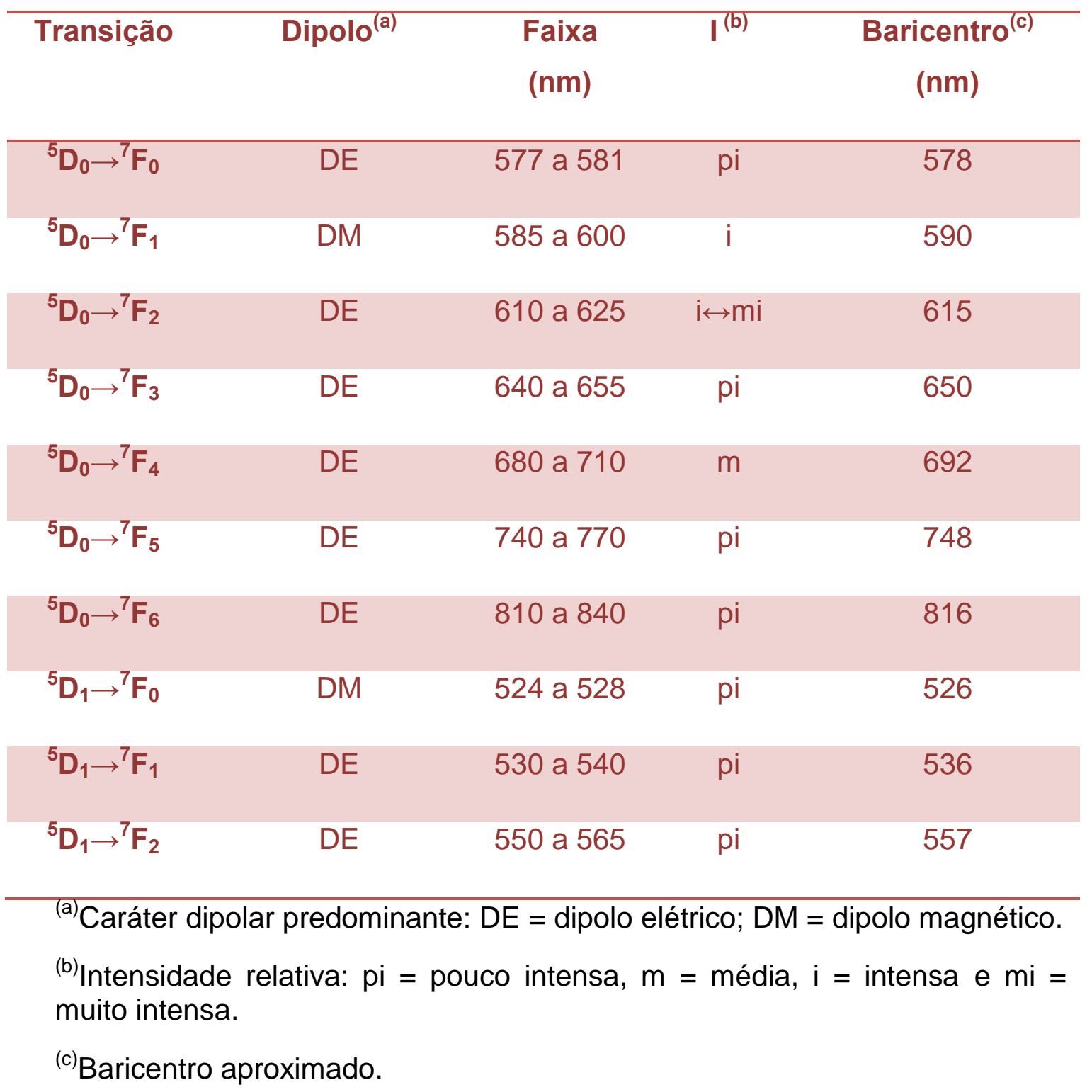

Para comparar a intensidade de luminescência de complexos de európio, um método muito utilizado é calcular a relação entre a área sob a curva de emissão da transição hipersensível ${ }^{5} D_{0} \rightarrow{ }^{7} F_{2}$ permitida por dipolo elétrico forçado e a transição permitida por dipolo magnético, ${ }^{5} \mathrm{D}_{0} \rightarrow{ }^{7} \mathrm{~F}_{1}$. Quanto maior 0 valor de $I\left({ }^{5} \mathrm{D}_{0} \rightarrow{ }^{7} \mathrm{~F}_{2}\right) / /\left({ }^{5} \mathrm{D}_{0} \rightarrow{ }^{7} \mathrm{~F}_{1}\right)$, mais intensa é a cor vermelha da emissão, e quanto menor o valor desta relação, maior o caráter centrossimétrico, indicando que o complexo de $\mathrm{Eu}^{3+}$ apresenta centro de inversão. Porém, deve-se salientar que a intensidade da mesma também possui relação com a polarizabilidade do ambiente químico ao redor do íon metálico ${ }^{[00-53]}$. Por outro 
lado, a relação de intensidades experimentais, $R_{02}$, obtida através da razão entre as áreas de ${ }^{5} D_{0} \rightarrow{ }^{7} F_{0}$ e ${ }^{5} D_{0} \rightarrow{ }^{7} F_{2}$ exibidas no espectro do composto com $\mathrm{Eu}^{3+}$, fornece informações a respeito da mistura de J's associadas aos níveis citados.

\subsection{Investigação a partir dos espectros de excitação}

Os estudos fotoluminescentes dos $\beta$-dicetonatos de európio com ligantes auxiliares TPPO, TOPO, DB18C6 e 18C6, neste trabalho, foram feitos com base nos espectros de excitação e emissão registrados a temperatura ambiente ( 298 K. Os espectros de excitação foram registrados no intervalo de 250 a 600 $\mathrm{nm}$, com emissão monitorada na transição hipersensível ${ }^{5} \mathrm{D}_{0} \rightarrow{ }^{7} \mathrm{~F}_{2}(\sim 615 \mathrm{~nm})$.

$\mathrm{Na}$ FIGURA 5.42 apresentam-se os espectros de excitação dos complexos contendo ligantes auxiliares TPPO, TOPO, DB18C6 e 18C6. Os espectros mostram bandas alargadas no intervalo de 250 a $450 \mathrm{~nm}$ com máximos em torno de $330 \mathrm{~nm}$ associada à transição permitida $\mathrm{S} \rightarrow \mathrm{S}_{0}$ pertencente ao ligante tta. As bandas finas oriundas das transições intraconfiguracionais- $4 f^{6}{ }^{7} \mathrm{~F}_{0} \rightarrow{ }^{5} \mathrm{G}_{6},{ }^{5} \mathrm{H}_{4}$ e ${ }^{5} \mathrm{~L}_{6}$ apresentam-se sobrepostas com as bandas largas dos ligantes. Deve-se informar que bandas finas com menores intensidades são observadas em torno de 464, 532 e $578 \mathrm{~nm}$, as quais são atribuídas as transições ${ }^{7} \mathrm{~F}_{0} \rightarrow{ }^{5} \mathrm{D}_{2},{ }^{5} \mathrm{D}_{1}$ e ${ }^{5} \mathrm{D}_{0}$ do íon $\mathrm{Eu}^{3+}$. De um modo geral, não é observada uma mudança significativa entre os espectros de excitação dos complexo hidratado (FIG. 5.42) e aqueles dos complexos contendo TPPO, TOPO, DB18C6 e 18C6. As pequenas diferenças estão, provavelmente, associadas a pequenas mudanças nos níveis de energia do TTA, devido as distorções causadas pelos ligantes TPPO, TOPO, DB18C6 e 18C6, os quais são maiores do que a molécula de água.

É observado que os espectros de excitação dos complexos apresentam bandas de maior intensidade na região de absorção dos ligantes (dicetonatos) comparados com aquelas das transições ${ }^{7} \mathrm{~F}_{0} \rightarrow{ }^{5} \mathrm{D}_{\mathrm{J}}$ do íon $\mathrm{Eu}^{3+}$, evidenciando 0 
grande potencial do ligante tta de atuar como "antena" no processo de transferência de energia Ligante-Eu ${ }^{3+}$.

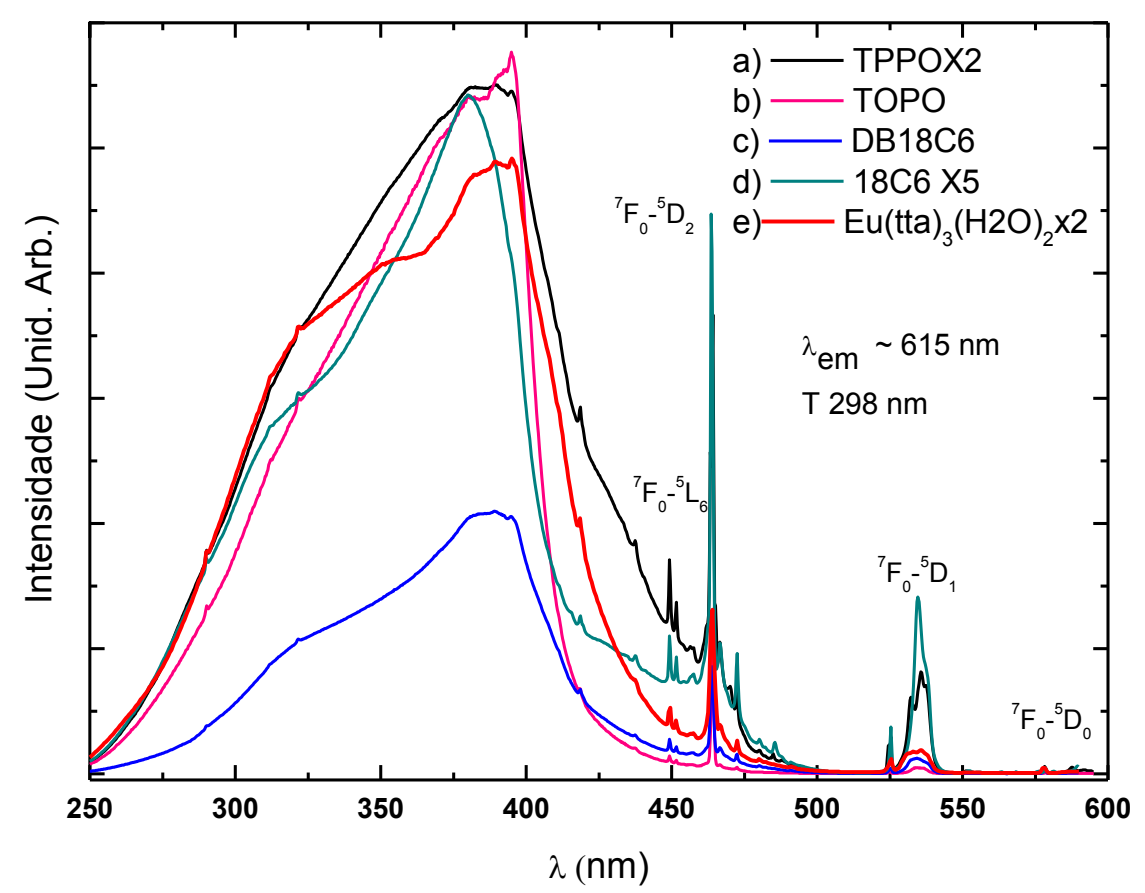

FIGURA 5.42 - Espectros de excitação dos complexos de tta de $\mathrm{Eu}^{3+} \mathrm{com}$ ligantes orgânicos auxiliares TPPO, TOPO, DB18C6 e 18C6 no intervalo de 250-600 nm, registrados à temperatura ambiente, e sob emissão em 615 nm.

\subsection{Investigação a partir dos espectros de emissão}

Os espectros de emissão dos complexos contendo $\beta$-dicetonato (tta') de európio com ligantes auxiliares TPPO, TOPO, DB18C6 e 18C6, exibem desdobramentos característicos para o íon $\mathrm{Eu}^{3^{+}}$(FIG. 5.43) apresentando bandas finas atribuídas às transições ${ }^{5} D_{0} \rightarrow{ }^{7} F_{J}$, onde $J=0-4$ com emissões intensas de cor vermelha $(\sim 615 \mathrm{~nm})$, sendo a transição ${ }^{5} \mathrm{D}_{0} \rightarrow{ }^{7} \mathrm{~F}_{2}$ a mais proeminente. Dentre os complexos analisados, o que apresentou maior intensidade luminescente foi o complexo contendo o ligante auxiliar TOPO (FIG. 5.43).

Os espectros de emissão dos complexos de terras raras com tta, foram registrados no intervalo de 500 a 750 nm, a 300 K, com excitação via banda do 
ligante $(\sim 380 \mathrm{~nm})$. Estes espectros exibem bandas finas atribuídas às transições ${ }^{5} \mathrm{D}_{0} \rightarrow{ }^{7} \mathrm{~F}_{\mathrm{J}}$ (onde $\mathrm{J}=0,1,2,3,4$ ), sendo a transição hipersensível ${ }^{5} \mathrm{D}_{0} \rightarrow{ }^{7} \mathrm{~F}_{2}$ a mais intensa. A FIGURA 5.43 (inserida) também apresenta bandas finas na região espectral de 520 a $570 \mathrm{~nm}$ oriundas das transições ${ }^{5} D_{1} \rightarrow{ }^{7} F_{0}$ (532 nm), ${ }^{5} D_{1} \rightarrow{ }^{7} F_{1}$ (539 nm) and ${ }^{5} D_{1} \rightarrow{ }^{7} F_{2}$ (558 nm), no entanto, essas bandas apresentam intensidade muito baixas, sendo somente observadas com ampliação da escala espectral.

É importante frisar que os espectros de emissão dos complexos de $\mathrm{Eu}^{3+}$ não apresentaram bandas largas oriundas da fosforescência do tta no intervalo espectral de 420-600 nm. Esse resultado indica que os processos de transferência de energia do estado tripleto desses ligantes para os níveis excitados do európio são muito eficientes.

A presença da banda correspondente à transição ${ }^{5} \mathrm{D}_{0} \rightarrow{ }^{7} \mathrm{~F}_{0}$ nos espectros de emissão dos complexos de TTA como um único pico ( $581 \mathrm{~nm}$ ), indica a existência de somente um único sítio de simetria em torno do ambiente químico do íon $\mathrm{Eu}^{3+}$. Além disso, de acordo com a regra de seleção por simetria, essa transição só é permitida quando o $\mathrm{Eu}^{3+}$ está classificado em um dos grupos pontuais $\mathrm{C}_{\mathrm{nv}}, \mathrm{C}_{\mathrm{n}}$ ou $\mathrm{C}_{\mathrm{s}}{ }^{[53]}$.

Adicionalmente, pode-se observar que as bandas correspondentes à transição ${ }^{5} \mathrm{D}_{0} \rightarrow{ }^{7} \mathrm{~F}_{2}$ estão desdobradas em no mínimo 4 componentes para os compostos derivados de fosfinóxido, indicando que os possíveis grupos pontais para estes compostos estão limitados `aqueles de baixa simetria, $C_{2 v}, C_{2}, C_{1}$ ou $\mathrm{C}_{\mathrm{s}}$. Para os compostos com macrocíclico esta transição apresenta apenas uma componente sugerindo que a microssimetria é tetraédrica. Os valores das energias das transições ${ }^{5} D_{0} \rightarrow{ }^{7} F_{J}$ obtidos a partir dos espectros de emissão dos complexos de európio com tta com ligantes auxiliares TPPO, TOPO, DB18C6 e 18 C6 estão apresentados na TABELA 5.12. 


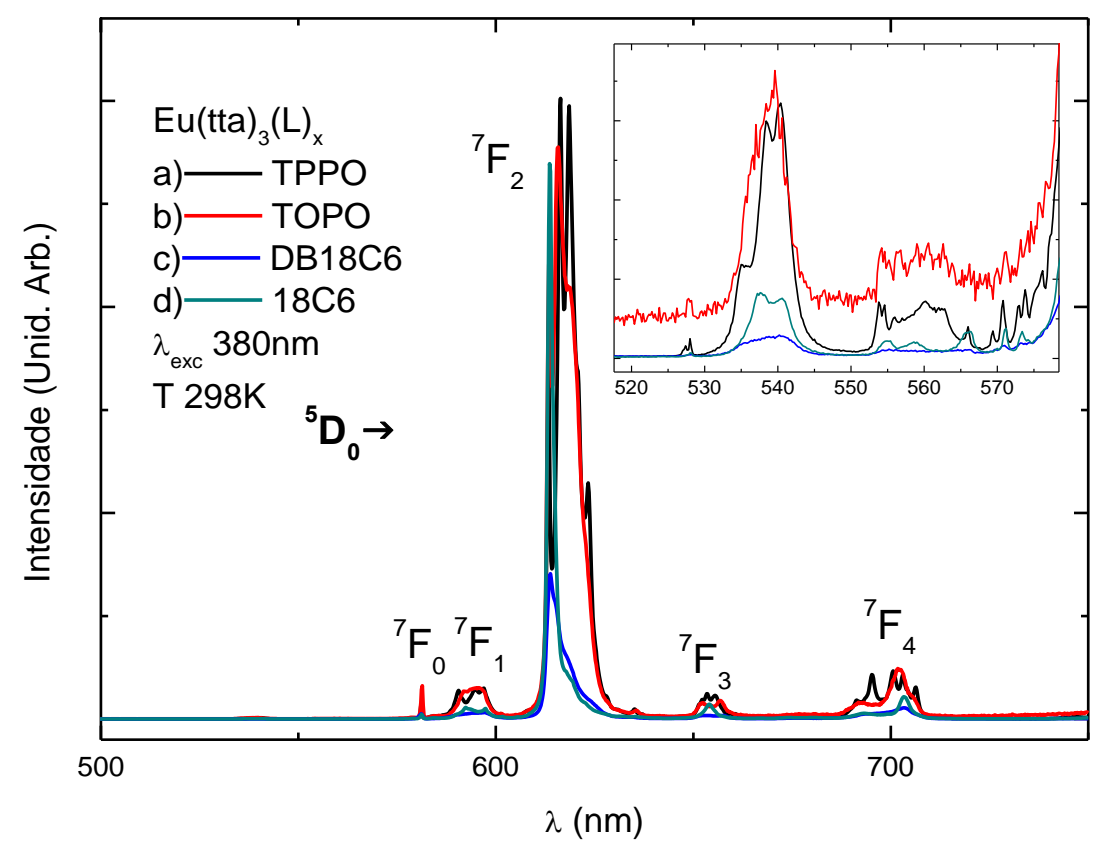

FIGURA 5.43 - Espectros de emissão dos complexos de tha de $\mathrm{Eu}^{3+}$ com diferentes ligantes orgânicos auxiliares no intervalo de 400-800 nm, registrados à temperatura ambiente, e sob excitação em $380 \mathrm{~nm}$. 
TABELA 5.12 - Atribuição das energias das transições ${ }^{5} \mathrm{D}_{0} \rightarrow{ }^{7} \mathrm{~F}_{0-4}\left(\mathrm{~cm}^{-1}\right)$ observados nos espectros de emissão dos complexos [Eu(TTA $)_{3} \cdot(\mathrm{L})_{2}$ ] onde $\mathrm{L}=$ $\mathrm{H}_{2} \mathrm{O}$ TPPO, TOPO, DB18C6 e 18C6, a $300 \mathrm{~K}$.

\begin{tabular}{|c|c|c|c|c|c|}
\hline Transições & $\mathrm{H}_{2} \mathrm{O}$ & TOPO & TPPO* & DB18C6 & $18 C 6^{*}$ \\
\hline${ }^{5} D_{0} \rightarrow{ }^{7} F_{0}$ & 17271 & 17199 & 17212 & 17211 & 17206 \\
\hline${ }^{5} D_{0} \rightarrow{ }^{7} F_{1}$ & $\begin{array}{l}17018 \\
17012 \\
17018\end{array}$ & $\begin{array}{l}16891 \\
16812 \\
16784\end{array}$ & $\begin{array}{l}16932 \\
16812 \\
16750\end{array}$ & $\begin{array}{r}16949 \\
16745\end{array}$ & $\begin{array}{l}16880 \\
16840 \\
16739\end{array}$ \\
\hline${ }^{5} D_{0} \rightarrow{ }^{7} F_{2}$ & $\begin{array}{l}16366 \\
16382 \\
16366 \\
16318 \\
16291\end{array}$ & $\begin{array}{l}16297 \\
16239 \\
16165 \\
16056\end{array}$ & $\begin{array}{l}16302 \\
16223 \\
16165 \\
16103 \\
16041\end{array}$ & 16292 & 16297 \\
\hline${ }^{5} D_{0} \rightarrow{ }^{7} F_{4}$ & $\begin{array}{l}14568 \\
14530 \\
14568 \\
14513 \\
14522 \\
14513 \\
14484 \\
14413 \\
14488\end{array}$ & $\begin{array}{l}14446 \\
14249\end{array}$ & $\begin{array}{l}14463 \\
14384 \\
14273 \\
14220 \\
14196 \\
14156\end{array}$ & $\begin{array}{l}14421 \\
14216\end{array}$ & $\begin{array}{l}14434 \\
14216\end{array}$ \\
\hline
\end{tabular}

Para determinar os tempos de vida dos complexos de $\mathrm{Eu}^{3+}$ estudados foram registradas as curvas de decaimento à temperatura de $300 \mathrm{~K} \mathrm{com}$ emissão monitorada em $614 \mathrm{~nm}$ e excitação na transição $\left({ }^{7} \mathrm{~F}_{0} \rightarrow{ }^{5} \mathrm{~L}_{6}\right) 380 \mathrm{~nm}$ do 
ín $\mathrm{Eu}^{3+}$. As curvas estão apresentadas na FIGURA 5.44, e ajustam-se a uma exponencial simples, sugerindo que não há outro canal de despopulação para o nível emissor ${ }^{5} \mathrm{D}_{0}$. Os valores de decaimento para os complexos de $\mathrm{Eu}^{3+}$ estão apresentados na TABELA 5.13, o menor valor de tempo de vida do nível emissor foi encontrado para o complexo [Eu(tta) $\left.)_{3}(\mathrm{DB} 18 \mathrm{C} 6)_{2}\right]$ com $0,65 \mathrm{~ms}$. Para os complexos de európio com ligante tta e ligante auxiliar TPPO foi observado o tempo de subida para população do nível emissor FIGURA 5.44.

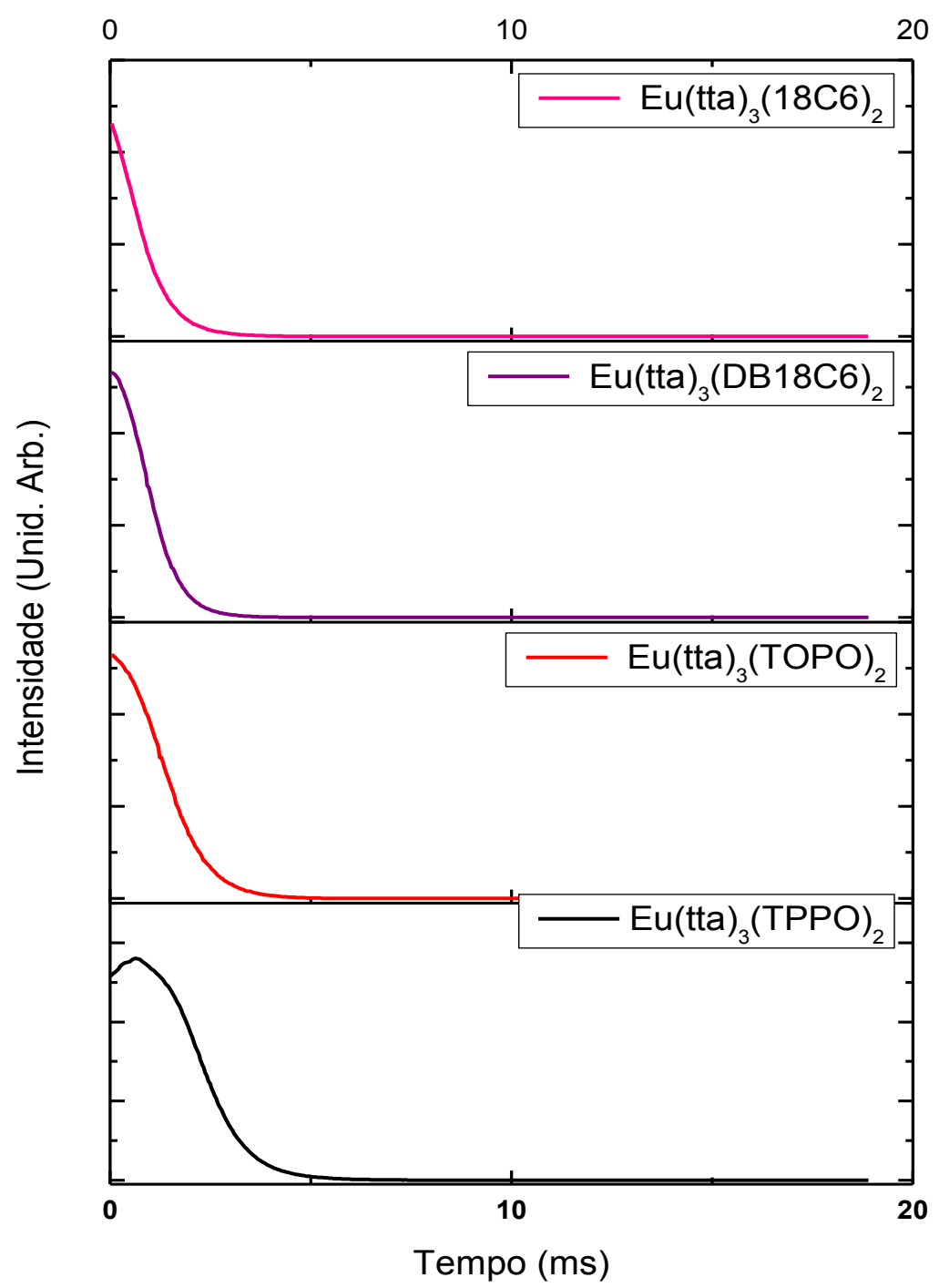

FIGURA 5.44 - Curvas de decaimento da luminescência do estado emissor dos complexos ${ }^{5} \mathrm{D}_{0}$ do íon $\mathrm{Eu}^{3+}$. 
TABELA 5.13 - Tempos de vida do nível emissor do $\mathrm{Eu}^{3+}$.

\begin{tabular}{lc}
\hline Composto & Tempo de vida $(\mathrm{ms})$ \\
\hline$\left[\mathrm{Eu}(\mathrm{tta})_{3}(\mathrm{TPPO})_{2}\right]\left({ }^{5} \mathrm{D}_{0}\right)$ & 0,937 \\
{$\left[\mathrm{Eu}(\mathrm{tta})_{3}(\mathrm{TOPO})_{2}\right]\left({ }^{5} \mathrm{D}_{0}\right)$} & 0,925 \\
{$\left[\mathrm{Eu}(\mathrm{tta})_{3}(\mathrm{DB} 18 \mathrm{C} 6)_{2}\right]\left({ }^{5} \mathrm{D}_{0}\right)$} & 0,651 \\
{$\left[\mathrm{Eu}(\mathrm{tta})_{3}(\mathbf{1 8 C 6})_{2}\right]\left({ }^{5} \mathrm{D}_{0}\right)$} & 0,985 \\
\hline
\end{tabular}

\subsection{Parâmetros de intensidade experimental para compostos de $\mathrm{Eu}^{3+}$}

Os parâmetros de intensidade experimental $\Omega_{\lambda}(\lambda=2,4$ e 6$)$, também chamados de parâmetros de Judd-Ofelt, são determinados por meio das intensidades das respectivas transições ${ }^{5} \mathrm{D}_{0} \rightarrow{ }^{7} \mathrm{~F}_{\mathrm{J}}\left(\mathrm{J}=2,4\right.$ e 6) do íon $\mathrm{Eu}^{3+}$ onde os mecanismos de $D E$ forçado e acoplamento dinâmico $(A D)$ são considerados simultaneamente. Tais parâmetros são determinados experimentalmente, e incorporam as contribuições de DE forçado e AD. A dependência da polarizabilidade dos átomos vizinhos confere para 0 mecanismo de acoplamento dinâmico uma maior dependência da natureza do ambiente químico. Considera-se que nos compostos de $\mathrm{Eu}^{3+}$ que possuem maior grau de covalência, apresentam maiores valores de $\Omega_{2}$ sugerindo que nestes casos, há uma predominância do mecanismo de $A D$ em relação ao $D E$ forçado ${ }^{[54-57]}$.

A partir dos espectros de emissão dos complexos de $\mathrm{Eu}^{3+}$ obtidos são determinados os parâmetros de intensidade experimentais $\Omega_{2,4,6}$ baseados nas respectivas transições ${ }^{5} \mathrm{D}_{0} \rightarrow{ }^{7} \mathrm{FJ}$ do íon $\mathrm{Eu}^{3+}{ }^{[58]}$. A intensidade destas transições é expressa pela equação 5.7 :

$$
\mathrm{I}_{0 \rightarrow \mathrm{J}}=\hbar \omega_{0 \rightarrow \mathrm{J}} \mathrm{A}_{0 \rightarrow \mathrm{J}} \mathrm{N}_{0}
$$

onde $A_{0 \rightarrow J}$ é o coeficiente de emissão espontânea de Einstein, $N_{0}$ é a população do nível emissor $\left({ }^{5} D_{0}\right.$ no caso do íon $\left.E u^{3+}\right)$ e $\hbar \omega$ é a energia da 
transição. Os valores dos parâmetros $A_{0 \rightarrow J}$ podem ser determinados experimentalmente a partir dos espectros de emissão tomando a transição ${ }^{5} \mathrm{D}_{0} \rightarrow{ }^{7} \mathrm{~F}_{1}$ como referência. Desta forma, os valores de $A_{0 \rightarrow \mathrm{J}}$ para as transições de DE forçado, ${ }^{5} \mathrm{D}_{0} \rightarrow{ }^{7} \mathrm{~F}_{2,4,6}$ são determinados de acordo com a equação 5.8

$$
A_{0 \rightarrow J(\exp )}=\left(\frac{\sigma_{0 \rightarrow 1}}{S_{0 \rightarrow 1}}\right)\left(\frac{S_{0 \rightarrow J}}{\sigma_{0 \rightarrow J}}\right) A_{0 \rightarrow 1}
$$

onde $S_{0 \rightarrow J}$ é a área sob a curva relacionada à transição ${ }^{5} D_{0} \rightarrow{ }^{7} F_{J}$ obtida a partir dos dados experimentais e $\sigma_{0 \rightarrow \mathrm{J}}$ é o baricentro da transição.

Considerando que para o íon $\mathrm{Eu}^{3+}$, a transição ${ }^{5} \mathrm{D}_{0} \rightarrow{ }^{7} \mathrm{~F}_{1}$ é permitida por $D M$, sua taxa radiativa $A_{0 \rightarrow 1}$ é praticamente independente da influência do campo cristalino, o que permite seu uso como transição de referência para as demais transições ${ }^{[59]}$. Assim, o coeficiente de emissão espontânea de Einstein para a transição ${ }^{5} \mathrm{D}_{0} \rightarrow{ }^{7} \mathrm{~F}_{1}$ vem dado por

$$
\mathrm{A}_{0 \rightarrow 1}=0,31 \cdot 10^{-11} \mathrm{n}^{3} \sigma^{3}
$$

onde n é o índice de refração do meio. Considera-se que o valor do coeficiente $\mathrm{A}_{0 \rightarrow 1}$ é aproximadamente $50 \mathrm{~s}^{-1}$.

Por outro lado, o coeficiente de emissão espontânea de Einstein $\left(A_{0 \rightarrow J}\right)$ para o nível emissor ${ }^{5} D_{0}$ para ${ }^{7} F_{J}(J=2,4$ e 6) pode ser obtido por meio da

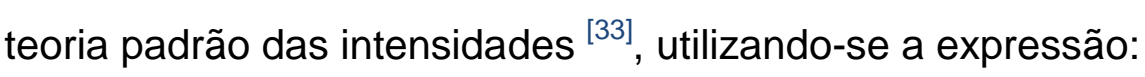

$$
\mathrm{A}_{0 \rightarrow \mathrm{J}}=\frac{4 \mathrm{e}^{2} \varpi^{3}}{3 \hbar \mathrm{c}^{3}} \chi \frac{1}{(2 \mathrm{~J}+1)} \sum_{\lambda} \Omega_{\lambda}\left\langle\alpha \mathrm{J}\left\|\mathrm{U}^{(\lambda)}\right\| \alpha^{\prime} \mathrm{J}^{\prime}\right\rangle^{2}
$$

onde $\varpi$ é a freqüência angular da transição, e é a carga do elétron, c é a velocidade da luz, $n$ é a constante de Planck reduzida e n é o índice de refração do 
meio, $\chi$ é o termo de correção de Lorentz para o campo local, o qual é dado por $\chi=\frac{n\left(n^{2}+2\right)^{2}}{9}, \Omega_{\lambda}(\lambda=2,4$ e 6$)$ são os parâmetros de intensidade experimental, e os elementos de matriz reduzidos $\left\langle{ }^{5} \mathrm{D}_{0}\left\|\mathrm{U}^{(\lambda)}\right\|{ }^{7} \mathrm{~F}_{2}\right\rangle^{2}=0,0032,\left\langle{ }^{5} \mathrm{D}_{0}\left\|\mathrm{U}^{(\lambda)}\right\|{ }^{7} \mathrm{~F}_{4}\right\rangle^{2}=$ 0,0023 e $\left\langle{ }^{5} \mathrm{D}_{0}\left\|\mathrm{U}^{(\lambda)}\right\|{ }^{7} \mathrm{~F}_{6}\right\rangle^{2}=0,0002$ para as transições ${ }^{5} \mathrm{D}_{0} \rightarrow{ }^{7} \mathrm{~F}_{2} ;{ }^{5} \mathrm{D}_{0} \rightarrow{ }^{7} \mathrm{~F}_{4} \mathrm{e}$ ${ }^{5} D_{0} \rightarrow{ }^{7} F_{6}$ respectivamente. A taxa total das contribuições radiativas $\left(A_{\text {rad }}\right)$ é determinada pela somatória das contribuições $A_{0 \rightarrow J}$ de cada transição.

O tempo de vida (T) do estado emissor ${ }^{5} \mathrm{D}_{0}$ do íon $\mathrm{Eu}^{3+} \mathrm{e}$ as contribuições radiativas $\left(A_{\text {rad }}\right)$ e não-radiativas $\left(A_{\text {nrad }}\right)$ são relacionadas pela expressão: $\mathrm{A}_{\text {total }}=\frac{1}{\tau}=\mathrm{A}_{\mathrm{rad}}+\mathrm{A}_{\text {nrad }}$ onde $\mathrm{T}$ é $\mathrm{o}$ tempo de vida determinado experimentalmente através da curva exponencial de decaimento luminescente do nível emissor ${ }^{5} D_{0}$. Para todos os coeficientes $A_{0 \rightarrow J}$, é possível calcular a emissão espontânea total para o nível emissor ${ }^{5} D_{0}$ por $A_{\text {rad }}=\Sigma A_{0 \rightarrow J}=A_{00}+A_{01}$ $+A_{02}+A_{03}+A_{04}+A_{06}$.

De posse desses valores de $A_{\text {rad, }}$ pode-se calcular a eficiência quântica do nível emissor ${ }^{5} D_{0}(\eta)$ do íon $E u^{3+}$, que é definida como a razão entre as contribuições radiativas $\left(A_{\text {rad }}\right)$ e totais (radiativas e não radiativas, $\left.A_{\text {total }}=A_{\text {rad }}+A_{\text {nrad }}\right)$ (eq. 5.11):

$$
\eta=\frac{A_{\text {rad }}}{A_{\text {rad }}+A_{\text {nrad }}}
$$

Os parâmetros de intensidades experimentais $\Omega_{\lambda}$, coeficiente de emissão espontânea $(A)$, tempos de vida $(\tau)$ e eficiência quântica do nível emissor ${ }^{5} D_{0}$ (n) dos complexos, foram determinados a partir dos dados espectrais experimentais (TAB. 5.14).

Os resultados obtidos mostram que o complexo hidratado tem o maior valor de $\Omega_{2}$, o que é refletido em termos de uma maior polarizabilidade. Este parâmetro está também relacionado com a simetria. Já os demais complexos com ligantes auxiliares apresentam maior caráter covalente, pois possuem os maiores valores de $\Omega_{4}$. 
TABELA 5.14 - Parâmetros de intensidade experimental $\left(\Omega_{\lambda}\right)$, eficiência

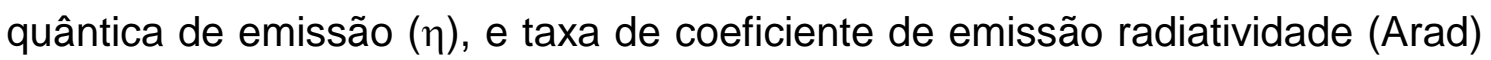
e não radiatividade (Anrad) para os complexos $\left[\mathrm{Eu}(\mathrm{tta})_{3}(\mathrm{~L})_{2}\right]$.

\begin{tabular}{|c|c|c|c|c|c|c|}
\hline Complexos & $\begin{array}{l}\Omega_{2 \cdot 10^{-}} \\
20 \\
\left(\mathrm{~cm}^{2}\right)\end{array}$ & $\begin{array}{l}\Omega_{4} 10^{-} \\
20 \\
\left(\mathrm{~cm}^{2}\right)\end{array}$ & $\begin{array}{l}A_{\text {RAD }} \\
\left(s^{-1}\right)\end{array}$ & $\begin{array}{l}A_{\text {NRAD }} \\
\left(s^{-1}\right)\end{array}$ & $\begin{array}{l}A_{\text {tot }} \\
\left(s^{-1}\right)\end{array}$ & $\begin{array}{l}\eta \\
(\%)\end{array}$ \\
\hline$\left[\mathrm{Eu}(\mathrm{tta})_{3}\left(\mathrm{H}_{2} \mathrm{O}\right)_{2}\right]$ & 33,0 & 4,6 & 1110 & 3730 & 3840 & 29 \\
\hline$\left[\mathrm{Eu}(\mathrm{tta})_{3}(\mathrm{TPPO})_{2}\right]$ & 27,73 & 7,59 & 990 & 77 & 1067 & 93 \\
\hline$\left[\mathrm{Eu}(\mathrm{tta})_{3}(\mathrm{TOPO})_{2}\right]$ & 28,78 & 6,81 & 1013 & 68 & 1081 & 94 \\
\hline$\left[\mathrm{Eu}(\mathrm{tta})_{3}(\mathrm{DB} 18 \mathrm{C} 6)_{2}\right]$ & 21,38 & 7,51 & 806 & 195 & 1001 & 52 \\
\hline$\left[\mathrm{Eu}(\mathrm{tta})_{3}(18 \mathrm{C} 6)_{2}\right]$ & 26,63 & 6,72 & 956 & 548 & 1504 & 94 \\
\hline
\end{tabular}

- Parâmetros de intensidade experimental $\left(\Omega_{\lambda}\right)$, eficiência quântica de emissão

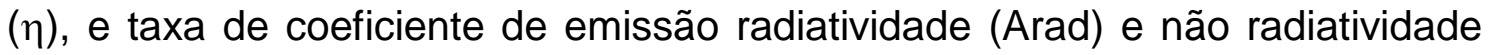
(Anrad) para os complexos $\left[\mathrm{Eu}(\mathrm{tta})_{3}(\mathrm{~L})_{2}\right]$.

\subsection{Coordenadas $x$ e y do Diagrama de Cromaticidade (CIE)}

As cores do espectro visível podem ser reproduzidas pela combinação criteriosa de três componentes monocromáticas. A Comission Internationale l'Eclairage (CIE) adota um colorímetro padrão que representa os atributos de cor através de um diagrama tridimensional.

Os valores cartesianos deste diagrama tridimensional derivam-se dos estímulos espectrais $x(\lambda), y(\lambda)$ e $z(\lambda)$ (FIG. 5.45), os quais são visualizados pelo olho humano devido à incidência de luz. A curva $y(\lambda)$ corresponde à resposta fotônica pelo olho humano da cor verde e a normalização desta curva corresponde a um pico de $550 \mathrm{~nm}{ }^{[60,61]}$. As curvas $z(\lambda)$ e $x(\lambda)$ correspondem à cor azul e vermelha, respectivamente. 


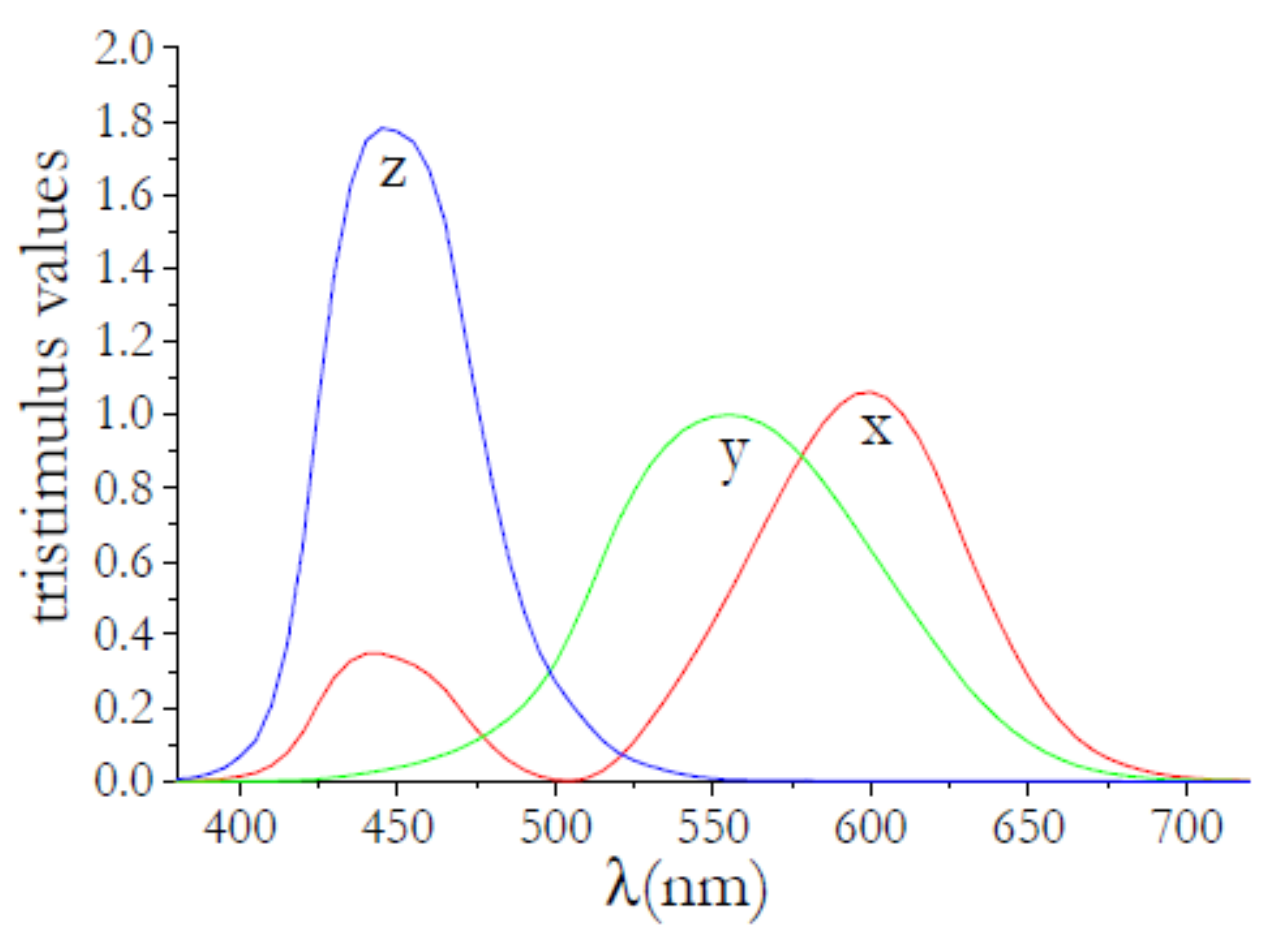

FIGURA 5.45 - Curvas das cores padrões CIE para $x(\lambda), y(\lambda)$ e $z(\lambda)^{[60]}$.

Normalmente apresentam-se apenas os valores das variáveis $\mathrm{x}$ e $\mathrm{y}$, pois a variável z pode ser determinada a partir destes valores. Desta forma, o mapa de cor pode ser expresso como projeção bidimensional num plano xy; o qual define pelo diagrama de cromaticidade CIE (FIG. 5.46).

Calculam-se as coordenadas xy a partir dos espectros de emissão obtidos e no que se referem a dispositivos multicoloridos, tais coordenadas devem localizar-se nos vértices do diagrama $\mathrm{CIE}$, os quais correspondem às cores primárias. Tais cores correspondem ao vermelho, verde e azul, e através da combinação criteriosa destas três componentes podem-se obter todas as cores do espectro visível ${ }^{[60]}$. 


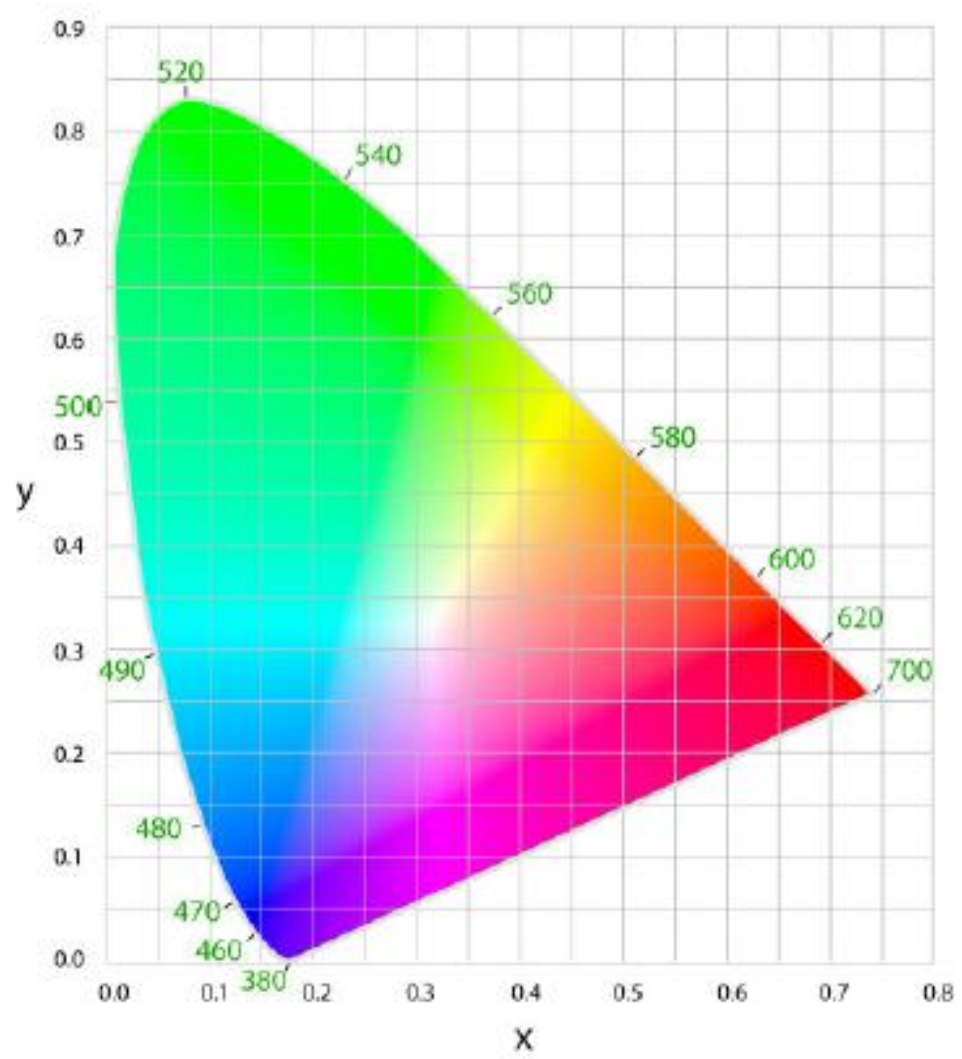

FIGURA 5.46 - Diagrama de cromaticidade CIE ilustrando as coordenadas de cores da região espectral visível ${ }^{[60]}$.

Para os complexos de $\operatorname{TR}(\beta \text {-dicetonatos })_{3}(L)_{2}$ desenvolvidos nesse trabalho as cores observadas por nosso olho na emissão destes complexos estão mostradas nos diagramas de L'Eclerrage apresentados na FIGURA 5.47 e na TABELA 5.15 tem se as coordenadas $x, y$ no que se segue. 


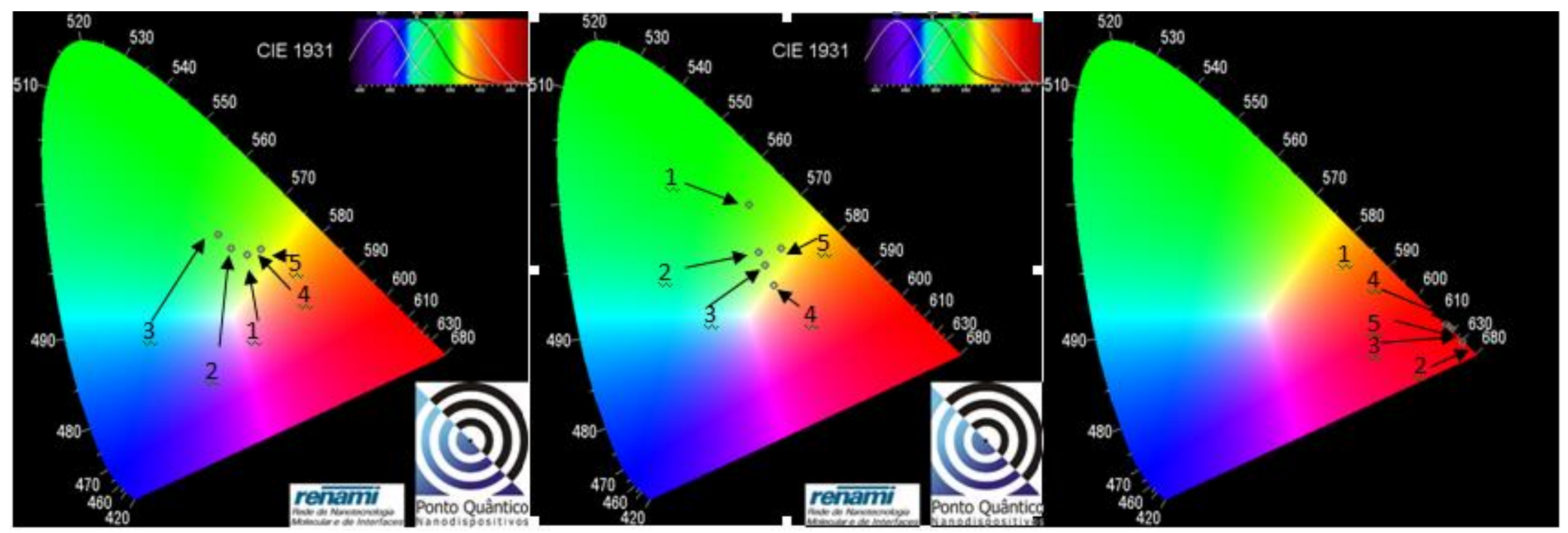

FIGURA 5.47 - Diagrama de cromaticidade CIE ilustrando as coordenadas das cores emitidas pelos complexos TR( $\beta$-dicetonatos) 3 L2 a)TR=Gd e $\beta$-dicetonatos =acac; b) TR=Tb e $\beta$-dicetonatos =acac e c) TR=Eu e $\beta$-dicetonatos =tta; representados por círculo. 1)H2O; 2) TOPO; 3)TPPO; 4) 18C6 e 5)DB18C6 
TABELA 5.15 - Valores aproximados das coordenadas de cores dos materiais funcionalizados.

\begin{tabular}{lcc}
\hline \multicolumn{1}{c}{ Complexo } & $\mathbf{x}$ & $\mathbf{y}$ \\
\hline$\left[\mathrm{Eu}(\mathrm{tta})_{3}(\mathrm{TOPO})_{2}\right]$ & 0,708 & 0,288 \\
{$\left[\mathrm{Eu}(\mathrm{tta})_{3}(\mathrm{TPPO})_{2}\right]$} & 0,688 & 0,311 \\
{$\left[\mathrm{Eu}(\mathrm{tta})_{3}(\mathrm{DB} 18 \mathrm{C} 6)_{2}\right]$} & 0,683 & 0,314 \\
{$\left[\mathrm{Eu}(\mathrm{tta})_{3}(18 \mathrm{C} 6)_{2}\right]$} & 0,679 & 0,320 \\
{$\left[\mathrm{Gd}(\mathrm{acac})_{3}(\mathrm{TOPO})_{2}\right]$} & 0,345 & 0,456 \\
{$\left[\mathrm{Gd}(\mathrm{acac})_{3}(\mathrm{TPPO})_{2}\right]$} & 0,323 & 0,481 \\
{$\left[\mathrm{Gd}(\mathrm{acac})_{3}(\mathrm{DB} 18 \mathrm{C} 6)_{2}\right]$} & 0,399 & 0,454 \\
{$\left[\mathrm{Gd}(\mathrm{acac})_{3}(18 \mathrm{CC})_{2}\right]$} & 0,399 & 0,454 \\
{$\left[\mathrm{~Tb}(\mathrm{acac})_{3}(\mathrm{TOPO})_{2}\right]$} & 0,367 & 0,449 \\
{$\left[\mathrm{~Tb}(\mathrm{acac})_{3}(\mathrm{TPPO})_{2}\right]$} & 0,379 & 0,426 \\
\hline$\left[\mathrm{Tb}(\mathrm{acac})_{3}(\mathrm{DB} 18 \mathrm{C} 6)_{2}\right]$ & 0,408 & 0,456 \\
\hline$\left[\mathrm{Tb}(\mathrm{acac})_{3}(18 \mathrm{CC})_{2}\right]$ & 0,396 & 0,389 \\
\hline$\left[\mathrm{Tb}(\mathrm{acac})_{3}(\mathrm{H} 2 \mathrm{O})_{2}\right]$ & 0,350 & 0,535 \\
\hline$\left[\mathrm{Gd}(\mathrm{acac})_{3}(\mathrm{H} 2 \mathrm{O})_{2}\right]$ & 0,375 & 0,444 \\
\hline$\left[\mathrm{Eu}(\mathrm{tta})_{3}\left(\mathrm{H}_{2} \mathrm{O}\right)_{2}\right]^{2}$ & 0,680 & 0,321 \\
\hline & &
\end{tabular}




\subsection{Nanopartículas Poliméricas de PHB e PMMA Dopadas com o Complexo Luminescente $\left[\mathrm{Eu}(\mathrm{tta})_{3}(\mathrm{TOPO})_{2}\right]$ e com 0 Complexo $\left[\mathrm{Gd}(\mathrm{tta})_{3}(\mathrm{TOPO})_{2}\right]$}

$\mathrm{Na}$ segunda parte deste trabalho direcionaram-se os esforços na obtenção de nanopartículas poliméricas dopadas com um dos complexos luminescentes dentre os desenvolvidos na primeira etapa da pesquisa. $O$ objetivo como anteriormente estabelecido (Cap. 2) era a obtenção de uma nanopartícula para posterior utilização como marcador do 17 $\beta$-estradiol. Para tanto se investiu na síntese de nanopartículas poliméricas de PHB e PMMA pois ambos os polímeros possuem todo um "know how" como materiais luminescentes em filmes e OLEDs. A produção destas nanoparticulas abrirá um leque de aplicações nas áreas de segurança, energia e de marcadores que, neste trabalho como já explicado, atua na área de nanomarcadores biológicos.

A partir dos resultados das investigações dos materiais luminescentes baseados em TR, foi possível concluir que o complexo de tha de európio contendo o ligante auxiliar TOPO dentre os complexos de $\mathrm{Tb}^{3+}$ e $\mathrm{Eu}^{3+}$ estudados apresentava a maior eficiência luminescente no processo de transferência de energia para o íon $\mathrm{Eu}^{3+}$. A partir destes resultados, este complexo foi escolhido para servir como dopante das matrizes poliméricas estudadas neste trabalho (PMMA e PHB). As dopagens foram realizadas em diferentes concentrações mássicas com relação à massa polimérica $(0,5 ; 1 ; 3$; 5 e 7\%). Para estudar os processos de fosforescência do ligante e dos polímeros no sistema luminescente, o complexo de gadolínio com o mesmo ligante auxiliar TOPO dopou as duas matrizes poliméricas nas mesmas concentrações mássicas equivalentes às concentrações de dopagens feitas com o complexo de $\mathrm{Eu}^{3+}$. A partir desta etapa do trabalho, serão discutidos os resultados obtidos a partir de experimentos para obtenção das nanopartículas. 


\subsubsection{Nanopartículas Poliméricas PMMA e PHB Dopadas com $\left[\mathrm{Eu}(\mathrm{tta})_{3}(\mathrm{TOPO})_{2}\right]$ Produzidas pelo Método de Nanoprecipitação por Crioscopia}

As nanopartículas de PMMA e PHB obtidas pelo método de nanoprecipitação por crioscopia foram obtidas e apresentaram as características qualitativas descritas a seguir:

\subsubsection{Características Qualitativas das Nanopartículas} POL:X\%[Eu(tta) $\left.)_{3}(\mathrm{TOPO})_{2}\right](\mathrm{POL}=\mathrm{PHB}, \mathrm{PMMA} \mathrm{X}=0,5 ; 1 ; 3 ; 5$ e 7 )

Os polímeros de PMMA e PHB dopados com 0 complexo $\left[\mathrm{Eu}(\mathrm{tta})_{3}(\mathrm{TOPO})_{2}\right]$ apresentaram-se na forma de aglomerado de nanopartículas de cor branca que são resistentes ao intemperismo, principalmente à umidade. As nanopartículas obtidas de PMMA e PHB dopadas com o complexo $\left[\mathrm{Eu}(\mathrm{tta})_{3}(\mathrm{TOPO})_{2}\right]$ geraram materiais altamente luminescentes que, sob iluminação do sol, exibe coloração branca, e sob irradiação UV exibe emissão de cor vermelha (FIG. 5.48). 

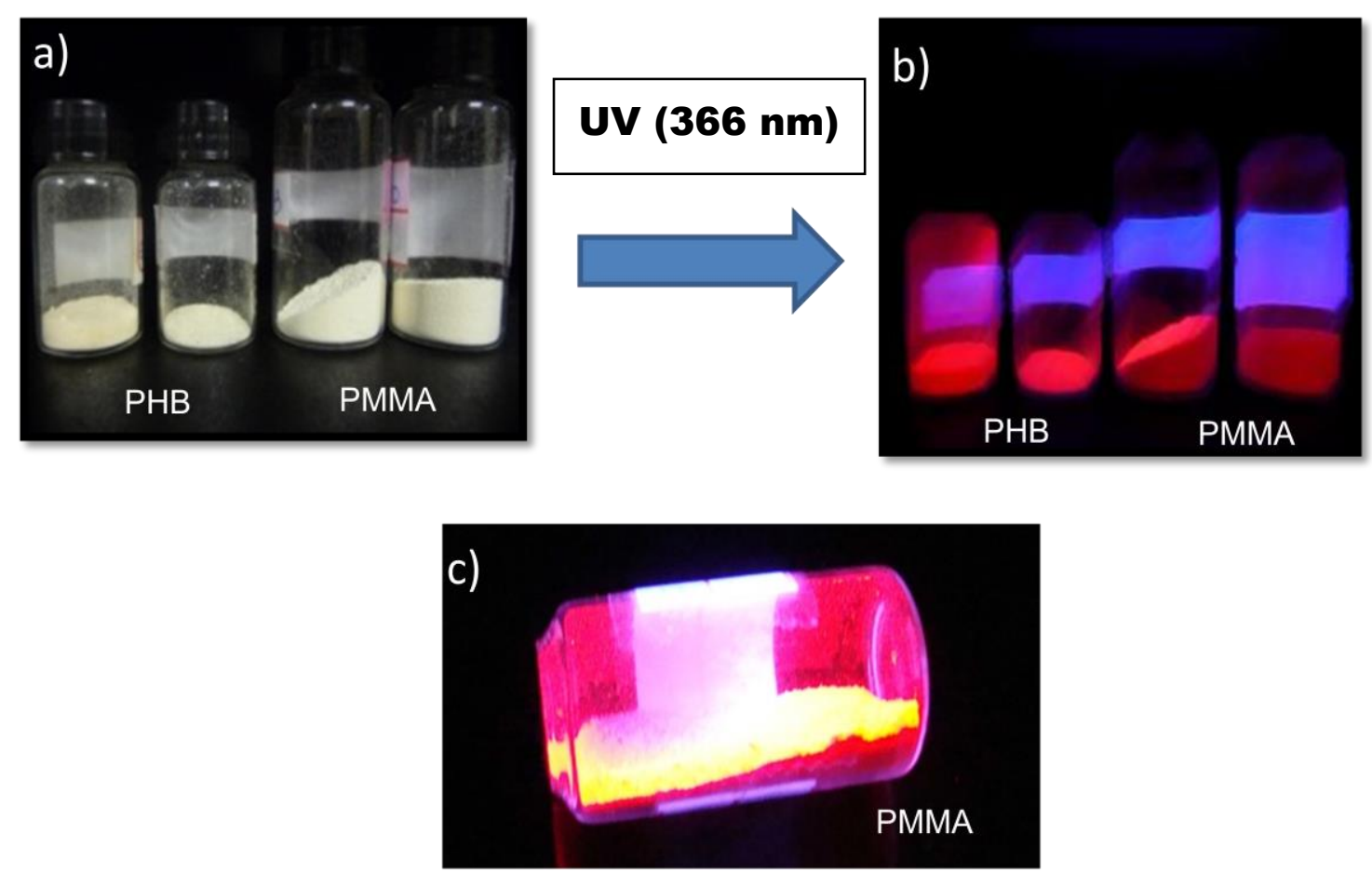

FIGURA 5.48 - Fotografias das nanopartículas poliméricas de PMMA e PHB dopadas com o complexo $\left[\mathrm{Eu}(\mathrm{tta})_{3}(\mathrm{TOPO})_{2}\right] ;$ a) sob luz ambiente; b) sob irradiação ultravioleta $(366 \mathrm{~nm})$; c) PMMA:5\%[Eu(tta $\left.)_{3}(\mathrm{TOPO})_{2}\right]$ sob irradiação ultravioleta (366 nm).

\subsubsection{Características Qualitativas das Nanopartículas} POL:X\%[Gd(tta) (TOPO) $_{2}$ (POL= PHB, PMMA; X= 0,5; 1; 3; 5 e 7) Obtidas pelo Método Crioscópico.

As nanopartículas de PHB e PMMA dopadas com o complexo de gadolínio $\left[\mathrm{Gd}(\mathrm{tta})_{3}(\mathrm{TOPO})_{2}\right.$ ] apresentaram-se na forma de material sólido de coloração branca sem emissão de cor sob irradiação ultravioleta (FIG. 5.49), comportamento inerente aos complexos de gadolínio. Estes materiais apresentaram-se também resistentes às intempéries do ambiente. 

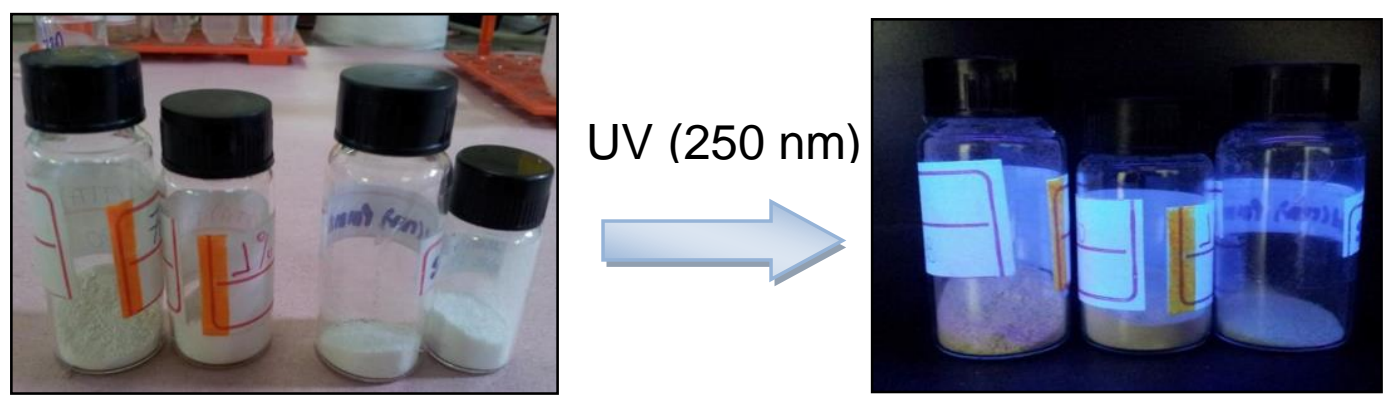

FIGURA 5.49 - Fotografias das nanopartículas poliméricas de PMMA e PHB dopadas com o complexo [Gd(tta) $)_{3}(\mathrm{TOPO})_{2}$ ] a) sob luz ambiente; b) sob irradiação ultravioleta $(250 \mathrm{~nm})$.

\subsubsection{Caracterizações}

Para caracterização destas nanopartículas dopadas com complexos de $\left[\mathrm{TR}(\mathrm{tta})_{3}(\mathrm{TOPO})_{2}\right]\left(\mathrm{TR}=\mathrm{Eu}^{3+} \mathrm{e} \mathrm{Gd}^{3+}\right)$ foram utilizadas técnicas convencionais de caracterização de materiais já desenvolvida pelo grupo de pesquisa que são: a Espectroscopia de Absorção no Infravermelho, Análise Termogravimétrica, Análise de Difração de Raios X, Microscopia Eletrônica de Varredura, Espectroscopia de Luminescência para avaliar as propriedades espectroscópicas e luminescentes das nanopartículas dopadas, análise do espalhamento de luz pelas nanopartículas em solução-efeito Tyndall e testes de biocompatibilidade.

\subsection{Espectroscopia de Absorção no Infravermelho por Transformada de Fourier (FTIR) das Nanopartículas de PHB e PMMA Obtidas pelo Método de Nanoprecipitação por Crioscopia}

Os sistemas estudados neste trabalho compreendem polímeros dopados com complexos de $\mathrm{TR}^{3+}$, com concentração de dopagem variando de 0,5 a 7\% em massa. Os espectros apresentam os perfis das matrizes poliméricas na sua totalidade, ou seja, apenas as bandas atribuídas às matrizes poliméricas foram observadas. Já as bandas referentes aos modos vibracionais dos compostos 
de coordenação são pouco observadas. Apenas com 0 aumento da concentração mássica da dopagem é que alguns destes modos vibracionais do complexo aparecem no espectro (FIG. 5.50 e 5.51).

\subsection{Nanopartículas Poliméricas PHB e PMMA Dopadas com o Complexo [Eu(tta) $)_{3}(\mathrm{TOPO})_{2}$ ] em Diferentes Concentrações Obtidas pelo Método Crioscópico}

Os espectros de absorção na região do infravermelho do sistema PHB:X\%[Eu(tta $\left.)_{3}(\mathrm{TOPO})_{2}\right](\mathrm{X}=0,5 ; 1 ; 3 ; 5$ e 7\%) estão ilustrados na FIGURA 5.50. Observa-se bandas atribuídas ao modo de estiramento assimétrico $v_{\text {as }}\left(\mathrm{CH}_{3}\right)$ em $2998 \mathrm{~cm}^{-1}$; $v_{\text {as }}\left(\mathrm{CH}_{2}\right)$ em $2975 \mathrm{~cm}^{-1}$; estiramento simétrico $v_{\mathrm{s}}\left(\mathrm{CH}_{2}\right)$ em $2930 \mathrm{~cm}^{-1}$; v(C=O) em $1723 \mathrm{~cm}^{-1}$; v(C-O) em 1044 e $1056 \mathrm{~cm}^{-1}$ (TAB. 5.16). Observam-se também várias bandas na região de impressão digital da molécula de $1409 \mathrm{~cm}^{-1}$ a $500 \mathrm{~cm}^{-1}$, bandas tanto atribuídas ao complexo (maior concentração de dopagem) quanto à matriz polimérica.

Os espectros de absorção na região do infravermelho do sistema PMMA:X\%[Eu(tta) $\left.)_{3}(\mathrm{TOPO})_{2}\right](X=0,5 ; 1 ; 3 ; 5$ e 7\%), ilustrados na FIGURA 5.51, apresentam bandas na região atribuída ao modo de estiramento $(\mathrm{C}-\mathrm{H}) \rightarrow \mathrm{CH}_{3}$ $\left(1438 \mathrm{~cm}^{-1}\right)$ das formas cis e trans dicetona, e bandas atribuídas ao estiramento $\mathrm{v}(\mathrm{O})\left(\mathrm{CH}_{3}\right)$ em $2996 \mathrm{~cm}^{-1} ; \mathrm{v}(\mathrm{O})\left(\mathrm{CH}_{3}\right)$ em $2952 \mathrm{~cm}^{-1} ; \mathrm{v}(\mathrm{O})\left(\mathrm{CH}_{3}\right)$ em $2843 \mathrm{~cm}^{-1}$; $\mathrm{v}(\mathrm{C}=\mathrm{O})$ em $1748 \mathrm{~cm}^{-1} ; \delta(\mathrm{C}=\mathrm{O})$ em $1458 \mathrm{~cm}^{-1}$ (TAB.5.17).

Os espectros de Infravermelho das matrizes poliméricas dopadas com $\left[\mathrm{Gd}(\mathrm{tta})_{3}(\mathrm{TOPO})_{2}\right]$ apresentaram um mesmo perfil das bandas e não foram apresentadas as atribuições dos modos vibracionais neste texto. 


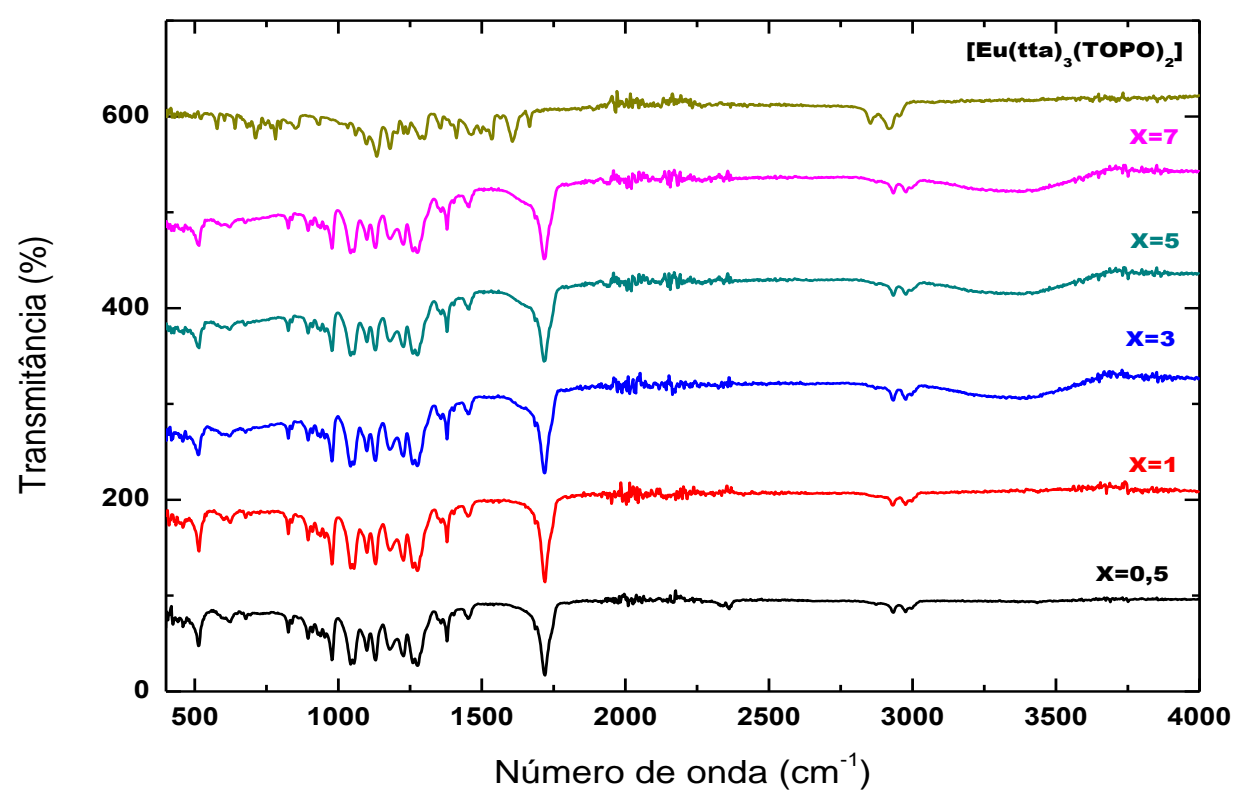

FIGURA 5.50 - Espectros de absorção no infravermelho registrados à temperatura ambiente no intervalo de 400 a $4000 \mathrm{~cm}^{-1}$, das nanopartículas PHB:X\%[Eu(tta $\left.)_{3}(\mathrm{TOPO})_{2}\right]$ e do complexo $\left[\mathrm{Eu}(\mathrm{tta})_{3}(\mathrm{TOPO})_{2}\right]$.

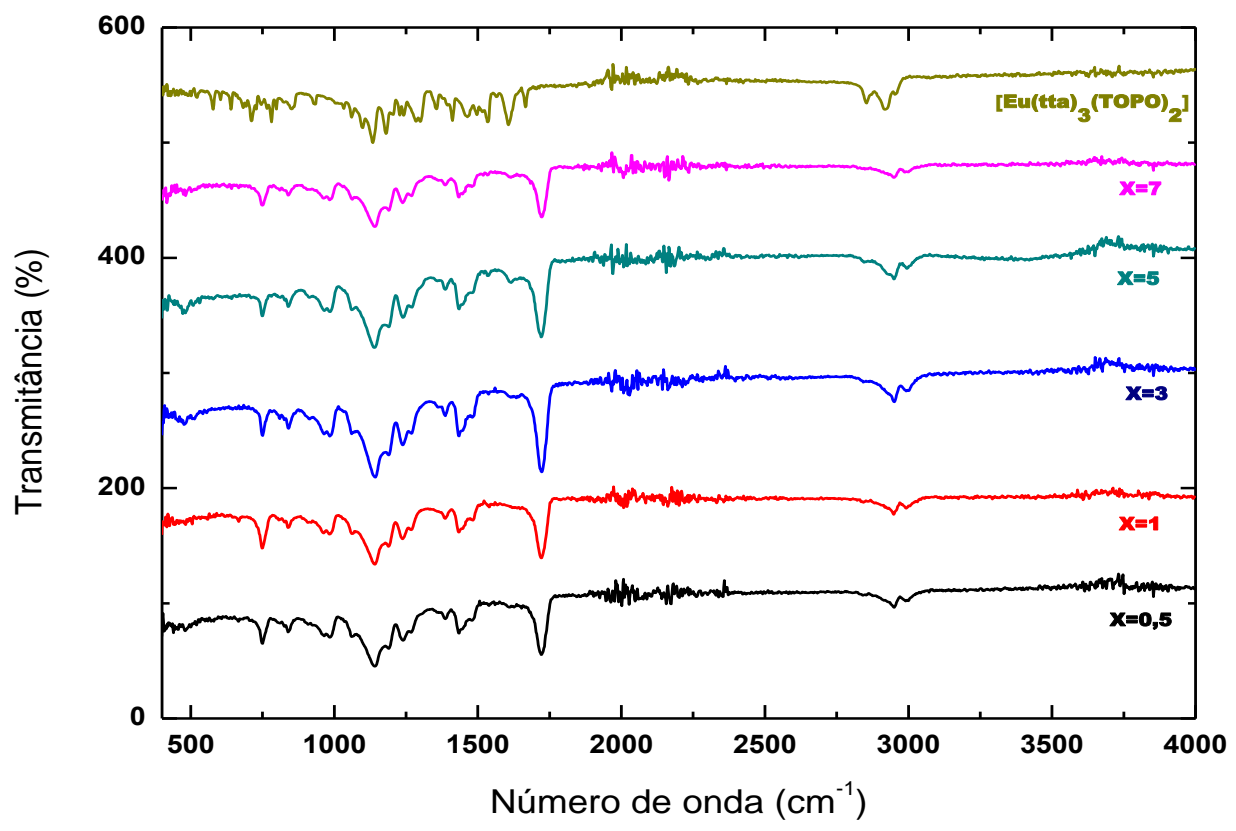

FIGURA 5.51 - Espectros de absorção na região do infravermelho registrado à temperatura ambiente no intervalo de 400 a $4000 \mathrm{~cm}^{-1}$, das nanopartículas PMMA:X\% [Eu(tta) $\left.)_{3}(\mathrm{TOPO})_{2}\right]$ e do complexo $\left[\mathrm{Eu}(\mathrm{tta})_{3}(\mathrm{TOPO})_{2}\right]$. 
TABELA 5.16 - Atribuição das frequências $\left(\mathrm{cm}^{-1}\right)$ dos principais modos vibracionais das nanopartículas poliméricas $\mathrm{PHB}$.

\begin{tabular}{|c|c|c|c|c|c|c|}
\hline NPs & $\begin{array}{c}\text { Dopagem } \\
(\%)\end{array}$ & $\begin{array}{c}\mathrm{U}_{a s} \\
\left(\mathrm{CH}_{2}\right)\end{array}$ & $\begin{array}{c}\mathrm{U}_{a s} \\
\left(\mathrm{CH}_{3}\right)\end{array}$ & $\begin{array}{c}\mathrm{U}_{s} \\
\left(\mathrm{CH}_{2}\right)\end{array}$ & $\mathrm{v}\left(\mathrm{COO}^{-}\right)$ & $\mathrm{v}\left(\mathrm{CO}^{-}\right)$ \\
\hline \multirow{6}{*}{ PHB:X\%[Eu(tta) $\left.)_{3}(\mathrm{~L})_{2}\right]$} & 0,5 & 2975 & 2998 & 2933 & 1722 & 1044 \\
\hline & 1 & 2973 & 3000 & 2929 & 1722 & 1054 \\
\hline & 3 & 2973 & 2998 & 2929 & 1722 & 1054 \\
\hline & 5 & 2975 & 2998 & 2931 & 1718 & 1047 \\
\hline & 7 & 2977 & 2998 & 2933 & 1718 & 1047 \\
\hline & $0 \%$ * & 2976 & 2997 & 2873 & 1748 & 1044 \\
\hline
\end{tabular}

* retirados da referência [1]

TABELA 5.17 - Atribuição das frequências $\left(\mathrm{cm}^{-1}\right)$ dos principais modos vibracionais das nanopartículas poliméricas PMMA.

\begin{tabular}{|c|c|c|c|c|c|c|}
\hline NPs & $\begin{array}{c}\text { Dopagem } \\
(\%)\end{array}$ & $\mathrm{v}(\mathrm{O})\left(\mathrm{CH}_{3}\right)$ & $\mathrm{v}(\mathrm{O})\left(\mathrm{CH}_{3}\right)$ & $\mathrm{v}_{s}\left(\mathrm{CH}_{2}\right)$ & $v(C=0)$ & $\delta(C=0)$ \\
\hline \multirow{6}{*}{$\begin{array}{l}\text { PMMA:X\%[Eu(tta) } 3 \\
\left.(\mathrm{~L})_{2}\right]\end{array}$} & 0,5 & 2991 & 2949 & 2853 & 1722 & 1433 \\
\hline & 1 & 3005 & 2949 & 2860 & 1722 & 1433 \\
\hline & 3 & 3001 & 2950 & 2860 & 1722 & 1435 \\
\hline & 5 & 2994 & 2950 & 2860 & 1722 & 1435 \\
\hline & 7 & 2999 & 2947 & - & 1722 & 1433 \\
\hline & $0 \%{ }^{*}$ & 2996 & 2952 & 284 & 1748 & 1488 \\
\hline
\end{tabular}

* retirados da referência [1] 


\subsection{Análise Termogravimétrica (TG/DTG)}

\subsection{Análise Termogravimétrica (TG/DTG) para as Nanopartículas Poliméricas de PMMA Dopadas com [Eu(tta) $)_{3}(\mathrm{TOPO})_{2}$ ] em Diferentes Concentrações Obtidas pelo Método Crioscópico}

Nas FIGURAS 5.52 a $\mathbf{5 . 5 6}$ estão apresentadas as curvas TG/DTG das nanopartículas poliméricas (NPs) com diferentes concentrações de dopagens $\left(0,5 ; 1 ; 3 ; 5\right.$ e $7 \%$ em peso) do complexo $\left[\mathrm{Eu}(\mathrm{tta})_{3}(\mathrm{TOPO})_{2}\right]$ na matriz PMMA. Estas curvas foram obtidas em atmosfera inerte de $\mathrm{N}_{2}$ e apresentam dois eventos de termodecomposição. O primeiro evento é abaixo de $200{ }^{\circ} \mathrm{C}$ e se refere a perda de umidade das amostras. O segundo evento de perda de massa e mais representativo do sistema apresenta diminuição da temperatura onset de decomposição inicial $\left(\mathrm{T}_{\text {onset }}=\mathrm{T}_{1}\right)$ à medida que aumenta a concentração da dopagem, exceto para 7\%. Quando comparados com o PMMA sem dopagem, observa-se um decaimento na $\mathrm{T}_{\text {onset }} \mathrm{e}$ um aumento pequeno na $\mathrm{T}_{\text {offset }}$, conferindo a estes materiais uma maior estabilidade térmica quando dopadas.

Nota-se também diminuição da perda de massa em $\mathrm{T}_{1}$ em direção às maiores dopagens (5 e 7\%) do complexo no polímero, consequentemente, um aumento no resíduo do sistema polimérico, o que já era esperado devido ao aumento da concentração de [Eu(tta) $\left.)_{3}(\mathrm{TOPO})_{2}\right]$.

A TABELA 5.18 resume os dados de comportamento de decomposição térmica das nanopartículas poliméricas estudadas. 

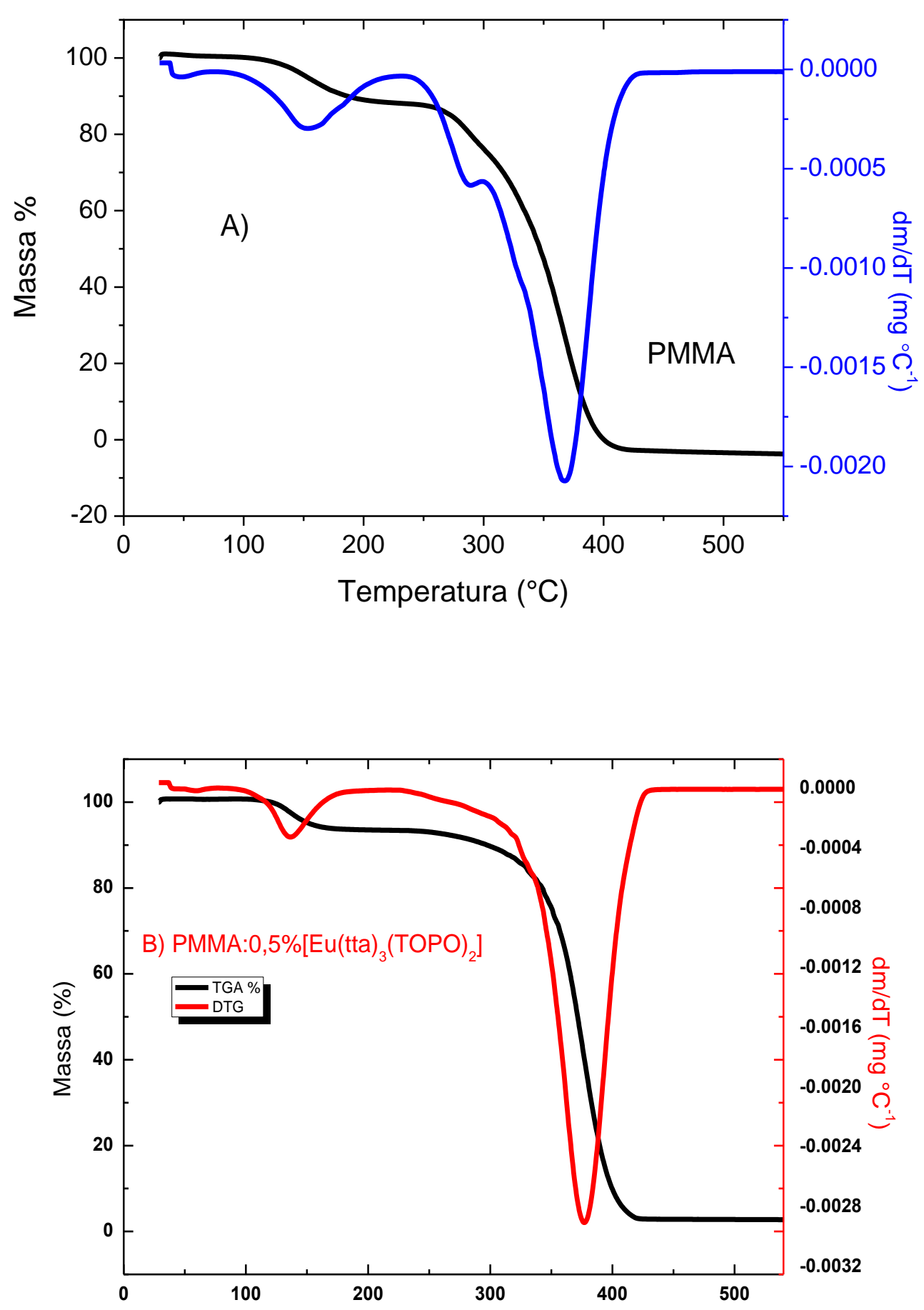

Temperatura $\left({ }^{\circ} \mathrm{C}\right)$

FIGURA 5.52 - Curvas TGA/DTG registradas no intervalo de 0 a $540{ }^{\circ} \mathrm{C}$, sob atmosfera dinâmica de $\mathrm{N}_{2}, A$ ) do polímero PMMA e B) do sistema polimérico PMMA:0,5\%[Eu(tta $\left.)_{3}(\text { TOPO })_{2}\right]$. 


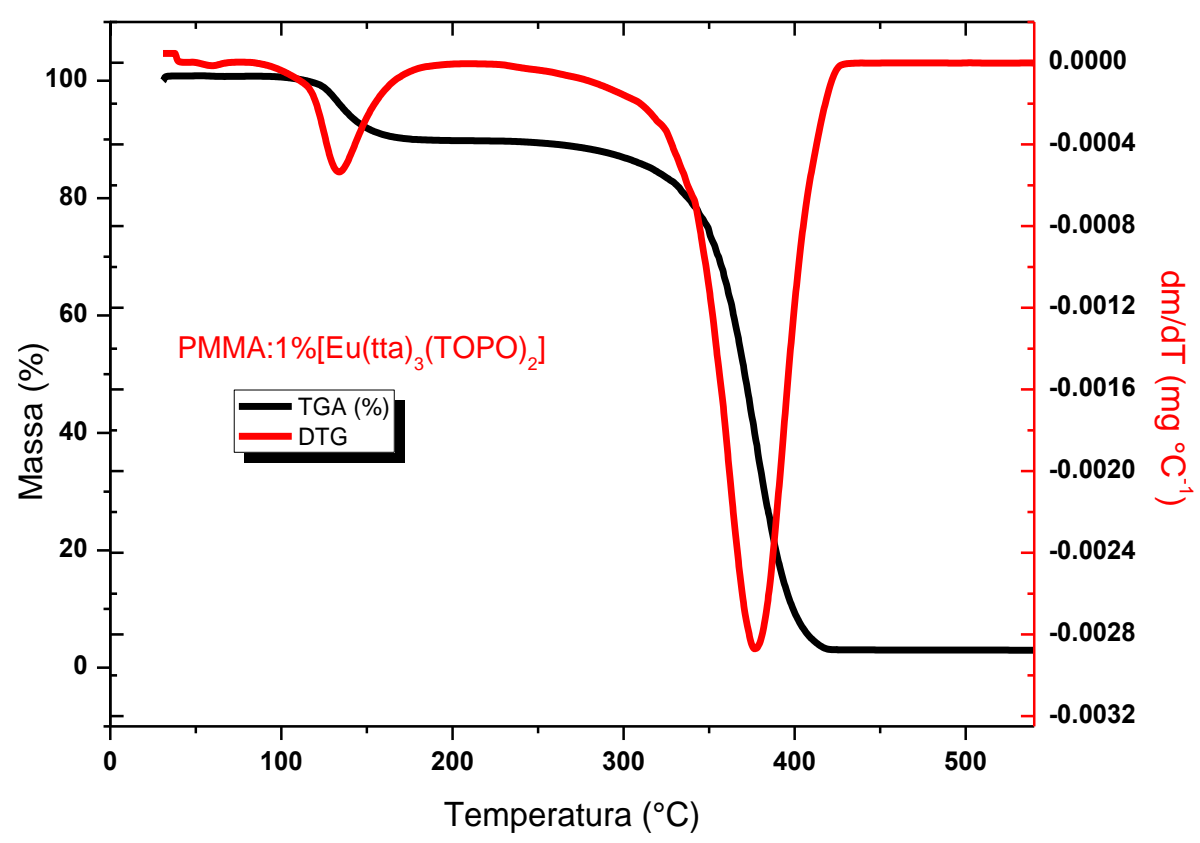

FIGURA 5.53 - Curvas TGA/DTG registradas no intervalo de 0 a $540{ }^{\circ} \mathrm{C}$, sob atmosfera dinâmica de $\mathrm{N}_{2}$, do sistema polimérico PMMA:1\%[Eu(tta) $\left.)_{3}(\mathrm{TOPO})_{2}\right]$.

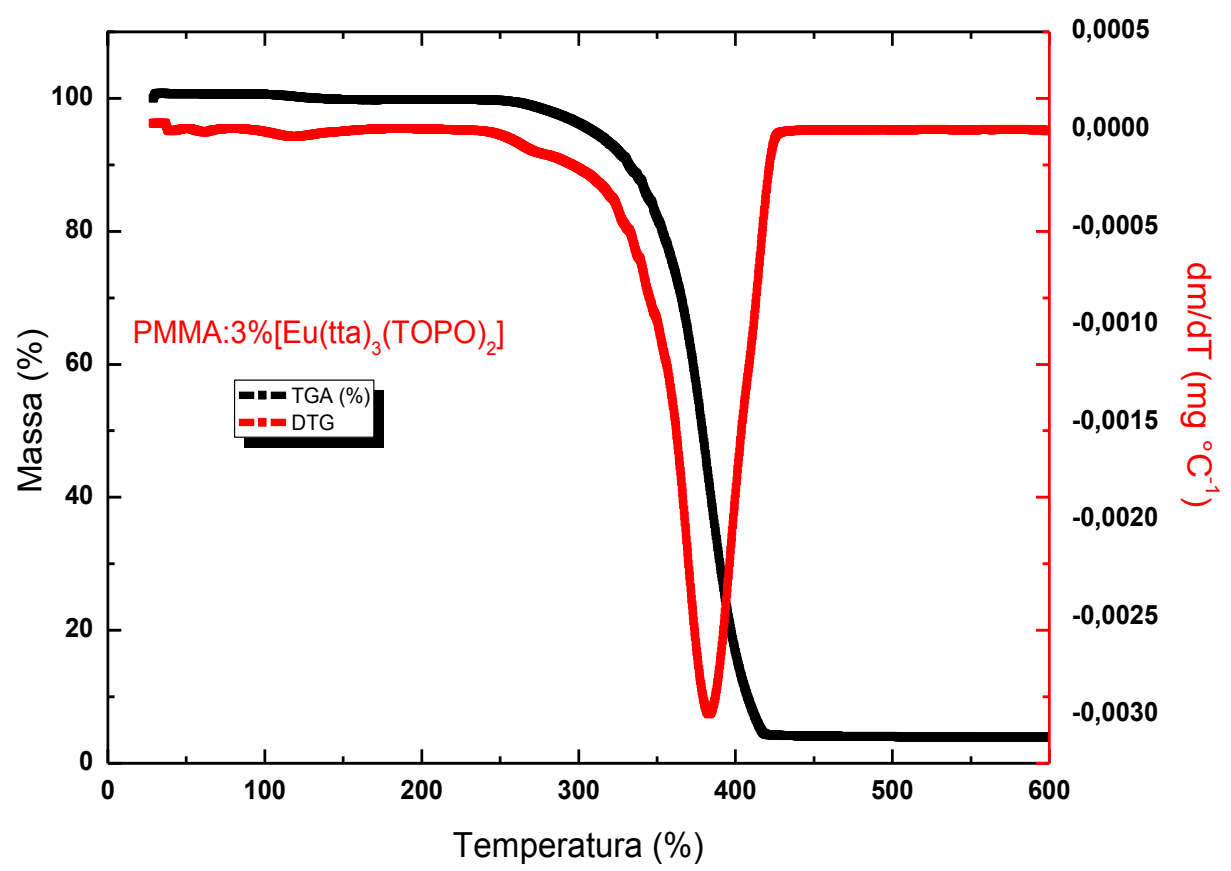

FIGURA 5.54 - Curvas TGA/DTG registradas no intervalo de 0 a $540{ }^{\circ} \mathrm{C}$, sob atmosfera dinâmica de $\mathrm{N}_{2}$, do sistema polimérico PMMA:3\%[Eu(tta) $\left.)_{3}(\mathrm{TOPO})_{2}\right]$. 


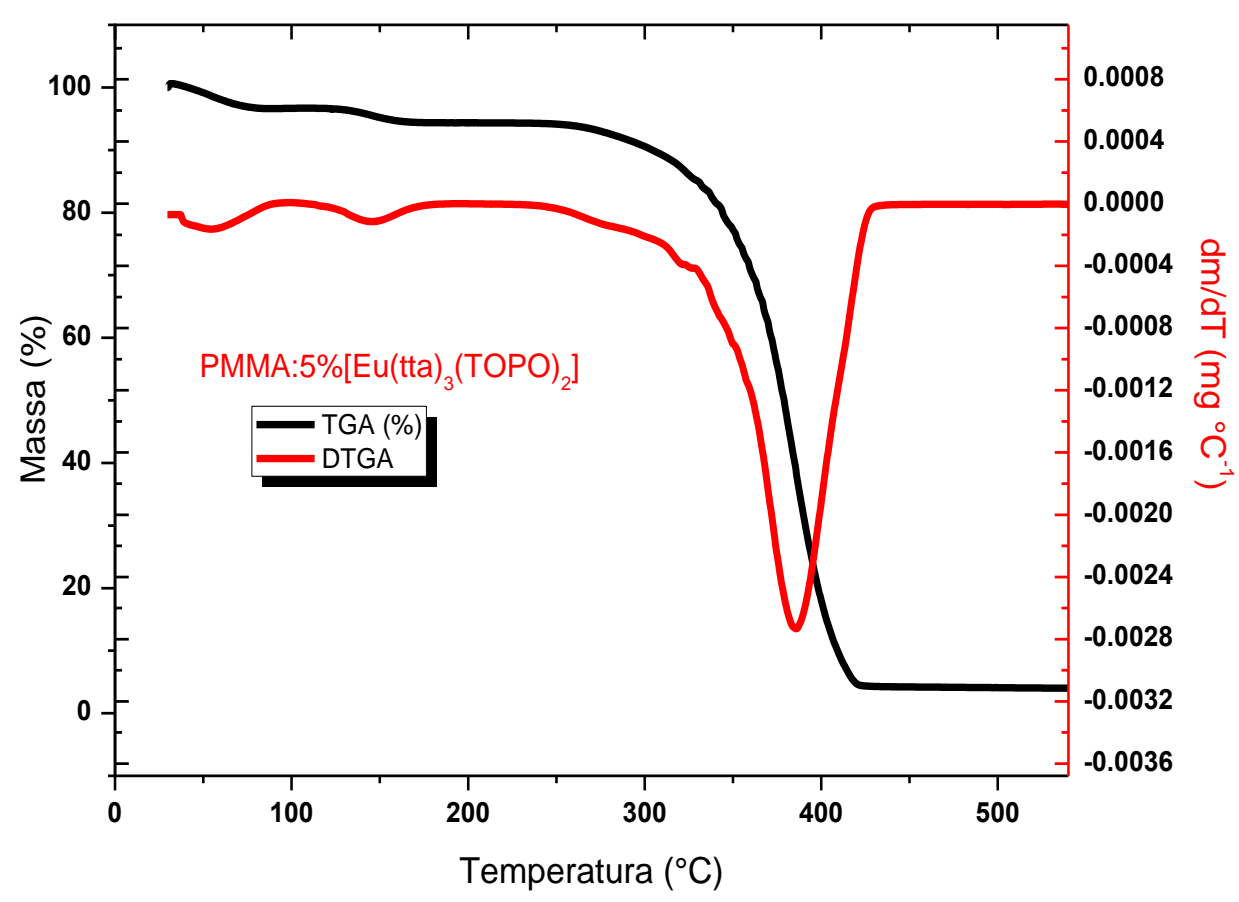

FIGURA 5.55 - Curvas TGA/DTG registradas no intervalo de 0 a $540{ }^{\circ} \mathrm{C}$, sob atmosfera dinâmica de $\mathrm{N}_{2}$, do sistema polimérico PMMA:5\%[Eu(tta) $\left.)_{3}(\mathrm{TOPO})_{2}\right]$.

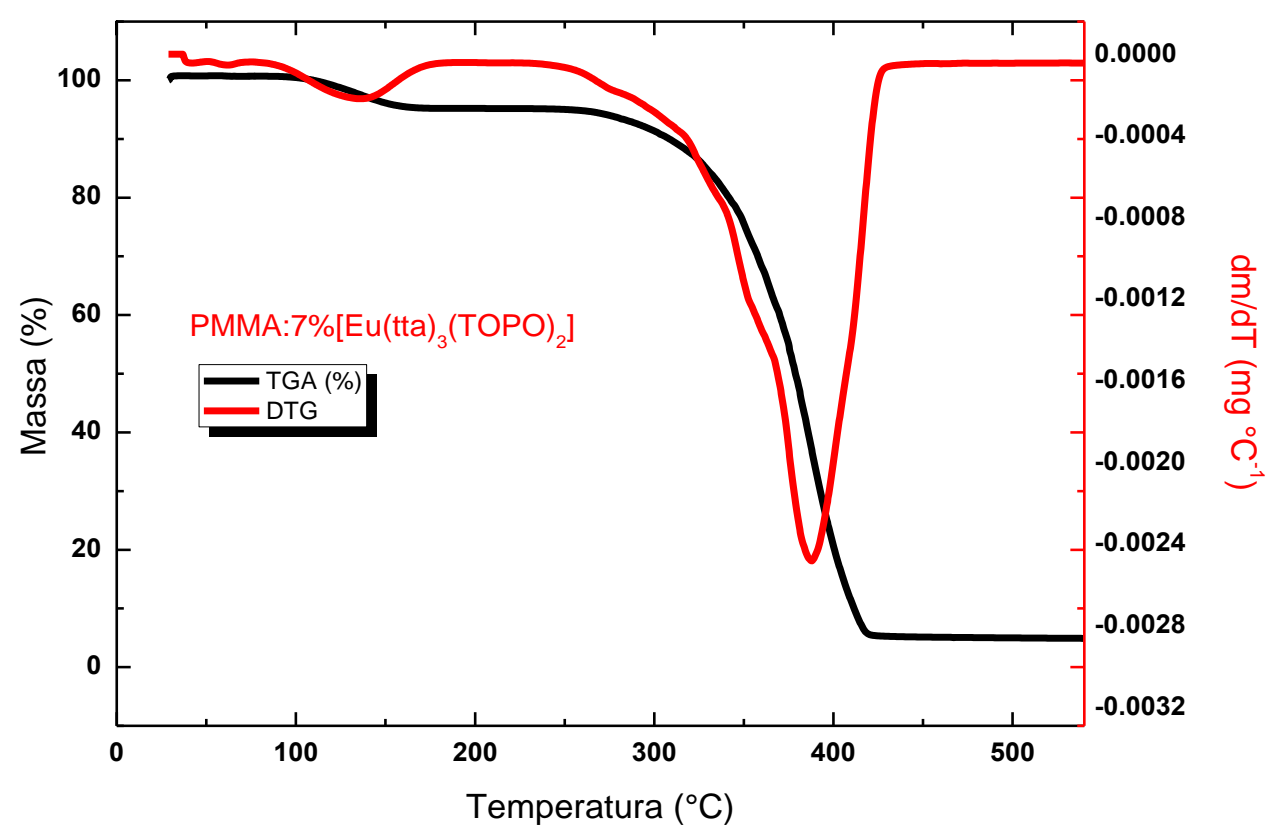

FIGURA 5.56 - Curvas TGA/DTG registradas no intervalo de $\theta 540{ }^{\circ} \mathrm{C}$, sob atmosfera dinâmica de $\mathrm{N}_{2}$, do sistema polimérico PMMA:7\%[Eu(tta) $\left.)_{3}(\mathrm{TOPO})_{2}\right]$. 
TABELA 5.18 - Dados de perda de massa dos sistemas poliméricos PMMA:X\%[Eu(tta $)_{3}(\mathrm{TOPO})_{2}(\mathrm{X}=0,5 ; 1 ; 3 ; 5 ; 7 ;)$ no intervalo de temperatura 0 a $540 \stackrel{\circ}{C}$.

\begin{tabular}{lcccc}
\hline \multicolumn{1}{c}{ Amostra } & $\mathbf{T}_{\text {onset }}\left({ }^{\circ} \mathbf{C}\right)$ & $\mathbf{T}_{\text {offset }}\left({ }^{\circ} \mathbf{C}\right)$ & $\Delta \mathbf{m}(\%)$ & Resíduo (\%) \\
\hline PMMA0,0\%Eu(tta) $)_{3}(\mathrm{TOPO})_{2}$ & 304 & 418 & 91,5 & 2,08 \\
PMMA:0,5\%Eu(tta) $)_{3}(\mathrm{TOPO})_{2}$ & 232 & 428 & $97,15 \%$ & $2,85 \%$ \\
PMMA:1\%Eu(tta) $)_{3}(\mathrm{TOPO})_{2}$ & 230 & 425 & $96,94 \%$ & $3,06 \%$ \\
PMMA:3\%Eu(tta) $)_{3}(\mathrm{TOPO})_{2}$ & 250 & 430 & $95,85 \%$ & $4,15 \%$ \\
PMMA:5\%Eu(tta) $)_{3}(\mathrm{TOPO})_{2}$ & 240 & 436 & $95,76 \%$ & $4,24 \%$ \\
PMMA:7\%Eu(tta $)_{3}(\mathrm{TOPO})_{2}$ & 237 & 438 & $94,57 \%$ & $5,43 \%$ \\
\hline
\end{tabular}

\subsection{Análise Termogravimétrica (TG/DTG) para as Nanopartículas Poliméricas de PHB Dopadas com [Eu(tta) $\left.)_{3}(\mathrm{TOPO})_{2}\right]$ em Diferentes Concentrações Obtidas pelo Método Crioscópico}

Nas FIGURAS 5.57 a 5.61 estão apresentadas as curvas TGA/DTG das nanopartículas poliméricas de PHB não dopadas e dopadas com o complexo $\left[\mathrm{Eu}(\mathrm{tta})_{3}(\mathrm{TOPO})_{2}\right]$ com percentagem de dopagem em massa de 0,$5 ; 1 ; 3 ; 5$ e 7\%. As curvas termogravimétricas ilustradas na FIGURA 5.57 A mostram que o polímero não dopado apresenta decomposição em uma única etapa no intervalo de temperatura de 265 e $281^{\circ} \mathrm{C}$. As curvas das amostras dos sistemas poliméricos apresentam até dois eventos de decomposição. $O$ sistema apresenta diminuição da temperatura de decomposição inicial ( $T_{\text {onset }}$ $\left.=\mathrm{T}_{1}\right), 245 ; 230 ; 232 ; 236 ; 220$; com o aumento das concentrações de dopagens 0,$5 ; 1 ; 3 ; 5 ; 7 \%$, respectivamente. Os resultados também mostram perda de massa na região de 80-120 ํ C nos sistemas dopados com 3 e 5\% do complexo, tal fato é atribuído a água de desidratação do sistema. Após perda inicial de massa na região mencionada, o sistema mantém-se estável até aproximadamente $220 \stackrel{\circ}{\circ}$ onde acontecem os eventos relacionados à queima 
do polímero. Nas demais porcentagens de dopagem $(0,5 ; 1$ e $7 \%$ ) não foi evidenciado perda de massa na região de 80-120 ํ․

Nota-se também diminuição da perda de massa em $T_{1}$ nas dopagens de 3 e $5 \%$ do complexo no polímero, consequentemente, o aumento de resíduo do sistema polimérico (TAB. 5.19)

Vale salientar que as nanopartículas $\mathrm{PHB}: \mathrm{X} \% \mathrm{Eu}(\mathrm{tta})_{3}(\mathrm{TOPO})_{2}$ dopadas são mais estáveis termicamente do que as não dopadas.

TABELA 5.19 - Dados de perda de massa dos sistemas poliméricos $\mathrm{PHB}: \mathrm{X} \% \mathrm{Eu}(\mathrm{tta})_{3}(\mathrm{TOPO})_{2}(\mathrm{X}=0,5 ; 1 ; 3 ; 5 ; 7)$ no intervalo de temperatura $0 \mathrm{a}$ $540^{\circ} \mathrm{C}$.

\begin{tabular}{lcccc}
\hline \multicolumn{1}{c}{ Amostra } & $\mathbf{T}_{\text {onset }}\left({ }^{\circ} \mathbf{C}\right)$ & $\mathbf{T}_{\text {offset }}\left({ }^{\circ} \mathbf{C}\right)$ & $\Delta \mathbf{m}(\%)$ & Resíduo (\%) \\
\hline PHB & 263 & 281 & 99,10 & 0,91 \\
PHB:0,5\%Eu(tta) ${ }_{3}(\mathrm{TOPO})_{2}$ & 245 & 315 & $98,21 \%$ & $1,79 \%$ \\
PHB:1\%Eu(tta) $)_{3}(\mathrm{TOPO})_{2}$ & 230 & 304 & $97,42 \%$ & $2,57 \%$ \\
PHB:3\%Eu(tta) $)_{3}(\mathrm{TOPO})_{2}$ & 232 & 295 & $96,65 \%$ & $3,35 \%$ \\
PHB:5\%Eu(tta) $)_{3}(\mathrm{TOPO})_{2}$ & 236 & 295 & $96,64 \%$ & $3,36 \%$ \\
PHB:7\%Eu(tta) $)_{3}(\mathrm{TOPO})_{2}$ & 220 & 309 & $96,70 \%$ & $3,30 \%$ \\
\hline
\end{tabular}



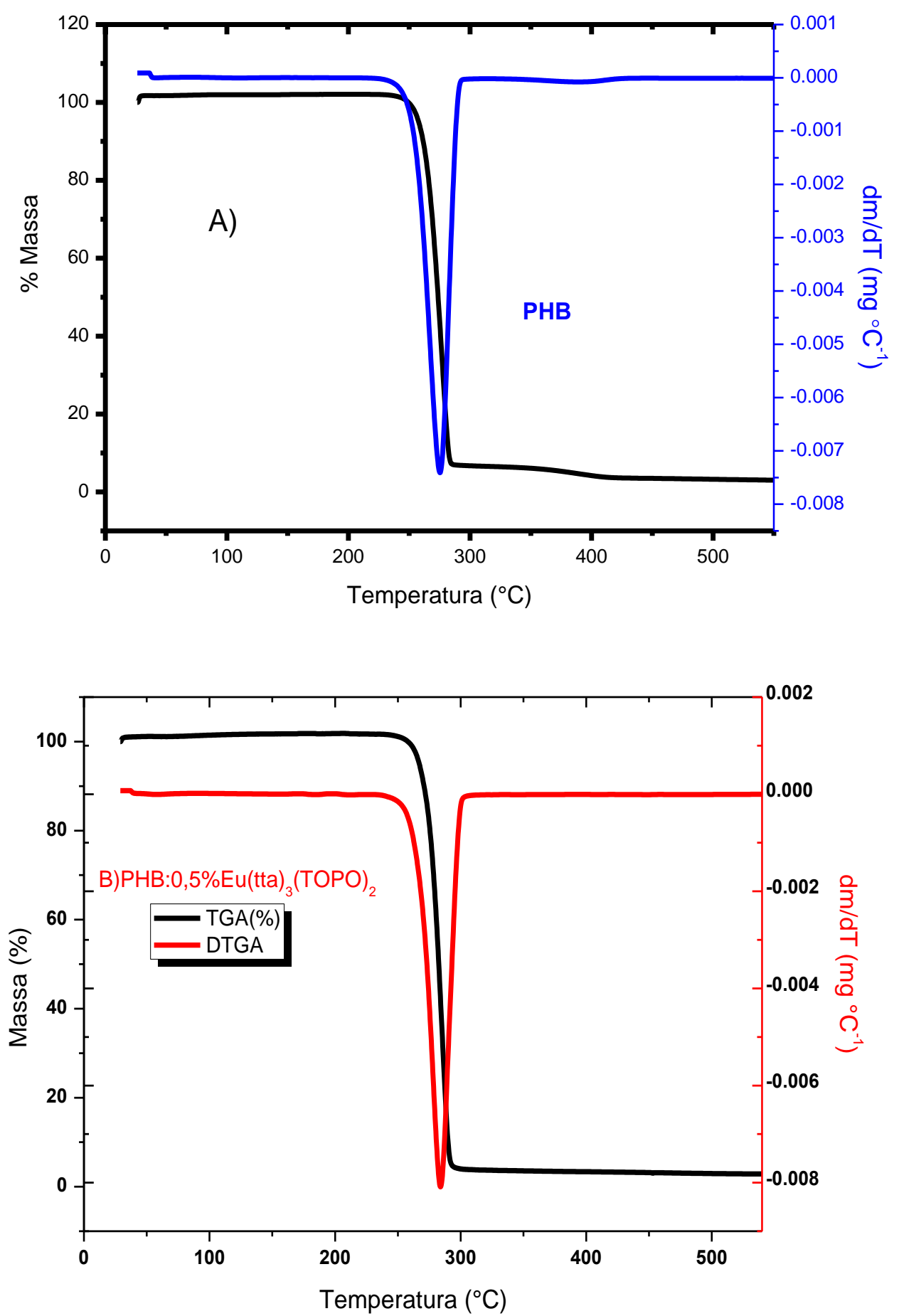

FIGURA 5.57 - Curvas TGA/DTG registradas no intervalo de 0 a $540{ }^{\circ} \mathrm{C}$, sob atmosfera dinâmica de $\mathrm{N}_{2}$, A) do PHB e B) do sistema polimérico PHB:0,5\%[Eu(tta) $\left.)_{3}(\mathrm{TOPO})_{2}\right]$. 


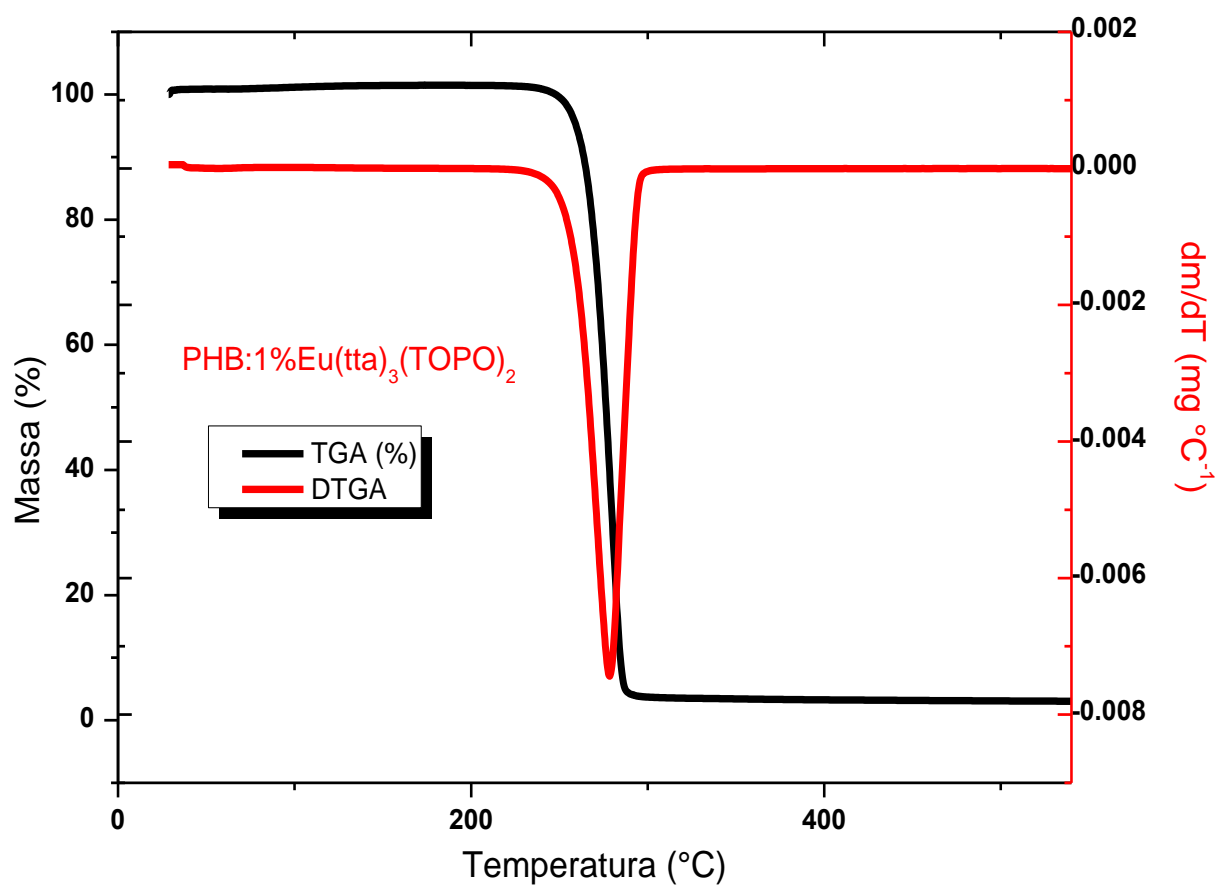

FIGURA 5.58 - Curvas TGA/DTG registradas no intervalo de 0 a $540{ }^{\circ} \mathrm{C}$, sob atmosfera dinâmica de $\mathrm{N}_{2}$, do sistema polimérico PHB:1\%[Eu(tta) $\left.)_{3}(\mathrm{TOPO})_{2}\right]$.

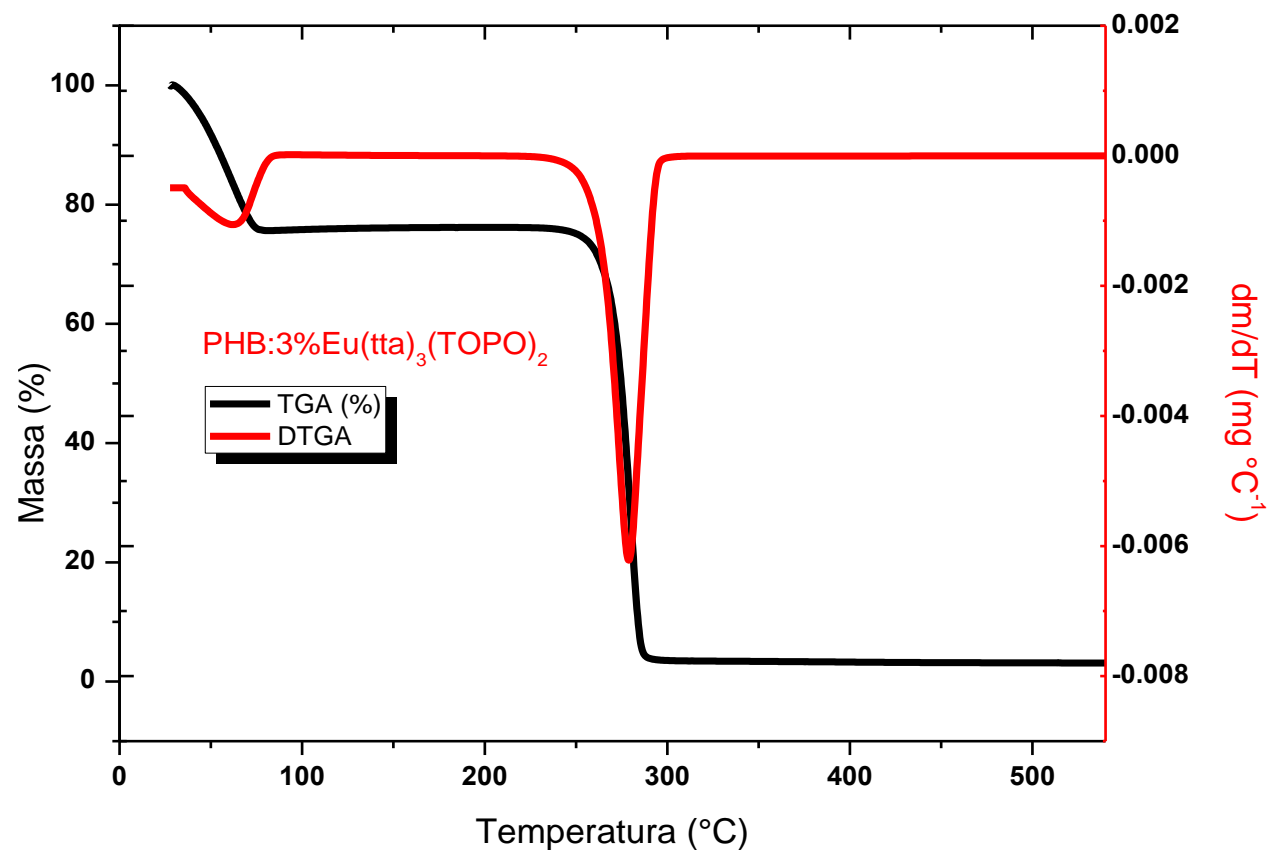

FIGURA 5.59 - Curvas TGA/DTG registradas no intervalo de 0 a $540{ }^{\circ} \mathrm{C}$, sob atmosfera dinâmica de $\mathrm{N}_{2}$, do sistema polimérico PHB:3\%[Eu(tta) $\left.)_{3}(\mathrm{TOPO})_{2}\right]$. 


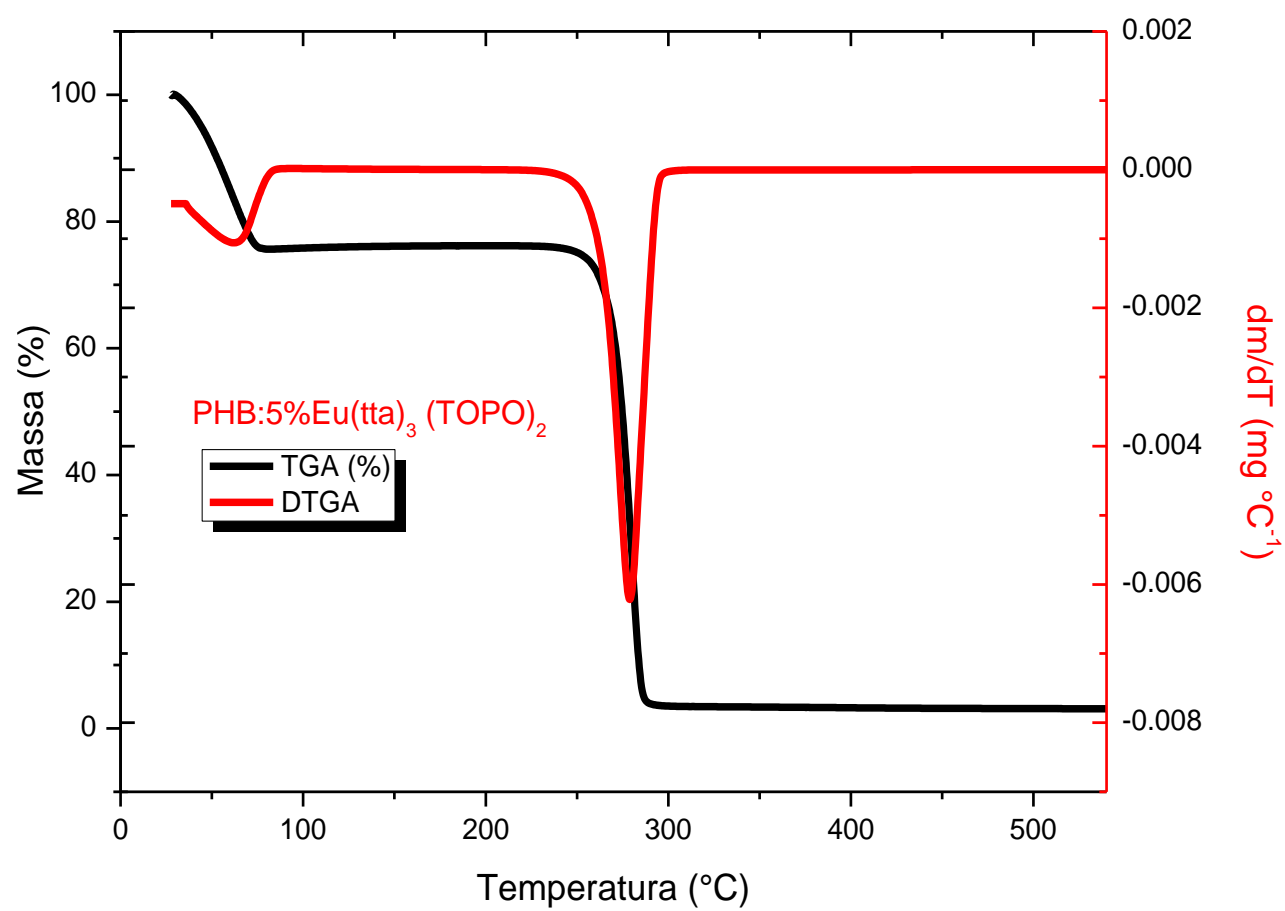

FIGURA 5.60 - Curvas TGA/DTG registradas no intervalo de 0 a $540{ }^{\circ} \mathrm{C}$, sob atmosfera dinâmica de $\mathrm{N}_{2}$, do sistema polimérico PHB:5\%[Eu(tta) $\left.)_{3}(\mathrm{TOPO})_{2}\right]$.

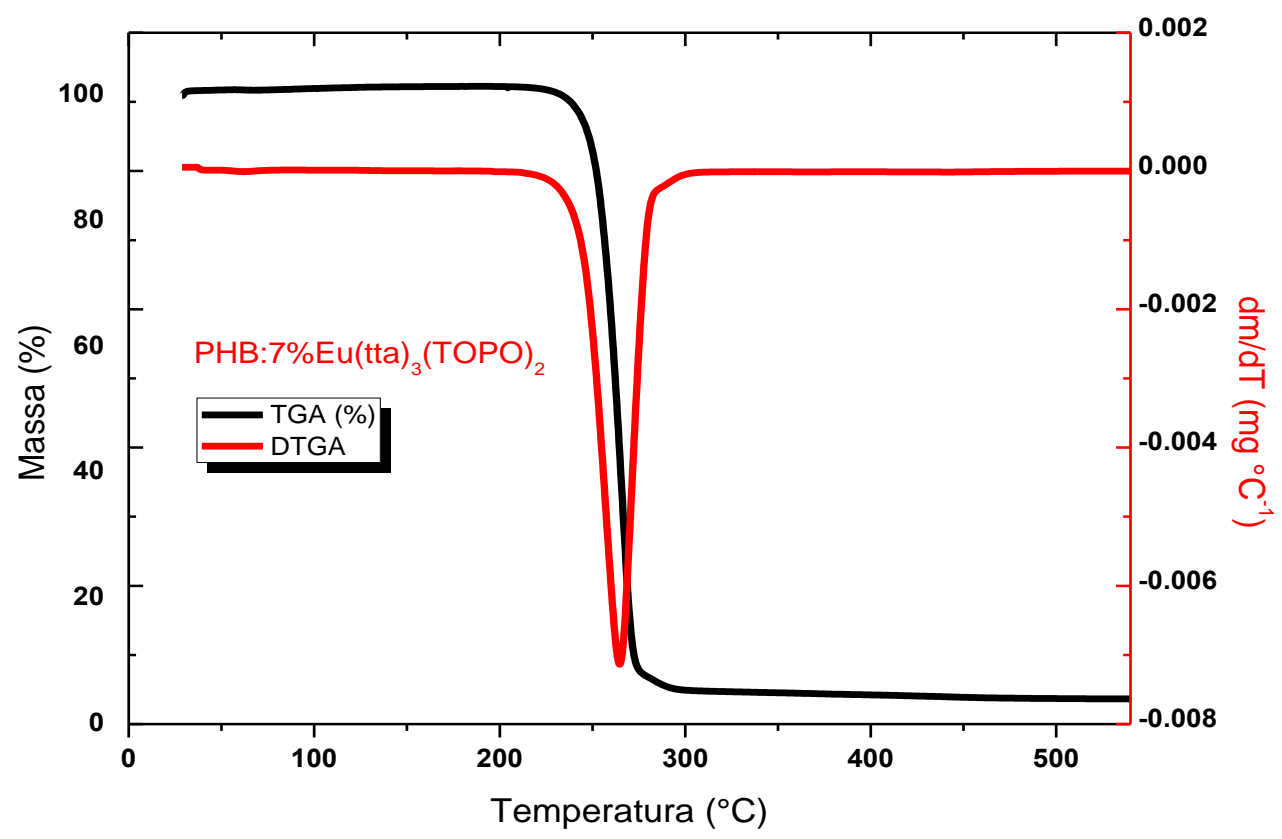

FIGURA 5.61 - Curvas TGA/DTG registradas no intervalo de 0 a $540{ }^{\circ} \mathrm{C}$, sob atmosfera dinâmica de $\mathrm{N}_{2}$, do sistema polimérico PHB:7\%[Eu(tta) $\left.3(\mathrm{TOPO})_{2}\right]$. 
TABELA 5.19 - Dados de perda de massa dos sistemas poliméricos $\mathrm{PHB}: \mathrm{X} \% \mathrm{Eu}(\mathrm{tta})_{3}(\mathrm{TOPO})_{2}(\mathrm{X}=0,5 ; 1 ; 3 ; 5 ; 7)$ no intervalo de temperatura 0 a $540 \stackrel{\circ}{ } \mathrm{C}$.

\begin{tabular}{lcccc}
\hline \multicolumn{1}{c}{ Amostra } & $\mathrm{T}_{\text {onset }}\left({ }^{\circ} \mathrm{C}\right)$ & $\mathrm{T}_{\text {offset }}\left({ }^{\circ} \mathrm{C}\right)$ & $\Delta \mathrm{m}(\%)$ & Resíduo (\%) \\
\hline PHB & 263 & 281 & 99,10 & 0,91 \\
\hline PHB:0,5\%Eu(tta) $)_{3}(\mathrm{TOPO})_{2}$ & 245 & 315 & $98,21 \%$ & $1,79 \%$ \\
PHB:1\%Eu(tta) $)_{3}(\mathrm{TOPO})_{2}$ & 230 & 304 & $97,42 \%$ & $2,57 \%$ \\
PHB:3\%Eu(tta) $)_{3}(\mathrm{TOPO})_{2}$ & 232 & 295 & $96,65 \%$ & $3,35 \%$ \\
PHB:5\%Eu(tta) $)_{3}(\mathrm{TOPO})_{2}$ & 236 & 295 & $96,64 \%$ & $3,36 \%$ \\
PHB:7\%Eu(tta) ${ }_{3}(\mathrm{TOPO})_{2}$ & 220 & 309 & $96,70 \%$ & $3,30 \%$ \\
\hline
\end{tabular}

5.4.1.2.2.2 Análise Termogravimétrica (TG/DTG) para as Nanopartículas Poliméricas de PMMA e PHB Dopadas com [Gd(tta $\left.)_{3}(\mathrm{TOPO})_{2}\right]$ em Diferentes Concentrações Obtidas pelo Método de Precipitação por Crioscopia.

Para os sistemas poliméricos de PHB e PMMA dopados com 0 complexo de gadolínio pode-se dizer que apresentam o mesmo perfil dos sistemas poliméricos dopados com o complexo de európio. No entanto, o material de PHB dopado apresenta características de adsorvedor de umidade, pois apresenta um evento de perda de água adsorvida de quase $50 \%$ do seu peso inicial antes da temperatura de $100{ }^{\circ} \mathrm{C}$. Já as nanopartículas de PMMA apresentaram processo de decomposição equivalente às partículas dopadas com $\left[\mathrm{Eu}(\mathrm{tta})_{3}(\mathrm{TOPO})_{2}\right]$ (FiGs 5.62- 5.63). 


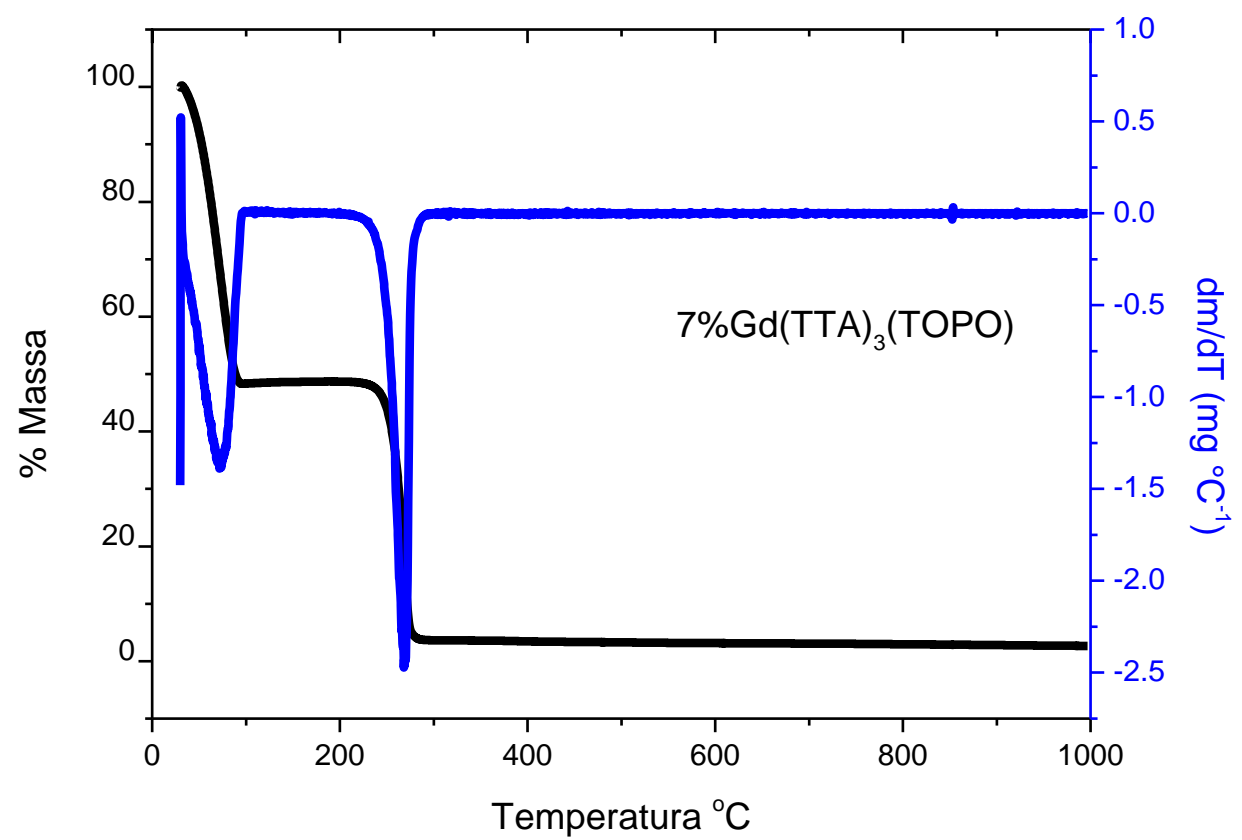

FIGURA 5.62 - Curvas TGA/DTG registradas no intervalo de 0 a $540{ }^{\circ} \mathrm{C}$, sob atmosfera dinâmica de $\mathrm{N}_{2}$, do sistema polimérico PHB:7\%[Eu(tta) $\left.3(\mathrm{TOPO})_{2}\right]$.

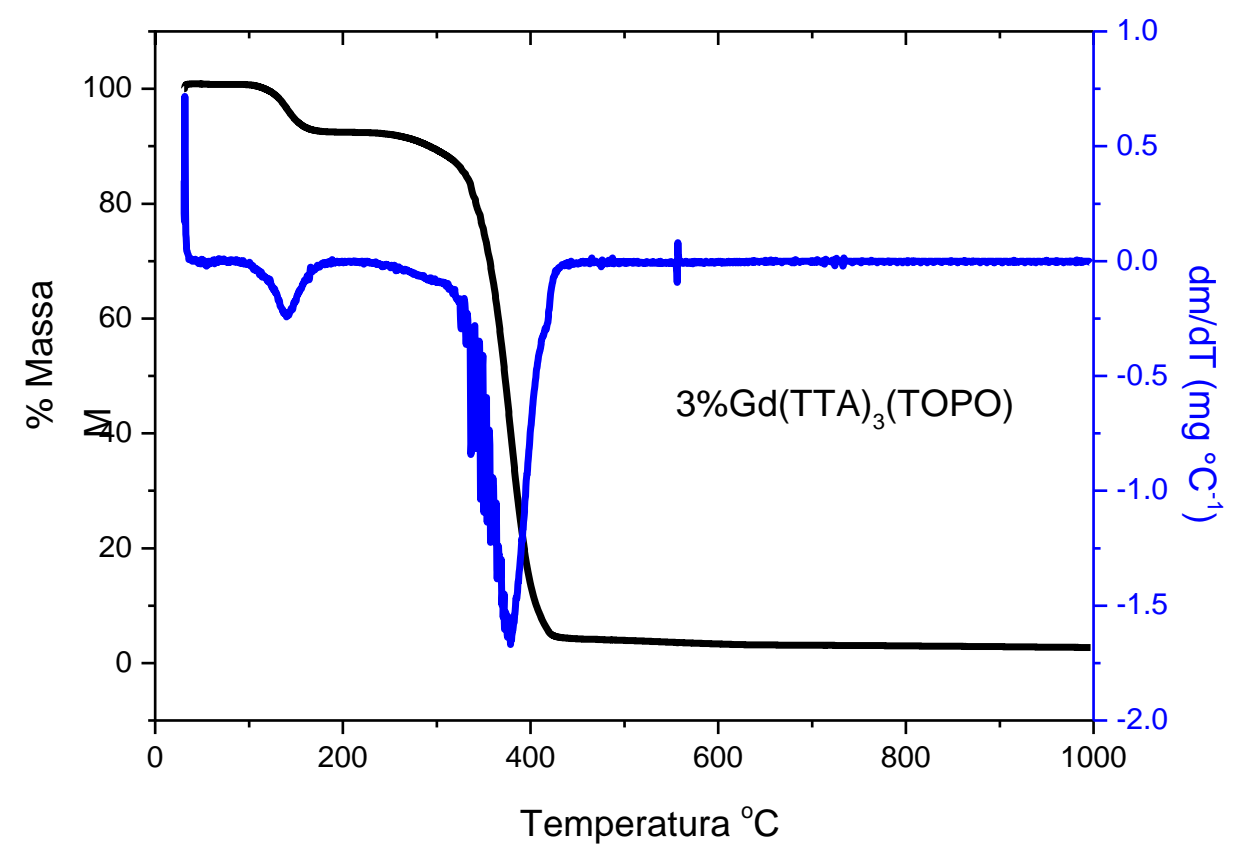

FIGURA 5.63 - Curvas TGA/DTG registradas no intervalo de 0 a $540{ }^{\circ} \mathrm{C}$, sob atmosfera dinâmica de $\mathrm{N}_{2}$, do sistema polimérico PMMA:3\%[Gd(tta) $\left.)_{3}(\mathrm{TOPO})_{2}\right]$. 


\subsection{Difratometria de Raios $X(D R X)$ das Nanopartículas Poliméricas} de PHB e PMMA Dopadas com o Complexo X\%[TR(tta) $\left.)_{3}(\mathrm{TOPO})_{2}\right]$ onde (TR=Eu e Gd) em Diferentes Concentrações ( $X=0,5 ; 1 ; 3 ; 5 ; 7 \%$ ) Obtidas pelo Método de Nanoprecipitação por Crioscopia

Uma das técnicas mais empregadas na caracterização de materiais é a difração de raios $X$ pelo método de pó, que permite, também, a identificação de espécies cristalinas e amorfas. Este método fornece informações qualitativas para uma série de sistemas com propriedades características próximas, possibilitando a obtenção de informações sobre isomorfismo e o grau de cristalinidade das amostras ${ }^{[22]}$. Foi realizada a análise de difração de raios $X$ pelo método de pó para todas as nanopartículas poliméricas descritas neste trabalho e os resultados estão discutidos abaixo e agrupados por complexo dopante.

\subsection{Nanopartículas Poliméricas PHB e PMMA Dopadas com o Complexo X\%[Eu(tta) $)_{3}(\mathrm{TOPO})_{2}$ ] em Diferentes Concentrações $(\mathrm{X}=0,5 ; 1 ; 3$;} $5 ; 7 \%)$

A FIGURA 5.63 mostra os difratogramas de raios $X$ das NPs poliméricas de PHB e de PHB dopadas com o complexo [Eu(tta) $)_{3}(\mathrm{TOPO})_{2}$ ] em diferentes concentrações $(0,5 ; 1 ; 3 ; 5 ;$ e $7 \%)$. Observa-se a tendência de aumento na cristalinidade devido ao aumento de concentração de dopagem. Quando se compara os dois sistemas de nanopartículas PHB e PMMA, a presença de picos de difração mais finos mostram maior grau de cristalinidade das NPs contendo PHB do que nos sistemas contendo PMMA, para as dopagens de európio (FIG. 5.64 e 5.65). Os difratogramas das NPs poliméricas PMMA apresentam bandas largas, indicando característica amorfa e baixíssima cristalinidade (FIG. 5.65). 


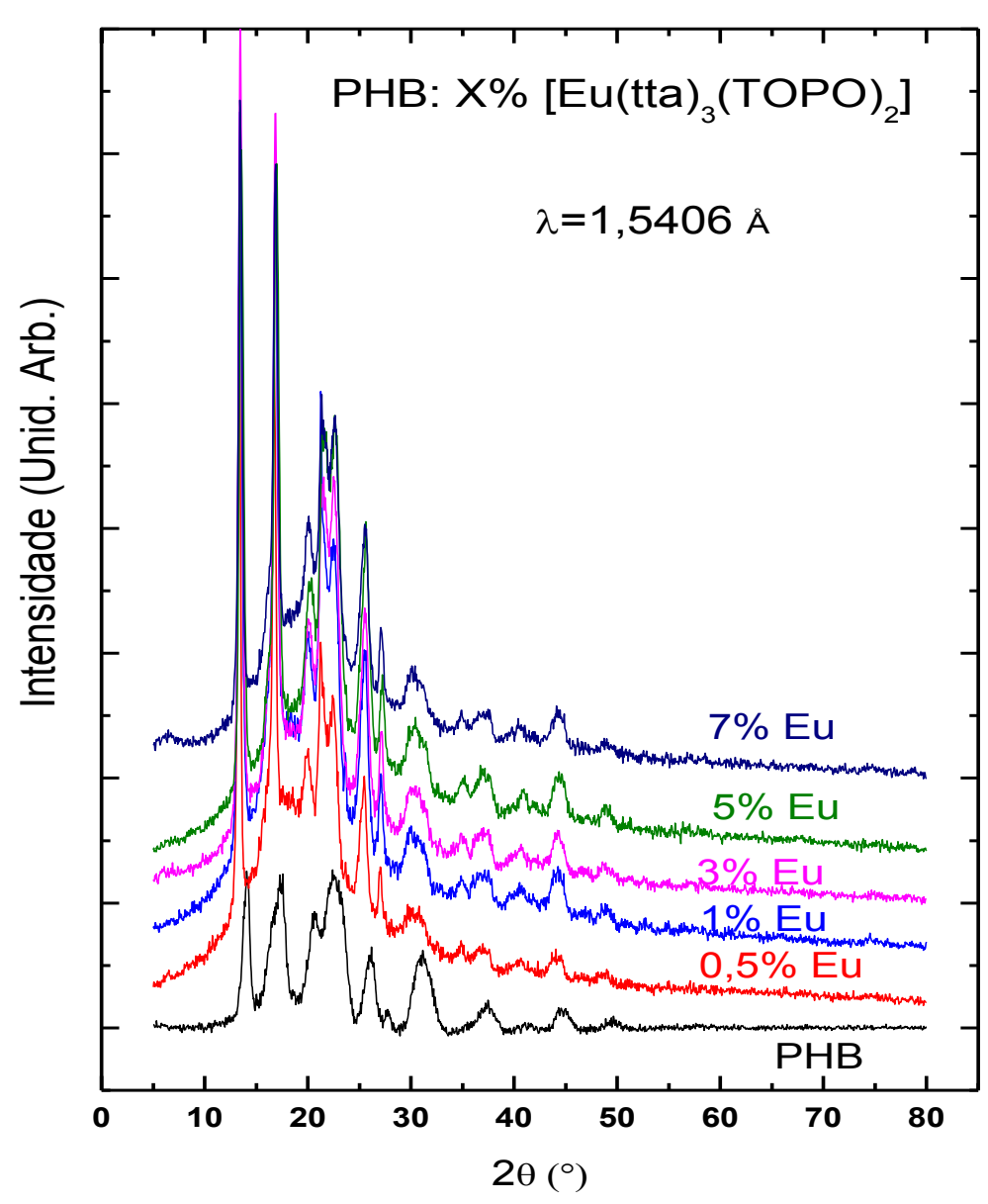

FIGURA 5.64 - Difratogramas de raios $X$ (método de pó) das NPs poliméricas PHB em diferentes concentrações de dopagem do complexo [Eu(tta $\left.)_{3}(\mathrm{TOPO})_{2}\right]$ : PHB, PHB:X\%[Eu(tta $\left.)_{3}(\mathrm{TOPO})_{2}\right](\mathrm{X}=0,5 ; 1 ; 3 ; 5$ e $7 \%)$ 


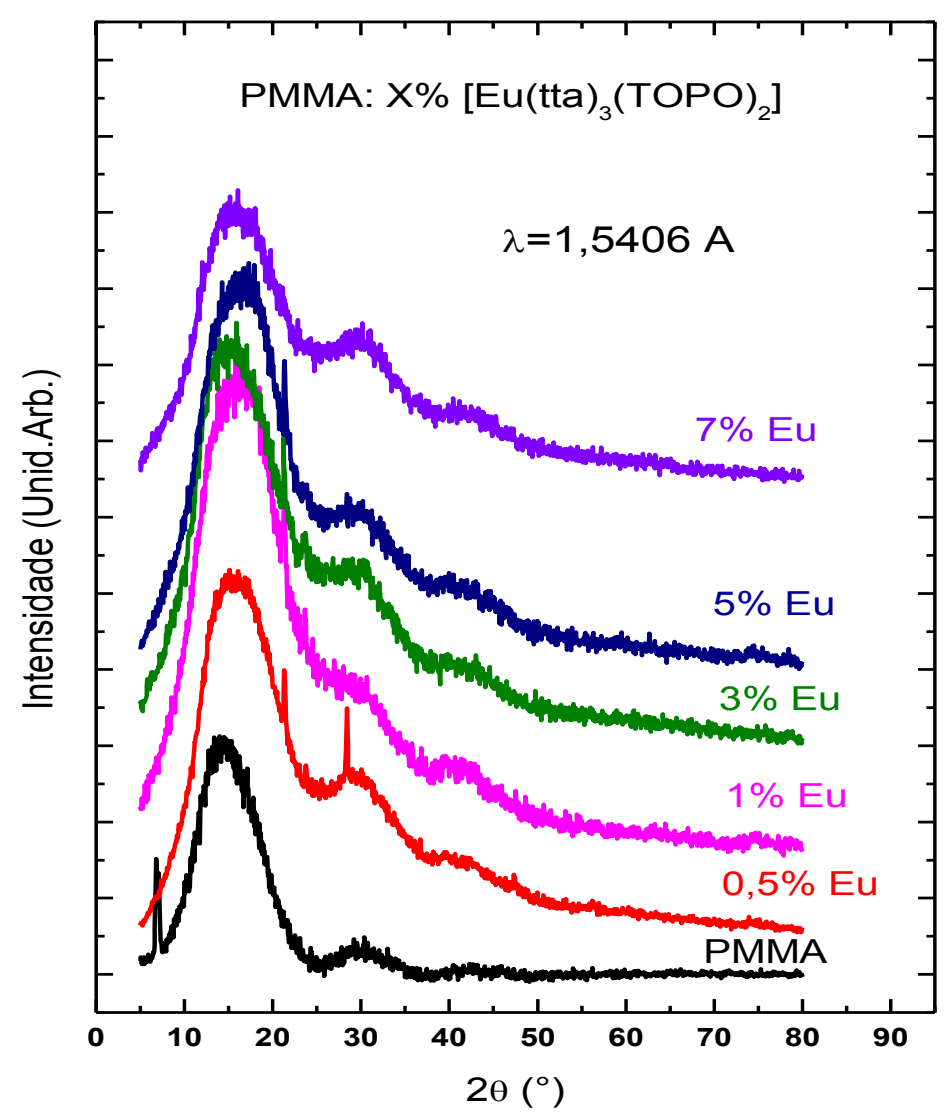

FIGURA 5.65 - Difratogramas de raios X (método de pó) das NPs poliméricas PMMA em diferentes concentrações de dopagem do complexo $\left[\mathrm{Eu}(\mathrm{tta})_{3}(\mathrm{TOPO})_{2}\right]:$ PMMA, PMMA:X\%Eu(tta) $)_{3}(\mathrm{TOPO})_{2}(\mathrm{X}=0,5 ; 1 ; 3 ; 5$ e $7 \%)$.

\subsection{Nanopartículas Poliméricas PHB e PMMA Dopadas com 0} Complexo $X \%\left[G d(t t a)_{3}(\text { TOPO })_{2}\right]$ em Diferentes Concentrações $(X=0,5 ; 1$; $3 ; 5$ e $7 \%)$

A FIGURA 5.66 mostra os difratogramas de raios-X das NPs poliméricas PHB dopados pelo complexo $\left[\mathrm{Gd}(\mathrm{tta})_{3}(\mathrm{TOPO})_{2}\right]$ em diferentes concentrações $(0,5 ; 1 ; 3 ; 5 ;$ e $7 \%)$. Observa-se, assim como nas nanopartículas PHB dopadas com complexo de $\mathrm{Eu}^{3+}$ (FIG. 5.64), a tendência de aumento na cristalinidade 
das NPs devido ao aumento de concentração de dopagem, atribuindo tal comportamento ao recobrimento do composto polimérico PHB.

A FIGURA 5.67 mostra os difratogramas de raios $X$ das NPs poliméricas PMMA dopados em diferentes concentrações $(0,5 ; 1 ; 3 ; 5$ e 7\%) pelo complexo $\left[\mathrm{Gd}(\mathrm{tta})_{3}(\mathrm{TOPO})_{2}\right]$. Os difratogramas apresentam perfis semelhantes entre si com característica amorfa, corroborando com os dados obtidos para as nanopartículas de PMMA dopadas $\mathrm{com} \mathrm{Eu}^{3+}$ (FIG. 5.65), atribuindo tal característica ao recobrimento do composto polimérico PMMA.

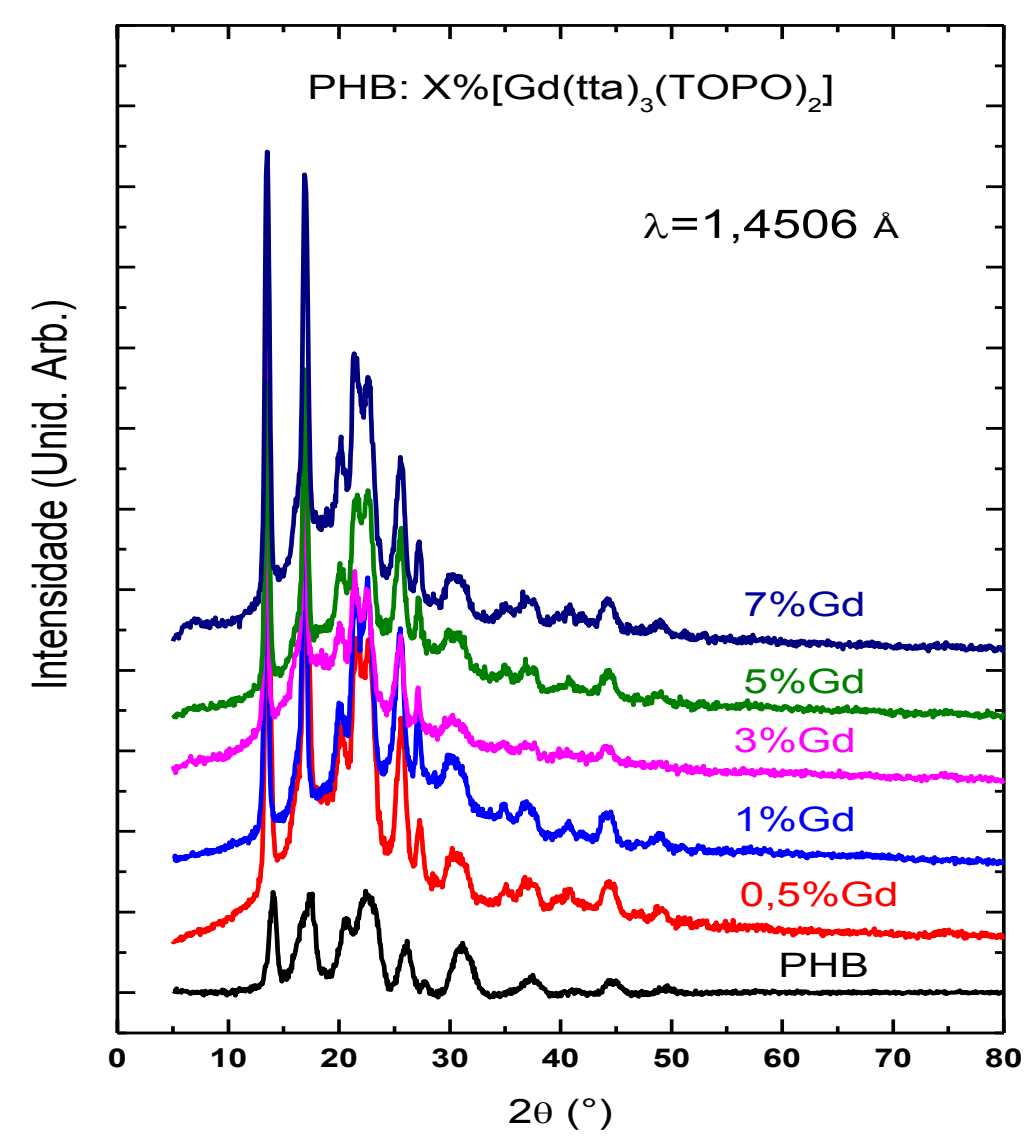

FIGURA 5.66 - Difratogramas de raios $X$ (método de pó) das NPs poliméricas PHB em diferentes concentrações de dopagem do complexo $\left[\mathrm{Gd}(\mathrm{tta})_{3}(\mathrm{TOPO})_{2}\right]$ : PHB, PHB:X\%Gd(tta) $)_{3}(\mathrm{TOPO})_{2}(\mathrm{X}=0,5 ; 1 ; 3 ; 5$ e $7 \%)$. 


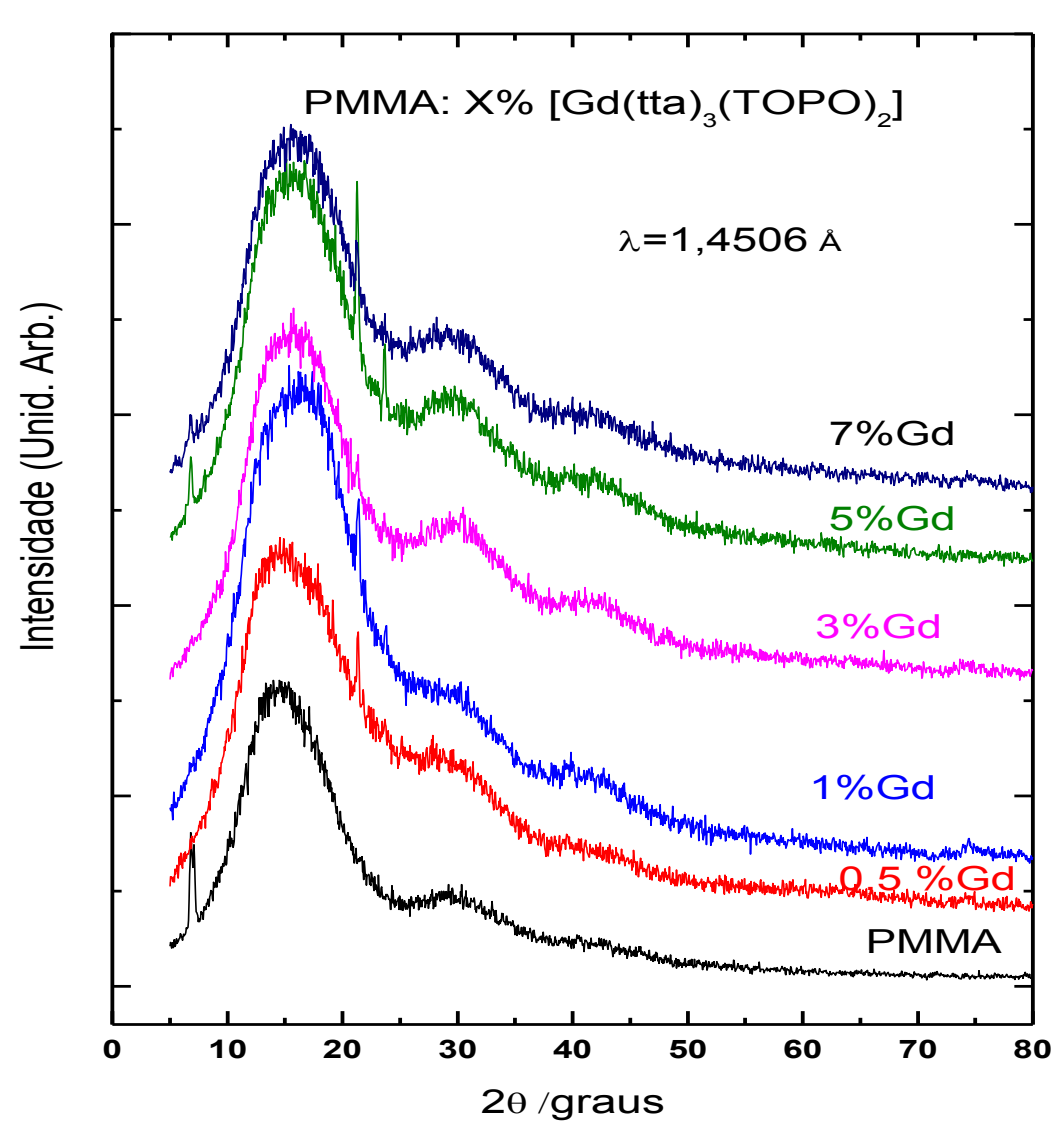

FIGURA 5.67 - Difratogramas de raios $X$ (método de pó) das NPs poliméricas PMMA em diferentes concentrações de dopagem do complexo $\left[\mathrm{Gd}(\mathrm{tta})_{3}(\mathrm{TOPO})_{2}\right]:$ PMMA, PMMA:X\%[Gd(tta $\left.)_{3}(\mathrm{TOPO})_{2}\right](\mathrm{X}=0,5 ; 1 ; 3 ; 5$ e $7 \%)$.

\subsection{Microscopia Eletrônica de Varredura (MEV) das Nanopartículas} Poliméricas de PHB e PMMA Dopadas com 0 Complexo $\mathrm{X} \%\left[\mathrm{TR}(\mathrm{tta})_{3}(\mathrm{TOPO})_{2}\right]$ onde $(\mathrm{TR}=\mathrm{Eu}$ e $\quad 0,5 \% \mathrm{Gd})$ em Diferentes Concentrações $(X=0,5 ; 1 ; 3 ; 5 ; 7 \%)$ e (TR= $0,5 \% G d)$ Obtidas pelo Método de Nanoprecipitação por Crioscopia

As FIGURAS 5.68 a $\mathbf{5 . 7 3}$ apresentam as micrografias das nanopartículas poliméricas PHB e PMMA dopadas com diferentes concentrações mássicas do complexo $\left[\mathrm{Eu}(\mathrm{tta})_{3}(\mathrm{TOPO})_{2}\right]$. As imagens mostram 
morfologia diferenciada com formação de gotas não uniformes ou microesferas de vários tamanhos pela coalescência do molde. Aparece também cavidades esféricas e porosas nas várias composições estudadas. Vale salientar a excelente formação homogênea das partículas de gadolínio PMMA:0,5\%[Gd(tta $\left.)_{3}(\mathrm{TOPO})_{2}\right]$ com forma esférica e heterogeneidade de tamanho.

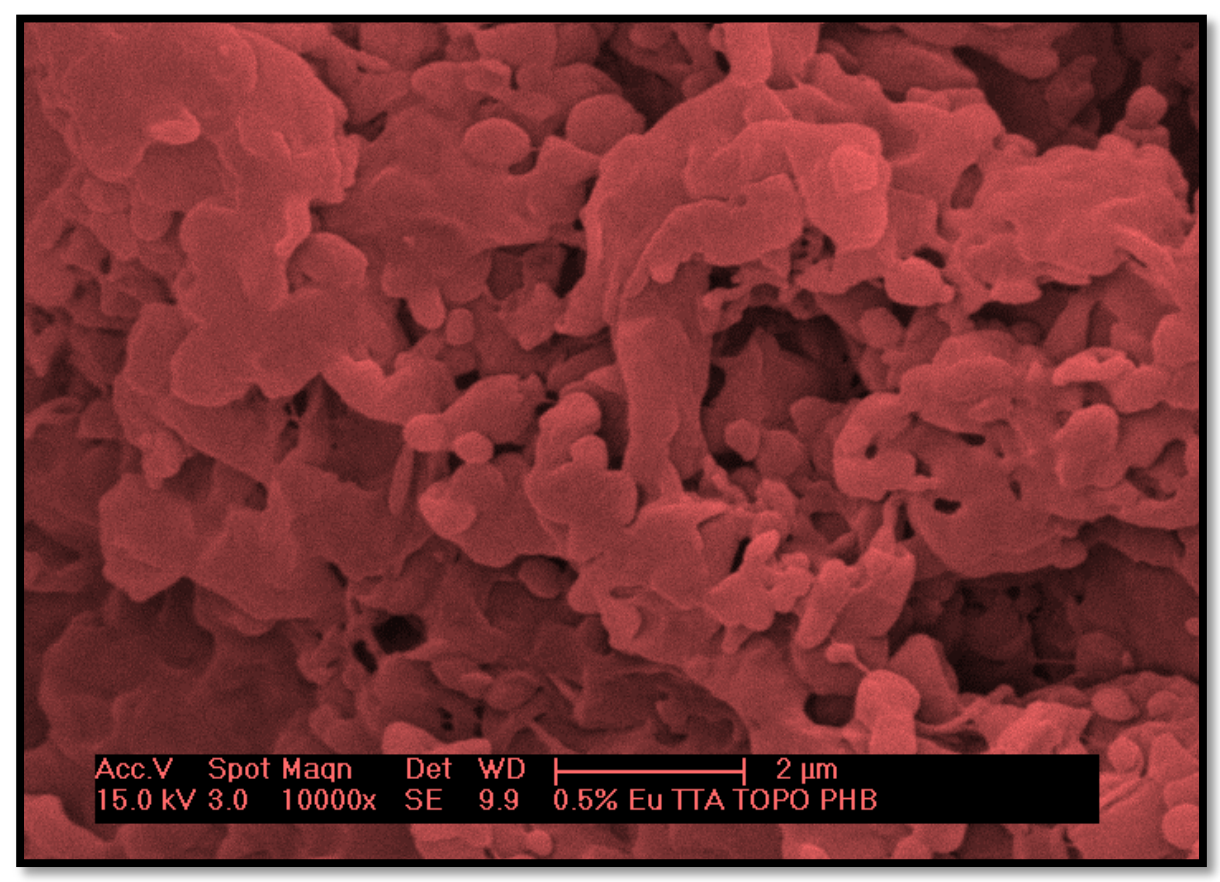

FIGURA 5.68 - Micrografia das NPs PHB dopadas com complexo $\left[\mathrm{Eu}(\mathrm{tta})_{3}(\mathrm{TOPO})_{2}\right]$ em concentração mássica de $0,5 \%$ com magnificação de (10000x). 


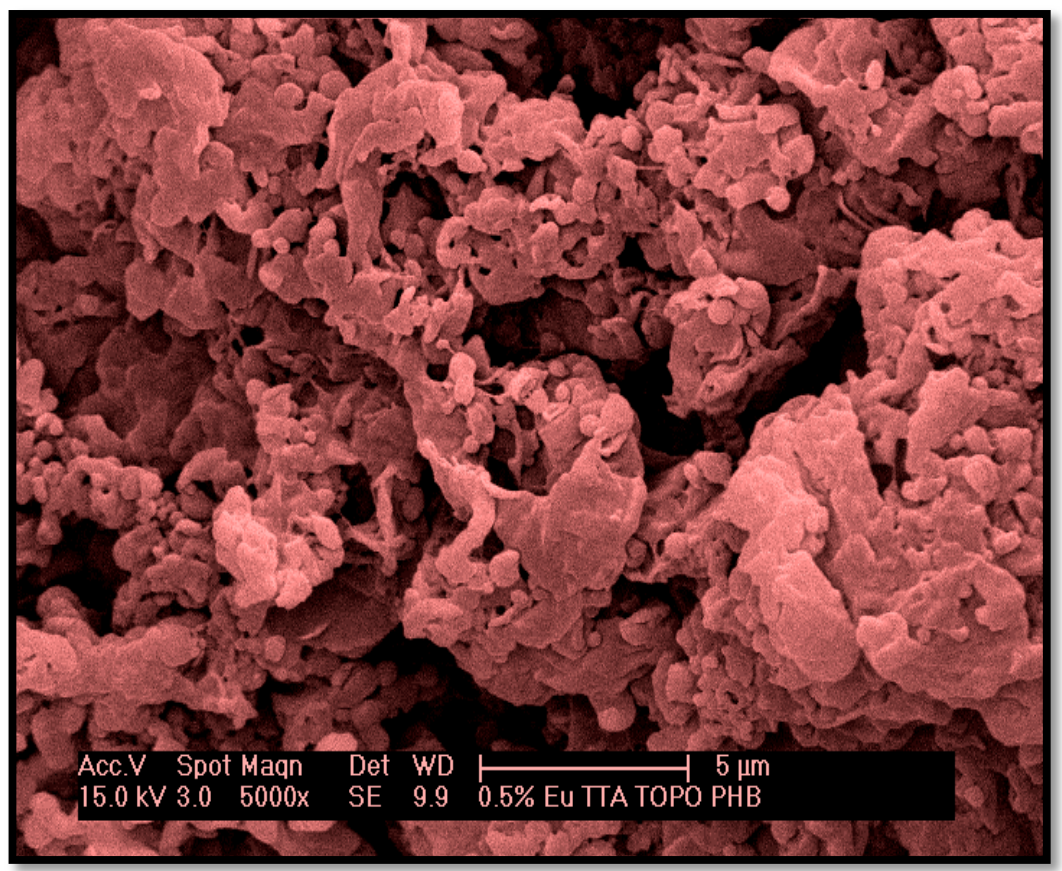

FIGURA 5.69 - Micrografia das NPs PHB dopadas com complexo $\left[\mathrm{Eu}(\mathrm{tta})_{3}(\mathrm{TOPO})_{2}\right]$ em concentração mássica de $1 \%$ com magnificação de (5000x).

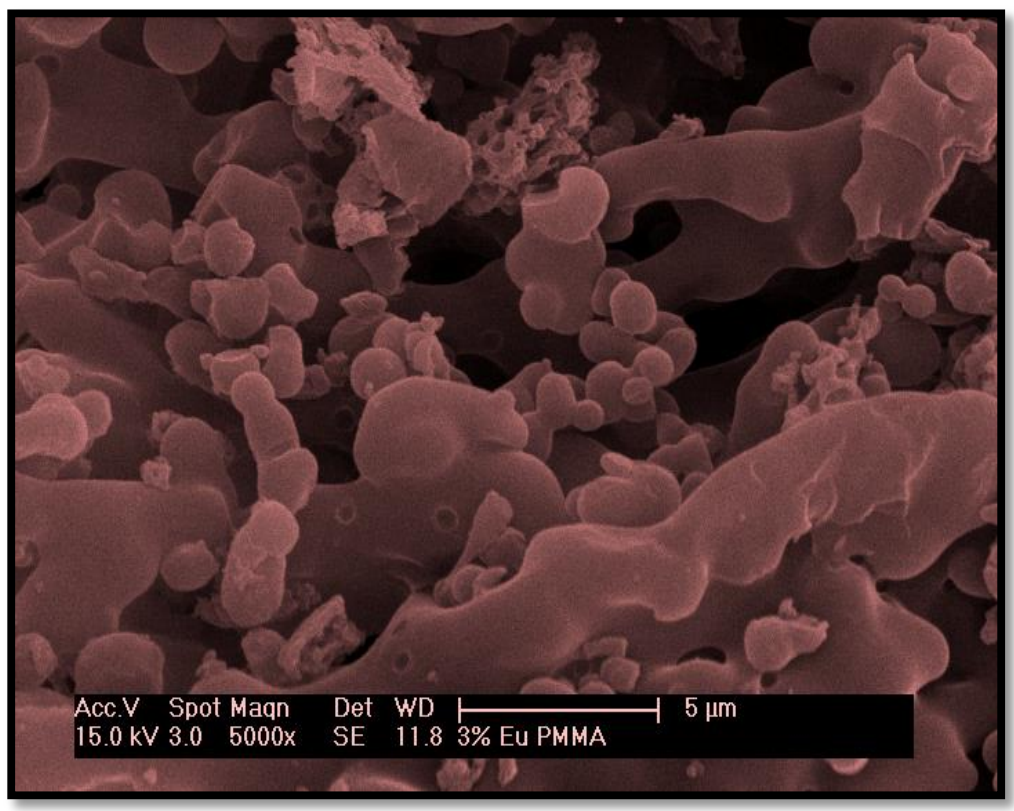

FIGURA 5.70 - Micrografia das NPs PMMA dopadas com complexo $\left[\mathrm{Eu}(\mathrm{tta})_{3}(\mathrm{TOPO})_{2}\right]$ em concentração mássica de $3 \%$ com magnificação de (5000X). 


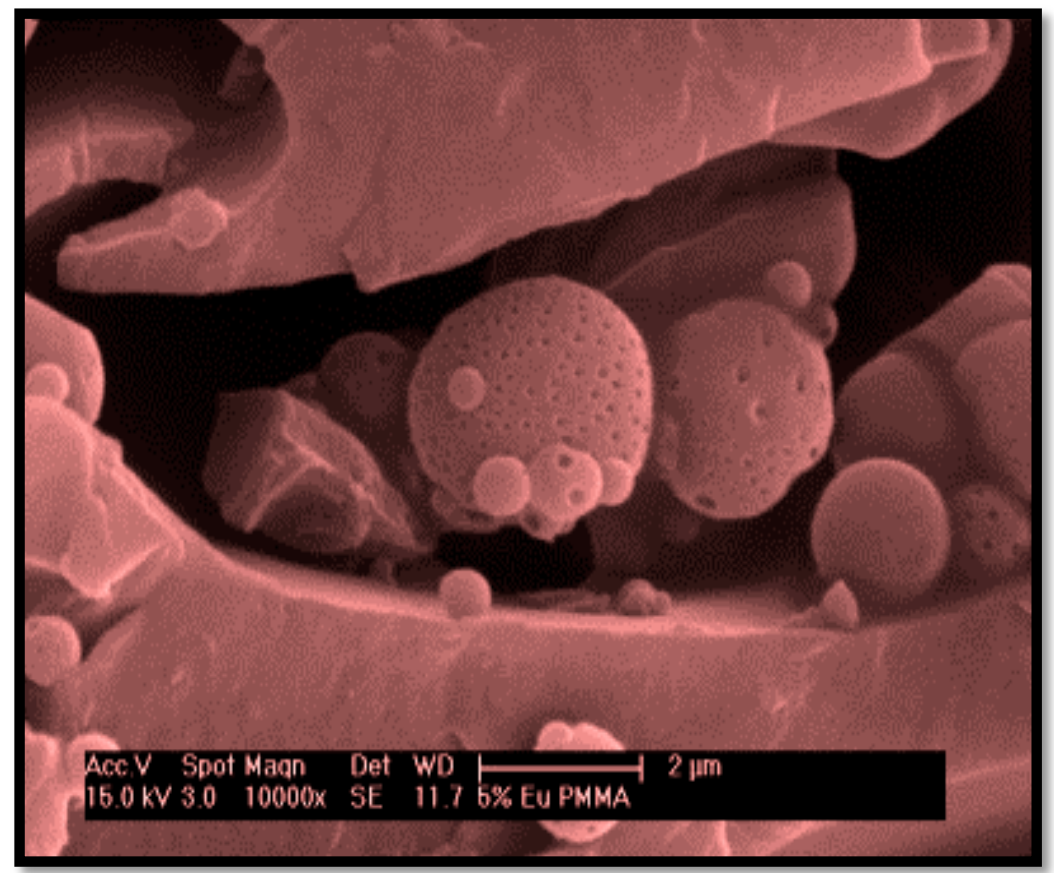

FIGURA 5.71 - Micrografia das NPS PMMA dopadas com complexo $\left[\mathrm{Eu}(\mathrm{tta})_{3}(\mathrm{TOPO})_{2}\right]$ em concentração mássica de $5 \%$ com magnificação de (10000X).

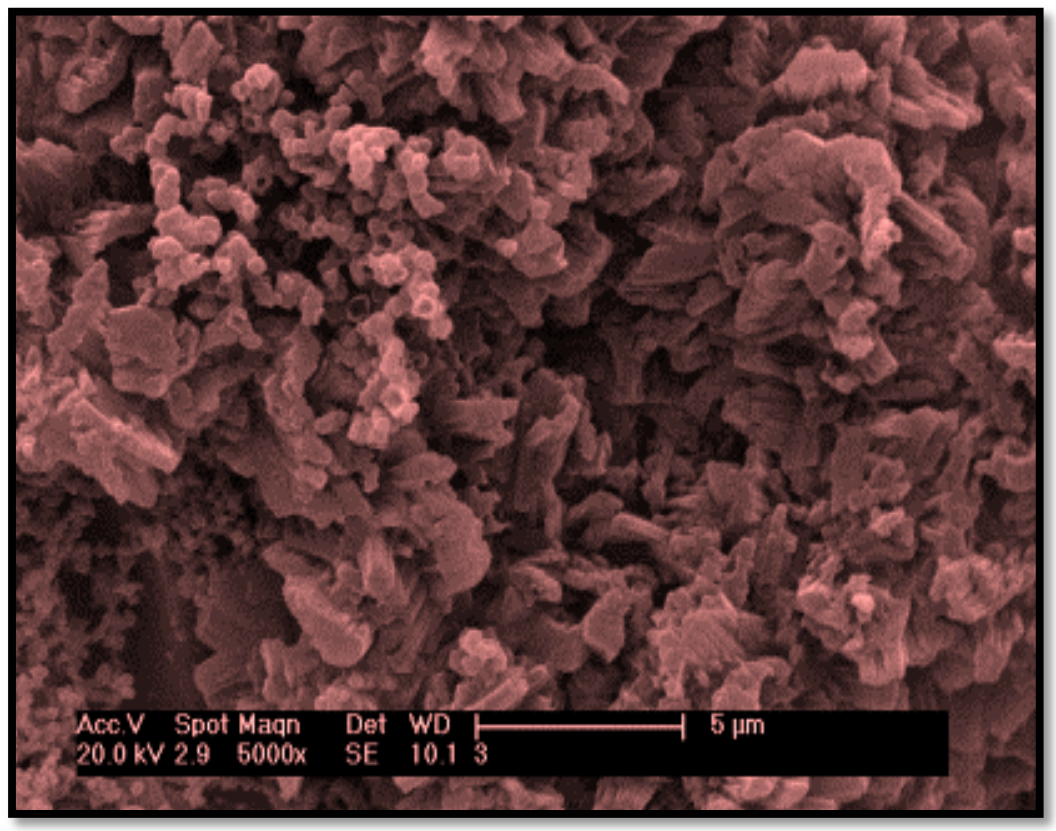

FIGURA 5.72 - Micrografia das NPS PMMA dopadas com complexo $\left[\mathrm{Eu}(\mathrm{tta})_{3}(\mathrm{TOPO})_{2}\right]$ em concentração mássica de $7 \%$ com magnificação de (5000X). 


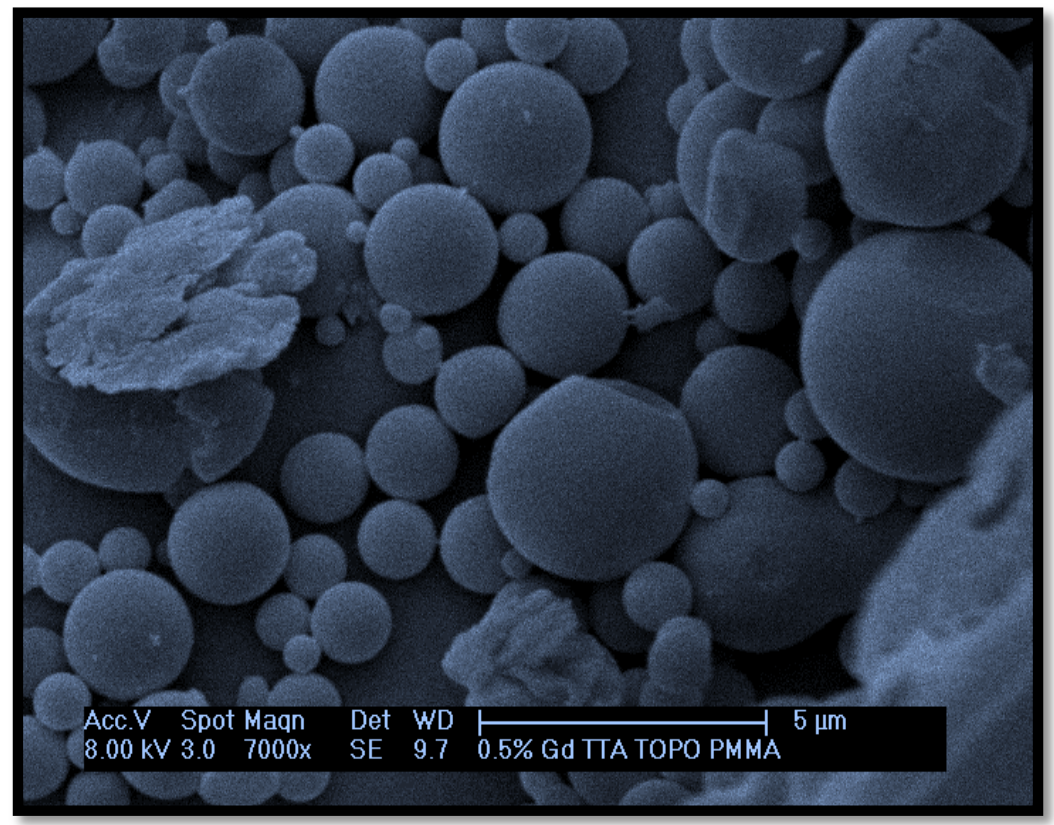

FIGURA 5.73 - Micrografia das NPs PMMA dopadas com complexo $\left[\mathrm{Gd}(\mathrm{tta})_{3}(\mathrm{TOPO})_{2}\right]$ em concentração mássica de $0,5 \%$ com magnificação de (7000X).

\subsubsection{Estudos de luminescência das nanoparticulas poliméricas}

Vários estudos têm sido desenvolvido em nosso grupo de pesquisa dopando materiais, na sua maioria filmes poliméricos dopados com terras raras, para atuarem como materiais luminescentes em varias áreas [62 - 67]. Embora vários esforços tenham sido feitos nesse sentido, nunca se tinha investigado a obtenção de nanopartículas para marcação.

\subsection{Fosforescência das Nanopartículas Poliméricas PHB e PMMA} Dopadas em Diferentes Concentrações com 0 Complexo $\mathrm{X} \%\left[\mathrm{Gd}(\mathrm{tta})_{3}(\mathrm{TOPO})_{2}\right](\mathrm{X}=0,5 ; 1 ; 3 ; 5$ e $7 \%)$

Os espectros de emissão dos complexos de $\beta$-dicetonato (tta') de $\mathrm{Gd}^{3+}$ registrados no intervalo de 420 a 720 nm, a $77 \mathrm{~K}$, com excitação monitorada nos estados singletos dos ligantes, em torno de $350 \mathrm{~nm}$, são apresentados na 
FIGURA 5.74 para as NPs de PHB e de PMMA. Como são observados, estes espectros apresentam bandas largas que são atribuídas à fosforescência do tta', oriundas das transições tripleto-singleto. Pode-se observar ainda que estes espectros são constituídos de três bandas sobrepostas com máximos em torno de 510, 550 e 585 nm, correspondentes às emissões características de três estados tripletos de cada dicetonato.

Os espectros de gadolínio exibem uma banda de emissão fraca em torno de $400 \mathrm{~nm}$ (visível apenas para PHB 0,5\%Gd nas figuras) a qual está associada à fluorescência dos estados singletos dos ligantes $\beta$-dicetonatos, isto indica que a conversão interna e cruzamento intersistema para o estado tripleto de menor energia é muito eficiente nos sistemas estudados. Na TABELA 5.20 estão listadas as energias do estado tripleto $\mathrm{T}$ do ligante calculados por dois métodos. Estas energias diferem por aproximadamente $1000 \mathrm{~cm}^{-1}$ nestes sistemas. Estes dados corroboram com os dados de vários sistemas de PMMA e PHB que se encontram publicados na literatura ${ }^{[63,64]}$. 
TABELA 5.20 - Energias do estado $\mathbf{T}_{1}$ das NPs poliméricas dopadas com complexo de gadolínio em diferentes concentrações $\mathrm{X} \%\left[\mathrm{Gd}(\mathrm{tta})(\mathrm{TOPO})_{2}\right](\mathrm{X}=$ $0,5 ; 1 ; 3 ; 5$ e 7$)$.

\begin{tabular}{cccc}
\hline Composição NP & $\mathbf{X \%}$ & $\begin{array}{c}\text { Energia de } \mathbf{T}_{\mathbf{1}} \\
\text { baricentro }\left(\mathbf{c m}^{-1}\right)\end{array}$ & $\begin{array}{c}\text { Energia de } \mathbf{T}_{\mathbf{1}} \\
\text { zero fônon }\left(\mathbf{c m}^{-1}\right)\end{array}$ \\
\hline & 0,5 & 20,350 & 21512 \\
& 1 & 18,995 & 21595 \\
PMMA:X\%[Gd(tta) $\left.)_{3}(\mathrm{TOPO})_{2}\right]$ & 3 & 20,072 & 21604 \\
& 5 & 20,194 & 21614 \\
& 7 & 20,202 & 21599 \\
& 0,5 & 20,040 & 21233 \\
& 1 & 19,968 & 21087 \\
PHB:X\%[Gd(tta $\left.)_{3}(\mathrm{TOPO})_{2}\right]$ & 3 & 20,080 & 20964 \\
& 5 & 20,040 & 20851 \\
& 7 & 20,056 & 20911 \\
\hline
\end{tabular}



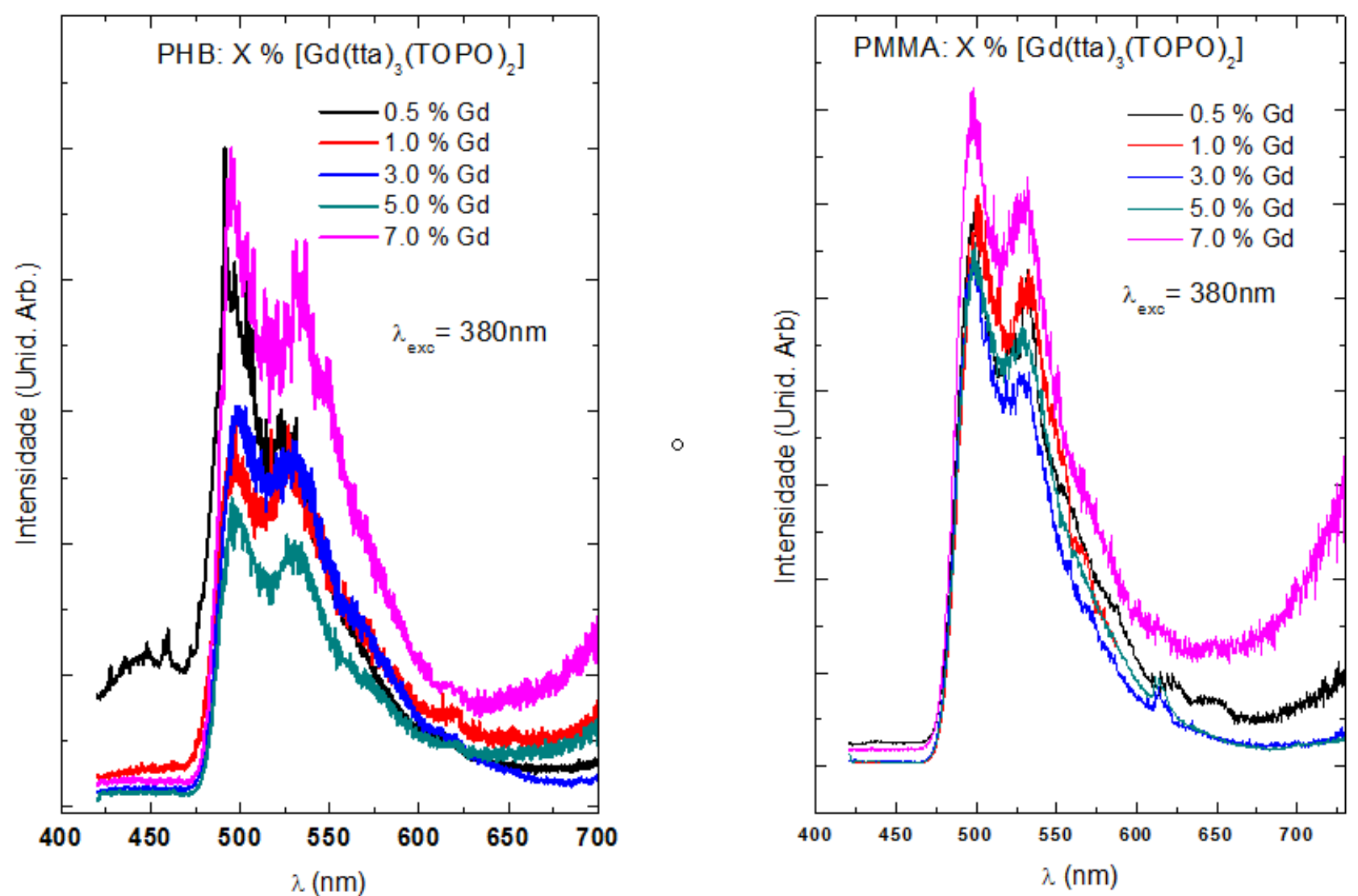

FIGURA 5.74 - Espectros de fosforescência das nanopartículas de PHB e PMMA, dopado com o complexo $\left[\mathrm{Gd}(\operatorname{tta})_{3}(\mathrm{TOPO})_{2}\right]_{3}$ e registrados no intervalo de 425 a $750 \mathrm{~nm}$, sob excitação em $380 \mathrm{~nm}$, em diversas concentrações de dopagens $(0,5 ; 1 ; 3 ; 5$ e $7 \%)$. 


\subsection{Propriedades Luminescentes das Nanopartículas Poliméricas PHB e PMMA Dopadas em Diferentes Concentrações com o Complexo $\mathrm{X} \%\left[\mathrm{Eu}(\mathrm{tta})_{3}(\mathrm{TOPO})_{2}\right](\mathrm{X}=0,5 ; 1 ; 3 ; 5$ e $7 \%)$}

\subsection{Espectros de Excitação}

Os estudos fotoluminescentes das NPs de PMMA e PHB dopadas com $\left[\mathrm{Eu}(\mathrm{tta})_{3}(\mathrm{TOPO})_{2}\right]$ foram baseados nos espectros de excitação e emissão registrados a temperatura ambiente ( $298 \mathrm{~K})$. Os espectros de excitação foram registrados no intervalo de 250 a 600 nm, com emissão monitorada na transição hipersensível ${ }^{5} \mathrm{D}_{0} \rightarrow{ }^{7} \mathrm{~F}_{2}(\sim 614 \mathrm{~nm})$. Enquanto que os espectros de emissão foram obtidos com excitação no íon $\mathrm{TR}^{3+}(\sim 394 \mathrm{~nm})$ e via banda do ligante ( 380 nm) no intervalo de 420 a $720 \mathrm{~nm}$, correspondente às transições intraconfiguracionais ${ }^{5} \mathrm{D}_{0} \rightarrow{ }^{7} \mathrm{~F}_{0-4}$.

A FIGURA 5.75 mostra os espectros de excitação das NPs poliméricas PHB e PMMA dopadas com [Eu(tta) ${ }_{3}(\mathrm{TOPO})_{2}$ ]. Na região de $250 \mathrm{a} \sim 450 \mathrm{~nm}$, os espectros apresentam uma banda larga com máximos em torno de $350 \mathrm{~nm}$ associada à transição permitida $S \rightarrow S_{0}$ pertencente aos ligantes tta ${ }^{-}$e TOPO. As bandas finas sãooriundas das transições intraconfiguracionais $4 f^{6,7} \mathrm{~F}_{0} \rightarrow{ }^{5} \mathrm{~L}_{6}$ (394 $\mathrm{nm}),{ }^{7} \mathrm{~F}_{0} \rightarrow{ }^{5} \mathrm{D}_{3}(415 \mathrm{~nm})$, apresentam-se sobrepostas as bandas largas do ligante e matriz polimérica . [̉̉eve-se informar que bandas finas com menores intensidades são observadas em torno de 467, 534 e 578 nm, as quais são atribuídas às transições ${ }^{7} F_{0} \rightarrow{ }^{5} D_{2},{ }^{5} D_{1}$ e ${ }^{5} D_{0}$ do íon $E u^{3+}$. De um modo geral, é observada uma mudança significativa entre os espectros de excitação do complexo (FIG. 5.43) e aqueles das NPs poliméricas; as bandas alargadas referentes à transição permitida $S \rightarrow S_{0}$ têm seus máximos deslocados para a região do vermelho com o aumento da concentração do dopante e para o azul quando comparadas com o complexo sozinho. Nota-se também que, devido à alta intensidade desta banda, ficam imperceptíveis as transições intraconfiguracionais $4 f$ do íon $\mathrm{Eu}^{3+}$, exceto aquelas ${ }^{7} \mathrm{~F}_{0} \rightarrow{ }^{5} \mathrm{~L}_{7}(380 \mathrm{~nm})$ e ${ }^{7} \mathrm{~F}_{0} \rightarrow{ }^{5} \mathrm{D}_{2}(465 \mathrm{~nm}){ }^{[37,68]}$. 

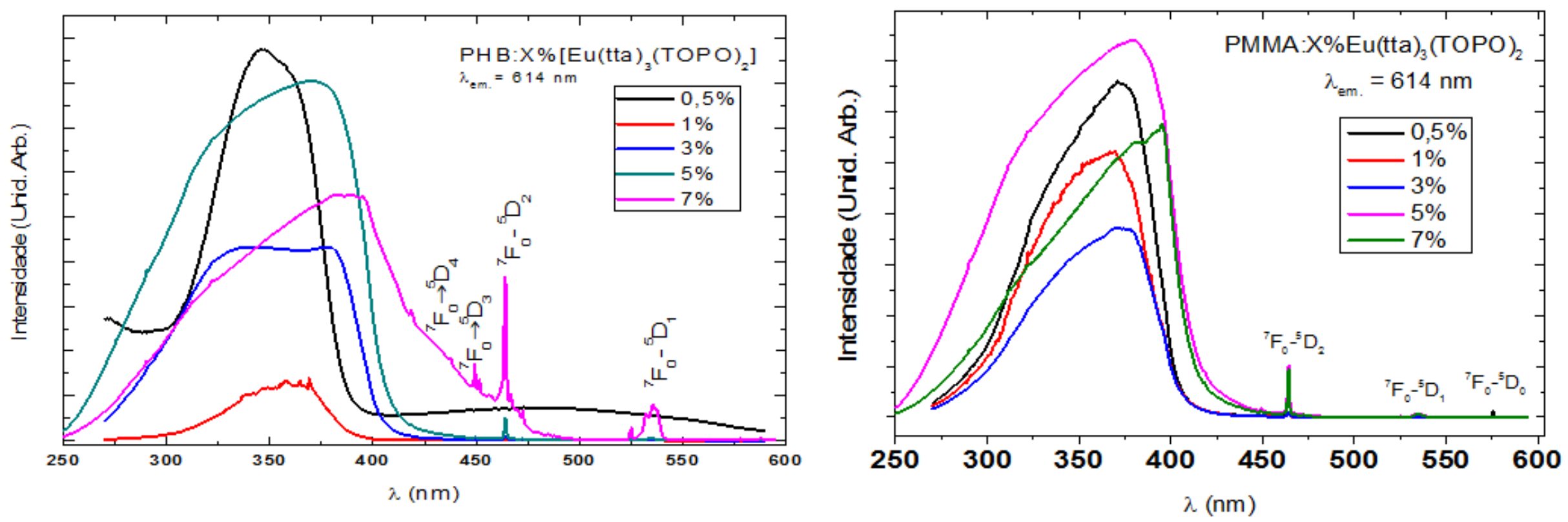

FIGURA 5.75 - Espectros de excitação do complexo $\left[\mathrm{Eu}(\mathrm{tta})_{3}(\mathrm{TOPO})_{2}\right]$ dopado em concentrações de 0,5; 1; 3 ; 5 e 7 em PHB e PMMA a temperatura ambiente e emissão monitorada em $614 \mathrm{~nm}$. 


\subsection{Espectros de emissão}

Os espectros de emissão das NPs PHB:X\%[Eu(tta $\left.)_{3}(\mathrm{TOPO})_{2}\right]$, onde $\mathrm{X}=0,5 ; 1 ; 3 ; 5$ e 7\%, foram registrados na região de 420 a $720 \mathrm{~nm}$ e estão ilustrados a partir de $500 \mathrm{~nm}$ (FIG. 5.76 A). São apresentadas bandas características das transições ${ }^{5} \mathrm{D}_{0-}{ }^{7} \mathrm{~F}_{\mathrm{J}}(\mathrm{J}=0-4),{ }^{5} \mathrm{D}_{0-}{ }^{7} \mathrm{~F}_{0}$ em $\sim 580 \mathrm{~nm},{ }^{5} \mathrm{D}_{0-}{ }^{7} \mathrm{~F}_{1}$ em $\sim 592 \mathrm{~nm},{ }^{5} \mathrm{D}_{0^{-}}{ }^{7} \mathrm{~F}_{2} \sim 613 \mathrm{~nm},{ }^{5} \mathrm{D}_{0^{-}}{ }^{7} \mathrm{~F}_{3} \mathrm{em} \sim 654 \mathrm{~nm} \mathrm{e}{ }^{5} \mathrm{D}_{0^{-}}{ }^{7} \mathrm{~F}_{4} \sim 700 \mathrm{~nm}$.

Observa-se que o sistema polimérico não exibe bandas largas oriundas da fosforescência da parte orgânica na região do espectro de 400 a 560 nm. Isto sugere que os processos de transferência de energia do estado tripleto dos ligantes para os níveis excitados do íon európio, ${ }^{5} D_{0}$ e ${ }^{5} D_{1}$ são muito eficientes [69].

Os resultados fotoluminescentes sugerem que existe uma maior transferência de energia ligante-metal para o complexo de concentração de dopagem em $3 \%$, quando este é excitado na banda de absorção do íon $\mathrm{Eu}^{3+}$, indicando que o sistema apresenta supressão de luminescência induzida pela concentração quando esta ultrapassa 3\% de dopagem.

Os espectros de emissão das NPs PMMA:X\%[Eu(tta $\left.)_{3}(\mathrm{TOPO})_{2}\right]$, onde $\mathrm{X}=0,5 ; 1 ; 3 ; 5$ e 7\%, foram registrados na região do visível de 550 a $720 \mathrm{~nm}$, e com excitação em 380 nm (FIG. 5.76 B). Nota-se supressão de luminescência em 3 e 7\% de concentração de dopagem, sendo que a concentração de $5 \%$ foi a que apresentou maior intensidade luminescente, indicando maior transferência de energia ligante-Eu ${ }^{3+}$ para este sistema (FIG. 5.75). Ademais, o comportamento espectroscópico é semelhante para 0 sistema PHB, apresentando bandas características das transições ${ }^{5} \mathrm{D}_{0}{ }^{-7} \mathrm{~F}_{\mathrm{J}}(\mathrm{J}=0-4)$. 
A

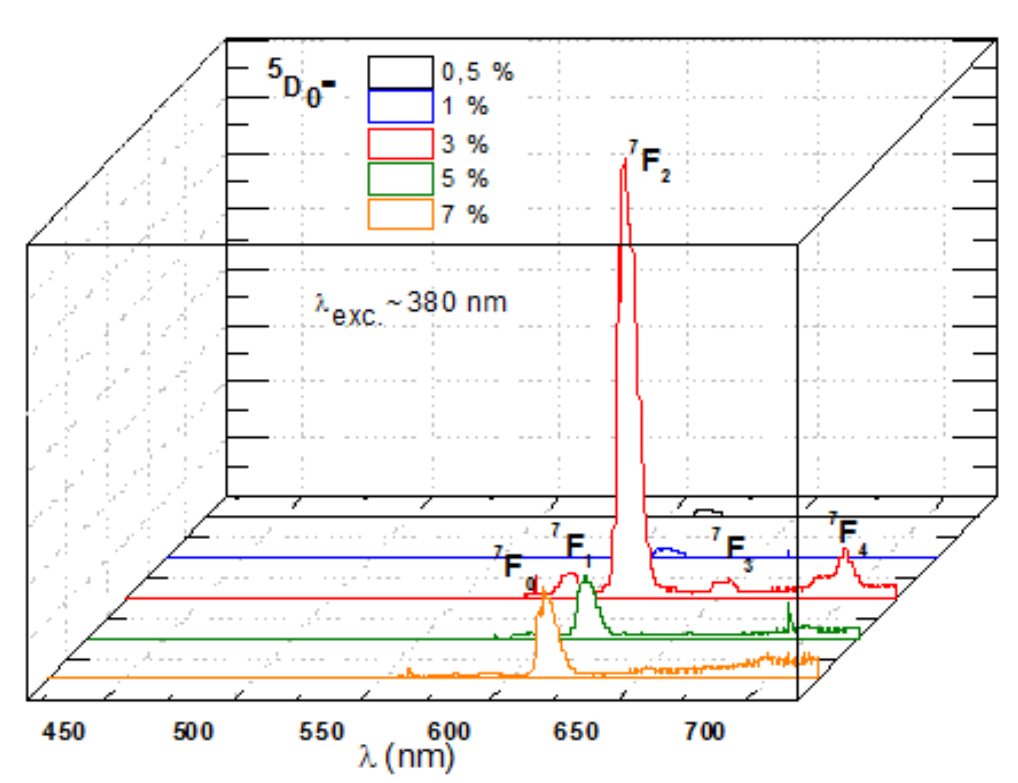

800000

700000 은

600000

$500000 \stackrel{5}{巳}$

400000 뭉

300000

200000 过

100000

0

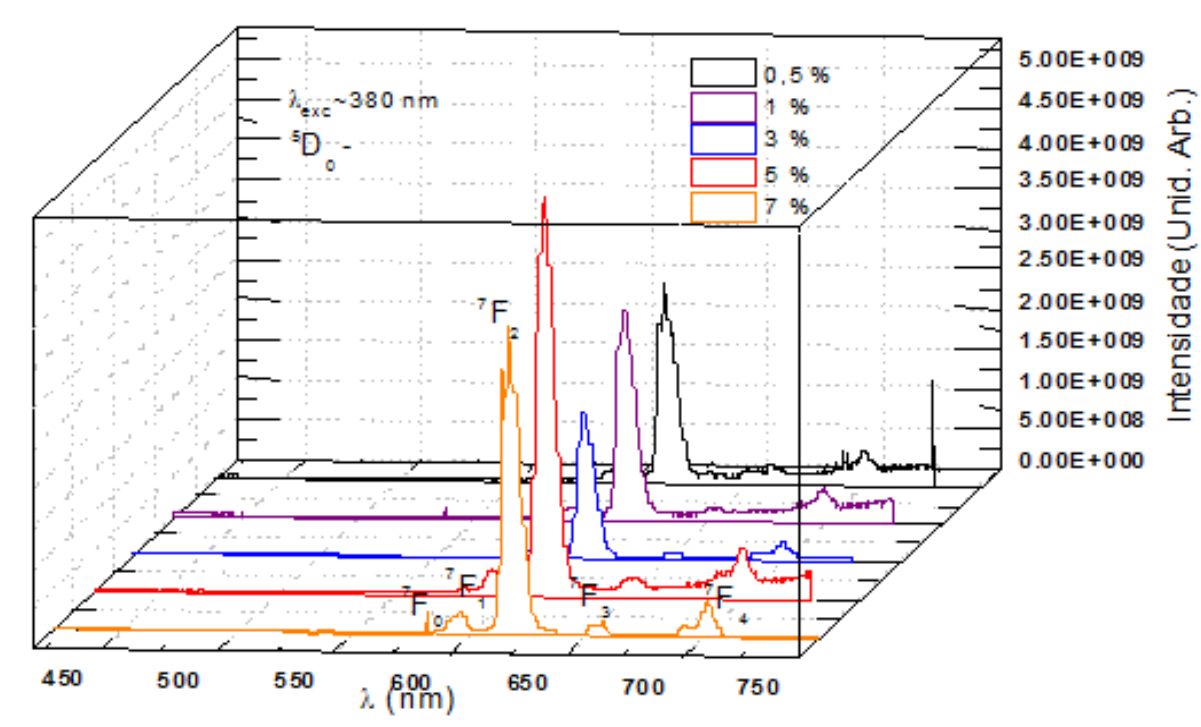

FIGURA 5.76 - Espectros de emissão do complexo [Eu(tta) $)_{3}(\mathrm{TOPO})_{2}$ ] dopado em concentrações de 0,5; 1; 3; 5 e 7 em A) PHB e B) PMMA à temperatura ambiente e sob excitação em $380 \mathrm{~nm}$. 


\subsection{3 Cálculo dos Parâmetros de Intensidades Experimentais para as NPs Poliméricas de PHB e PMMA Dopadas com Pol: $X \%\left[E u(t t a)_{3}(T O P O)_{2}\right]$ em Diferentes Concentrações $(X=0,5 ; 1 ; 3 ; 5$ e $7 \%)$}

Os parâmetros de intensidades experimentais $\Omega_{\lambda}$, coeficiente de emissão espontânea $(A)$, tempos de vida $(\tau)$ e eficiência quântica do nível $\begin{array}{llllll}\text { emissor } & { }^{5} \mathrm{D}_{0} & (\eta) & \text { das } & \mathrm{NPs} & \mathrm{PHB}: \mathrm{X} \%\left[\mathrm{Eu}(\mathrm{tta})_{3}(\mathrm{TOPO})_{2}\right] \quad \text { e }\end{array}$ PMMA:X\%[Eu(tta $\left.)_{3}(\mathrm{TOPO})_{2}\right]$, foram determinados a partir dos dados espectrais experimentais (TAB. 5.21).

Os resultados obtidos mostram que o complexo hidratado tem o maior valor de $\Omega_{2}$, o que é refletido em termos de uma maior polarizabilidade. Este parâmetro está também relacionado com a estrutura. Já os materiais poliméricos de PHB refletem um maior caráter covalente destas NPs, pois possuem os maiores valores de $\Omega_{4}$.

TABELA 5.21 - Parâmetros de intensidade experimental $\left(\Omega_{\lambda}\right)$, eficiência quântica de emissão $(\eta)$, tempos de vida( $\tau)$, e taxa de coeficiente de emissão radiatividade (Arad) e não radiatividade (Anrad) para amostras dos sistemas PMMA e PHB, e para os complexos $\left[\mathrm{Eu}(\mathrm{tta})_{3}(\mathrm{~L})_{2}\right]$.

\begin{tabular}{|c|c|c|c|c|c|c|}
\hline Complexos/NPs dopadas & $\begin{array}{l}\Omega_{2 \cdot 10^{-20}} \\
\left(\mathrm{~cm}^{2}\right)\end{array}$ & $\begin{array}{l}\Omega_{4} 10^{-20} \\
\left(\mathrm{~cm}^{2}\right)\end{array}$ & $\begin{array}{l}A_{\text {RAD }} \\
\left(s^{-1}\right)\end{array}$ & $\begin{array}{l}A_{\text {NRAD }} \\
\left(s^{-1}\right)\end{array}$ & $\begin{array}{l}A_{\text {tot }} \\
\left(s^{-1}\right)\end{array}$ & $\begin{array}{l}\eta \\
(\%)\end{array}$ \\
\hline$\left[\mathrm{Eu}(\mathrm{tta})_{3}(\mathrm{TOPO})_{2}\right]$ & 28,78 & 6,81 & 1013 & 68 & 1081 & 94 \\
\hline PMMA:0,5\% [Eu(tta $\left.)_{3}(\mathrm{TOPO})_{2}\right]$ & 22,8 & 14,89 & - & - & - & - \\
\hline PMMA:1\% [Eu(tta) $\left.)_{3}(\mathrm{TOPO})_{2}\right]$ & 19,89 & 13,07 & 845 & 180 & 1025 & 82 \\
\hline PMMA:3\%[Eu(tta) $\left.)_{3}(\mathrm{TOPO})_{2}\right]$ & 19,97 & 12,18 & 834 & 145 & 979 & 85 \\
\hline PMMA:5\%[Eu(tta) $\left.)_{3}(\mathrm{TOPO})_{2}\right]^{*}$ & 26,44 & 10,84 & 975 & 0 & 975 & 100 \\
\hline PMMA:7\%[Eu(tta) $\left.)_{3}(\mathrm{TOPO})_{2}\right]$ & 23,79 & 10,66 & 925 & 71 & 996 & 93 \\
\hline PHB:0,5\%[Eu(tta $\left.)_{3}(\mathrm{TOPO})_{2}\right]$ & 26,63 & 6,73 & 377 & - & - & - \\
\hline $\mathrm{PHB}: 1 \%\left[\mathrm{Eu}(\mathrm{tta})_{3}(\mathrm{TOPO})_{2}\right]$ & 17,50 & 8,75 & 646 & 533 & 1179 & 55 \\
\hline $\mathrm{PHB}: 3 \%\left[\mathrm{Eu}(\mathrm{tta})_{3}(\mathrm{TOPO})_{2}\right]$ & 27,28 & 10,64 & 1032 & 80 & 1112 & 92 \\
\hline $\mathrm{PHB}: 5 \%\left[\mathrm{Eu}(\mathrm{tta})_{3}(\mathrm{TOPO})_{2}\right]$ & 14,51 & 13,26 & 689 & 407 & 1096 & 63 \\
\hline $\mathrm{PHB}: 7 \%\left[\mathrm{Eu}(\mathrm{tta})_{3}(\mathrm{TOPO})_{2}\right]$ & 12,80 & 15,90 & 669 & 506 & 1175 & 57 \\
\hline
\end{tabular}


As FIGURAS 5.77 e $\mathbf{5 . 7 8}$ apresentam os diagramas de cromaticidade CIE ilustrando as coordenadas das cores emitidas pelas NPs poliméricas PHB:x\% $\left[\mathrm{Eu}(\mathrm{tta})_{3}(\mathrm{TOPO})_{2}\right]$ e PMMA:x\%[Eu(tta) $\left.)_{3}(\mathrm{TOPO})_{2}\right]$, obitidos a partir dos espectros de emissão. Os sistemas apresentam alta intensidade de emissão, possibilitando a percepção a olho nu. Os valores das coordenadas de cores estão apresentadas na TABELA 5.22 onde se pode notar uma discrepância dos dados das coordenadas do $\mathrm{PHB}: 0,5 \%\left[\mathrm{Eu}(\mathrm{tta})_{3}(\mathrm{TOPO})_{2}\right]$ que apresenta suas coordenadas numa região central do diagrama, na cor rosa, não possuindo então pureza de cor .

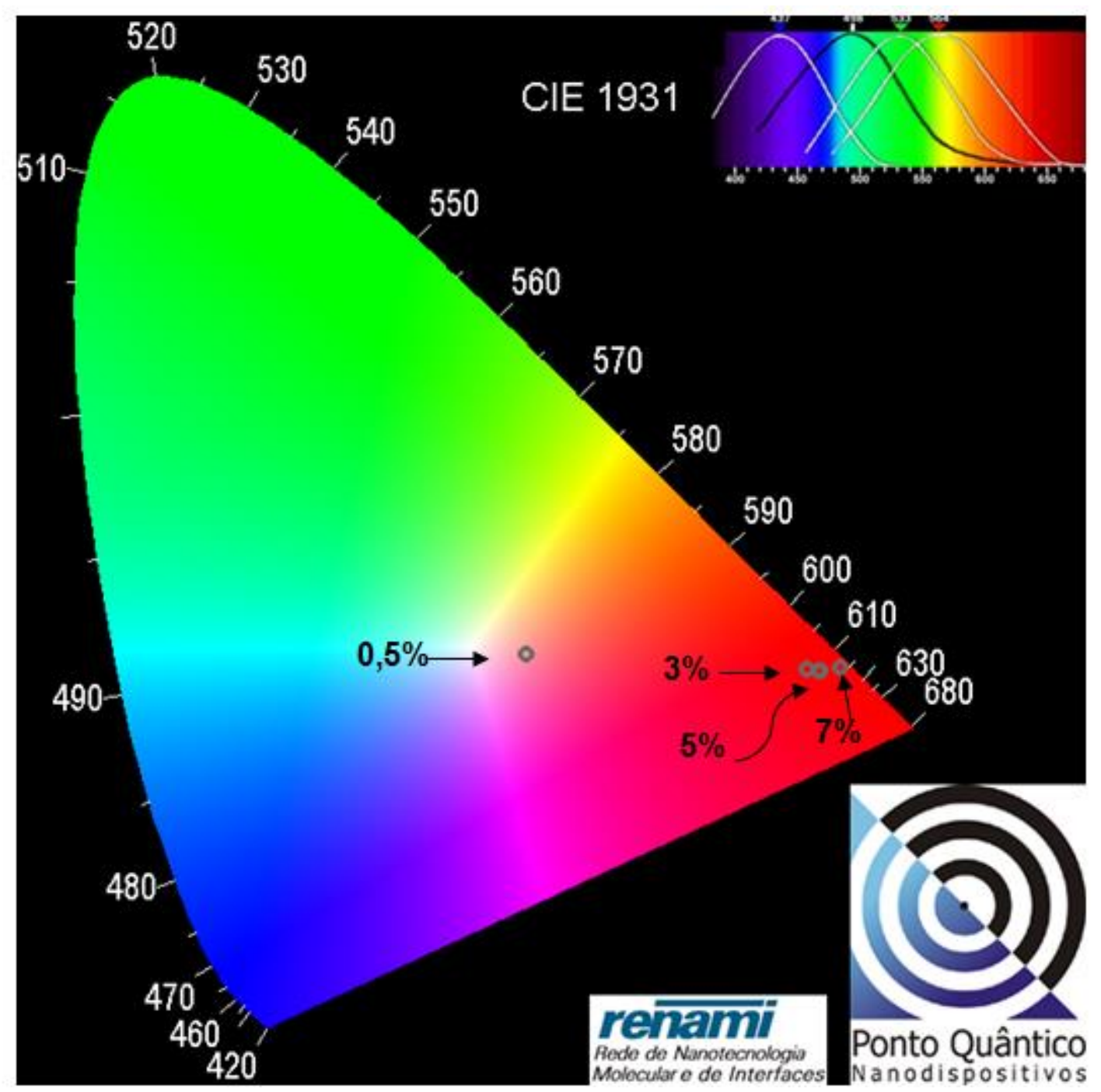

FIGURA 5.77 - Diagramas de cromaticidade CIE ilustrando as coordenadas das cores emitidas pelo sistema polimérico $\mathrm{PHB}: \mathrm{x} \%\left[\mathrm{Eu}(\mathrm{tta})_{3}(\mathrm{TOPO})_{2}\right]$. 


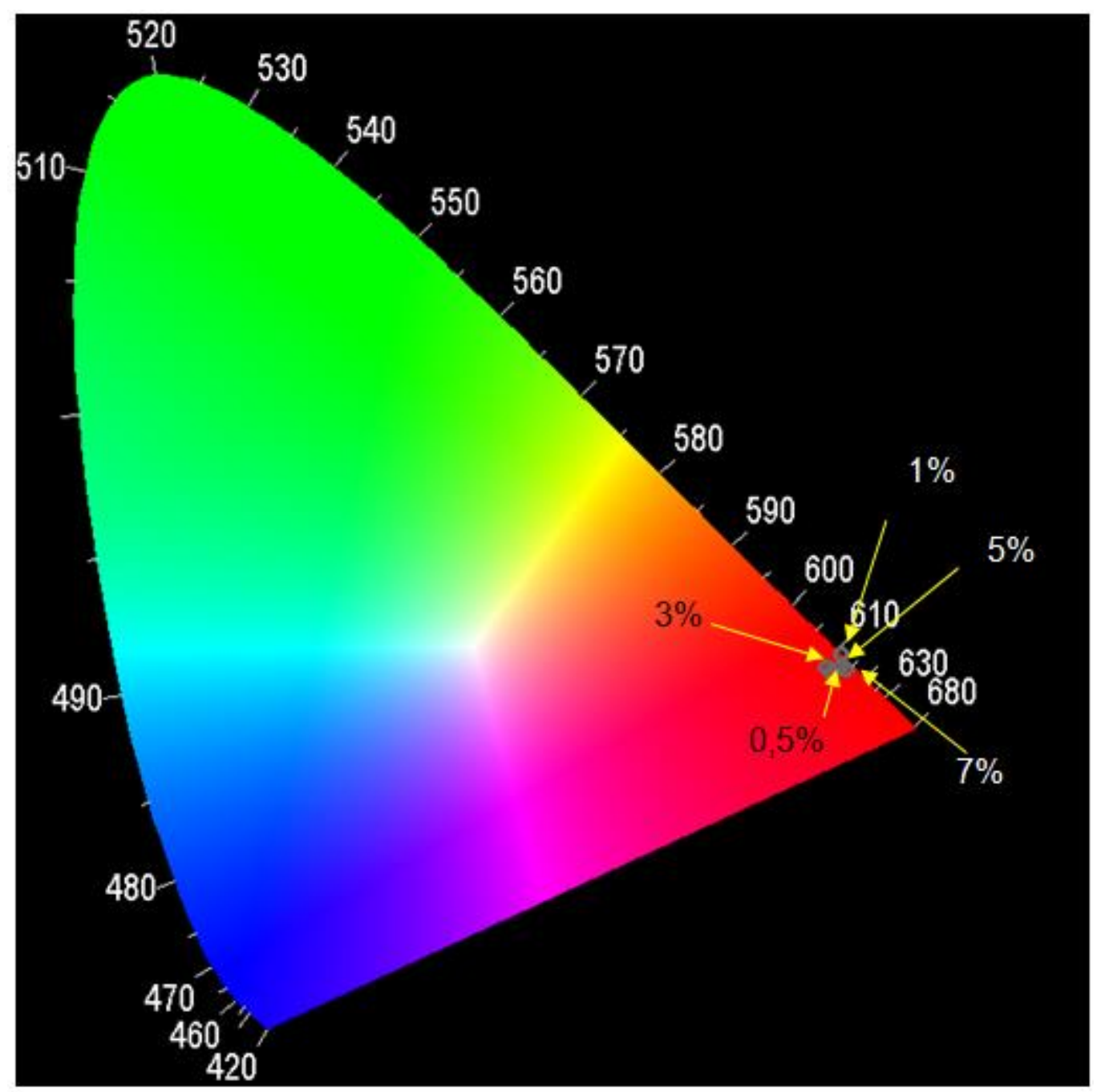

FIGURA 5.78 - Diagramas de cromaticidade CIE ilustrando as coordenadas das cores emitidas pelo sistema polimérico PMMA:x\%[Eu(tta $\left.)_{3}(\mathrm{TOPO})_{2}\right]$. 
TABELA 5.22 - Valores aproximados das coordenadas de cores dos sistemas poliméricos dopados PHB:x\%[Eu(tta) $\left.)_{3}(\mathrm{TOPO})_{2}\right]$ e PMMA:x\%[Eu(tta $\left.)_{3}(\mathrm{TOPO})_{2}\right]$.

\begin{tabular}{ccc}
\hline Polímero & Coord. & $\mathbf{y}$ \\
\hline $0,5 \%$ & PMMA & \\
1 & 0,659 & 0,313 \\
3 & 0,668 & 0,328 \\
5 & 0,656 & 0,316 \\
7 & 0,673 & 0,316 \\
& 0,667 & 0,316 \\
\hline, $5 \%$ & PHB & \\
\hline 3 & 0,396 & 0,328 \\
5 & 0,641 & 0,315 \\
7 & 0,670 & 0,316 \\
\hline
\end{tabular}




\subsubsection{Teste do Espalhamento de Luz das Nanopartículas em Solução - Efeito Tyndall}

Os sistemas coloidais são compostos por partículas de tamanho muito pequeno, não sendo possível identificá-las a olho nu. Assim, as partículas que compõem os sistemas coloidais podem parecer sistemas realmente homogêneos. Entretanto, essas partículas nanométricas, embora muito pequenas, ainda são grandes o suficiente para espalhar a luz que incide sobre o sistema (FIG. 5.79). Dessa maneira, a identificação de um sistema coloidal utilizando o efeito Tyndall, descoberto por John Tyndall, baseia-se na visualização de um feixe de luz, de preferência monocromático e coerente, como um laser, atravessando o sistema coloidal ${ }^{[70,71]}$. Por isso, uma luz que atravesse um sistema coloidal será refratada pelas partículas ${ }^{[71]}$. Esta é uma técnica utilizada para classificar uma dispersão coloidal ${ }^{[70]}$.

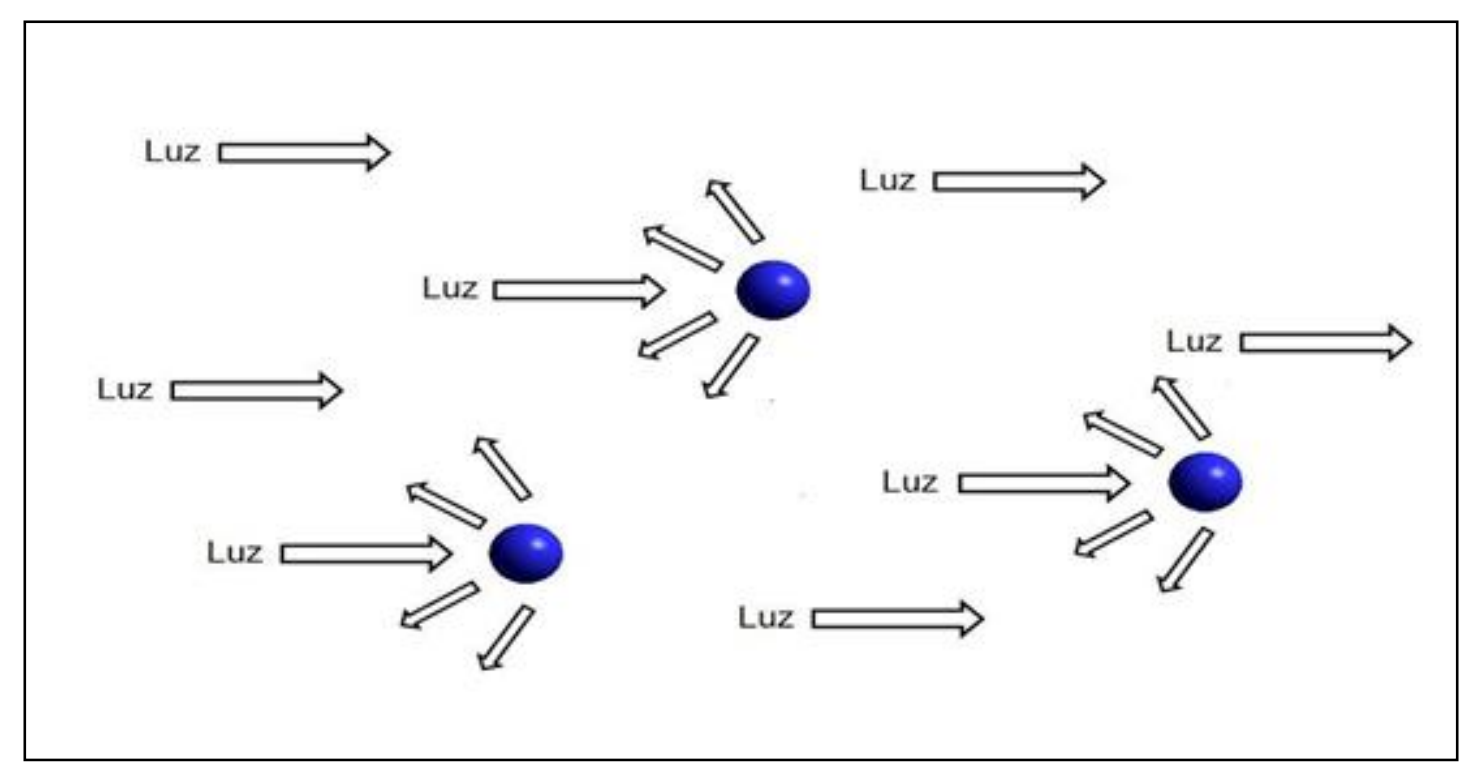

FIGURA 5.79 - Espalhamento de luz pelas partículas dispersas em um sistema coloidal (Efeito Tyndall).

As amostras contendo as nanopartículas poliméricas de PHB e PMMA quando em solução aquosa, refratam a luz de uma ponta laser, resultado positivo ao efeito Tyndall. Observa-se uma nítida diferença entre as amostras de background contendo apenas água bidestilada(FIG. 5.80 a)) e as amostras 
contendo as nanopartículas provenientes dos sistemas PHB:3\%[Eu(tta $\left.)_{3}(\mathrm{TOPO})_{2}\right]$ (FIG. 5.79 b)) e PMMA:5\%[Eu(tta) $\left.)_{3}(\mathrm{TOPO})_{2}\right]$ (FIG. 5.81 b)). A água não refrata a luz comportando-se de maneira oposta às nanoparticulas poliméricas. Este teste embora simples é de grande valia durante a preparação de biomarcadores.

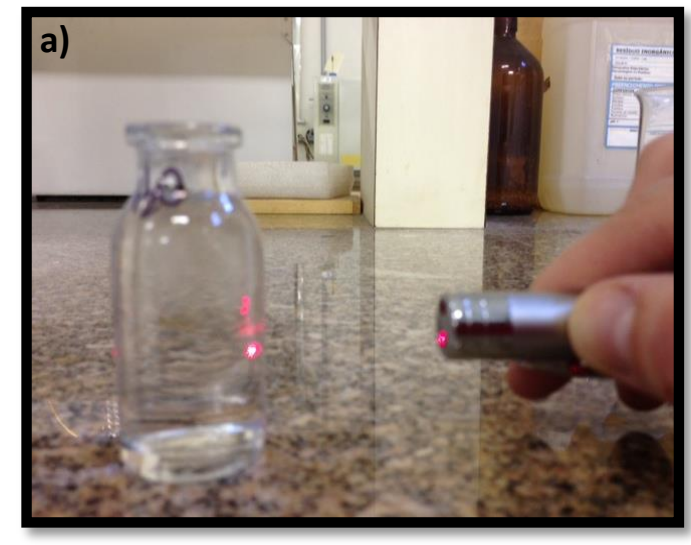

FIGURA $\mathbf{5 . 8 0}$ - Teste do Efeito b) $\mathrm{PHB}: 3 \%\left[\mathrm{Eu}(\mathrm{tta})_{3}(\mathrm{TOPO})_{2}\right]$.
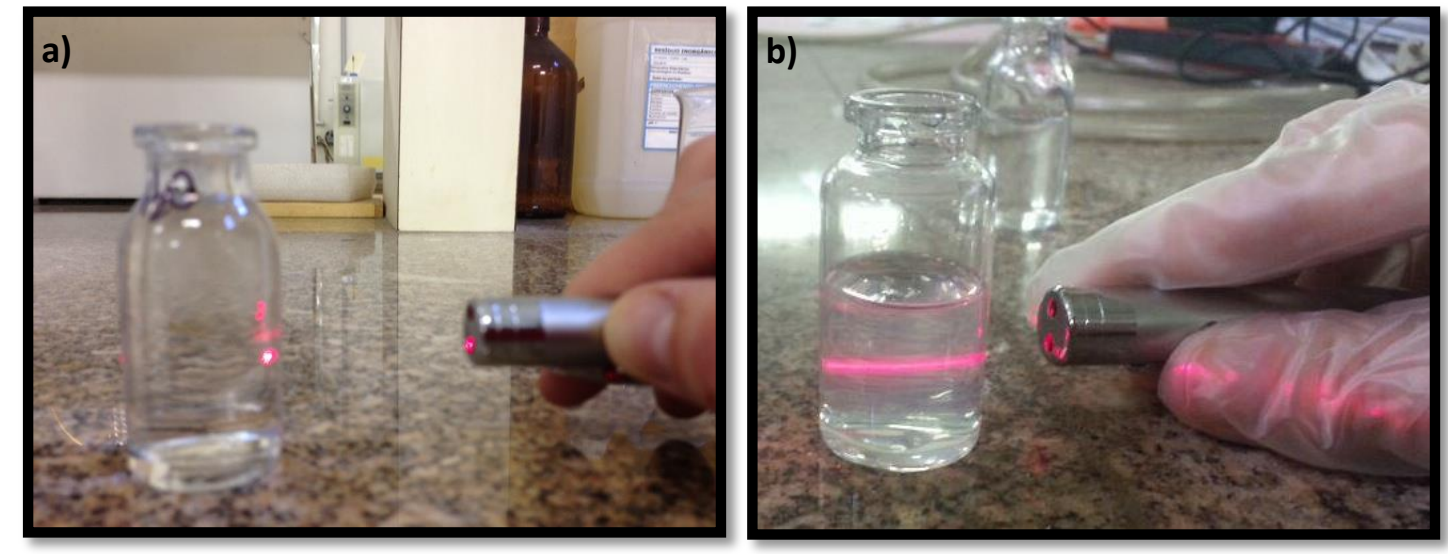

FIGURA 5.81 - Teste do Efeito Tyndall das amostras a) $\mathrm{H}_{2} \mathrm{O}$; b) PMMA:5\%[Eu(tta) $\left.)_{3}(\mathrm{TOPO})_{2}\right]$.

\subsubsection{Teste de Hemocompatibilidade por Adesão de Plaquetas}

Um material não trombogênico é aquele cuja superfície é inerte frente ao contato com o sangue, não desencadeando o mecanismo de formação de 
trombos na interface sangue-superficie estranha. Sabe-se que o primeiro fenômeno que ocorre quando um material sintético entra em contato com o sangue é a adsorção quase instantânea de proteínas do plasma (albumina, globulina e fibrinogênio) na superfície do material. Esta capa proteica modifica a superfície do material e determina as interações posteriores que se produzem no sistema sangue-superfície sintética, dando lugar a um material trombogênico ou não ${ }^{[72]}$. Sendo que a tendência de adesão plaquetária é determinada pela natureza da capa proteica.

Para execução deste teste de hemocompatibilidade foi necessário sintertizar-se filmes na mesma composição das nanopartículas PHB:3\%[Eu(tta) $\left.)_{3}(\mathrm{TOPO})_{2}\right]$ e PMMA:5\%[Eu(tta $\left.)_{3}(\mathrm{TOPO})_{2}\right]$. Após contato destes filmes com o plasma rico em plaquetas, o número de plaquetas aderidas foi determinado a partir da imagem de microscopia eletrônica de varredura (MEV) dos mesmos. Na FIGURA 5.82 observa-se que a agregação plaquetária na superfície do filme contendo PHB foi consideravelmente mais abundante do que na superfície do filme contendo PMMA (FIG. 5.83). Esta análise nos permite concluir que o filme contendo PHB é de natureza trombogênica (presença de grandes agregados plaquetários) e o filme contendo PMMA demonstrou adesão plaquetária, porém sem grandes formações de trombos.

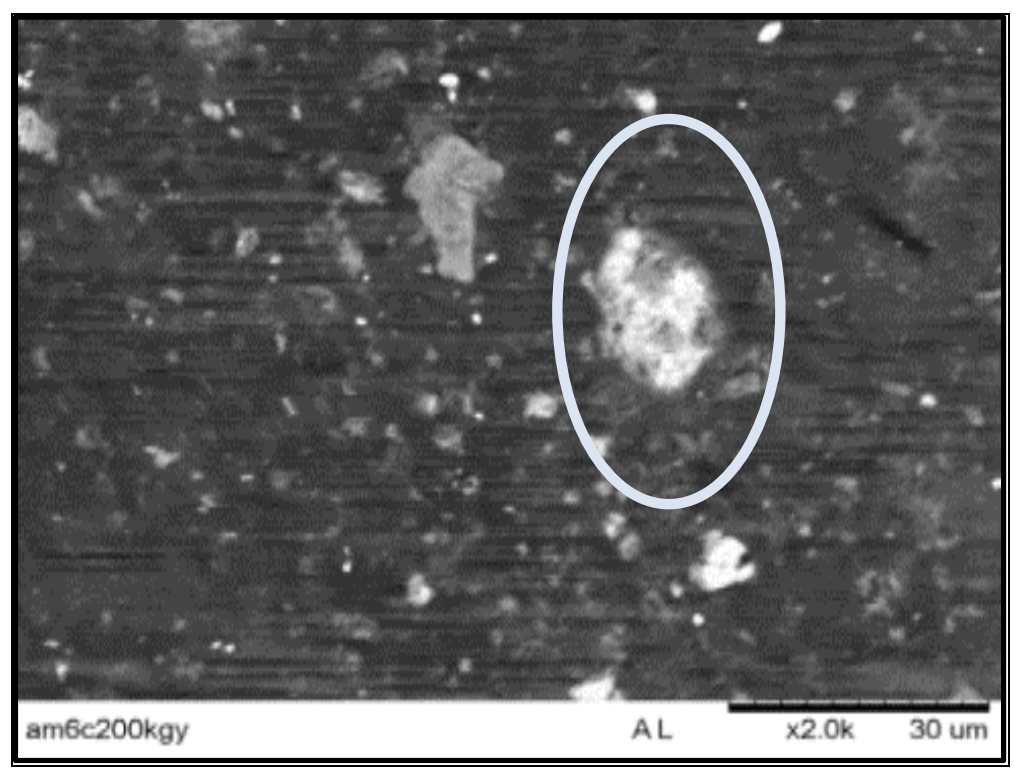

FIGURA 5.82 - MEV do filme de PHB:3\%[Eu(tta) $\left.)_{3}(\mathrm{TOPO})_{2}\right]$ exposto ao sangue humano. 


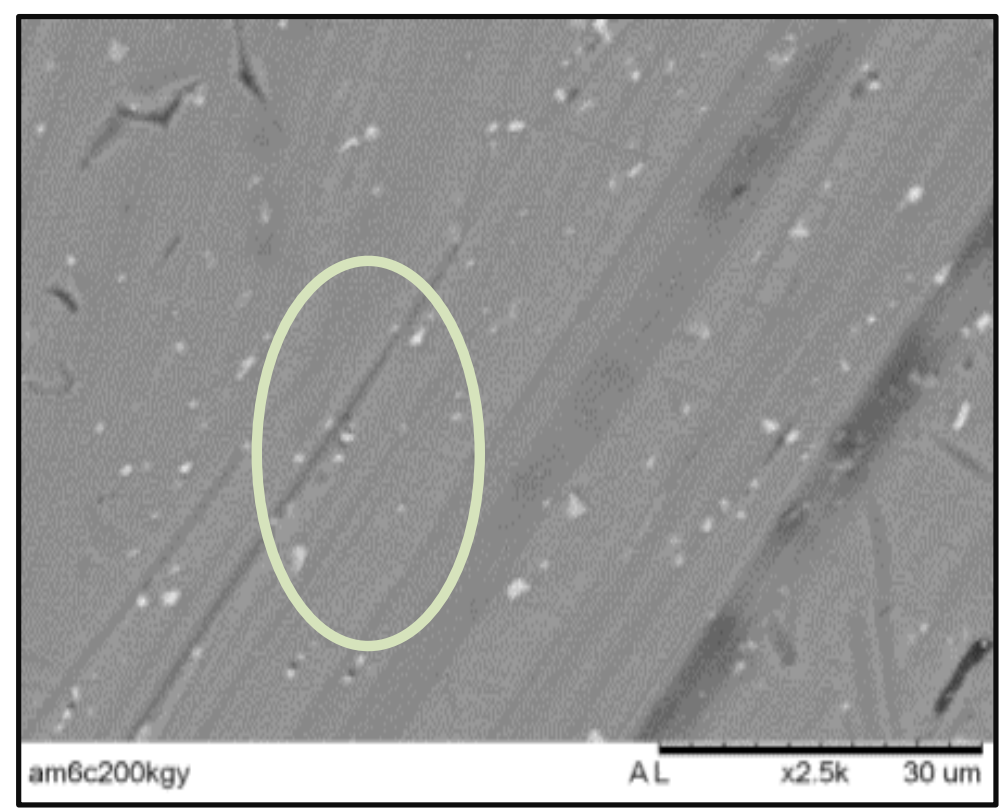

FIGURA 5.83 - Imagem de MEV do filme de PMMA:5\%[Eu(tta $\left.)_{3}(\mathrm{TOPO})_{2}\right]$ exposto ao sangue humano.

\subsubsection{Nanopartículas do tipo core @shell onde a casca é o poliméro PHB, e o núcleo é o complexo $\left[\mathrm{Eu}(\mathrm{tta})_{3}(\mathrm{TOPO})_{2}\right.$ ] produzidas pela técnica emulsão-difusão.}

O método de emulsão a partir da polimerização de um monômero é um dos processos mais rápidos para obtenção de nanopartículas poliméricas. $O$ método pode ser dividido em duas categorias, de acordo com o uso de um solvente orgânico ou aquoso em fase continua. No caso de uma fase orgânica, o monômero é disperso em uma emulsão ou uma microemulsão ou ainda em um material onde o monômero não é solúvel, sempre com o auxílio de um agente dispersante. No caso da fase aquosa contínua, o monômero é dissolvido em uma solução aquosa, sem necessidade de agentes emulsionantes. O processo de polimerização se inicia por ativação por catalisador ou através de alta energia (ultravioleta ou luz visível forte) ${ }^{[73-75]}$. 
Neste trabalho foram produzidas nanopartículas poliméricas PHB:[Eu(tta) ${ }_{3}(\mathrm{TOPO})_{2}$ ] pela técnica de emulsão-difusão descrita no item 4.2.5.2 deste trabalho. As nanopartículas foram produzidas de duas formas:a primeira utilizando como dispersante o Tween 20 e a segunda utilizando o estabilizante PVA e um crioprotetor (sacarose).

\subsubsection{Características Qualitativas}

As NPs contendo dispersante Tween 20 e as NPs contendo estabilizante PVA + sacarose foram obtidas em forma de sólido cristalino branco que, sob irradiação ultravioleta $(366 \mathrm{~nm})$, apresentam alta intensidade luminescente, emitindo cor vermelha (FIG. 5.84). As nanopartículas apresentam uma alta dispersão em água e é parcialmente solúvel em solventes como acetona álcool e cloroformio.
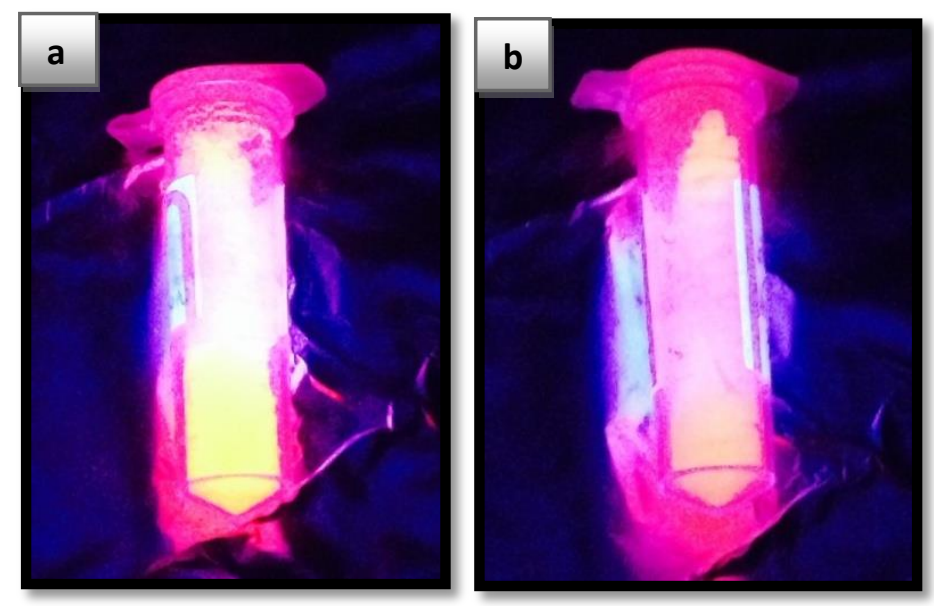

FIGURA 5.84 - Fotografias das NPs de PHB produzidas pela técnica de emulsão-difusão sob irradiação ultravioleta (366 nm), a) NPs + Tween 20 e b) NPs + PVA + sacarose. 


\subsubsection{Caracterizações}

As duas nanopartículas obtidas pela técnica de emulsão-difusão foram caracterizadas por MEV, TEM e foram estudadas as propriedades luminescentes através dos espectros de excitação e emissão.

\subsection{Microscopia Eletrônica de Varredura (MEV)}

A FIGURA 5.85 apresenta a micrografia das nanopartículas de PHB: $\left[\mathrm{Eu}(\mathrm{tta})_{3}(\mathrm{TOPO})_{2}\right]$ sintetizadas com o estabilizante PVA e a sacarose como crioprotetor em proporção 1:1 (PHB:Complexo). As micrografias mostram aglomerados de NPs em forma de folhas de tamanho heterogêneo. As micrografias das nanopartículas PHB:[Eu(tta) $\left.)_{3}(\mathrm{TOPO})_{2}\right]+$ Tween 20 via técnica de Microscopia Eletronica de Varredura não foram obtidas devido o tamanho das mesmas serem menor do que o limite mínimo de deteç̧ão do aparelho utilizado.

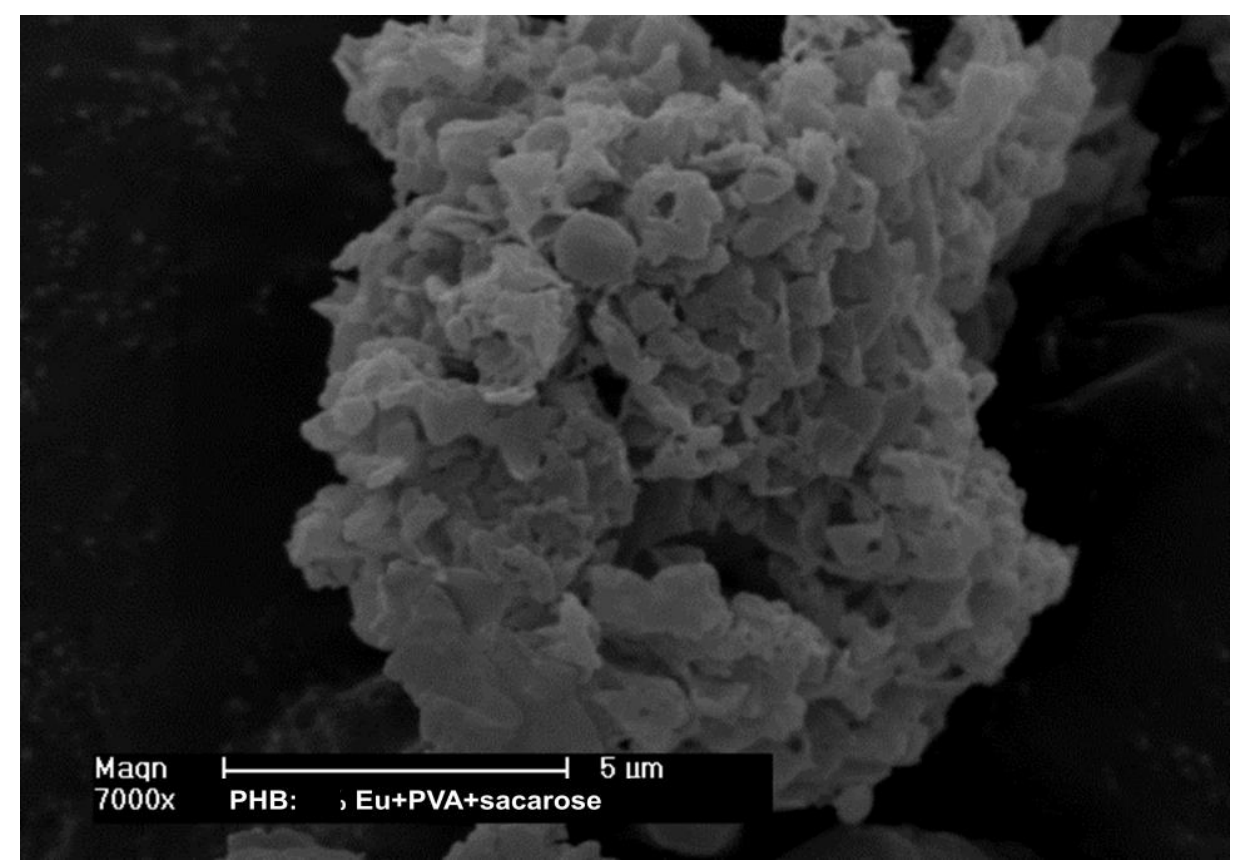

FIGURA 5.85 - Micrografia das NPs PHB dopadas com complexo $\left[\mathrm{Eu}(\mathrm{tta})_{3}(\mathrm{TOPO})_{2}\right]$ contendo PVA+sacarose com magnificação de (7000X). 


\subsection{Microscopia Eletrônica de Transmissão (TEM)}

A FIGURA 5.86 mostra as imagens de TEM das nanopartículas de PHB:[Eu(tta) $\left.)_{3}(\text { TOPO })_{2}\right]+$ Tween 20 e PHB:[Eu(tta) $\left.)_{3}(\text { TOPO })_{2}\right]+P V A+$ sacarose.

As nanopartículas $\mathrm{PHB}:\left[\mathrm{Eu}(\mathrm{tta})_{3}(\mathrm{TOPO})_{2}\right]+$ Tween 20 apresentam-se como formas heterogêneas e, na FIGURA 5.86-a, pode-se observar que estas nanoparticulas são formadas por aglomerados de nanocristais de formato tubular e apresentam disposição do complexo dentro da matriz polimérica (região mais escura) e os planos do cristal são desordenados.. Já na imagem da FIGURA 5.86-b, a nanopartícula apresenta disposição do complexo de $\mathrm{Eu}^{3+}$ de formato heterogêneo; ambas as imagens do sistema PHB:[Eu(tta $\left.)_{3}(\mathrm{TOPO})_{2}\right]$ +Tween 20 não têm organização nos planos cristalográficos.. A nanopartícula de menor tamanho registrado (item c) FIG. FIGURA 5.86-c) pertence ao sistema PHB:[Eu(tta $\left.)_{3}(\mathrm{TOPO})_{2}\right]+P V A+$ sacarose e apresenta disposição do complexo de $\mathrm{Eu}^{3+}$ de formato semiesférico. Fica bem estabelecida na imagem a posição interna do complexo com a formação de uma capa externa provavelmente de composição PHB+PVA+sacarose. Pode-se observar também os planos cristalográficos da nanopartícula bem alinhados. 

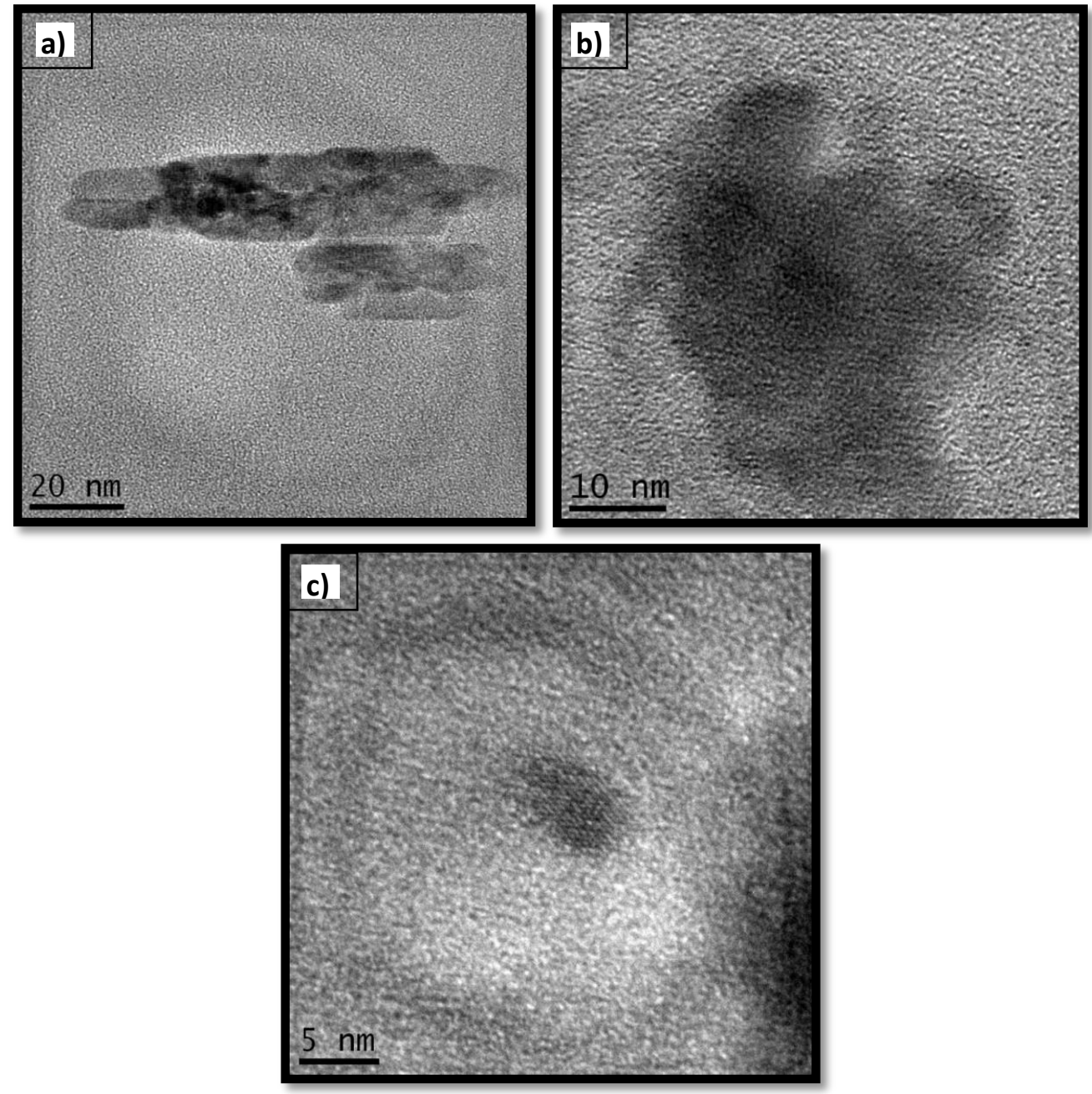

FIGURA 5.86 - Imagens de TEM das amostras contendo nanopartículas poliméricas a) $\quad$ e b): $\quad \mathrm{PHB}:\left[\mathrm{Eu}(\mathrm{tta})_{3}(\mathrm{TOPO})_{2}\right]+\mathrm{Tw}$ ween20;

c) PHB:[Eu(tta $\left.)_{3}(\text { TOPO })_{2}\right]+P V A+$ sacarose.

5.4.2.3. Investigação dos processos de luminescência a partir dos espectros de excitação e emissão das nanopartículas poliméricas do tipo core@shell

5.4.2.3.1. NPs do tipo core @shell do sistema PHB:[Eu(tta) $\left.)_{3}(\mathrm{TOPO})_{2}\right]+T$ ween 20

Os estudos fotoluminescentes das NPs do tipo core shell de PHB:[Eu(tta) $\left.)_{3}(\text { TOPO })_{2}\right]+$ Tween 20 foram fundamentados nos espectros de excitação e emissão registrados à temperatura ambiente ( 298 K). O espectro 
de excitação (FIG. 5.87) foi registrado no intervalo de 250 a 590 nm, com emissão monitorada na transição hipersensível do ion $E u^{3+}{ }^{5} D_{0} \rightarrow{ }^{7} F_{2}(\sim 613 \mathrm{~nm})$. O espectro apresenta uma banda larga centrada em torno de $352 \mathrm{~nm}$ associada à transição permitida $\mathbf{S}_{1} \rightarrow \mathbf{S}_{0}$ pertencente ao ligante tta sobreposta com as bandas finas oriundas das transições intraconfiguracionais-4f ${ }^{6}$ relativas aos níveis de energia ${ }^{7} \mathrm{~F}_{0} \rightarrow{ }^{5} \mathrm{~L}_{6}(394 \mathrm{~nm}),{ }^{7} \mathrm{~F}_{0} \rightarrow{ }^{5} \mathrm{D}_{3}(415 \mathrm{~nm})$. Esta banda é tão intensa que invalida as demais transições esperadas para o complexo de európio, ${ }^{7} \mathrm{~F}_{0} \rightarrow{ }^{5} \mathrm{D}_{2}(464 \mathrm{~nm}),{ }^{7} \mathrm{~F}_{0} \rightarrow{ }^{5} \mathrm{D}_{1}(525 \mathrm{~nm})$ e ${ }^{7} \mathrm{~F}_{0} \rightarrow{ }^{5} \mathrm{D}_{0}(578 \mathrm{~nm})$, da configuração $4 \mathrm{f}-4 \mathrm{f}$. O que podemos observar também é que a banda da nanopartícula do tipo core-shell tem um formato mais homogêneo que 0 espectro das nanopartículas de mesma composição feitas pelo método de precipitação por crioscopia. Então se pode afirmar que a produção de NPs usando o agente estabilizador TWEEN 20 suprime a luminescência das nanopartículas.

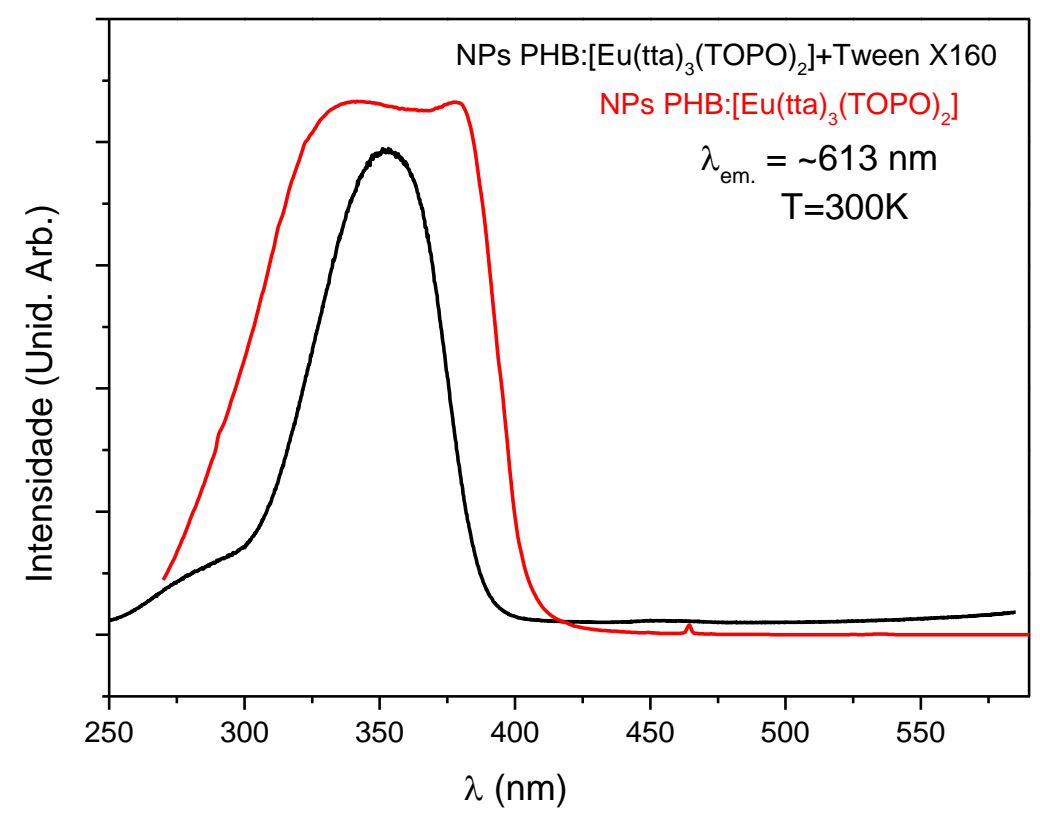

FIGURA 5.87 - Espectro de excitação das NPs PHB:[Eu(tta $\left.)_{3}(\mathrm{TOPO})_{2}\right]+$ Tween 20 e PHB:[Eu(tta) $\left.)_{3}(\mathrm{TOPO})_{2}\right]$ à temperatura ambiente, no intervalo de 250 a 590 $\mathrm{nm}$, e sob emissão em $\sim 613 \mathrm{~nm}$. 
O estudo das propriedades fotoluminescente baseados no espectro de emissão foi fundamentado nos dados experimentais estes espectros para a NPs PHB:[Eu(tta) $\left.)_{3}(\mathrm{TOPO})_{2}\right]+$ Tween 20 (FIG. 5.88).

Os espectros de emissão do sistema PHB:[Eu(tta $\left.)_{3}(\mathrm{TOPO})_{2}\right]+$ Tween 20, foram registrados na região do visível de 400 a $750 \mathrm{~nm}$, a $300 \mathrm{~K}$, monitorando a excitação no máximo da bandas de absorção do ligante em 352 nm (FIG. 5.88).

O espectro apresenta bandas referentes às transições intraconfiguracionais ${ }^{5} \mathrm{D}_{0} \rightarrow{ }^{7} \mathrm{~F}_{0-4}$. em ${ }^{5} \mathrm{D}_{0}{ }^{7} \mathrm{~F}_{0}$ em $\sim 580 \mathrm{~nm},{ }^{5} \mathrm{D}_{0}{ }^{7} \mathrm{~F}_{1} \mathrm{em} \sim 592 \mathrm{~nm}$, ${ }^{5} \mathrm{D}_{0}{ }^{-} \mathrm{F}_{2} \mathrm{em} \sim 613 \mathrm{~nm},{ }^{5} \mathrm{D}_{0}{ }^{-}{ }^{7} \mathrm{~F}_{3} \sim 654 \mathrm{~nm} \mathrm{e}{ }^{5} \mathrm{D}_{0}{ }^{-} \mathrm{F}_{4} \sim 700 \mathrm{~nm}$.

A banda larga referente a fosforescência do ligante que deveria aparecer na região de $400 \mathrm{~nm}$ não foi observada, corroborando com a afirmação de que este sistema apresenta uma elevada transferência de energia ligante-Eu ${ }^{3+}$, resultando em alta eficiência na transferência de energia no processo de absorção-emissão. Comparando-se o espectro destas partículas com o espectro das partículas obtidas por crioscopia, as nanopatículas do tipo coreshell tem o Maximo de suas bandas referentes as transições ${ }^{5} \mathrm{D}_{0} \rightarrow{ }^{7} \mathrm{~F}_{0-4}$ deslocadas para o azul. 


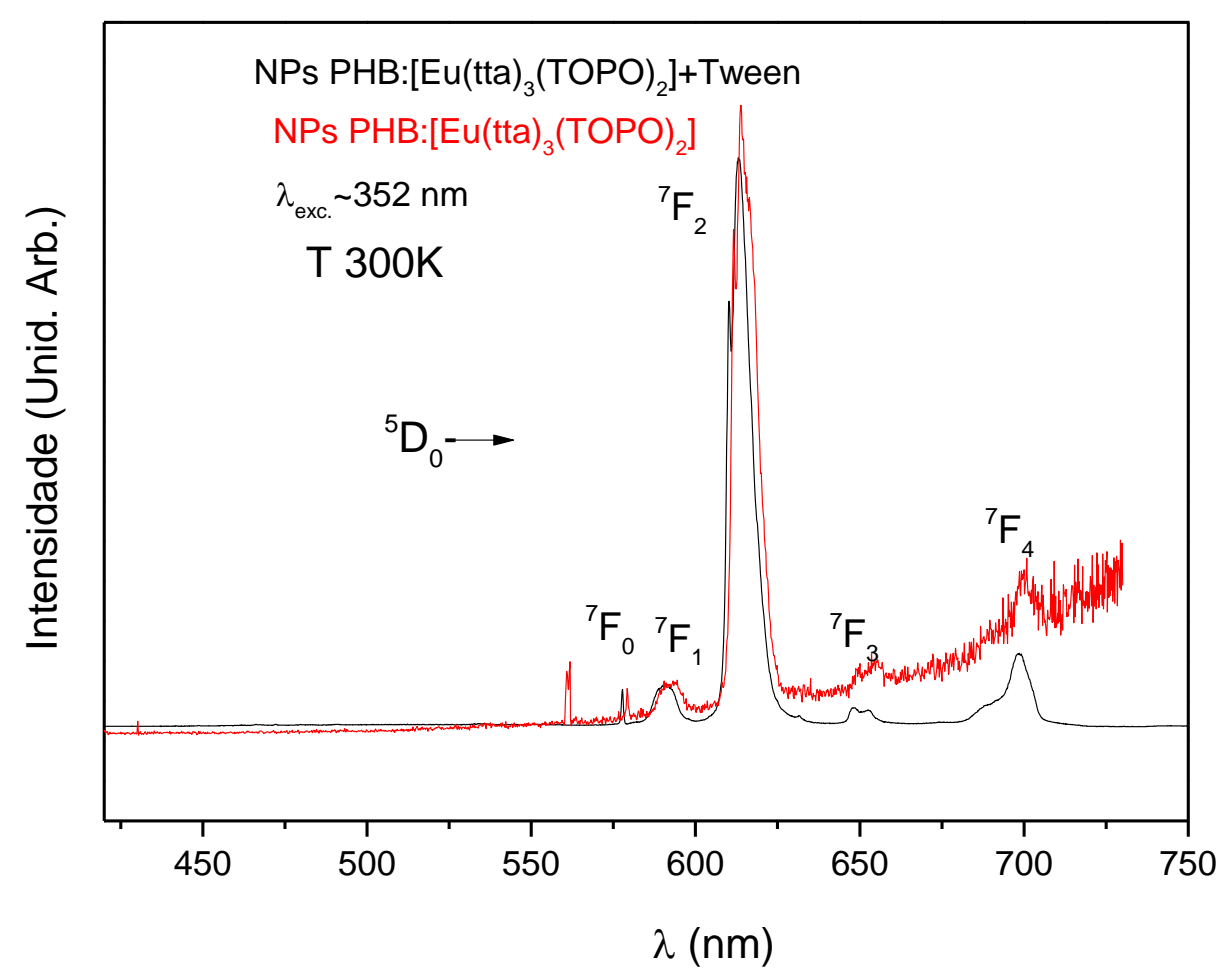

FIGURA 5.88 - Espectro de emissão das NPs PHB:[Eu(tta $\left.)_{3}(\mathrm{TOPO})_{2}\right]+$ Tween 20 à temperatura ambiente, no intervalo de 400 a 800 nm, e sob excitação em $352 \mathrm{~nm}$.

\subsection{NPs do tipo core @shell do sistema PHB: $\left[\mathrm{Eu}(\mathrm{tta})_{3}(\mathrm{TOPO})_{2}\right]+$ PVA+sacarose}

Os estudos fotoluminescentes das nanopartículas (NPs) de PHB produzidas pela técnica de emulsão-difusão dopadas com o complexo $\left[\mathrm{Eu}(\mathrm{tta})_{3}(\mathrm{TOPO})_{2}\right.$ ] e utilizando como dispersante PVA e como crioprotetor a sacarose foram feitos com base nos espectros de excitação e emissão registrados à temperatura ambiente ( 298 K). O espectro de excitação (FIG. 5.89) foi registrado no intervalo de 250 a $600 \mathrm{~nm}$, com emissão monitorada na transição hipersensível ${ }^{5} \mathrm{D}_{0} \rightarrow{ }^{7} \mathrm{~F}_{2}(\sim 614 \mathrm{~nm})$. 


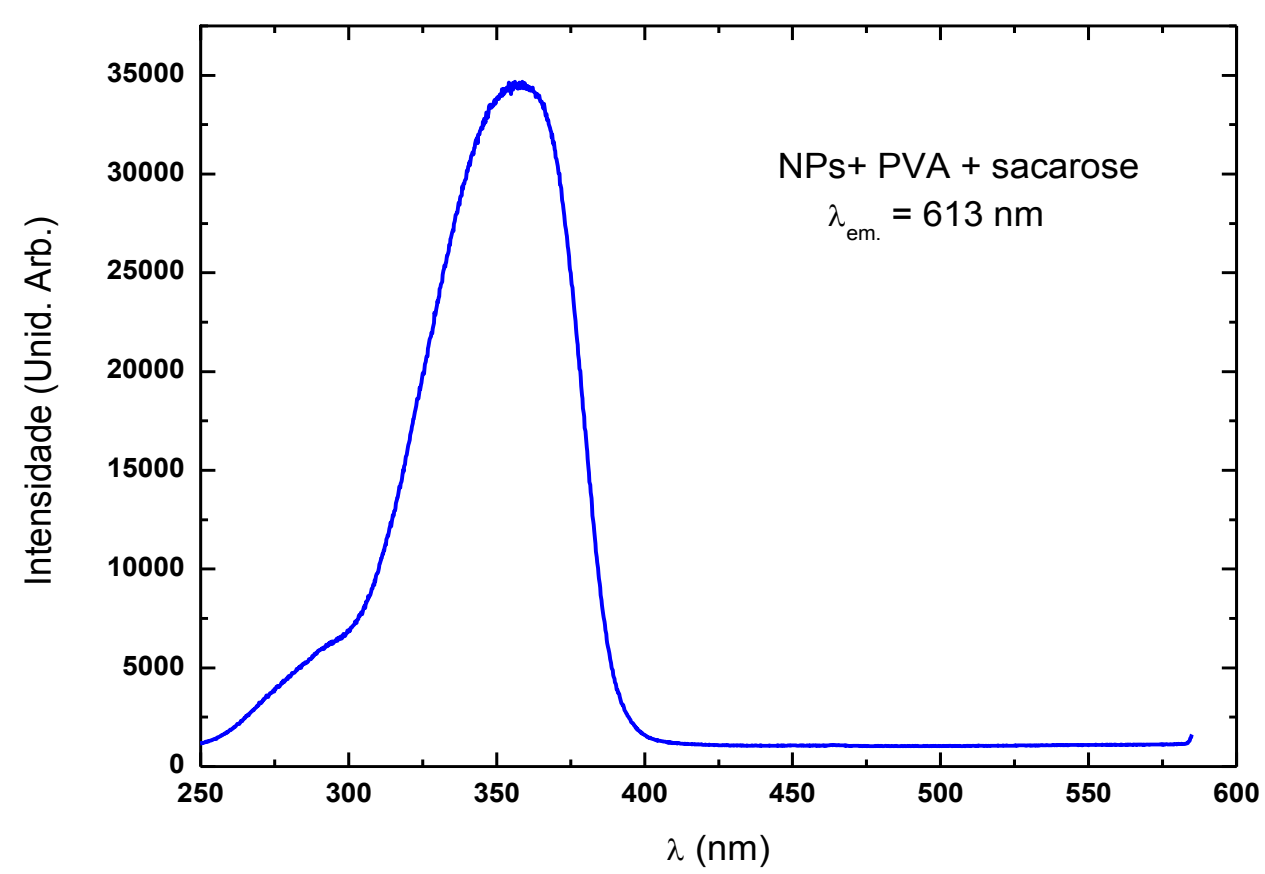

FIGURA $5.89 \quad$ - $\quad$ Espectro de excitação das NPs $\mathrm{PHB}:\left[\mathrm{Eu}(\mathrm{tta})_{3}(\mathrm{TOPO})_{2}\right]+\mathrm{PVA}+$ sacarose à temperatura ambiente e sob emissão em $613 \mathrm{~nm}$.

Enquanto que o espectro de emissão (FIG. 5.90) foi obtido com excitação via banda do ligante $S 0 \rightarrow S 1(\sim 350 \mathrm{~nm})$ no intervalo de 450 a $800 \mathrm{~nm}$, correspondente às transições intraconfiguracionais ${ }^{5} \mathrm{D}_{0} \rightarrow{ }^{7} \mathrm{~F}_{0-4}$. 


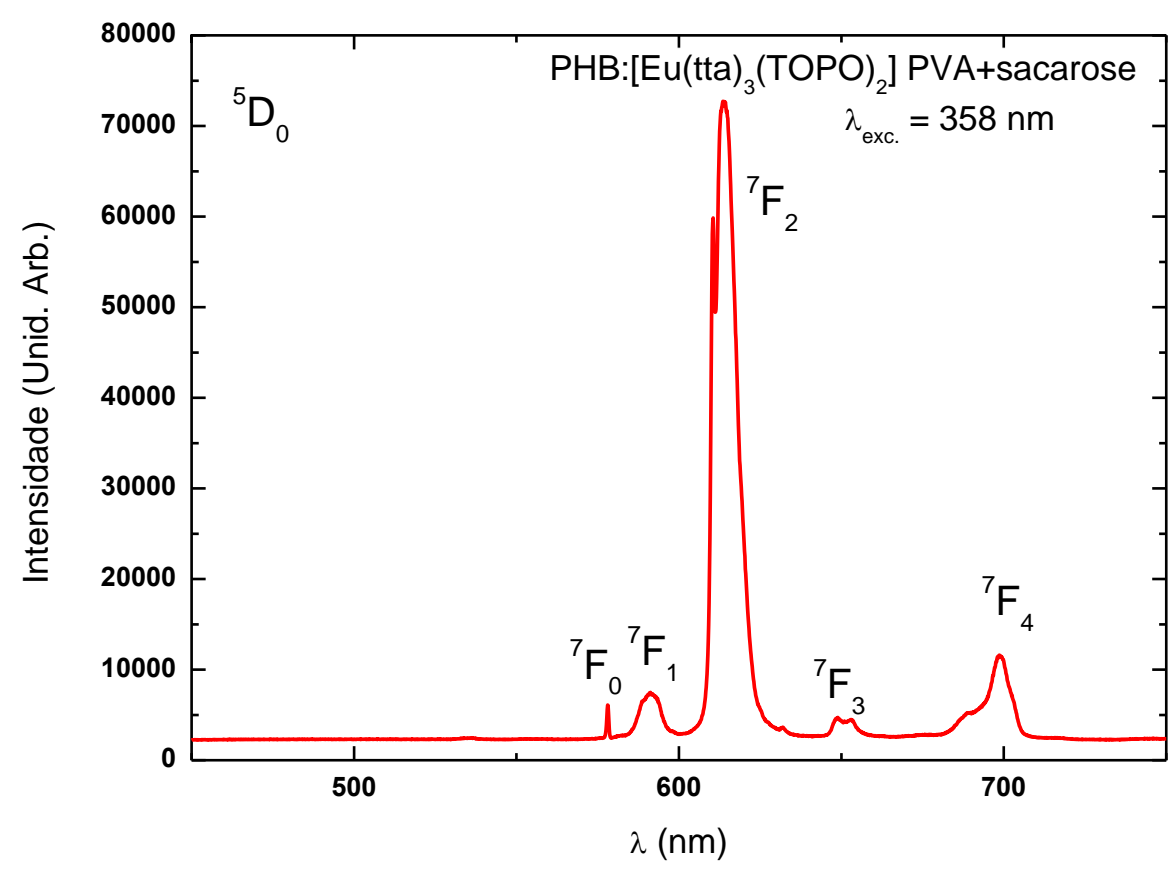

FIGURA 5.90 - Espectro de emissão das nanopartículas PHB: $\left[\mathrm{Eu}(\mathrm{tta})_{3}(\mathrm{TOPO})_{2}\right] \mathrm{PVA}+$ sacarose à temperatura ambiente e sob excitação em $358 \mathrm{~nm}$.

\subsubsection{Teste do Efeito Tyndall}

A observação da existência do efeito Tyndall na solução contendo nanopartículas poliméricas PHB:[Eu(tta) $\left.)_{3}(\mathrm{TOPO})_{2}\right]+$ Tween20 e PHB:[Eu(tta $\left.)_{3}(\text { TOPO })_{2}\right]+P V A+$ sacarose foi realizada incidindo um feixe de laser nas amostras. Houve uma nítida diferença entre a amostra contendo água (FIG. 5.91 a) e FIG. 5.92 a)) e as amostras contendo as partículas provenientes dos sistemas estudados (FIG. 5.91 b) e FIG. 5.92 b)). As soluções contendo as amostras de NPs foram centrifugadas a $3000 \mathrm{rpm}$ por 10 minutos e o sobrenadante resultante da centrifugação foi exposto ao feixe de laser, as amostras contendo as NPs demonstraram refração da luz, resultado positivo ao efeito Tyndall. 

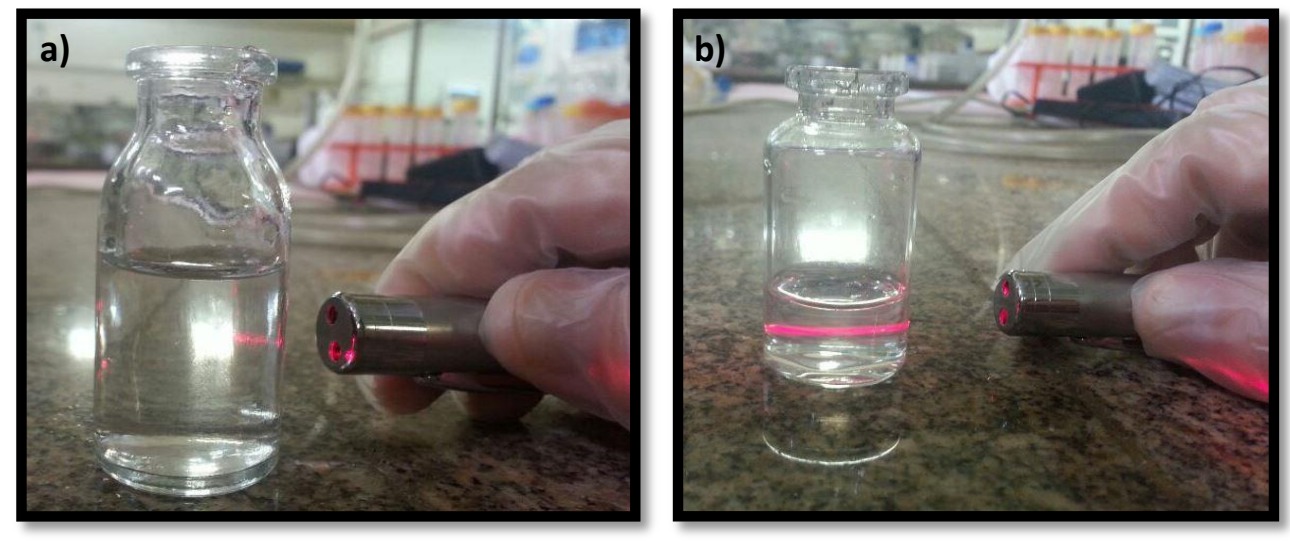

FIGURA 5.91 - Teste do Efeito Tyndall das amostras a) $\mathrm{H}_{2} \mathrm{O}$;

b) PHB:[Eu(tta) $\left.)_{3}(\mathrm{TOPO})_{2}\right]+$ Tween 20 .
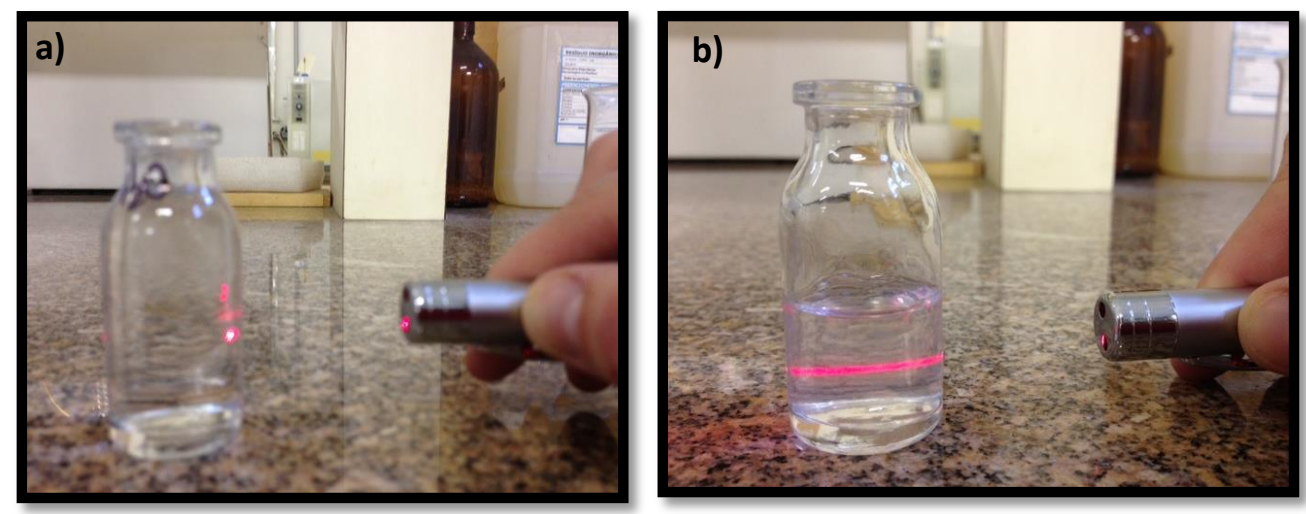

FIGURA 5.92 - Teste do Efeito Tyndall das amostras a) $\mathrm{H}_{2} \mathrm{O}$;

b) $\mathrm{PHB}:\left[\mathrm{Eu}(\mathrm{tta})_{3}(\mathrm{TOPO})_{2}\right]+\mathrm{PVA}+$ sacarose

\subsection{Funcionalização das nanopartículas poliméricas para aplicações na} área biológica

Os tipos de partículas utilizadas em aplicações biológicas são extremamente variadas. Na maioria das vezes, elas são de natureza não porosa e esférica na forma. No entanto, a revolução na ciência dos materiais em nanotecnologia tem proporcionado tipos de partículas e composições de forma e tamanho quase ilimitado, incluindo partículas esféricas, amorfas, ou agregadas, bem como formas geométricas elaboradas como barras, tubos, cubos, triângulos, e cones.

Partículas poliméricas podem ser construída a partir de um número de diferentes monômeros ou combinações de copolímero. Algumas das mais 
comuns incluem poliestireno ( tradicionais partículas " látex " ), poli ( estireno / divinilbenzeno ), copolímeros de poli ( estireno / acrilato ), copolímeros de polimetilmetacrilato (PMMA), poli ( hidroxietil metacrilato ) ( pHEMA ), poli (viniltolueno), poli (estireno / butadieno) copolímeros, e poli (estireno / viniltolueno) copolímeros. Além disso, através da mistura para as combinações de reação de polimerização de monômeros funcionais, pode-se criar os grupos reativos ou funcionais na superfície da partícula para o acoplamento subsequente por afinidade de ligantes. .

Para serem usadas em biomarcação as partículas desenvolvidas neste trabalho precisaram ser funcionalizadas com um agente homobifuncional, que contém o mesmo grupamento nas suas extremidades, no caso foi usado a 1,6hexadiamina. Um dos grupamentos aminicos ligando-se a partícula polimérica e o outro ficando na outra extremidade para se ligar a um espaçador que no nosso caso foi o glutaraldeido.

Neste trabalho foram funcionalizadas as nanoparticulas descritas a seguir:

$\checkmark$ Nanopartículas obtidas pelo método de precipitação crioscópica

- PMMA:0,5\%[Eu(tta) $\left.)_{3}(\text { TOPO })_{2}\right]$,

- PMMA:5\%[Eu(tta) $\left.)_{3}(\mathrm{TOPO})_{2}\right]$,

○ PMMA:7\%[Eu(tta) $\left.)_{3}(\text { TOPO })_{2}\right]$

○ PHB:3\%[Eu(tta) $\left.)_{3}(\mathrm{TOPO})_{2}\right]$.

$\checkmark$ Nanopartículas do tipo core @shell produzidas pela técnica de emulsão-difusão.

○ (PHB:[Eu(tta) $\left.)_{3}(\mathrm{TOPO})_{2}\right]+\mathrm{PVA}+$ sacarose $)-$ 


\subsubsection{Características qualitativas}

\subsubsection{NPs PHB e PMMA produzidas pela técnica de nanoprecipitação}

As NPs foram funcionalizadas usando a técnica de Fixe et al. [72] descrita no item 4.2.7 deste trabalho. As nanopartículas funcionalizadas NPFs, foram obtidas como sólidos cristalinos brancos, mantendo sua alta intensidade luminescente quando submetidas à irradiação ultravioleta, como mostra a FIG. 5.93 .
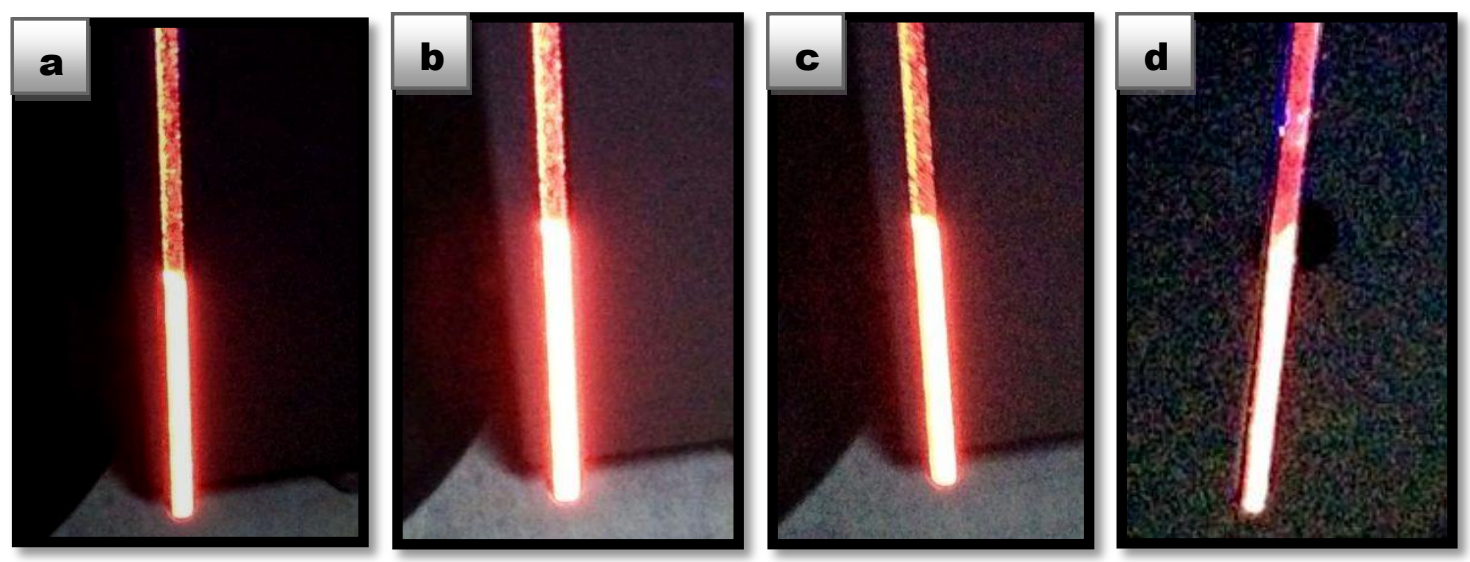

FIGURA 5.93 - Fotografias das NPs PMMA e PHB amino-funcionalizadas sob

irradiação ultravioleta,

PMMA:5\%[Eu(tta) $\left.)_{3}(\mathrm{TOPO})_{2}\right]$,

$\mathrm{PHB}: 3 \%\left[\mathrm{Eu}(\mathrm{tta})_{3}(\mathrm{TOPO})_{2}\right]$. a) PMMA:0,5\%[Eu(tta $\left.)_{3}(\mathrm{TOPO})_{2}\right]$,

c) PMMA:7\%[Eu(tta $\left.)_{3}(\mathrm{TOPO})_{2}\right]$ e

\subsubsection{NPs funcionalizadas de PHB produzidas pela técnica de emulsão-} difusão

As NPs produzidas pela técnica de emulsão-difusão também foram funcionalizadas pela técnica de Fixe et al. ${ }^{[72] \text { e }}$ foram obtidas como sólidos cristalinos brancos com alta intensidade luminescente quando submetidas à irradiação ultravioleta. Na FIGURA 5.94 é apresentada a fotografia da NPFs funcionalizadas contendo PVA e sacarose. 


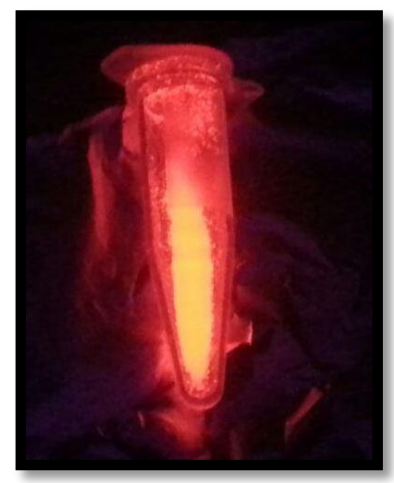

FIGURA 5.94 - Nanopartículas poliméricas de PHB aminofuncionalizadas (PHB: $\left[\mathrm{Eu}(\mathrm{tta})_{3}(\mathrm{TOPO})_{2}\right]+\mathrm{PVA}+$ sacarose)-amina quando submetidas a radiação UV.

\subsubsection{Espectroscopia de Infravermelho por Transformada de Fourier (FTIR)}

Todas as amostras aminofuncionalizadas deste trabalho foram analisadas para comprovar a efetividade da funcionalização via espectroscopia de infravermelho. Será apresentado apenas o resultado da análises por FTIR de uma das amostras para efeito ilustrativo.

A FIGURA 5.95 mostra os espectros de absorção na região do infravermelho das partículas de PMMA dopadas com 0 complexo $\left[\mathrm{Eu}(\mathrm{tta})_{3}(\mathrm{TOPO})_{2}\right]$ em concentração mássica de 0,5\% funcionalizadas com 1,6 diamino-hexano. A funcionalização foi comprovada pelas bandas de deformação $\delta \mathrm{N}-\mathrm{H}$ que aparecem na região de $1640-1560 \mathrm{~cm}^{-1}$ para o 1,6 hexanodiamina e na partícula funcionalizada em 1591-1454 cm-1, e também da deformação fora do plano $\delta \mathrm{N}-\mathrm{H}$ próximo a $800 \mathrm{~cm}^{-1}$ para 1,6 hexanodiamina livre que se desloca para região de maior energia $844 \mathrm{~cm}^{-1}$ no material funcionalizado. Assim como observado nas FIGURAS 5.96b, 5.96c e 5.96d

para as partículas PMMA:5\%[Eu(tta) $\left.)_{3}(\mathrm{TOPO})_{2}\right]$ amina; $\mathrm{PHB}: 3 \%\left[\mathrm{Eu}(\mathrm{tta})_{3}(\mathrm{TOPO})_{2}\right]$ amina e $\mathrm{PHB}: 3 \%\left[\mathrm{Gd}(\mathrm{tta})_{3}(\mathrm{TOPO})_{2}\right]$ amina, respectivamente. 


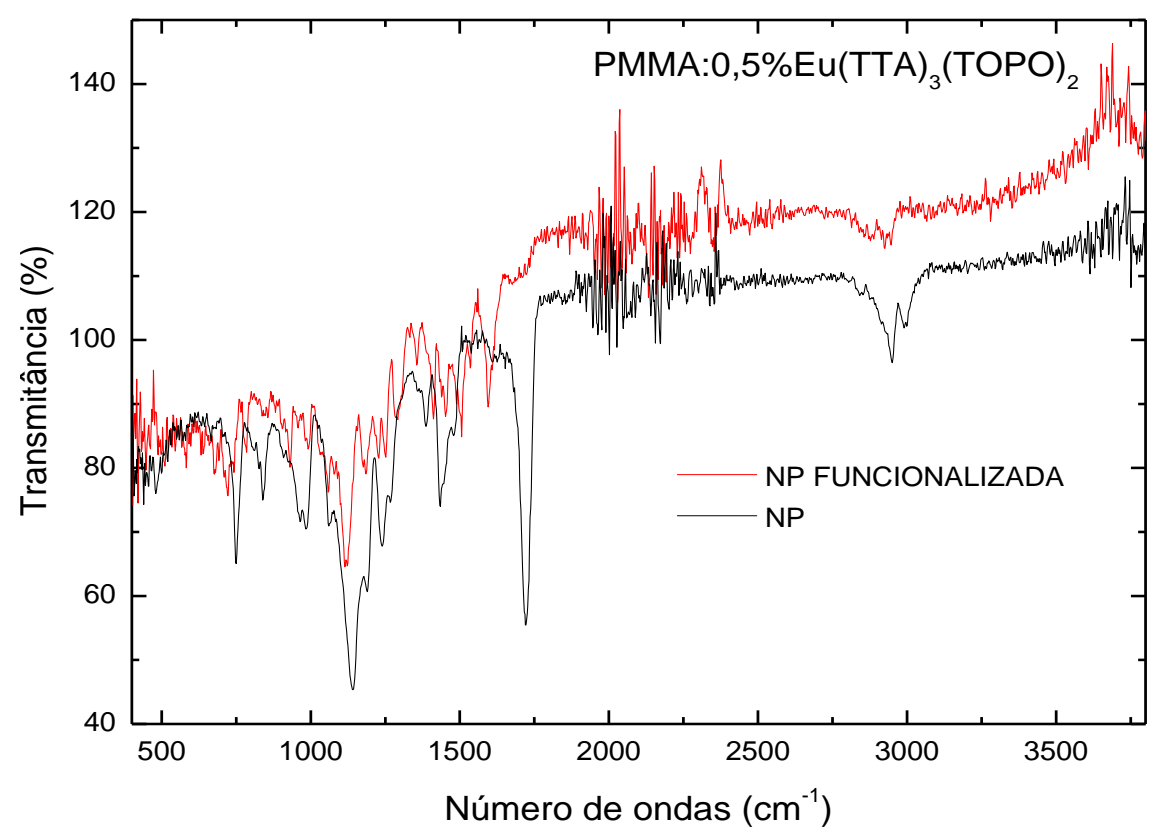

FIGURA 5.95 - Espectros de absorção no infravermelho registrados à temperatura ambiente no intervalo de 4000 a $400 \mathrm{~cm}^{-1}$, do sistema PMMA:0,5\%[Eu(tta $\left.)_{3}(\mathrm{TOPO})_{2}\right]$ aminofuncionalizado e não aminofuncionalizado. 

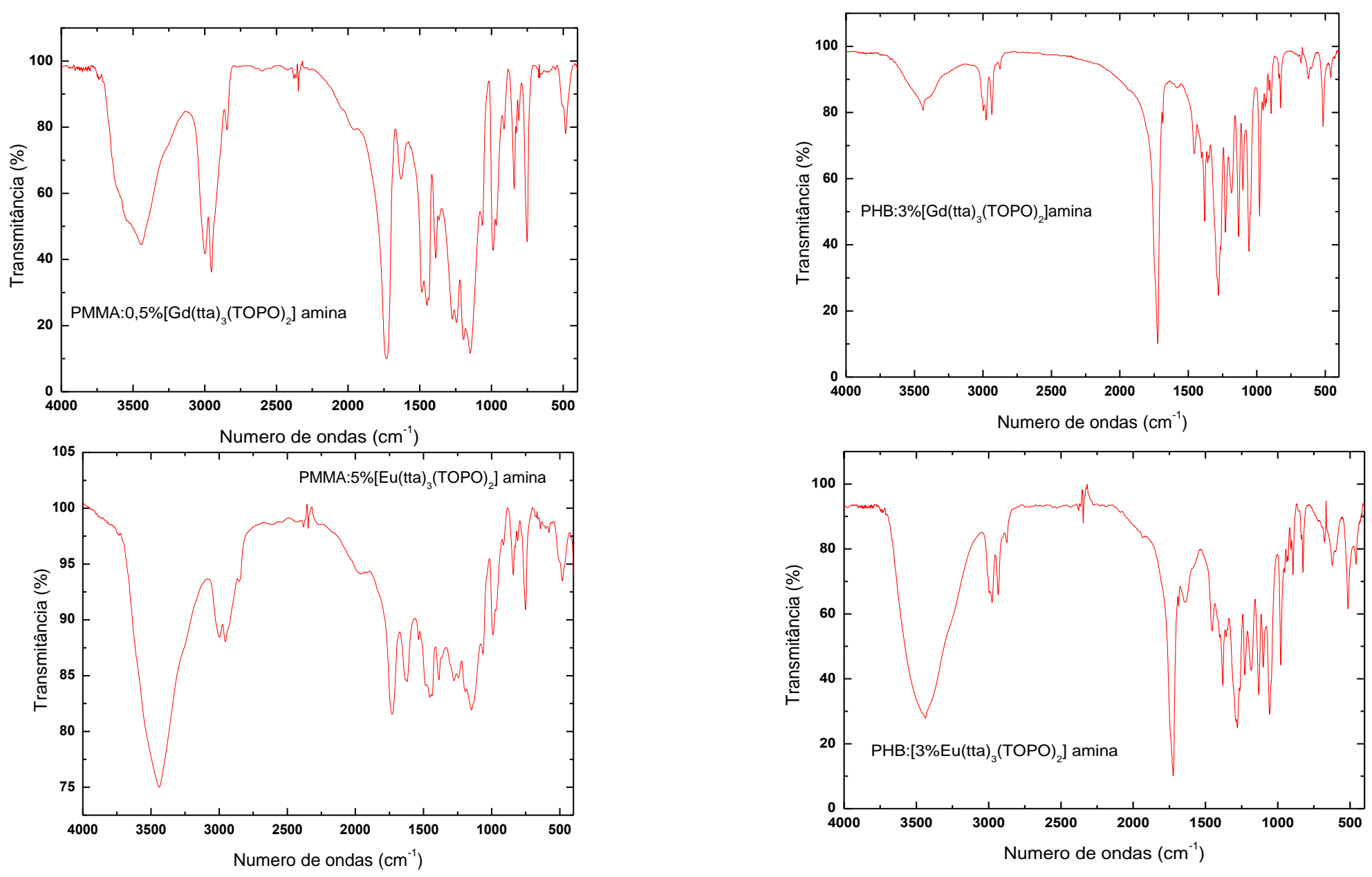

FIGURA 5.96 - Espectros de absorção no infravermelho registrado à temperatura ambiente no intervalo de 400 a $4000 \mathrm{~cm}^{-1}$, dos sistema PMMA:0,5\%[Gd(tta) $\left.)_{3}(\mathrm{TOPO})_{2}\right] ; \quad \mathrm{PMMA}: 5 \%\left[\mathrm{Eu}(\mathrm{tta})_{3}(\mathrm{TOPO})_{2}\right] \quad ; \mathrm{PHB}: 3 \%\left[\mathrm{Gd}(\mathrm{tta})_{3}(\mathrm{TOPO})_{2}\right]$ e PHB:3\%[Eu(tta)$\left.)_{3}(\mathrm{TOPO})_{2}\right]$ aminofuncionalizadas 


\subsubsection{Difratometria de Raios X (DRX)}

A FIGURA 5.97 mostra os difratogramas de raios $X$ das NPs PMMA:5\% $\left[\mathrm{Eu}(\mathrm{tta})_{3}(\mathrm{TOPO})_{2}\right]$ obtidas pelo método de crioscopia e aminofuncionalizadas e não funcionalizadas. Como mostram os difratogramas não foi possível observar quaisquer diferenças no perfil dos difratogramas de raios $X$ (método do pó) após a funcionalização das NPs.

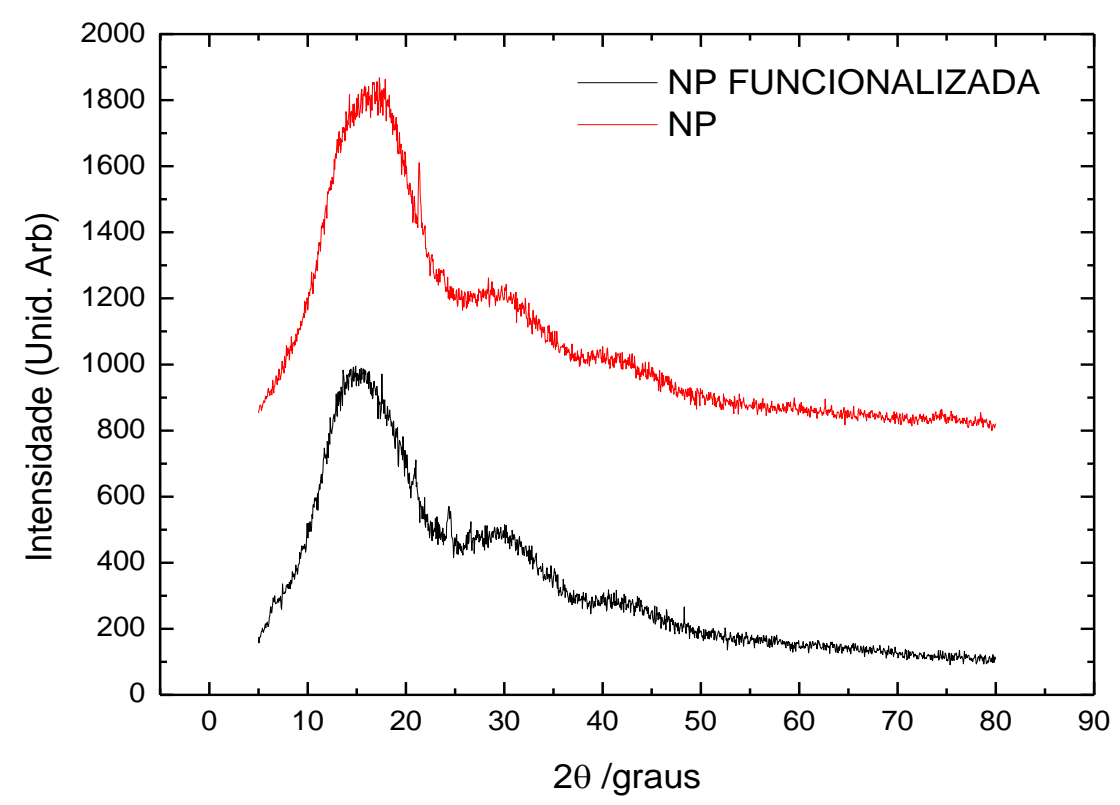

FIGURA 5.97 - Difratogramas de raios X (método de pó) das nanopartículas poliméricas de PMMA: $5 \%\left[\mathrm{Eu}(\mathrm{tta})_{3}(\mathrm{TOPO})_{2}\right]$ funcionalizadas e não funcionalizadas.

\subsubsection{Estudo de Luminescência}

\subsubsection{Investigação a partir dos Espectros de Excitação e Emissão NPs} Aminofuncionalizadas Produzidas pelo Método de Nanoprecipitação

O estudo de luminescência das amostras funcionalizadas foi feito com base nos espectros de excitação e emissão registrados a temperatura 
ambiente ( 298 K). Os espectros de excitação das NPs PMMA:0,5\% $\left[\mathrm{Eu}(\mathrm{tta})_{3}(\mathrm{TOPO})_{3}\right.$ aminofuncionalizadas (FIGs. 5.98 a 5.100) foram registrados no intervalo de 250 a $600 \mathrm{~nm}$, com emissão monitorada na transição hipersensível ${ }^{5} \mathrm{D}_{0} \rightarrow{ }^{7} \mathrm{~F}_{2}(\sim 614 \mathrm{~nm})$, apresentando uma banda larga atribuída ao ligante TTA e TOPO $\mathrm{S}_{0^{-}} \mathrm{S}_{1}$ e com máximo em $\sim 380 \mathrm{~nm}$ e transições intraconfiguracionais características ${ }^{7} \mathrm{~F}_{0}-{ }^{5} \mathrm{D}_{2}$ em $\sim 464 \mathrm{~nm} \mathrm{e}{ }^{7} \mathrm{~F}_{0}-{ }^{5} \mathrm{D}_{1}$ em $\sim 535 \mathrm{~nm}$. Já os espectros de emissão ((FIGs. 5.98 b à $\mathbf{5 . 1 0 0}$ b) foram obtidos com excitação via banda do ligante $(\sim 380 \mathrm{~nm})$ no intervalo de 420 a $720 \mathrm{~nm}$, correspondente às transições intraconfiguracionais ${ }^{5} D_{0} \rightarrow{ }^{7} F_{J}(J=1-4)$.

Na FIGURA 5.101 apresentam-se os espectros de emissão, das NPs $\mathrm{PHB}: 3 \%\left[\mathrm{Gd}(\mathrm{tta})_{3}(\mathrm{TOPO})_{3} \quad\right.$ e $\quad \mathrm{PHB}:\left[\mathrm{Eu}(\mathrm{tta})_{3}(\mathrm{TOPO})_{3}+\mathrm{PVA}+\right.$ sacarose aminofuncionalizadas. $O$ espectro da NPF $\mathrm{PHB}:\left[\mathrm{Eu}(\mathrm{tta})_{3}(\mathrm{TOPO})_{3}+\mathrm{PVA}+\right.$ sacarose tem perfil semelhante aos das NPFs obtidas pelo método de precipitação por crioscopia. Já o espectro da nanoparticula aminofuncionalizada do PHB:3\%[Gd(tta $)_{3}(\mathrm{TOPO})_{3}$ tem perfil semelhante as partículas não funcionalizadas e apresenta energia do estado tripleto medido na região da zero fônon igual a $21670 \mathrm{~cm}^{-1}$. 

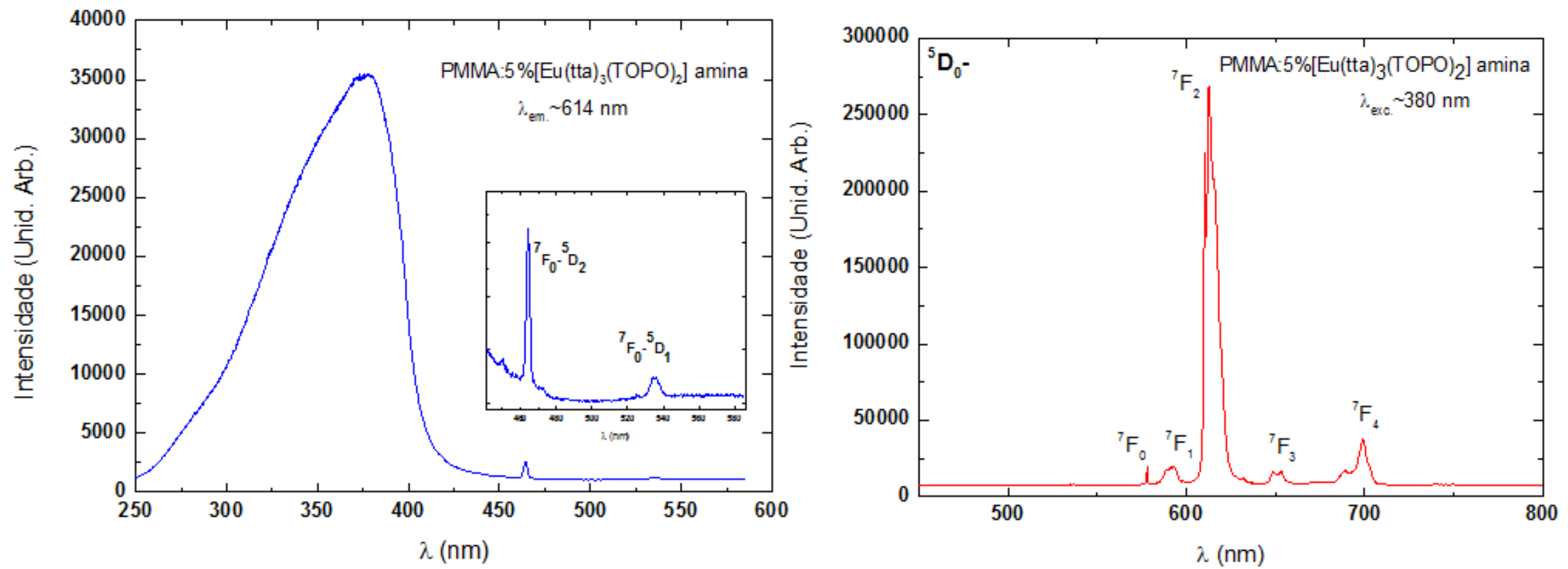

FIGURA 5.98 - Espectro de excitação e emissão das NPs aminofuncionalizadas PMMA:5\%[Eu(tta) $\left.)_{3}(\mathrm{TOPO})_{2}\right]$, à temperatura ambiente. 

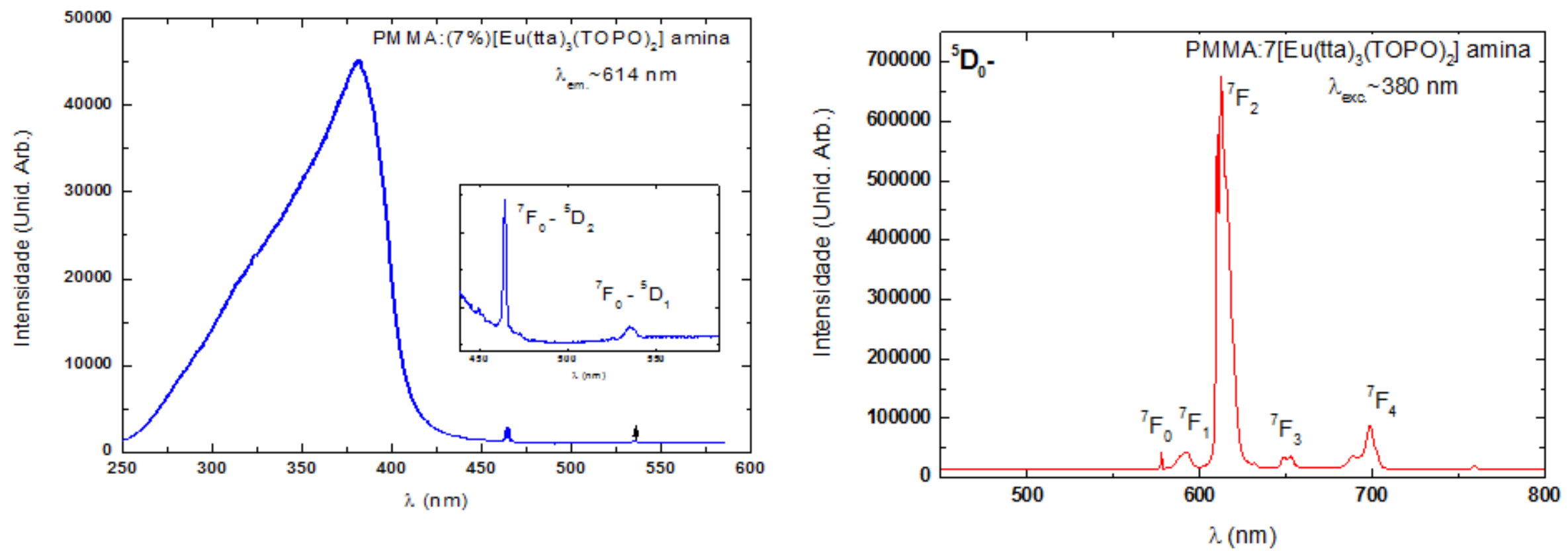

FIGURA 5.99 - Espectro de excitação e emissão das NPs aminofuncionalizadas PMMA:7\%[Eu(tta) $\left.)_{3}(\mathrm{TOPO})_{2}\right]$, à temperatura ambiente. 

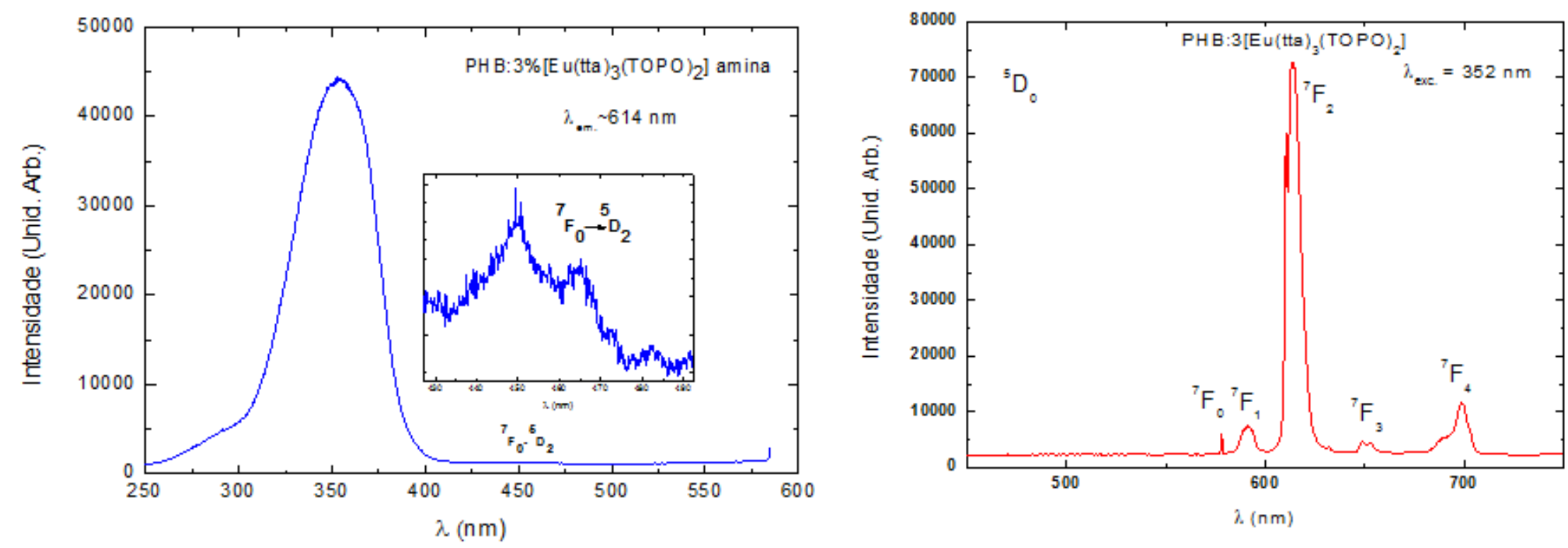

FIGURA 5.100 - Espectro de excitação e emissâo das NPs aminofuncionalizadas PHB:3\%[Eu(tta) $\left.)_{3}(\mathrm{TOPO})_{2}\right]$, à temperatura ambiente. 

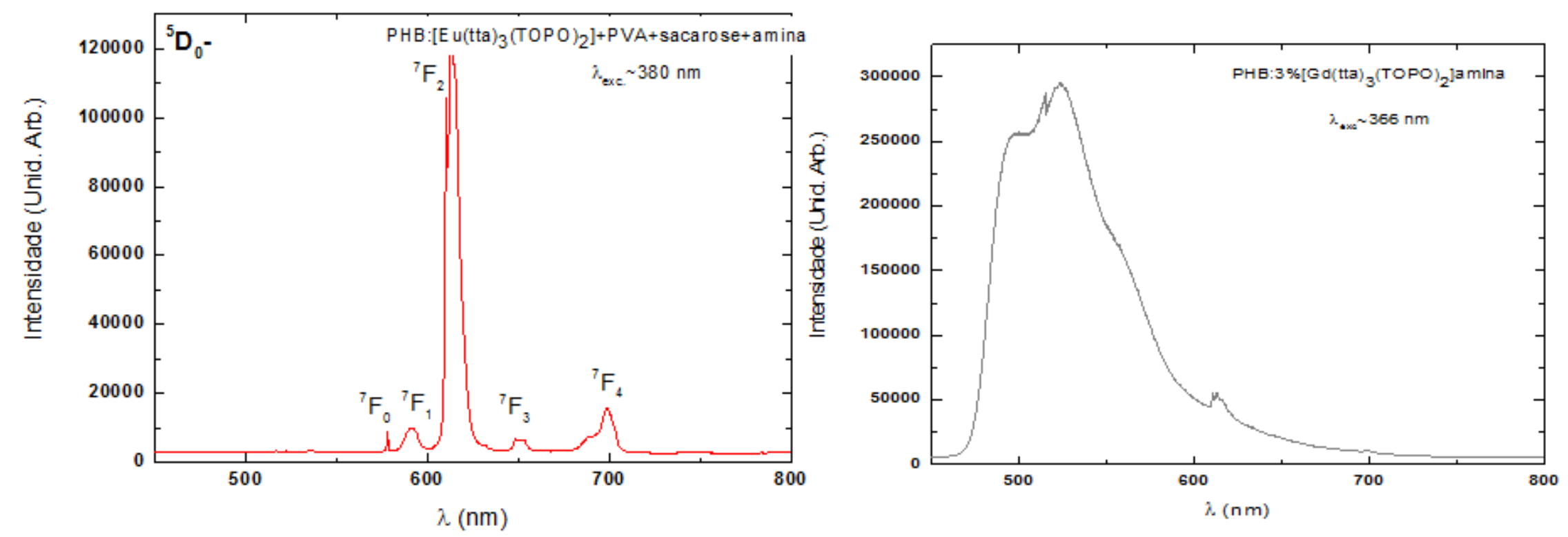

FIGURA 5.101 - Espectro de emissão das NPs aminofuncionalizadas PHB:3\%[Eu(tta) $\left.)_{3}(\mathrm{TOPO})_{2}\right]$ e PHB:3\%[Gd(tta) $\left.)_{3}(\mathrm{TOPO})_{2}\right]$, à temperatura ambiente, no intervalo de 400 a 800 nm, e com excitação em 380 e 360 nm respectivamente. 


\subsubsection{Determinação de Aminas Primárias - Método da Ninidrina}

Para a detecção e quantificação dos grupamentos de aminas primárias na superfície das nanopartículas aminofuncionalizadas foi utilizado o método da ninidrina, como descrito no item 4.2.7.

\subsubsection{Curva Padrão}

As leituras de absorbância foram realizadas a $570 \mathrm{~nm}$, que corresponde ao $\lambda_{\max }$ do cromóforo Ruhemann de coloração azul-violácea ${ }^{[76]}$. A partir destes dados foi contruída uma curva padrão de concentração da glicina, como material de referência, conforme mostra a FIGURA 5.102.

Foram consideradas para construção da curva sete concentrações de glicina:[água $(\mathrm{mL})$, são elas: 0:10; 0,5:9,5; $1: 9 ; 2: 8 ; 4: 6 ; 5: 5 ; 7,5: 2,5]$.

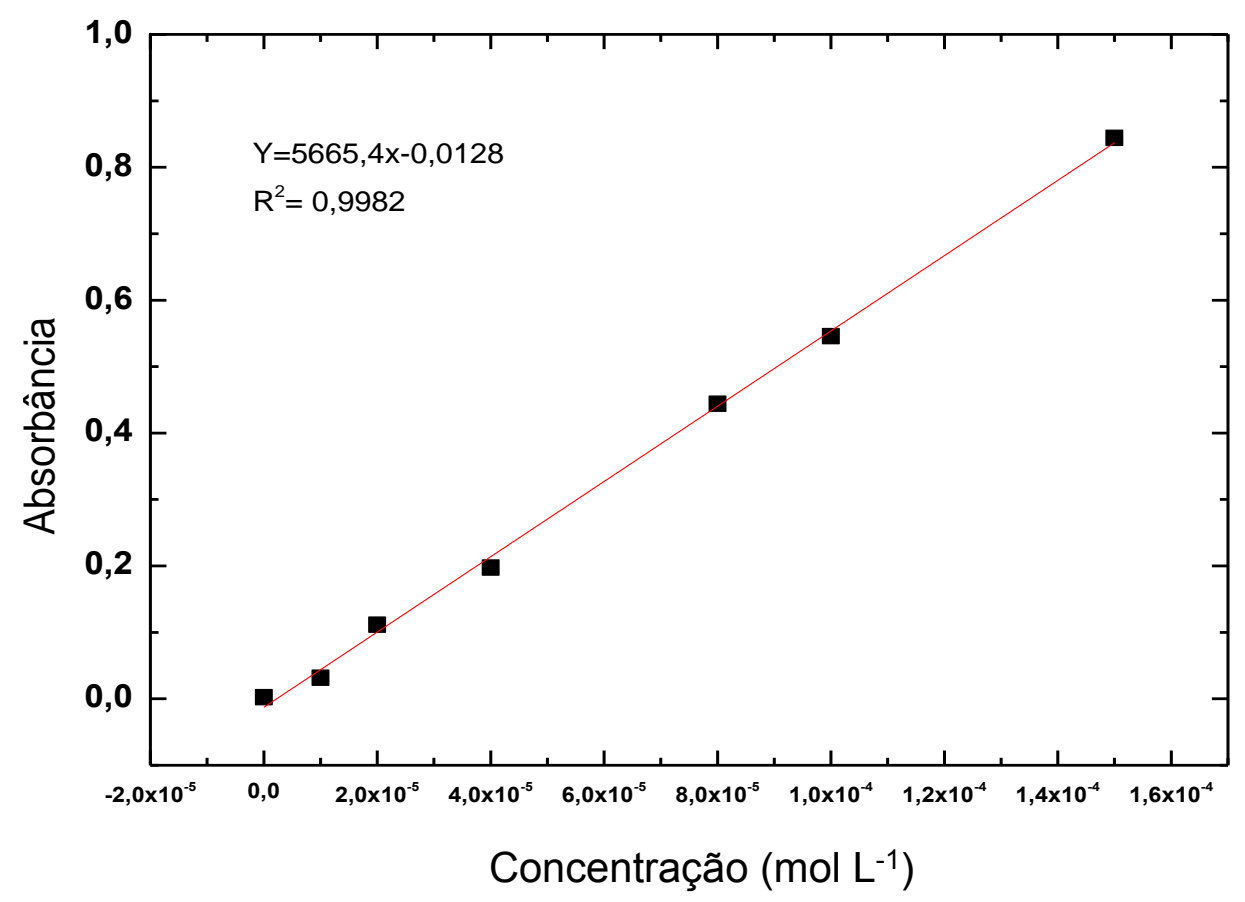

FIGURA 5.102 - Curva padrão construída a partir da concentração de glicina com absorbância medida em $570 \mathrm{~nm}$. 
As nanopartículas funcionalizadas reagiram com a ninidrina, apresentando cor violeta, indicando a presença de aminas primárias na superfície da nanopartícula, portanto, pode-se afirmar que a funcionalização foi efetiva e que as nanopartículas apresentam grupamentos de aminas primárias na superfície. Com isso, a aplicação destas nanopartículas como marcadores luminescentes de espécies biológicas torna-se viável. Estes materiais também foram submetidos à conjugação com glutaraldeído, para verificar a disponibilidade destas aminas primárias para reações biológicas.

A TABELA 5.22 apresenta os resultados obtidos na quantificação de aminas primárias das nanopartículas aminofuncionalizadas antes da reação com o espaçador glutaraldeído, observa-se a quantidade (mmol $\mathrm{mg}^{-1}$ ) de grupamentos amina identificada em cada amostra, indicando efetiva ligação das aminas pelo método de funcionalização utilizado, com alta porcentagem de de $\mathrm{NH}_{2}$ disponível para a interação com o espaçador glutaraldeído.

A TABELA 5.23 apresenta os resultados obtidos na quantificação de aminas primárias das nanopartículas após a reação com o espaçador glutaraldeído. A coluna 3 mostra a porcentagem de $\mathrm{NH}_{2}$ que interagiu com 0 espaçador glutaraldeído, indicando que as nanopartículas estudadas atuam como potenciais candidatos a marcadores biológicos luminescentes 
TABELA 5.22 - Concentração de aminas primárias das nanopartículas aminofuncionalizadas antes da reação com o glutaraldeído, em mmol mg-1, determinadas pelo método da ninidrina.

\begin{tabular}{lcc}
\hline \multicolumn{1}{c}{$\mathrm{NPs}$} & $\boldsymbol{\mu m o l \mathbf { N H } _ { 2 } \mathbf { ~ m g } ^ { - 1 }}$ & Desvio Padrão \\
\hline PMMA:0,5\%[Eu(tta $\left.)_{3}(\mathrm{TOPO})_{2}\right]$ & 21,45 & 4,97 \\
PMMA:5\%[Eu(tta $\left.)_{3}(\mathrm{TOPO})_{2}\right]$ & 12,90 & 5,18 \\
PMMA:7\%[Eu(tta $\left.)_{3}(\mathrm{TOPO})_{2}\right]$ & 6,44 & 0,12 \\
PHB:3\%[Eu(tta $\left.)_{3}(\mathrm{TOPO})_{2}\right]$ & 17,98 & 1,30 \\
PHB:[Eu(tta $\left.)_{3}(\mathrm{TOPO})_{2}\right]-P V A-$ & 7,02 & 1,26 \\
sacarose & & \\
\hline
\end{tabular}

TABELA 5.23 - Concentração de aminas primárias das nanopartículas aminofuncionalizadas após a reação com o glutaraldeído, em $\mathrm{mmol} \mathrm{mg}^{-1}$, determinadas pelo método da ninidrina.

\begin{tabular}{|c|c|c|c|}
\hline NPs & $\mu \mathrm{molNH} \mathrm{mg}_{2} \mathrm{~m}^{-1}$ & $\begin{array}{l}\text { Desvio } \\
\text { Padrão }\end{array}$ & $\% \mathrm{NH}_{2}$-GLU \\
\hline PMMA:0,5\%[Eu(tta $\left.)_{3}(\mathrm{TOPO})_{2}\right]$ & 2,45 & 1,65 & 88,6 \\
\hline PMMA:5\%[Eu(tta $\left.)_{3}(\mathrm{TOPO})_{2}\right]$ & 1,46 & 0,55 & 88,7 \\
\hline PMMA:7\%[Eu(tta $\left.)_{3}(\mathrm{TOPO})_{2}\right]$ & 0,70 & 1,96 & 89,2 \\
\hline PHB:3\%[Eu(tta) $\left.)_{3}(\mathrm{TOPO})_{2}\right]$ & 3,54 & 1,46 & 80,3 \\
\hline $\begin{array}{l}\left.\text { PHB:[Eu(tta })_{3}(\mathrm{TOPO})_{2}\right] \text {-PVA- } \\
\text { sacarose }\end{array}$ & 4,49 & 0,26 & 36,1 \\
\hline
\end{tabular}




\section{REFERÊNCIAS BIBLIOGRÁFICAS}

[1] KAI, J. Desenvolvimento de sistemas luminescentes à base dos polímeros PHB e PMMA dopados com complexos de terras raras. Tese de doutorado. Instituto de Química, Universidade de São Paulo, 2009.

[2] STRASSER, A.; VOGLER, A. Phosphorescence of gadolinium(III) chelates under ambient conditions. Inorganic Chim. Acta, 357, 2345-2348, 2004.

[3] LATVA, M.; TAKALO, H.; MUKALLA, V.M.; MATACHESCU, C.; RODRÍGUEZ-UBIS, J.C.; KANAKARE, J. Correlation between the lowest triplet state energy level of the ligand and lanthanide (III) luminescence quantum yield. J. Lumin., V. 75, p. 149-169, 1997.

[4] BINNEMANS, K. Handbook on the Physics and Chemistry of Rare Earths; Gschneidner Jr., K. A.; Bünzli, J. -C. G.; Pecharsky, V. K., eds.; Elsevier: Amsterdam, , vol. 35, p. 107, 2005.

[5] RINEHART, R.W. Spectrophotometric of some rare earths and yttrium with Alizarine Red S. Anal. Chem.. v. 26, n.11, p. 1820-1822, 1954.

[6] WANG, X.; SUMMERS, C.J; WANG, Z. L. Large-scale hexagonal-patterned growth of aligned $\mathrm{ZnO}$ nanorods for nano-optoelectronics and nanosensor arrays. Nano Lett;4:423-6,2004.

[7] SABBATINI, N.; MECATI, A.; GUARDIGLI, M.; BALZANI, V.; LEHN, J.N.; ZIESSEL, R.; UNGARO, R. Lanthanide luminescence im supramolecular species. J. Lumin., v.48, p.463-468, 1991.

[8] WYBOURNE, B.G. Spectroscopy Properties of rare earths. New York: Interscience Publishers, 1965.

[9] HOLTZCLAW , H. F.; COLLMAN, P.J.Jr. A Normal Coordinate Treatment on Bis-(Acetylacetonato)-Cu(II). J. Am. Chem. Soc.,79, 3318, 1957. 
[10] NAKATO,Y.; TSUMURA, A.; DUBOW, M. Electrochim. Acta., 23, 1117, 1978.

[11] SILVA JR., FRANCISCO A. ; NASCIMENTO, HELENISE A. ; PEREIRA, DARISTON K. S. ; TEOTONIO, ERCULES E. S. ; BRITO, Hermi F. ; FELINTO, MARIA CLÁUDIA F. C. ; ESPÍNOLA, JOSÉ GERALDO P. ; SÁ, GILBERTO F. ; Faustino, Wagner M. . Energy Transfer Processes in $\mathrm{Tb}(\mathrm{III})$ Dibenzoylmethanate Complexes with Phosphine Oxide Ligands. J. Brazil. Chem. Soc. (Impresso) JcR, v. 00, p. XX-XX, 2013.

[12] TEOTONIO, E. E. S. ; BRITO, Hermi F. ; VIERTLER, Hans ; FAUSTINO, W M ; MALTA, O L ; SÁ, Gilberto F de ; FELINTO, Maria Cláudia França da Cunha ; SANTOS, R H A ; CREMONA, Marco . Synthesis and luminescent properties of $\mathrm{Eu}^{3+-}$ complexes with 2-acyl-1,3-indandionates (ACIND) and TPPO ligands: The first X-ray structure of Eu ACIND complex. Polyhedron scr, v. 25, p. 3488-3494, 2006.

[13] FELINTO, Maria Cláudia França da Cunha ; TOMIYAMA, C. S. ; BRITO, Hermi F. ; TEOTONIO, E. E. S. ; MALTA, O L . Synthesis and luminescent properties of supramolecules of $\beta$-diketonate of $\mathrm{Eu}(\mathrm{III})$ and crown ethers as ligands. J. Solid State Chem. ıск, United States, v. 171, n.1-2, p. 189-194, 2003.

[14] BRITO, Hermi F. ; MALTA, Orcar Loureiro ; FELINTO, Maria Cláudia França da Cunha ; TEOTONIO, E. E. S. ; MENEZES, J. F. S. ; SILVA, C. F. B. ; TOMIYAMA, C. S. ; CARVALHO, C. A. A. . Luminescence investigation of the Sm(III)-?-diketonates with sulfoxides, phosphine oxides and amides ligands. Journal of Alloys and Compounds scr, Elsevier Science B.V. New York, v. 344, n.1-2, p. 293-297, 2002.

[15] BRITO, H. F. ; MALTA, O L ; FELINTO, Maria Cláudia França da Cunha ; TEOTONIO, E. E. S. . Luminescence phenomena involving metal enolates. In: In: Editor Patai Series - - Jacob Zabicky. (Org.). (Org.). The Chemistry of 
Metal Enolates. Chichester- England: John Willey \& Sons Ltd,, 2009, v. Jacob, p. 131-184.

[16] GIBELLI, EDISON B. ; KAI, JIANG ; TEOTONIO, ERCULES E.S. ; MALTA, OSCAR L. ; Felinto, Maria C.F.C. ; BRITO, Hermi F. . Photoluminescent PMMA polymer films doped with Eu3+- $\beta$-diketonate crown ether complex. Journal of Photochemistry and Photobiology. A, Chemistry Jcr, v. 251, p. 154-159, 2013.

[17] DA SILVA, C.F.B. Eletroluminescência e fotoluminescência de $\beta$ dicetonatos de terras raras contendo ligantes sulfóxidos e fosfinóxidos. USP 2001 dissertação (MESTRADO) - Instituto de Química da Universidade de São Paulo, São Paulo.

[18] GIBELLI E.B. Preparação e caracterização de dispositivos eletroluminescentes de complexos de $\beta$-Dicetonatos de íons $\mathrm{Tb}^{3+}, \mathrm{Eu}^{3+}$, $\mathrm{Gd}^{3+}$ com ligantes macrocíclicos e fimes de $\mathrm{UO}_{2}{ }^{2+}$. Dissertação (MESTRADO) - IPEN -Universidade de São Paulo, 2010.

[19] QUIRINO, W. G. ; ADATI, R. D. ; LIMA, S. A. M. de ; LEGNANI, Cristiano ; JAFELICCI JUNIOR, M. ; DAVOLOS, M.R. ; CREMONA, M. . Electroluminescence of a device based on europium $\beta$-diketonate with phosphine oxide complex.. Thin Solid Films scr, v. 515, p. 927-931, 2006.

[20] DOLLIMORE, D. The application of thermal analysis in studying the thermal decomposition of solids. Thermochim. Acta, 1992, v.203, p.70.

[21] WENDLAND, W.W. Thermal Analysis - 3rd edition, Wiley, New York, 1986.

[22] BROWN, ME. Introduction to thermal analysis techniques and applications, Campany and Hall, London, 1988.

[23] HAINES, P.J. Thermal methods of analysis principles, applications and problems, Blackie Academic and Professional, Glasgow, 1995. 
[24] SHOEMAKER, D.; GARLAND, C., NIBLER, J.; Experiments in Physical Chemistry. $6^{\text {th }}$ Edition, McGraw Hill Co., New York, p. 472, 1996.

[25] AZÁROF, L.V., Elements of X-ray Crystallography. McGraw Hill Co., Internation Student Edition, New York, cap. 6, p. 86, 1968.

[26] LADD, M.F.C.; PALMER, R.A. Structure determination by X-ray crystallography. Plenum Press, New York, 1977.

[27] KLUG, H.P.; ALEXANDER, L.E. X-ray diffraction procedures for polycrystalline and amorphous material. $2^{\text {nd }}$ edition, Wiley-Interscience Publication, New York, (1974).

[28] GLUSKER, J.P.; TRUEBLOOD, K.N. Crystal structure analysis. University Press, New York, 1972

[29] GOSDSTEIN, J. I.; NEWBURY, D. E.; ECHLIN, P.; JOY, D. C.; LYMAN, C. E.; LIFSHIN, E.; SAWYER, L.; MICHAEL, J. R. Scanning electron microscopy and X-ray microanalysis. 3 Ed. New York, N.Y.; Kluwer Academic, 2003.

[30] LI, B.; GU, Z.N.; LIN, J.H.; SU, M.Z. Acta Phys-Chim. Sin., 15, 794, 1999.

[31] LIAN, S.X.; SHI, P.T.; LI, C.Z.; ZHU, A.L.; MAO, X.G.; J. Rare Earths, 21, 68, 2003.

[32] BABIN, V.; KRASNIKOV, A.; MARES, J.A.; NIKL, M.; NITSCH, K.; SOLOVIEVA, N.; ZAZUBOVICH, S. Phys Status Solid A, 196, 484, 2003.

[33] DE SA, G.F.; MALTA, O.L.; DONEGA, C.D.; SIMAS, A.M.; LONGO, R.L.; SANTA-CRUZ, P.A.; SILVA, E.F. Coord. Chem. Rev., 196, 165, 2000. 
[34] BRITO, H. F.; MALTA, O. L.; FELINTO, M. C. F. C.; TEOTONIO, E. E. S. Luminescence phenomena involving metal enolates in The Chemistry of Metal Enolates, John Willey \& Sons Ltd. 2007. Em fase de correção.

[35] TEOTONIO, E.E.S. Síntese e investigação das propriedades fotoluminescentes de dispositivos moleculares conversores de luz (DMCL) de complexos dicetonatos de terras raras com ligantes amidas. Tese de Doutorado. Instituto de Química, Universidade de São Paulo, São Paulo, Brasil (2004).

[36] GUEDES, M. A. Comportamento Fotoluminescente dos Ânions Complexos tetrakis( $\beta$-dicetonatos) de ĺons Terras Raras - $\mathrm{Eu}^{3+}, \mathrm{Gd}^{3+}, \mathrm{Tb}^{3+}$ e $\mathbf{T m}^{3+}$. Tese de Doutorado, Instituto de Química, Universidade de São Paulo, São Paulo, Brasil, 2007.

[37] CARNALL W. T., GOODMAN G. L., RAJNAK K., RANA R. S. A Systematic Analysis of the Spectra of the Lanthanides Doped into Single-Crystal $\mathrm{LaF}_{3}$. Journal of Chemical Physics, 90(7), p. 3443-3457, 1989.

[38] BUNZLI J. C., CHOPPIN G. R. Lanthanide Probes in life. Chemical an Earth Sciences - Theory and Practice. Elsevier, Amsterdam. 1989.

[39] SILVA, F. A. Síntese e propriedades fotoluminescentes de complexos bis-dicetonatos de íons lantanídeos trivalentes com ligantes fosfinóxidos. Dissertação (Mestrado em Quimica) - Universidade Federal da Paraíba, Paraíba, 2011.

[40] SILVA, H.R.M. Complexos Luminescentes de Európio Trivalente Imobilizados em Vermiculitas Modificadas com 1-Metil-Imidazol. (Dissertação de Mestrado) Universidade Federal da Paraíba. João Pessoa, 2012.

[41] MA, Y.; WANG, H.; LIU, W.; WAN, Q.; XU, J. E TANG, Y. Microstructure, Luminescence, and Stability of a Europium Complex Covalently Bonded to an Attapulgite Clay. J. Phys. Chem. B; 113, 14139-14145, 2009. 
[42] WEN, X.; LI, M.; WANG, Y.; ZHANG, J.; FU, L.; HAO, R.; MA, Y.; AI, X. Colloidal nanoparticles of a europium complex with enhanced luminescent properties. Langmuir 24, 6932-6, 2008.

[43] HAGERMAN, M. E.; SALAMONE, S. J.; HERBST, R. W.; PAYEUR, A. L. Chem. Mater. 15, 443, 2003.

[44] MARTÍNEZ MARTÍNEZ, V.; LÓPEZ ARBELOA, F.; BANUELOS PRIETO, J.; LÓPEZ ARBELOA, I. Characterization of Rhodamine 6G Aggregates Intercalated in Solid Thin Films of Laponite Clay. 2 Fluorescence Spectroscopy. J. Phys. Chem. B, 109, 7443-7450, 2005.

[45] MALTA, O.L.; BRITO, H.F.; MENEZES, J.F.S.; GONÇALVES E SILVA, F.R.; ALVES Jr, S.; FARIAS Jr, F.S.; ANDRADE, A.V.M.; J. Lumin., 75, 255, 1997.

[46] COTTON, F.A. Chemical Application of Group Theory, WileyIntercience, New York, 1971.

[47] BUNZLI, J.-C.G. and CHOPPIN, G.R.; Eds. Lanthanide Probes in Life, Chemical and Earth Sciences - Theory and Practice. Elsevier, Amsterdam, 1989

[48] RICHARDSON, F.S. Terbium(III) and europium(III) ions as luminescent probes and stains for biomolecular systems. Chem Rev., 82:541-552, 1982.

[49] SASTRI, V. S.; BUNZLI, J. C.; RAO, V. R.; RAYUDU, G. V. S.; PERUMAREDDI, J. R. Modern Aspects of Rare Earths and Their Complexes. Elsevier, 2003.

[50] BUNZLI, J. C. G.; MORET E.; FOIRET, V.; SCHENK, K. J.; WANG, M. Z., JIN, L. P. Structural and Photophysical Properties of Europium(lii) Mixed Complexes with Beta-Diketonates and O-Phenanthroline. J. Alloys Comp., 207, p. 107-111, 1994 
[51] MALANDRINO, G.; BETTINELLI, M.; SPEGHINI, A.; FRAGALA, I. Europium "Second Generation" Precursors for Metal-Organic Chemical Vapor Deposition: Characterization and Optical Spectroscopy. European J. Inorg. Chem., (4), p. 1039-1044, 2001.

[52] BRITO, H. F.; MALTA, O. L.; FELINTO, M.; TEOTONIO, E. E. S.; MENEZES, J. F. S.; SILVA, C. F. B., et al. Luminescence Investigation of the Sm(III)-beta-diketonates with Sulfoxides, Phosphine Oxides and Amides Ligands. J. Alloys Comp., 344(1-2) p. 293-197, 2002.

[53] WANG, K. Z.; GAO, L. H.; HUANG, C. H. Optical Properties of the Highly Ordered Langmuir-Blodgett Film of a Strongly Luminescent Eu(III) Complex. J. Photochem. Photobiol. a-Chem.,156(1-3), p. 39-43, 2003.

[54] PEACOCK, R. D. The Intensities of Lanthanide $\boldsymbol{f} \leftrightarrow \boldsymbol{f}$ Transitions. Structure and Bonding. 22, p. 83, 1975.

[55] OFELT, G. S. Intensities of Crystal Spectra of Rare-Earth Ions. J. Chem. Phys.1962;37(3):511-520.

[56] JUDD, B. R. Optical Absorption Intensities of Rare-Earth Ions. Physical Review, 127(3), p. 750-761, 1962.

[57] MALTA, O. L.; CARLOS, L. D. Intensities of 4f-4f Transitions in Glass Materials. Quimica Nova, 26(6), p. 889-895, 2003.

[58] MALTA, O. L.; BRITO, H. F.; MENEZES, J. F. S.; SILVA, F.; ALVES, S.; FARIAS, F. S., et al. Spectroscopic Properties of a new Light-Converting Device $\mathrm{Eu}($ Thenoyltrifluoroacetonate)(3) 2(Dibenzyl Sulfoxide). A Theoretical Analysis Based on Structural Data Obtained from a Sparkle Model. J. Lumin., 75(3), p. 255-268, 1997. 
[59] BRITO, H. F. Propriedades Luminescentes dos Elementos do Bloco-f. Tese de Livre Docência. IQ-USP, São Paulo, 2000.

[60] ONO, Y.A. Eletroluminescent Displays. World Scientific, Singapura, 1995.

[61] CAPANEMA, S.P. Instrumentação e Controle de uma Estação de Tratamento de Água. Dissertação de mestrado. Universidade Federal de Minas Gerais, Belo Horizonte, 2004.

[62] GIBELLI, EDISON B. ; KAI, J. ; TEOTONIO, E. E.S. ; MALTA, O. L. ; FELINTO, M. C.F.C. ; BRITO, H. F. . Photoluminescent PMMA polymer films doped with Eu3+- $\beta$-diketonate crown ether complex. J. Photochem. Photobiol. A, Chem. scR, v. 251, p. 154-159, 2013.

[63] FORSTER, L. ; PARRA, D. F. ; KAI, J. ; BRITO, H. F. ; LUGAO, A. B. . Influence of gamma irradiation on photoluminescence properties of polycarbonate films doped with Eu3+- $\beta$-diketonate complex. Rad. Phys. Chem. JCR, v. 84, p. 47-50, 2012, 1993.

[64] KAI, J. ; FELINTO, M. C. F. C. ; NUNES, L. A. O. ; MALTA, O. L. ; BRITO, $H$. F. Intermolecular energy transfer and photostability of luminescencetuneable multicolour PMMA films doped with lanthanide ?-diketonate complexes. J. Mat. Chem. Jcr, p. 3796-3802, 2011.

[65] BRITO, H.F.; KAI, J.; STEFANI, R.; PARRA, D.F. Filmes bicolores, processo de preparo de $\beta$-dicetonatos de terras raras para os mesmos, processo de preparo dos mesmos, processo de preparo de sistema luminescente bicolor em forma de filme independente e método de identificação de objetos. Patent Number(s): P.I. 1.004.409-8. (2011).

[66] PARRA, D.F.: BRITO, H.F.; KAI, J.; LUGAO, A.B. Marcador óptico polimérico biodegradável para substratos biodegradáveis. Instituto de pesquisa e Energéticas e Nucleares (IPEN) e Universidade de São Paulo (USP). P.I. 0802426-0 , 2008. 
[67] KAI, J; PARRA, D.F.; BRITO, H.F. Polymer matrix sensitizing effect on photoluminescence properties of $\mathrm{Eu}^{3+}-\beta$-diketonate complex doped into poly- $\beta$ hydroxybutyrate (PHB) in film form. J. Mater. Chem., 18, 4549-4554 (2008).

[68] KODAIRA, C.A.; BRITO, H.F.; MALTA, O.L.; SERRA, O.A. Luminescence and energy transfer of the europium (III) tungstate obtained via the Pechini method. J. Lumin., v.101, p.11-21, 2003.

[69] FAUSTINO, W.M.; TERRA, I.A.A.; NUNES, L.A.O.; FELINTO, M.C.F.C.; BRITO, H.F.; MALTA, O.L. Temperature dependence of ligand-to-metal energy transfer rates in lanthanide complexes: the first direct experimental observation and theoretical modeling. J. Lumin., 137, 369-373, 2013.

[70] CAPANEMA, S.P. Instrumentação e Controle de uma Estação de Tratamento de Água. Dissertação de mestrado. Universidade Federal de Minas Gerais, Belo Horizonte, 2004.

[71] Efeito Tyndall. In Infopédia,Porto: Porto Editora, 2003-2010. (Consult. 2013-10-23). Disponível: http://www.infopedia.pt/\$efeito-tyndall

[72] FIXE, F.; DUFVA, M.; TELLEMAN, P.; CHRISTENSEN, C.B.V. Funcionalization of poly(methyl methacrylate) (PMMA) as a substrate for DNA microarrays. Nucl. Ac. Research, vol. 32, n.1, 2004.

[73] SOUTO, E. ; SEVERINO, P.; SANTANA, M. H. A. Preparação de Nanopartículas Poliméricas a partir de Polímeros Pré-Formados - Parte II. Polimeros, São Carlos, v. 22, n. 1, p. 101-106, 2012.

[74] GOTO, P. L. Desenvolvimento de nanopartículas poliméricas por polimerização in situ a partir de nanoemulsões produzidas por inversão de fases. 2011 - Tese (Mestrado) - Universidade Federal de Ouro Preto. 
[75] NEUfELD, R. J.; REIS, C. P.; RIBEIRO, A. J.; VEIGA, F. Nanoencapsulation I. Methods for preparation of drug-loaded polymeric nanoparticles. Nanomedicine: Nanotechnology, Biology, and Medicine, v. 2, p. 8-21, 2005. 


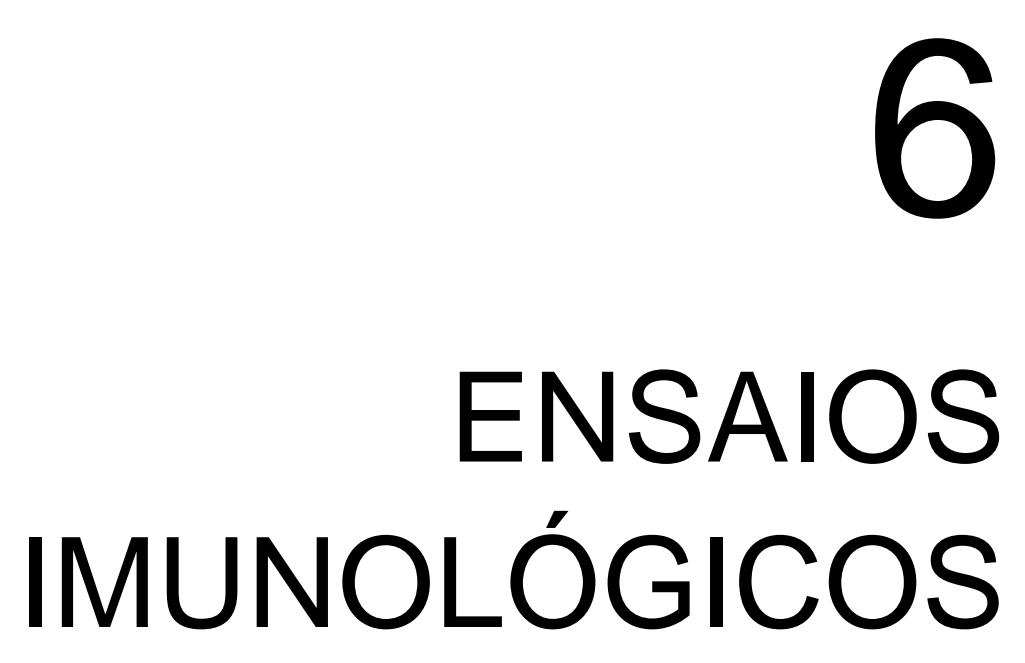


desconsiderar pagina 
desconsiderar pagina 
desconsiderar pagina 
desconsiderar pagina 


\section{ENSAIOS IMUNOLÓGICOS}

\subsection{Imunoensaios com Nanomarcadores Luminescentes à Base de Terras Raras}

Os testes imunológicos dependem da ligação de antígenos com anticorpos específicos. $\mathrm{O}$ anticorpo específico ao antígeno é sintetizado sob influência das características estruturais do antígeno em questão, sendo a capacidade de ligação do anticorpo com o antígeno que estimula sua síntese. Foram utilizados nos imunoensaios deste trabalho anticorpos específicos ao hormônio 17- $\beta$-estradiol, chamado no imunoensaio de antígeno. Como anticorpo de captura foi utilizado o IgG de espécie compatível ao anticorpo específico, formando uma cadeia de bioconjugação específica ao $17 \beta$-estradiol.

As nanopartículas poliméricas aminofuncionalizadas contendo complexo de $\mathrm{Eu}^{3+}$ foram aplicadas como potenciais candidatas a nanomarcadores luminescentes em sisttemas biológicos, neste caso, para a marcação da cadeia de bioconjugação específica ao $17 \beta$-estradiol.

A partir fa produção de uma hipótese, foram sintettizados os nanomarcadores luminescentes, escolhidos com base nos resultados das caracterizações dos materiais, evoluindo para biomarcadores luminescentes candidatos e, então, foi desenvolvido um protocolo para imunoensaio com o intuito de conjugar o nanomarcador ao sistema biológico de interesse deste trabalho. 
A utilização de um anticorpo de captura ( $\lg G$ ) na base da cadeia de reação imunológica desenvolvida tem o intuito de aumentar a especificidade do ensaio, uma reação denominada Ac-Ac-Ag. No entanto, o Ag ligado ao nanomarcador identifica a conjugação das espécies biológicas, específicas a ele, como apresentado na FIGURA 6.1.

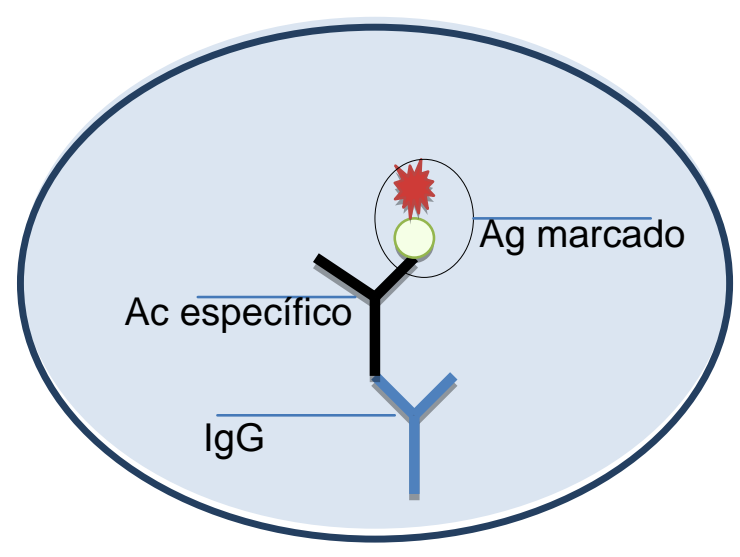

FIGURA 6.1 - Ilustração da interação Ac-Ac-Ag marcado ocorrida no imunoensaio por ELISA de captura.

Com isto, foi possível desenvolver um método in vitro de detecção e quantificação do 17- $\beta$-estradiol.

Vale ressaltar que, para a obtenção destes resultados, foi realizada uma série de experimentos para optimizar as condições reacionais.

As reações de bioconjugação empregaram as seguintes nanopartículas produzidas: 
- Nanomarcador 1 - PHB:3\%[Eu(tta $\left.)_{3}(\mathrm{TOPO})_{2}\right]-G L U-a m i n a$, por ser 0 sistema PHB de melhor intensidade luminescente representado nos estudos fotoluminescentes;

- Nanomarcador 2 - PHB: [Eu(tta $\left.)_{3}(\mathrm{TOPO})_{2}\right]$-PVA-sacarose-GLU-amina, por ser o sistema que apresentou alta eficiência luminescente e menor tamanho de partícula;

- Nanomarcador 3 - PMMA:5\%[Eu(tta) $\left.)_{3}(\mathrm{TOPO})_{2}\right]-G L U$-amina, por ser 0 sistema PMMA de melhor intensidade luminescente representado nos estudos fotoluminescentes;

- Nanomarcador 4 - PMMA:7\%[Eu(tta $\left.)_{3}(\mathrm{TOPO})_{2}\right]-G L U-a m i n a$, também por ter apresentado alta eficiência luminescente nos estudos fotoluminescentes.

Foram utilizadas diferentes concentrações do anticorpo de captura ( $\lg G)$, sendo elas: $0,5 \mu \mathrm{g} / \mathrm{mL}, 0,1 \mu \mathrm{g} / \mathrm{mL}, 0,01 \mu \mathrm{g} / \mathrm{mL}$ e $0,001 \mu \mathrm{g} / \mathrm{mL}$ (IgG:TBS); no gráfico representado por: $\square 0,001 \mu \mathrm{g} / \mathrm{mL}$; $0,01 \mu \mathrm{g} / \mathrm{mL} ; \quad 0,1 \mu \mathrm{g} / \mathrm{mL}$ e $0,5 \mu \mathrm{g} / \mathrm{mL}$; diferentes concentrações do anticorpo específico (anti-17- $\beta$ estradiol), sendo elas: $0,1 \mu \mathrm{g} / \mathrm{mL}, 0,5 \mu \mathrm{g} / \mathrm{mL}$ e $1 \mu \mathrm{g} / \mathrm{mL}$; e diferentes concentrações do antígeno marcado $\left(25.10^{-3}, 25.10^{-4}, 25.10^{-5}\right.$ e $25.10^{-6} \mathrm{mg} \mathrm{mL}$ ${ }^{1}$ ), sendo a concentração de antígeno $25.10^{-3} \mu \mathrm{g} / \mathrm{mL}$ para o nanomarcador 1 , $25.10^{-4} \mathrm{\mu g} / \mathrm{mL}$ para o nanomarcador $2,25.10^{-5} \mathrm{\mu g} / \mathrm{mL}$ para o nanomarcador $3 \mathrm{e}$ $25.10^{-6} \mathrm{\mu g} / \mathrm{mL}$ para o nanomarcador 4 .

Foram também utilizadas em todas as análises, para meios de comparação, amostras branco ( $\mathrm{Ac}-\mathrm{Ac}-\mathrm{Ag}_{\text {não }}$ marcado), e amostras padrão (nanomarcadores conjugados ao antígeno - $\mathrm{Ag}_{\text {marcado }}$ ) .

Os valores apresentados referentes à intensidade de sinal luminescente (TAB. 6.1) a partir da bioconjugação foram feitos por meio do cálculo da média destes, uma vez que cada amostra foi feita em triplicata.

As placas de 96 poços dos experimentos utilizando os nanomarcadores citados ligado ao antígeno em questão, por sua vez ligado ao conjugado

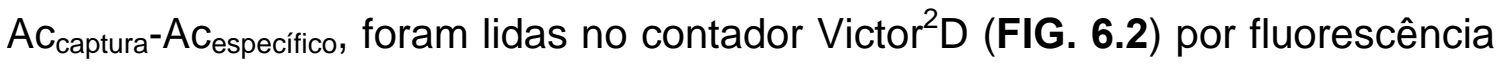
resolvida no tempo. Para o registro da contagem de fótons foi utilizado um 
protocolo para leitura de európio existente no instrumento, usando os filtros de $340 \mathrm{~nm}$ na excitação e 615 nm na emissão.

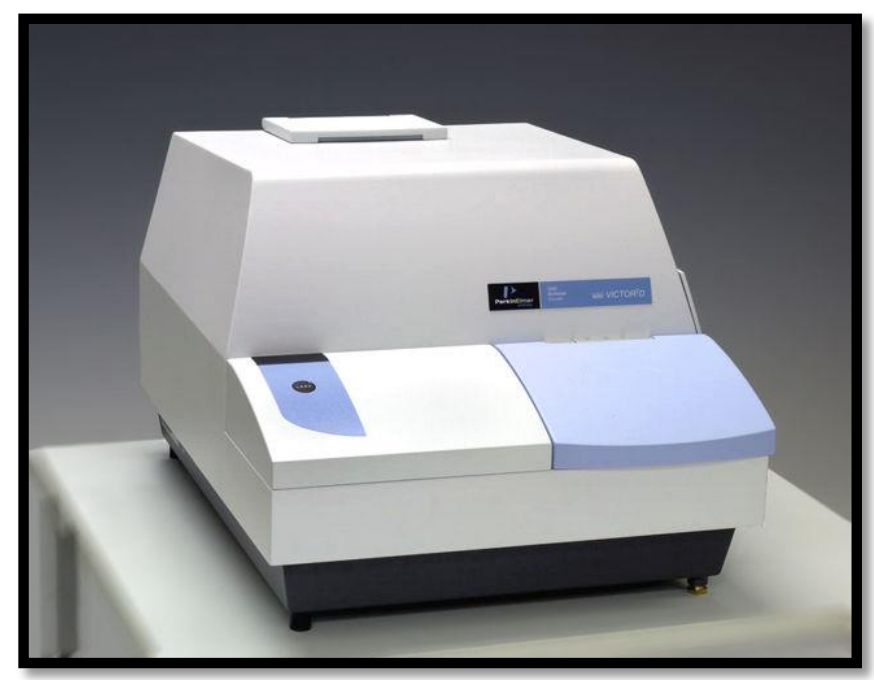

FIGURA 6.2 - Fotografia do fluorímetro Victor ${ }^{2} D$ da Perkin Elmer.

\subsubsection{Imunoensaios utilizando 0 nanomarcador 1 (PHB:3\%[Eu(tta) $\left.{ }_{3}(\mathrm{TOPO})_{2}\right]$-GLU-amina)}

Com base nas análises dos resultados dos imunoensaios contendo 0,1 $\mu \mathrm{g} / \mathrm{mL}$ de anticorpo específico variando a concentração do $\lg \mathrm{G}(1: 1,1: 10,1: 100$ e 1:1000) (TAB. 6.1), é possível observar pela quantificação de sinal luminescente que as maiores intensidades luminescentes são observadas para as concentrações de 1:1 e 1:1000(IgG/TBS), chegando a 31.692.776 CPS para concentração de 1:1000, com queda nas concentrações medianas de 1:10 e 1:100 lgG/TBS(IgG/TBS). Sugerindo a melhor concentração lgG/TBS para o

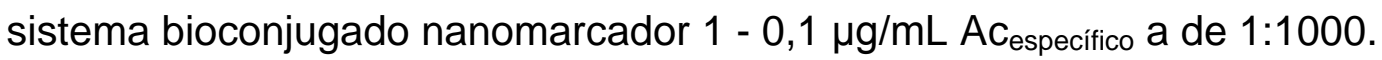

Para os imunoensaios contendo $0,5 \mu \mathrm{g} / \mathrm{mL}$ de anticorpo específico variando também a concentração do IgG (1:1, 1:10, 1:100 e 1:1000) (FIG 6.3), observa-se aumento de sinal luminescente conforme aumento de diluição do IgG até 1:100 (lgG/TBS), chegando a 20.009.391 CPS, porém com pequena queda de sinal na concentração menor de lgG, a de 1:1000 (lgG/TBS). 
Os resultados dos imunoensaios contendo $1 \mu \mathrm{g} / \mathrm{mL}$ de anticorpo específico variando a concentração do $\lg G(1: 1,1: 10,1: 100$ e 1:1000) estão apresentados na FIGURA 6.4, onde-se observa o maior sinal luminescente do estudo com o nanomarcador 1 , o de 45.212.522 CPS, quando a concentração do $\lg G$ foi de 1:1000 ( $\mathrm{gg} / \mathrm{TBS}$ ), apresentando queda abrupta da emissão de sinal quando a concentração do IgG foi aumentando: 1:1, 1:10 e 1:100.

As colorações demonstrativas referentes à intensidade de sinal medida nos poços, demonstração dada pelo programa operacional do espectrofluorímetro, estão apresentadas na FIGURA 6.5.

Com base neste estudo, é possível sugerir que o melhor sistema de bioconjugação para o nanomarcador 1 conjugado a $25.10^{-3} \mathrm{\mu g} / \mathrm{mL}$ de antígeno foi: $A c_{\text {captura }}$ (IgG) na concentração de 1:1000 (lgG/TBS) e $A c_{\text {especifico (anti-17- } \beta \text { - }}$ estradiol) na concentração de $1 \mu \mathrm{g} / \mathrm{mL}$, validando o sistema Ac-Ac-Ag marcado. 


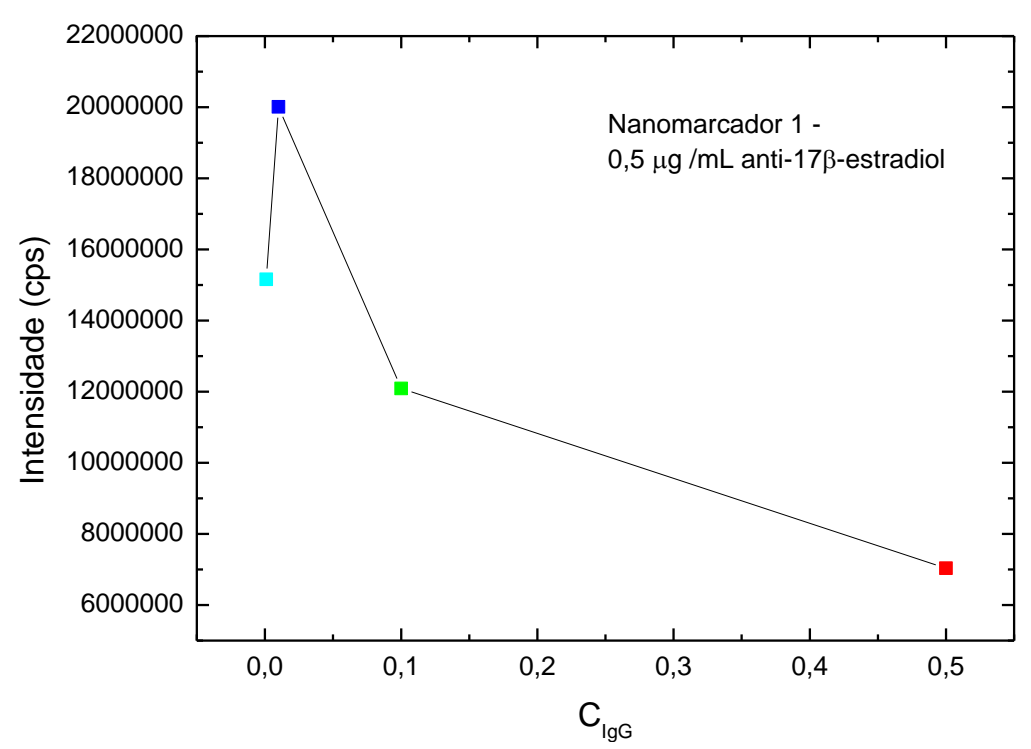

FIGURA 6.3 - Influência da concentração de IgG (1:1, 1:10, 1:100 e 1:100 (lgG/TBS) na resposta de detecção de conjugação do nanomarcador 1 na concentração de $0,5 \mu \mathrm{g} / \mathrm{mL}$ de anticorpo específico.

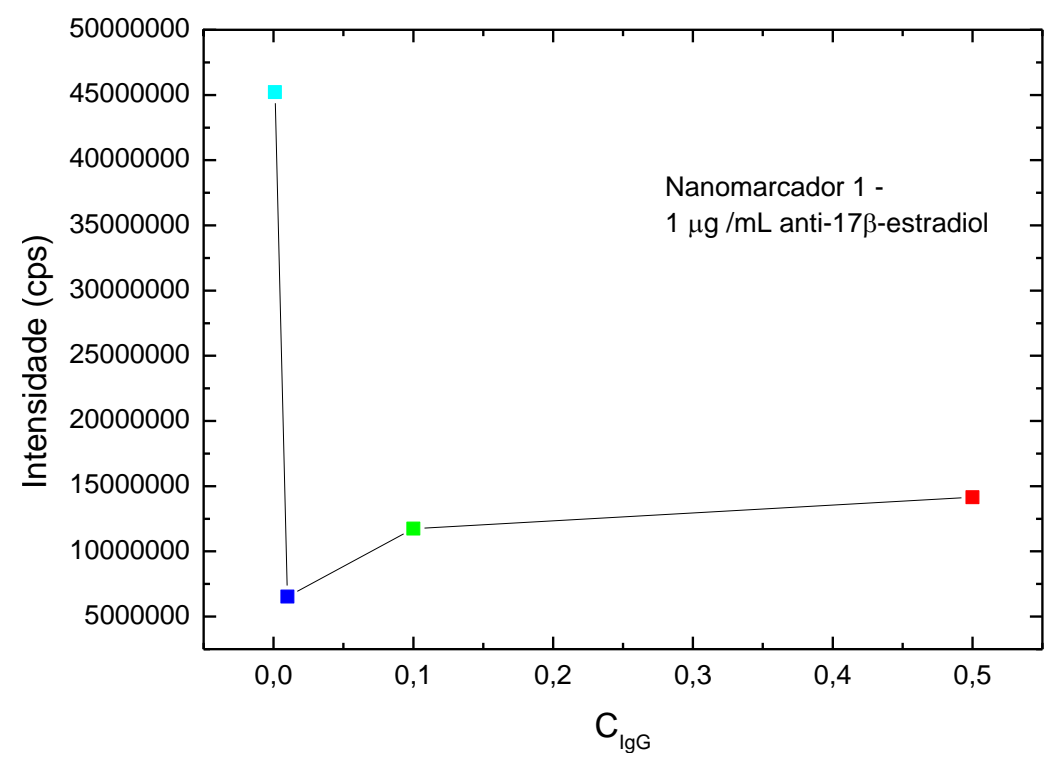

FIGURA 6.4 - Influência da concentração de IgG (1:1, 1:10, 1:100 e 1:100 (IgG/TBS)na resposta de detecção de conjugação do nanomarcador 1 na concentração de $1 \mu \mathrm{g} / \mathrm{mL}$ de anticorpo específico. 


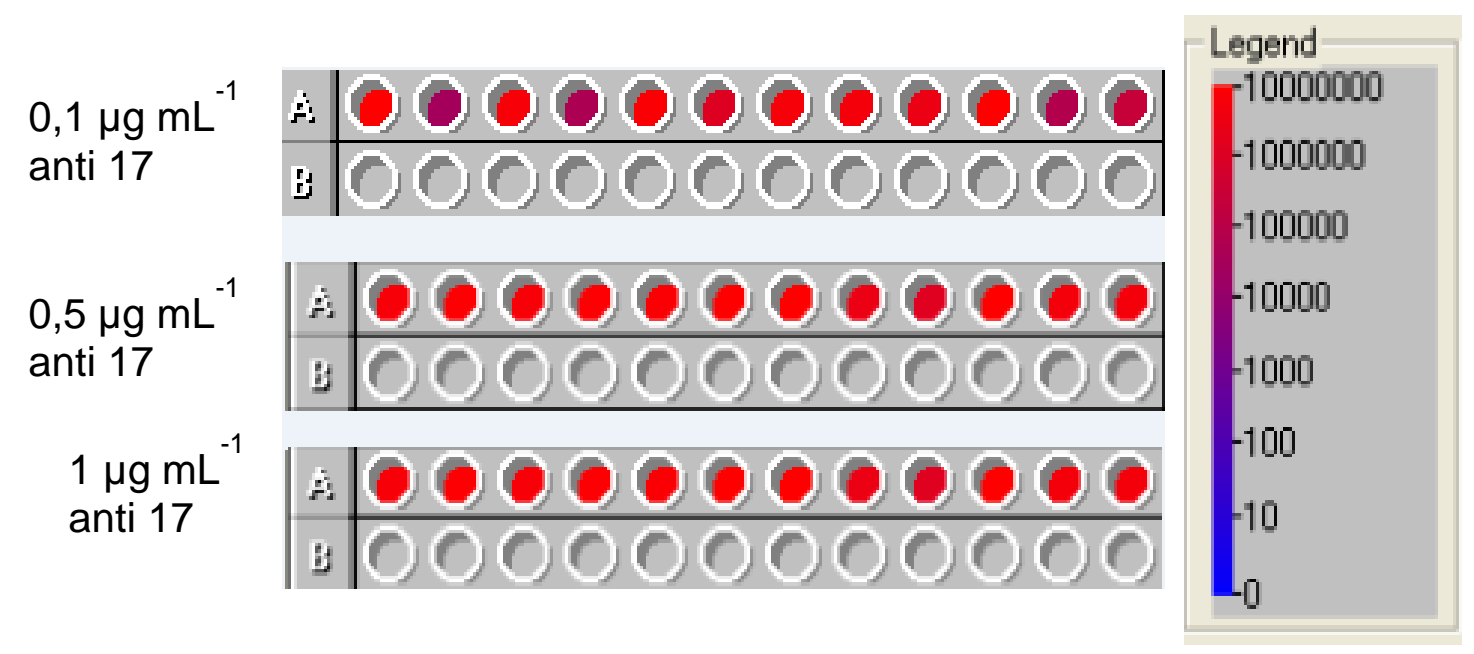

FIGURA 6.5 - llustração dos poços da placa de poliestireno contendo as informações colorimétricas do sinal emitido pelo sistema de conjugação biológica contendo 0 nanomarcador 1 nas diferentes concentrações de anticorpo específico anti-17ß-estradiol.

\subsubsection{Imunoensaios utilizando o nanomarcador 2 (PHB:[Eu(tta $\left.)_{3}(\mathrm{TOPO})_{2}\right]-$ PVA-sacarose-GLU-amina)}

As análises dos resultados dos imunoensaios contendo $0,1 \mu \mathrm{g} / \mathrm{mL}$ de anticorpo específico variando a concentração do $\lg G(1: 1,1: 10,1: 100$ e 1:1000) (FIG 6.6) para a marcação pelo nanomarcador PHB:[Eu(tta) $\left.)_{3}(\mathrm{TOPO})_{2}\right]-P V A-$ sacarose-GLU-amina mostra maior sinal luminescente proveniente da amostra contendo concentração de $\lg$ G 1:1 (IgG/TBS), com queda de sinal conforme a diluição do IgG aumenta. No entanto, o sinal máximo apresentado deste nanomarcador (136.662 CPS) é muito menor do que o apresentado para o nanomarcador 1 nas mesmas diluições do IgG. Com o aumento da concentração do anticorpo específico nos imunoensaios: $0,5 \mu \mathrm{g} / \mathrm{mL}$ (FIG. 6.7) e $1 \mu \mathrm{g} / \mathrm{mL}$ (FIG. 6.8), o sinal diminui para em torno de 20.000 CPS, diferença visível pela coloração demonstrativa referente à intensidade de sinal medida nos poços, demonstração dada pelo programa operacional do espectrofluorímetro (FIG. 6.9), sugerindo que o melhor sistema de bioconjugação para o nanomarcador 2 conjugado a $25.10^{-4} \mathrm{\mu g} / \mathrm{mL}$ de antígeno 
foi: Ac captura (IgG) na concentração de 1:1 (IgG/TBS) e Ac específico (anti17 - $\beta$-estradiol) na concentração de $0,1 \mu \mathrm{g} / \mathrm{mL}$.

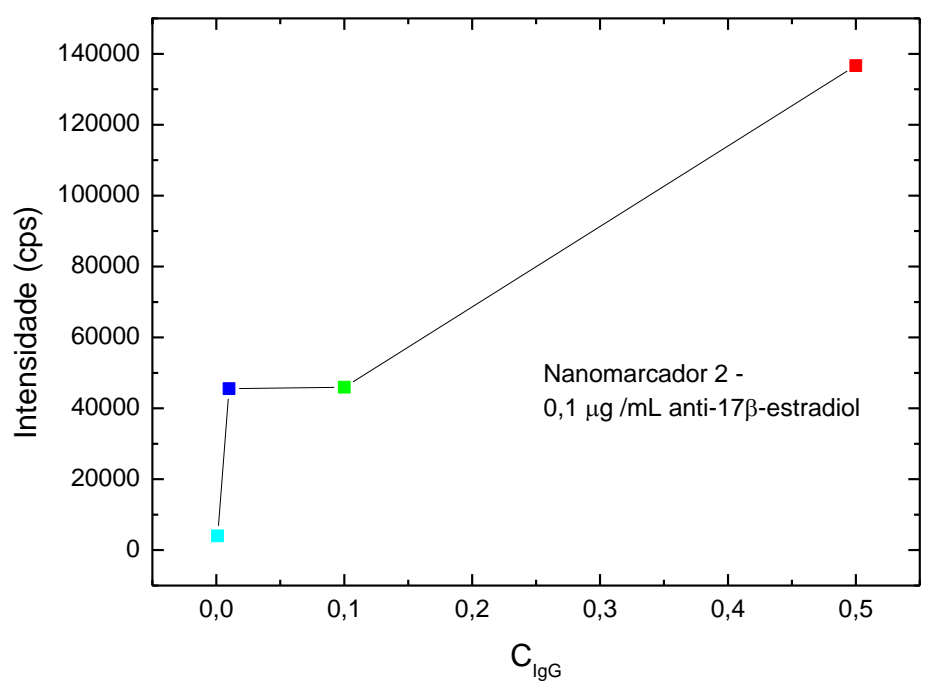

FIGURA 6.6 - Influência da concentração de $\lg$ (1:1, 1:10, 1:100 e 1:100 (IgG/TBS) na resposta de detecção de conjugação do nanomarcador 2 na concentração de $0,1 \mu \mathrm{g} / \mathrm{mL}$ de anticorpo específico.

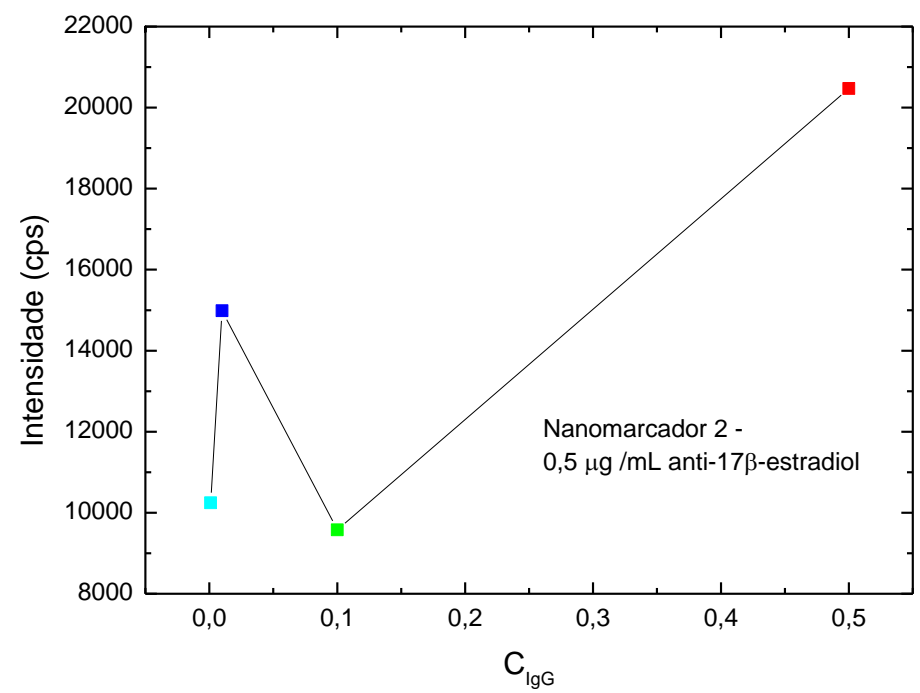

FIGURA 6.7 - Influência da concentração de $\lg$ (1:1, 1:10, 1:100 e 1:100 (lgG/TBS) na resposta de detecção de conjugação do nanomarcador 2 na concentração de $0,5 \mu \mathrm{g} / \mathrm{mL}$ de anticorpo específico. 


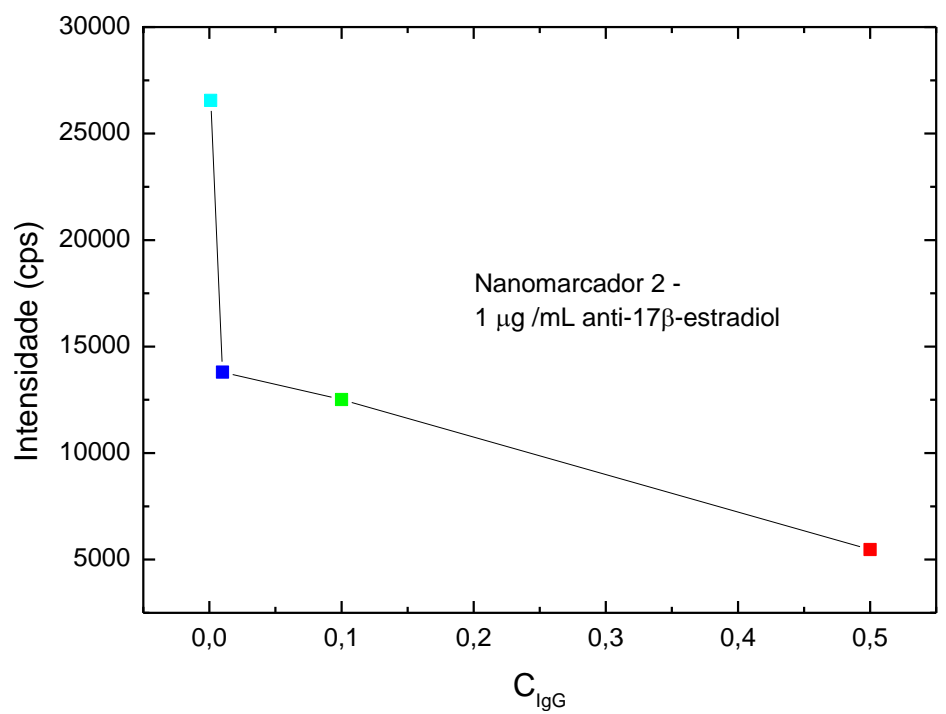

FIGURA 6.8 - Influência da concentração de $\operatorname{lgG}(1: 1,1: 10$, 1:100 e 1:100 (lgG/TBS) na resposta de detecção de conjugação do nanomarcador 2 na concentração de $1 \mu \mathrm{g} / \mathrm{mL}$ de anticorpo específico); amostras branco (Ac-Ac-Ag) e amostras padrão (nanomarcador - $\mathrm{Ag}$ ).

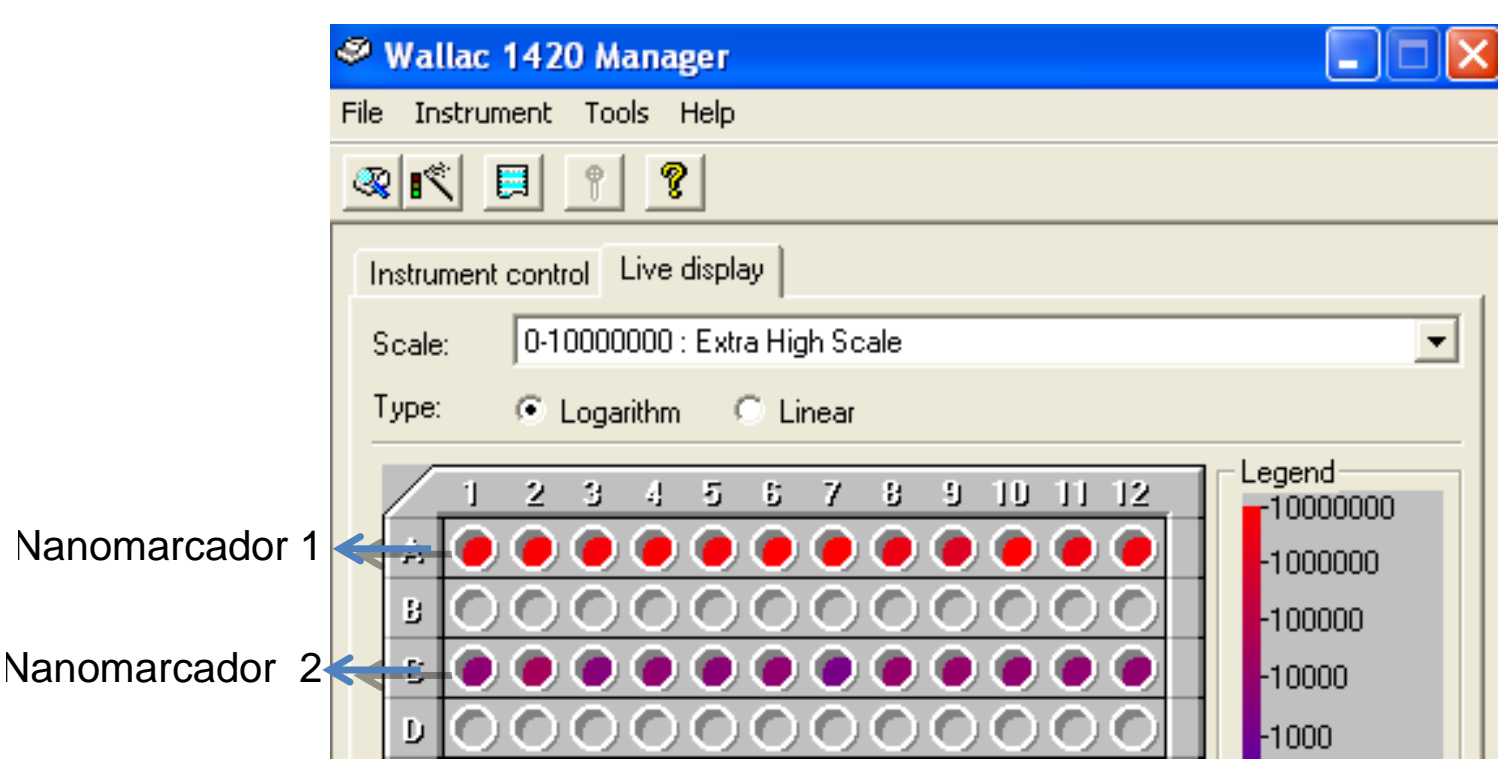

FIGURA 6.9 - Ilustração dos poços da placa de poliestireno contendo as informações colorimétricas do sinal emitido pelo sistema de conjugação biológica contendo os nanomarcadores 1 e 2 , respectivamente. 


\subsubsection{Imunoensaios utilizando 0 nanomarcador 3 (PMMA:7\%[Eu(tta) (TOPO) $_{2}$ ]-GLU-amina)}

As análises dos resultados dos imunoensaios contendo $0,1 \mu \mathrm{g} / \mathrm{mL}$ de anticorpo específico variando a concentração do $\lg G(1: 1,1: 10,1: 100$ e 1:1000) (FIG 6.10) para a marcação pelo PMMA:7\%[Eu(tta) $)_{3}(\text { TOPO) })_{2}$-GLU-amina mostra maior sinal luminescente (19.209.470 CPS) proveniente da amostra contendo concentração de $\operatorname{lgG} 1: 1$ (lgG/TBS), com queda de sinal conforme a diluição do lgG aumenta. No entanto, com o aumento da concentração de anticorpo específico: $0,5 \mu \mathrm{g} / \mathrm{mL}$ (FIG. 6.11) e $1 \mu \mathrm{g} / \mathrm{mL}$ (FIG. 6.12), o sinal luminescente aumenta bruscamente, observando-se o máximo de sinal (32.206.897 CPS) para a concentração de 0,5 $\mu \mathrm{g} / \mathrm{mL}$ de ac específico e diluição de 1:1 de Ac de captura ( $\lg G)$, sugerindo que o melhor sistema de bioconjugação para o nanomarcador 3 conjugado a $25.10^{-5} \mu \mathrm{g} / \mathrm{mL}$ de antígeno foi: Ac captura (lgG) na concentração de 1:1 (lgG/TBS) e Ac específico (anti17- $\beta$-estradiol) na concentração de $0,5 \mu \mathrm{g} / \mathrm{mL}$, validando o sistema Ac-Ac$\mathrm{Ag}_{\text {marcado. }}$

As colorações demonstrativas referentes à intensidade de sinal medida nos poços, demonstração dada pelo programa operacional do espectrofluorímetro, estão apresentadas na FIGURA 6.13. 


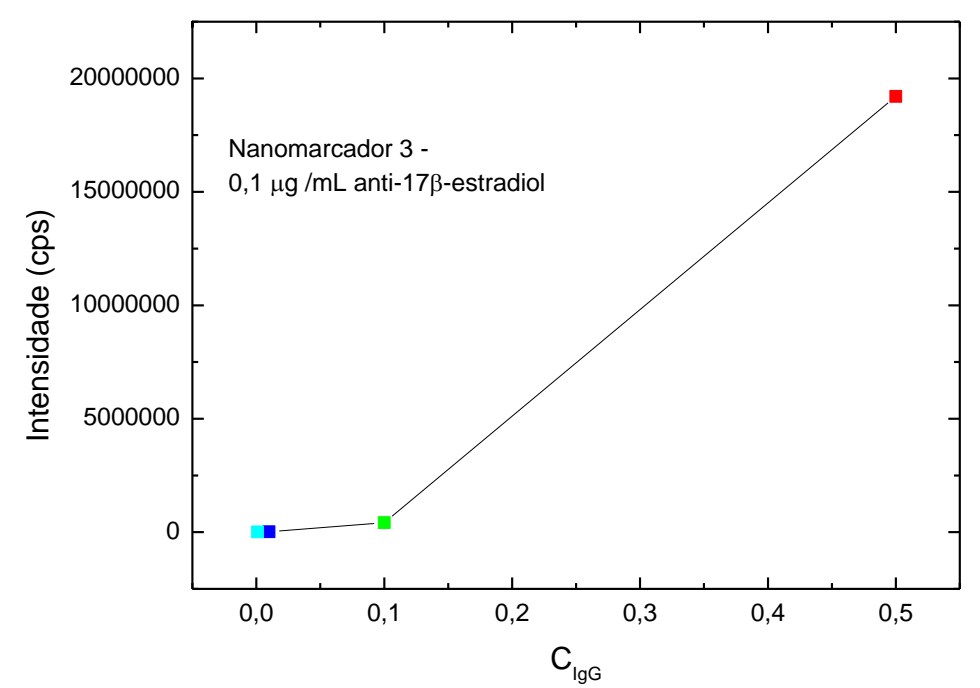

FIGURA 6.10 - Influência da concentração de IgG (1:1, 1:10, 1:100 e 1:100 (lgG/TBS) na resposta de detecção de conjugação do nanomarcador 3 na concentração de $0,1 \mu \mathrm{g} / \mathrm{mL}$ de anticorpo específico.

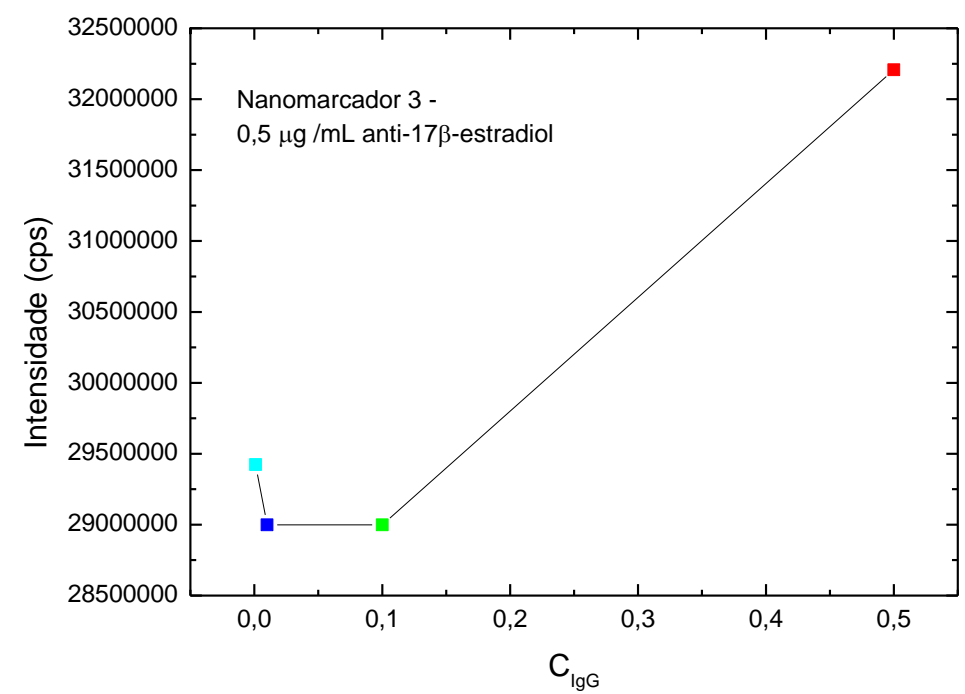

FIGURA 6.11 - Influência da concentração de IgG (1:1, 1:10, 1:100 e 1:100 (lgG/TBS) na resposta de detecção de conjugação do nanomarcador 3 na concentração de $0,5 \mu \mathrm{g} / \mathrm{mL}$ de anticorpo específico. 


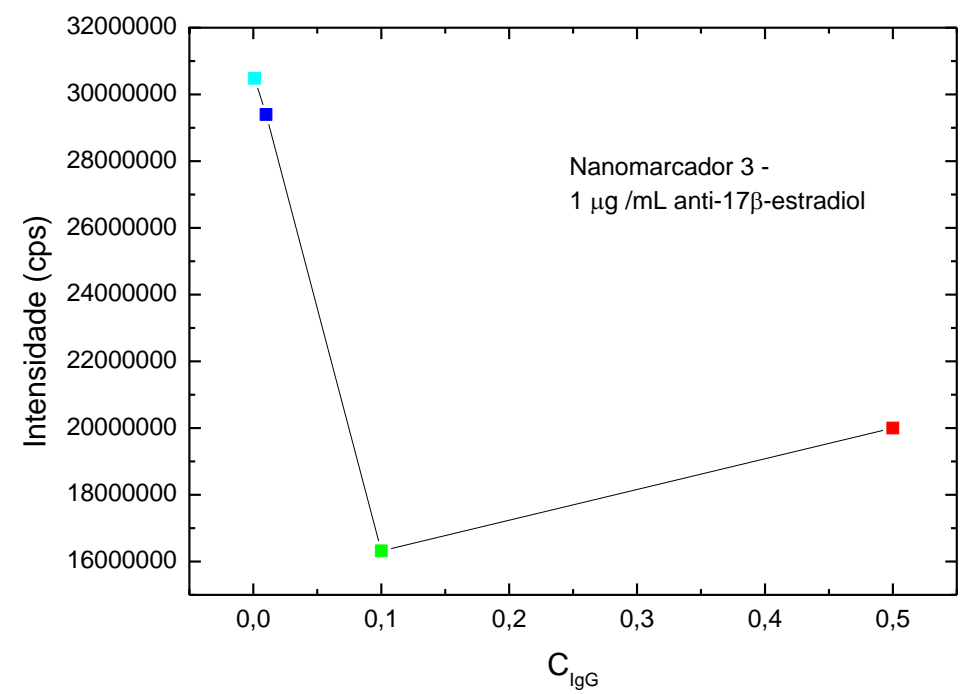

FIGURA 6.12 - Influência da concentração de IgG (1:1, 1:10, 1:100 e 1:100 (lgG/TBS) na resposta de detecção de conjugação do nanomarcador 3 na concentração de $1 \mu \mathrm{g} / \mathrm{mL}$ de anticorpo específico.

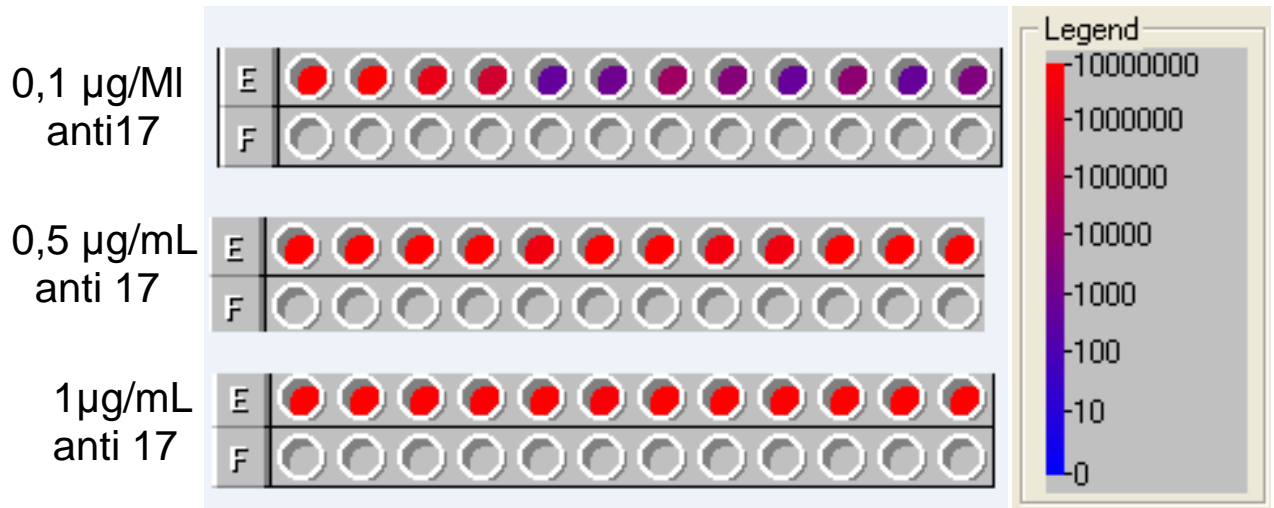

FIGURA 6.13 - llustração dos poços da placa de poliestireno contendo as informações colorimétricas do sinal emitido pelo sistema de conjugação biológica contendo o nanomarcador 3 nas diferentes concentrações de anticorpo específico anti-17ß-estradiol. 


\subsubsection{Imunoensaios utilizando $\quad 0 \quad$ nanomarcador 4 (PMMA:5\%[Eu(tta) (TOPO) $_{2}$ ]-GLU-amina)}

Os resultados dos imunoensaios contendo $0,1 \mu \mathrm{g} / \mathrm{mL}$ de anticorpo específico variando a concentração do $\lg G(0.5,0,1,0,01$ e 0,001$)$ estão apresentados na FIGURA 6.14, onde observa-se maior sinal luminescente quando na concentração de 1:1000 (IgG/TBS) com 23.461.783 CPS, apresentando queda abrupta da emissão de sinal quando a concentração do IgG foi de 1:1, 1:10 e 1:100. Para o imunoensaio contendo $0,5 \mu \mathrm{g} / \mathrm{mL}$ de $A c$ específico (FIG. 6.15), observa-se maior sinal luminescente (33.508.894 CPS) com a menor diluição do $\lg G(1: 1)$, apresentando diminuição do sinal com o aumento da diluição do $\lg G(1: 10,1: 100$ e 1:1000).

O estudo contendo $1 \mu \mathrm{g} / \mathrm{mL}$ de ac específico específico (FIG. 6.16), observa-se maior sinal luminescente (20.574.109 CPS) com a diluição do IgG (1:10), sugerindo o melhor sistema de bioconjugação para o nanomarcador 4 conjugado a $25.10^{-6} \mathrm{\mu g} / \mathrm{mL}^{-1}$ de antígeno, apresentando diminuição do sinal nas diluições 1:1, 1:100 e 1:1000 (lgG/TBS)..

As colorações demonstrativas referentes à intensidade de sinal medida nos poços, demonstração dada pelo programa operacional do espectrofluorímetro, estão apresentadas na FIGURA 6.17. 


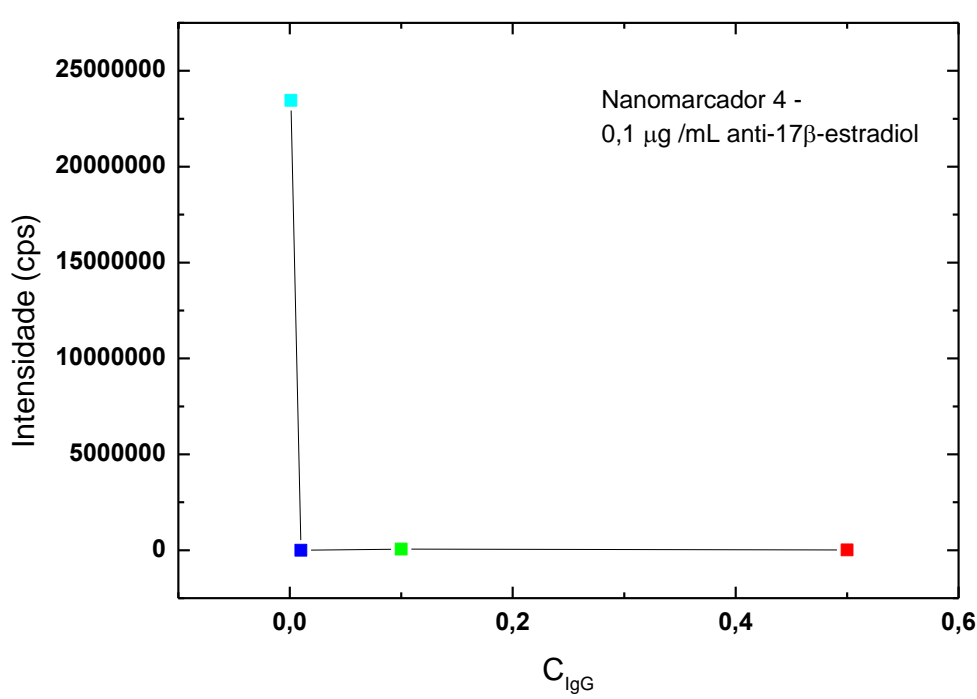

FIGURA 6.14 - Influência da concentração de $\operatorname{lgG}(1: 1,1: 10,1: 100$ e 1:100 (IgG/TBS) na resposta de detecção de conjugação do nanomarcador 4 na concentração de $0,1 \mu \mathrm{g} / \mathrm{mL}$ de anticorpo específico.

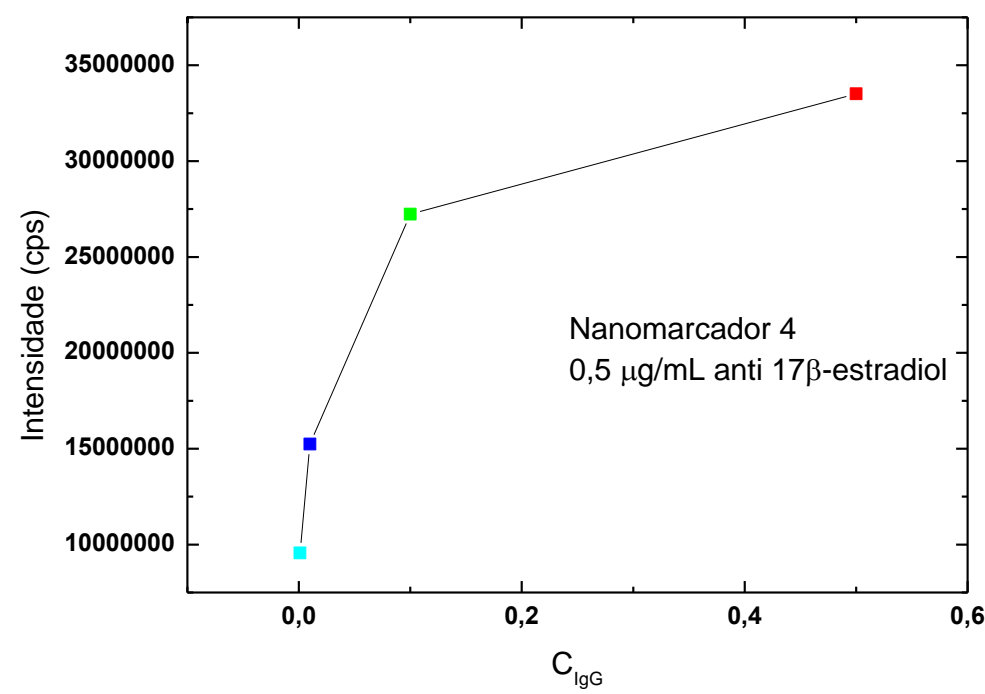

FIGURA 6.15 - Influência da concentração de IgG (1:1, 1:10, 1:100 e 1:100 (lgG/TBS) na resposta de detecção de conjugação do nanomarcador 4 na concentração de $0,5 \mu \mathrm{g} / \mathrm{mL}$ de anticorpo específico. 


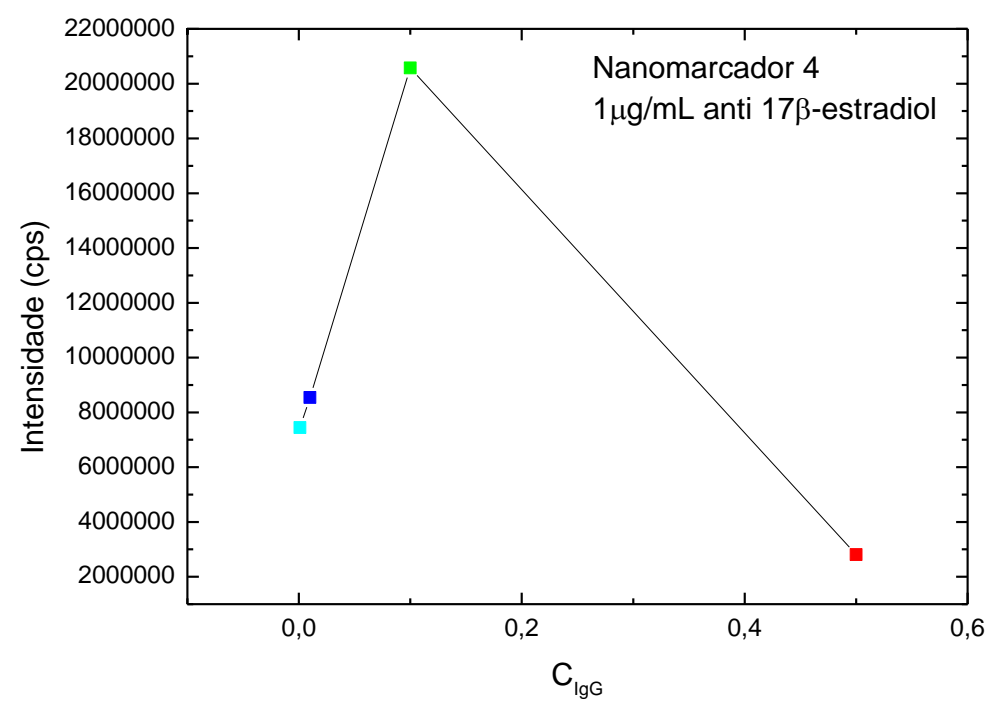

FIGURA 6.16 - Influência da concentração de $\lg$ (1:1, 1:10, 1:100 e 1:100) (IgG/TBS) na resposta de detecção de conjugação do nanomarcador 4 na concentração de $1 \mu \mathrm{g} / \mathrm{mL}$ de anticorpo específico.

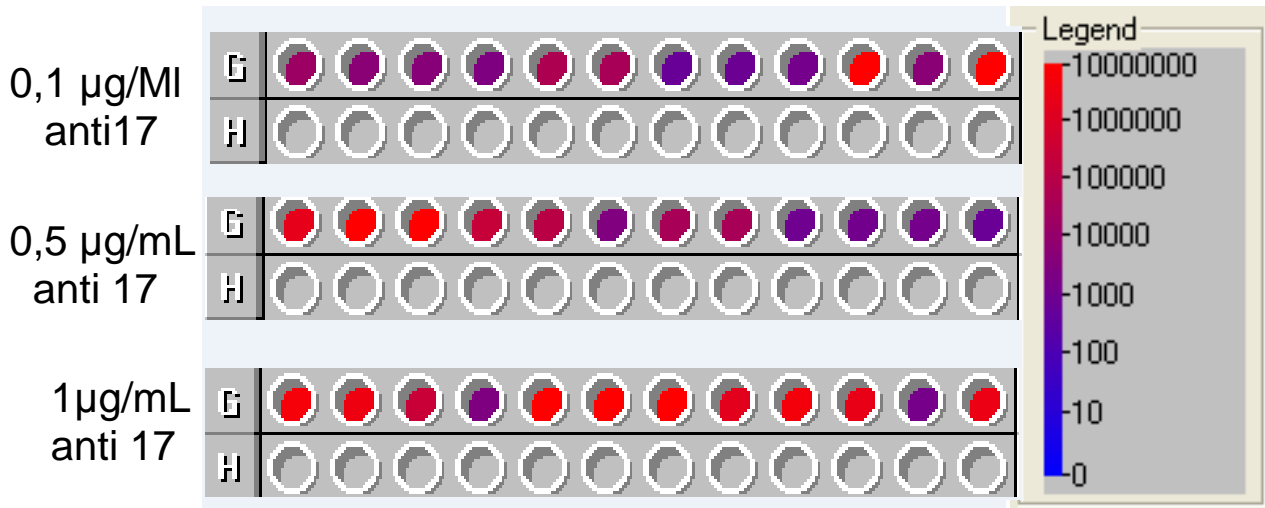

FIGURA 6.17 - llustração dos poços da placa de poliestireno contendo as informações colorimétricas do sinal emitido pelo sistema de conjugação biológica contendo o nanomarcador 4 nas diferentes concentrações de anticorpo específico anti-17ß-estradiol. 
TABELA 6.1 - Valores das emissões de sinal luminescente nas diferentes concentrações de cada espécie biológica utilizada nos imunoensaios de conjugação:IgG, amostras padrão (17ß-estradiol-nanomarcador), anti-17ß-estradiol e amostras branco (IgG-anti$17 \beta$-estradiol-17ß-estradiol).

\begin{tabular}{|c|c|c|c|c|c|c|}
\hline Nanomarcador & $\begin{array}{c}\mathbf{C}_{\mathrm{IgG}} \\
(\mathrm{IgG} / \mathrm{TBS}) \\
\mu \mathrm{g} / \mathrm{mL}\end{array}$ & $\begin{array}{c}\text { Padrão } \\
\text { cps }\end{array}$ & $\begin{array}{l}0,1 \mu \mathrm{g} / \mathrm{mL} \\
\text { anti-17ß- } \\
\text { estradiol }\end{array}$ & $\begin{array}{l}0,5 \mu \mathrm{g} / \mathrm{mL} \\
\text { anti-17 } \\
\text { estradiol }\end{array}$ & $\begin{array}{c}1 \mu \mathrm{g} / \mathrm{mL} \\
\text { anti-17ß- } \\
\text { estradiol }\end{array}$ & Branco \\
\hline \multirow{4}{*}{ Nanomarcador 1} & 0,5 & 21.094 .064 & 29.087 .866 & 7.032 .357 & 14.144 .637 & 370 \\
\hline & 0,1 & 21.546 .543 & 18.634 .558 & 12.090 .132 & 11.750 .899 & 391 \\
\hline & 0,01 & 19.254 .365 & 16.597 .928 & 20.009 .391 & 6.525 .445 & 382 \\
\hline & 0,001 & 20.748 .389 & 31.692 .776 & 15.159 .148 & 45.212 .522 & 413 \\
\hline \multirow{4}{*}{ Nanomarcador 2} & 0,5 & 96.662 & 136.662 & 20.471 & 5.473 & 370 \\
\hline & 0,1 & 85.459 & 45.969 & 9.579 & 12.509 & 391 \\
\hline & 0,01 & 95.565 & 45.552 & 14.985 & 13.802 & 382 \\
\hline & 0,001 & 78.012 & 4.012 & 10.246 & 26.552 & 413 \\
\hline \multirow{4}{*}{ Nanomarcador 3} & 0,5 & 15.205 .421 & 19.209 .470 & 32.206 .897 & 20.001 .158 & 370 \\
\hline & 0,1 & 14.569 .452 & 417.978 & 28.998 .482 & 16.320 .238 & 391 \\
\hline & 0,01 & 14.639 .450 & 20.287 & 28.562 .157 & 29.400 .191 & 382 \\
\hline & 0,001 & 15.965 .232 & 7.686 & 29.424.022 & 30.483 .505 & 413 \\
\hline \multirow{4}{*}{ Nanomarcador 4} & 0,5 & 15.205 .421 & 18.334 & 33.508 .894 & 2.806 .439 & 370 \\
\hline & 0,1 & 14.569 .452 & 59.752 & 27.235 .652 & 20.574 .109 & 391 \\
\hline & 0,01 & 14.639 .450 & 1.419 & 15.245 .965 & 8.543 .566 & 382 \\
\hline & 0,001 & 15.965 .232 & 23.461 .783 & 9.562 .321 & 7.445 .645 & 413 \\
\hline
\end{tabular}




\section{REFERÊNCIAS BIBLIOGRÁFICAS}

[1] GOSLING, J.P. Immunoassays. A Pratical Approach Oxford University Press., 2000

[2] EMON, J.M.V. Immunoassay and other Bioanalytical Techniques.CRC Press, 2007.

[3] KALIA, J.; RAINES, R.T. Advances in Bioconjugation. Curr Org Chem. Jan; 14(2): 138-147, 2010.

[4] STEPHANOPOULOS, N.; FRANCIS, M.B. Choosing an effective protein bioconjugation strategy. Nature Chemical Biology 7, 876-884, 2011. 


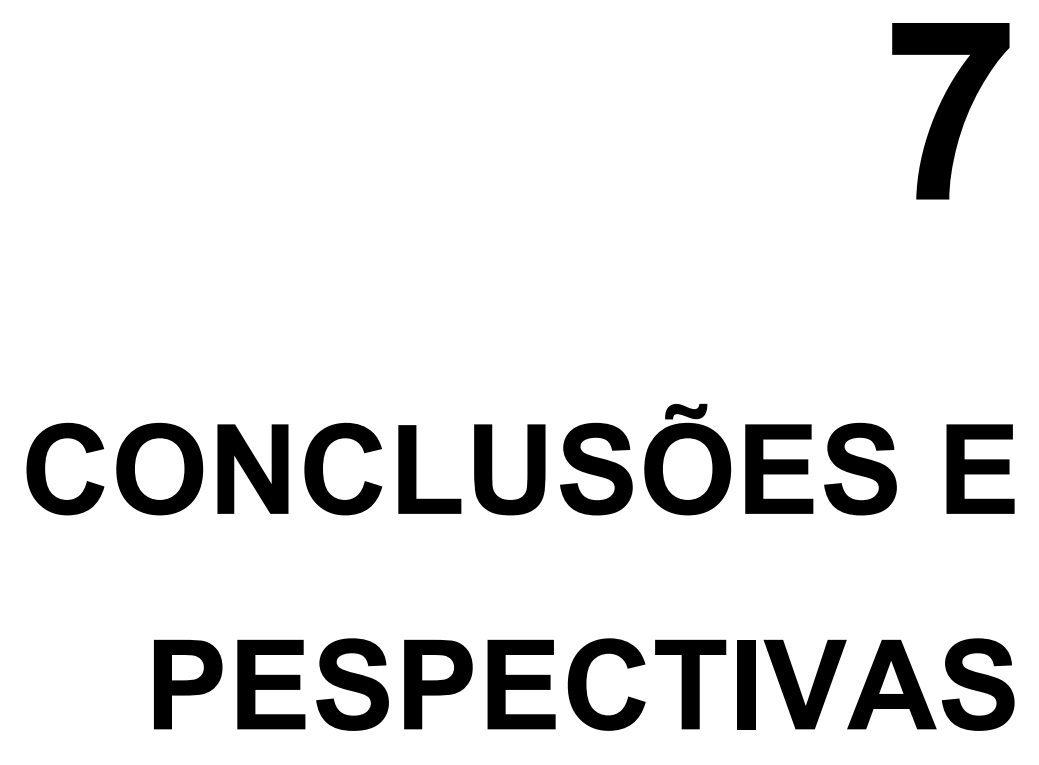




\subsection{CONCLUSÕES}

Este trabalho apresentou a preparação, caracterização e estudos sobre as propriedades de fotoluminescência de doze complexos de terras raras $\left[\mathrm{TR}(\beta \text {-dicetonato })_{3}(\mathrm{~L})_{2}\right]$ onde $\beta$-dicetonato=acac e tta, $\mathrm{TR}=\mathrm{Eu}, \mathrm{Tb}, \mathrm{Gd}$ e $\mathrm{L}=$ TOPO, TPPO, "18C6 e DB18C6

Os dados de espectroscopia no Infravermelho evidenciaram a ocorrência da interação entre os complexos de $\beta$-dicetonatos hidratados precussores, e os ligantes auxiliares L= TOPO, TPPO, "18C6 e DB18C6

As análises termogravimétricas TGA/DTG sugeriram o caráter anidro para maioria dos sistemas poliméricos dopados. Vale ressaltar que a maioria dos complexos de terras raras $\left[\operatorname{TR}(\beta \text {-dicetonato })_{3}(L)_{2}\right]$ apresentaram até três eventos de decomposição.

Os difratogramas de raios $X$ (método do pó) evidenciam que os complexos são cristalinos exceção feita aos complexos de $\mathrm{Eu}(\mathrm{tta})_{3}(\mathrm{DB} 18 \mathrm{C} 6)_{2}$, $\mathrm{Gd}(\mathrm{tta})_{3}(18 \mathrm{C} 6)_{2}$ e $\mathrm{Gd}(\mathrm{tta})_{3}(\mathrm{TPPO})_{2}$ que têm carater amorfo.

As imagens registradas pela técnica de microscopia eletrônica de varredura evidenciaram formas cristalinas desde aglomerados de nanoparticulas com tendências à esfericidade até fios micrométricos.

Através dos espectros de emissão fosforescente dos complexos de gadolínio $\mathrm{Gd}^{3+}$, utilizando as técnicas do estado estacionário e baricentro da banda de fosforescência do ligante, foram obtidas as energias do estado $T_{1}$. Com base nestes dados, foram evidenciados que os estados $\mathbf{T}$ do ligante tta mostraram-se mais ressonantes com os níveis excitados ${ }^{5} \mathrm{D}_{0}$ do íon $\mathrm{Eu}^{3}$, favorecendo mais os processos radiativos de transferência de energia Ligante $\mathbf{T}_{1}$-Metal. Por outro lado, os estados $\mathbf{T}$ do ligante acac estão mais ressonante com o nível emissor ${ }^{5} \mathrm{D}_{4}$ do íon $\mathrm{Tb}^{3+}$.

As propriedades fotoluminescentes foram investigadas a partir dos espectros de emissão dos complexos de $\mathrm{Eu}^{3+}$ e $\mathrm{Tb}^{3+}$ e apresentaram bandas 
características das transições intraconfiguracionais oriundas dos íons $\mathrm{Eu}^{3+}$ $\left({ }^{5} D_{0} \rightarrow{ }^{7} F_{J}, J=0-6\right)$ e $\quad \mathrm{Tb}^{3+}\left({ }^{5} D_{4} \rightarrow{ }^{7} F_{J}, J=60\right)$, exibindo emissões de cores vermelha e verde, respectivamente. Foi observado, também, que a maioria dos complexos luminescentes exibe maior intensidade luminescente quando a excitação é monitorada na parte orgânica ao invés da excitação diretamente nas transições $4 \mathrm{f}$ dos íons $\mathrm{TR}^{3+}$. Além disso, a ausência das bandas de fosforescência pertencente à parte orgânica indicou uma transferência eficiente de energia intramolecular.

Os dados de fotoluminescência de emissão apresentam maiores valores de eficiência quântica do estado emissor ${ }^{5} \mathrm{D}_{0}(\eta)$ dos complexo com ligantes fosfinóxidos.

Os tempos de vida dos estados emissores ${ }^{5} D_{0}$ e ${ }^{5} D_{4}$ são muito longos e as curvas de decaimento experimental apresentaram um perfil diferenciado dos existentes na literatura, mostrando o tempo de subida.

Os complexos precursores sintetizados obtiveram intensidade luminescente efetiva, sendo que o complexo de tta de európio contendo o ligante auxiliar TOPO apresentou a melhor eficiência luminescente comparado a todos os complexos de európio e térbio estudados. Por conta disto, o complexo $\left[\mathrm{Eu}(\mathrm{tta})_{3}(\mathrm{TOPO})_{2}\right)$ e o de $\left[\mathrm{Gd}(\mathrm{tta})_{3}(\mathrm{TOPO})_{2}\right)$ foram escolhidos como dopantes nas matrizes poliméricas,sendo o $\left[\mathrm{Eu}(\mathrm{tta})_{3}(\mathrm{TOPO})_{2}\right)$ candidato potencial para marcação.

Também conclui-se neste trabalho a preparação, caracterização e estudos sobre as propriedades de fotoluminescência de partículas poliméricas (PMMA e PHB) dopadas com o complexo de coordenação tris(tenoiltrifluoroacetonato) de európio com ligante auxiliar TOPO, produzindo nanopartículas poliméricas luminescentes via dois metodos de síntese: nanoprecipitação por crioscopia e técnica de emulsão-difusão.

Os dados de espectroscopia no Infravermelho evidenciaram a ocorrência de interação entre as matrizes poliméricas PHB e PMMA com os complexos de $\beta$-dicetonato $\mathrm{Eu}^{3+} \mathrm{e} \mathrm{Gd}^{3+}$. 
As análises termogravimétricas TGA/DTG sugeriram o caráter anidro na maioria dos sistemas poliméricos dopados. Vale ressaltar que a maioria dos filmes poliméricos apresentou um único evento de perda de massa, correspondendo à decomposição térmica junto ao complexo e polímero. Ademais, estas curvas evidenciaram que ambas as séries de nanopartículas, PHB e PMMA apresentam um pequeno aumento de termoestabilidade em função do aumento da concentração de dopagem.

Os difratogramas de raios $X$ (método do pó) evidenciam que os dois grupos de nanopartículas poliméricas são semicristalinas e cada série (PHB e PMMA) apresentou perfis de difratograma semelhantes entre si. Portanto, aqueles do PHB são mais cristalinos em relação aos sistemas com PMMA. A cristalinidade dos sistemas aumentou em função da porcentagem de dopagem

As imagens registradas pela técnica de microscopia eletrônica de varredura mostraram imagens micrométricas de aglomerado de partículas que possuíam canais, cavidades e poros.

Através dos espectros de emissão fosforescente dos sistemas PHB e PMMA dopados com os complexos de $\mathrm{Gd}^{3+}$, utilizando as técnicas do estado estacionário e baricentro das bandas de fosforescência, foram obtidas as energias do estado $\mathbf{T}_{1}$. Com base nestes dados, foram evidenciados que os estados $\mathbf{T}$ do ligante tta são deslocados para menor energia quando comparados aos do complexo livre embora continuem favorecendo mais os processos radiativos de transferência de energia Ligante $\mathbf{T}_{1}-$ Metal.

A partir dos espectros de excitação dos complexos de $\mathrm{TR}^{3+}$ dopados nos polímeros PHB e PMMA $\left(\mathrm{TR}^{3+}=\mathrm{Gd}^{3+}\right.$ e $\left.\mathrm{Eu}^{3+}\right)$, foram observadas que as bandas finas características das transições intraconfiguracionais $4 \mathrm{f}-4 \mathrm{f}$ provenientes dos íons $\mathrm{Eu}^{3+}$ foram suprimidas, evidenciando uma maior intensidade de absorção pela parte orgânica e uma eficiente transferência de energia Ligante-Metal.

As propriedades fotoluminescentes foram investigadas a partir dos espectros de emissão dos sistemas PHB e PMMA dopados com complexo de 
$\mathrm{Eu}^{3+}$ e apresentaram bandas características das transições intraconfiguracionais oriundas do íon $\mathrm{Eu}^{3+}\left({ }^{5} \mathrm{D}_{0} \rightarrow{ }^{7} \mathrm{~F}_{\mathrm{J}}, \mathrm{J}=0-6\right)$ exibindo cor de emissão vermelha. Estas transições $4 \mathrm{f}-4 \mathrm{f}$ apresentaram 0 fenômeno alargamento não homogêneo devido a uma distribuição dos sítios de simetria provocada pela interação da matriz do polímero PHB e PMMA. Foi observado, também, que a maioria das nanopartículas luminescentes exibe maior intensidade luminescente quando a excitação é monitorada na parte orgânica ao invés da excitação diretamente nas transições 4 dos íons $\mathrm{TR}^{3+}$. Além disso, a ausência das bandas de fosforescência pertencente à parte orgânica indicou uma transferência eficiente de energia intramolecular, indicando que os polímeros PHB e PMMA atuam como co-sensibilizadores luminescentes. Para a maioria das nanopartículas dopadas, houve supressão de luminescência em função da concentração (\% mássica) de dopagem.

Os dados de fotoluminescência de emissão dos polímeros PHB e PMMA dopados com complexo $\left[\mathrm{Eu}(\mathrm{tta})_{3}(\mathrm{TOPO})_{2}\right]$ exibiram bandas finas oriundas das transições ${ }^{5} \mathrm{D}_{0} \rightarrow{ }^{7} \mathrm{~F}_{0-4}\left(\mathrm{Eu}^{3+}\right)$, dominados pelas transições hipersensíveis ${ }^{5} \mathrm{D}_{0} \rightarrow{ }^{7} \mathrm{~F}_{2}(\sim 614 \mathrm{~nm})$ indicando que íon $\mathrm{Eu}^{3+}$ encontra-se em um ambiente químico não centrossimétrico. Os filmes PHB:Eu(tta) $)_{3}$ e PMMA:Eu(tta) apresentaram valores de $\Omega_{2}$ menores sugerindo que 0 íon $\mathrm{Eu}^{3+}$ localiza-se num ambiente químico menos polarizável.

As nanopartículas poliméricas estudadas apresentaram efetiva luminescência, ressaltando as nanopartículas de PMMA que, através do estudo espectroscópico, demonstraram maior intensidade luminescente quando comparadas com as nanopartículas contendo PHB. Dentre todas as dopagens estudadas para ambos os polímeros (0,5; $1 ; 3 ; 5$ e 7\%), a dopagem de 5\% do complexo precursor de európio apresentou maior intensidade luminescente quando incorporada na matriz polimérica PMMA, e a dopagem de $3 \%$ do complexo precursor de európio apresentou maior intensidade luminescente quando incorporada na matriz polimérica PHB, sendo que estas amostras foram escolhidas para o ensaio imunológico para detecção das espécies biológicas propostas neste trabalho. 
A técnica de nanoprecipitação com evaporação do solvente foi a mais efetiva para produzir nanopartículas poliméricas luminescentes à base de európio, enquanto que a técnica de emulsão por difusão foi a técnica mais efetiva para menores tamanhos de partículas e uniformidade. No entanto, apesar da elevada eficiência luminescente, estas são menos eficientes do que as apresentadas pela técnica de nanoprecipitação com evaporação do solvente..

As nanoparticulas mais luminescentes PMMA:0,5\%[Eu(tta) $\left.)_{3}(\mathrm{TOPO})_{2}\right]$; PMMA:5\%[Eu(tta) $\left.)_{3}(\mathrm{TOPO})_{2}\right]$; $\quad$ PMMA:7\%[Eu(tta) $\left.)_{3}(\mathrm{TOPO})_{2}\right]$; PHB:3\%[Eu(tta $\left.)_{3}(\mathrm{TOPO})_{2}\right], \quad$ PHB: $\quad 3 \%\left[\mathrm{Gd}(\mathrm{tta})_{3}(\mathrm{TOPO})_{2}\right] ; \quad$ PMMA:5\% $\left[\mathrm{Eu}(\mathrm{tta})_{3}(\mathrm{TOPO})_{2}\right]+\mathrm{PVA}+$ sacarose; foram funcionalizadas com 1,6hexanodiamina e a funcionalização foi efetiva, segundo dados de infravermelho (bandas de deformação $\delta \mathrm{N}-\mathrm{H}$ em $1640-1560 \mathrm{~cm}^{-1}$ para $\circ 1,6$ hexanodiamina e na partícula funcionalizada em $1591-1454 \mathrm{~cm}^{-1}$, deformação fora do plano $\delta \mathrm{N}-\mathrm{H}$ próximo a $800 \mathrm{~cm}^{-1}$ para 1,6 diamino-hexano livre que se desloca para região de maior energia $844 \mathrm{~cm}^{-1}$ ) e da determinação de aminas primárias pelo método da ninidrina.

Nos ensaios imunológicos para detecção do 17ß-estradiol, todas as nanopartículas utilizadas

(PMMA:5\%[Eu(tta) $\left.)_{3}(\mathrm{TOPO})_{2}\right]$; PMMA:7\%[Eu(tta $\left.)_{3}(\text { TOPO })_{2}\right]$; $\mathrm{PHB}: 3 \%\left[\mathrm{Eu}(\mathrm{tta})_{3}(\mathrm{TOPO})_{2}\right]$,

PHB:3\%[Eu(tta) $\left.)_{3}(\mathrm{TOPO})_{2}\right]+$ PVA+sacarose) emitiram sinal intenso de detecção luminescente pelo espectrofluorímetro e a maior intesidade de sinal foi observada para os imunoensaios utilizando como marcadores as nanopartículas poliméricas de $\mathrm{PHB}$, indicando transferência eficiente de energia da parte orgânica do sistema biológico (Ac-Ac) para o nanosensor ligado ao hormônio alvo.

Conclui-se, portanto, que todas as nanopartículas sintetizadas e conjugadas ao sistema biológico de interesse são eficientes candidatas a nanosensores para diagnóstico qualitativo e quantitativo do hormônio $17 \beta$ estradiol e de outras entidades biológicas. 


\subsection{PERSPECTIVAS FUTURAS}

A metodologia diagnóstica proposta neste trabalho apresenta inúmeras vantagens por se tratar de nanomarcadores luminescentes de alta intensidade com entidades específicas de detecção do 17ß-estradiol. Em trabalho futuro de pós-doutorado, pretende-se estudar os métodos de funcionalização cabíveis, testar os melhores métodos e aplicá-los, comparativamente, ao imunoensaio de detecção do hormônio.

Pretende-se também realizar estudos de concentrações do anticorpo de captura, do anticorpo específico, do hormônio alvo e das nanopartículas marcadoras, para que se estabeleça o melhor sistema de detecção e quantificação do hormônio, com concentrações bem definidas de cada entidade biológica do sistema.

Tambem será alvo dos nossos trabalhos futuros, obter a licença do Comitê de Ética de Pesquisa em Seres Humanos (SISNEP) para desenvolver a tecnologia com soros de pacientes humanos. 